Bengt Erik Bethmann

\title{
Gesellschaftliches Wesen und soziales Phänomen
}

Zur negativen Dialektik von Phänomen, Wesen, gesellschaftlicher Totalität und der Bedeutung für die Kritik des modernen Antisemitismus 

Bengt Erik Bethmann

Gesellschaftliches Wesen und soziales Phänomen

Dieses Werk ist lizenziert unter einer

Creative Commons

Namensnennung - Weitergabe unter gleichen Bedingungen

4.0 International Lizenz.

(c) $\underset{\mathrm{BY}}{(1)}$ (2) 
erschienen in der Reihe der Universitätsdrucke im Universitätsverlag Göttingen 2018 
Bengt Erik Bethmann

\section{Gesellschaftliches Wesen und soziales Phänomen}

Zur negativen Dialektik

von Phänomen, Wesen, gesellschaftlicher Totalität

und der Bedeutung für die Kritik des modernen Antisemitismus

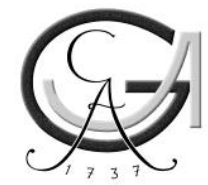

Universitätsverlag Göttingen 2018 


\section{Bibliographische Information der Deutschen Nationalbibliothek}

Die Deutsche Nationalbibliothek verzeichnet diese Publikation in der Deutschen Nationalbibliographie; detaillierte bibliographische Daten sind im Internet über $<$ http://dnb.dnb.de $>$ abrufbar.

\section{Autorenkontakt}

Bengt Erik Bethmann

E-Mail: BengtBethmann@gmx.de

Dieses Buch ist auch als freie Onlineversion über die Homepage des Verlags sowie über den Göttinger Universitätskatalog (GUK) bei der Niedersächsischen Staats- und Universitätsbibliothek Göttingen (http://www.sub.uni-goettingen.de) erreichbar.

Es gelten die Lizenzbestimmungen der Onlineversion.

Satz und Layout: Alice von Berg

(C) 2018 Universitätsverlag Göttingen

https://univerlag.uni-goettingen.de

ISBN: 978-3-86395-359-1

DOI: https://doi.org/10.17875/gup2018-1092 
Für Kirsten

und alle, die mich unterstütat haben. 



\section{Vorwort}

Die vorliegende Untersuchung wurde im Wintersemester 2016 unter dem Titel Gesellschaftliches Wesen und soziales Pbänomen. Zur negativen Dialektik von Pbänomen, Wesen, gesellschaftlicher Totalität und der Bedeutung für die Kritik des modernen Antisemitismus im Fachbereich Sozialwissenschaften der Universität Göttingen als Dissertation eingereicht und angenommen. Die mündliche Verteidigung folgte im Mai 2017. Bis zur Einreichung als Dissertation hatte die vorliegende Untersuchung eine bereits längere Geschichte hinter sich. Entstanden ist sie in jeweils verschiedenen Zusammenhängen und ihre Thesen wurden an verschiedenen Orten formuliert - immer mit der tatkräftigen Unterstützung von mir nahestehenden Menschen, denen in diesem Vorwort deshalb mein besonderer Dank gilt.

Zunächst möchte ich meinen drei Prüfern, Samuel Salzborn, Michael Städtler und Walter Reese-Schäfer danken. Samuel Salzborn trug als Erstgutachter die Hauptlast des gesamten Prozesses. Ihm möchte ich insbesondere für die unkomplizierte Annahme meiner Dissertation zu einem Zeitpunkt danken, zu dem ich selbst nicht mehr an das Gelingen meines Unterfangens geglaubt habe. Seine Art und Weise der sehr offen gehaltenen Zusprache, mich weiterhin an meinen Thesen und meiner Dissertation zu versuchen, gab mir den nötigen Mut und das nötige Selbstvertrauen zurück, das man für die wissenschaftliche Arbeit einer solchen Größenordnung braucht. Michael Städtler möchte ich für die Erstellung des Zweitgutachtens danken. Michael kenne ich bereits aus meiner Zeit als Student an 
der Leibniz Universität Hannover. Ich glaube, es ist an der Stelle nicht vermessen zu behaupten, dass Michael mir mit seinen Vorlesungen und Schriften den entscheidenden Impuls gegeben hat, kritisch zu denken und Dinge immer wieder substantiell zu hinterfragen.

Meinen Eltern, Margot und Heinz Bethmann, möchte ich für die jahrelange, vielfältige und sorgfältige Unterstützung danken. Ohne ihren unermüdlichen und mutigen Zuspruch und ihren entschlossenen Einsatz wäre die Arbeit heute noch nicht fertig. Für all ihre Unterstützung bin ich so unendlich dankbar.

Selbstverständlich möchte ich auch ganz herzlich all jenen danken, die mich seit Jahren schon begleitet haben und mir auf ihre Art und Weise ganz unterschiedlich im Rahmen der vorliegenden Untersuchung halfen. Marcel Grzyb möchte ich nicht nur für so viele schöne Stunden der Freundschaft, sondern auch die moralische und tatkräftige Unterstützung bei diesem Projekt danken, was mir so vieles enorm erleichtert hat, da Marcel immer ein offenes Ohr für meine Sorgen und Nöte hatte. Alexander Johnston danke ich für die vielen freundschaftlichen Ratschläge im Umgang mit der Dissertation und die nötigen wie helfenden Ablenkungen. Den Mitarbeitern des Gesellschaftswissenschaftlichen Instituts und den vom Institut organisierten Arbeitsgruppen danke ich für die vielen Anregungen und Gedanken, die in dieser Arbeit ihren Niederschlag gefunden haben. Dem Kolloquium von Samuel Salzborn an der Georg-August-Universität Göttingen danke ich für die etlichen Hinweise, Diskussionen und die vielen guten Einwände. Stephanie Heck danke ich für ihre Freundschaft und für die vielen guten und tiefen Gespräche, die selbstverständlich nicht nur im Rahmen dieser Untersuchung weiterführend waren. Für seine freundschaftliche Unterstützung möchte ich auch Elmar Schumacher ganz besonders danken. Ein ganz besonderer Dank gilt Sabrina und Christoph Begemann, die mir beide insbesondere eine moralische und freundschaftliche Stütze waren. Sie haben mir immer im richtigen Moment vor Augen geführt, dass die Gesellschaftstheorie und meine Untersuchung zwar schon wichtig, aber eben auch nicht das Wichtigste auf dieser Welt sind.

$\mathrm{Zu}$ guter Letzt möchte ich, weil sie von Anfang bis Ende der Arbeit in allen Belangen bereit stand und das Projekt (an verschiedenen historischen Punkten auch gegen mich) verteidigte, meiner Frau Kirsten Bethmann für die glücklichen Stunden und den unermüdlichen Zuspruch in manch aussichtslos scheinenden Sackgassen danken. Liebe Kirsten, ohne Dich wäre diese Arbeit eine kaum in Angriff genommene Baustelle geblieben; so wie vieles andere in meinem Leben auch. Mir gehen an dieser Stelle die Worte aus bei dem Gedanken daran, meinen Dank an Dich in Worte zu fassen. 


\section{Inhaltsverzeichnis}

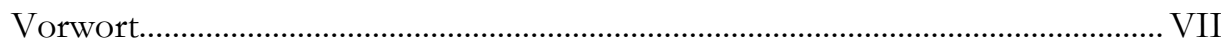

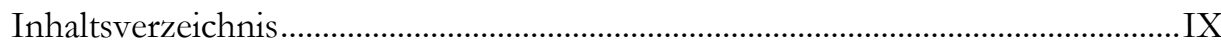

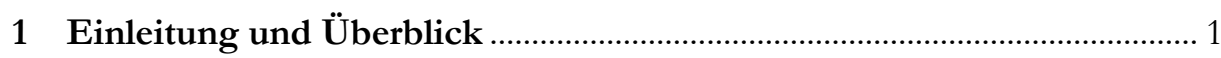

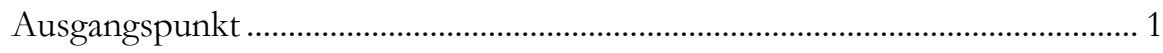

Relevanz und Begründung des Gegenstands.................................................... 9

Zum Aufbau der Untersuchung ....................................................................... 15

2 Gesellschaftstheoretische Grundlagen. Subjekt, Gesellschaft

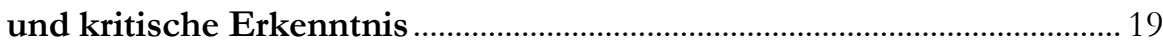

2.1 Der Wahrheitsbegriff als Maßstab von Kritik.......................................... 19

2.2 Der transzendentale Idealismus Kants als kritischer Ausgangspunkt gesellschaftstheoretischer Überlegungen ...................... 34

2.2.1 Kants transzendental-zeitliches Subjekt als kritische Voraussetzung der Formulierung einer objektiven

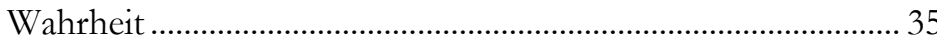


2.2.2 Zur emanzipativen Dialektik des Kantischen

Transzendentalsubjekts als Kritik des

philosophischen Subjektivismus

2.2.3 Die Wahrheit der Aussage im autonomen Objekt.

Kausalität und notwendige Intelligibilität. .51

2.3 Die Emanzipation des transzendentalen Idealismus in der Kritischen Theorie

2.3.1 Das Adornosche Subjekt der (Selbst-)Kritik und der Zeitkern. Genese und Geltung oder: $\mathrm{Zu}$ Theorie und Praxis

2.3.2 Horkheimers, instrumentelle Vernunft ${ }^{`}$ oder:

Die Vernunft als Mittel zum Zweck

2.3.3 Grenzen der Vernunft. Beherrschung oder Bearbeitung von Natur? Gedanken zum Begriff der Herrschaft.

2.4 Die negative Dialektik Adornos als Voraussetzung emphatischer Kritik

2.4.1 Hegels System: (Positive) Dialektik als Methode .90

2.4.2 Logik und Geschichte bei Hegel. Idealistische Widerspiegelungstheorie oder Geschichte als Methode

2.4.3 Adornos Rettung des restontologisch Unmittelbaren.

2.4.4 Negative Dialektik: eine Ontologie? 107

2.4.5 Die verdoppelte intentione obliqua als Kritik subjektivistischer Suppositionen

2.5 Das Gesellschaftsphänomen im Kontext.....

2.5.1 Zu Ontologisierung und Subjektivierung des modernen Antisemitismus

2.5.2 Die gesellschaftstheoretische Vermittlung von Wesen und Phänomen.

2.5.3 Zur Dialektik von Naturgesetzen, Naturbearbeitung und Gesellschaftsphänomenen

2.6 Zum Handeln der Subjekte in Gesellschaft.

2.6.1 Integration: Die bürgerliche Gesellschaft im subjektiven Handeln

2.6.2 Integration und Differenzierung. Subjektives Handeln und Geschichte.

2.6.2.1 Der frühe Marx und das subjektive Handeln in der Geschichte. 
2.6.2.2 Der späte Marx und das subjektive

Handeln in der Geschichte 158

2.6.3 Gesellschaftliche Integration als universaler Zwang, konform zu handeln

2.6.4 Das sozialpsychologische Moment der Integration.

Selbstdifferenzierung und Ich-Dialektik.

\section{Gesellschaft, Staat und Kapital. Reflexionen zu Totalität} und Herrschaft

3.1 Aller Anfang ist Gewalt. Historische Voraussetzungen gesellschaftlicher Totalität

3.1.1 Vor Staat und Eigentum. Rationalität und Irrationalität des gesellschaftlichen Umbruchs

3.1.2 Die ursprüngliche Akkumulation' bei Marx als irrationale Rationalisierung der kapitalistischen Produktionsweise.

3.2 Postrevolution, Gewalt und Zwang. Die Garantie von Eigentum als entscheidendes Moment der bürgerlichen Totalität

3.2.1 Die Systematisierung der revolutionären Gewalt. Zum Begriff des Eigentums

3.2.2 Das Verhältnis von Eigentum und Gewalt.

3.2.3 Kapitalistisches Eigentum ohne Staat? Gedanken zum konsequenten Liberalismus ....

3.2.4 Entfremdung: Das Resultat des abstrahierenden Eigentumstitels

3.2.5 Verdinglichung durch Vereigentümlichung. Ware Arbeitskraft und Privateigentum

3.3 Zur praktischen Diskussion des abstrakten Eigentumstitels.

Die Allgemeine Erkelärung der Menschenrechte von 1948

3.4 Form als reales Versprechen.

Die Realität der Marxschen fictio juris im Kontext

3.5 Zur Diskussion des permanenten Staatseingriffs

in die Ökonomie in der Kritischen Theorie.

3.6 Wille und Staat. Zur Dialektik von Subjekt und totaler, heteronomer Gesellschaft.

3.6.1 Zur unfreiwilligen Freiwilligkeit der eigenen Reproduktion.

Zur Dialektik von Körper und Geist

3.6.1.1 Die unfreiwillige Freiwilligkeit der an

Produktionsmitteln Eigentumslosen 
3.6.1.2 Die unfreiwillige Freiwilligkeit der Eigentümer an Produktionsmitteln 257

3.6.2 Sozialisation I: Thesen zum Nationalismus ............................ 260

3.6.3 Sozialisation II: Mehrwertproduktion und Eigentum ............275

3.6.4 Sozialisation III: Zwang zur Produktion des

Allgemeinwohls 280

\section{Aufbau- und Zwischenkapitel. Wert, Eigentum und}

Reichtumsproduktion.

4.1 Vom Äquivalententausch zur Ware Arbeitskraft

4.1.1 Zur Waren- und Wertformanalyse. Reflexion der

Zirkulationssphäre 284

4.1.2 Reflexionen zur Objektivität des Warenwerts....

4.1.3 Zur Logik der hinausweisenden Abstraktion: Vom Sinn der Abwesenheit der Ware Arbeitskraft in der Wertformanalyse

4.1.4 Zur Ware Arbeitskraft im Eigentumstausch............................ 305

\section{Der moderne Antisemitismus und seine gegenwärtig} gesellschaftskritische Reflexion

5.1 Zur Wertkritischen Theorie des Antisemitismus

5.1.1 Zum notwendig falschen Bewusstsein als richtiges

Bewusstsein 316

5.1.2 Fetisch ohne Freiheit, Phänomene ohne Wesen 324

5.1.3 Zu Postones (negativer) Widerspiegelungstheorie. 343

6 Résumé. 351

Literaturverzeichnis 357 


\section{Einleitung und Überblick}

„Dialektische Vernunft folgt dem Impuls, den Naturzusammenhang und seine Verblendung, die im subjektiven Zwang der logischen Regeln sich fortsetzt, zu transzendieren, ohne ihre Herrschaft ihm aufzudrängen: ohne Opfer und Rache. Auch ihr eigenes Wesen ist geworden und vergänglich, wie die antagonistische Gesellschaft.“1

\section{Ausgangspunkt}

Die Frage nach einem gesellschaftlichen Wesen klingt anachronistisch und deshalb trivial. Jede akademische Forschung, die heute versucht, empirische Fakten, die aus der Erfahrung unmittelbar gewonnen sind, wesentlich zu ergründen, gilt deshalb großen Teilen der heutigen Gesellschaftswissenschaften als verstaubte Metaphysik. Spätestens seit der Comteschen philosophie positive ${ }^{2}$ wird der philosophischen Arbeitsweise in den Gesellschaftswissenschaften sukzessive ein anti-

\footnotetext{
1 Adorno: Negative Dialektik, S. 145.

${ }^{2}$ Vgl. Comte: Die Soziologie. Die positive Philosophie im Auszug (Cours de philosophie positive), S. 5: „Es wird mir nun leicht sein, das Wesen der positiven Philosophie darzulegen. Für diese Philosophie sind alle Vorgänge unveränderlichen Gesetzen unterworfen; für sie ist es ein vergebliches Unternehmen, nach den ersten Ursachen oder den letzten Zwecken zu forschen. Die positiven Erklärungen bieten keine Ursachen, welche Erscheinungen erzeugen“".
} 
quierter, ja gar unaufgeklärter Anstrich untergeschoben. Comte nimmt für seine Diskredition der Philosophie die philosophische Tradition des Nominalismus auf und nutzt die mit dem Nominalismus aufkommenden Überlegungen, den Allgemeinbegriff für seine spezifischen Zwecke zu entsubstantialisieren. Im Zuge der nominalistischen Abschaffung des Allgemeinbegriffs emanzipiert er geschickt die Soziologie als akademisch eigenständiges Fach von der Philosophie. ${ }^{3}$ Dadurch gehen der Soziologie auch klassische philosophische Begriffe verloren. Die Behauptung, dass es etwas wie ein begrifflich aufzubrechendes gesellschaftliches Wesen als Realgrund hinter der faktischen Erscheinung gebe, wird für den Positivisten Comte durch seinen Nominalismus zur reinen Begriffsjongliererei ohne Substanz, zur philosophischen Spekulation ohne jede Sicherheit. Die metaphysischen Spekulationen gingen demnach als abzulehnender philosophischer Restbestand am konkreten, zu erforschenden Gegenstand, den harten sozialen „Tatsachen" “4, vorbei. Dementsprechend gerät auch noch ein wissenschaftliches Arbeiten, das Begriffliches mit Fakten belegen möchte, ins Hintertreffen, weil auch hier mit angeblich unlängst Überholtem wie dem Begriff überhaupt hantiert werde. Der Verdacht einer unwissenschaftlichen Arbeitsweise macht sich deswegen nach dem Siegeszug des Positivismus deswegen überall dort breit, wo überhaupt noch mit an Metaphysik erinnernden Allgemeinbegriffen, zumal mit Strukturbegriffen, gearbeitet wird. Der nominalistische Positivismus möchte nicht mehr am begrifflichen Wesen hinter den Fakten forschen, auch nicht bezüglich sozialer Phänomene. Deshalb gilt heute auch die Frage nach den Ursprüngen des Erkenntnisgrundes der sozialen Phänomene der empirischen Sozialforschung, als in der Tradition des Positivismus stehende Wissenschaft, als unwissenschaftlich. Der qualitativen und quantitativen Feldforschung, die das faktische - allerdings durch Methoden bereits zugerichtetes Material - sammelt, bleibt damit jedoch notwendig unklar, wodurch das von ihr untersuchte Faktum als individuiertes überhaupt existiert. ${ }^{5}$ Durch ihre Begriffslosigkeit zerfällt der Sozialforschung der eigene Gegenstand in unzusammenhängende, empirisch jeweils zerforschte Einzelteile. Wenn derglei-

\footnotetext{
${ }^{3}$ Die Zersprengung der Philosophie in verschiedene, aus ihr hervorgehende Teilwissenschaften im 19. Jahrhundert fordert auch ihren inhaltlichen Tribut. In den neuen Wissenschaften werden Probleme zum Gegenstand, die zwar schon lange Gegenstand der philosophischen Tradition sind, sich in den emporkommenden Disziplinen aber, zuweilen weil karrierefördernd, als unmittelbar neu gerieren. Anführen lassen sich beispielsweise die Wiederaufnahmen der spezifischen Thematiken des Universalienstreits unter anderen Vorzeichen. Im Bereich der Sprachwissenschaft stellt ihr Begründer, Ferdinand de Saussure, im Auftrag der Linguistik die Frage nach Zeichen, Arbitrarität usw. ,neu'. (Vgl. Ferdinand de Saussure: Cours de linguistique générale.) Schon Ockham wollte res durch signa ersetzen; schon für ihn hat die Wissenschaft seinerzeit bloß Zeichen zum Gegenstand.

(Vgl. dazu Haag: Der Fortschritt in der Philosophie, S. 58.)

${ }^{4}$ Comte: Die Soziologie, S. 2.

${ }^{5}$ Ausnahmen, die allerdings auch selbst Existenzialurteile eigener Thesen aufspüren und nicht positivistisch argumentieren, lassen sich finden: Salzborn: Der Antisemitismus als negative Leitidee der Moderne,. Holz: Nationaler Antisemitismus. Wissenssoziologie einer Weltanschauung. Adorno: Studies in the Authoritarian Personality, S. 237 ff.
} 
chen jedoch das Wesen vor lauter Fakten vergessen wird, kann das quantitativ oder qualitativ erhobene Phänomen weder selbst, noch können die spezifischen Differenzen am untersuchten Gegenstand erkannt werden. Der Positivismus beschränkt sich dementsprechend selbst auf eine Bestimmung der nur relationalen Eigenschaften der empirischen Dinge. Selbst der von der Sozialforschung bisweilen noch angeführte abstrakte Hinweis auf ,die Gesellschaftlichkeit' des erscheinenden Faktums kann dabei nicht die notwendige Reflexion darauf ersetzen, wie, warum und ob das soziale Phänomen überhaupt ein wesentlich mit der bürgerlichen Gesellschaft und ihren strukturellen Bewegungsgesetzen Zusammenhängendes ist. Schon Adorno registriert, dass dem begriffsfeindlichen Positivismus jeder genuine Forschungsgegenstand entgleiten muss: „Mit anderen Worten also: das Denken des Positivismus ist prinzipiell ein Dinghaftes, ein verdinglichtes Denken, das eigentlich die Erkenntnis reduzieren möchte auf die Behandlung der Resultate von Denken, ohne daß der Ursprung dieser Resultate und ohne daß der Ursprung der Gegenstände, um die es dabei geht, eigentlich in das Blickfeld treten. "6 Auch die empirische Antisemitismusforschung ist begriffsfeindlich und positivistisch. In welchem gesellschaftlichen, politischen und ökonomischen Kontext der Totalität der moderne Antisemitismus erscheint, kann und will auch von ihr im Zuge des eigenen Nominalismus nicht mehr kritisch beantwortet werden: „Fehlt aber der Analyse der Blick für die gesellschaftliche Totalität, so zerfällt der Antisemitismus wieder in viele unverbundene, wiewohl quantifizierbare Stereotypen, die einer gewissen Beliebigkeit nicht entbehren. ${ }^{\text {'7 }}$

Positivistische Prämissen der Forschung resultieren nun gerade durch die Verdinglichung des Denkens auch noch in einer gewissen Definitionswut. Weil die wesentlichen Ursprünge des Antisemitismus durch die verdinglichte, positivistische Verfahrensweise ignoriert werden, gilt der moderne Antisemitismus durch Definitionen heute schnell als begriffen. ${ }^{8}$ Die Europäische Stelle zur Beobachtung von Rassismus und Fremdenfeindlichkeit (EUMC) verkürzt den Antisemitismus jedoch, indem sie ihn viel zu schnell als eine bloße Merkmalseinheit bestimmt. Ihre Working Definition of Antisemitism hält dabei fest, was alles an subjektiven Handlungen antisemitisch sei, um das Herausgefundene dann dadurch als Antisemitismus zu überführen. Das antisemitische Handeln gehe demnach auf eine, bestimmte Wahrnehmung“ (certain perception) der Antisemiten von Juden zurück: „Antisemitism is a certain perception of Jews, which may be expressed as hatred toward Jews. Rhetorical and physical manifestations of antisemitism are directed toward Jewish or non-Jewish individuals and/or their property, toward Jewish community

\footnotetext{
${ }^{6}$ Adorno: Vorlesung zur Einleitung in die Erkenntnistheorie, S. 24.

${ }^{7}$ Claussen: Grenzen der Aufklärung, S. 41.

8 Samuel Salzborn weist anhand des Rechtsextremismus nach, dass dieser mit einer bloßen Definition nicht zu erklären ist. Nur ,auf den ersten Blick scheint die Frage leicht zu beantworten.“

(Salzborn: Rechtsextremismus, S. 13.)
} 
institutions and religious facilities. "9 Dass sich der Antisemitismus im Hass auf Juden ausdrückt, ist allerdings keine bahnbrechende Entdeckung. So bleibt die Definition von Antisemitismus durch die EUMC letztendlich eine offensichtliche und allzu abstrakte Tautologie; nämlich die, dass Antisemitismus Judenhass sei.

Aber nicht nur die EUMC verfällt bei der Diskussion des Antisemitismus der positivistischen Oberflächlichkeit. Auch die Antonio Amadeu Stiftung definiert den Antisemitismus, und unterstützend wird von ihr dafür auf ihrer Homepage Wolfgang Benz, Zentrum für Antisemitismusforschung der TU Berlin, herangezogen: „Unter dem Begriff ,Antisemitismus' kann man ,die Gesamtheit judenfeindlicher Äußerungen, Tendenzen, Ressentiments, Haltungen und Handlungen unabhängig [!] von ihren religiösen, rassistischen, sozialen oder sonstigen Motiven' fassen. "10 Auch diese Definition stellt, wie schon die der EUMC, das Phänomen als bereits begriffenes Faktum dar. Die sinnlich wahrnehmbaren, quantifizierbaren Stereotypen' müssten demnach, und einmal mehr wird der Antisemitismus als eine Merkmalseinheit gedacht, nur noch empirisch zusammengetragen werden, um den Antisemitismus dadurch als ein gesellschaftliches Phänomen dingfest zu machen. Das entspricht jener positivistischen Comteschen „Beziehung“11 der Fakten, die ein komplettes Bild vom Gegenstand zeichnen soll - weil demnach alles in einen funktionalen Zusammenhang gestellt werden kann. Woher jedoch die einzelne ,Äußerung ' des Merkmals bzw. der sich äußernde Antisemitismus wesentlich stammt, bleibt dem funktionalistischen, positivistischen Vorgehen dabei fremd. $\mathrm{Zu}$ schnell wird deshalb mittels der Definitionen bestimmt, was Antisemitismus sei $^{12}$, vom gesellschaftlich Wesentlichen, das notwendig begrifflich vermittelt ist, wird dabei jedoch abstrahiert.

Die sozialwissenschaftliche Reflexion des Wesens hat nun generell nie etwas anderes als Begriffe zur Bezeichnung der Sache. Diese notwendige Aporie von Begriff und Inhalt beschreibt Adorno als die notwendig widersprüchliche Anstrengung einer kritischen Theorie. Weil man nicht einfach „Einzeldinge in die Texte kleben“"13 könne, müsse sich der anstrengenden intellektuellen Vermittlungsarbeit von Begriff und Gegenstand gestellt werden. Diese von Adorno ernst genommene Vermittlungsarbeit hat gewisse Voraussetzungen, die eine Vermittlung von Subjekt und Objekt überhaupt erst zulässt. Keine kritische Aussage über das den Begriffen korrelativ Zugrundeliegende könnte möglich sein, wenn dem durch Begriffe bezeichnetem Material nicht auch selbst noch eine Substanz zuge-

\footnotetext{
${ }^{9}$ european-forum-on-antisemitism.org: Definition of Antisemitism.

10 amadeu-antonio-stiftung.de: Was ist Antisemitismus?.

11 Comte: Die Soziologie, S. 5.

12 „Der Positivismus beansprucht ja gegenüber der Metaphysik, gegenüber der naiven Sprache, gegenüber allen möglichen Erscheinungsformen eben außerordentlich kritisch zu sein; er hat immerzu die Frage bei der Hand, wo die Evidenz sei, was ein Ausdruck bedeute, ob die Begriffe klar definiert seien, und was nicht noch alles." (Adorno: Vorlesung zur Einleitung in die Erkenntnistheorie, S. 24.)

13 Adorno: Negative Dialektik, S. 23.
} 
sprochen würde, sondern Begriffe und Sprache wie in der Linguistik als lediglich subjektive Instrumente der Bezeichnung von Dingen gesehen werden. Die beispielhaft genannten Definitionen allerdings befreien sich dagegen subjektivistisch willkürlich von der autonomen Substanz ihres korrelativen Gegenstands: Jede Definition kann immer nur mit dem Erklären von Begriffen mit Begriffen durch Prädikate beginnen und enden, darüber aber kommt sie notwendig nicht hinaus. Dieses tautologische Verfahren schränkt den Blick auf das dem sozialen Phänomen zugrundeliegende gesellschaftliche Wesen notwendig und unmittelbar ein. Auch der Begriff des modernen Antisemitismus bedarf erst der vermittelnden „Reflexion eben auf die Sache“"14, „welche zugunsten von begrifflicher Handlichkeit durchs Definieren abgeschnitten wird. "'15

Die Reflexion auf die wesentliche, gesellschaftliche Sachlichkeit des sozialen Phänomens verlangt nun nach der substantiellen Kritik der Gesellschaft, denn die moderne, kapitalistische Gesellschaft bringt den modernen Antisemitismus als Merkmalseinheit erst hervor, Dass sich der Antisemitismus im Hass auf Juden ausdrückt, ist allerdings keine bahnbrechende Entdeckung. So bleibt die Definition von Antisemitismus durch die EUMC letztendlich eine offensichtliche und allzu abstrakte Tautologie; nämlich die, dass Antisemitismus Judenhass sei. ${ }^{16} \mathrm{Um}$ eine wirklich substantielle Kritik am sozialen Phänomen zu üben, bedarf es deshalb eines gesellschaftstheoretischen Maßstabs, der nicht als selbstverständlich vorausgesetzt werden kann und der sich auch nicht aus den rein definitorischen Beschreibungen des Phänomens ergibt. Weil der moderne Antisemitismus damit über seine eigene Erscheinung und seine Merkmale hinausgeht, ist er deshalb nicht ohne den emphatischen, totalen Begriff von der bürgerlichen, kapitalistischen Gesellschaft zu begreifen. Auch der gesellschaftliche Totalitätsbegriff lässt sich nicht einfach empirisch verifizieren. Er ist kein zu erschließendes Faktum, sondern er geht über jedes einzelne Faktum hinaus. Jeder Versuch einer emphatischen Bestimmung des sozialen Phänomens hat demnach über faktisch Seiendes und faktisch Fixierbares mit Begriffen hinauszugehen. Diesen Zwang zur Reflexion des gesellschaftlichen Wesens der sozialen Fakten übersehen die positivistischen Sozialwissenschaften; ganz anders als Adorno: „Weil nichts Seiendes ist, das nicht, indem es bestimmt wird und sich selbst bestimmt, eines anderen bedürfte, das nicht es selber ist - denn durch es selbst allein wäre es nicht zu bestimmen -,

\footnotetext{
${ }^{14}$ Adorno: Zu Subjekt und Objekt, S. 741.

${ }^{15}$ Ebd. S. $741 \mathrm{f}$.

${ }^{16}$ Der im Entstehen begriffene moderne Antisemitismus verweist auf ein politisch-ökonomisches Wesen hinter ihm. Es sind „eben gesellschaftliche Bedingungen und Strukturen (...), die (...) Antisemitismus (...) hervorbringen." (Brainin: Psychoanalyse des Antisemitismus nach 1945, S. 106. Vgl. auch Löwenthal: Individuum und Terror, S. 163.) Versuche, den Antisemitismus als der bürgerlichen Gesellschaft und der kapitalistischen Produktionsweise äußerlich zu beschreiben, hat es jedoch auch im Dunstkreis der Kritischen Theorie gegeben. Ernst Simmel z.B. sieht den Antisemitismus als „Nebenprodukt unserer Zivilisation“ (Simmel: Antisemitismus und Massen-Psychopathologie, S. 58.) und analysiert ihn deshalb als „Massenpsychose“ (ebd., S. 64.)
} 
weist es über sich hinaus. “"17 Gesellschaftlich Wesentliches, das nicht im phänomenal Seienden unmittelbar erscheint, kann demnach also immer erst mit entsprechend rationalen Begriffen eruiert werden.

Deshalb muss eine Untersuchung, die wie diese soziale Phänomene zum Gegenstand hat, letztendlich wesentliche Bestimmungen des Phänomens und seine Eingebundenheit in die gesellschaftliche Totalität ernster nehmen als dieses selbst. Durch den faktischen Antisemitismus hindurch vermitteln sich nämlich erst wesentliche gesellschaftliche Missstände. Der moderne Antisemitismus verweist insofern durch seine Artikulation auf Historisches und Gesellschaftliches, auf sein gesellschaftliches Wesen, das nicht aus der Welt ist. Für die wesentliche Erkenntnis des Phänomens müssen deshalb innere wie äußere Zusammenhänge der gesellschaftlichen Totalität und die Konstellation des Phänomens in ihr betrachtet werden. Der Antisemitismus ist insofern eine sachliche Erscheinung von etwas, das er nicht selbst ist, weil er nicht nichts ist. Er ist darum auch nicht als Grund und Folge gesetzt, wie als wenn er eben nur als in verschiedenen Formen auftretender Judenhass definiert und qualifiziert würde. Die Konsequenz aus den Definitionen von Antisemitismus als Judenhass konnte ja immer nur das wenig erkenntnisreiche tautologische Verhältnis von Grund und Begründetem sein. Gegen jeden Positivismus soll in dieser Untersuchung aufgezeigt werden, wie entscheidend die sozialen Phänomene mit wesentlichen gesellschaftlichen Gesetzen zusammenhängen, die selber empirisch nicht wesentlich erforscht bzw. methodisch erhoben werden können. Ohne diese gesellschaftlichen Gesetze kann das soziale Phänomen auch gar nicht wesentlich gedacht werden - geschweige denn kann es ohne die Reflexion seiner Strukturgesetze kritisch auf den Begriff gebracht werden. Trotzdem darf die Erforschung sozialer Tatsachen an dieser Stelle auch nicht kleingeredet werden, und die elementare Wichtigkeit der empirischen Sozialforschung für die Reflexionen auf Gesellschaft darf nicht vernachlässigt werden. Die empirische Sozialforschung ist zu retten, weil soziale Fakten in der Gesellschaftswissenschaft nicht einfach übergangen werden können. Die wesentlichen, objektiven Bewegungsgesetze der Gesellschaft haben bloß Gültigkeit, wenn sie sich auch in sozialen Fakten ausdrücken: „Aber diese objektiven Bewegungsgesetze haben Gültigkeit nur so weit, wie sie tatsächlich in sozialen Phänomenen sich ausdrücken und nicht, wenn sie im Sinn einer bloß deduktiven Ableitung aus reinen Begriffen, und mögen diese Ableitungen noch so tief in gesellschaftlicher Erkenntnis verwurzelt sein, sich erschöpfen." ${ }^{18}$

Die These, dass eine emphatische Antisemitismusforschung über empirische Erhebungsverfahren hinausgehen muss, verfolgt auch Lars Rensmann. ${ }^{19}$ Dem Großteil der heutigen mit qualitativen oder quantitativen Methoden arbeitenden Antisemitismusforschung wirft er im Zuge dessen die „Marginalisierung antisemi-

\footnotetext{
17 Adorno: Negative Dialektik, S. 109.

18 Adorno: Vorlesung zur Einleitung in die Soziologie, S. 23.

${ }^{19}$ Rensmann: Kritische Theorie über den Antisemitismus.
} 
tismus-theoretischer Reflexionen in den Sozialwissenschaften“ ${ }^{20}$ vor. So gut wie gar nicht würde in den heutigen Sozialwissenschaften das Wesen des untersuchten Gegenstands reflektiert. Nur oberflächlich hole man hier und da empirische Daten über den Antisemitismus ein, und mithilfe von bereits vorgefertigten Parametern solle dann ein entsprechend exaktes Bild des Antisemitismus gezeichnet werden. ${ }^{21}$ Solch ein Bild bleibe jedoch durch die Faktenzentriertheit immer gefährlich eindimensional, weil selbstbeschränkt. Rensmann stellt sich damit in die Tradition der klassischen Kritischen Theorie: „Nach dem einfachsten common sense treibt Empirie zur Totalität." 22

Auch der klassischen Kritischen Theorie gilt der moderne Antisemitismus als wesentlich mit der gesellschaftlichen Totalität der bürgerlichen, kapitalistischen Produktionsweise vermitteltes Phänomen. In den ,Elementen des Antisemitismus` der Dialektik der Aufklärung bestimmen Adorno und Horkheimer nicht grundlos die konkrete bürgerliche Gesellschaft mitsamt ihrer kapitalistischen Produktionsform als das, was wesentlich hinter dem sozialen Phänomen als jenes in den gesellschaftlichen Zusammenhang einbindende Totalität walte: „Der bürgerliche Antisemitismus hat einen spezifischen ökonomischen Grund: die Verkleidung der Herrschaft in Produktion. "23 Dem profunden Urteil aus der Dialektik der Aufklärung, dass hinter dem sozialen Phänomen Antisemitismus die wirkmächtige, wesentliche gesellschaftliche Totalität steht, in die das Phänomen konstellativ eingebunden ist und die selbst nicht faktisch erhoben werden kann, verschreibt sich auch die vorliegende Arbeit. Sie fragt deshalb dezidiert nach der politisch-

\footnotetext{
${ }^{20}$ Ebd., S. 8.

${ }^{21}$ Rensmann zitiert Werner Bergmann, der wie der bereits genannte Wolfgang Benz Professor am Zentrum für Antisemitismusforschung (ZfA) in Berlin ist: ,,[E]ine theoretisch orientierte empirische Forschung findet nicht statt. Die empirische Soziologie weist genau den komplementären Mangel auf: Die erhobenen Daten werden nicht zur Theoriebildung benutzt, sondern jeweils ad hoc kurzatmig ausgewertet.“ (Bergmann: Politische Psychologie des Antisemitismus, S. 219, zitiert nach Rensmann: Kritische Theorie über den Antisemitismus, S. 8.)

Fraglich ist, ob erhobene Daten zur Theoriebildung ,benutzt“" werden können, wie Bergmann vermutet. Was sich nach tendenziöser Zurichtung von Theorie anhört, beruht ebenfalls auf zweifelhaften positivistischen Prämissen. Bergmann begeht nämlich den Kardinalfehler positivistischer Theoriebildung: „Des Aberglaubens, daß die Forschung als tabula rasa zu beginnen habe, auf welcher die voraussetzungslos sich einfindenden Daten zugerichtet werden, müßte die empirische Sozialforschung gründlich sich entschlagen und dabei freilich längst durchgefochtener erkenntnistheoretischer Kontroversen sich erinnern, die das kurzatmige Bewußtsein unter Berufung auf die vordringlichen Erfordernisse des Betriebs nur zu gern vergisst." (Adorno: Soziologie und empirische Forschung, S. 211.) Dieser klassischen Falle positivistischer Theoriebildung entgeht Rensmann, obwohl er Bergmann affirmativ zitiert. „Eine Theorie über den Antisemitismus, die sich ins Verhältnis setzt zu seiner gegenwärtigen gesellschaftlichen Relevanz, wurde seit den kritisch-theoretischen Analysen nur vereinzelt und unzureichend versucht.“ (Rensmann: Kritische Theorie über den Antisemitismus, S. 8.)

22 Adorno: Einleitung zum ,Positivismusstreit in der deutschen Soziologie‘, S. 291.

23 Adorno/Horkheimer: Dialektik der Aufklärung, S. 197.
} 
ökonomischen Beschaffenheit der bürgerlichen Gesellschaft, die den modernen Antisemitismus als ein solch manifestes soziales Phänomen erst konstituiert.

Die Suche nach vermittelten Antworten, wie denn Grund und Begründetes, Grund und Folge bezüglich eines sozialen Phänomens überhaupt gedacht werden können, ist insofern der theoretisch kritische Ausgangspunkt dieser Arbeit. Dafür werden hier weiterhin metaphysisch anmutende und inzwischen in Verruf geratene Begriffe wie Wesen und Phänomen verwendet, weshalb in dieser Arbeit „Wesen und Erscheinung (...) kein Märchen aus alten Zeiten, sondern bedingt von der Grundstruktur einer Gesellschaft, die notwendig ihren eigenen Schleier zeitigt", 24 bleiben. In dieser Arbeit wird gerade durch die Reflexion auf das Wesen der Erscheinung auch ein kritischer, emphatischer Begriff von (totaler) Gesellschaft zwingend. Über die Begrifflichkeit vermittelt kann dann erst wesentlich über das gesprochen werden, was in der Gesellschaft faktisch erscheint. So wird hier auch eine kritische Substanz als wesentlicher Bestandteil einer kritischen Theorie gerettet, gerade weil in dieser Arbeit nicht verbissen am Phänomen gearbeitet wird. Das soziale Phänomen wird in dieser Untersuchung nicht unter eine vermittlungsarme Glocke gesteckt, weil man, getreu dem positivistischen Credo, „alle (...) Prinzipien auf die geringste Zahl“ 25 beschränken möchte. Der moderne Antisemitismus wäre letztendlich, so die Überzeugung des Autors, durch jede Zersprengung in Einzelbereiche keiner substantiellen Kritik mehr zugänglich. Die positivistische Herauslösung des Antisemitismus aus der Totalität lasse deshalb auch „das Identische in der Vielfalt der Antisemitismen“26 nicht mehr „zu Bewusstsein“27 kommen, wie Wolfram Stender und Detlev Claussen zu Recht bemängeln: „Das Neue oder Alte am Antisemitismus läßt sich nicht erkennen, wenn man nur auf den Antisemitismus starrt. Nicht einmal der Antisemitismus läßt sich so erkennen. “28 Ein intendiert eingeschränkter positivistischer Blick auf vereinzelte Phänomene und dessen Auswüchse würde demzufolge nichtssagend und notwendig ausdruckslos bleiben, weil dem Positivismus der Blick aufs konkrete Ganze fehlt. Gegen diesen positivistischen Verlust der zusammenhängenden, substantiellen Erklärung des Phänomens muss das Phänomen moderner Antisemitismus also begreifbar und auch substantiell angreifbar bleiben.

Die mit tautologischen, schnellen Definitionen arbeitenden Positivisten sind nun, weil ihnen der Blick aufs konkrete Ganze fehlt, auch noch davon überzeugt, dass der moderne Antisemitismus nicht einmal mehr rational erklärbar sei. Er sei demnach einfach nur das Ergebnis eines irrationalen subjektiven Verhaltens. Irrational kann der moderne Antisemitismus jedoch immer nur in Bezug auf das gesellschaftliche Ganze sein, nicht aber in Bezug auf die zweckbestimmte gesell-

\footnotetext{
${ }^{24}$ Adorno: Gesellschaftstheorie und empirische Forschung, S. 544.

${ }^{25}$ Comte: Die Soziologie, S. 8.

${ }^{26}$ Stender: Konstellationen des Antisemitismus, S. 8.

${ }^{27}$ Ebd.

${ }^{28}$ Claussen: Grenzen der Aufklärung, S. VIII.
} 
schaftliche Erklärung. Ansonsten würde man sich an der Stelle bewusst oder unbewusst von jeder weiteren rationalen Erklärung des Phänomens suspendieren. Denn angenommen, das Verhalten der Antisemiten (und damit das Phänomen selbst) wäre einfach nur irrational, so wäre jede substantielle, gesellschaftstheoretische Erklärung des Phänomens hinfällig und unmöglich. Darum bleibt der Antisemitismus für Adorno, der diese Widersprüche von Rationalität und Irrationalität des Antisemitismus dialektisch reflektiert, „das zu begreifende Unbegreifliche. “29 „Das wissenschaftliche Bewusstsein darf sich nicht dabei bescheiden, das Rätsel der antisemitischen Irrationalität auf eine selber irrationale Formel zu bringen. "30

Das Handeln der Antisemiten muss insofern hinsichtlich der Eingebundenheit des subjektiven Handelns in die gesellschaftliche Totalität rational erklärbar bleiben. Diese gesellschaftliche Rationalität des Antisemitismus, bei aller zugestandener gesamtgesellschaftlicher Irrationalität, versucht die Untersuchung mit der Reflexion des Phänomens als gesellschaftlicher Gegenstand aufzuzeigen. Reflektiert wird hier deshalb das empirische Faktum hinsichtlich seiner Konstellation in der gesellschaftlichen Totalität. Die Untersuchung befasst sich darum mit einer Ätiologie des modernen Antisemitismus, weshalb sie die wesentlich gesellschaftliche Bedingung des modernen Antisemitismus, die totale bürgerliche Gesellschaft als das entsprechende Konstituens des Phänomens gedacht, auch nicht außer Acht lässt.

\section{Relevanz und Begründung des Gegenstands}

Eigentlich muss sich mit dem neuem Kategorischen Imperativ Adornos, „daß Auschwitz sich nicht wiederhole“ ${ }^{* 31}$, jeder Nachweis der Relevanz und auch der Begründung von Antisemitismusforschung erübrigen: „Dieser Imperativ ist so widerspenstig gegen seine Begründung wie einst die Gegebenheit des Kantischen. “32 Adorno fordert als höchsten Zweck der postauschwitzschen Geschichte die bedingungslose und unbegründbar bleibende Arbeit gegen das Vergessen und das Wiederholen der Gräuel.

Dem neuen Kategorischen Imperativ entsprechend wäre es zynisch und es entspräche eigentlich auch einer theoretischen Selbstdemontage, einer Untersuchung, in der der moderne Antisemitismus wesentlich zum Gegenstand wird, eine Begründung voranzustellen. Weil aber der Kategorische Imperativ, wie Kant ihn denkt, nur formales Prinzip einer Handlungsbeurteilung nach Vernunftprinzipien ist ${ }^{33}$, mit dem letztendlich auch jede materiale Norm gerechtfertigt werden kann,

\footnotetext{
${ }^{29}$ Adorno: Vorworte zu den ,Frankfurter Beiträgen zur Soziologie‘, S. 652.

${ }^{30}$ Ebd.

31 Adorno: Negative Dialektik, S. 358.

32 Ebd.

${ }^{33}$ Kant: Grundlegung der Metaphysik der Sitten, BA 52: „Wenn es denn also ein oberstes praktisches Prinzip, und, in Ansehung des menschlichen Willens, einen kategorischen Imperativ geben soll, so muß es ein solches sein, das aus der Vorstellung dessen, was notwendig für jedermann
} 
sollte doch einmal auf den entscheidenden Unterschied zwischen altem und neuem Kategorischen Imperativ nach Auschwitz, der unweigerlich historisch sachhaltig sein muss, hingewiesen werden. Der Kantische Imperativ in der Grundlegung der Metaphysik der Sitten ${ }^{34}$ setzt nun überhaupt keine konkreten Bedingungen voraus (also keine zweckgerichteten Interessen am Gegenstand, kein politisches Wollen etc.), die ihn begründen. Anders als der ihm gegenübergestellte Hypothetische ist der Kategorische Imperativ als allgemeiner und notwendiger Selbstzweck des Willens formuliert. ${ }^{35}$ Der Kategorische Imperativ hat universelle Geltung aus der Vernunft a priori heraus, weshalb man für ihn keine Begründung aus der Geschichte braucht. Jedweder Begründungsversuch würde jene axiomatische Formulierung des Kantischen Imperativs dialektisch nur wieder in Frage stellen.

Mindestens implizit muss die Kritik des modernen Antisemitismus dagegen eine am historischen Material herausgearbeitete, begründete Handlungsanleitung beinhalten: eine begründete gesellschaftlich emanzipative Antisemitismusforschung mit dem Ziel einer gesellschaftlichen Emanzipation von der Erscheinung sein. Die Kritik des Phänomens Antisemitismus kann deshalb nur begründetermaßen zum höchsten Zweck sozialwissenschaftlicher Forschung werden. Dass Antisemitismus und Massenvernichtung in Gänze unvernünftig sind, muss sich deshalb erst vernünftig am aufbereiteten gesellschaftlichen und geschichtlichen Material zeigen. Das aktive Handeln aufgeklärter Subjekte gegen den modernen Antisemitismus kann also auch erst mithilfe einer gewissenhaften Reflexion auf Geschichte, Gegenwart und Gesellschaft begründet werden. Dafür ist auf die gesellschaftliche Virulenz des Gegenstands in Vergangenheit wie Gegenwart hinzuweisen.

Auschwitz lässt die Antisemiten, zumindest sofern sie sich selbst als solche begreifen, bis heute völlig unbeeindruckt. Der gegenwärtige Blick in die moderne bundesrepublikanische Gesellschaft und ihre Medien genügt, um zu zeigen, dass der moderne Antisemitismus nach, trotz und wegen Auschwitz hochaktuell und brandgefährlich ist. ${ }^{36}$ Seine öffentliche Artikulation nimmt aktuell sogar wieder zu: „Der Rückblick auf die jüngste Geschichte zeigt, dass Antisemitismus in allen Teilen der bundesdeutschen Gesellschaft nicht nur vorhanden ist, sondern zunehmend (wieder) öffentlich artikuliert wird." "37 Dass in der Bundesrepublik wieder öffentlich antisemitische Töne zu hören sind, verweist auf einen über einen

\footnotetext{
Zweck ist, weil es Zweck an sich selbst ist, ein objektives Prinzip des Willens ausmacht, mithin zum allgemeinen praktischen Gesetz dienen kann.“

${ }^{34}$ Ebd., BA 52: „Der kategorische Imperativ ist also nur ein einziger, und zwar dieser: handle nur nach derjenigen Maxime, durch die du zugleich wollen kannst, daß sie ein allgemeines Gesetz werde. ${ }^{\circ}$

${ }^{35}$ Ebd., BA 52: „Wenn ich mir einen hypothetischen Imperativ überhaupt denke, so weiß ich nicht zum voraus, was er enthalten werde: bis mir die Bedingung gegeben ist.“

${ }^{36}$ Yves Kugelmann im Gespräch mit Jobst Paul: „Antisemitismus ist für uns Pflicht und nicht Kür im redaktionellen Alltag“, in: Holz/Kauffmann/Paul (Hrsg.), Die Verneinung des Judentums, S. $73 \mathrm{ff}$.

${ }^{37}$ Salzborn: Antisemitismus, S. 5.
} 
längeren Zeitraum, zumindest öffentlich, verstummten Antisemitismus. Diese historische Phase des nichtöffentlichen Antisemitismus wird in der Forschung als sekundärer Antisemitismus bezeichnet, der sich aber vom modernen Antisemitismus qualitativ nicht trennen lässt. ${ }^{38}$ In der Bundesrepublik Deutschland und Österreich bezeichnet der sekundäre Antisemitismus die spezifische, nichtöffentliche Artikulation des modernen Antisemitismus nach und insbesondere ,wegen Auschwitz“39: „Der Antisemitismus wandelte sich vom gesellschaftlichen common sense zu einer in der Öffentlichkeit als tabuiert wahrgenommenen Einstellung. ${ }^{\text {" } 40}$ Der sekundäre Antisemitismus beschreibt also einen historischen, raumzeitlich begrenzten Sonderfall in der Geschichte als unmittelbare Folge der systematischen Vernichtung der Juden im Nationalsozialismus. Für den modernen Antisemitismus und seine traditionell öffentliche Artikulation wirkt die industriell betriebene Massenvernichtung mittelfristig hemmend, was ihn in der deutschen und österreichischen Nachkriegsgesellschaft aus der Öffentlichkeit verbannt. Diese raumzeitliche Spaltung des modernen Antisemitismus nach Auschwitz oder besser: diese Parallelführung seines gesellschaftlichen Ausdrucks, bezieht sich jedoch nur auf seine öffentliche Quantität; qualitativ hat es in beiden deutschsprachigen, bürgerlichen Nachkriegsgesellschaften nicht plötzlich weniger Antisemitismus wegen Auschwitz gegeben. ${ }^{41}$

Es sind Scham und gesellschaftliche Schuldabwehr gleichermaßen, die die vorher offene Judenfeindschaft inzwischen historisch verklausulieren und durch die der Antisemitismus mit einem nichtöffentlichen, gesellschaftspolitischen Tabu belegt wird. Der sekundäre Antisemitismus ist darum eine den modernen Antisemitismus verklausulierende Verdinglichung. Das antisemitische Bewusstsein brandmarkt dabei historisch mit Juden identifizierte Tätigkeiten als gesellschaftlich verhängnisvoll, während im Gegenzug Juden als Personen aus der (öffentlichen) rhetorischen Schusslinie genommen werden: „Der sekundäre Antisemitismus prangert nicht die Juden als Störenfriede an, sondern die Entfremdung ist zur Verdinglichung fortgeschritten - nur noch die ehemaligen als jüdisch charakterisierten Qualitäten, Spekulationen in Geld und Geist, gelten ohne spezifisch kenntlich gemachte Träger als Repräsentanten der Bedrohung. "42 Das Wort Jude wird also längere Zeit bei gleicher gesellschaftlicher Konnotation öffentlich einfach nicht mehr ausgesprochen. Der Antisemit streicht insofern einschlägig antisemitische Vokabeln aus seinem öffentlichen Wortschatz, und der weiterhin virulente gesellschaftliche Antisemitismus manifestiert sich in dieser Phase des sekundären Antisemitismus in der verklausulierten, aber trotzdem genügend Rezipienten er-

\footnotetext{
${ }^{38}$ Der sekundäre Antisemitismus ist „,nicht unabhängig von den Voraussetzungen des modernen

Antisemitismus“. (Ebd., S. 232.)

${ }^{39}$ Broder: Der ewige Antisemit, S. 11.

${ }^{40}$ Salzborn: Antisemitismus, S. 15. (Herv. im Original)

${ }^{41}$ Vgl. dazu auch ebd., S. 28 ff.

42 Claussen: Grenzen der Aufklärung, S. 74.
} 
reichenden Sprache. Erst mühsam musste man die antisemitische ,Geheimsprache aufbrechen, um den versteckten Antisemitismus unter scheinbar ,harmlosen Termini aufzudecken.

Zwar ist es in der Bundesrepublik selbst noch zu Hochzeiten des sekundären Antisemitismus vereinzelt immer wieder zum offenen Antisemitismus gekommen. Das zeigen die Fassbinderkontroverse ${ }^{43}$ und der Historikerstreit von $1986^{44}$ auf. Doch der Antisemitismus wird hier, bei beiden Ereignissen, in der Öffentlichkeit noch, ganz zeitgemäß als ein ,märtyrerischer ' Tabubruch inszeniert - was er auch noch ist. Mit ihm werden Grenzen und Möglichkeiten des gesellschaftlich Sagbaren hinsichtlich des Antisemitismus ausgetestet. Allerdings bleiben diese Beispiele noch gesellschaftlich scheiternde Versuche, den bundesrepublikanischen „latenten Antisemitismus zu wecken. “45

Das öffentlichkeitsscheue Tabu des sekundären Antisemitismus der Nachkriegszeit lässt den Antisemitismus unter der gesellschaftlichen Oberfläche allerdings noch besser gedeihen, denn dialektisch wird das Tabu zu seinem Substitut. Aus dem verdinglichten Tabu wird somit ein nichtöffentliches, den Antisemitismus rationalisierendes Argument, was ihn auf erhöhter Stufenleiter sanktioniert. Seine Tabuisierung bietet ihm eine enorme Plattform: „Es wird sozusagen gerade aus dem öffentlichen Tabu über dem Antisemitismus ein Argument für den Antisemitismus gemacht: wenn man nichts weiter gegen den Antisemitismus sagen darf, dann - so läuft die assoziative Logik weiter - sei an dem, was man gegen sie sagen könnte, auch schon etwas dran." ${ }^{46}$

Dieses Tabu löst sich dann sukzessive ca. 10 Jahre nach der politischen Wende, dem politischen Zerfall der realsozialistischen Sowjetunion, auf. Der Antisemitismus ist dann, anders als noch zu Zeiten Fassbinders etc., kein öffentliches Tabu mehr und die historische Phase des sekundären Antisemitismus ist damit offensichtlich vorbei: „Seit den öffentlich nur mangelhaft sanktionierten antisemitischen Äußerungen von Walser 1 (Paulskirchen-Rede) und Walser 2 (,Tod eines Kritikers'), Möllemann, Hohmann und Augstein fühlen sich Antisemit(inn)en in

\footnotetext{
${ }^{43}$ Das 1975 geschriebene Theaterstück Rainer Werner Fassbinders, Der Müll, die Stadt und der Tod, löst eine Debatte darüber aus, ob es antisemitisch oder nicht sei. Geführt wird daneben auch eine generelle Debatte über die Freiheit und Grenzen der Kunst. Befürworter der Kunstfreiheit wollen jedoch in den seltensten Fällen die wirklichen Grenzen der Kunst reflektieren, die unbestreitbar bestehen. So zeigt beispielsweise die Aktionskunst des Wiener Aktionismus von 1968, Kunst und Revolution, recht schnell die Grenzen von Kunst und Protest auf. Auf die Aktion folgten Gefängnisstrafen der Künstler. (Vgl. Dreher: Aktionstheater als Provokation: groteske Körperkonzeption im Wiener Aktionismus.)

Wirklich kritische Kunst versetzt Schocks, die über das Alltägliche hinausgehen, so dass sie staatliche Organe herausfordert und als Herrschaftsinstrumente demaskieren kann. Sie bildet jedoch nicht, wie Fassbinder, Alltägliches wie den Antisemitismus einfach nur verklausuliert ab, um politische Propaganda für etwas zu machen.

44 Vgl. Diner (Hrsg.): Ist der Nationalsozialismus Geschichte?

45 Salzborn: Antisemitismus, S. 45.

46 Adorno: Zur Bekämpfung des Antisemitismus heute, S. 368.
} 
Deutschland immer mehr bemüßigt, ihre Ressentiments öffentlich zu kommunizieren." ${ }^{47}$ Zwar existiert in der Bundesrepublik und Österreich selbst heute noch eine ziemlich explosive Mixtur von nichtöffentlichem und offenem Antisemitismus. Das vor der Jahrtausendwende noch tabuierte Vokabular wider die political correctness wird jetzt jedoch mit ganz offensichtlichen Anspielungen und ganz direkten antisemitischen Aussagen, beispielsweise bei Demonstrationen für Gaza ${ }^{48}$ etc., öffentlich manifest. ${ }^{49}$ Der moderne Antisemitismus, der sich zunächst hinter Antiintellektualismus, Antizionismus und Täter-Opfer-Verschiebungen verdinglicht versteckt und getarnt hat, tritt dadurch sukzessive wieder in die Öffentlichkeit. Auch die einschlägigen Zuschriften an den Zentralrat der Juden in der Bundesrepublik dokumentieren diese neue Offenheit und Schamlosigkeit von Antisemiten. ${ }^{50}$ Das geschichtsvergessene und Geschichte vergessen wollende Bewusstsein tut in dieser gesellschaftlichen Konstellation noch sein Übriges. Die Gräuel des Zweiten Weltkriegs durch den Faschismus geraten gesellschaftlich immer mehr in Vergessenheit, weshalb sich heute auch kaum mehr große medienwirksame Debatten, Talkshows etc. des Themas als diskussionswürdig annehmen. In der öffentlichen Argumentationskultur der Bundesrepublik und Österreich spielt Auschwitz also kaum mehr eine noch die allgemeine Moral tangierende Rolle. Und wenn doch, dann werden die Vernichtungslager des Nationalsozialismus schon mal zu einem nationalen Auftrag umfunktioniert: Die Rechtfertigung des Kosovoeinsatzes 1999 durch Außenminister Fischer zeigt dies so beispielhaft wie eindrucksvoll. 51

In jenem Kontext von nationaler deutscher Moralstiftung als angeblich historischer Auftrag nach Auschwitz wird auch der im gesellschaftlichen Bewusstsein immerwährende Nahostkonflikt kreativ umgedeutet: „Wenn israelische Streitkräfte in der Westbank teilweise so vorgehen wie Milosevics Truppen im Kosovo, dann dürfen wir nicht schweigen. Wir schulden den Opfern des Holocaust tätige

\footnotetext{
${ }^{47}$ Salzborn: Antisemitismus, S. 5.

${ }^{48}$ Vgl. z.B. taz.de: Pro-Palästina-Demo entzweit Linke. Keine antisemitischen Positionen.

49 Antisemitische Zeilen enthält ein Song von Xavier Naidoo, dem auch nach seiner Veröffentlichung noch gern gesehenen Juror, Entertainer und Popmusiker in Deutschland, Österreich und der Schweiz. Das zur Bundestagswahl 2009 aufgenommene Lied Raus aus dem Reichstag enthält offensichtlich antisemitische Anspielungen wie diese: „Wie die Jungs von der Keinherzbank, die mit unserer Kohle zocken / Ihr wart sehr, sehr böse, steht bepisst in euren Socken / Baron Totschild gibt den Ton an, und er scheißt auf euch Gockel / Der Schmock ist'n Fuchs und ihr seid nur Trot-

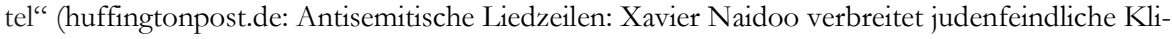
schees.)

${ }^{50}$ Einen prägnanten Überblick über den offenen Antisemitismus in Europa gibt ein Welt-Artikel von 2009: welt.de: Offener Antisemitismus bedroht Europa. „Es ist für manche Menschen kein Tabu mehr, ihre Judenfeindschaft auszuleben und zu zeigen“, so Dieter Graumann, Präsident des Zentralrats der Juden. (zeit.de: Graumann: Antisemitismus wird immer offener ausgelebt.)

${ }^{51}$ Mit den Worten „Ich habe nicht nur gelernt: Nie wieder Krieg. Ich habe auch gelernt: Nie wieder Auschwitz" rechtfertigt Joschka Fischer am 07.04.1999 den ersten Kampfeinsatz deutscher Soldaten nach dem Zweiten Weltkrieg im Kosovo (sueddeutsche.de: ,Ich habe gelernt: Nie wieder Auschwitz‘. Die Erinnerung gehört zu den Leitlinien von Außenminister Joschka Fischer.)
} 
Reue durch glaubwürdiges Tun. “52 Um der Rechtfertigung des eigenen Antisemitismus Willen wird dabei, ahistorisch allemal, die Täter-Opfer-Rolle einfach umgekehrt. Palästinenser werden par tout zu Opfern stilisiert, Israelis dagegen zu Tätern gemacht, die man vor dem Hintergrund deutscher Geschichte moralisch erziehen müsse und auch könne. ${ }^{53}$ Angesichts dieser gesellschaftlichen Lage kann durchaus angezweifelt werden, ob denn der Satz Detlev Claussens - „Auschwitz affiziert alles, was nach ihm kommt" 54 - in der Bundesrepublik so noch gilt. Der selbstverständliche Imperativ der akademischen Antisemitismusforschung ist heute vielleicht viel eher ein bescheidender Konjunktiv, weil gesellschaftlich die Bedeutung von Auschwitz immer undeutlicher wird.

Die heute zunehmende Schärfe des offenen Antisemitismus ist sicher nicht auf die Bundesrepublik oder Österreich zu begrenzen. Doch die Verschiebung vom sekundären zum offenen Antisemitismus in Deutschland und Österreich unmittelbar nach dem Zerfall der Sowjetunion hat selbstverständlich Auswirkungen auf seine weltweite öffentliche Artikulation. Denn durch den Aufschluss Deutschlands und Österreichs gegenüber offenem modernen Antisemitismus zeigt sich wieder verstärkt ein weltweiter, noch virulenterer gleichzeitiger Antisemitismus, in dem die regionalen Unterschiede wieder mehr verschwimmen; ein Fakt, der historisch selbstverständlich nicht neu, sondern dem modernen Antisemitismus generell wesentlich ist. ${ }^{55}$ Seine heutige globale Gleichzeitigkeit in der Öffentlichkeit lässt sich durch den Aufschluss von Deutschland und Österreich, vor allem auch durch die verstärkte Nutzung sozialer Medien, wieder ein Stück weit mehr in allen Winkeln der Welt feststellen. ${ }^{56}$ Die identische Ausprägung des Antisemitismus, durch die die antisemitischen Beiträge nicht nur in den sozialen Netzwerken weltweit einander zum Verwechseln ähnlich werden, verweist erneut auf die gesellschaftlich substantiellen, wesentlich homogenen gesellschaftlichen Bedingungen seiner Artikulation.

In der Relevanz, die der moderne Antisemitismus in der heutigen bürgerlichen Gesellschaft hat, liegt deshalb ein Auftrag für eine kritische, über bloße Analysen hinausgehende Wissenschaft: Sich an einer Begründung für die weitere Existenz des Phänomens Antisemitismus in der bürgerlichen Gesellschaft nach und trotz

\footnotetext{
52 Pott: Der Nahost-Konflikt, S. 30.

${ }^{53}$ Vgl. auch Rosa: Unterricht über Holocaust und Nahostkonflikt, S. 47 ff. Besonders verstörend ist diese Sichtweise in Teilen der Linken, wo man den so falschen wie plumpen Antiimperialismus zur Deutung des Nahostkonflikts heranzieht. Antisemitismus ist hier Resultat von Personifizierung und falscher Kapitalismuskritik, vgl. auch Thomas Haury: Die ideologischen Grundlagen des Antizionismus in der Linken.

${ }^{54}$ Claussen: Grenzen der Aufklärung, S. 35.

55 „Große räumliche Distanzen sind keine Kommunikations-, Informations- und Wissensgrenzen mehr. Sozialität löst sich vom Raum und es entsteht eine globale Gleichzeitigkeit von Ereignissen und Informationen." (Schwinn: Weltgesellschaft, multiple Moderne und die Herausforderungen für die soziologische Theorie, S. 208.)

56 Vgl. gov.il: Measuring the Hate: The State of Antisemitism in Social Media.
} 
Auschwitz zu versuchen. Dass dabei auf die Verbindung von sozialem Phänomen und gesellschaftlichem Wesen zu schauen ist, dass also in einem sich auf die relevanten Fakten berufenden Gedankenexperiment die Vermittlungen von bürgerlicher, kapitalistischer Gesellschaft und modernem Antisemitismus herausgearbeitet werden können, auf dieser These baut diese Untersuchung auf. Und sie möchte dabei den Versuch einer wesentlichen Begründung des gesellschaftlichen Phänomens moderner Antisemitismus unternehmen. Ob es ihr gelingen wird, der Diskussion über den modernen Antisemitismus entscheidende gesellschaftstheoretische Punkte zur Kritik des Phänomens Antisemitismus an die Hand zu geben, wird erst expost zu entscheiden sein.

\section{Zum Aufbau der Untersuchung}

Das Kapitel 2 dieser Untersuchung beschäftigt sich mit Fragen zur objektiven, wahren Erkenntnis.

In 2.1 wird dafür zunächst ein absoluter, kompromissloser Wahrheitsbegriff gegen den Relativismus und Positivismus gehalten. Die Arbeit mit dem absoluten Wahrheitsbegriff wird sich hier als in der Wissenschaft unverzichtbar zeigen.

In $2.2 \mathrm{ff}$ wird dann betrachtet, was denn die allgemeinen und notwendigen $\mathrm{Vo}_{\mathrm{O}}$ raussetzungen für die subjektive Erkenntnis von Objektivität und Wahrheit überhaupt sind. Zunächst wird dafür, in 2.2.1, der transzendentale Idealismus Kants Gegenstand sein, der am rationalistischen Zweifel Descartes und den Voraussetzungen des Empirismus' Lockes anknüpft, um die Objektivität der Erkenntnis im Subjekt herauszustellen. Der darauf folgende Unterabschnitt 2.2.2 zeigt dann auf, dass schon Kant die Erkenntnis von Objekt aufgrund seiner Vermittlung von Rationalismus und Empirismus dialektisch denkt; und sich damit bei ihm bereits gewisse Voraussetzungen materialistischen Denkens finden lassen. Abschnitt 2.2.3 nimmt sich dieses materialistischen Bezugs bei Kant an. Er behandelt die Intelligibilität des Objekts, die erst ein wirkliches, rationales Erkennen des Objekts durch das Subjekt ermöglicht. Zugleich setzt der Erkenntnisprozess, so wird zu zeigen sein, bei aller Vermittlung, in beiden Momenten, Subjekt wie Objekt, ein Stück weit Autonomie, Widerständigkeit gegen das Andere, voraus.

In den Unterabschnitten $2.3 \mathrm{ff}$. geht es dann um die emanzipative Reflexion des Kantischen Materialismus in der Kritischen Theorie. Diese reflektiert, indem sie über Kant hinausgeht, ohne ihn abstrakt zu negieren, emanzipativ (nicht nur) gesellschaftliche Dinge. Zunächst einmal wird dafür in 2.3.1 die Vermittlung von Praxis und Theorie reflektiert; ebenso wird in diesem Unterabschnitt das selbstkritische Subjekt der Erkenntnis im Anschluss an Kants Subjekttheorie Gegenstand sein. Schon in diesem Abschnittwird deutlich, dass das Subjekt eben auch nur als physisches, lebendiges Subjekt für seine eigene Reproduktion in der kooperativ organisierten Gesellschaft sorgen kann. Das wird im Unterabschnitt 2.3.2 noch genauer untersucht, der die instrumentelle Vernunft bei Horkheimer zum Gegen- 
stand hat. Abschnitt 2.3.3 reflektiert dann das notwendig dem Subjekt gegenüber Heteronome, die immer widerständige Natur, wobei auch der Begriff der Herrschaft noch genauer zum Gegenstand der Untersuchung wird.

Abschnitt 2.4 ff. beschäftigt sich mit der negativen Dialektik Adornos, die explizit die Dialektik Hegels kritisiert. Hegel wiederum kritisiert Kants materialistische Momente, die in den Unterabschnitten $2.2 \mathrm{ff}$. gegenständlich wurden, idealistisch. Für eine kritische Gesellschaftstheorie, die in dieser Untersuchung verfolgt werden soll, wird eine Kritik an Hegels dialektischer Methode und Geschichtsphilosophie deswegen besonders wichtig, weil Gesellschaftskritik, wenn man es bei Hegels rationalistischer, logischer Ausarbeitung beließe, ohne die Kritik an seiner affirmativen Dialektik hinfällig würde. Das verdeutlichen die Unterabschnitte 2.4.1 ff, in denen sich auch mit der Frage auseinandergesetzt wird, ob die negative Dialektik eine geeignete, (Anti-)Methode ' ist, um Gesellschaftstheoretisches richtig zu reflektieren. Darum wird in Unterabschnitt 2.4.3 ff. die Frage verfolgt, ob die negative Dialektik gerade durch ihr autonom Unmittelbares einen Vorteil gegenüber dem subjektivistischen Positivismus in den Wissenschaften hat - der die negative Dialektik über die (nahezu traditionelle) Tautologie der (gesellschaftstheoretischen) Bestimmungen hinausgehen lässt.

Die Unterabschnitte 2.5 ff. reflektieren, warum das Gesellschaftsphänomen und das Naturphänomen der Sache nach dem Subjekt als gleiches Unmittelbares gegenübertreten, was also beide Phänomene dem subjektiven erkennen nach gleich macht, was sie identifizierbar macht. Auch die Begriffe Wesen und Phänomen werden hier zum Gegenstand der Untersuchung.

Die Unterabschnitte $2.6 \mathrm{ff}$. behandeln dann das, was mit der Bestimmung von Totalität und Wesen in den Unterabschnitten zuvor bereits deutlich wurde. Sie reflektieren das Subjekt der Praxis und sein Handeln unter dem als heteronom bestimmten Zwang der bürgerlichen Gesellschaft.

Das Kapitel 3 knüpft dann an den Punkt der gesellschaftlichen Totalität und der Bestimmung des Wesens des gesellschaftlichen Phänomens an. In diesem Kapitel soll die Totalität der bürgerlichen Gesellschaftsform zum entscheidenden Gegenstand der Untersuchung werden. Dabei soll nicht vorrangig mit ökonomischen Bestimmungen gearbeitet werden, sondern der heteronome Zwang herausgearbeitet werden, der sonst immer nur in sekundärer Hinsicht thematisiert wird. Die Unterabschnitte 3.1.1 und 3.1.2 bestimmen dabei zunächst einmal die historische Voraussetzung von bürgerlicher Gesellschaft, also die Voraussetzung der konkreten gesellschaftlichen Totalität der kapitalistischen Gesellschaft.

Die Unterabschnitte $3.2 \mathrm{ff}$. knüpfen daran unmittelbar an und reflektieren die grundlegende Bedingung für die Aufrechterhaltung des aus der historischen Gewalt gewonnenen bürgerlichen Herrschaftsverhältnisses. Es ist dies der Eigentumstitel $(3.2 .1$; 3.2.2), der den entscheidenden Hinweis auf die rationale Aufrechterhaltung der kapitalistischen Produktionsweise liefert. Dieser Eigentumstitel kann auch nur vom Staat geschützt werden, weshalb in Unterabschnitt 3.2.3 die 
Frage aufgeworfen wird, unter welchen Umständen eine kapitalistische Gesellschaftsform überhaupt ohne objektiv geschützten Eigentumstitel gedacht werden kann. Unterabschnitt 3.2.4 ordnet dann den Begriff der Entfremdung in den Zusammenhang des Begriffs Eigentum ein. Dabei wird deutlich, dass der Entfremdungsbegriff grundsätzlich nicht von den heteronomen Zwängen der totalen bürgerlichen Gesellschaft auszunehmen ist. Der Unterabschnitt 3.2.5 geht dann noch auf die erzwungene Verdinglichung der bürgerlichen Staatsbürgersubjekte im Zusammenhang einer Reflexion auf die wesentlichen Zwänge in der totalen bürgerlichen Gesellschaft ein.

Abschnitt 3.3 der Untersuchung reflektiert den Eigentumstitel als wichtige Voraussetzung für die kapitalistische Produktionsweise und das auf der Erscheinungsebene mit ihr Einhergehende. Kritisiert wird die Ideologie des Eigentumstitels, der zufolge seine durchgesetzte Existenz allen Menschen die gleichen Voraussetzungen zuteilwerden lasse.

Abschnitt 3.4 möchte anschließend nachweisen, dass die juristische Rechtsform in der bürgerlichen Gesellschaft bereits allgemein durchgesetzt ist, was vielfach bestritten wird. Der Marxsche Begriff der fictio juris wird zum Nachweis der These interpretiert.

Abschnitt 3.5 der Untersuchung stellt dar, was die bürgerliche Produktionsweise in ihrer Totalität so wirksam macht und deshalb die Dialektik von Staat und Produktion untersuchen. Nachgewiesen wird anhand des permanenten Eingriffs in den Produktionszusammenhang durch den Staat, dass Staat und Kapital bislang immer, solang Kapitalismus herrscht, eine Einheit darstellen; und darstellen werden. Das macht erst wirklich den Zusammenhang von kapitalistischer Produktionsweise und bürgerlichem Staat ersichtlich, der nicht allein mit dem Schutz der Rechtsform sich begnügt, sondern den direkten Eingriff in den Produktionszusammenhang immer auf der Tagesordnung behält. Geführt wird die Diskussion in dieser Untersuchung, indem der, vor allem in der Zeitschrift für Sozialforschung, ausgetragene Streit um den faschistischen Staat und den von ihm scheinbar organisierten Monopolkapitalismus dargestellt und kommentiert wird.

Die Unterabschnitte 3.6 ff. dieser Untersuchung nehmen unter dem Eindruck des reziproken Vertragsabschlusses verschiedene Punkte in den Blick. 3.6.1 untersucht den Zwang, sich über den willentlich abgeschlossenen Vertrag um seiner eigenen Reproduktion Willen verkaufen zu müssen. 3.6.2 reflektiert diesen Zwang insofern, als hier der bürgerliche Staat, der das reziproke Vertragsverhältnis objektiv sichert, in den Fokus rückt: Das Subjekt muss sich beim Vertragsabschluss zu seiner eigenen Reproduktion auf das Recht des Staates berufen und erkennt diesen Staat deshalb auch als konkreten Staat an, was einen systematischen Nationalismus zur Folge hat. 3.6.3 weist dann darauf hin, dass jedem Vertragsabschluss ein Zwang zur Mehrwertproduktion immanent ist. 3.6.4 benennt diesen Zwang zur Mehrwertproduktion dann entscheidend als den Zwang zur Produktion des Allgemeinwohls. 
Das Kapitel 4 dieser Untersuchung ist ein Reflexionskapitel im strengen Sinne. Es liefert notwendige Bestimmungen ex post, die implizit zwar schon im vorangegangenen Kapitel Gegenstand waren, dort jedoch noch nicht in den Fokus des Interesses rückten. Gleichzeitig, indem diese Voraussetzungen eingeholt werden, werden auch Voraussetzungen für das nächste Kapitel geliefert. Der Unterabschnitt 4.1.1 nimmt deshalb eine Reflexion auf die Waren- und Wertformanalyse vor, weshalb dieses Kapitel insbesondere hinsichtlich des folgenden Kapitels 5 wichtig wird. 4.1.2 reflektiert daran anschließend die Objektivität des Warenwerts, wodurch dann auch das schon in Kapitel 3 untersuchte Eigentum überhaupt erst als Eigentum von jemandem als schützenswert nachvollziehbar wird. Der Unterabschnitt 4.1.3 dieser Untersuchung beantwortet dann die wichtige Frage, warum die Wertformanalyse die Ware Arbeitskraft noch nicht zum Gegenstand hat, warum Marx in der Wertformanalyse also noch von für die kapitalistische Produktionsweise Wesentlichem abstrahiert. Der Unterabschnitt 4.1.4 behandelt, und damit wird das Reflexionskapitel abgeschlossen, die Ware Arbeitskraft als vergleichendes Drittes und mehrwertschöpfende Bedingung für den Wert der Eigentumstitel auf dem kapitalistischen Markt.

Kapitel 5 ist das letzte beweisführende Kapitel der Arbeit. Es nimmt sich der wertkritischen Antisemitismustheorie an, die vermittelt mit der Kritik an der kapitalistischen Produktionsweise, genauer gesagt mit der Kritik des Werts, den Antisemitismus als Fetisch kritisieren möchte. Unterabschnitt 5.1.1 führt zunächst einmal den Begriff der Ideologie und des falschen Bewusstseins aus, um dann eine Interpretation des Fetischabschnitts bei Marx im Kapital vorzunehmen. Dieser Abschnitt ist der Grundlagenabschnitt der wertkritischen Antisemitismustheorie. Unterabschnitt 5.1.2 soll dann aufzeigen, dass schwerlich eine materialistische Kritik des modernen Antisemitismus möglich ist, wenn man den Fetischabschnitt aus dem Kapital verabsolutiert. Unterabschnitt 5.1.3 reflektiert auf die eklatanten Schwierigkeiten, die sich aus der wertkritischen Interpretation des Antisemitismus als Fetisch notwendig ergeben.

Kapitel 6 ist die abschließende kritische Reflexion der vorliegenden Arbeit und stellt den Versuch dar, das adäquat einzuordnen, was die Arbeit geleistet hat und was aus dem Geleisteten folgen kann. 


\section{Gesellschaftstheoretische Grundlagen. Subjekt, Gesellschaft und kritische Erkenntnis}

\subsection{Der Wahrheitsbegriff als Maßstab von Kritik}

Der prima philosophia ( $₫ \varrho \dot{\omega} \tau \eta ~ \varphi \iota \lambda о \sigma o \varphi i \alpha)$ gilt die grundsätzliche Möglichkeit der Erkenntnis objektiver Wahrheit noch als nicht verhandelbar. Aristoteles bestimmt sie deshalb - wie später Thomas ${ }^{57}$ im Zuge der christlichen Renaissance des Aris-

\footnotetext{
57 Thomas formuliert mit dem Identitätssatz von Denken und Sein, der adaequatio rei et intellectus, das korrespondenztheoretische Prinzip der Wahrheit wissenschaftlicher Aussagen. Die Korrespondenz von Denken und Sein wird für Thomas zum einzigen Maßstab der allgemeinen, objektiv wahren Erkenntnis: „Respondeo dicendum quod veritas consistit in adaequatione intellectus et rei, sicut supra dictum est. Intellectus autem qui est causa rei, comparatur ad ipsam sicut regula et mensura, e converso autem est de intellectu qui accipit scientiam a rebus." (Thomas von Aquin: Summa Theologiae, 29338).

Somit liegen die erkenntnistheoretisch zu erschließenden Voraussetzungen sachlich richtiger, widerspruchsloser Aussagen für Thomas auf Seiten des Denkens wie des Seins. Die allgemeine, objektive Wahrheit der an sich seienden Dinge geht dabei aus einem keinen Widerspruch duldenden subjektiven Identitätsprinzip hervor. Das führt allerdings in dieser positivistischen/nominalistischen Konsequenz auf Probleme, die sich spätestens seit Aristoteles ausprägen und bis in die Gegenwart Bestand haben: „Die thomistische Metaphysik lebt - in konsequentester Fortsetzung der aristotelischen von dem naiven Vertrauen, daß im sinnlichen Bild der Dinge sich unmittelbar deren intelligibles Wesen manifestiere.“ (Haag: Der Fortschritt in der Philosophie, S. 50.)
} 
toteles - als die notwendige Übereinstimmung von Denken und Gegenstand. ${ }^{58}$ Sie ist und bleibt für Aristoteles, der in diesem Punkt entscheidende Thesen aus dem Lehrgedicht des Parmenides ${ }^{59}$ aufnimmt, Prinzip einer wissenschaftlichen, objektiven Aussage. Als Prinzip sei die Wahrheit der Erkenntnis bei der Reflexion auf Gegenstände notwendig, weil ansonsten Irrelevantes zum für den Gegenstand Konstitutiven erhoben werde. Solche Prinzipienlosigkeit wäre bloß sophistische, gegenstandslose Schwätzerei, die nach Aristoteles keinen Maßstab für die Richtigkeit eigener Aussagen habe. Als Maßstab für Wahrheit und Richtigkeit könne dabei aber auch nicht gelten, dass viele Menschen ein und dasselbe als wahr behaupten ${ }^{60}$ : „Es sieht also so aus, daß sie vom Unbestimmbaren reden, und im Glauben, sie sprächen von dem, was ist, reden sie von solchem, was nicht ist, denn, was nur der Möglichkeit nach ist und nicht in eingetretener Wirklichkeit, ist doch das (...) Unbestimmte. “61

Mit seinem gegen jeglichen Relativismus intervenierenden ontologischen Wahrheitsbegriff legt Aristoteles insofern einen entscheidenden Grundstein für den Maßstab von Kritik. Er nimmt von Objektivität, von wahren Urteilen über die Dinge, anders als die Sophisten, keinen relativistischen Sicherheitsabstand, sondern er nimmt die Relevanz von Aussagen jeglicher Art ernst. ${ }^{62}$ Auch eine substantielle Kritik an Gesellschaft und ihren Phänomenen könnte ohne einen entsprechenden Wahrheitsbegriff nicht formuliert werden, weil ohne diesen der kritische Maßstab in den Urteilen über Gesellschaft fehlen würde. Nichts Verbindliches könnte unter den Voraussetzungen der Aufgabe des Wahrheitsbegriffs mehr über Gesellschaft und ihre Phänomene formuliert werden. Relativistische Theorien in den Gesellschaftswissenschaften, die den Wahrheitsbegriff auflösen, lassen deshalb das substantiell kritische Denken vermissen. Auf die relativistische Pluralismusdebatte bezogen formuliert Adorno: „Nichtig aber ist der Relativismus darum, weil, was er einerseits für beliebig und zufällig, andererseits für irreduzibel hält, selbst aus der Objektivität - eben der einer individualistischen Gesellschaft entspringt, abzuleiten ist als gesellschaftlich notwendiger Schein. "63

Die bereits von Adorno angekündigten Konsequenzen, durch Ablehnung des Wahrheitsbegriffs bloß noch Ideologie hervorzubringen, lassen viele moderne

\footnotetext{
58 Vgl. Aristoteles: Metaphysik, 1011 b. Das brachte dem Aristotelischen Wahrheitsbegriff die Bezeichnung einer ,Korrespondenztheorie“ ein: „The correspondence theory is often traced back to Aristotle's well-known definition of truth.“ (David: The Correspondence Theory of Truth.)

${ }^{59}$ Vgl. Diels: Parmenides. Lehrgedicht.

60 Aristoteles: Metaphysik, 1006 a.

${ }^{61}$ Ebd., 1007 a.

${ }^{62}$ Dass der ontologische Wahrheitsbegriff, der Denken und Sein in der ,Korrespondenztheorie dergleichen unreflektiert miteinander in Verbindung bringt und deshalb selbst problematisch und auch subjektivistisch ist, sei zunächst dahingestellt. Im Verlaufe der Arbeit wird die Kritik dieser tautologischen, nominalistischen Identifikation von Subjekt und Objekt jedoch wiederholt zum Gegenstand.

63 Adorno: Negative Dialektik, a.a.O., S. 46.
} 
Theoretiker aber trotzdem nicht davor zurückschrecken, den Wahrheitsbegriff immer weiter zu unterhöhlen. Michel Foucault, der vielleicht prominenteste Vertreter des Poststrukturalismus, kritisiert Mitte des 20. Jahrhunderts den metaphysischen, ontologischen Wahrheitsbegriff der philosophischen Tradition scharf: Wahrheit sei als Theoriebestandteil bloß ein metaphysisches Überbleibsel, und die mit dem Wahrheitsbegriff arbeitende Theorie sei dementsprechend überholt. Über die Jahre habe sie deshalb, dem Fortschritt des Denkens geschuldet ${ }^{64}$, Staub angesetzt, und es sei deshalb an der Zeit, den Wahrheitsbegriff endlich einmal zu entstauben und zu modifizieren. Der Wahrheitsbegriff solle jetzt nicht mehr in den viel zu eng gesteckten Grenzen der Metaphysik verweilen und die Wahrheit solle sich endlich als das erweisen, was sie sei: längst nichts Ontologisch-Ideologisches, sondern etwas Gesellschaftliches. Foucault bestimmt Wahrheit deswegen gegen die prima philosophia als völlig offenen intersubjektiven, gesellschaftlichen Prozess, als Resultat eines Diskurses. Wahrheit sei also nicht länger ontologisch impotent und ohne jede Kraft auf die Dinge hinter den Erscheinungen, also ohne raumzeitliche Rückbindung - sondern sie tauche endlich aus ihrer platonischen Versenkung im ideologisch völlig unsensiblen Hinterland auf. Foucault schreibt in Dispositive der Macht. „Die Wahrheit ist von dieser Welt; in dieser wird sie aufgrund vielfältiger Zwänge produziert, verfügt sie über geregelte Machtwirkungen. Jede Gesellschaft hat ihre eigene Ordnung der Wahrheit, ihre ,allgemeine Politik ${ }^{6}$ der Wahrheit: d.h. sie akzeptiert bestimmte Diskurse, die sie als wahre Diskurse funktionieren läßt.“"65

So aber, wie sich Foucault der Wahrheit annimmt, wird sie zur relativen Beliebigkeit, wird sie zur rein gesellschaftlichen, diskursiv-intersubjektiven Entscheidung über Gegenstände. Foucault will den traditionellen, ontologischen Wahrheitsbegriff, der von den oben kennengelernten Prinzipien der Logik nicht einfach zu trennen ist, relativieren. ${ }^{66}$ Wahrheit sei demnach nicht mehr auch mit den Dingen selbst vermittelt, sondern sie existiere nur noch im Subjekt und stamme allein, quasi gespiegelt, aus diesem. Diese Relativierung von Wahrheit durch ihre Intersubjektivierung, wider ontologische Wahrheiten in den Dingen gedacht, sowie ihr Hineinlegen in die offensichtliche Welt der Sinne bleibt nicht allein auf die Foucaultsche Diskursanalyse beschränkt. Sie bekommt nach und mit Foucault entscheidenden Einfluss im wissenschaftlichen Betrieb. ${ }^{67}$ Die deutschsprachige

\footnotetext{
${ }^{64}$ Das trifft sich auch mit dem Festhalten an der Kontinuität der Geschichte als Fortschrittsprozess bei Foucault: „Und die konkreten Durchführungen wie in Überwachen und Strafen zeigen, wie sehr selbst Foucault an einer verborgenen Kontinuität der Geschichte, ja sogar an der Steigerung des Zivilisationsprozesses festhält.“"Rohbeck: Geschichtsphilosophie zur Einführung, S. 146.

${ }^{65}$ Foucault: Dispositive der Macht, S. 51.

${ }^{66}$ Nach Demirovic ,verteidigt“ Foucault damit den Begriff der Wahrheit. Formell, rein sprachlich, kann die abgefertigte Worthülle tatsächlich verteidigt werden, doch das gibt ihr nicht gleich Substanz. (Demirovic: Das Wahr-Sagen des Marxismus: Foucault und Marx, S. 180.)

${ }^{67}$ So in der Literaturwissenschaft: „Die starke Resonanz, die Michel Foucaults Diskursanalyse bei Literaturwissenschaftlern gefunden hat, könnte bei interessierten Laien zu dem Fehlschluß führen, er
} 
poststrukturalistische Diskursanalyse knüpft nahtlos an Foucaults Überlegungen zur Wahrheit an: „Was als Wahrheit gilt, ist ja nichts anderes als ein diskursiver Effekt. Wahrheit ist demnach nicht irgendwie diskurs-extern vorgegeben. Sie wird jeweils erst historisch diskursiv hervorgebracht.“68 Auch der an Foucault anschlieBenden Diskursanalyse gilt Objektivität also nicht als den einzelnen Subjekten und ihrer Sinnlichkeit vorrangiges. Viele der logischen Probleme des Poststrukturalismus ergeben sich erst durch die inhaltliche Aufgabe des Wahrheitsbegriffs. Denn wenn das Subjekt, in Form intersubjektiver Diskursivität, die Objektivität und somit Wahrheit erst diskursiv erzeugt ${ }^{69}$, stellen Subjekt und Objekt dadurch keine dialektisch in sich vermittelten Momente mehr dar. Damit ist dann die genuine Dialektik von zwei in sich vermittelten Momenten, auch deren negative Vermittlung, mittels des in der Diskursanalyse steckenden identifizierenden Konstruktivismus abgeschafft. ${ }^{70}$ Das vom (allgemeinen) Subjekt erst erzeugte, gewissermaBen aus sich und der Intersubjektivität gestiftete Objekt kann insofern nicht mehr das auch autonome Moment der Vermittlung als Anderes, Nichtidentisches, mehr sein. Ein Objekt kann jedoch, wenn es nicht auch als autonom bestimmt wird, nichts mehr an sich haben, was allgemein und notwendig vom Subjekt mithilfe der Prinzipien der Logik an diesem bestimmt werden könnte. Das ist problematisch, denn „[o]hne Beziehung auf ein dem Denken transzendentes Objekt wäre dieses Denken ein Denken von Nichts, also kein Denken, und nicht einmal ein Bewusstsein seiner selbst wäre möglich.“"71

Die Identifikation des Dings durch den intersubjektiven Diskurs ist insofern keine aus der dialektischen Vermittlung von Subjekt und Objekt als autonome Momente in sich kommende Bestimmung des Objekts, sondern die Bestimmungen des Gegenstands werden bloß äußerlich durch das Subjekt an ihn herangetragen, dem Objekt also oktroyiert. Jede Bestimmung von transzendenter Allgemeinheit und Notwendigkeit wäre dann jedoch eine durch den intersubjektiven Diskurs dem Objekt nur angedichtete Bestimmung. Es wären damit Bestimmungen, die das Subjekt immer bereits kennt. Das Material hätte insofern keinerlei Bestimmtheit in sich. Wäre aber eine wahre Aussage über ein transzendentes Etwas nicht auch allgemein und notwendig, würde sie also nicht auch die Bestimmtheit des Materials treffen, so könnte jedoch kein gültiges, wahres Urteil vom Subjekt formuliert werden. Dann aber wäre, wenn das Subjekt seine Bestimmungen dem Objekt dergleichen gewaltsam oktroyiert, in der Konsequenz alles, was als allgemeingültig am Gegenstand bestimmt wird, immer nur Schall und Rauch. Das Objekt wäre demnach, je nach Lage des gesellschaftlichen Diskurses, der dieses ja

selbst sei Literaturwissenschaftler gewesen und seine Arbeiten handelten von ,fiktionaler' Literatur." (Kammler: Historische Diskursanalyse, S. 32.)

68 Jäger: Kritische Diskursanalyse, S. 129.

${ }^{69}$ Vgl. etwa Foucault: Die Archäologie des Wissens, S. 74.

${ }^{70}$ Dabei zeigt sich auch als gleichgültig, wie sehr die Diskursanalyse das einzelne Subjekt im intersubjektiven Diskurs zurückgestellt und es sich der mysteriös bleibenden Macht unterordnen muss.

${ }^{71}$ Bulthaup: Möglichkeiten und Grenzen philosophischer Naturerkenntnis, S. 149. 
erst erzeugt, heute so, morgen aber vielleicht wieder ganz anders. So zerfällt jede Festigkeit des Gegenstands in eine undialektische, relativistische Beliebigkeit. ${ }^{72}$

Das Objekt ist jedoch ein transzendent an sich seiendes Objekt und deswegen als ein autonom und in sich Bestimmtes vom Subjekt getrennt, weshalb auch physikalische Gesetze nicht nur zusammengetragene subjektive Erfahrungswerte sein können. Physikalische Gesetze sind demnach kein bloßes Ergebnis von wiederholtem trial and error, die Gesetze der Newtonschen Mechanik sind nach sachlichen Gesetzen als reproduzierbar bestimmt. Sie treffen deshalb auch immer etwas an der ontologischen Wirklichkeit. Wenn dieses (rest-)ontologische Moment von Wissenschaft jedoch negiert und in Subjekt aufgelöst wird, muss jede GesetzmäBigkeit gegenwärtig und in Zukunft nur noch möglich, nicht aber wirklich und ,unabhängig ${ }^{67}$ sein: das Flugzeug fliegt, weil es schon mal geflogen ist, das Auto fährt, weil es bereits fuhr und die Brücke hält, weil sie hielt usw.: „,Ohne festgehaltene Meinung, ohne Hypostasis eines nicht ganz Erkannten, ohne Hinnahme von etwas als Wahrheit, von dem man gar nicht weiß, ob es die Wahrheit sei, ist Erfah-

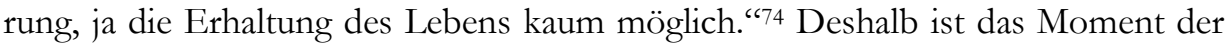
transzendenten Autonomie des nichtidentischen Objekts zugleich ein ontologisches Moment der Voraussetzung der Subjekt-Objekt-Vermittlung. Subjekt und Objekt wären durch die reductio des Objekts auf Subjekt jedoch dichotomisch durch einen Hiatus wieder voneinander getrennt, weil ein autonomes Objekt nicht mehr Gegenstand der Erkenntnis ist. Gegen diese undialektische Trennung von Subjekt und Objekt erhebt Adorno schwerwiegende Einwände: „Die Trennung von Subjekt und Objekt ist real und Schein. Wahr, weil sie im Bereich der Erkenntnis der realen Trennung, der Gespaltenheit des menschlichen Zustands, einem zwangvoll Gewordenen Ausdruck verleiht; unwahr, weil die gewordene Trennung nicht hypostasiert, nicht zur Invarianten verzaubert werden darf.“75

Der Wissenschaft wäre, wenn ein objektives und allgemeingültiges Urteil über Prinzipien der Logik und den Begriff vermittelt nicht mehr gefällt werden könnte, jede Grundlage, jede Substanz entzogen. Die positivistische Wissenschaft hat es deshalb auch, weil sie diese emphatische Objektivität aufgibt, nur noch mit vagen Wahrscheinlichkeiten von rein subjektiven Erfahrungswerten zu tun. Sie formuliert aus eigenen Konsequenzen heraus keine universal geltenden, objektiven Urteilen über die Gegenstände mehr. Sie möchte insofern aus Prinzip heraus kein ontologisches Moment am transzendenten Gegenstand mehr treffen. Doch ohne dieses vorausgesetzte ontologische Moment wären, wie oben schon angeführt, materielle Gegenstände nicht kontrollierbar und reproduzierbar. Wenn man also

\footnotetext{
72 Das gilt auch hinsichtlich gesellschaftlicher Phänomene. Der Rechtsextremismus sei eine „diskursive Konstruktion“ und: „Was als Rechtsextremismus gilt, unterliegt gesellschaftlichen, politischen und wissenschaftlichen Diskursen und Kräfteverhältnissen.“ (Klärner/Kohlstruck: Rechtextremismus, S. 14.)

${ }^{73}$ Unabhängig vom einzelnen Subjekt, aber nicht vom Subjekt der Erkenntnis.

${ }^{74}$ Adorno: Meinung, Wahn, Gesellschaft, S. 576 f.

75 Adorno: Zu Subjekt und Objekt, S. 742.
} 
die Geltung wissenschaftlicher Urteile, die sich auf ein ontologisches Moment in den Dingen selbst beziehen, diskurstheoretisch infrage stellt, verliert die Wissenschaft jede Verlässlichkeit. Obwohl sich der Poststrukturalismus eine linke, ja sogar eine an Marx angelehnte Gesellschaftskritik auf die Fahnen schreibt ${ }^{76}$, entfernt er sich gerade durch diese Ablehnung von ontologischer Wahrheit von marxistischen Gesellschaftstheorien und Marx selbst. ${ }^{77}$ Eine nominalistische, relativistische Aufgabe des Wahrheitsbegriffs lässt sich im Kapitalp nicht finden. Wenn Marx den Kapitalismus im Kapital kritisiert, unterstellt er dabei die objektive Verlässlichkeit seiner Untersuchung. ${ }^{79}$ Foucault und den poststrukturalistischen Diskurstheoretikern hingegen bleibt durch ihre Bestimmung von Wahrheit als Resultat intersubjektiver gesellschaftlicher Diskurse nichts relevant Festes mehr. Was der diskurstheoretisch arbeitenden Poststrukturalismus also selbst als Fortführung traditioneller Marxscher Gedanken begreift, kann deswegen auch nur eine statusgebende Wahlverwandtschaft sein, eben weil Marx den Wahrheitsbegriff aus guten Gründen der substantiellen Kritik nicht aufgibt.

Durch seine Aufgabe von autonomer Objektivität fällt der Poststrukturalismus letztendlich auch noch auf die positivistisch identifizierenden Aussagen von Denken und Sein zurück, wie sie bereits aus der traditionellen Metaphysik und der ,Korrespondenztheorie“ der prima philosophia bekannt sind. ${ }^{80}$ Insofern geht er, anders als in seinem Selbstverständnis, gerade nicht über die metaphysische Tradition hinaus, sondern unreflektiert einfach über diese hinweg. ${ }^{81}$ Ohne jede emphatische Annahme einer ontologischen Transzendenz des Gegenstands als nichtidentisches Moment, der seine Geltung erst subjektiv objektiviert, ist eine Wissenschaft, ganz gleich ob nun von Gesellschaft oder Natur, nicht mehr möglich: „Die Geltung universaler Urteile ist die Voraussetzung jeder Wissenschaft." 82 Jede wissenschaftliche Reflexion, die wahre Urteile zum Gegenstand hat und die auch die

\footnotetext{
${ }^{76}$ Der Poststrukturalismus mache sich, so der Frankfurter Foucaultforscher Thomas Lemke, die „Fortsetzung des Marxschen Projekts“ zur Aufgabe. (Lemke: Marx ohne Anführungszeichen.) Was sich als Fortsetzung versteht, kann hier auch bedeuten: Abschaffung.

77 Vgl. zu Marx' Festhalten am Aristotelischen ontologischen Wahrheitsbegriff: Haag: Der Fortschritt, S. 109 f.: „Während die ,äußere Form“ der Dinge relativ ist auf die Veränderungen von bereits geformter Materie, etwa wenn ,dem Holz die Form des Tisches‘ oder ,dem Eisen die Form der Walze' gegeben wird, zeigt die, immanente Form‘ stofflicher Entitäten sich gleichgültig gegen jede Veränderung, die ihnen widerfährt. In der immanenten Form visierte Marx das ,immanente Gesetz ${ }^{`}$ der Genesis von Naturstoffen."

${ }^{78}$ Vgl. zu Marx und seinem Festhalten am ontologischen Wahrheitsbegriff auch Haag: Der Fortschritt in der Philosophie, S. 107 ff.

${ }^{79}$ Vgl. zum Wahrheits- und Wesensbegriff bei Marx insbesondere Unterabschnitt 2.5.2 in dieser Arbeit.

${ }^{80} \mathrm{Vgl}$. dazu auch Haag: Der Fortschritt, S. 39 ff.

${ }^{81}$ So gilt das Urteil Hegels, dass die traditionelle metapysische via antiqua und nominalistische via moderna „nur Zweige eines und desselben Ganzen“ sind. (Hegel: System der Philosophie, I. Teil, WW VIII.)

82 Bulthaup: Idealistische und materialistische Dialektik, S. 131.
} 
Möglichkeit von wahren Urteilen begründen muss, hat deswegen ,zumindest implizit den ontologischen Wahrheitsbegriff zum Thema"83.

Objektivität und Wahrheit sind jedoch nicht nur im Poststrukturalismus, sondern inzwischen ganz allgemein zu problematischen Begriffen geworden. Bei der Extinktion von Objektivität und Wahrheit kann Foucault und dem diskurstheoretischen Poststrukturalismus deshalb keine Vorreiterrolle zugeschrieben werden. Objektivität und Wahrheit werden mittlerweile gerne als Begriffe vermieden, um sich dadurch auch des Vorwurfs zu erwehren, man sei ein engstirniger ,Dogmatiker $^{6}{ }^{84}$ In der sich empirisch orientierenden Sozialwissenschaft seit Comte kommt man spätestens mit den Verfahrenswissenschaften, den positivistischen Erhebungsverfahren, zu der recht problematischen Überzeugung, dass es über in von Fakten abstrahierenden Begriffen Formuliertes hinaus keine richtige oder falsche Aussage gebe. Der substantielle Allgemeinbegriff wird dadurch zu einer völlig unzulässigen Form bei der Erkenntnis von Objektivität und Wabrheit. Wenn es demzufolge überhaupt noch wahre Aussagen gäbe, dann doch nur über vereinzelte protokollierte Sätze. ${ }^{85}$ Dass das Ganze - unweigerlich in universalen Allgemeinbegriffen formuliert! - nicht mehr als eine Abstraktion des Subjekts sei, ist in der empirischen Sozialforschung insofern unlängst zum Konsens geworden. Wabrheit wird, wenn überhaupt, allein in sensible Fakten gelegt. Weil aber dagegen der allgemeine und von unmittelbaren Fakten abstrahierende Begriff nicht in den Sinnen sei, sei er nichts, mit dem sich etwas an objektiver Wahrheit noch adäquat darstellen ließe. ${ }^{86}$ Er sei, weil rein geistige Zutat des Subjekts, nur willkürlich gedachtes Zeichen, also ein ausschließlich logisches Werkzeug. Mit diesem logischen Werkzeug der Abstraktion von den Tatsachen sollen die äußeren, sinnlichen und einzig wahren Fakten, die Comteschen ,Tatsachen', nur noch begrifflich geordnet werden. Der Allgemeinbegriff ist für den sozialwissenschaftlichen Positivismus kein Repräsentant notwendig ontologischer Überlegungen von Wabrheit, die auch eine autonome Transzendenz des Gegenstands erfordern. Wie im universalen Urteil über den Gegenstand der Wahrheit festgehalten wird, stecken aber im adäquaten Allgemeinbegriff logische, rationale Bestimmungen, die sich empirisch gar nicht beweisen lassen. ${ }^{87}$

\footnotetext{
${ }^{83}$ Frank Kuhne: Marx’ Ideologiebegriff im Kapital, S. 10, Fn. 4.

${ }^{84}$ Pejorativ wird der Begriff der Dogmatik erst spät in der Geschichte gebraucht, nämlich mit dem Aufkommen subjektivistischer Positionen. Dogmatiker zu sein heißt eigentlich nur, dass man „von der festen, dinghaften Gestalt und nicht von dem lebendigen Erzeugten der Gegenstände ausgeht.“ (Adorno: Philosophische Terminologie, Bd. 2, S. 30.)

85 Adorno arbeitet den positivistischen Rückschritt hinter Positionen, die den Positivismus ins Leben riefen, Durkheim und Comte, heraus. (Vgl. Adorno: Notiz über sozialwissenschaftliche Objektivität, S. 238 ff.)

${ }^{86}$ Die Erkenntnis von Wahrheit alleine durch Sinnlichkeit wird von Lenin zu Recht als substanzloser Subjektivismus kritisiert. (Vgl. Lenin, Materialismus und Empiriokritizismus.)

${ }^{87}$ Nicht nur die Idiosynkrasie gegen alle -Ismen, wie bei Jacques Derrida, verdeutlicht die akademische Ablehnung von Allgemeinbegriffen. Derrida nennt die Kategorisierung von Historischem schlicht und einfach „Fortschrittsideologie.“ (Derrida: Am Nullpunkt der Verrücktheit, S. 216.) Ein
} 
Am Gesellschaftsbegriff lässt sich die entsprechende Problematik einer Abschaffung des Allgemeinbegriffs modellhaft darstellen. Weil sich der Gesellschaftsbegriff aus vielen Einzelteilen zusammensetze, die sich nicht zusammenfügen ließen, wird auch Gesellschaft als Allgemeinbegriff für einige Theoretiker konkret unbestimmbar. Die Überzeugung von jener verstellten pointilistischen Verpixelung des gesellschaftlichen Ganzen, ohne dass sich das Ganze aus den versprengt scheinenden atomisierten Klecksen wie bei Seurat, Signac oder Pissarro - zugegebenermaßen ebenfalls positivistisch gedacht - zusammenfügt, drückt sich nirgends so präzise aus wie in Margaret Thatchers Aussage über Gesellschaft: „They are casting their problems at society. And, you know, there's no such thing as society. There are individual men and women and there are families." 88 Dieses atomistische Paradigma der ästhetischen Pulverisierung des Gesellschaftsbegriffs in all seine Einzelteile verhindert die Möglichkeit allgemeiner und notwendiger Aussagen über objektive Zusammenhänge wie Gesellschaft. Der Begriff der Gesellschaft sei demnach nur noch eine unwissenschaftliche, unlautere Abstraktionsblase des Subjekts, die von den viel entscheidenderen, konkreten Fakten Abstand nehme.

Das sieht auch der Soziologe Norbert Elias so, weshalb der Gegenstand der Gesellschaft für ihn zu einer bloß willk:ürlichen Bezeichnung vereinzelter sozialer Realitäten allein aus individuellen Handlungen zusammenrutscht: „Zu den Aufgaben der Soziologie gehört es also nicht nur, die spezifischen Zwangsläufigkeiten zu untersuchen und zu erklären, denen die Menschen in bestimmten empirisch beobachtbaren Gesellschaften und Gruppen oder in Gesellschaften überhaupt ausgesetzt finden, sondern auch, das Denken und Sprechen über solche Zwangsläufigkeiten von seiner Bindung an heteronome Vorbilder zu lösen und statt der Wort- und Begriffsbildungen, deren Gepräge auf magisch-mythische oder auf naturwissenschaftliche Vorstellungen zurückgeht, allmählich andere zu entwickeln, die der Eigenart der von Individuen gebildeten gesellschaftlichen Figurationen besser gerecht werden." ${ }^{89}$ Gewonnen sei der unangemessene Allgemeinbegriff also bloß aus einer logischen Spielerei, die der harten Realität der Fakten und Individuen jedoch nicht standhalte. Nach Elias bezeichne man mit dem Allgemeinbegriff willkürlich, subjektiv Realitäten. Mit ihm ordne das Subjekt aus sich heraus die äußeren Dinge. Das Subjekt konstruiere sich demnach auch für Elias die eigene Realität - und er möchte als Wissenschaftler helfen, diese richtig zu konstruieren..$^{90}$

objektiver Klassenbegriff jedoch, der nicht spürbar ist, sondern ausschließlich der Reflexion Gegenstand sein kann, wäre damit unmöglich zu formulieren.

88 Thatcher, A life in quotes.

${ }^{89}$ Elias, Was ist Soziologie, S. 15.

${ }^{90}$ Auch der Begriff der Dekonstruktion von Derrida lässt sich hieran anschließen. Mithilfe dieser neologistischen Wortschöpfung versucht Derrida, Texte in ihrer vermeintlichen absoluten Einheit zu destruieren und in neuer, ihrer geschichtlichen und willkürlichen Bedeutung zu rekonstruieren. So ist der Begriff eben nicht als nur entlarvende Kritik, sondern eben wiederum auch als positive Konstruktion vermeintlich neuer Realitäten zu bestimmen. Mit der Dekonstruktion soll der Sinn des 
Damit verneint auch Elias, dass jedweder emphatische, allgemeine Begriff auf Objektivität und Wahrheit abzielt.

Es ist jedoch das entscheidende Merkmal des emphatischen Begriffs z.B. von Gesellschaft, dass er mehr als nur den impliziten objektiven Zusammenhang von objektiven Aussagen, als Konglomerat von wahren Sätzen über vorgefundene Daten, aufzeigt. Der emphatische Begriff von Gesellschaft ist vom Begriff der wesentlichen gesellschaftlichen Totalität nicht zu trennen. ${ }^{91}$ Der Totalitätsbegriff von Gesellschaft zielt dialektisch auf ein Wesentliches, das als das hinter den faktischen sozialen Erscheinungen diese erst substantiell Konstituierende begriffen werden muss. Spätestens mit dem Totalitätsbegriff von Gesellschaft muss sich deshalb auch von dem Versuch des pointilistischen Atomismus Seurats und co., der sich auch in Émile Durkheims ${ }^{92}$ positivistisch-soziologischer Bestimmung von Gesellschaft finden lässt, getrennt werden.

Der objektive Inhalt jeden Begriffs drückt immer sehr viel mehr aus als die additiv unter ihm befassten Sätze und Daten zusammengenommen. Der emphatisch reflektierte Begriff als auf ein totales Ganzes gehender Totalitätsbegriff ist deshalb logisch auch immer mehr als die bloße Summe seiner (Einzel-)Teile. Der emphatische Begriff der Gesellschaft ist darum auch einer, der nicht eine positivistische, logische Abstraktionsleistung von unter ihm Befassten ist. Er zielt dialektisch vermittelt immer auf die Totalität des unter ihm Befassten ab. Weil sich aus den einzelnen Protokollsätzen z.B. über subjektives Verhalten in der Gesellschaft

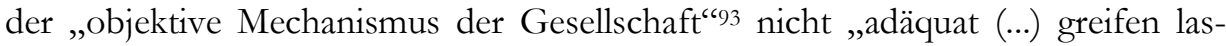

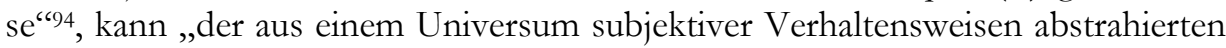

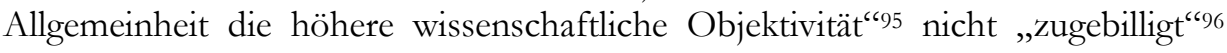
werden: „Ideologisch bietet das [die Verabschiedung vom emphatischen Begriff der Wahrheit, B.E.B.] den Vorteil, daß kritische Theorie der Gesellschaft durch ordnende Begriffsschemata substituiert wird, die ihrerseits nichts anderes sind als Klassifikationen von subjektiv Vorfindlichem. ${ }^{\text {(697 }}$

\footnotetext{
Ursprünglichen, des Wahren etc. bewusst in ein objektives Unverständnis zerlegt werden, weil es diesen Sinn nicht geben würde, was sich theoretisch an das Unterfangen der Zerstörung von Allgemeinbegriffen (transzendentales Signifikat) anschließen lässt. Das „Feld und das Spiel des Bezeichnens“ erweitert sich für Derrida „ins Unendliche“. (Vgl. Derrida: Die Schrift und die Differenz, S. 424.) ${ }^{91}$ Der Begriff der Totalität bezieht sich bei Marx auf den inneren Zusammenhang von Gesellschaft. Aber auch der allgemeine Begriff selbst geht auf eine Totalität. Mit ihm wird nicht nur auf das eingegangen, was unter ihm subsumiert wird, sondern notwendig dialektisch auch auf sein unsubsumierbares, nicht-identisches Moment.

92 Vgl. Durkheim: Über die Teilung der sozialen Arbeit.

${ }^{93}$ Adorno: Notiz über sozialwissenschaftliche Objektivität, S. 239.

${ }^{94}$ Ebd.

${ }^{95}$ Ebd.

${ }^{96}$ Ebd.

${ }^{97}$ Ebd.
} 
Die Postmoderne, offiziell von Lyotard ${ }^{98}$ eingeleitet, orientiert die eigene Negation des Wahrheits- und Wesensbegriffs an Dialektik. Notwendige Widersprüche des widerspruchslos gedachten Begriffs oder seine notwendigen Denkwidersprüche überhaupt, die, um den Sachverhalt zu begreifen, eingegangen werden müssen, hypostasiert Lyotard dabei als allgemeine und unauflösliche Widersprüchlichkeit des Ganzen. Die postmoderne Kritik von Tradition und Moderne soll insofern vermeintlich über die alten Fehler der wahrheitsliebenden Rationalität hinausgehen. Lyotard und die ihm folgende postmoderne Konzeptionen ${ }^{99}$ wollen demnach den aus der philosophischen Tradition und Moderne kommenden ontologischen Wahrheitsbegriff als irrationales Relikt ganz aus der Wissenschaft streichen. Wahrheitsdenken sei ihnen heute demnach obsolet und auch nur ledigliches Mittel der Bevormundung - wie noch jedes Prinzip der Logik. ${ }^{100}$ Die Philosophie der Aufklärung, die noch mit logischen Prinzipien nach zeitloser Wahrheit sucht, gilt Lyotard deshalb konsequent als entwurzelte rationalistische „große Erzählung "“101, und ihre heute unzeitgemäße Rationalität sei deswegen als geisteswissenschaftliches Märchen abzuschaffen.

Mit seiner konsequenten Entledigung von der Rationalität der Prinzipien der Logik bringt sich Lyotard jedoch auch um die eigene Logik und um die eigene Ergebnisse und Forderungen: „Die postmoderne Wissenschaft ist diskontinuierlich, katastrophisch, nicht nachprüfbar im klassischen Sinne, paradox. “102 Fragen nach den erkenntnistheoretischen und logischen Voraussetzungen von gesellschaftlichen wie natürlichen Phänomenen der Erfahrung werden dabei wie der widerspruchlose Wahrheitsbegriff als unbequem drückender Appendix ad acta gelegt: „Darum wird die unbequeme [objektive Erkenntnis, B.E.B.] als unwissenschaftlich vernachlässigt. “103 Soll jedoch die Frage nach der den Prinzipien der Logik entsprechenden widerspruchslos gedachten ontologischen Wahrheit, die notwendig in logischen, rational nachzuvollziehenden Begriffen dargestellt werden muss, nicht abgeschafft werden, muss die begriffliche Allgemeinheit und Notwendigkeit im gedachten Urteil über den autonomen Gegenstand anhaltend wie nachhaltig bleiben. Die relativierende Aussage Lyotards von den vielen einzelnen und widersprüchlichen Wahrheiten ${ }^{104}$ isolierter „Sprachspiele“105 verschiedener Diskurse zum gleichen Sachverhalt, die in keinem wesentlichen Zusammenhang mehr

\footnotetext{
${ }^{98}$ Lyotard: Das postmoderne Wissen.

99 „Bei extremer Vereinfachung hält man die Skepsis gegenüber den Metaerzählungen für ,postmodern'“" (Ebd., S. 14.)

100 Vgl. Ebd.

101 Ebd., S. 13.

102 Reese-Schäfer: Lyotard zur Einführung, S. 29.

103 Adorno: Notiz über sozialwissenschaftliche Objektivität, S. 238.

104 Auch, wenn sich Lyotard ,nur' von der sogenannten Letztbegründung verabschiedet, steht das für Vittorio Hösle sinnbildlich für den Abschied von echter Philosophie. (Vgl. Hösle: Die Krise der Gegenwart und die Verantwortung der Philosophie.).

105 Lyotard: Das postmoderne Wissen, S. 36 ff.
} 
stünden und damit nicht die Wahrheit repräsentierten - was immer die Wahrheit sein soll -, verabschiedet sich dabei offiziell von der Frage nach dem emphatischen Begriff einer objektiven, absoluten und ontologischen Wahrheit.

Konkurrierende Wahrheiten am selben Gegenstand kann es jedoch schon aus dem einfachsten logischen Prinzip, dem des zu vermeidenden Widerspruchs, nicht geben. Kein Maßstab der Richtigkeit des Denkens der Gegenstände könnte gelten, wenn sich zwei Aussagen über den gleichen Gegenstand als wahr erweisen sollten. Der Gegenstand bliebe dann tatsächlich postmodern chaotisch, irrational und unbestimmbar. Die grundlegenden Überlegungen des Aristoteles zur Logik widersprechen diesem postmodernen Chaosgedanken vehement: „Daß eines und dasselbe zugleich vorliegen und nicht vorliegen könne, das ist an demselben (Gegenstand) und in derselben Hinsicht unmöglich."106 Im Rahmen dialektischen Denkens wird nun zwar deutlich, dass jedes Urteil sogleich auch schon das in sich einschließt, was es nicht sei. Das zeigt jedoch erst, was der Gegenstand eigentlich ist. Weil Dialektik trotz der eingeschlossenen Widersprüche keine Irrationalität zu ihrem Resultat hat, macht die Postmoderne dann auch nicht, wie Paul Feyerabend überzeugt ist, mit der Dialektik ernst. ${ }^{107}$ Im Gegenteil, die Postmoderne schafft durch die Irrationalisierung von Gegenständen das auf Wahrheit gehende dialektische, rationale Denken der eingeschlossenen Widersprüche ab. Feyerabend bestreitet dabei vehement, dass es Wahrheit, Wahrheiten oder Vernunft gibt: „Anything goes“ ist die Weise, in der traditionelle Rationalisten, die an universelle Maßstäbe und Regeln der Vernunft glauben [!], meine Darstellung von Traditionen, ihrer Wechselwirkung und ihrer Änderungen werden beschreiben müssen. "108 Für Feyerabend gibt es deshalb dann auch, anders als für Lyotard, keine mehr zugestandenen, kleinen nebeneinanderstehenden, konkurrierenden Wahrheiten als Resultat einzelner Diskurse. Auch aus dem Diskurs könnte demzufolge keine zumindest noch intersubjektive Wahrheit aus einem Konsens folgen, weil es nicht nach Feyerabend mal mehr diese subjektivistisch, reduktionistisch übergestülpte Form der Wahrheit gibt.

Diese Position Feyerabends von einer allgemeinen Wahrheits- und Vernunftfeindlichkeit lässt sich allerdings recht simpel kritisieren. Das allgemeine Urteil, es gäbe keine Wahrheit (oder Vernunft), muss ja dabei auch immer auf die eigene negative Aussage angewendet werden. ${ }^{109}$ Deshalb ist, die Maßstäbe dieser Ver-

\footnotetext{
106 Aristoteles: Metaphysik, 1005 a.

107 Paul Feyerabend meint, dass eine dialektische Argumentation „,nicht feste Maßstäbe“ verwende, sondern „eine sich ständig ändernde Rationalität“, weshalb diese Argumente „oft die ersten Schritte auf dem Weg zu einer ganz neuen Rationalitätsform“ seien. (Feyerabend: Erkenntnis für freie Menschen, S. 98.)

108 „Anything goes ‘ ist die Weise, in der traditionelle Rationalisten, die an universelle Maßstäbe und Regeln der Vernunft glauben [!], meine Darstellung von Traditionen, ihrer Wechselwirkung und ihrer Änderungen werden beschreiben müssen.“ (Ebd., S. 97.)

${ }^{109}$ Eine solche Kritik allein anzuführen ist nach Adorno ,armselig“: „Mehr dürfte es fruchten, den Relativismus als eine beschränkte Gestalt des Bewußtseins zu erkennen.“ (Adorno: Negative Dialek-
} 
nunftkritik einmal ernst genommen, die Aussage, dass es keine Wahrheit geben könne, logisch unwahr. Denn wenn es keine Wahrheit gibt, muss auch deren Negation unwahr sein. Der immanente Widerspruch durch die Negation von Wahrheit durch die Behauptung, die ihrerseits Wahrheit beansprucht, heißt insofern, dass es Wahrheit gibt. Diese Selbstnegation ist kein dialektischer Widerspruch mehr, sondern ein platter, naiver (Selbst-)Widerspruch. Aristoteles schreibt kritisch hinsichtlich der seinerzeit scheinbar revolutionären, nihilistischen Sophisterei: „Sie fordern die grundsätzliche Möglichkeit, Widersprüchliches zu sagen, indem sie sich gleich einmal widersprechen. "110 Feyerabends ,Naivität' macht sich dabei jedoch bewusst angreifbar, weil sie eine ganz selbstbewusste Naivität ist. ${ }^{111}$ Diesem bewusst naiven Relativismus und Pluralismus werden wahre Urteile zur beliebigen, bereits von Hegel kritisierten Meinung ${ }^{112}$ als eine unter vielen. Meinung formuliert dem eigenen Begriff nach aber schon keine Wahrheit mehr, sondern sie steht nur für jederlei subjektive Beliebigkeit in einer Aussage ohne jegliche Substanz. ${ }^{113}$ Obwohl ihm Aussagen nur Meinungen ohne Wahrheitsanspruch sind, plädiert der naive Relativismus aber nicht, was an der Stelle nur konsequent wäre, fürs Schweigen. Alle Meinungen zu Gegenständen präsentieren sich ihm als aneinander reiben könnende, einander widersprechende Erklärungsmodelle ohne rationale, in sich nachvollziehbare Denkstruktur. ${ }^{114}$ Das ist konsequent insoweit, weil das Wesen hinter den Erscheinungen, als diese intelligibel konstituierende und rational nachvollziehbar machende, negiert wird. Der Begriff einer ontologischen Wahrheit wird also negiert, soll aber trotzdem irgendwo auch negativer Begriff der eigenen Konzeption bleiben. So wird, ambivalent aber logisch notwendig, auch von der vermeintlich alles Verstaubte über Bord werfenden Postmoderne weiterhin nur in der kritisierten Begriffssprache und notwendig mithilfe der traditionellen Logik argumentiert. Die Radikalität der Postmoderne lässt insofern eine wirkliche Radikalität vermissen: „Derlei einleuchtende Erwägungen sind zu radikal und sind es darum, wie meist radikale Fragen, zu wenig." ${ }^{\text {"115 }}$ Feyer-

tik, S. 46.) Diese Erkenntnis über den Postmodernismus/Relativismus ist aber wiederum nur an dessen eigener Argumentation nachzuweisen.

110 Aristoteles: Metaphysik, 1011 a.

$111 \mathrm{Vgl}$. Feyerabend: Erkenntnis für freie Menschen.

112 „Eine Meinung ist eine subjektive Vorstellung, ein beliebiger Gedanke, eine Einbildung, die ich so oder so und ein anderer anders haben kann; - eine Meinung ist mein, sie ist nicht ein in sich allgemeiner, an und für sich seiender Gedanke. Die Philosophie aber enthält keine Meinungen; es gibt keine philosophischen Meinungen. Man hört einem Menschen - wenn es auch selbst ein Geschichtsschreiber der Philosophie wäre - sogleich den Mangel der ersten Bildung an, wenn er von philosophischen Meinungen spricht. Die Philosophie ist objektive Wissenschaft der Wahrheit, Wissenschaft ihrer Notwendigkeit, begreifendes Erkennen, - kein Meinen und kein Ausspinnen von Meinungen." (Hegel: Vorlesungen über die Geschichte der Philosophie I, S. 30.)

113 Adorno: Meinung Wahn Gesellschaft, S. 579: „Bloße Meinung neigt zu jenem NichtaufhörenKönnen, das pathische Projektion heißen darf.“

$114 \mathrm{Vgl}$. etwa Feyerabend: Erkenntnis für freie Menschen, S. 27 ff.

115 Adorno, Negative Dialektik, S. 158. 
abends Radikalität ist zwar durchaus eine bewusste Freiheit des Denkens. Dieses radikal freie Denken aber weiß letztendlich selbst nicht mehr, was es denkt oder besser: will gar nicht wissen, was es denkt - und hält genau das für radikal. Es ist tatsächlich eine radikale Befreiung: nämlich die von allen substantiellen Inhalten.

Diese anarchische Radikalität der Theoriekonzeption kann die Gesellschaftstheorie nicht unberührt lassen, wie überhaupt der positivistische Relativismus nicht folgenlos für die Gesellschaftswissenschaften bleibt. Über Logik, wissenschaftliche Radikalität und die Frage nach wirklicher theoretischer Emanzipation oder der Wahrheit lässt sich zwar leidenschaftlich streiten, und all dies wäre weniger aufreibend, wenn wahrheitsfeindliche Konzepte nicht auch auf politische Diskussionen übertragen würden. Der philosophische Relativismus geht jedoch in einen gesellschaftstheoretischen Relativismus über - oder mit ihm einher; beide Sphären, Philosophie und Gesellschaft, sind generell nur gewaltsam voneinander zu trennen. Die Philosophie ohne gesellschaftlichen impact kann es so wenig wie eine Gesellschaftstheorie ohne Rückgriff auf philosophische Begriffe geben. Weil sich philosophische Grundlagen der Erkenntnis, der Maßstab von der Richtigkeit des Denkens der Gegenstände überhaupt, auf Gesellschaft und ihre Phänomene erstrecken, sind gesellschaftstheoretische Voraussetzungen der Erkenntnis von ihren erkenntnistheoretischen Grundlagen nicht zu trennen. Erkenntnistheoretische Überlegungen, die auf Gesellschaft und ihre Phänomene gehen, sind insofern

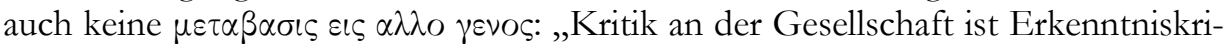
tik und umgekehrt." 116 Dass sich die Gesellschaftstheorie von der klassischen Erkenntnistheorie der philosophischen Tradition selbstredend ein Stück weit zu trennen hat und beide Zweige nicht absolut miteinander identifizierbar -, sondern dialektisch in sich als Momente vermittelt sind, zeigt sich im weiteren Verlauf dieser Arbeit (vgl. z.B. 2.5.3).

Unter dem Deckmantel der Demokratisierung von Richtig und Falsch zieht der relativistische Meinungspluralismus ziemlich drastische gesellschaftliche Konsequenzen nach sich. Der postmoderne Relativismus hat durch seine logischen Inkonsequenzen auch politische Konsequenzen. Weil man sich nicht mehr auf Prinzipien der Logik oder auf eine ontologische Wahrheit bezieht, kann demnach alles richtig oder falsch sein. Als ausreichender Maßstab für Wahrheit und Richtigkeit gilt für die Pluralisten allein der höchste Zuspruch an subjektiven Meinungen für oder gegen eine Sache. ${ }^{117}$ Den Rahmen für das vermeintlich realitätsgerechte Urteil soll dabei die demokratisch erschlossene Mehrheitsmeinung im Sinne

\footnotetext{
116 Adorno: Zu Subjekt und Objekt, S. 748.

117 Einen strengen Positivismus/Relativismus formuliert der österreichische Rechtsphilosoph Hans Kelsen in Bezug auf das bürgerliche Recht. Mit der Reinen Rechtslehre soll der Gegenstand des Rechts davon ,reingehalten' werden, was nicht Recht und deshalb nicht Gegenstand der rechtswissenschaftlichen Debatte sein soll. Eine Begründung der Rechtsnormativität zählt für Kelsen nicht. Deswegen ist für ihn auch „,jeder beliebige Inhalt Recht““. (Kelsen: Reine Rechtslehre, S. 201.)
} 
der political correctness geben, die sich auf den common sense $e^{118}$ beruft. Die political correctness ist jedoch so wenig fix wie der Inhalt des common sense allgemeingültig. Der common sense beruft sich ganz pragmatisch auf den gemeinsamen Nenner von allerhand zusammengefassten und zum Teil auseinandergehenden Meinungen, die den Rahmen dessen angeben, was gesellschaftlich als normative political correctness gelten soll. Durch die systematische Ablösung von der sach- und stichhaltigen ontologischen Objektivität ist es darum schon kein wahres, adäquates Urteil, das den Ausschlag für die Richtigkeit auch des subjektiven Handelns gibt. Die, Wahrheit' wird im politischen Relativismus als $\delta \circ \xi \alpha^{119}$ relativ und man kann dadurch willkürlich (freiheitlich!) zwischen Mehrheitsmeinungen jeder couleur hin- und herschwenken. Dergleichen an das Modell demokratischer Wahlen angepasst wird die Wahrheit einfach nur Mehrheiten zugesprochen, womit sie wählbar wird. ${ }^{120}$ Das enthebt sie eines jeden objektiven Maßstabs. Dadurch wird, von unzähligen formell bleibenden Debatten der Wissenschaftstheorie um die richtige Methode der Erkenntnis angefeuert ${ }^{121}$, um Wahrheit nur noch gekreist. Jedes (rest-)ontologisch gedachte wahre Urteil muss jedoch nichts mit der demokratischen Mehrheitsmeinung gemein haben, denn Wahrheit kennt keine Relativität.

Dem Methodenzwang vielleicht bewusst, aber auf jeden Fall ohne die Intention, daran etwas zu ändern, passt sich auch ein Gesellschaftswissenschaftler wie Jürgen Habermas mit seiner Konsenstheorie ${ }^{122}$ an das maßstabslose Motto who cares, anything goes ${ }^{123}$ an: „Die Diskussion wissenschaftstheoretischer Ansätze auf der Grundlage eines konsensuellen Wahrheitsbegriffs aber verbindet zu nichts und schließt deshalb vorweg ein Resultat der Diskussion aus.“" ${ }^{24}$ Die methodologische Formalisierung von Wahrheit trägt von innen verfaulte Früchte, weil durch den wissenschaftstheoretischen Relativismus alles ein Sprachrohr finden kann. ${ }^{125}$ Der Meinungspluralismus kann darum zum entscheidenden Helfershelfer für genau

\footnotetext{
118 Thomas Paine versucht mit seiner begriffsgebenden Schrift Politisches, in dem Fall die Amerikanische Unabhängigkeit von 1776, zu begründen. Auch seinen common sense zeichnet eine objektive Inhaltslosigkeit durch den Pragmatismus seiner Schrift aus. Seinem strengen Formrealismus zufolge wird jeder wirkliche Gehalt relativ. (Vgl. Paine: Common Sense.)

119 Vgl. Diels: Parmenides. Lehrgedicht. Bereits Parmenides unterscheidet zwischen Meinung und Wahrheit.

120 Das erinnert nicht ganz ohne Grund an die Diskurstheorie Foucaults.

${ }^{121}$ Vgl. zu den Methoden(zwängen) in den Sozialwissenschaften: Wenturis/Van Hove/Dreier: Methodologie der Sozialwissenschaften.

${ }^{122}$ Die Konsenstheorie der Wahrheit in den Gesellschaftswissenschaften geht auf nahezu simultane Überlegungen von Jürgen Habermas und Karl-Otto Apel in den 70er Jahren des 20. Jahrhunderts zurück. Habermas entwickelt seine subjektivistischen Gedanken in dem Aufsatz Wabrbeitstheorien. (Vgl. dazu auch Karl-Otto Apel: Transformation der Philosophie.)

${ }^{123}$ Vgl. exemplarisch zum anything goes in den Geisteswissenschaften: Feyerabend: Wider den Methodenzwang.

${ }^{124}$ Kuhne: Begriff und Zitat bei Marx, S. 15 f.

125 Das macht sich in Medien bemerkbar, die massentauglich sein wollen und die sich darum eine möglichst ,objektive Berichterstattung' vorschreiben. Jedem Argument, und sei es noch so rassistisch, wird so häufig ein es relativierendes Pro und Contra in der Berichterstattung gegeben.
} 
das werden, was mit der Demokratisierung der Meinungen und der Relativierung von Richtig und Falsch eigentlich verhindert werden sollte: „Stets war dem Relativismus, mochte er noch so progressiv sich gebärden, das reaktionäre Moment gesellt, schon in der Sophistik als Verfügbarkeit für die stärkeren Interessen. "126 Oder noch deutlicher: „Vielleicht ist es in diesem Zusammenhang nicht uninteressant, daran zu erinnern, daß der Faschismus in seiner ersten, noch durchdachten Version, in der italienischen des Mussolini, seinen diktatorischen Absolutheitsanspruch verbunden hat mit einem extremen philosophischen Relativismus, sei es Nietzschescher, sei es Paretoscher Observanz."127 Der common sense kann also ebenso wenig wie die political correctness Garant für Wahrheit, Richtigkeit oder Objektivität sein, weshalb sich mit dem common sense oder der political correctness der Faschismus auch nicht bekämpfen lässt. Auf beiden Begriffen kann sich nicht ausgeruht werden, wenn man eine emphatische Kritik gesellschaftlicher Zustände leisten möchte. Dass eine gelebte political correctness hinsichtlich des Antisemitismus in der Bundesrepublik Deutschland zwar einen offenen Antisemitismus in vielen Situationen zu verhindern wusste, trägt an der Stelle praktisch - wenn auch eingeschränkt gedacht! - zu etwas Positivem bei. Das lässt sich jedoch nicht zu einer blinden Favorisierung der political correctness ausweiten, weil sich der inhaltslose, rein formelle gesellschaftliche common sense durch seinen Relativismus demokratisch schnell ändern kann.

Ganz gleich ob in der Natur- oder der Geisteswissenschaft, der Begriff der Wahrheit muss der Wissenschaft also immer gegenständlich bleiben, weshalb er nicht relativiert werden darf; was an der Stelle keinen Rückfall auf den auch von Adorno, allerdings aus anderen Gründen, verunglimpften objektivistischen ,Szientismus ${ }^{` 128}$ bedeutet. Wenn Wahrheit allgemein und notwendig sein soll, muss sie auch für ausnahmslos jede Wissenschaft gelten. Auch in Bezug auf die Gesellschaft existiert demnach ein begrifflich zu bestimmendes Wesen als Wahrheit der manifesten sozialen Erscheinung. Die erscheinenden sozialen Phänomene weisen nun aber auch immer bloß vermittelt auf dieses gesellschaftliche Wesen, weil sie es nicht selbst sein können. Vermittelt über empirisch gewonnenes Material lassen sich deshalb erst wahre, substantielle Urteile über Gesellschaft, die ja nicht in Empirie aufgeht, fällen - womit Gesellschaft als Allgemeines, als Übergeordnetes der sozialen Fakten, notwendig selbst zum emphatischen Begriff wird und die Aussagen über Gesellschaftliches sich offensichtlich auch als wahr oder falsch erweisen können. Über das begrifflich einzukreisende Wesen der sich manifestierenden, erscheinenden sozialen Phänomene muss deshalb gesprochen werden, solange die Wissenschaft von der Gesellschaft auch Wissenschaft von seienden sozialen Gegen-

\footnotetext{
126 Adorno: Negative Dialektik, S. 47 f.

127 Adorno: Philosophische Terminologie, S. 121.

128 Adorno: Negative Dialektik, S. 53: „Die szientifische Objektivierung neigt, einig mit der Quantifizierungstendenz aller Wissenschaft seit Descartes, dazu, die Qualitäten auszuschalten, in meßbare Bestimmungen zu verwandeln.“
} 
ständen bleiben möchte. Gegen jeden Relativismus muss deshalb gelten, dass auch Urteilen über Gesellschaft eine absolute Wahrheit zugrunde liegt. Ohne diese Wahrheit würde die Sozialwissenschaft das Attribut Wissenschaft und auch den Maßstab jeglicher Kritik der sozialen Phänomene verlieren. Die sozialen Fakten wären ohne begrifflich bestimmbares Wesen hinter ihnen als gesellschaftliche Totalität auch nur noch willkürlich zusammenhängende soziale Erscheinungen, die sich wissenschaftlich nicht ordnen, geschweige denn substantiell kritisieren ließen. Sie blieben dadurch in ihrer chaotischen Mannigfaltigkeit und Prinzipienlosigkeit bestehen. Selbst wenn man, positivistisch, die gesamten relationalen Eigenschaften dieser empirischen Dinge positiv aufzeigen könnte, ginge man damit nicht auch nur ein Stück auf das politisch-ökonomische Wesen der sozialen Fakten als diese Konstituierendes ein (vgl. z.B. 2.5.2). So bleiben die Fragen nach Wahrheit und Objektivität auch für gesellschaftswissenschaftliche Theorien von wesentlichem Belang. Von einer allgemeinen, objektiven Wahrheit im Urteil des Subjekts über Gesellschaft und ihrer Phänomene muss deshalb ausgegangen werden, wenn von absoluter Wahrheit und widerspruchsfreier Objektivität als Gradmesser dessen, worüber und warum man zusammenhängend davon überhaupt sprechen kann, auch in den Gesellschaftswissenschaften noch gesprochen werden soll. Wenn der traditionelle, universelle ontologische Wahrheitsbegriff ein Thema bei der Reflexion auf Gegenstände ist, muss dann auch gleichgültig sein, ob die allgemeine und notwendige Reflexion auf Wahrheit eine Naturwissenschaftliche oder Gesellschaftstheoretische ist. Insofern erweist es sich für den Gesellschaftswissenschaftler also auch nicht als unberechtigter Gegenstandswechsel, Gesellschaftstheorie und klassische philosophische Voraussetzungen zusammen und als in sich und durch sich hindurch vermittelte Momente zu denken. Im Bereich der Gesellschaftstheorie schickt sich, anders als bei Comte ${ }^{129}$, eine strikte Trennung von Soziologie und Philosophie nicht.

\subsection{Der transzendentale Idealismus Kants als kritischer Ausgangspunkt gesellschaftstheoretischer Überlegungen}

Für Kant, den „größte[n] moderne[n] Philosoph[en]“"130, ist es das Subjekt, das nach der nominalistischen, Wende aufs Subjekt ${ }^{\star}$ die besondere Fähigkeit hat, objektive, wahre Urteile zu formulieren. Sein transzendentaler Idealismus versucht, Erkenntnis „,im Subjekte selbst als eine objektive zu begründen. “131 Kant ist damit der erste Philosoph in der Philosophiegeschichte, der das Subjekt äquivok und kritisch bestimmt. Für eine Arbeit wie diese, die sich mit Objektivität, Substanz

\footnotetext{
${ }^{129}$ Vgl. Comte: Die Soziologie, S. 8.

130 Scruton: Kant, S. 11.

131 Adorno: Kants ,Kritik der reinen Vernunft', S. 10.
} 
und Wesen beschäftigt, wird deshalb die Reflexion auf Kants Erkenntnistheorie wichtig. Diese beginnt in 2.2.1, das sich deswegen mit Objektivität und Subjektivität, Wahrheit und dem mit sich identischen Subjekt auseinandersetzt.

In 2.2.2 folgt dann eine Reflexion auf die Dialektik in der Kantischen Philosophie, die seine Theorie schon als eine dialektische Kritik an der bisherigen Erkenntnistheorie reflektiert. Von Kants transzendentalem Idealismus ist dabei mehr zu lernen als das seine moderne Erkenntnistheorie ,nur' als erste Begründung und Rettung einer Objektivität im Subjekt steht: Gegen Nominalismus und Subjektivismus in den großen Philosophien des Rationalismus und Empirismus geht Kant den beide Extreme vermittelnden, die jeweils für sich die Objektivität unterschiedlich zum Gegenstand machten, erkenntnistheoretischen Weg.

In 2.2.3 wird sich dann noch mit bereits bei Kant gegenständlichen entscheidenden Voraussetzungen des Objekts im Erkenntnisprozess beschäftigt. Es wird hier auf die entscheidende Substanz der Voraussetzung für die Erkenntnis einer Objektivität durchs Subjekt eingegangen.

\subsubsection{Kants transzendental-zeitliches Subjekt als kritische Voraussetzung der} Formulierung einer objektiven Wahrheit

Die notwendig dialektischen Vermittlungen von Subjekt, Wahrheit, Wesen, Objektivität und Totalität waren wie die Prinzipien der Logik bereits in 2.1 Gegenstand. Mit Blick auf Kants transzendentalen Idealismus wird nun der bislang schuldig gebliebene Nachweis von Wahrheit und der Möglichkeit einer Formulierung von Wahrheit geführt. Aufgrund seiner spezifischen Reflexion von Objektivität, Wahrheit und mit sich identischem Subjekt wird Kant heute allerdings entweder kritisiert oder einfach wortlos abgelehnt. Nicht nur einem Denker wie Feyerabend gilt Kant darum pejorativ als ein ,Rationalist' (vgl. 2.1). ${ }^{132}$ Diese Kritik an Kants Idealismus ist wiederum auch nicht als einfach äußerliche abzutun, denn die idealistische, ,rationalistische' Subjektphilosophie ist ein zentrales Moment auch des Kantschen transzendentalen Idealismus, der die entscheidenden Bedingungen der Möglichkeit von objektiver Erkenntnis im vernünftigen Subjekt zum Gegenstand hat. Wie das seiner selbst bewusste, mit sich identische Subjekt das mannigfaltig erscheinende Objekt notwendig und allgemein nach den Regeln der Vernunft erkennt und welche Voraussetzungen das Objekt dafür mitbringen muss, bildet den offensichtlichen Kern wie Ausgang der Kantischen Philosophie ${ }^{133}$ : „wie nämlich subjektive Bedingungen des Denkens sollten objektive Gültigkeit haben“"134. Kant

\footnotetext{
132 Das Transzendentalsubjekt hatte in den positivistischen Programmen des Strukturalismus und Poststrukturalismus keinen guten Ruf. Es wird in deren Subjekttheorie grundsätzlich, dabei mit der Konzeption Descartes vermischt, abgelehnt, weil es sich in den Rahmen einer angeblich unlängst überholten Rationalität einordnen lasse etc.

133 „Eine besondere Rolle spielt dabei das Problem des objektiven Wissens, wie es Descartes formuliert hat.“ (Scruton: Kant, S. 24.)

134 Kant: Kritik der reinen Vernunft, B 122.
} 
möchte also zur Beantwortung der Frage nach der Objektivität die widerspruchsfreie allgemeine und notwendige Objektivität des Erkannten, Wahrheit überhaupt, in den logischen Erkenntnisbedingungen des seiner selbst bewussten Subjekts a priori nachweisen. Die transzendente Objektivität soll insofern durch den Nachweis der Erkenntnisbedingungen a priori im Subjekt begründet werden: „Die Bedingungen a priori einer möglichen Erfahrung überhaupt sind zugleich Bedingungen der Möglichkeit der Gegenstände der Erfahrung.“"135

Diese Bedingungen der Möglichkeit von Erfahrung erweisen sich für Kant dabei als transzendental. Als transzendentale Bedingungen der Möglichkeit objektiver Erkenntnis stammen sie nicht aus Erfahrung, sondern sind, und das gilt den Kantkritikern als zu rationalistisch, als eine Voraussetzung von Erfahrung erschlossen; a priori: „Dagegen steht die reine Form der Anschauung in der Zeit, bloß als Anschauung überhaupt, die ein gegebenes Mannigfaltiges enthält, unter der ursprünglichen Einheit des Bewußtseins, lediglich durch die notwendige Beziehung des Mannigfaltigen der Anschauung zum Einen: Ich denke; also durch die reine Synthesis des Verstandes, welche a priori der empirischen zugrunde liegt." ${ }^{\text {"136 }}$

Gegen den nach der nominalistischen Wende einsetzenden Subjektivismus fragt Kant bei seiner Suche nach der Objektivität nach einem entscheidenden, allgemeingültigen Nachweis von Objektivität/Wahrheit im endlichen und tätigen Subjekt. Seine Transzendentalphilosophie, in der Kritik der reinen Vernunft entwickelt, fragt nach jener maßgeblichen, generellen „Umänderung der Denkart“"137 bezüglich der allgemeinen, objektiven Erkenntnis der Dinge durch ein tätiges, seiner selbst bewusstes, transzendentales Subjekt. Kant kritisiert die subjektivistisch/nominalistischen Konzeptionen insoweit, als dass diese die Subjekt-ObjektVermittlung einfach nur zur Seite des Subjekts hin auflösen - und damit eine autonome Objektivität außerhalb des Subjekts in Frage stellen würden: „Und wenn ich Ihnen das programmatisch einmal voranstellen darf, (...) so wäre der Kantische Versuch geradezu zu charakterisieren als einer - nicht etwa Objektivität der Erkenntnis durch Subjektivismus zu beseitigen; sondern die Objektivität, die vor ihm durch die Beziehung auf das Subjekt relativiert, skeptisch eingeschränkt gewesen ist, nun im Subjekte selbst als eine objektive zu begründen. “"138

Kants Reflexionen auf den Begriff des Selbstbewusstseins und die entsprechende Erkenntnis von Objektivität sind deshalb ein offensichtliches Resultat einer erstmals kritischen Rezeption aller nominalistischen Wendungen in der modernen Philosophie. Hinter den Nominalismus ist aber nun auch für Kant wiede-

\footnotetext{
135 Ebd., A 111.

136 Ebd., B 140.

137 Ebd., B XVI.

138 Adorno: Kants ,Kritik der reinen Vernunft', S. 9 f. Deswegen ist das beliebte Urteil, „[n]ach Kant ist es das Subjekt selbst, das die Allgemeinheit und Notwendigkeit von Erkenntnis garantiert"

(Weyand: Adornos Kritische Theorie des Subjekts, S. 22), zwar richtig, doch gleichzeitig auch sehr viel vermittelter zu sehen. Kant ging es vielmehr um die Rettung der Objektivität als um die nominalistische Wendung aufs Subjekt.
} 
rum nur noch um den Preis der intellektuellen Selbstaufgabe zurückzufallen. Entscheidend aufklärerische Mittel des Nominalismus würden ansonsten einfach nur wieder aus der Hand gegeben. ${ }^{139}$ Die entscheidende nominalistische Wendung aufs Subjekt ${ }^{140}$, der von Kant nicht mitgegangene Subjektivismus, nimmt seinen Anfang mit dem skeptizistischen Rationalismus Descartes und dessen cogito. ${ }^{141}$ Descartes' erkenntnistheoretische Reflexionen zu Subjekt und Objekt lernt Kant vor allen Dingen vermittelt über die Leibniz-Wolffsche-Schule kennen. Das bei der Suche nach Objektivität aus der Verzweiflung geborene cogito von Descartes liefert Kant dabei entscheidende philosophiegeschichtliche Hinweise auf das notwendige Sein des die Identität im Mannigfaltigen denkenden Subjekts, das ego. Jenes ego cogito, ergo sum ist für den Skeptizismus Descartes bekanntlich das unbezweifelbare Resultat eines rationalistischen Zweifelns an der subjektiven Erkenntnisfähigkeit von Wahrheit und Objektivität: „(...) so daß schließlich, nachdem ich es zur Genüge überlegt habe, festgestellt werden muß, daß dieser Grundsatz Ich bin, ich existiere, sooft er von mir ausgesprochen oder durch den Geist begriffen wird, notwendig wahr ist." ${ }^{142}$ Es ist der sich seiner selbst gewisse Maßstab von Descartes für die objektive Richtigkeit von Erkenntnis des Subjekts: die Selbstgewissheit des Denkens. ${ }^{143}$ (Logisch ist der Satz seinem eigenen Resultat schon vorausgesetzt.)

So sehr Kant aber auf die philosophiegeschichtlich so bedeutenden Ergebnisse Descartes' zurückgreift, so sehr geht er mit seinem transzendentalen Idealismus über die Ergebnisse des nominalistischen, rationalistischen Skeptizismus hinaus. ${ }^{144}$ Für diesen kritischen Schritt Kants erweisen sich die Ergebnisse des modernen, strengnominalistischen Empirismus von Locke und Hume als entscheidend. In Anlehnung an das rationalistische cogito Descartes' bleibt das Kantische transzendentale Subjekt jedoch immer ein logisch vorausgesetztes Selbstbewusstsein.

\footnotetext{
139 Auch in der Sozialwissenschaft ist der Weg zurück hinters Subjekt ein großer Fehler, wie Adorno anmerkt. Der neue kategorischen Imperativ (vgl. Einleitung) erfordere die Ernsthaftigkeit bei der Beschäftigung mit dem Subjekt, um die Wiederholung von Auschwitz zu verhindern: „Aufarbeitung der Vergangenheit als Aufklärung ist wesentlich solche Wendung aufs Subjekt, Verstärkung von dessen Selbstbewußtsein und damit auch von dessen Selbst.“ (Adorno: Was bedeutet: Aufarbeitung der Vergangenheit, S. 571.)

140 Vgl. Städtler: Kant und die Aporetik moderner Subjektivität, S. 18.

141 Vgl. Adorno: Kants ,Kritik der reinen Vernunft', S. 9.

${ }^{142}$ Descartes: Meditationen über die Erste Philosophie, S. 28.

143 „Nun hatte ich beobachtet, daß in dem Satz: ,Ich denke, also bin ich“ überhaupt nur dies mir die Gewißheit gibt, die Wahrheit zu sagen, daß ich klar einsehe, daß man, um zu denken, sein muß.“ (Descartes: Discours de la méthode, S. 55.)

${ }^{144}$ Lacan geht ohne die notwendigen Konsequenzen des Descartschen ego cogito fürs Denken abstrakt hinaus. Für Lacan sei das ,philosophische Cogito im Brennpunkt jener Täuschung, die den modernen Menschen so sicher macht, er selber zu sein in seinen Ungewißheiten über sich selbst“. (Lacan: Das Drängen des Buchstabens im Unbewußten oder die Vernunft seit Freud, S. 42.) Damit kann Lacan keinen Maßstab der Rationalität der Erkenntnis angeben. Die Feststellungen seiner eigens ausgearbeiteten Psychologie könnten demnach nicht mehr, aber auch nicht weniger als ein unangenehmer Traum sein.
} 
Durch den am Empirismus gewonnenen Eindruck subsistieren bei Kant die subjektiven, logischen Kategorien des Rationalismus jedoch nicht mehr in sich selbst. Sie gründen also nicht allein in reiner Vernunft, sondern setzen - anders als im Rationalismus, trotz dessen ego! - bereits die physische Sinnlichkeit eines denkenden Subjekts voraus. ${ }^{145}$ Solch emphatische Reflexion auf das lebendige Subjekt lässt der Rationalismus trotz des implementierten ego noch rigoros vermissen: „Daß dies transzendentale, alle inhaltliche Erfahrung konstituierende Subjekt seinerseits von den lebendigen einzelnen Menschen abstrahiert sei, wurde nicht erst von der Kritik am Idealismus entdeckt.“"146

Kant formuliert deshalb mit seiner Kritik am Rationalismus eine schon durchaus starke Kritik an der reinen Vernunft, die für ihn nur begriffslogischtautologisch in sich selbst subsistiere: „Kant und seine idealistischen Nachfolger wissen, daß die formale Logik, insbesondere deren Prinzipien der Identität, des zu vermeidenden Widerspruchs und des ausgeschlossenen Dritten nicht in sich, sondern in der transzendentalen Logik begründet sind." ${ }^{147}$ So bedarf es für Kant im Prozess der Erkenntnis, kritisch gegen die rationalistische Tautologie gedacht, sowohl der Sinnlichkeit wie auch des Verstandes - als voneinander abhängige Erkenntnisquellen der auswendigen Objektivität: „Ohne Sinnlichkeit würde uns kein Gegenstand gegeben, und ohne Verstand keiner gedacht werden. "“48 Diese erheischte Sinnlichkeit ist insofern als der vermittelte Ausdruck eines lebendigen, physischen Subjekts in der Kantschen Transzendentalphilosophie zu lesen. Eines der entscheidenden Verdienste des transzendentalen Idealismus ist deshalb auch, die gewaltsame Abstraktion vom offensichtlich Konkreten - von Vorstellungen im Rationalismus aufgedeckt zu haben. Ziemlich offensiv kritisiert Kant die rationalistische Unterschlagung des lebendigen, sinnlichen Subjekts als eines notwendig im Erkenntnisprozess tätig eingreifenden Naturwesens: „Die Vernunft muß mit ihren Prinzipien, nach denen allein übereinkommende Erscheinungen für Gesetze gelten können, in einer Hand, und mit dem Experiment, das sie nach jenen aus-

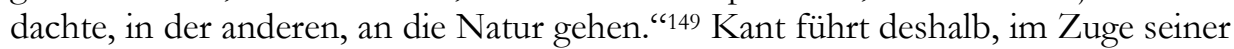
Kritik des Rationalismus, das zeitliche, seiner selbst bewusste Subjekt als in den Naturzusammenhang experimentell eingreifen Könnendes bei seiner Begründung von allgemeiner, widerspruchsfreier Objektivität als notwendig ein.

Weil nun der nominalistische Rationalismus eine vom Subjekt erst zu ordnende, chaotische Mannigfaltigkeit der seienden Einzelgegenstände in Raum und Zeit nicht ernst nimmt, ist der Rationalismus für Adorno ein Paradebeispiel für den

\footnotetext{
145 „Anschauung und Begriffe machen also die Elemente aller unserer Erkenntnis aus, so daß weder Begriffe, ohne ihnen auf einige Art korrespondierende Anschauung, noch Anschauung ohne Begriffe, ein[e] Erkenntnis abgeben können." (Kant: Kritik der reinen Vernunft, B 74.)

146 Adorno: Zu Subjekt und Objekt, S. 744.

${ }^{147}$ Kuhne, ,Bloss der Hegel'sche Begriff bringt es fertig, sich ohne äussern Stoff zu objektivieren‘. Anmerkungen zu Identität, Unterschied, Verschiedenheit, S. 83. (Herv. von mir)

148 Kant: Kritik der reinen Vernunft, A 51.

${ }^{149}$ Ebd., B XIII.
} 
philosophischen Subjektivismus: „Sie alle wissen, daß die denkende Substanz, also das Prinzip der Subjektivität bei Descartes selber einfach als eine Substanz und nicht als eine solche Tätigkeit bestimmt wird; dadurch, daß er nicht selber ein Tätiges, sondern nur ein Daseiendes ist, steht den älteren Metaphysiken der Geist wie durch einen Abgrund getrennt dem Ausgedehnten oder der Materie gegenüber." 150 Alles Objektive stehe im Rationalismus deshalb auch bloß in einer widerspruchsfreien, raumzeitlich perspektivfreien Einheit aus Geist: und deshalb gleiche das rationalistische ego auch einem Lippenbekenntnis. ${ }^{151}$ Dass Kant die notwendige Äquivokation im Subjektbegriff gegen den Rationalismus bereits sieht und deshalb ein materielles, physisch tätiges und rationales Subjekt in der Philosophiegeschichte erstmals ohne bloßes Lippenbekenntnis voraussetzt, ist für Adorno ein entscheidend emanzipatives Moment der Transzendentalphilosophie: „So kann ,Subjekt' sich auf das einzelne Individuum ebenso wie auf allgemeine Bestimmungen, nach der Sprache der Kantischen Prolegomena von „Bewußtsein überhaupt beziehen." ${ }^{152}$ Bis dahin kenne die philosophische Reflexion die dialektische Vermittlung von physisch tätigem selbstbewussten Subjekt und Objekt in sich und als Extreme durch sich hindurch nämlich noch gar nicht. Erst die von Kant eigens als „Kopernikanische Wende“"153 bezeichnete „Revolution“154 des Denkens vermittelt also beide philosophiegeschichtlichen Extreme als Momente in sich: dadurch schafft Kant einen entscheidenden „Ausgleich zwischen Rationalismus und Empirismus. "155 Kant möchte damit eine reflektierte Antwort auf die in der Philosophiegeschichte bereits von Beginn an gestellten Fragen geben (vgl. 2.1): „Mit der Intention auf sie hält Kant am Erkenntnisideal der metaphysischen via antiqua fest: auch für ihn besteht es in der Rückführung aller Dinge auf ihre letzten Gründe. Nur sie, die höchste Form des Wissens, vermag das ,spekulative Interesse der Vernunft' $\mathrm{zu}$ befriedigen. Aber dieses Ideal wird tangiert vom Bewußtsein der nominalistischen via moderna." "156 Im Zuge seiner Reflexion stellt Kant nun auch nicht bereits bekannte Fragen nach dem Verhältnis von Identität und Nichtidentität vermittels philosophisch unverbraucht wirkender Neologismen einfach neu. Im Gegenteil: er versucht, die alte Frage nach der Aristotelischen Korrespondenz und der Thomistischen adaequatio rei et intellectus mit modernem, fortschrittlichem Fokus zu beantworten. ${ }^{157}$

\footnotetext{
150 Adorno: Philosophische Terminologie, S. 68.

151 Vgl. Scruton: Kant, S. 47.

152 Adorno: Zu Subjekt und Objekt, S. 741.

153 „Selbstbewußtsein setzt voraus, daß die Welt so erscheint, daß sie sich ,nach den Kategorien richtet'. Diese Behauptung umfaßt den Kern dessen, was Kant seine ,kopernikanische Revolution“ in der Philosophie nennt.“ (Scruton: Kant, S. 44.)

${ }^{154}$ Kant: Kritik der reinen Vernunft, B XVI.

${ }^{155}$ Hösle: Die Krise der Gegenwart und die Verantwortung der Philosophie, S. 45 f.

156 Haag: Der Fortschritt in der Philosophie, S. 73.

157 Vgl. zu Aristoteles und Thomas Abschnitt 2.1.
} 
Der für die Transzendentalphilosophie nun so entscheidende Punkt, der sich auch gegen die philosophische Tradition und den Nominalismus richtet, ist Kants synthetische Einheit der Apperzeption. Diese drückt entsprechend aus, dass das Bewusstsein als denkendes Bewusstsein aller Verknüpfung von Vorstellungen in einem materiellen, empirischen Bewusstsein vorausgesetzt sein muss: „Das Ich denke ist, wie schon gesagt, ein empirischer Satz, und bält den Satz, Ich existiere, in sich." "158 Die synthetische Einheit der Apperzeption verweist das im Erkenntnisprozess in den Naturzusammenhang noch nicht selbsttätig eingreifende Subjekt des Rationalismus damit auf ein physisch tätiges, praktisches Subjekt - das von Kant aber nicht minder selbstbewusst gedacht wird. Kant verweist dadurch auf das ichliche, individuelle Subjekt, das ein in der Zeit liegendes Bewusstsein bei der Formulierung von Objektivität hat. Seine transzendentale Logik ist, gegen den nominalistischen Rationalismus, auch von vorausgesetztem und extramentalem Material der Erkenntnis als notwendig zu erfahrendem Material, das in Form mannigfaltig sinnlicher Eindrücke, als Vorstellung, in das Subjekt kommt, nicht unabhängig. Sie fragt nach allgemeinen Gesetzen der widerspruchsfreien Identität von selbstbewusster Identität und mannigfaltiger Nichtidentität, über die man zu gegenständlicher, allgemeingültiger und notwendig objektiver Erkenntnis gelangt: „Sie [die transzendentale Logik, B.E.B.] fragt nach den Bedingungen im subjektiven Bewußtsein, durch die dieses Bewußtsein auf Gegenständliches sich bezieht; sie hat es also nicht etwa mit reinen Denkformen unabhängig von der Möglichkeit inhaltlicher oder gegenständlicher Erkenntnis zu tun, sondern fragt nach den Gesetzen, durch die wir zu gegenständlicher Erkenntnis und vollends zu allgemein gültiger und notwendiger objektiver Erkenntnis gelangen." 159

Kants synthetische Urteile a priori haben insofern überhaupt nur eine objektive Geltung, „so fern diese [Dinge, B.E.B.] als Gegenstände möglicher Erfahrung angenommen werden. "“60 Jede Empfindung und jede nach Kant mit allgemeinen Begriffen durchsetzte Erfahrung des materiellen, physischen Subjekts trägt deshalb schon Spuren zeitlicher wie räumlicher Ordnung in sich: „Zu urteilen soll dem kontingenten Subjekt möglich sein; seine Fähigkeit, Wahres zu erschließen, aber soll begrenzt werden auf den Bereich, in dem seine Schlüsse empirisch bestätigungsfähige Urteile zum Resultat haben. "161 Insofern kann es keinen vernünftigen Bewusstseinszustand geben, der nicht auch der ichlichen, stets nur subjektiv erfahrbaren Zeit und Räumlichkeit unterworfen bleibt: „,[D]urch diese Ordnung in unserer Erfahrung wird die Zeit für uns als wirklich gesetzt." 162 Dennoch votiert Kant dann widersprüchlich, nämlich in diesem Punkt ganz Idealist, für einen verabsolutierten zeitlosen Wahrheitsbegriff: „Dazu ist zu sagen, daß der Begriff der

\footnotetext{
158 Ebd., B 423.

159 Adorno: Philosophische Terminologie, S. 73.

160 Kant: Kritik der reinen Vernunft, B 148.

161 Bulthaup: Idealistische und materialistische Dialektik, S. 131.

162 Scruton: Kant, S. 47.
} 
Wahrheit selbst bei Kant - und das ist nun wieder etwas, was, ich möchte sagen: mit dem bürgerlichen Denken aufs allertiefste zusammenhängt - der einer zeitlosen Wahrheit ist." 163 Kant formuliert diesen zeitlosen Wahrheitsbegriff also trotz seines bereits von zeitlichem, individuellem durchsetzten Wahrheitsbegriff.

Doch wie ist bei Kant die dialektisch gegen die rationalistische Tautologie gedachte Erkenntnis allgemeingültiger Objektivität im einzelnen, erkennenden Subjekt ganz konkret zu begreifen? Das Kantische „Ich denke“, das eben „, alle meine Vorstellungen begleiten können"164 muss, ist im Zusammenhang seiner Bestimmung des äußeren, extramentalen Materials, dem ,gegebenen Mannigfaltigen“"165, durch Identifikation nicht von Empirischem unabhängig gedacht. Das Subjekt ist durch das Ich denke nicht perspektivfrei autonom wie noch im nominalistischen Rationalismus bestimmt. Es ist also nicht widerspruchsfrei ohne jedes raumzeitliche Erfahrungsmaterial als einzig unbezweifelbares ego cogito des Descartschen Skeptizismus: "Also nur dadurch, daß ich ein Mannigfaltiges gegebener Vorstellungen in einem Bewußtsein verbinden kann, ist es möglich, daß ich mir die Identität des Bewußtseins in diesen Vorstellungen selbst vorstelle, d.i. die analytische Einheit der Apperzeption ist nur unter der Voraussetzung irgend einer synthetischen möglich."166 Die vernunftbedingten Kategorien bleiben bei Kant insofern auf die materiellen Gegenstände möglicher Erfahrung, meiner einzelsubjektiven Erfahrung bezogen, der ich mir als vernünftiges, physisches Naturwesen sicher sein muss. Jedes selbstbewusste, lebendige Subjekt weiß, dass die Vorstellungen, die es als vernunftbegabtes physisches Subjekt vom mannigfaltigen AuBen hat, seine eigenen Vorstellungen sinnlicher Eindrücke sind. Diese dringen dabei als Gesehenes, Gehörtes und Gefühltes zunächst chaotisch und mannigfaltig in das vernünftige Subjekt ein. Durch diese physis ist das erkennende Subjekt zugleich ein raumzeitliches, individuiertes Subjekt und ein mit sich selbst nichtidentisches Objekt: „Das seiende Ich ist Sinnesimplikat noch des logischen ,Ich denke, das alle meine Vorstellungen soll [Anmerkung B.E.B.: im Original bei Kant: muss] begleiten können', weil es Zeitfolge zur Bedingung seiner Möglichkeit hat und Zeitfolge nur ist als eine von Zeitlichem. Das ,meine' verweist auf ein Subjekt als Objekt unter Objekten, und ohne dies ,meine ' wiederum wäre kein ,Ich denke‘." "167 Die Mannigfaltigkeit der Vorstellungen würde ansonsten auch in kein mit sich identisches Selbstbewusstsein fallen. Jede ,Erkenntnis“ des seiner selbst bewussten Subjekts wäre dadurch gegenstandslos, weil die allgemeinen Begriffe des Subjekts tautologisch leer blieben, wenn sie denn ohne nichtidentischen Widerspruch des Nichtbegrifflichen gedacht werden. ${ }^{168}$ Im Bewusstsein des Subjekts selbst findet also schon ein nichttautologischer Denkprozess statt, der reflexiv ist. Reine Ver-

\footnotetext{
163 Adorno: Kants ,Kritik der reinen Vernunft', S. 23.

164 Kant: Kritik der reinen Vernunft, B 132.

165 Ebd., B 133.

166 Ebd., B 133.

167 Adorno: Negative Dialektik, S. 185.

168 Vgl. Kant: Kritik der reinen Vernunft, B 146 ff.
} 
nunft wird sich auch darum zum Selbstwiderspruch, weil das Denken subjektiv reflektierte Tätigkeit ist. Im reflexiven Denkprozess hat sich die subjektive Vernunft auch notwendig selbst zum Objekt. Subjektive Vernunft ist, weil von der Vernunft eines raumzeitlichen Subjekts nicht zu trennen, eben auch eine Tätigkeit des Subjekts. Das eigene Bewusstsein des Subjekts verdinglicht sich dabei zum Objekt: ,[D]as Denken ist Tätigkeit und zugleich deren Gegenstand - es ist bei seinem Gegenstand bei sich selbst; so ist es das Modell selbstbewußter Tätigkeit." "169

Diese Selbstreflexion der Vernunft ist für Kant oberster Grundsatz allgemeiner synthetischer Urteile des vernunftbegabten Subjekts. Kant denkt dabei auch ganz universell, wer dieses jeweils selbstbewusste, erkennende Subjekt in der Welt ist: jedes vernünftige physische Subjekt ausnahmslos, das den Ausdruck ich auf sich anwenden kann - und damit auch überhaupt erst vernünftiges Subjekt ist. Jedes materielle Subjekt wird als Exemplar der Gattung Mensch in diesen Zusammenhang gestellt. Jedes einzelne selbstbewusste Subjekt hat mit seiner Erfahrung notwendig Teil am objektiven Zusammenhang der Erfahrungen. Die Vernunft ist deshalb nicht nur individuell, sondern zugleich auch individuiertes Allgemeinvermögen ${ }^{170}$ : „Kant versucht zu zeigen, daß Erfahrung, recht verstanden, bereits jenen objektiven Bezug aufweist, den Hume bestritt. Die Erfahrung beinhaltet in sich selbst die Merkmale von Raum, Zeit und Kausalität. Daher beziehe ich mich, wenn ich meine Erfahrung beschreibe, auf eine geordnete Sichtweise einer unabhängigen Wirklichkeit." ${ }^{\prime 11}$

Das Ich, das alle Vorstellungen muss begleiten können, existiert allerdings auch nur innerhalb einer konkreten Gesellschaft als ein physisch Tätiges, in der das individuierte Allgemeinvermögen auch erst seine Berechtigung hat. Erkenntnis selbst, Naturerkenntnis zumal, ist deshalb als kooperativer, arbeitsteiliger Prozess der gemeinsamen Einwirkung in den Naturzusammenhang begründet. Die sinnvolle kooperative Beziehung von Teilarbeitsprozessen ist aber nur deshalb möglich, weil alle daran beteiligten Subjekte formal als Gleiche jeweils miteinander kompatibel sind. Diese Einheit der subjektiven Form ist Resultat der Reflexion auf die Möglichkeit der Einheit von arbeitsteiligen Prozessen. Diese liegen den Erkenntnissen, auf die reflektiert wird, faktisch schon zugrunde. Die Einheit der Erkenntnis als Einheit des Bewusstseins hat damit ein notwendig gesellschaftliches Moment. Ein in Zeit und Raum liegendes Bewusstsein des Subjekts ist insofern ein bereits vergesellschaftetes Selbstbewusstsein: „Kein Lebewesen lebt durch sich allein.“'172 Die vernünftige Erfahrung der nichtbegrifflichen Extramentalität

\footnotetext{
${ }_{169}$ Bulthaup: Idealistische und materialistische Dialektik, S. 132.

${ }^{170}$ Eine allgemeine Einsicht gibt es nicht. Subjektive Einsicht kann nur im einzelnen Subjekt stattfinden, aber eben nicht bei allen gleichzeitig. Es kann keine Instanz geben, die eine allgemeine Einsicht als eine solch transzendente Instanz garantieren kann. (Vgl. dazu Bensch: Vom Reichtum der Gesellschaften, S. 17.)

171 Scruton: Kant, S. 32.

172 Bulthaup: Idealistische und materialistische Dialektik, S. 135.
} 
kann deshalb nicht von einer statisch gedachten Gesellschaftlichkeit getrennt werden (vgl. besonders 2.3.1). Denn ich kann eine Erfahrung nur als meine, in mein Bewusstsein fallende Erfahrung, identifizieren, wenn ich sie als notwendig vergesellschaftetes Vernunftsubjekt in der lebendigen Zeit und im Raum als lebendiges Subjekt verorten kann. So muss die Erfahrung einem Seienden, seiner selbst bewussten Subjekt zukommen, das perspektivisch in der Zeit existiert und Bestand hat. Deshalb ist das allgemeine synthetische Bewusstsein ohne unmittelbar empirisches Bewusstsein, das über seine Physis in die Gesellschaft eingebunden ist, gar nicht zu haben. Die Verwiesenheit, die Reziprozität beider Momente aufeinander als durch sich hindurch dialektisch vermittelte sind insofern bei der Bestimmung des seiner selbst bewussten Subjekts für Kant notwendig. Meine selbstbewussten Erfahrungen des Ich denke erweisen sich darum, und auch hier kommt vermittelt die notwendige und allgemeine Gesellschaftlichkeit in den Erkenntnisprozess hinein, als eine unmittelbar transzendentale Bedingung der Möglichkeit von Erfahrung. Das transzendentale Subjekt Kants ist durch den Verweis auf seine unmittelbare Physis und das individuierte Allgemeinvermögen darum als zugleich gemeinschaftliches Subjekt gedacht ${ }^{173}$ : „Übersteigt die Zahl der partikularen Urteile in einer solchen Konjunktion die von einem kontingenten Subjekt empirisch überprüfbaren Tatsachen, dann ist dieses Subjekt, will es wahre Aussagen über die Gegenstände eines von ihm nicht vollständig zu überschauenden Gegenstandsbereichs machen, auf die Geltung universaler Urteile angewiesen." 174 Dem transzendentalen Subjekt bleibt, trotz aller scheinbaren Entbundenheit von Raum und Zeit durch die reine Synthesis des Verstandes, das empirische Naturwesen und damit ein in Gesellschaft eingebundenes Ich denke reziprok vorausgesetzt - reziprok, aufeinander verwiesen, weil jenes diesem nicht vorangestellt, sondern beide mittels der synthetischen Einheit der Apperzeption als Äquivokationen des selbstbewussten, vergesellschafteten Subjekts selbst rekursiv in sich vermittelt sind. ${ }^{175}$

Die Kantische transzendentale Einheit der Apperzeption ist dabei ein Akt der Spontaneität. Das transzendentale, seiner selbst bewusste Subjekt wird zum Ausgangspunkt noch einer jeden allgemeinen, objektiven und widerspruchsfreien Erkenntnis der Gegenstände. Derart vermittelt wird es darum zur Voraussetzung der objektiven Erkenntnis von Gesellschaft, zur Bedingung der Möglichkeit von gesellschaftlicher Erkenntnis, da die Gesellschaft von extramentaler Objektivität und Urteilen über diese nicht einfach zu trennen ist. Jede Wissenschaft bleibt deshalb auf das reflexiv gedachte vernünftige Subjekt der Erkenntnis angewiesen: „Die

\footnotetext{
${ }^{173}$ Kant: Kritik der reinen Vernunft, A 349 f.: „Nun haben wir aber bei unserem Satze keine Erfahrung zum Grunde gelegt, sondern lediglich aus dem Begriffe der Beziehung, den alles Denken, auf das Ich, als das gemeinschaftliche Subjekt, hat, dem es inhäriert, geschlossen. “

174 Bulthaup: Idealistische und materialistische Dialektik, S. 131.

175 Vgl. hierzu Weyand: Adornos Kritische Theorie des Subjekts, S. 46 f.
} 
ursprüngliche Apperzeption garantiere die Objektivität der Erkenntnis, weil von ihr alle empirische Synthesis, also einzelwissenschaftliche Erkenntnis, abhänge." "176

Dadurch, dass die scheinbar allgemeine, zeitlose Subjektivität des Rationalismus trotz oder gerade durch die unmittelbare physische Tätigkeit des erfahrenden, daseienden Subjekts aufgegeben und nicht verabsolutiert wird, kann die vernünftige subjektive Erkenntnis des Objekts, auch der offensichtlich extramentalen Gesellschaft, dialektisch überhaupt erst als Resultat subjektiver Reflexion allgemein und „objektiv gültig“'177 werden. Nur im seiner selbst bewussten Subjekt als Ich denke kann die Voraussetzung von objektiver, wahrer Erkenntnis liegen. Nur Subjekt kann die Objektivität der Erkenntnis als konsistent Erkanntes garantieren. Das erkennende, unmittelbare Subjekt ist als selbstbewusstes Subjekt der objektiven Erkenntnis immer auch notwendig überindividuell bestimmt. Alles gültig durch Subjekt gedachte ist notwendig allgemein und objektiv und muss, als Kern von allgemeiner und interdisziplinärer Objektivität überhaupt, von allen anderen raumzeitlichen und ebenfalls selbstbewussten Subjekten als allgemein und notwendig nachvollzogen werden können. Damit ist das Transzendentalsubjekt für Kant das allgemeine und gemeinschaftliche Subjekt objektiver Erkenntnis, das die Bedingungen der Möglichkeit von objektiver Erkenntnis in sich als seiner selbst bewusstes Subjekt enthält, die für jedes Daseiende, endliche und vergesellschaftete Subjekt notwendig gelten. ${ }^{178}$

Deshalb, weil notwendig überindividuell, gehen die notwendig allgemeinen Bestimmungen des Subjekts auch über jede individuelle Erfahrung des physisch daseienden, einzelnen, aber vernünftigen Subjekts hinaus. Sie transzendieren im Erkenntnisprozess selbst das immer seiende Einzelmoment der Erkenntnis realistisch. Jede selbstbewusste Subjektivität bleibt auf die je eigene vereinzelt seiende Objektivität und die eigene Vergesellschaftung verwiesen, womit das seiner selbst bewusste Subjekt im Erkenntnisprozess auf die eigene wie äußere Objektivität verwiesen ist. Mit dem Verweis auf die eigene physische Materialität wird der Begriff des Subjekts als Motor allgemeiner und notwendiger Erkenntnis von Kant aufs Individuum verpflichtet.

\subsubsection{Zur emanzipativen Dialektik des Kantischen Transzendentalsubjekts als Kritik des philosophischen Subjektivismus}

Wenn über die objektive, wahre Erkenntnis von gesellschaftstheoretischen Phänomenen gesprochen werden soll, muss sich über die ausschlaggebenden Reflexionen Kants zum vernunftbegabten Subjekt als Ich denke und alleinigem Maßstab der Objektivität Klarheit verschafft werden. Die innersten Begründungen von Kants Reflexionen geben mehr Aufschluss über die Zusammenhänge des Den-

\footnotetext{
176 Ebd., S. 45.

177 Adorno: Zu Subjekt und Objekt, S. 757.

178 Vgl. Kant: Kritik der reinen Vernunft, A 349 f.
} 
kens von Objektivität, auch der Stellung von Objektivität, als es dem systematischen Ansatz in 2.2.1 aufzuzeigen möglich war. Auch die Motivation des Denkens der Objektivität wird deutlicher, wenn Kants philosophiehistorischer Ausgangspunkt genauer reflektiert wird. Die wahre Erkenntnis wird von Kant systematisch als Resultat der transzendentalen Logik, als Vermittlung von erkennendem Subjekt und nichtidentischem Objekt begriffen. Damit entwickelt er bereits eine denknotwendige Vermittlung von vernünftig tätigem Subjekt und nichtidentischem Objekt. Obwohl Kant die Dialektik im Rahmen der Erkenntnis von Objektivität als eine „Logik des Scheins“179 bezeichnet, ist seine Subjekt-Objekt-Reflexion selbst schon dialektisches Denken. Auch die Kritik der philosophischen Tradition wird von Kant bereits in der Form einer dialektischen Vermittlung der beiden philosophiegeschichtlichen Extreme Rationalismus und Empirismus vorgetragen, und in 2.2.1 wurde bereits Vittorio Hösle zitiert, der an der Stelle nicht zu unrecht vom „Ausgleich zwischen Rationalismus und Empirismus“180 bei Kant spricht.

Kant will die nichttautologische, objektiv wahre Erkenntnis aus dem vernünftigen Subjekt selbst und seinen Prinzipien der Logik, als transzendentale Logik, formulieren. Die alleinige Erkenntnis von allgemeiner Objektivität sollte im Zuge dessen nicht empiristisch auf das rein materielle Individuum, aufs unmittelbar physische Subjekt restringiert werden. Aber sie sollte auch nicht rationalistisch aus einem rein vernünftigen Subjekt deduktiv herausgeschraubt werden. Das ist Kants kritisches Resultat der Reflexion der verschiedenen nominalistischen Wendungen auf das Subjekt: „Mit einem Worte: Leibniz intellektuierte die Erscheinungen, so wie Locke die Verstandesbegriffe nach einem System der Noogonie (...) insgesamt sensifiziert, d.i. für nichts, als empirische, oder abgesonderte Reflexionsbegriffe ausgegeben hat. " 181 Die für Kant tautologischen, weil gleichermaßen subjektivistischen Positionen der Philosophiegeschichte - Rationalismus und Empirismus sollen mit dem transzendentalen Idealismus und einer spezifischen Reflexion der Subjekt-Objekt-Dialektik überwunden werden. Er vermittelt deshalb beide Extreme als Momente dialektisch schon in sich, was ihre Vermittlung durch sich hindurch meint. ${ }^{182}$ Kants Kritik an Rationalismus und Empirismus gleichermaßen deckt damit generelle Schwachstellen dieser beiden subjektivistischen Positionen auf. ${ }^{183}$

\footnotetext{
${ }^{179}$ Ebd., A 61 / B 86.

${ }^{180}$ Hösle: Die Krise der Gegenwart, S. 45 f.

181 Kant: Kritik der reinen Vernunft, A 271 / B 327.

182 Nach Nietzsche ist jede dialektische Vermittlung, auch die Kantische, „mittelmäßig“: , Wer zwischen zwei entschlossenen Denkern vermitteln will, ist gezeichnet als mittelmäßig: er hat das Auge nicht dafür, das Einmalige zu sehen; die Ähnlichseherei und Gleichmacherei ist das Merkmal schwacher Augen." (Nietzsche: Die fröhliche Wissenschaft, S. 495.)

${ }^{183}$ Ein Beispiel für den Subjektivismus in den Sozialwissenschaften ist die Wissenssoziologie Karl Mannheims. Wenn Mannheim sich durch seinen standpunktunabhängigen Ideologiebegriff des erkenntnistheoretisch reflektierten Wahrheitsbegriffs entledigt und einzig die freischwebende Intelli-
} 
Den rationalistischen Deduktionen weist Kant zunächst nach, dass sie eine subjektivistisch gedachte Tautologie des reinen Geists, der reinen Vernunft seien. Die daraus resultierende Inhaltslosigkeit der Urteile wirft er dem nominalistischen Rationalismus dann als seinen entscheidenden Mangel vor: „Die reinen Verstandesbegriffe beziehen sich durch den bloßen Verstand auf Gegenstände der Anschauung überhaupt, unbestimmt ob sie die unsrige oder irgend eine andere, doch sinnliche sei, sind aber eben darum bloße Gedankenformen, wodurch noch kein bestimmter Gegenstand erkannt wird." ${ }^{184}$ Aus erfahrungsarmen allgemeinen Begriffen könnten, so Kant, keine objektiven Urteile über Gegenstände jeglicher Art deduktiv abgeleitet werden. Die Außenwelt könne deshalb kein Resultat einer widerspruchslosen rationalistischen Deduktion aus dem identischen Begriff sein. Dieser subsistierte sonst auch allein in sich selbst. Durch eine Fortführung des bloß rationalistischen Identitätsdenkens, der Widerspruchslosigkeit der Welt qua Geist und notwendigem Begriff, würde sich das seiner selbst bewusste Subjekt tautologisch selbst im Spiegel betrachten. Es würde daneben auch die eigene, unmittelbar historische Existenz als Tätigkeit in der Welt verleugnen. Deshalb werde das materiell-somatische, nichtbegriffliche Moment der Erkenntnis als Voraussetzung von zu erkennender Objektivität gebraucht (vgl. 2.2.1). Das konstituiere die Subjektivität erst und diese sei bekanntlich aus dem Erkenntnisprozess nicht wegzudenken. Wenn die Objektivität als Raumzeitlichkeit des Subjekts wegfiele würde, wie bei Hegel, der durch seine absolute Vermittlung von Subjekt und Objekt den Rationalismus Descartes und Spinozas gewissermaßen nur auf eine höhere Stufe als durch die tätige Vermittlung hindurchgegangen hebt, „der Geist zum schlechthin anderen des Körpers gemacht ${ }^{\text {“185 }}$. So ist Kants Vermittlungsleistung des transzendentalen Idealismus auch ein Ergebnis einer Kritik des eigenen, früher vertretenen ,Dogmatismus' der reinen Vernunft, den er stellvertretend an den rationalistischen Dogmatikern Leibniz, Descartes und Spinoza kritisiert. Diese Schaffensperiode wird gemeinhin als Kants sogenannte vorkritische frühschriftliche Periode, seine Schaffensperiode vor den Kritiken, bezeichnet.

Hier soll jedoch vor allem auf die Kantische Kritik des ebenfalls subjektivistischen Empirismus eingegangen werden. Diese Kritik am philosophischen Empirismus kann auch schon gegen empiristische, positivistische Strömungen in den Sozialwissenschaften gelesen werden. Obwohl sich auch Kant auf ein physisches Individuum als daseiendes, zeitliches Subjekt beruft und damit scheinbar einen sinnlich-nichtbegrifflichen Empirismus vertritt, kritisiert er den Empirismus letztendlich scharf. Seine selbsternannten Erwecker aus seinem ,dogmatischen Schlummer', Hume und Locke, werden von Kant dabei genauso offensiv wie die nominalistischen Rationalisten angegangen: „Ich gestehe frei: die Erinnerung des

genz als ins Ganze einsichtig propagiert, zieht er die objektive Wahrheit auch noch ins (elitäre) Subjekt. (Vgl. dazu Mannheim: Ideologie und Utopie.)

184 Kant: Kritik der reinen Vernunft, B 150.

185 Adorno: Negative Dialektik, S. 194. 
David Hume war eben dasjenige, was mir vor vielen Jahren zuerst den dogmatischen Schlummer unterbrach und meinen Untersuchungen im Felde der speculativen Philosophie eine ganz andere Richtung gab. "186 Dass also die Erscheinungen der Natur nach Kant nur von einem seiner selbst bewusst tätigen, endlichen und damit auch materiellen Subjekt rational als objektiv seiend, in ihrem an sich Sein zu beurteilen sind, könnte deshalb zwar zunächst auch als eine bloße Anlehnung Kants an einen empiristischen Nominalismus gesehen werden. Der Empirismus kritisiert ja gerade mittels seiner spezifischen Subjektphilosophie, mittels der subjektbezogenen Datengewinnung, die rationalistische wie realistische Erkenntnis (die intentio recta) scharf: „Mit dem Nominalismus war die Reduktion der Objektivität auf die Empfindungen und Wahrnehmungen der Subjekte gesetzt, die zuvor als objektiv vorgegeben gedachte Ordnung zerfallen, und damit die Orientierung der einzelnen Subjekte an einer allen gemeinsamen Objektivität theoretisch unmöglich geworden. "187 Auch für Kant resultieren aus dem Erkenntnisprozess nun, wie für den Empirismus, keine allgemeinen Wahrheiten a priori, keine Wahrheiten, wie die Dinge an sich selbst sind. Allgemeine synthetische Wahrheiten a priori vermitteln für ihn insofern kein Wissen über eine materielle Welt, das ohne dialektisch vermittelten Rekurs auf die subjektiven Bedingungen der Möglichkeit von Erkenntnis erfasst wird. Synthetische Wahrheiten a priori sind keine ontologischen Wahrheiten intentione recta, sondern sind nur durch das selbstbewusst vernünftige, aber sogleich materielle, physische Subjekt der Praxis hindurch vermittelt wahr: intentione obliqua. Erkenntnis von Dingen gibt es für Kant also nur, sofern sie auch Gegenstände möglicher Erfahrung eines seiner selbst bewussten Subjekts sind: „Ich dagegen sage: es sind uns Dinge als außer uns befindliche Gegenstände unserer Sinne gegeben, allein von dem, was sie an sich selbst sein mögen, wissen wir nichts, sondern kennen nur ihre Erscheinungen, d. i. die Vorstellungen, die sie in uns wirken, indem sie unsere Sinne affizieren. "188 Dieser scheinbare Kantische Nominalismus ist jedoch auch nicht zu verabsolutieren. Kant weist den Empirismus entsprechend scharf in seine Schranken, indem er die wahre Erkenntnis auch an das transzendentale Subjekt fesselt (vgl. 2.2.1).

Dass Erkenntnis nur noch intentio obliqua möglich sei, ist der für Kant notwendig gewordene Rekurs auf den Nominalismus, der ihm durch den Empirismus Humes, Lockes, aber auch vermittelt über den Rationalisten Descartes und dessen cogito offenbar wird. Beide philosophischen Konzeptionen, Empirismus wie Rationalismus, sind also ausdrückliche, aber verschiedene Formen eines subjektivistischen Nominalismus; und beide Denkrichtungen werden von Kant gleichermaßen kritisiert. Das bekannte Zitat aus der Kritik der reinen Vernunft unterstreicht diese

\footnotetext{
${ }^{186}$ Kant: Prolegomena zu einer jeden künftigen Metaphysik, die als Wissenschaft wird auftreten können, AA IV.

187 Bulthaup: Die transzendentale Einheit der Apperzeption, das System des Wissens und der Begriff gesellschaftlicher Arbeit, S. 77.

188 Ebd., S. 62.
} 
doppelte Kritik Kants: „Gedanken ohne Inhalt sind leer, Anschauungen ohne Begriffe blind." ${ }^{189}$ Pointiert bedeutet das, dass die rationalistische Auffassung objektiver Erkenntnis an sich seiender Dinge bloß Form ohne Inhalt vermittelt, die empiristische Version von Erkenntnis bloß Inhalt ohne Form. Beide Positionen vermitteln nun für Kant ihre immanenten Widersprüche nicht miteinander, erfassen diese nicht kritisch. Diese ihre Widersprüche löst Kant in seiner Theorie mit der entsprechenden Äquivokation im Subjektbegriff, der die Eindimensionalität des Nominalismus entsprechend auflösen soll (vgl. 2.2.1). Die nominalistischen Momente von reiner Vernunft und empiristischer Auflösung will die Dialektik des transzendentalen Idealismus in sich und durch sich hindurch vermitteln. Kants Äquivokation des in sich vermittelten, dialektischen Subjektbegriffs geht deshalb über eine identitätsstiftende Dichotomie des Rationalismus hinaus, will aber auch über nur agglomerierte Einzelurteile als vermeintliche Erkenntnis von den Dingen hinausgehen. Kant wirft dem reinen Tätigkeitsgedanken des erfahrenden Individuums im Empirismus - allein aus induktiver Erfahrung des Materials resultiere eine Erkenntnis der Dinge - vor, dass dieser sich gegen jedes objektive Wissen von den Dingen blind mache. Jede Erfahrung, auf die der Inhalt eines jeden Gedankens sich zurückführen lassen soll, soll nur der Gedanke von vereinzelt seienden Subjekten sein, weshalb das Urteil nicht allgemein objektiv und notwendig wahr sein könne.

Kant sieht darum, trotz seiner scharfen Kritik des Rationalismus, die Lösung der Frage nach der Objektivität von Erkenntnis nicht im Empirismus und seiner vermeintlichen Materialität. Er macht eine alles entscheidende Schwäche des subjektivistischen Empirismus aus: die ins bodenlose fallenden Subjektlosigkeit durch die Überhöhung des sensualisierten, physischen Individuums - weil es dem Empirismus zufolge immer nur Einzelnes und dessen assoziative Verknüpfung im individuellen Bewusstsein gibt. Nach Kant hingegen haben allgemeine und notwendige Urteile die unmittelbare Einzelerfahrung des Individuums zu transzendieren, um eine autonome, allgemeine Objektivität der subjektiven Urteile als vernünftig zu garantieren. Der empiristischen Erkenntnistheorie fehlt jedoch das seiner selbst bewusste, vernünftige Subjekt als notwendiges Moment der objektiven Erkenntnis. Deshalb fehle dem Empirismus die wesentliche, entscheidende Begründung für die bestimmte Objektivität. So ist und bleibt der Empirismus subjektiv(istisch) gerichtet, weil ohne vernünftig formendes und damit tätiges Subjekt das autonome Objekt nicht widerspruchsfrei gedacht werden kann.

Obwohl der Empirismus zwar fortwährend über ein unmittelbares Material und die nichtbegriffliche Gegenständlichkeit spricht, hat er durch die von jedem konkreten Gegenstand abstrahierende Gegenständlichkeit notwendig jedoch nur die Form der Erkenntnis, selten jedoch wirklich das Material zum Gegenstand. Diesen erkenntnistheoretischen Subjektivismus im Stande des vermeintlichen

\footnotetext{
${ }^{189}$ Kant: Kritik der reinen Vernunft, A 51.
} 
materialistischen Objektivismus macht Adorno als eine entscheidende Schwäche des Empirismus aus. Über die empiristische Erkenntnistheorie Humes schreibt er: „An der Schwäche von Humes Erkenntnistheorie wird das flagrant. Sie war subjektiv gerichtet, während sie des Subjekts entraten zu können wähnte."190 Trotz des entscheidenden und wichtigen Stichs gegen den Rationalismus verfällt der Empirismus dadurch dem nominalistisch-idealistischen Identitätsdenken von Subjekt und Objekt. Auch der Empirismus enthält sich damit also des wirklich materialistischen und ernstgenommenen nichtbegrifflichen Moments. ${ }^{191}$

Weil Kant die identitätsstiftende Schwäche des Nominalismus reflektiert, führen für ihn insofern weder rationalistischer Verstand noch empiristische Sinnlichkeit zu einer objektiv gültigen Erkenntnis von den Dingen an sich selbst. Anders als im Empirismus wird ihm das Individuum zum notwendigen Moment im Erkenntnisprozess, nicht aber zum entscheidenden Element. Adorno schreibt bezüglich der synthetischen Einheit der Apperzeption und das ihr immanente, not-

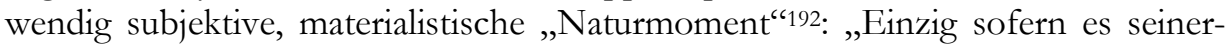
seits auch Nichtich ist, verhält das Ich sich zum Nichtich, ,tut' etwas, und wäre selbst das Tun Denken. Denken bricht in zweiter Reflexion die Suprematie des Denkens über sein Anderes, weil es Anderes immer in sich schon ist. "193 Das beschreibt die Vermittlungsleistung von Überindividuellem und physisch Individuellem im transzendentalen Subjekt adäquat. Das vernünftige Subjekt wird von Kant eben auch als ein materielles Naturwesen gedacht. Das transzendentale Subjekt ist insofern der entscheidende Kern der reflektierten Vermittlungsleistung Kants von Rationalismus und Empirismus. Es lässt sich von der Empirie nicht, durch die Rückbindung an das Naturwesen Subjekt, lösen, geht aber auch nicht in ihr auf.

In Folge seiner Vermittlungsleistung werden für Kant das Experiment am Naturgegenstand und die Art seiner Vermittlung das entscheidende Momentum, das das transzendentale Subjekt als Autonomes von Tautologien der Philosophiegeschichte lösen soll, ohne dass dabei die zu vermeidende Widersprüchlichkeit im Urteil aufgegeben wird. Das erkennende Subjekt muss, um allgemeine und notwendige Urteile zu fällen, „da die Subjekte nur als empirische Naturwesen auf Naturgegenstände einwirken können“"194, gegen die umgebende Umwelt selbstständig und experimentell tätig sein. Das tätige Experiment zu Erkenntniszwecken ist deshalb vom transzendentalen Subjekts als ein notwendig und allgemein erkennendes nicht wegzudenken. Das zeitliche, materielle Subjekt stellt überschaubare, feste und widerholbare Rahmenbedingungen im Experiment her, mithilfe derer

\footnotetext{
190 Adorno: Zu Subjekt und Objekt, S. 756.

191 Vgl. hierzu auch die treffende Kritik Lenins insbesondere an Mach und Avenarius in: Lenin:

Materialismus und Empiriokritizismus.

192 Adorno: Negative Dialektik, S. 201.

${ }^{193}$ Ebd.

194 Bulthaup: Die transzendentale Einheit der Apperzeption, das System des Wissens und der Begriff gesellschaftlicher Arbeit, S. 97.
} 
die Gegenstände der Beobachtung wiederholt in derselben Weise ,manipuliert ${ }^{6}$ werden können. Die wiederholten Abläufe des Experiments sollen dabei stets identische und nicht widersprüchliche Ergebnisse liefern. Erkenntnis, wenn wie in diesem Fall auch von ,nur' komparativer Allgemeinheit, kann insofern ohne individuelles, objektives Moment der Vermittlung dem Subjekt nicht einfach ,zukommen', sondern dafür bedarf es subjektiver Interventionen; es bedarf also eines handfesten äußeren Betätigungsfeldes.

Weil das Subjekt insoweit ein Stück weit autonom gegen die Natur sei - auch gegen die eigene als Naturwesen - ist es ein selbstbewusst und vernünftig in den Naturzusammenhang eingreifendes Subjekt der Praxis. Als tätiger Eingriff stehe jede allgemeine Erkenntnis wider die passive Kontemplation des zeitlichen Subjekts als funktionelles Mittel von Anderem gegenüber dem Naturzusammenhang: „Als Galilei seine Kugeln die schiefe Fläche mit einer von ihm selbst gewählten Schwere herabrollen, oder Torricelli die Luft ein Gewicht, was er sich zum voraus dem einer ihm bekannten Wassersäule gleich gedacht hatte, tragen ließ, oder noch in späterer Zeit Stahl Metalle in Kalk und diesen wiederum in Metall verwandelte, indem er ihnen etwas entzog und wiedergab; so ging allen Naturforschern ein Licht auf." "195 Das zeitliche, als Naturwesen vergesellschaftete Subjekt sei deshalb nicht gegen den es umgebenden Naturzusammenhang, seine Umwelt, ohnmächtig. Die Natur sei auch keine rationalistische, reine Spiegelung des allwissenden und diese bewegenden Subjekts. Weil das Experiment als Eingriff des Subjekts als Naturwesen in den Naturzusammenhang zur Erkenntnis des Extramentalen vorausgesetzt ist, löst das transzendentale Subjekt Kants als Naturwesen nicht rationalistisch gedacht Natur aus sich selbst heraus, sondern kann und muss auch auf diese reagieren. Für Kant kann es insofern nur ein vernünftiges Subjekt geben, wenn es ein extramentales Objekt in seiner ontologischen (Rest-)Beschaffenheit als an sich Seiendes, Widersprüchliches, nicht gleich durch Subjekt schon Zugerichtetes gibt. Diese notwendige, den Widerspruch denkende Ontologie, die über die Erscheinungen hinausgeht, kulminiert im Kantischen Begriff der unerkennbaren Dinge ,an sich selbst" ${ }^{\text {"1966 }}$. Das unerkennbare, noumenale Ding sei zwar subjektiv nicht weiter begrifflich identifizierbar, weshalb es ein denknotwendiges Allgemeines und die Substanz hinter den dem reflexiven Subjekt erscheinenden Phaenomena sei. Als Grenze und gleichzeitig die widerspruchsfreie Erkenntnis Stiftendes ist das Ding an sich für Kant ein über das Bewusstsein Hinausgehendes. Es ist damit ein unmittelbar allgemeines, ontologisches Moment der Subjekt-Objekt Vermittlung. Es ist also ein über jede Perspektivfreiheit hinausgehendes Unmittelbares der dialektischen Vermittlung von autonomen Extremen in sich und durch sich hindurch, eine nicht positivistisch aufzulösende Möglichkeit.

Gegen ein solch negativ dialektisches ontologisches Relikt, gegen derlei ontologische Unergründbarkeiten und gegen derart selbstgesetzte Grenze subjektiver

\footnotetext{
195 Kant: Kritik der reinen Vernunft, B XIII.
}

${ }^{196}$ Ebd., B XX. 
Erkenntnis erhebt Hegel dann schwere Einwände. Er akzeptiert solch Vermittlungsbedingendes, unmittelbar Nichtbegriffliches nicht - das bei Kant allerdings ganz anders als beispielsweise Aldous Huxley in Doors of Perception ${ }^{197}$ durch Vernunft selbst vermittelt wird und nicht Resultat eines nichtbegrifflichen Mythos ist. Die Abschaffung des Dings als an sich Seiendem befördert Hegel, selbstbewusst, in die subjektivistische Tradition der Philosophiegeschichte ${ }^{198}$ : „Die Kritik am naiven Realismus im gesamten Empirismus, gipfelnd in der Abschaffung des Dings durch Hume, war vermöge des Faktizitätscharakters der Unmittelbarkeit, an den er sich band, und der Skepsis gegen das Subjekt als Schöpfer, trotz allem stets noch rudimentär ,realistisch'. Hat aber einmal Denken von der Supposition eines Vorrangs des Subjekts sich befreit, so entfällt auch der Rechtstitel der empiristischen Erkenntnistheorie, eine Art von Minimum des Objekts, als Residualbestimmung, vermöge subjektiver Reduktion in die Unmittelbarkeit der Daten zu verlegen." 199 (Zur Kritik Hegels an Kant vergleiche insbesondere 2.4.1; 2.4.2.)

\subsubsection{Die Wahrheit der Aussage im autonomen Objekt. Kausalität und notwendige Intelligibilität}

Adorno verdeutlichte bereits an Humes idealistisch verfahrendem Empirismus, dass, nur weil Hume vom Objekt spricht, er nicht zugleich das Objekt zum Gegenstand habe. Bloß ,rudimentär ' habe Hume die Autonomie des Objekts begriffen (vgl. 2.2.1). ${ }^{200}$ Die Gegenstandslosigkeit seiner positivistischen Theorie zeigt sich daran, dass er kein transzendentes, autonomes und dem Subjekt gegenüber widerständiges Objekt zum Gegenstand hat. Sein Positivismus verabsolutiert, wie der Positivismus allgemein, das Subjekt als gesicherte Erkenntnisquelle von Objektivität. Das transzendente, autonome Objekt kann jedoch kein tautologisch aus dem Subjekt, als seinem gleichen Anderen, deduktiv Gestiftetes sein. Ansonsten bliebe jegliche Objektivität auf das Subjekt reduziert und wäre nichts anderes als dieses. Kants transzendentaler Idealismus liefert nun gegen den Positivismus die präzise Bestimmung eines autonomen Objekts. Ihm zufolge konnte das Objekt durchs transzendentale Subjekt nur deswegen vernünftig erschlossen werden, weil es als Material wissenschaftlicher Erkenntnis, als immanenter in sich rationaler, intelligibler Gegenstand dem selbstbewussten, vernunftbegabten Subjekt gegenüber auch autonom und transzendent sei (vgl. 2.2.1). Diese substantielle Autonomie des Gegenstands ist von seiner negativen, vorrangigen Objektivität des Dings als der unbekannten Ursache aller Erscheinungen nicht zu trennen.

Adorno hält nun insbesondere diesen von Kant reflektierten Vorrang von Objektivität als emanzipatives und materialistisches Moment hoch: „Kant noch hat

\footnotetext{
197 Vgl. Huxley: The Doors of Perception.

198 Vgl. dazu Haag: Der Fortschritt in der Philosophie, S. 96 f.

199 Adorno: Negative Dialektik, S. 188.

${ }^{200}$ Diese unreflektierte Objektlosigkeit von Theorien wurde schon oben thematisch, als es um die Notwendigkeit des Wahrheitsbegriffs in der Gesellschaftstheorie ging (vgl. 2.1).
} 
das Moment des Vorrangs von Objektivität nicht sich ausreden lassen.“201 Adorno schätzt an Kants Transzendentalphilosophie, dass sie ein entscheidendes Wahrheitsmoment wider den tautologischen, nominalistischen Subjektivismus enthalte: „Auch nach der zweiten Reflexion der Kopernikanischen Wende behält Kants anfechtbarstes Theorem, die Distinktion von transzendentem Ding an sich und konstituiertem Gegenstand, einige Wahrheit. Denn Objekt wäre einmal das Nichtidentische, befreit vom subjektiven Bann und zu greifen durch dessen Selbstkritik hindurch." 202

Das Subjekt beschränkt sich bei Kant zunächst selbst, indem dem Material als an sich Seiendes ein Moment zugesprochen wird, das sich vom Subjekt nicht sogleich identitätsphilosophisch und positivistisch ausfüllen lässt: „Diese Reflexion der Selbstbeschränkung bildet den Hintergrund von Kants berühmter Unterscheidung zwischen ,Ding an sich“ und ,Erscheinung." "203 Der im Zentrum von Kants Überlegungen stehende negative Realismus setzt demnach bereits eine innere Logik der erkennbaren Dinge zugunsten ihrer Erkenntnis voraus. Auf diese schon Kantische innere Logik der Dinge als ontologische, materialistische Bedingung ihrer objektiven Erkenntnis weist insbesondere Karl Heinz Haag hin. In seiner eigenen ,negativen Metaphysik' in Der Fortscbritt in der Philosophie übernimmt er zentrale Reflexionen Kants: „Stünden die Phänomene nicht durch ihre ontologische Beschaffenheit in gesetzmäßigen Zusammenhängen, so besäße menschliches Denken keinen Ansatzpunkt, auch nur eines - vom Stand des tradierten Wissens her - physikalisch zu bestimmen." 204

Die Dinge haben demnach eine erkennbare autonome und ontologische Eigengesetzlichkeit in sich und stünden in gesetzmäßigen Zusammenhängen funktional zueinander. Diese im autonomen Objekt liegende Struktur werde vor allem dann entscheidend, wenn das reflexive Subjekt die ontologische Objektivität der Dinge erfahren und beurteilen möchte. Als ontologisch in sich gesetzmäßig verfasster Gegenstand steht der erscheinende Gegenstand notwendig auch im kausalen Zusammenhang der Gegenstände. Dadurch seien die innere und intelligible, autonome Struktur der natürlichen Zusammenhänge auch erst vernünftig durch das Subjekt erkennbar: keine Erscheinung ohne Kausalität, keine Erscheinung ohne Ursache. Die vernunftbedingte Erkenntnis von Naturphänomenen kann überhaupt nur deshalb möglich sein, weil das Naturding ein der Möglichkeit nach in sich rational durchdringbares objektives Phänomen ist. An stofflichen Dingen ist nun für Kant, als Resultat seines negativ bestimmten Begriffs vom Ding an sich, einzig ihr funktionales Verhalten positiv bestimmbar. Worin sie ontologisch Gründen, das „Prinzip ihrer Genesis“205, bleibe für ihn demnach unerkennbar.

\footnotetext{
201 Adorno: Negative Dialektik,, S. 185.

202 Adorno: Zu Subjekt und Objekt, S. 752.

203 Haag: Der Fortschritt, S. 77.

204 Ebd., S. 14.

205 Ebd., S. 11.
} 
Damit verzichte Kant, so Haag, negativ metaphysisch „auf eine affirmative Bestimmung des Wesens der Dinge“"206.

Dadurch lässt sich das Ding von Kant auch nicht als mit dem Subjekt Identisches vollends kassieren, was logisch auch einen unendlichen Regress vermeidet. Mit dem unerkennbaren Ding an sich als Ursache aller Erscheinungen erhält sich somit ein logisches Moment der Autonomie der Materie bei Kant. Die Metaphysik geht für Kant insofern nicht in einer alles bestimmenden Positivität auf; den unerkennbaren, übersinnlichen Realgrund ${ }^{207}$ der Natur bestimmt er also anders als der Rationalismus nicht affirmativ. Trotz der Möglichkeiten der Erkenntnis der naturwissenschaftlich bestimmbaren Dinge lasse sich zu diesem nicht, unendlich durch besinnungslose Identität regredierend, fortschreiten. Kants transzendentaler Idealismus gelangt dadurch zunächst über den identitätsphilosophischen Subjektivismus der Philosophiegeschichte hinaus. Die die Transzendenz des Materials entsubstantialisierende reductio ad hominem greift er dabei vor allem in ihrer ausgeprägtesten nominalistischen Extremform an. Dabei möchte Kant mit seinem transzendentalen Idealismus allerdings nicht wieder hinter die nominalistische Wende zurück (vgl. 2.2.1; 2.2.2). Er behält die oben bereits angeführten nominalistische Voraussetzungen bei der vernünftigen Erkenntnis des autonom Extramentalen bei: insbesondere gegen Humes subjektivistischen Positivismus, so Haag, „intendierte Kant einen objektiven Zusammenhang der Natur in höchster Potenz." "208

Der Eingriff in den Naturzusammenhang wurde in 2.2.2 bereits als notwendige Bedingung für die vernünftige Erkenntnis der wesentlich intelligiblen Logik in den Dingen selbst bestimmt. Mit subjektiven Prinzipien der Logik konnte demnach die den transzendenten, autonomen Dingen immanente Logik erforscht werden. Die allgemeingültige objektive Struktur der materiellen Wirklichkeit ist nur durch die immanente Intelligibilität des Materials, die innere Logik der Dinge, die im Begriff des Dings an sich unerkennbar begründet ist, als durch das vernünftige Subjekt erkennbar, als eine auf den vernünftigen Begriff zu bringende Wirklichkeit, vorausgesetzt. Der autonome Naturgegenstand ist im Experiment überhaupt auch durchs Subjekt nur deshalb bestimmbar, weil er diese in sich erkennbare innere Eigengesetzlichkeit besitzt: „Daß die Wirklichkeit erkannt werde setzt ihre Erkennbarkeit voraus, setzt voraus, daß sie nach Prinzipien des Erkenntnisvermögens, der Vernunft, organisiert sei." 209 Die wahre Erkenntnis beruht insofern auf der prinzipiellen „Idee des Ganzen“210, in der die in sich bestimmbare Rationalität der Naturdinge gründet. Im tätigen Subjekt und seinen Prinzipien liegt somit die Erkenntnissicherheit des transzendenten Objekts, was subjektiv aber nur

\footnotetext{
206 Ebd., S. 72.

207 Vgl. dazu ebd., S. 77.

208 Ebd., S. 80.

209 Bulthaup: Rechtspragmatik oder von der Zwangsläufigkeit des sittlichen Verfalls der Justiz, S. 67.

210 Kant: Kritik der Urteilskraft, B 351.
} 
deshalb bestimmbar ist, weil es eben an sich bestimmt ist. Die Wahrheit der subjektiven Aussage liegt demnach also in der intelligiblen, erkennbaren Struktur des autonomen, transzendenten Materials begründet: „So sehr auch alle Erkenntnis konstitutiv durch das erkennende Subjekt vermittelt ist, wird sie doch erst dadurch wahr, dass das Objekt selbst ein an sich bestimmtes und bestimmbares ist." “211

Wahrheit kann deshalb, weil sie auch in der intelligiblen, erkennbaren Struktur des autonomen Materials begründet ist, auch keine den Dingen mittels der subjektiven Prinzipien der Logik nur übergestülpte tautologische Phantomwahrheit sein. Subjekt und Objekt sind dialektisch Einheit und Verschiedenes zugleich. Diese dialektische Vermittlung bei der adäquaten Erkenntnis des nichtidentischen Objekts beschreibt Peter Bulthaup treffend: „Das setzt für die identische Subjektivität die materielle Einheit der empirischen Natur voraus, wobei Einheit den Zusammenhang des Verschiedenen bedeutet, und zugleich, daß aus dem Verschiedenen identische Strukturen herauszuarbeiten sind. Verschiedene Subjekte können die gleichen Antecedensbedingungen nur realisieren, wenn sie untereinander durch irgendeine Art des Informationsaustausches zusammenhängen. Da, wenn telepathische Informationsübermittlung auszuschließen ist, Informationsaustausch nur als Austausch von Materie oder Energie möglich ist, müssen die die Antecedensbedingungen realisierenden empirischen Subjekte sowohl untereinander als auch mit den Gegenständen materiell zusammenhängen, was, da die empirischen Subjekte ihrerseits auch Naturgegenstände sind, mittelbar den Zusammenhang aller Naturgegenstände, soweit sie mögliche Gegenstände der Wissenschaft sind, voraussetzt. “" 212 Insbesondere im naturwissenschaftlichen Erkenntnisprozess zeigt sich diese autonome Intelligibilität des Objekts. Durch die entsprechenden Experimente werden hier mannigfaltige Naturerscheinungen in distinkte Klassen eingeteilt. Im Experiment wirken die Naturkräfte planmäßig aufeinander, was nur deshalb überhaupt möglich sein kann, weil die Naturstoffe in sich eigengesetzlich verfasst sind. Darum können sie auch erst zweckgerichtet vom Subjekt verformt werden; weil an den stofflichen Dingen ihr funktionales Verhalten positiv bestimmbar ist und bleibt: „Es [das erkennende vernünftige Subjekt, B.E.B.] vermag die Natur nur in dem Maße experimentell zu erforschen und technisch zu beherrschen, wie es ihm gelingt, sie - unter Ausnutzung ihrer erkannten Gesetzmäßigkeit - auf sich selbst wirken zu lassen.“213

Nach Kant werde durch die Anwendung des Verstandesgrundsatzes der Naturkausalität gestattet, spekulativ darauf zu schließen, dass wenn identische experimentelle Ausgangsbedingungen gegeben sind, auch dieselbe Ereigniskette ablaufe. Für die experimentelle Erforschung und technische Beherrschung von Material bleibt insofern vorausgesetzt, dass das erkennende Subjekt wesentliche Bedingungen der Möglichkeit der ontologischen Erscheinungen der Natur prin₹ipiell, als aus

\footnotetext{
211 Wallat: Das Bewusstsein der Krise, S. 532.

212 Bulthaup: Die transzendentale Einheit der Apperzeption, S. 97.

${ }^{213}$ Haag: Der Fortschritt in der Philosophie, S. 113.
} 
dem teleologischen Prinzip der Natur selbst stammend, muss begreifen können. Für Kant steht deshalb „fest: wie weit menschliche Vernunft in der Erkenntnis mechanischer Naturgesetze auch fortschreiten mag, ein teleologisches Prinzip wird ihrer Erklärung organisierter Körper immer unentbehrlich bleiben. Ohne ein solches Prinzip fehlte das Ziel - die Idee des Ganzen, gemäß der die Teile sich in mechanischen Prozessen verbinden und selbst ihre ,Beschaffenheit und Wirkungsart" erhalten. “214 Die Erfahrungsdinge sind insofern mit der intelligiblen Kausalität der Dinge selbst verknüpft, das subjektive Prinzip des zureichenden Grundes ist von dieser wesentlichen Intelligibilität nicht zu trennen. Kant: „Also ist der Satz vom zureichenden Grunde der Grund möglicher Erfahrung, nämlich der objektiven Erkenntnis der Erscheinungen, in Ansehung des Verhältnisses derselben, in Reihenfolge der Zeit.“"215 Ohne diese wesentlichen, dem Ding an sich inhärenten objektiven Möglichkeiten könnte insofern die Naturwissenschaft die erscheinende Natur auch überhaupt nicht objektiv gültig bestimmen, sondern nur nominalistisch-empiristisch mit ihr verfahren.

Wenn experimentelle Bedingungen ceteris paribus erfüllt sind ${ }^{216}$, dann haben beobachtbare Resultate des notwendigen Eingriffs in den Naturzusammenhang allgemeine, objektive Geltung. Durch spekulative Schlüsse aus der Erfahrung präpariert das selbstbewusste, vernünftige Denken allgemeine Begriffe von Gegenständen, allgemeine Urteile über den Zusammenhang verschiedener Gegenstände und Schlüsse auf die allgemeine Geltung von Gesetzen, denen die extramentalen, transzendenten Dinge notwendig unterliegen. Im Resultat werden die Gegenstände der Erkenntnis dann als allgemeine und identische, als ewig so und unveränderlich und notwendig so seiend, wie sie an sich ontologisch sind, bestimmt. Die natürlichen Phänomene werden sogleich auch einer identischen Klasse zugeordnet, klassifiziert, wenn an ihnen allgemeine Merkmale ausgemacht werden, die sich an anderen nicht finden lassen. Deshalb können sie überhaupt auch differenten Klassen von Naturphänomenen zugeordnet werden.

Die auf dem experimentellen Weg gebildeten Erfahrungen von der ,Dieselbigkeit der Phänomene' erlauben nach Kant jedoch nur subjektivistische, nominalistische Vorstellungen von Erkenntnis, weshalb sie auch nur von komparativer Allgemeinheit seien. Die Konsistenz der Klasse der Erscheinungen sei deshalb nicht mittels Experimentalität allein objektiv abgesichert. Für den experimentier- und erfahrungsfreudigen, weniger begriffsfreundlichen Nominalismus muss Natur deshalb in dieser Mannigfaltigkeit von unverbundener Sachlichkeit stehen bleiben. Ihm bleibt dadurch eine Sachlichkeit Gegenstand, die auf keinen objektiven Zusammenhang der Faktizität als ihrem objektiven, im Grunde unerkennbaren Wesen mehr abzielt. Die Objektivität würde somit vom Subjekt nur formell und tautologisch in das damit nicht mehr transzendente Objekt hineingelegt werden. Un-

\footnotetext{
${ }^{214}$ Ebd., S. 75 f.

215 Kant: Kritik der reinen Vernunft, A 201.

${ }^{216}$ Vgl. Mill: A System of Logic.
} 
ter diesen subjektivistischen Prämissen könnte Wahrheit deshalb nicht auch, wie bei Kant, im Objekt oder den Dingen selbst liegen. Dem Objekt würde die eigene Wahrheit durch die im Erkenntnisprozess verabsolutierte subjektive Logik bloß übergestülpt. Die Dinge könnten als auf den Begriff gebrachte nicht als das substantiell Andere der subjektiven Vernunft identifiziert werden, sondern sie wären bloß ein konstruiertes Produkt. Ohne dass das zu erkennende Material ein begründetes, intelligibel an sich seiendes wäre, hätte das seiner selbst bewusste Subjekt letztendlich auch keinen wirklichen Beweis dafür, dass das eigene Urteil gilt und den Dingen adäquat ist. Deswegen muss jedes naturwissenschaftliche Erkennen die Erkenntnis von ontologischen Prinzipien der Natur zum Gegenstand haben. Ein abstrakt ontologiekritischer Positivismus/Nominalismus/Idealismus stößt insofern schnell an die eigenen logischen Grenzen. Solchen Subjektivismus kritisiert Kants Begriff des Dings an sich, der dagegen die Autonomie der Materie gegenüber dem Subjekt ernst nimmt.

Das Subjekt der Erkenntnis wird jedoch trotz aller Voraussetzungen der intelligiblen Objektivität der Gegenstände nicht unwichtig. Das reflektierende Denken erkennt sich in den Gegenständen immer auch selbst, indem es die Gegenstände der Erkenntnis als objektive erkennt und anerkennt, und nur ein Subjekt kann die allgemeine und notwendige Wahrheit in grammatikalisch verfasster Sprache kommunizieren. ${ }^{217}$ Das Nichtbegriffliche ist insofern, anders als beispielsweise in der Kunst, immer nur mit und durch Sprache identifizierbar. Erkenntnis scheint

${ }^{217}$ Der linguistic turn registriert diese Unersetzbarkeit der Sprache im Erkenntnisprozess und verabsolutiert sie, wodurch ihm die bezeichneten Gegenstände sekundär werden. Er bleibt deshalb ganz dem subjektivistischen Idealismus verpflichtet. (Vgl. Wittgenstein: Philosophische Untersuchungen.) Insbesondere John L. Austin, konstruiert in ,Zur Theorie der Sprechakte' mittels seines performativen Modells Gegenstände als ein bloßes Resultat von Sprache bzw. Sprechakten, womit er auf eine vermeintlich ubiquitäre Macht der Form verweist: die Methode oder die Methodologie. (Austin: Zur Theorie der Sprechakte.) Franz von Kutschera nimmt dieses Austinsche Modell auf: „Die Struktur unserer Welt ist aber nur die Struktur unserer Sprache, in der wir sie beschreiben, d.h. aber im wesentlichen die durch die alltagssprachlichen Formen bestimmte Struktur.“ (von Kutschera: Sprachphilosophie, S. 220 f.) Solche methodologische Konstruktionen von Wirklichkeit übersehen dabei, dass der raumzeitlichen Welt tatsächlich eine ontologische Wirklichkeit zukommt, was sie völlig unabhängig von Subjekt und Sprache auch ,ohne Zeugen` existieren lässt. Die Sprachphilosophie stülpt dem Objekt dagegen eine subjektive Sprachform über, womit die Erkenntnis des Objekts sich allein auf Sprachlogik reduziert. Aus diesen zunächst nominalistisch-positivistischen Überlegungen zieht Judith Butler eine gesellschaftswissenschaftliche Konsequenz: Geschlecht, wissenschaftlich objektiv bestimmbar, sei für sie bloß Resultat einer (konventionellen) und durch Herrschaft geprägten Sprachkonstruktion. Sex löse sich demzufolge gänzlich in gender auf, weil Butler „die Relevanz des Biologischen bei der Determinierung der Geschlechtsidentität gänzlich“ verneint. (Butler: Körper von Gewicht. Die diskursiven Grenzen von Geschlecht, S. 9, vgl. dazu auch Städtler: Kant und die Aporetik moderner Subjektivität, S. 22, Fn. 28.) Nach Butler erschafft sich der Kapitalismus unbegründbare Unterschiede nach nur scheinbar unterschiedlichen biologischen Voraussetzungen. Völlig willkürliche geschlechtliche Unterschiede würden zu gesellschaftlichen, unbegründbaren Repressionszwecken konstruiert und hochgehalten. So wird für Butler alles Objektive relativ, weil es einzig Konstrukt/Resultat von Sprache sei. Die Wahrheit bzw. Objektivität erschlafft, wie auch bei Foucault, in ihrem ,Diskurs' (vgl. 2.1). 
dem subjektivistischen Idealismus, weil das Subjekt allein Wahrheit formuliert, deswegen auch bloß ein Anschmiegen des subjektiv tätigen Denkens an sich selbst zu sein, ein im Material realisiertes eigenes Denken (im Spiegel). Das ist nicht nur falsch, sondern ein rationeller Kern des Idealismus ${ }^{218}$, der allerdings nicht zu verabsolutieren ist.

Die hartnäckig sich haltenden beziehungsweise wiederholt akademisch Karriere machenden positivistischen, idealistischen Tendenzen in den Wissenschaften kritisiert bereits Lenin. In Materialismus und Empiriokritiz̧ismus möchte er gegen jede Sensualisierung der Daten, vor allem gegen seine Zeitgenossen Mach und Avenarius, Objektivität beweisen. Mach und Avenarius wirft er vor, ein bloß stumpfes „Widerkäuen des Berkeleyanismus“219 zu betreiben. Um die kritischen Thesen gegen den Subjektivismus oder den ,modernen Berkleyanismus' zu untermauern, richtet sich Lenins Kritik insbesondere gegen den russischen Machisten Bogdanow. Dieser intellektuelle „Spaßvogel“ 220 brächte nämlich mit seinem positivistischen Subjektivismus die gesamte Wissenschaft in Verruf, weil er davon ausgehe, dass die Wahrheit nur eine Form menschlicher Erfahrung sei. Das kritisiert Lenin zunächst in Kantischer Manier: „Wenn die Wahrheit eine Form der menschlichen Erfahrung ist, dann kann es also keine von der Menschheit unabhängige Wahrheit, kann es keine objektive Wahrheit geben."221 Die Logik werde durch den positivistischen Subjektivismus Bogdanows einfach in die objektiven Dinge, als ein Resultat der tautologischen reductio ad hominem, hineingelegt, was den

\footnotetext{
218 Weil der das disparate und autonome Material identifizierende Begriff ein subjektiv gedachter Begriff ist, behält der idealistische, tätigkeitsbezogene Subjektivismus immer auch ein logisch wahres Moment. Als Modell der notwendigen Subjektbezogenheit der Erkenntnis der Materie gilt die idealistische Formulierung Schopenhauers von der Vorstellung. Schopenhauers Vorstellung des Objekts meint gegenüber allem Korrelat, als dem von mir Vorgestellten, an sich seiendem Phänomen, ein dezidiert Subjektives als der Materie vorrangiges Prinzip. Ohne subjektiv-physische Vermittlungsleistung vom nichtidentischem Material mit der subjektiven Formgebung hätte das Subjekt als Erkennendes keine Vorstellung vom Ding: „Es wird ihm dann deutlich und gewiß“, so Schopenhauer zur Rolle des zeitlichen Subjekts im Erkenntnisprozess, „daß er keine Sonne kennt und keine Erde; sondern immer nur ein Auge, das eine Sonne sieht, eine Hand, die eine Erde fühlt; daß die Welt, welche ihn umgiebt, nur als Vorstellung da ist, d.h. durchweg nur in Beziehung auf ein Anderes, das Vorstellende, welches er selbst ist.“ (Schopenhauer: Die Welt als Wille und Vorstellung, S. 29.) Die mit Zeit gefüllte Vorstellung des Subjekts vom Objekt wird von Adorno nochmals von der unmittelbaren sinnlichen Gegebenheit unterschieden als das, was das disparate Material als sinnlich unmittelbar Vorgestelltes nachträglich vermittelt zum Bewusstsein trägt: „Vorstellungen sind stets, wie man das dann in der empiristischen Sprache ausgedrückt hat, mittelbare Gegebenheiten; sie geben uns etwas mittelbar, sie sind selbst nichts Unmittelbares.“ (Adorno: Philosophische Terminologie, Bd. 2, S. 56.) So ist die Erkenntnis der Gegenstände von Subjektivität als notwendiges Moment der gesellschaftlichen Bestimmung von Materie vom Bestimmenden selbst nicht wegzudenken. Die Bestimmung der Materie kann aber nicht empiristisch das Resultat aus den vielen einzelnen Bewusstseinen sein, genau so wenig wie Subjekt aufgrund seiner Dauerhauptrolle im Erkenntnisprozess nicht hypostasiert werden darf (vgl. etwa 2.2.1).

${ }^{219}$ Lenin: Materialismus und Empiriokritizismus, S. 40.

220 Ebd., S. 18.

${ }^{221}$ Ebd., S. 152 f.
} 
Dingen letztendlich all die autonome Substanz nehme, die Kant noch mit dem Begriff des Dings an sich negativ bestimmt. Die durch das autonome, selbstbewusste und physische Subjekt zu identifizierenden, also zu erkennenden, autonomen, an sich seienden Naturerscheinungen existieren demnach auch für Lenin durch ihre Eigengesetzlichkeit ohne erkennende Subjekte. Auch ohne die Dialektik von selbstbewusst vernünftigem Subjekt und verunftadäquatem Objekt sei die Existenz von Naturphänomenen zumindest der Möglichkeit nach sehr wohl vernünftig und durch ein Selbstbewusstsein denkbar: „Kein halbwegs gebildeter Mensch mit einigermaßen gesunden Sinnen zweifelt daran, daß die Erde bereits zu einem Zeitpunkt existierte, als auf ihr kein Leben, keine Empfindung, kein ,Zentralglied'sein konnte." 222

Selbst wenn diese vorzeitlichen natürlichen Sachverhalte, denn Zeit ist eine subjektive Kategorie der Identifikation, dann für kein Selbstbewusstsein und nach dem Philosophen Quentin Meillasoux ein „Ereignis ohne Zeugen“223 waren, lassen sie sich durch die Vernunft zumindest potentiell als existent gewesen denken. Denn das vernunftbegabte, selbstbewusste Subjekt kann abstrakt vor und nach seiner Zeit denken, es kann logisch/ontologisch etwas als existent denken, selbst wenn es zum Zeitpunkt von dessen Existenz noch kein selbstbewusstes Subjekt, kein reflexives Denken gegeben haben mag. Diese entzeitlichte, rein logische Abstraktionsleistung des vernünftigen Subjekts bleibt eine widersprüchliche Denkform utopischer Potenzialität. Kein Subjekt wäre tatsächlich in der Lage, eine allgemeine Objektivität in einer postsubjektiven, postgesellschaftlichen Zukunft zu denken; weil es kein Subjekt mehr gibt: „Von Objektivität kann Subjekt potentiell, wenngleich nicht aktuell weggedacht werden; nicht ebenso Subjektivität von Objekt." 224

Obwohl Lenin den zeitgenössischen Subjektivismus zunächst einmal in Kantischer Manier kritisiert, kritisiert er in seinem Werk auch Kant. Lenin greift dafür kritisch Kants idealistische Widersprüche auf.225 Er will Kant deshalb „,von links" ${ }^{\text {“26, }}$, als zu wenig negativ und materialistisch kritisieren. Auch Haag weist Kants „negative[r] Metaphysik“"227 eine solche idealistische Widersprüchlichkeit nach: „Aber es ist ein Unterschied ums Ganze, welche Konsequenz aus diesem Wissen gezogen wird: soll die Metaphysik sich auf die negative Bestimmung der essentia rerum beschränken oder soll sie sich positiv geben, indem sie Substanzbegriffe durch Funktionsbegriffe ersetzt? Beide Konsequenzen finden sich bei Kant." ${ }^{228}$ Die zunächst scheinbar ontologisch gedachten Substanzbegriffe lässt Kant dann nämlich doch ganz idealistisch in Funktionsbegriffen aufgehen. Damit

\footnotetext{
222 Ebd., S. 89.

223 Meillassoux: Nach der Endlichkeit, S. 37.

224 Adorno: Zu Subjekt und Objekt, S. 747.

${ }^{225}$ Vgl. Lenin: Materialismus und Empiriokritizismus, S. 257.

226 Ebd., S. 259.

227 Haag: Der Fortschritt in der Philosophie, S. 72.

228 Ebd.
} 
entsubstantialisiert er das eigene unerkennbare Ding an sich. Diese idealistische Funktionalisierung in Kants Konzeption der transzendentalen Einheit der Apperzeption weist Haag nach: „Die transzendentale Einheit der Apperzeption war kein inhaltliches Prinzip, sondern leere Einheit: ein Gebilde der philosophierenden Abstraktion, die sich in dem ,höchsten Punkte' ihrer Tätigkeit hypostasiert hatte. Ihr Wesen, das sie in der Identität reinen Denkens aufgehen ließ, reduzierte sie auf ihre Funktion: das Stiften ,der notwendigen Gesetzmäßigkeit aller Erscheinungen'،"229 Zwar wendet Kant gegen jede Verabsolutierung der nur subjektivistischen Vorstellung von Materie ein, dass ohne Reflexion auf das Ansichsein des strukturell in sich erkennbaren Materials dieses „unter gar keinem Gesetze der Verknüpfung, als demjenigen, welches das verknüpfende Vermögen vorschreibt" ${ }^{\text {“230 }}$ stünde, durch seine Reduktion der Substanzbegriffe auf bloße Funktionsbegriffe fällt er dann aber doch - trotz aller in ihm enthaltenen emanzipativen vermittelnden Momente der negativen Metaphysik - auf ein entsprechend idealistisch-positivistisches Denken zurück. Dadurch verabsolutiert er ganz unmaterialistisch und unkritisch das Subjekt und seine funktionale Logik, wie ihm deshalb auch Krahl etwas überspitzt nachweist: „Die synthetische Einheit der transzendentalen Apperzeption, welche die rhapsodisch zerstreuten Wahrnehmungen allererst zur einheitlichen Erfahrung zusammenschliesst, sperrt die Dinge, wie sie an sich ohne Zutun des erkennenden Subjekts wären, als Gegenstände möglicher Erfahrung aus dem Kontext der Objektivität überhaupt aus."231 So also fällt Kants zunächst emanzipativer, kritischer Idealismus dann doch wieder auf eine tautologische Erklärung des extramentalen Außen zurück. Das erst überführt seine Philosophie überhaupt des Idealismus. An diese idealistischen Thesen Kants knüpft dann Hegel mit dem spezifischen Positivismus des objektiven Idealismus an (vgl. $2.4 .1 ; 2.4 .2)$.

\subsection{Die Emanzipation des transzendentalen Idealismus in der Kritischen Theorie}

Der idealistische Rückfall Kants auf eine positive Dialektik und die identitätsphilosophische, tautologische Erklärung von Seiendem soll in dieser Untersuchung ausgeklammert bleiben. Im Folgenden wird sich deshalb ausschließlich auf seine emanzipativen Thesen hinsichtlich der Kritischen Theorie fokussiert.

Das im objektiven Erkenntnisprozess schon bei Kant notwendig über den kooperativen Eingriff in den Naturzusammenhang vermittelte gesellschaftliche Moment stellt Adorno als entscheidendes Moment der dialektischen Betrachtungsweise von vergesellschaftetem Subjekt und Gesellschaft heraus. Adornos Subjekt-

\footnotetext{
229 Ebd., S. 91.

230 Kant: Kritik der reinen Vernunft, B 164.

${ }^{231}$ Krahl: Konstitution und Klassenkampf, S. 73.
} 
konstitution verweist auf die Dialektik von vergesellschaftetem, transzendentalem Subjekt und gesellschaftlichem Objekt. Mit Adornos Thesen wird sich deshalb in 2.3.1 auseinandergesetzt, um die oben bei Kant kennengelernten Bestimmungen auf gesellschaftstheoretisch fruchtbaren Boden fallen zu lassen. Das vernünftige Urteil des Subjekts innerhalb des naturwissenschaftlichen Erkenntnisprozesses ist dialektisch betrachtet ein immer in kooperativer Vergesellschaftung geäußertes Urteil von selbstbewussten Subjekten. Dadurch kommt ein äußerliches, von den materiellen Zwecken der jeweils konkreten Gesellschaft untrennbares materielles Moment in jedes vernünftige, auf den Prinzipien der Logik beruhende Urteil hinein. Wenn Adorno die Heteronomie des gesellschaftlich Allgemeinen als vorrangig bestimmt, so kritisiert er das von Kant schlussendlich hypostasierte autonome und vernünftige Subjekt, die Kantische Konsequenz des ,Rückfalls ${ }^{`}$ auf den Idealismus.

In 2.3.2 kommt ein weiterer wichtiger Protagonist der Kritischen Theorie zur Sprache. Mit Max Horkheimers Überlegungen können die in dieser Untersuchung aufgestellten Thesen zur Vergesellschaftung der Urteile verdeutlicht werden, weil das Subjekt durch Horkheimer funktionell in den Rahmen der gesellschaftlichen Totalität gestellt wird. Mit seinen Reflexionen richtet sich der Fokus der Untersuchung auf das, was in Adornos Bestimmungen zum Subjekt noch außen vor blieb, aber auch bei ihm bereits zu finden ist: den transzendenten Zwang zur gesellschaftlichen Selbsterhaltung, der ein das Subjekt körperlich zwingender und seine Vernunft instrumentell auf gesellschaftliche Zwecke zurichtender Zwang ist. Weil die instrumentelle Vernunft aber immer auch auf ihr entsprechendes Gegenteil verweist, die objektive Vernunft, ist sie allerdings auch nicht zu verabsolutieren.

Da nun das Subjekt immer von nichtidentischen und auch nicht mit Subjekt irgend absolut zu identifizierenden Momenten, Natur und Gesellschaft, abhängig ist und bleibt, beschäftigt sich 2.3.3 mit der Bedeutung dieser logischen, objektiven Grenzen der Vernunft. Dabei wird auch auf den Begriff der Herrschaft reflektiert.

2.3.1 Das Adornosche Subjekt der (Selbst-)Kritik und der Zeitkern. Genese und Geltung oder: Zu Theorie und Praxis

In der Kantischen Philosophie lassen sich, trotz seines idealistischen Rückfalls auf die positive Metaphysik, emanzipative Momente für eine kritische Wissenschaft der Gesellschaft finden. Wenn Kant in der Kritik der reinen Vernunft den Nachvollzug des Urteils durch alle vernünftigen, physisch daseienden Subjekte als Merkmal von allgemeiner und notwendiger Objektivität beschreibt, vermittelt er bereits implizit den objektiven Erkenntnisprozess der Natur mit Gesellschaft. Auch wenn dieses gesellschaftliche Moment in der objektiven Naturerkenntnis in den Kritiken nun weitestgehend unreflektiert bleibt, wendet Kant mit der synthetischen Einheit der Apperzeption den Ausdruck des, wir ${ }^{\star}$ auf jedes vergesellschaftete, weil seiende Subjekt an, welches den Ausdruck ,ich` auf sich selbst anwenden kann (vgl. dazu 
2.2.1). Adorno insbesondere nimmt den äquivok gedachten Subjektbegriff Kants auf, in dem sich das dem einzelnen Subjekt transzendent Allgemeine im Begriff von Subjekt als notwendig Allgemeinem ausdrückt. Der lebendige Einzelne sei „nicht nur das Dies da irgendeines besonderen Menschen“232, sondern „,bereits zu einem Allgemeinen gemacht, ähnlich dem, was im idealistischen Subjektbegriff ausdrücklich wurde“"233.

Weil das Subjekt nicht nur körperlos überindividuell, sondern als materielles Naturwesen eben auch individuell gegenständlich sei, wird Subjekt auch von Adorno äquivok bestimmt. ${ }^{234}$ Seine Reflexion der erkenntnistheoretischen Mehrdeutigkeit im Subjektbegriff, von dem „das Moment der Einzelmenschlichkeit““235 nie wegzudenken ist, orientiert er dabei an Kant: „So kann ,Subjekt" sich auf das einzelne Individuum ebenso wie auf allgemeine Bestimmungen, nach der Sprache der Kantischen Prolegomena von „Bewußtsein überhaupt ${ }^{\star}$ beziehen. “236 Das endliche Subjekt sei zwar als Individuum ein tätig Erkennendes, als erkennendes Subjekt sei das Subjekt der Erkenntnis jedoch notwendig überindividuell. Objektives, gültig gedachtes, könne und müsse von anderen individuellen Subjekten, weil sie ebenfalls rationale Wesen seien, nachvollzogen werden; Vernunft erweist sich bei Kant deshalb als individuiertes Allgemeinvermögen (vgl. 2.2.1). Kein Einzelsubjekt lässt sich insofern ohne den Allgemeinbegriff von Subjekt denken, der Allgemeinbegriff nicht ohne einzelnes Subjekt; Subjekt meint den Gattungsbegriff und die spezifische Bezeichnung eines Individuums. Diese Äquivokation arbeitet die in sich vermittelten Bestimmungen des Subjektbegriffs als dialektisch in sich vermittelte Momente entsprechend heraus. Die entscheidenden Bedeutungen von Subjekt „,bedürfen einander reziprok.“237

Die Äquivokation des Subjektbegriffs hat nun auch entscheidende Auswirkungen auf die Dialektik von Theorie und Praxis. Die Äquivokation im Subjektbegriff vermittelt das Subjekt als Gesellschaftliches. Sie verweist dabei dialektisch auf das raumzeitliche Moment des kooperativ sich selbst erhalten müssenden Subjekts in Gesellschaft und auf den gesellschaftstheoretischen Allgemeinbegriff, den Gattungsbegriff Subjekt. Adorno hält dieses universalisierende Moment von Erkenntnis im Gattungsbegriff Subjekt, als durch individuelle, lebendige Subjekte der Praxis erst begründetem, fest - und arbeitet daran dann auch das notwendig vergesellschaftete Urteil von Sachverhalten heraus.

Die Überlegungen Kants zum Subjekt aufnehmend geht Adorno gesellschaftstheoretisch über dessen Transzendentalsubjekt hinaus. Das führt ihn zur reflektierten gesellschaftstheoretischen Aufhebung Kants, die keine bloß abstrakte Ne-

\footnotetext{
232 Adorno: Zu Subjekt und Objekt, S. 741.

233 Ebd.

${ }^{234}$ Vgl. Weyand: Adornos Kritische Theorie, S. 26 ff.

235 Ebd.

236 Theodor W. Adorno: Zu Subjekt und Objekt, S. 741.

${ }^{237}$ Ebd.
} 
gation der Philosophie Kants ist, sondern die die Bestimmungen des transzendentalen Idealismus kritisch in sich aufhebt. Ohne Rückgriff auf den transzendentalen Idealismus hätten diese gesellschaftstheoretischen Reflexionen gar nicht gemacht werden können. Mit den kritischen Reflexionen Adornos lässt sich deshalb die von Kant vernachlässigte, notwendige Vergesellschaftung des urteilenden lebendigen Subjekts der Praxis zeigen. Adorno versucht dafür zunächst einmal die innersten materiellen Voraussetzungen von Erkenntnis nicht nur des transzendentalen Idealismus, sondern des Idealismus überhaupt mit und gegen diesen herauszuarbeiten. In Anlehnung an den Idealismus im Allgemeinen spricht er im Rahmen seiner gesellschaftstheoretischen Subjektkonstitution von der schon vorausgesetzten Tätigkeit bei der allgemeinen und notwendigen Bestimmung der Umwelt durch das Subjekt. In Anlehnung an den transzendentalen Idealismus Kants spricht er vom physisch seienden, tätig vernünftigen, lebendigen Subjekt der Erkenntnis. Adorno führt dabei den entscheidenden gedanklichen Ursprung des selbstbewussten und zugleich physischen Subjekts der Praxis auf die moderne Philosophie der nominalistischen Neuzeit zurück, auf Descartes und das trotz aller philosophischen Skepsis unbezweifelbare subiectum der objektiven Erkenntnis (vgl. hierzu 2.2.1.): „Sondern das, worauf ich hinausmöchte, ist, Ihnen zu zeigen, daß im Sinn der Phänomene der res cogitans, wenn ich auf die cartesianische Terminologie noch einmal zurückgreifen darf, bereits notwendig der Verweis auf faktisches Sein und damit auf tatsächliche reale Menschen liegt; daß er also nicht ein diesem Sinn äußerlich Hinzugefügtes ist, sondern daß ich zu einem solchen Begriff wie der Vernunft überhaupt gar nicht kommen kann, ohne daß er in sich selbst Realität auch einbegreift, weil sein eigener Realitätsanspruch, also die Behauptung, daß er so etwas wie Vernunft oder so etwas wie Geist sei, sich in letzter Instanz eben daher schreibt, daß es Menschen gibt, die solchen Geist oder solche Vernunft haben." 238 Als Rationalist sei sich Descartes des antithetischen Realitätsmoments des Subjekts im Erkenntnisprozess also noch nicht bewusst gewesen. ${ }^{239}$ Er verweile deswegen, zumindest beim Vollzug seiner Thesen, noch beim reinen Selbstbewusstsein ohne jede Praxis. So kommt es gerade durch den radikalen Dualismus zur konsequenten Dichotomie vom Leib, der Maschine (machine de

\footnotetext{
238 Adorno: Vorlesung zur Einleitung in die Erkenntnistheorie, S. 91.

${ }^{239} \mathrm{Im}$ vernünftigen Erkenntnisprozess der Natur kann nicht, wie es Descartes in seinen Meditationen veranschlagt, über das einzelne, materielle und notwendig tätige Subjekt unreflektiert als quantité negliable hinweggegangen werden. Das geht auch nicht, wenn man dafür gut rationalistisch den allwissenden Gott als eine reine Hilfskonstruktion des körperlosen allgemeinen Subjekts einführt. Dann empfinge die Welt ihre objektive Geltung nur als Objekt eines göttlichen (Selbst-)Bewusstseins. Die objektive Geltung muss jedoch durch das tätige selbstbewusste Subjekt vermittelt sein, woran sich Kants und Adornos Kritik am rationalistischen und sonstigen Deduktionismus der Welt aus reinem Geist aufhängt. Es ist das dem reflexiven und seiner selbst bewussten Subjekt unmittelbar zur Seite gestellte, ihm immanente und kritische Zeitmoment - und zudem neben dem unbedingten Existenzmoment des reflexiven Subjekts der Motor von subjektiv-rationaler Erkenntnis durch die individuell eingreifende Tätigkeit am Material - was das erkennende individuelle Selbstbewusstsein von dem abstrakt körperlosen, göttlichen und reinen Bewusstsein unterscheidet.
} 
terre), dem physikalischen Körper, und der selbstbewussten (unsterblichen) Seele; ${ }^{240}$ das deckt sich mit den bereits in 2.2.2 angestellten Überlegungen zu Descartes.

Die Descartesche erkenntnistheoretische Ignoranz der menschlichen physis ist auf seine Immanenzphilosophie zurückzuführen, die eine tautologische ,Reflexionsphilosophie' ist, wie sie Adornos kritische Dialektik vermeiden will. Die These Adornos, dass das endliche Subjekt, der reale und raumzeitliche Mensch als physisches Naturwesen, allen natur- und gesellschaftswissenschaftlichen Urteilen zugrundeliegt, weil ein Urteil anders als mit praktisch Seiendem vermittelt nicht gefällt werden kann, beinhaltet insofern die entscheidende und materialistische Wendung gegen Rationalismus und subjektivistische Immanenzphilosophie. Sie lässt sich dabei zunächst an Kants zentrale und entscheidende Thesen der transzendentalen Erkenntnistheorie anschließen. Denn erst durch Kant bekommt das Subjekt wirklich ein nicht zu verleugnendes, unmittelbar physisch-materielles Moment durch den notwendig tätigen Eingriff des Subjekts in den Naturzusammenhang (s.o.). Adorno macht deshalb an Kant stark, dass dieser bereits gegen den Rationalismus gesehen habe, dass das einzelne, materielle Subjekt der Praxis das Zugrundeliegende, das subiectum der Erkenntnis sei. Das physisch seiende und tätige Subjekt der Praxis sei die durch den transzendentalen Idealismus stark gemachte Voraussetzung aller vernünftigen Erkenntnis des Mannigfaltigen, die nach Prinzipien der Logik verfährt: „Es [das endliche Subjekt, B.E.B.] setzt das bereits voraus, was als Kantisches ,Konstitutum“ durch die Transzendentalphilosophie erst erklärt werden soll.“241 Erkenntnis sei demnach ohne die subjektive Tätigkeit eines materiellen, weltlichen Individuums nicht zu denken.

Mit diesem antithetisch intervenierenden, zum bloß kontemplativen Geist des Rationalismus Hinzutretenden daseienden, tätigen Subjekt der Praxis erübrigt sich auch jede weitere Erklärung, wie das Subjekt als rationalistischer oder objektiv idealistischer Geist tätig sein soll, ohne dialektisch vermittelt ein in den Naturzusammenhang eingreifendes Objekt (weil Subjekt der Praxis) zu sein. Ein praktischtätiger Eingriff in die materielle Umwelt durch einen zeitlos reinen, und damit nicht-physischen Geist als eines reinen (Selbst-)Bewusstseins, reiner Theorie etc. sei generell unvermittelbar: „Es soll eingreifen, wie wenn der Eingriff von reinem Geist irgend vorstellbar wäre." ${ }^{242}$ Die Rede von Subjekt und Selbstbewusstsein wäre ohne ein endliches, daseiendes Subjekt, das als individuelles, materielles in den Naturzusammenhang eingreife, unmöglich: „Von keinem Subjektbegriff ist das Moment der Einzelmenschlichkeit (...) wegzudenken. “243 Die Weltlichkeit des

\footnotetext{
${ }^{240}$ Vgl. Descartes: Abhandlung über die Methode, richtig zu denken und Wahrheit in den Wissenschaften zu suchen, S. $26 \mathrm{ff}$.

241 Adorno: Drei Studien zu Hegel, S. 262.

242 Adorno: Negative Dialektik, S. 226.

243 Ebd., S. 203.
} 
Subjekts ist demnach immer vorausgesetzt: „Das endliche Subjekt ist, wie Husserl es nannte, ein Stück Welt.“"244

Weil also der körperliche Eingriff des physisch daseienden individuellen Subjekts für die objektive Erkenntnis konstitutiv sei und bleibe, finde demnach ein vermittelter Übergang vom Bewusstsein zur tätigen Handlung des raumzeitlichen Individuums in Gesellschaft statt. Erst die vermittelnde Tätigkeit des unmittelbar raumzeitlichen, physischen Subjekts der Praxis als am natürlichen Erkenntnismaterial vergesellschaftet Handelndes setze voraus, dass das autonome, vernunftbegabte Subjekt als Naturwesen ein nichtidentisches, eigengesetzlich autonomes, Erkenntnisobjekt allgemein und notwendig, also allgemein objektiv, bestimmen kann: „Zum Sinn von Subjektivität rechnet es, auch Objekt zu sein.“245 In der Negativen Dialektik bezeichnet Adorno den in sich vermittelt theoretischpraktischen Übergang von Bewusstsein zur körperlichen Handlung, eines Fakti-

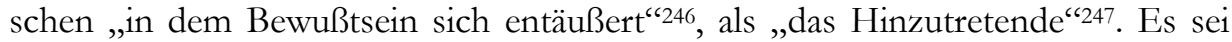
die Manifestation des selbstbewussten Bewusstseins des Subjekts im extramentalen Außen. Theorie und Praxis bleiben im selbstbewussten Subjekt als Momente somit streng ineinander und durch sich hindurch vermittelt (vgl. auch 2.1.). Keine Theorie ohne immanente Tätigkeit, keine Praxis ohne immanente Theorie.

Über die praktische Tätigkeit vermittelt hängt die Erkenntnis somit immer auch an der Individualität jedes Einzelnen. Das physische Individuum ist selbst ein Stück belebte Natur. Es ist ein Stück nichtgeistige, natürliche, materielle Welt. Jedes vernünftige Subjekt hat dieses irreduzible ,somatische Moment“248 als seine spezifische Individualität. Das Subjekt ist deshalb auch ein lebendiges Subjekt der Praxis. Das ist die alles entscheidende Antithese zur reinen Geistkonzeption des Rationalismus und der „philosophische[n] Tradition“"249. In der traditionell konzipierten reinen Kognition, das heißt im Geist, der ohne Körper und deshalb auch ohne Praxis ist, konnte das notwendig existentielle Moment der Erkenntnis nicht aufgehen. Der absolute Geist ist deshalb als rein theoretisches Moment ohne dialektisch vermittelte Praxis bestimmt, denn: „Irreduzibel ist das somatische Moment als das nicht rein cognitive an der Erkenntnis. “250

Auch wenn es für Kant wie Adorno also ein materielles, physisches Individuum ist, das bei der Vermittlung von Theorie und Praxis entscheidend wird, unterscheidet sich Adornos Herangehensweise an den Gegenstand von Kants Transzendentalphilosophie an wesentlichen Stellen deutlich: In der Willenskonzeption beispielsweise kommt Adorno zu einem anderen, viel kritischeren Ergebnis als der Idealist Kant. Weil das Subjekt als Objekt unter Objekten heteronom, unfrei, be-

\footnotetext{
244 Adorno: Drei Studien zu Hegel, S. 262.

245 Adorno: Negative Dialektik, S. 184.

246 Ebd., S. 226.

247 Ebd.

248 Adorno: Negative Dialektik, S. 194.

249 Ebd., S. 226.

250 Ebd., S. 194.
} 
stimmt ist, erweist sich für Adorno der im Idealismus noch unbedingt freie Wille 251 des Subjekts als gebrochen: „Das identifizierende Prinzip des Subjekts ist selber das verinnerlichte der Gesellschaft. Darum hat in den realen, gesellschaftlich seienden Subjekten Unfreiheit vor der Freiheit bis heute Vorrang. "252 Damit entfernt sich Adorno materialistisch entscheidend auch von Kantischen Reflexionen des freien Willens: „Kants Theorie, daß alle empirischen Handlungen durch den empirischen Charakter determiniert seien, dieser jedoch ursprünglich vom intelligiblen gesetzt, zurückdatierend auf einen Akt der Freiheit"“, drücke schon aus „wie schwer es (...) fällt, irgend sich vorzustellen, das Subjekt vermöchte seinen Charakter sich selbst zu geben. "253 Auch im transzendentalen Idealismus Kants wird also das nichtempirische Subjekt idealistisch noch als vollkommen autonomes Subjekt gedacht. ${ }^{254}$ Das drückt sich nirgends so deutlich wie in der idealistischen Konzeption des grundsätzlich freiwilligen Handelns der Subjekte wider jede Heteronomie aus. Kant identifiziert Wille und Vernunft idealistisch. Der Kantische Wille ist die gesetzmäßige Einheit aller Impulse, die sich sowohl als spontan als auch vernunftbestimmt erweisen: „Der Wille ist eine Art von Kausalität lebender Wesen, sofern sie vernünftig sind, und Freiheit würde diejenige Eigenschaft dieser Kausalität sein, da sie unabhängig von fremden sie bestimmenden Ursachen wirkend sein kann; so wie Naturnotwendigkeit die Eigenschaft der Kausalität aller vernunftlosen Wesen, durch den Einfluß fremder Ursachen zur Tätigkeit bestimmt zu werden."255 Dieses Kantische Oxymoron von Kausalität aus Freiheit kennt dabei auch keinen fremden, heteronomen Zwang von Außen auf das lebendige Subjekt der Praxis. Damit fallen jegliche materiellen Zwänge, physische und gesellschaftliche, vom Subjekt ab. Über die Willenskonzeption wird Vernunft von Kant als reine Vernunft, die sich in reinem Willen ausdrücke, hypostasiert: „Der reine Wille ist Kant zufolge eben nur der Wille, der rein im Sinn des Vernunftprinzips ist, ohne daß er von irgendeinem Seienden, das selbst nicht vernünftig einsichtig ist, irgend sich abhängig macht. “256

\footnotetext{
${ }^{251}$ Die Konzeption der absoluten Freiheit des Subjekts kann als allen Philosophen des Idealismus (Kant, Fichte, Schelling, Hegel etc.) gemeinsamer terminus ad quem ihrer philosophischen Anstrengungen gesehen werden.

252 Adorno: Negative Dialektik, S. 239.

253 Adorno: Sexualtabu und Recht heute, S. 548.

${ }^{254}$ Die von Kant aufgemachte Trennung von nichtempirischem transzendentalen Subjekt der reinen Vernunft und empirischem Subjekt der praktischen Vernunft, mit der er Unfreiheit begründen möchte, wird nicht zum Gegenstand. Sie kann, da sie den Raum meiner Abhandlung übersteigen würden, nicht behandelt werden. Deshalb muss an dieser Stelle ein Zitat Adornos ausreichen, um den Widerspruch zu schlichten: „Den Widerspruch [der Vernunft, B.E.B.] schlichtet Kant, mit den Mitteln undialektischer Logik, durch die Distinktion des reinen und des empirischen Subjekts, die von der Vermitteltheit beider Begriffe absieht.“ (Adorno: Negative Dialektik, S. 238 f.) Die notwendige Vermittlung vom empirischen und reinen Subjekt war bereits in Abschnitt 2.2.1 Gegenstand. ${ }^{255}$ Kant: Grundlegung zur Metaphysik der Sitten, BA 97.

256 Adorno: Philosophische Terminologie, Bd. 1, S. 177.
} 
Dem Willen des vernünftigen Subjekts spricht Kant insofern die Möglichkeit zu, aus sich selbst heraus freiheitlich eine Kausalreihe der Tätigkeit zu beginnen. Im somit absolut freien Willen des Subjekts allein liegt daher das Setzen von Determinanten, die subjektiv freiheitliche Erzeugung von Kausalreihen und Ursachen, begründet. Die unbedingt freien Handlungen des empirischen, praktischen Subjekts haben insofern einen Bestimmungsgrund, die Autonomie der Vernunft des intelligiblen Subjekts, die sich von beeinflussenden Antrieben der heteronomen Sinnenwelt vollkommen unabhängig, frei von jeglicher Determination, ein Gesetz geben würde: ,[W]as kann denn wohl die Freiheit des Willens sonst sein, als Autonomie, d.i. die Eigenschaft des Willens, sich selbst ein Gesetz zu sein?"“257 Insofern ist die Kantische Konstruktion der transzendentalen Willensfreiheit monadologisch als idealistische Theorie der Vernunft konzipiert. Allein in der (selbst-) kritikfreien Immanenz des Subjekts findet sich dabei die Kantische Bestimmung der Freiheit des Willens.

Eine solch absolute Freiwilligkeit des Subjekts ist nun aufgrund der eigenen physischen und sonstigen vorrangigen Materialität des lebendigen Subjekts der Praxis schwer zu rechtfertigen. Mit dem praktischen, in der heteronomen, antagonistischen Gesellschaft handelnden Subjekt verträgt sich diese Autonomie nicht: „Bewußtsein, vernünftige Einsicht ist nicht einfach dasselbe wie freies Handeln, nicht blank dem Willen gleichzusetzen." "258 Adorno schreibt dazu in Sexualtabu und Recht heute: „Die Frage nach der Freiheit des Willens ist wahrscheinlich überhaupt nicht abstrakt, nämlich von Idealkonstruktionen des Individuums und seines rein für sich seienden Charakters her zu lösen, sondern nur im Bewußtsein der Dialektik von Individuum und Gesellschaft. “259 Das (Transzendental-)Subjekt ist für Adorno demzufolge immer schon kritisch mit der heteronomen modernen Gesellschaft vermittelt. Es sei dadurch, weil immer schon gesellschaftliches, auch ein nicht unbedingt freies Subjekt. Aber es wird damit auch nicht gleich als selbstbewusstes, vernünftig urteilendes Subjekt negiert. Es wird von Adorno als ein durch die heteronome Gesellschaft in seinem Selbstbewusstsein beschädigtes Subjekt bestimmt: „In der antagonistischen Gesellschaft sind die Menschen, jeder einzelne, unidentisch mit sich, Sozialcharakter und psychologischer in einem, und kraft solcher Spaltung a priori beschädigt.“" 260 Auch Peter Bulthaup bestimmt die Abhängigkeit des Willens und des subjektiven Handelns im Kontext der heteronomen, dem einzelnen Subjekt transzendent gegenübertretenden, produzierenden Gesellschaft. In dieser bewegen sich Subjekte als Erkennende und Urteilende notwendig: „Der freie Wille ist per definitionem unbedingt. Vermöchte er sich als freier Wille zu realisieren, so wäre er potestas absoluta, unbedingte Macht, die die Bedingungen ihrer Realisation selbst schüfe. Ihre Manifestationen wären eine

\footnotetext{
${ }^{257}$ Kant: Grundlegung zur Metaphysik der Sitten, BA 98.

258 Adorno: Negative Dialektik, a.a.O., S. 226.

259 Adorno: Sexualtabu und Recht heute, S. 548.

260 Adorno: Zum Verhältnis von Soziologie und Psychologie, S. 69.
} 
creatio ex nihilo. Der Wille endlicher Wesen kann sich nur unter heteronomen Bedingungen realisieren." "261

Kants idealistische Konzeption des unbedingt freien Willens wirft ihn nun auch hinter seine Kritik am Rationalismus und der reinen Vernunft zurück, so wie er bereits mit der positiven Metaphysik hinter seine eigene emanzipative Konzeption des Dings an sich zurückfiel (vgl. 2.2.3). Weil das materielle, physische Moment in die reine Form von Subjektivität unmittelbar als die antithetische Selbstkritik einer hypostasierten Subjektivität hineinspielt und die unmittelbare Vergesellschaftung des sich selbsterhaltenden praktischen Subjekts selbst aufdeckt, kann das vergesellschaftete Subjekt als Naturwesen - gegen Kants radikal-autonome, weil idealistische Willenskonzeption - nur ein eingeschränkt autonomes Subjekt sein. Zum einen kann die physische Vergänglichkeit jedes daseienden Subjekts niemals unter die vollständige Autonomie des vernünftigen Subjekts fallen. Die eigene Physis beschränkt das reflexive Subjekt dabei entscheidend; was als subjektive Selbstkritik auch gegen eine unbedingt gedachte Autonomie des Willens steht. Das selbstbewusste Subjekt hat als praktisches Naturwesen aber auch immer die eigenen körperlichen Bedürfnisse mit der bereits vorgeordneten Gesellschaft in Einklang zu bringen. Auch das steht deshalb der unbedingten Autonomie des Willens konkret entgegen. Das verdeutlicht die transzendente, gesellschaftliche Heteronomie, die eine das Subjekt negierende, transzendente gesellschaftliche Objektivität ist. Gegen das körperliche wie allgemein Heteronome kann sich das vereinzelte Subjekt mittels Geist/Vernunft/Theorie darum gar nicht durchsetzen. Das verursacht die entscheidende „Gespaltenheit des menschlichen Zustands“262. Dieser beschreibt den entsprechend beschädigten Zustand des reflexiven, seiner selbst bewussten und vergesellschafteten Subjekts. Subjekt ist durch die individuelle Körperlichkeit als die innereigenste Widersprüchlichkeit - weil das reflexive Subjekt eben nicht nur Natur oder tierische Körperlichkeit ist, weil es gegen die eigenen heteronomen, auch gesellschaftlich heteronomen Voraussetzungen denken kann - nicht wie im Idealismus als unbedingt autonomes, vernunftbegabtes Subjekt denkbar. Das selbstbewusste (Transzendental-)Subjekt widerspricht sich als individuelles Naturwesen mit bedürftiger Körperlichkeit, die in gesellschaftlicher Kooperation stets befriedigt werden muss, immer auch selbst. Dieser nicht durch einen Vernunftakt zu glättende Widerspruch kann den $\mathrm{Haß}$ des vernünftigen Subjekts auf die eigene heteronome, im Akt der Selbsterhaltung zu pflegende Körperlichkeit, hervorrufen. Auf diesen „quälbaren Leib“263 des vergesellschafteten Subjekts ist darum im Verlauf der Arbeit zurückzukommen.

\footnotetext{
${ }^{261}$ Bulthaup: Elemente des Antisemitismus, S. 120.

262 Adorno: Zu Subjekt und Objekt, S. 742.

263 Brecht: Zum Freitod des Flüchtlings W.B., S. 336. Der quälbare Leib als verletzbarer Körper wird als ästhetisches Sujet in der Renaissance bei Hieronymus Bosch (1450-1516) über die unheimliche Nähe des Lebens zum Tode dargestellt.
} 
Die gesellschaftliche Heteronomie des Subjekts, seine Bestimmung als quantité negliable ist aus bestimmten Gründen der Theorie-Praxis-Vermittlung jedoch auch nicht einfach zu verabsolutieren. Das äquivoke Subjekt als Individuum und überindividuelles (meta-physisches) Subjekt denkt Adorno als Momente, die im reflexiven Subjekt selbst nun wieder vermittelt sind. Die Heteronomie des reflexiven Subjekts als körperliches Individuum kann deshalb nicht stiftend sein, sondern sie ist dialektisch zu vermitteln. Die mögliche vernünftige Einsicht des Subjekts muss also ein autonomes Moment gegen alle äußeren Einflüsse immer behalten, die Theorie kann und muss sich ein Stück weit gegenüber der Notwendigkeit der Eingebundenheit des Subjekts in Praxis autonom verhalten. Ein reflexiv bestimmtes Subjekt kann als selbstbewusstes Subjekt deshalb nicht einfach aus heteronomen Voraussetzungen - generell gesprochen aus Objekt - entspringen; oder vice versa. Das selbstbewusste Subjekt lässt sich darum nicht, gegen alle Widerspiegelungstheorien in Geschichte und Gegenwart, einfach mal aus seinen objektiven, allgemeinen gesellschaftlichen Voraussetzungen begründen: „Weil Subjekt reflexiv ist, läßt es sich nicht aus seinen Voraussetzungen begründen."264

Die widerspiegelungstheoretische, subjektivistische Unterstellung, dass das vernünftige, lebendige Subjekt aus etwas anderem entsprungen sei - wie vernünftiges Subjekt aus Gesellschaft - aber auch, (sozial-)konstruktivistisch gedacht, Objekt aus vernünftigem Subjekt, ist immer ein Resultat eines positivistischen Identitätsdenkens von Subjekt und (gesellschaftlichem) Objekt. Das Identitätsdenken steht darum auch der Realität der Umwelt und der Reflexivität des selbstbewussten Subjekts quer. Das vernunftbegabte Subjekt ist ein zumindest weitestgehend autonomes Subjekt gegenüber dem Naturzusammenhang und der Gesellschaft, ein selbstbewusstes Subjekt der Erkenntnis, wodurch es erst am Mannigfaltigen objektiv etwas erkennen und sich zudem auch selbst kritisieren kann. Die Autonomie des reflexiven, aber vergesellschafteten selbstbewussten Subjekts führt damit zu ihm immanenten Widersprüchen und Kämpfen, da es als materielles

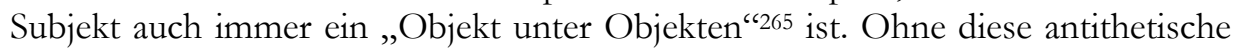
Heteronomie ist das autonome, selbstbewusste Subjekt insofern undenkbar. Weil sich die körperliche Selbsterhaltung des Einzelnen ,quälbaren Körpers' ohne die das Subjekt präformierende Gesellschaft als völlig unmöglich erweist, bleibt es selbst als das autonome, vernünftige Subjekt, auf die eigene heteronome Vergesellschaftung dialektisch verwiesen. Das einzelne Subjekt bleibt so zwar an ein gesellschaftlich gewonnenes Material gebunden, um sich als physisches Subjekt der Praxis in der Welt, ergo in Gesellschaft zu reproduzieren. Verwiesen bleibt es dabei aber auch immer auf die Gesetze der Natur, denen es als vernünftiges, aber physisches Naturwesen immer unterliegen wird - in die es allerdings als selbstbewusstes Subjekt vernünftig zweckmäßig, willentlich rational, hinzutretend eingreifen kann.

${ }^{264}$ Weyand: Adornos Kritische Theorie des Subjekts, S. 24.

265 Adorno: Negative Dialektik, S. 185. 
Die Autonomie des Selbstbewusstseins, gegen seine eigenen Voraussetzungen überhaupt vernünftig zu denken, kommt dem Subjekt deshalb zu, weil das Denken ein entscheidendes Moment der begriffslosen und damit nicht theoretisierbaren Spontaneität gegen all seine äußeren Voraussetzungen hat. Im vernünftigen Denken werden somit die eigenen materiellen Voraussetzungen nicht identitätsphilosophisch/widerspiegelungstheoretisch, nur idealistisch gedacht reproduziert. Gesetzt, nur diese bloße Reproduktion der materiellen Voraussetzungen durch das selbstbewusste Subjekt existiere, so könnte kein Denken bzw. selbstbewusstes, reflexives Subjekt je wirklich sein. Übrig bliebe dann ein bloß tierischer Instinkt wider jede Vernunft, was wiederum reine Praxis wäre. Freiheit, als ein spekulativer, regulativer Begriff, wäre damit undenkbar. ${ }^{266}$ Das wäre ein dem Subjektbegriff widersprechender Schluss, der im Urteil selbst jedoch darum unhaltbar ist, weil es ein Urteil eines selbstbewussten Subjekts darüber geben müsste, das es im Akt des selbstbewussten Denkens seine eigene Subjektivität und sein eigenes Selbstbewusstsein gleich wieder negiert. Insofern würde einzig ein vermeintlich funktionalistischer Reflex eines völlig und nicht nur zur antithetisch bedürftigen Körperlichkeit heruntergebrachten Subjekts gelten. Das selbstbewusste, vergesellschaftete Subjekt ist jedoch nicht als diese vollends verdinglichte, materielle res extensa zu bestimmen. Die selbstbewusste Vernunft des lebendigen Subjekts kann insofern nicht nur ein identitätsphilosophischer Reflex sein. Die Theorie muss ein autonomes Moment haben.

Weil die objektive Wahrheit nur vom tätigen, endlichen Subjekt mittels seiner autonomen Prinzipien der Logik formuliert werden kann, bekommt nun auch jedes wahre Urteil einen entsprechenden Zeitkern. Die Formulierung von Wahrheit hat insofern immer auch raumzeitliche Voraussetzungen. Subjekte sind keine reinen, absoluten Subjekte, sondern historische Subjekte.267 Weil das reflexive Subjekt ein vergesellschaftetes Subjekt einer vorrangig gesellschaftlichen Heteronomie ist, müssen die von Kant erschlossenen Bedingungen der Möglichkeit von wahrer Erkenntnis für Adorno gesellschaftlich vermittelte Bedingungen von Erkenntnis sein. Das Subjekt ist zwar ein vernünftiges und selbstbewusstes Subjekt, es ist aber definitiv kein idealistisch zu verabsolutierendes, autonomes Subjekt mit unbedingtem Willen. Diese Erkenntnis bringt das entscheidende gesellschaftliche Moment in die naturwissenschaftliche und philosophische Erkenntnistheorie hinein. Die transzendente, ontologische Unabhängigkeit der Dinge schließt ihre erkenntnistheoretische Unabhängigkeit nicht gleich mit ein: „Jedes erkannte Objekt ist durch die Mittel und Methoden seiner Erkenntnis relativ auf deren geschichtli-

\footnotetext{
266 Sartres Begriff von Freiheit beschränkt sich aufs einzelne Subjekt. Er hat keinen objektiven, gesellschaftlichen Freiheitsbegriff, der Freiheit jedoch einzig begründen kann. „Ich kann gewiß nicht eine Freiheit beschreiben, die dem anderen und mir selbst gemeinsam ist. (...) Doch es handelt sich in Wirklichkeit um meine Freiheit.“ (Vgl. Sartre: Das Sein und das Nichts, S. 761 f.)

267 „Seine Abhängigkeit von heterogenem Material kennzeichnet dieses Subjekt als nicht-absolutes; die Historizität des Materials kennzeichnet es als nicht-transzendentales, historisches Subjekt.“

(Kuhne: Begriff und Zitat bei Marx, S. 10.)
} 
che Basis.“268 Offensichtlich ist dabei, dass das Subjekt als vergesellschaftetes Subjekt das Mannigfaltige allgemein nach den Regeln der Vernunft (das Vermögen, zu schließen) und des Verstandes (das Vermögen, zu urteilen) bestimmt. Die Erkenntnis des Objekts ist deshalb auch nie von den ,realen Menschen' der Praxis und auch nicht von dessen kooperativer Vergesellschaftung abtrennbar. Die konkrete Gesellschaft stellt erst, vermittelt über die in ihr organisierte Produktivität, praktische Mittel wie theoretische Methoden von Erkenntnis. Wahre Erkenntnis ist insofern nicht von Gesellschaft zu trennen, denn das lebendige Subjekt der forschenden Praxis ist in ihr verwurzelt, in der es sich als Subjekt zu reproduzieren hat. Das Objekt der Erkenntnis - in welchem akademischen Genre als Sachverhalt bestimmt ist dabei gleichgültig - wird auch niemals nur zum Spaß erkannt. Jede Erkenntnis ist ein Mittel zur Erreichung eines bestimmten Zwecks in und durch Gesellschaft. ${ }^{269}$ Die notwendigen und allgemeinen Urteile des vernünftigen Subjekts haben deshalb immer schon einen bestimmten, über die gesellschaftliche Kooperation vermittelten Zweck. Es ist ein gesellschaftlicher, allgemeiner Zweck, der sich im subjektiven Zweck und durch die subjektive Zwecksetzung eines schon vergesellschafteten, seienden, lebendigen Subjekts zeigt: „Alle Tätigkeiten der Gattung verweisen auf ihren physischen Fortbestand, mögen sie es auch verkennen, sich organisatorisch verselbständigen und ihr Geschäft nur noch beiher besorgen." ${ }^{270}$ Dem bedürftigen Subjekt und den besonderen Zwecken seiner Reproduktion sind gesellschaftliche Zwecke der allgemeinen Reproduktion dabei immer bereits objektiv vorgeordnet. Die subjektiven Zwecke bei der Verformung des extramentalen Naturstoffs sind insofern keine autonom subjektiven Zwecke, sondern sie offenbaren die aufs lebendige Subjekt einwirkenden heteronomen Zwecke der immer bereits organisierten Gesellschaft. Weil jedes wahre, objektive Urteil seine theoretischen wie praktischen Voraussetzungen damit vermittelt in der dem Subjekt vorgeordneten Gesellschaft hat, verkommt das nicht nur in der Metaphysik Kants, sondern im gesamten Idealismus avisierte zeitlose ontologische Urteil zum abstrakten, obsoleten Ideal. In der Realität hat es sich nämlich immer an seiner eigenen erkenntnistheoretischen, subjektiven Raumzeitlichkeit des nichtabsoluten, historischen Subjekts zu messen. Adorno zeigt diese Dialektik des zeitlos gedachten synthetischen Urteils a priori bei Kant durch das auch bei ihm historisch tätige Bewusstsein als eines in der Zeit und Vergesellschaftung liegenden Subjekts auf. Er weist dabei auf die kopfzerbrechende Schwierigkeit hin, das Urteil dergleichen dialektisch überhaupt vermittelt denken zu können: „Ein Problem

\footnotetext{
${ }^{268}$ Haag: Der Fortschritt in der Philosophie, S. 130.

${ }^{269}$ Das verweist vermittelt auf die Zwecke jeder akademischen Wissenschaft, mit ihren zu realisierenden Projekten die gesellschaftliche, kapitalistische Reproduktion zu fördern. (Vgl. niedersachsen.de: Hochschulentwicklungsvertrag und Zielvereinbarungen als Elemente der Hochschulsteuerung in Niedersachsen.). Deswegen ist die Forderung nach einer unpolitischen Hochschule obsolet, weil sie dem Schein unterliegt, dass Forschung von gesellschaftlichen und damit politischen Zwecken zu trennen sei.

270 Adorno: Negative Dialektik, S. 203.
} 
[das des genetischen Sinnesimplikats, B.E.B.], das im übrigen auch bei Kant vorkommt, wo ja auf der einen Seite die synthetischen Urteile a priori schlechterdings zeitlos gelten sollen; wo sie aber doch konstituiert werden durch die Tätigkeit, die Spontaneität des Bewußtseins, - also schließlich durch die Arbeit des Geistes; so daß also das angeblich Zeitlose als die Bedingung seiner eigenen Möglichkeit auch ein Moment von Zeit hat.“'271

Dieses entscheidende Problem Kants reicht tief bis in die Voraussetzungen von Erkenntnis hinein - auch in die Dialektik von Genesis und Geltung. Die erkenntnistheoretische Genesis des ontologisch wahren Urteils ist von den gesellschaftlichen Voraussetzungen und Zwecken als historischen und ökonomischen Bedingungen von der Möglichkeit der Wissenschaften und ihrer wahren Erkenntnis, ihren theoretischen Methoden und praktischen Mitteln, unabtrennbar. Doch das ontologisch wahre Urteil selbst kann trotzdem von seiner Genesis und damit von den gesellschaftlichen Bedingungen seiner Formulierung getrennt werden; allerdings auch nur mit Gewalt: „Nur wenn der immanente Spannungscharakter des Urteils verkannt wird, kann vom ,Entstehen' des Inhalts abgesehen werden. “272 Weil dieser ambivalente Spannungscharakter des wahren, geltenden Urteils real ist, sedimentiert sich, widersprüchlich zumal, im Kantischen Transzendentalsubjekt als dem allgemeinen Subjekt schon ambivalent vermittelt bereits Gesellschaftliches, weil Zeitliches. Quasi unmittelbar vermittelt ist das allgemeine Subjekt der Erkenntnis, weil die Reflexion auf das Transzendentalsubjekt auf die Reflexivität des Subjekts notwendig verweist. Das vergesellschaftete Subjekt bezieht sich in der Reflexion auf das Verhältnis der selbstbewussten Denkformen immer auch schon auf sich selbst. Die Herleitung objektiver Denkformen ist also gewissermaßen paradox, weil die ontologische Gültigkeit der erkenntnistheoretischen, selbstbewussten Denkformen vorausgesetzt sein muss und diese subjektiven Voraussetzungen objektiver Erkenntnis auch nicht aus nichtidentisch Anderem stammen können. Diesen stark ambivalenten Spannungscharakter des ontologisch wahren Urteils als subjektiv-objektives erkenntnistheoretisches Urteil streicht Adorno als den entscheidenden Zeitkern der objektiven Wahrheit heraus. Dieser reflektiert die erkenntnistheoretischen und gesellschaftlichen Bedingungen des Gehalts von ontologisch wahren Aussagen: „Schwebend ist sie [die Wahrheit, B.E.B.], zerbrechlich vermöge ihres zeitlichen Gehalts.“273 Ontologisch wahre Urteile können von technischen und akademischen Fertigkeiten der konkreten, bürgerlichen Gesellschaft nicht einfach getrennt werden - auch wenn die gesellschaftlichen Voraussetzungen des wahren naturwissenschaftlichen Urteils in diesem untergehen: „Die Tradition der Naturwissenschaften“, so Frank Kuhne, „,ist geronnen in Apparaturen und standardisierten Verfahren. “"274 Diese Nichttrenn-

\footnotetext{
271 Adorno: Metaphysik, S. 72 f.

272 Adorno: Zur Metakritik der Erkenntnistheorie, S. 82.

273 Adorno: Negative Dialektik, S. 45.

${ }^{274}$ Kuhne: Begriff und Zitat bei Marx, S. 17.
} 
barkeit der objektiven Wahrheit auch von ihrer eigenen Geschichte ist nicht als eine sich selbstwidersprechende Relativierung zu verstehen, sondern als die konsequente Aufdeckung des Ideologiecharakters angeblicher Zeitlosigkeit subjektiv formulierter Wahrheiten. Die Sicherheit, mit der Dialektik von Genesis und Geltung nicht gleich in einen platten relativistischen Selbstwiderspruch zu geraten, liegt im Detail: Wenn der ontologische Wahrheitsbegriff gegen jeden relativierenden Subjektivismus auch von Adorno vorausgesetzt wird (vgl. auch etwa 2.1), dann relativiert jede Argumentation von einer historischen Standpunktabhängigkeit der Wahrheit diesen Gehalt zwar zunächst einmal und auch recht augenscheinlich; doch das erkenntnistheoretische Urteil vom Zeitkern der Wahrheit betrifft bei Adorno als raumzeitliches Moment des scheinbar zeitlosen naturwissenschaftlichen Urteils nicht den ontologischen Wahrheitsbegriff als solchen. Deshalb relativiert er die absolute Wahrheit der Aussage mit dem Zeitkern der Wahrheit nicht. Die objektive Wahrheit wird insofern nicht in die eigene intersubjektivistische Gesellschaftlichkeit qua Hypostasierung der Methoden oder sonstigen wissenschaftlichen praktischen Mitteln zum Zweck aufgelöst: „[O]hne Hinnahme von etwas als Wahrheit, von dem man gar nicht durchaus weiß, ob es die Wahrheit sei, ist Erfahrung, ja die Erhaltung des Lebens kaum möglich.“275

Was zunächst mit den obigen Reflexionen deutlich wurde ist, dass sich die Zwecke der Gesellschaft im vergesellschafteten Urteil wiederfinden lassen. Der Zeitkern allgemeiner Wahrheiten verweist fortwährend auf die notwendig zeitlichen, erkenntnistheoretisch-subjektiven Momente und gesellschaftlichen Bedingungen sowie auf gesellschaftliche Zwecksetzungen zuzeiten der subjektiven Aussage über Dinge als absolute, ontologische Wahrheit. Die Entzeitlichung der Wahrheit als ontologische Wahrheit kann deshalb auch nur über die subjektive Abstraktionsleistung vom erkenntnistheoretisch Zeitlichen erfolgen. Auch ontologische Bestimmungen lassen sich nur und ausschließlich durch lebendige Subjekte in Zeit und Raum formulieren und die Zeitlosigkeit bekommen sie immer erst mittels eines spezifischen subjektiven Abstraktionsvorgangs. Nur Abstraktionen des Subjekts lassen die Resultate des Denkens deshalb als scheinbar völlig vom Subjekt unabhängig erfahren. Erst die logische Abstraktionsleistung im Reflexionsvorgang macht es insofern möglich, von unbedingt subjektiven konstitutiven Formanten aufgrund der ontologischen Objektivität der Aussage abzusehen: „[W]enn man einfach die Erkenntnisse von ihrer Genese trennt, wenn man also, mit anderen Worten, die sedimentierte Geschichte, die in einer jeglichen Erkenntnis enthalten ist, ausklammert, so geht damit ebenso etwas von der Wahrheit verloren; die Wahrheit wird dann gewissermaßen punktuell festgenagelt auf den Anspruch ihrer Zeitlosigkeit, der seinerseits selbst einem Innerzeitlichen, nämlich dem Vorgang der Abstraktion, die von den zeitlichen Momenten absieht, sich verdankt.“'276 Deutlich wird das vor allem in geisteswissenschaftlichen Reflexio-

275 Adorno: Meinung Wahn Gesellschaft, S. 576 f.

276 Adorno: Metaphysik, S. 71 f. 
nen, die ihre eigenen Bedingungen nie dergleichen abstrakt wie die Naturwissenschaften verleugnen können. Die transzendente Autonomie des Gegenstands bleibt vom gesellschaftlichen Subjekt und seiner Logik trotzdem ein Stück weit unabhängig, auch wenn diese Ontologie nur durch subjektive Prinzipien der Logik gedacht werden kann: „Der konkrete Gedanke läßt sich nicht als unabhängig vorstellen von dem, was gedacht wird, wohl aber die Dinge als unabhängig vom menschlichen Denken. “277 Die logische Leistung des Subjekts, das die Voraussetzungen von universal gültigen, ontologischen Urteilen durch die Möglichkeit der Abstraktion von gesellschaftlichen Bedingungen nicht mehr zu reflektieren braucht, beschreibt Peter Bulthaup in einer Reflexion auf die Resultate des subjektiven Denkens: „Die Resultate des Denkens des Denkens, die logischen Formen, die die Konsistenz des Gedachten garantieren, sind Organon, Handwerkszeug, mit dem bewußtlos zu hantieren ist, und nur die Reflexion auf die historisch gewordene Begründung ihrer Geltung vermag das in ihnen untergegangene Selbstbewußtsein erwecken." 278

Dass die Wahrheit ihre Genese nicht verleugnen kann, zeigt sich also an den Überlegungen zum Zeitkern der ontologischen Wahrheit. Adornos Einsichten dazu sind selbst wiederum raumzeitliche Gedanken. Sie haben eine sich in diesen Gedanken sedimentierende (Theorie-)Geschichte, die auf recht unorthodoxe Reflexionen Walter Benjamins zurückgeht. Dessen Passagenwerk entnimmt Adorno erst den Terminus des Zeitkerns der Wahrheit. Benjamin weist der absoluten Wahrheit kritisch den immer aktuell bleibenden Zeitkern als notwendigen erkenntnistheoretischen Subjektbezug im Objekt nach: „Entschiedne Abkehr vom Begriffe der ,zeitlosen Wahrheit““279 sei für ihn ,am Platz. Doch Wahrheit ist nicht - wie der Marxismus es behauptet - nur eine zeitliche Funktion des Erkennens sondern an einen Zeitkern, welcher im Erkannten und Erkennenden zugleich steckt, gebunden." 280 Der Zeitkern der Wahrheit erklärt sich für Benjamin aus dem beständigen Changieren von zeitlichem, vergehendem und vergesellschaftetem Subjekt, allgemeinem und entzeitlichtem Urteil sowie erkanntem Objekt. Im allgemeinen, schon gesellschaftlich konnotierten Begriff objektivieren sich demzufolge überindividuelle, objektive Bestimmungen der Sache selbst. Die objektiven Resultate des allgemeinen, gesellschaftlichen Subjekts, bei Kant bereits im Begriff des Transzendentalsubjekts enthalten, konzentrieren sich in den allgemeinen und notwendigen Urteilen über die Sache, die mittels allgemeiner Begriffe abgefasst werden und die als objektive Begriffe mehr als jede individuelle Erfahrung und jedes individuelle Bewusstsein zusammengenommen sind. Weil die individuelle Erfahrung des Objekts an den gesellschaftlich allgemeinen Resultaten aus den potenzierten Einzelerfahrungen notwendig teilhat, ist die einzelzeitliche Erfahrung

\footnotetext{
277 Haag: Der Fortschritt in der Philosophie, S. 129.

278 Bulthaup: Idealistische und materialistische Dialektik, S. 132.

279 Benjamin: Gesammelte Schriften, Bd. V.1, S. 578.

${ }^{280}$ Ebd.
} 
immer auch überindividuell. Individuelle Erfahrung sei „[d]urch ihre Teilhabe am diskursiven Medium (...) der eigenen Bestimmung nach immer zugleich mehr als nur individuell. Zum Subjekt wird das Individuum, insofern es kraft seines individuellen Bewußtseins sich objektiviert, in der Einheit seiner selbst wie in der seiner Erfahrungen." 281 In den vernünftigen, überzeitlichen Urteilen, die vom Einzelurteil notwendig abstrahieren, bleibt das Zeitliche als dialektischer Subjektbezug auf die Sache vermittelt. Die individuelle Erfahrung eines endlichen, ,realen Menschen' hat an den allgemeinen, überindividuellen Urteilen, die sich ihrer Genesis längst entledigt haben, teil. Deshalb kann eine ontologische Wahrheit, egal welcher Gegenstand Teil der Reflexion ist, auch nicht ,dogmatisch“ „unverlierbar“282 sein. Sie ist und bleibt demnach fortwährend revidierbar, weil endliche Subjekte nicht unfehlbar sein können. Trotzdem erweisen sich allgemeine, universale und die Einzelerfahrungen transzendierende, allgemein theoretische Begriffe gegen jeden Nominalismus für eine adäquate Bestimmung der Sachen als unabdingbar. Die Kritik realistischer Positionen provoziert mit der Verabschiedung von notwendig realistischen Thesen den eigenen philosophisch-erkenntnistheoretischen Bruch. Es ist ein Bruch mit der Wissenschaft, die sich von der Möglichkeit ontologisch wahrer Urteile nicht freimachen kann: „Übersteigt die Zahl der partikularen Urteile in einer solchen Konjunktion die von einem kontingenten Subjekt empirische überprüfbaren Tatsachen, dann ist dieses Subjekt, will es wahre Aussagen über Gegenstände eines von ihm nicht vollständig zu überschauenden Gegenstandsbereichs machen, auf die Geltung universaler Urteile angewiesen." 283 Jener jedem wahren und ontologischen Urteil immanente Formrealismus - denn ein jeder Name soll im autonomen Begriff verloren gehen, insofern er in ihm aufgehoben und damit negiert wird - ist, aufgrund der notwendigen Negation der nur summierten Einzelurteile, logisch unvermeidbar: „Implizit wohnt noch den Eigennamen die Beziehung auf jenes Allgemeine inne." 284 Dieser Formrealismus ist das logische Resultat der erkenntnistheoretischen Vermittlung von lebendigem Subjekt und abstrakt entzeitlichtem Objekt. Der gesellschaftlich konnotierte Allgemeinbegriff ist ein emphatischer Begriff, in dem die einzelnen Subjekte und ihre in der Zeit gemachten Erfahrungen und Urteile zwar unmittelbar und notwendig enthalten sind und in ihm enthalten sein müssen, ${ }^{285}$ diese einzelsubjektiven Erfahrungen und Urteile können jedoch nicht als bloß summierte den autonomen Begriff von Etwas bilden. Die gesellschaftlich konnotierte ontologische Objektivität des Urteils ist deshalb mehr als die addierten einzelsubjektiven Urteile über die

\footnotetext{
281 Adorno, Negative Dialektik, S. 56.

282 Ebd., S. 45.

283 Bulthaup: Idealistische und materialistische Dialektik, S. 131.

284 Theodor W. Adorno: Zu Subjekt und Objekt, S. 741.

285 Adorno konnte, so Alfred Schmidt, deshalb, weil damit Gesellschaft bereits in jedem Allgemeinbegriff steckt, überhaupt versuchen, ,, in subtilen, zunächst werkimmanenten Analysen (...), im Innern der geistigen Gebilde selbst die antagonistische Struktur der Gesellschaft aufzuspüren.“ (Schmidt: Begriff des Materialismus bei Adorno, S. 26.)
} 
Sache. Die Summe der subjektiven Urteile ist mehr als jedes ihrer Teile, so wie das individuierte Allgemeinvermögen auch mehr als jedes vereinzelte vernünftige Ich denke ist. Jede gültig gedachte ontologische Wahrheit muss sich, wie gezeigt, nicht nur nach Benjamin und Adorno, an die eigenen gesellschaftlichen Bedingungen ihrer Genese historisch rückbinden. Und jedes Urteil eines selbstbewussten, lebendigen Subjekts qualifiziert sich erst durch die allgemeine Nachvollziehbarkeit durch andere vernünftige Subjekte als absolut wahres, ontologisches Urteil. Das beschreibt die präformierte Vorrangigkeit der gesellschaftlich vermittelten Objektivität im Urteil gegenüber jedem einzelnen Urteil durch ein notwendig vergesellschaftetes Subjekt. Ohne den Rückgriff auf den transzendentalen Idealismus hätte es diese kritischen, materialistischen Gedankengänge zur Voraussetzungen von Erkenntnis, Gesellschaft und Wahrheit, Theorie und Praxis etc. schwerlich geben können.

\subsubsection{Horkheimers, instrumentelle Vernunft ${ }^{\varsigma}$ oder: Die Vernunft als Mittel zum} Zweck

Die „Zwecke der Selbsterhaltung“286 des einzelnen Subjekts realisieren sich nur, wenn sich denn die nichtidentischen Naturstoffe mittels Vernunft als widerspruchsfrei identische, als erkannte und kontrollierbare gesellschaftlich angeeignet werden. Das subjektive Denken von allgemeinen, notwendigen Prinzipien erweist sich darum als entscheidendes Instrument der subjektiven, zwecksetzenden Selbsterhaltung in Gesellschaft. So wird darüber nicht nur die Selbsterhaltung des Subjekts in Gesellschaft realisiert, sondern auch noch die von Gesellschaft selbst. Die zwecksetzende Selbsterhaltung des einzelnen vergesellschafteten Subjekts ist nun immer eine instrumentelle Zwecksetzung durch das Subjekt. Es ist dessen entscheidende Zwecksetzung zur Realisation der eigenen Reproduktion in der Gesellschaft, wobei jedoch allein auf die Möglichkeit der Mittel zum bereits vorgegebenen gesellschaftlichen Zweck adäquat reflektiert wird.

Diese zwecksetzende Selbsterhaltung des vergesellschafteten Subjekts beschreibt insofern genau das, was Horkheimer in Zur Kritik der instrumentellen Vernunft als die, instrumentelle' oder die ,subjektive Vernunft' bezeichnet. Die instrumentelle/subjektive Vernunft bleibe demnach immer auf das funktionale Verhältnis von Mitteln und Zwecken bezogen. Die subjektive Vernunft drückt für Horkheimer insofern „die Fähigkeit“287 aus, „Wahrscheinlichkeiten zu berechnen und dadurch einem gegebenen Zweck die richtigen Mittel zuzuordnen. “288 Pragmatisch würde demnach vom Subjekt zu jedem Zweck instrumentell ein geeignetes Mittel der Realisation gesucht; nicht mehr, nicht weniger.

\footnotetext{
286 Adorno: Negative Dialektik, S. 285.

${ }^{287}$ Horkheimer: Zur Kritik der instrumentellen Vernunft, S. 17.

288 Ebd.
} 
Solche praktische Instrumentalität des subjektiven Denkens kann demnach nicht konkrete gesellschaftliche Zweckzusammenhänge reflektieren, unter denen erst immer zum Zweck der eigenen Selbsterhaltung überhaupt gedacht wird. Im Zuge jener Instrumentalität des Denkens wird die gesellschaftliche Metaebene jedoch nicht reflektiert, mit der Instrumentalität des Denkens wird nur eine gesellschaftlich ,blinde‘ Anwendung der Vernunft beschrieben. Die bloße Anwendung der Vernunft resultiert demnach in einer instrumentellen Praxis oder im zweckrationalen ,instrumentellen Handeln. ${ }^{289}$ Das instrumentelle Denken ist deshalb auch nicht vorschnell als irrationales Denken zu bezeichnen. Es ist und bleibt praktisch immer zweckbezogen - auch unter dem heteronomen Einfluss der gesellschaftlichen Kausalität. Horkheimer stellt das instrumentelle Denken deswegen in den Zusammenhang des vernünftigen, rationalen Denkens überhaupt. Es ist ihm ein rationales Denken von identitätsphilosophischer Widerspruchslosigkeit nicht nur, aber vor allem auch in Bezug der subjektiven Vernunft auf objektive Gesellschaft. Die Instrumentalität des Denkens sichere dem Subjekt das gesellschaftliche und persönliche Überleben. Dadurch realisiere sich dialektisch, als Mittel zum Zweck, immer wieder auch die konkrete gesellschaftliche Reproduktion. Das instrumentelle Denken ist insofern die selbsterhaltende Vernunft des Subjekts innerhalb der theoretischen und praktischen Grenzen, die das gesellschaftlich Allgemeine aber dialektisch dem Subjekt erst setzt. Es ist insofern auch als eine Art Eigenschaft des vernünftigen Selbstbewusstseins zu sehen, dass es die eigenen, rationell gesuchten Zwecke innerhalb der eng gesteckten Zwecke der Gesellschaft nicht auf ihre objektive Sinnhaftigkeit überprüfen muss, sondern im Rahmen der eigenen Selbsterhaltung als Subjekt der Praxis stur in der selbstbezogenen, rationalen Immanenz verbleiben kann: „Die subjektive Vernunft fügt sich allem.“2200

Das instrumentelle Denken des Subjekts bleibt insofern auf sich selbst wie die Zwecke des Subjekts in der Gesellschaft notwendig beschränkt. Die heteronome gesellschaftliche Kausalität wird vom Subjekt darum auch pragmatisch befolgt, ohne dass die gesellschaftlichen Zwecke des Handelns reflektiert werden. Insofern hat das instrumentelle Denken seinen terminus ad quem/cui bono ausschließlich innerhalb der konkreten Gesellschaft, in der sich das selbstbewusste lebendige Subjekt der Praxis reproduzieren muss. Im bereits gesetzten Rahmen der allgemeinen Reproduktion entfaltet es sich erst als rationales Denken der eigenen Selbsterhaltung, und über die theoretischen und praktischen Grenzen der Gesellschaft denkt das pragmatische Subjekt nicht hinaus.

\footnotetext{
289 Dem instrumentellen und strategischen Handeln aus nur egozentrischer Zweckrationalität hält Habermas deshalb dann das kommunikative Handeln kritisch entgegen: „Hingegen spreche ich von kommunikativen Handlungen, wenn die Handlungspläne der beteiligten Aktoren nicht über egozentrische Erfolgskalküle, sondern über Akte der Verständigung koordiniert werden.“ (Jürgen Habermas: Theorie des kommunikativen Handelns, Bd. 1, S. 385.) Dass die Theorie des kommunikativen Handelns als rationaler Ausweis von Freiheit problematisch ist, wird weiter unten verhandelt (vgl. 2.3.3). ${ }^{290}$ Max Horkheimer, Zur Kritik der instrumentellen Vernunft, a.a.O., S. 34.
} 
Diese durch die instrumentelle Vernunft die wirkliche, objektive Vernunft einschränkende Formalisierung ist für Horkheimer zwar nicht ein ausschließliches, aber eben doch auch ein Resultat eines sich durchsetzenden subjektivistischen Denkens in der Geschichte der Geisteswissenschaften. Im akademischen Wissenschaftsbetrieb setze sich der Subjektivismus im Verlauf des 20. Jahrhunderts sukzessive in Form eines pragmatischen Positivismus durch, der nur noch im nominalistisch-positivistischen Modus auf seine Gegenstände reflektiere: „Im formalistischen Aspekt der subjektiven Vernunft, wie er vom Positivismus hervorgehoben wird, wird ihre Beziehungslosigkeit zu einem objektiven Inhalt betont; in ihrem instrumentellen Aspekt, wie er vom Pragmatismus hervorgehoben wird, wird ihre Kapitulation vor heteronomen Inhalten betont.“"291 Deshalb komme es gerade auch durch die moderne akademische Wissenschaft zur fortschreitenden „Formalisierung der Vernunft ${ }^{\text {“292 }}$. Diese formalisierte Vernunft affirmiere theoretisch nun immer den objektiven Zweck der bereits durchgesetzten Gesellschaftsform, indem die Zwecke der aktuellen bürgerlichen Gesellschaft zu Zwecken der akademischen Wissenschaft, die Zwecke der Gesellschaft aber zu Zwecken der einzelnen, sich in ihr reproduzierenden Subjekte formalisiert bzw. ideologisiert sind: „Das Schema der gesellschaftlichen Arbeitsteilung wird automatisch auf das Leben des Geistes übertragen, und diese Aufteilung der Kultursphäre ergibt daraus, daß die allgemeine, objektive Wahrheit durch die formalisierte, zuinnerst relativistische Vernunft ersetzt wird." 293

Weil die instrumentelle Vernunft wie auch das Subjekt nun in der heteronomen gesellschaftlichen Kausalität gefangen bleibt, gleiche ihre theoretische Überhöhung jedoch einer ausweglosen Sackgasse ohne jegliches Kritikmoment. Damit wäre sogleich wieder ein Selbstwiderspruch der Vernunft formuliert: Das reflexive Moment, gegen die eigenen praktischen Voraussetzungen denken zu können (vgl. etwa 2.3.1), wird von der Vernunft selbst negiert. Diese Negation der Reflexivität würde jedoch jede emphatische Vernunft, die allein gesellschaftliche Zwecke transzendieren kann, zerstören. Horkheimer hätte seine kritischen Reflexionen über den Wissenschaftsbetrieb deshalb nicht formulieren können, wenn solch eine Aporie von Vernunft real und eine die eigene Selbsterhaltung reflektierende Theorie dadurch unmöglich wäre. Des Verlusts jeden Maßstabs der Kritik durch eine hypostasierte Formalisierung der Vernunft ist sich Horkheimer allerdings bewusst, weshalb er die Vernunft dialektisch bestimmt. Das selbstkritische Moment sei Resultat derselben Vernunft, ein in sich dialektisch vermitteltes Moment einer Vernunft, mit der man der Möglichkeit nach gegen den Zweck der eigenen praktischen Selbsterhaltung denken könne. Das instrumentelle Denken des Subjekts der Selbsterhaltung sei deswegen nicht mit einer verabsolutierten „Vernünftigkeit“"294

\footnotetext{
291 Ebd., S. 30.

292 Ebd., S. 28.

293 Ebd.

294 Ebd., S. 16.
} 
zu verwechseln. Dieses dem instrumentellen, auf die eigene Reproduktion bezogenen Denken Andere, das ambivalente Moment der Vernunft, sei der „objektive Begriff der Vernunft selbst“295. Vernunft transzendiere insofern der Möglichkeit nach immer auch gesellschaftliche Grenzen, weshalb die Vernunft sowohl eine instrumentelle wie auch eine selbstreflexive „objektive Vernunft“296 zugleich sei. Sie ist demnach äquivok bestimmt. Die objektive Seite der Vernunft hält dabei gegen alle gesellschaftlichen Widerstände des kapitalistischen Zeitgeistes immer

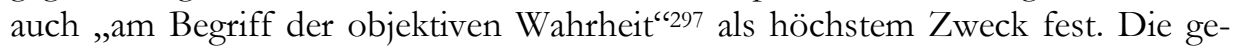
sellschaftlichen Zwecke können deshalb der Möglichkeit nach von ein und derselben Vernunft auf die Möglichkeit der Realisierung eines Besseren und Anderen hin untersucht werden, um die allgemeinen gesellschaftlichen Zwecke mit den Prinzipien der Logik als falsche Zwecke zu denunzieren. Wenn Vernunft der Möglichkeit nach immer die Zwecke der Gesellschaft, in die das sich reproduzierende praktische Subjekt eingebunden ist, reflektieren könne, muss sie auch immer allgemeine Zwecke der Gesellschaft als heteronom falsche, negative, weil herrschaftlich Erzwungene denunzieren können. Dieses Ineinander-Vermittelt-Sein der Bestimmungen beider dialektisch in sich vermittelter Seiten der subjektiven Vernunft, diese Dialektik der Vernunft in sich als instrumentelle und selbstreflexive sei entscheidend: „Dieser Begriff von [objektiver, B.E.B.] Vernunft schloß subjektive Vernunft niemals aus, sondern betrachtete sie als partiellen, beschränkten Ausdruck einer umfassenden Vernünftigkeit, von der Kriterien für alle Dinge und Lebewesen abgeleitet wurden. “298 Das vernünftige Subjekt kann Aspekte der Aufhebbarkeit der vorrängigen Gesellschaft auch nur deshalb äußern, weil beide Momente der Vernunft, subjektive und objektive, in sich vermittelt die Einheit des ichbezogenen Bewusstseins, die Einheit der Vernunft und damit des Selbstbewusstseins bilden. Jedes vernünftige, selbstbewusste Subjekt kann insofern jederzeit, aufgrund seiner reflexiven Vernunft, die eigenen, ebenfalls vernünftigen, aber gesellschaftlich immanent bleibenden gesellschaftlichen Zwecke der Möglichkeit nach reflektieren. So kann das Subjekt, wenn schon nicht in der Realität, so zumindest in Gedanken die herrschende Gesellschaft transzendieren. Die heteronome soziale, verdinglichte Kausalität der aktuellen Gesellschaft ist dadurch mindestens theoretisch jederzeit aufbrechbar.

Noch etwas deutlicher als bei Horkheimer ist die dialektisch-ambivalente eine Vernunft bei Adorno ausgeführt. Für Adorno wird die von Horkheimer angeführte Ambivalenz sogar zur Bedingung von theoretischer und praktischer Freiheit (vgl. 2.3.1). Die Dialektik der Vernunft wird von ihm dabei offensiv als Inbegriff selbstbewusster Vernunft formuliert. Ohne die instrumentelle Vernunft gäbe es überhaupt keine Grundlage für eine von falschen, selbst nur instrumentellen Zwe-

\footnotetext{
295 Ebd., S. 27.

296 Ebd., S. 23.

297 Ebd.

298 Ebd., S. 16.
} 
cken befreite Gesellschaft. Eine mögliche „vernünftig eingerichtete (...) Gesell-

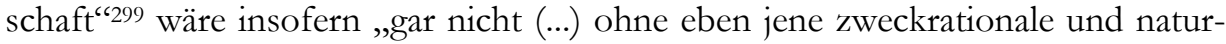
beherrschende Vernunft, die gleichzeitig in ihrer welt-historischen Konsequenz all das Unheil gehabt hat, an das sogar die Erinnerung in einem nicht vorstellbaren $\mathrm{Maß}$ durch die siegenden Mächte der Geschichte verdrängt oder vernichtet worden ist. “" ${ }^{\text {"300 }}$ Die sich selbst reflektierende Vernunft kann insofern also jederzeit die erzwungene gesellschaftliche Funktionalität des Subjekts wie die reaktive, adäquate Instrumentalität des verdinglichten Denkens zur eigenen Selbsterhaltung transzendieren. Das geschieht für Adorno in Form eines theoretisch unbestimmbaren, spontanen Aktes. 301

Insofern es also die Möglichkeit von vernünftiger, kritischer Selbstreflexion gibt, gibt es auch der Möglichkeit nach ein durch die Spontaneität angestoßenes Transzendieren der heteronomen gesellschaftlichen Verhältnisse. Einen totalen Verblendungszusammenhang der Vernunft, den die Reduktion der Vernunft auf ihre Instrumentalität darstellen würde, kann es deshalb gar nicht geben, auch wenn sich Ausführungen Adornos und Horkheimers in der Dialektik der Aufklärung stellenweise so lesen lassen. ${ }^{302}$ Ein kausaler Verblendungszusammenhang kann nach Regeln der vorgenommenen Vernunftdialektik deshalb schon kein totaler sein, weil die Verdinglichung des Subjekts nicht absolut sein kann. Jeder vermeintlich totale Verblendungszusammenhang bleibt demnach der Möglichkeit nach fürs Subjekt rational durchsichtig, die pragmatisch bestimmte Praxis bleibt dadurch immer theoretisch transzendierbar - und schon um logisch einen Verblendungszusammenhang zu bestimmen, muss das Subjekt über diesen auch bereits hinaus sein.

Die Möglichkeit zur spontanen Einsicht und zur autonomen Willensbestimmung, die eine autonome Praxis der Möglichkeit nach zur Folge hat, wird von Adorno und Horkheimer also nicht verneint - selbst wenn das verdinglichte Bewusstsein durch die herrschende Gesellschaft immer präformiert ist ${ }^{303}$ : „Ein Bewußtsein, das heute und hier jener Verhärtung der Meinung ganz entsagte, die das pathische Prinzip ist, wäre ebenso problematisch wie jene Verhärtung selbst.“304 Eine potentielle Überwindung gesellschaftlicher Herrschaftsverhältnisse wird

\footnotetext{
299 Adorno: Zur Lehre von der Geschichte und von der Freiheit, S. 82.

300 Ebd.

301 Adorno: Marginalien zu Theorie und Praxis, S. 760: „Was seitdem als Problem der Praxis gilt und heute abermals sich zuspitzt zur Frage nach dem Verhältnis von Praxis und Theorie, koinzidiert mit dem Erfahrungsverlust, den die Rationalität des Immergleichen verursacht. Wo Erfahrung versperrt oder überhaupt nicht mehr ist, wird Praxis beschädigt und deshalb ersehnt, verzerrt, verzweifelt überbewertet. So ist, was das Problem der Praxis heißt, mit dem der Erkenntnis verflochten. Die abstrakte Subjektivität, in der der Rationalisierungsprozeß terminiert, kann strengen Sinnes so wenig irgend etwas tun, wie vom transzendentalen Subjekt vorzustellen ist, was gerade ihm attestiert wird, Spontaneität.“

302 Vgl. Adorno/Horkheimer: Dialektik der Aufklärung, S. 141 ff.

303 Vgl. Adorno: Zum Verhältnis von Soziologie und Psychologie, S. 69.

304 Adorno: Meinung Wahn Gesellschaft, S. 592.
} 
durch die „Anstrengung, unermüdlich auf seine Aporien und auf sich selber zu reflektieren " 305 aufrechterhalten. Diese Dialektik der Freiheit des gesellschaftlich präformierten Selbstbewusstseins fällt unter die Frage nach der Freiheit und Autonomie im vergesellschafteten Subjekt selbst, das ein reflexives, lebendiges Subjekt der Praxis ist (vgl. 2.3.1). Selbst im gesellschaftlich noch so beschädigten Subjekt kann deshalb immer eine Freiheit der Reflexion statthaben: „Dem gesellschaftlichen Bann opponiert es mit Kräften aus jener Schicht, in der das principium individuationis, durch welches Zivilisation sich durchsetzte, noch gegen den Zivilisationsprozeß sich behauptet, der es liquidiert." "306 Die selbstbewusste Vernunft drängt also im Rahmen der Selbstreflexion zur Selbstkritik ihrer Verabsolutierung durch die Kritik der funktionellen Zwecke ihrer eigenen gesellschaftlichen Instrumentalität. Selbstreflexion drängt zur vernünftigen, einsichtigen Praxis: aber nur, weil Theorie und Praxis zwar nicht absolut ineinander, aber eben auch nicht dichotomisch voneinander zu trennen sind.

\subsubsection{Grenzen der Vernunft. Beherrschung oder Bearbeitung von Natur? Gedanken zum Begriff der Herrschaft}

Das instrumentelle, verdinglichte Denken der sich reproduzierenden empirischen Subjekte, das für deren gesellschaftliche Reproduktion notwendig ist, stößt in seiner formalisierten Funktionalität an objektive Grenzen der Natur, die sich nicht ignorieren lassen. Sie bleiben dem rationalen Denken immer nichtidentisch. Diese Unaufbrechbar- und Unberechenbarkeit der letzten Naturdinge durch das Subjekt erinnert deshalb an das Kantische Motiv des unerkennbaren Dings an sich. Das instrumentell-pragmatische Identitätsdenken kann darum auch nicht, weil objektiv begrenzt, aus sich selbst heraus als eine Art Allzweckwaffe der gesellschaftlichen Reproduktion gesehen werden, mit der alles und jedes extramentale Gegenüber vollständig rational bestimmt und beherrschbar wird. Nicht alle materiellen Widrigkeiten gesellschaftlicher Reproduktion können deshalb mit den Prinzipien der Logik als identisch mit sich aufgehoben werden. Sie können nicht einfach ihrer Bestimmtheit in sich enthoben werden. ${ }^{307}$ Die instrumentelle Vernunft stößt insofern an eine übrigbleibende, mit dem Subjekt nichtidentische natürliche Transzendenz, die sich in die identifizierende Immanenz der subjektiven Rationalität nie vernünftig überführen lässt. Das ist die entscheidend fortwährende, materielle Grenze der Nichtidentität, die nicht nur der Idealismus durch sein gewaltsames Anschmiegen des natürlich Nichtidentischen an das eigene Denken so offensiv wie teils bewusst missachtete. Der Idealismus reduzierte nämlich, neben anderen philosophischen Schulen, das Transzendente auf Identität.

\footnotetext{
305 Ebd.

306 Adorno: Postscriptum, S. 92.

307 „Etwas, das seiner Bestimmtheit beraubt ist, als solches nur bestimmbar ist, ist bloß formbares

Material.“ (Bensch: Vom Reichtum der Gesellschaften, S. 19.)
} 
Das subjektive Denken pragmatischer Selbsterhaltung, so Adorno, nötige „zur Sachhaltigkeit" ${ }^{\text {308 }}$. Die nichtidentische, transzendente Sachhaltigkeit bleibe dem mit sich identischen Geist als materielle Grenze des denkenden Subjekts transzendent. Zwischen Subjekt und Objekt existiere deshalb, negativ vermittelt, ein Hiatus. Der subjektiven Identifikation widerstehe insofern ein Rest an Nichtidentität. Wenn man also idealistisch oder subjektivistisch die Grenze der Vernunft erkenntnistheoretisch als eine Art Selbstverblendung der Vernunft verwischt, sie als eine unorthodox gedachte Einschränkung des Selbstbewusstseins setzt, ist sie damit nicht gleich überwunden, sondern sie wird dadurch nur generös versteckt. ${ }^{309}$ Sie bleibt trotz allem ein Eigenständiges, über jedes Subjekt hinausseiendes Etwas. Das weitestgehend autonome Material, das sich auch nicht grenzenlos für subjektive Zwecke instrumentalisieren lässt, bleibt insofern authentisch: nichtidentisch. Es ist dadurch ein Stück weit gegen die Funktionalisierung durch die Identifikation von Theorie und Praxis autonom; es entzieht sich dem vernünftigen Subjekt theoretisch wie praktisch. Weil das autonome Objekt dem wiederum autonomen reflexiven Subjekt transzendent ist, entzieht sich die zu bearbeitende Materie selbstredend der absoluten Beherrschung durch das instrumentell und objektiv vernünftige Subjekt und die Gesellschaft. Dem Subjekt bleibt die natürliche Materie als Naturzwang restontologisch Nichtidentisch.

Selbst die Physis des Subjekts, weil Materie, unterliegt einem heteronomen $\mathrm{Na}$ turzwang. Auch sie entzieht sich beispielsweise der vollständigen Beherrschung durch medizintechnische Funktionalisierungen. Als indifferentes, widerspenstiges und dem Geist transzendentes Ding entzieht sich selbst die eigene Körperlichkeit der vollständig rationalen Identifikation durch das Subjekt. Dadurch ist die eigene körperliche Materie dem erkennenden Subjekt ein Stück weit transzendent und auch nur bedingt durch den Geist beherrschbar.

Das heteronome Material der Nichtidentität prüft nun die lebendigen Subjekte auch beständig in ihrer Existenz, und die vergesellschafteten, selbstbewussten Subjekte sind von diesem Material existentiell abhängig. Als reflexive Subjekte sind sie insofern nicht vollkommen autonom, was auch wider ihre eigene Körperlichkeit wäre. Durch die ihnen äußere und ihre eigene restontologische, heteronome Objektivität sind sie als lebendige Naturwesen also notwendig heteronom, negativ bestimmt: „Seine [des Subjekts, B.E.B.] Abhängigkeit von heterogenem Material kennzeichnet dieses Subjekt als nicht-absolutes; die Historizität des Materials kennzeichnet es als nicht-transzendentales, historisches Subjekt.“310

Das Subjekt ist demnach bereits durch die innerste Dialektik des Subjekts, durch die ihm immanente Heteronomie über den verdinglicht idealistischen Sub-

\footnotetext{
308 Adorno: Negative Dialektik, S. 141.

309 Vgl. Hegel: Phänomenologie des Geistes, S. 68 f.

310 Kuhne: Begriff und Zitat bei Marx, S. 10.
} 
jektivismus hinaus. ${ }^{311}$ Gesetzt ist dadurch, weil kein beherrschbarer Wille eines vernünftigen selbstbewussten Subjekts, die Vorrangigkeit der Natur/des Objekts gegenüber dem vernünftigen Subjekt, der extramentalen Materie gegenüber dem diskursiven Denken. Diese subjektive Erkenntnis von der notwendigen Restontologie im Erkenntnisprozess lässt die autonome Vernunft einen bewusst selbstkritischen Akt gegen die idealistisch hypostasierte Autonomie des Selbstbewusstseins vollziehen, und zwar im und aus dem vernünftigen Denken dieses Akts selbst. Das ist das Resultat einer kritisch dialektischen Vermittlung von Immanenz und Transzendenz: Die Transzendenz in ihrer nichtidentischen Existenz zu akzeptieren, ist ein entscheidendes Eingeständnis einer gewissen Ohnmacht des Geists als endliches Subjekt. Es ist das Eingeständnis der Schwäche eines nicht absoluten, mit sich nichtidentischen Naturwesens. Dieses Eingeständnis selbst kann jedoch erst ein Resultat der identischen Selbstreflexion des lebendigen Subjekts sein.

Identifizierende Prinzipien der Logik helfen dem Subjekt dabei, die Reproduktion der Gattung durch die Distanzierung von allen natürlichen Zwängen reibungsloser sicherzustellen. Dadurch vergrößert sich die kooperativ vonstatten gehende gesellschaftliche Distanz zur Natur. Das Identitätsprinzip ist das Rationalisierungsprinzip der (ontologischen) Umwelt. Der subjektive, gesellschaftliche Herrschaftsanspruch findet hierin seinen Ausdruck: Denn „dieses Identitätsprinzip ist ja zutiefst nichts anderes als der absolute Anspruch von Herrschaft über die innere und außermenschliche Natur." ${ }^{\text {"312 }}$ Doch der bloße Anspruch auf Naturbeherrschung ist nun nicht gleichzusetzen mit der Beherrschung der Natur. Herrschaft gegen ein nichtidentisches Gegenüber wie beispielsweise die eigene Physis oder andere Naturdinge auszuüben, erweist sich als sinnlos, weil die Naturdinge keine autonom willensbegabte Subjekte sind. Herrschaftsverhältnisse erfüllen einzig zwischen willensbegabten Subjekten einen bestimmten, funktionellen Zweck. Darauf verweist Hegels Herrschafts-Knechtschafts-Abschnitt der Pbänomenologie des Geistes. Bezogen auf das notwendige Willensverhältnis als unabdingbare Voraussetzung des Herrschaftsverhältnisses heißt es hier: „Das Selbstbewußtsein erreicht seine Befriedigung nur in einem anderen Selbstbewnßtsein." ${ }^{1313}$ Nur ein denkbegabtes, selbstbewusstes Subjekt kann den entsprechenden Willen haben, der es aufgrund seiner dialektisch vermittelten Physis erst für andere willensbegabte, lebendige Subjekte beherrschbar macht. Weil die extramentale Natur keinen Willen hat, also kein vernünftiges Subjekt ist, sondern bloß ein willenloses Ding, wird die um-

\footnotetext{
311 Esoterische ,Theorien' basieren dabei insbesondere auf einem platten Subjektivismus. Mit Gewalt wird hier nämlich eine absolute Identitätsphilosophie restituiert. Das allmächtige, einzelne Subjekt könne demnach Objekte durch eine wie auch immer erreichte überstarke Mentalität beeinflussen. Selbst der eigene Körper und seine Funktionen seien deshalb nichts dem Subjekt ambivalent transzendentes. Esoterik, Yoga etc. sind deshalb Resultate eines krassen Subjektivismus. Allen Personen, die krank, behindert oder sonst wie aus dem Raster der Gesellschaft fallen, wird letztendlich noch selbst die Schuld daran gegeben.

312 Adorno: Philosophische Terminologie, Bd. 1, S. 184.

313 Vgl. Hegel: Phänomenologie des Geistes, S. 144. Vgl. auch ebd., S. 145 ff.
} 
gangssprachliche Rede von einer subjektiven Naturbeherrschung zumindest ungenau. Zwar lassen sich Phänomene der Natur mittels des Identitätsprinzips als in sich selbstbestimmtes Material erkennen und ordnen, in dem die Naturkräfte durch das vergesellschaftete Subjekt initiiert planmäßig aufeinander wirken können; dem Naturzwang kann deshalb durch kooperatives gesellschaftliches Einwirken auch gewissermaßen Einhalt geboten werden, aber Naturphänomene lassen sich, weil dem zeitlichen, lebendigen Subjekt mit seiner eigenen Vergänglichkeit gegenüber weitestgehend unabhängige Phänomene, nicht physisch oder psychisch in letzter Instanz beherrschen. Der letzte Mythos auswendiger Natur bleibt darum für Habermas restontologisch transzendent und deshalb unaufklärlich: „So erklärt sich, warum wir sie [die Natur, B.E.B.] bearbeiten können, obwohl kein Mensch auch nur einen kleinen Teil von ihr beherrschen kann. "314 Naturzwänge sind insofern prinzipiell unbeherrschbar, womit sie unberechenbar bleiben, weil ein ontologischer, materieller Rest im Rahmen ihrer Bestimmung immer übrigbleibt. Das wurde bereits mit der Kantischen Bestimmung, dass bestimmbar an stofflichen Dingen einzig ihr funktionales Verhalten sei, nicht jedoch ihr ontologischer Grund, angeschnitten (vgl. 2.2.1; 2.2.3). Als Beweis für die Beschränkung der reibungslosen Funktionalisierung der Natur durch das Subjekt und seine logischen Prinzipien bedarf es auch nicht erst eines Tornados, Hurrikans oder eines Erdbebens. Die relative Unbändigkeit der Naturgewalten und par tout nicht positiv zu tätigende Aussagen über den Weltgrund stehen den idealistischen Programmen subjektivistischer Verabsolutierungen diametral gegenüber. ${ }^{315}$ Es gibt insofern keine positive Letztbegründbarkeit aller Phänomene in einem als letzte Ursache gedachten identischen Prinzip. ${ }^{316}$ Das erkannt zu haben, hat das Kantische unerkennbare Ding an sich als unbekannte Ursache aller Erscheinungen jedem Subjektivismus insofern schon voraus, auch wenn das Programm des aufklärerischen Idealismus - „den Menschen die Furcht zu nehmen und sie als Herren einzusetzen““317 - das Kantische Programm dann ebenfalls ergreift, wie oben mittels seiner Aufgabe der Substanzbegriffe deutlich wurde (vgl. 2.2.3).

Geisteswissenschaftliche Programme der Naturbeherrschung haben jedoch ein geschichtliches wie gesellschaftliches fundamentum in re und sind deshalb nicht einfach aus der Luft gegriffen. Sie entstehen vor allem in Zeiten des aufkommenden verwertungstechnischen Zwangs des Kapitals während der ,Industrialisierung‘. Denn hier kommt es aus Gründen der Initiierung der kapitalistischen Produkti-

\footnotetext{
314 Habermas: Theorie des kommunikativen Handelns, Band 1, S. 117.

315 Voltaire kommt dabei im Candide mit seiner Kritik der prästabilierten Harmonie, dem rationalistischen Einheitsprinzips Leibniz und Lösung des Leib-Seele-Problems, der (naiv) materialistischen Kritik des Subjektivismus schon recht nahe. (Vgl. Voltaire: Candide oder die Beste aller Welten.) Leibniz entwickelt seine Idee von der, besten aller Welten' in: Die Theodizee.

316 Dass aber nach einer Letztbegründung gefragt werden muss, um überhaupt richtige Fragen zu stellen, wurde bereits in 2.1 mit dem Verweis auf Vittorio Hösle deutlich.

317 Adorno/Horkheimer: Dialektik der Aufklärung, S. 19.
} 
onsweise zu einem starken Drang der Funktionalisierung von Natur. ${ }^{318}$ Der zeitgleich aufkommende philosophische Idealismus versucht, die kapitalistische Ökonomie und seinen Drang zur effektiven Naturbeherrschung mit seiner Geistphilosophie zu rationalisieren. Mit Aggressivität reagiert der an der historischen Schnittstelle zur kapitalistischen Warenproduktion aufkommende Idealismus auf die Autonomie der Natur und formuliert daraus die subjektive Macht bezüglich ihrer Verwertung. Sein Programm sagt den praktischen Bedrohungen der gesellschaftlichen, kapitalistischen Reproduktion den Kampf an: „Das mythische Grauen der Aufklärung gilt dem Mythos.“319 Die bedrohliche Natur soll als des Menschen Untertan vermittelt werden: „Das Programm der Aufklärung war die Entzauberung der Welt.“"320 Dieses Programm resultiert in einer krassen Idiosynkrasie gegen jedwede auswendige Natur - auch des Subjekts als Naturwesen. Am deutlichsten wird das bei Hegel und dessen objektivem Idealismus: „Vergebens hypostasiert Hegel danach den Geist. Um es irgend zuwege zu bringen, muß er ihn zum Ganzen aufblähen, während Geist doch dem Begriff nach seine differentia specifica daran hat, daß er Subjekt, also nicht das Ganze ist: solche Subreption weicht keiner Anspannung des dialektischen Begriffs.“321 Die Reflexion des in Idiosynkrasie umschlagenden Hasses des Idealismus und dem anschließenden Versuch der subjektivistischen Einverleibung alles transzendent Nichtidentischen ist auch das kritische ,Leitmotiv“ oder die kritische Kernthematik der Dialektik der Aufklärung. Weil es in ihr dann jedoch heißt: „Seit je [sic!] hat Aufklärung im umfassendsten Sinn fortschreitenden Denkens das Ziel verfolgt, von den Menschen die Furcht zu nehmen und sie als Herren einzusetzen“, 322 wird die Aufklärung hier zum ausgedehnten, historisch allumfassenden Begriff. ${ }^{323}$ Die Dialektik der Aufkelärung bekommt deshalb, durch die nicht nur terminologische Ausdehnung und den Versuch nachzuweisen, dass Herrschaft von Menschen über Menschen mit der Herrschaft der instrumentellen ratio über Natur vermittelt zusammenhängt, den „falsche[n] Schein, als ob alles ab ovo vorherbestimmt wäre.“324 Aufklärung wird damit dialektisch als realer wie geistesgeschichtlicher Prozess von fortschreitender Naturbeherrschung bestimmt und nicht nur Begriff zur Bezeichnung einer bestimmten politisch-ökonomischen, raumzeitlichen Epoche.

Das ist jedoch nicht nur ein von den Autoren der Dialektik der Aufklärung eigens komponiertes aufklärerisches Leitmotiv, sondern ihre Interpretation hat ein historisches Fundament. Die Formulierung Adornos und Horkheimers von der

\footnotetext{
318 Vgl. hierzu auch insbesondere Karathanassis: Kapitalistische Naturverhältnisse.

319 Adorno/Horkheimer: Dialektik der Aufklärung, S. 46.

320 Ebd., S. 19.

321 Adorno: Negative Dialektik, S. 199.

322 Adorno/Horkheimer: Dialektik der Aufklärung, S. 19.

323 Philosophisch hebt die Aufklärung eigentlich erst zu Zeiten immer fortschreitender Warenproduktion, nämlich mit dem rationalistischen ego cogito von Descartes an. (Vgl. dazu Halder: Philosophisches Wörterbuch, S. 42.)

${ }^{324}$ Claussen: Grenzen der Aufklärung, S. 43. (Kursiv im Original, B.E.B.)
} 
Ewigkeit der Unterdrückung der Natur zu Reproduktionszwecken hat eine gewisse historische Substanz in der Menschheitsgeschichte und dem Prozess der Emanzipation des Menschen von den unmittelbaren Naturzusammenhängen. Die Entrüstung darüber, dass man als Subjekt dem natürlichen Realitätszwang Folge zu leisten hat, findet sich deshalb auch nicht erst im Idealismus. Schon bei Platon lässt sich der Hass auf das Auswendige nachweisen, worauf Adorno und Horkheimer Bezug nehmen. In einer späteren Vorlesung sagt Adorno über Platons Nichtseiendes, das $\mu \eta$ ov: „Es bedarf keines Wortes (...) um dieses Drastische zum Bewußtsein zu bringen, daß die Trennung der Idee von der Sinnenwelt, in der eigentlich bei Platon beschlossen ist die Lehre von dem Sinnlichen als dem Nichtseienden, von dem $\mu \eta$ ov, - daß die sich schwer durchhalten lässt. “325 Die Interpretationen Platons, die die extramentale, sinnliche Materie als eines nichtseienden und $\mu \eta$ ov nachweisen, zeigen die subjektive Abneigung gegenüber allem Materiellen, Nichtidentischen bereits in der klassischen griechischen Philosophie. Die Problematik des scheinbar als ewig ausgemachten Leitmotivs der Menschheitsgeschichte ist dabei nicht von der Hand zu weisen. Es ist ein aus dem quantitativ sich identisch gerierenden Moment gesellschaftlicher Herrschaft kommendes, kritisch gewendetes Urteil mit schwerwiegenden Folgen. Scheinbar wird dabei zwar einer kontinuierlichen gesellschaftlichen Herrschaft in der Geschichte gefolgt, weshalb das Leitmotiv auch erst als ewiges Leitmotiv komponiert wird. Es kann jedoch trotzdem kein ontologisches Prinzip sein. Gerade die Abstraktion von den entscheidenden gesellschaftlichen Zwecken der Naturbeherrschung führt deshalb zu den entscheidenden logischen Problemen in der Dialektik der Aufklärung und der Darstellung des Aufklärungsbegriffs. Seine Problematik resultiert auch nicht aus der bloßen Feststellung, dass sich in der Geschichte die gesellschaftliche Reproduktion seit jeher durch die Distanzierung des Subjekts von der Natur realisierte. Es ist die problematische Überführung jener Feststellung in eine materialblinde Logik. Horkheimer und Adorno bestimmen in der Dialektik der Aufkelärung gesellschaftliche Herrschaft mehrfach als eine aus der Subjektkonstitution selbst entspringende: aus der bloßen Form der instrumentalisierten gesellschaftlichen Naturbearbeitung resultiere die gesellschaftliche Herrschaft. In jeder bisherigen Epoche würde dadurch mittels der instrumentell gebrauchten Vernunft die gesellschaftliche Herrschaft über Menschen in der Geschichte laut Dialektik der Aufklärung verlängert: „Was die Menschen von der Natur lernen wollen, ist, sie anzuwenden, um sie und die Menschen vollends zu beherrschen." ${ }^{2326}$ Weil der Begriff der Aufklärung eine subjektkonstitutive Distanz zur Natur beschreibt und diese naturbeherrschende Distanz in jeweils historischer Form eines Mehrprodukts erscheinen muss - es wird also mehr produziert als zur gesellschaftlichen Reproduktion eigentlich notwendig -, wird die gesellschaftliche Herrschaft, die aus dieser Aneignung des durch die Herrschaft erzwungen produzierten Mehr-

\footnotetext{
325 Adorno: Metaphysik, S. 30.

326 Adorno/Horkheimer: Dialektik der Aufklärung, S. 20.
} 
produkts resultiere, nun ontologisch verewigt: „Die Distanz des Subjekts zum Objekt, Voraussetzung der Abstraktion, gründet in der Distanz zur Sache, die der Herr durch den Beherrschten gewinnt.“'327 Dann jedoch würde sich für die Subjekte unter dem Aspekt auch der Ausweg aus gesellschaftlicher Herrschaft erübrigen. Sie müssten dementsprechend in Herrschaft gefangen und als Subjekte befangen bleiben. Weil das für die Aufklärung aus den unmittelbaren Naturzusammenhängen nötige Mehrprodukt also als immer und notwendig aus der gesellschaftlichen Arbeit als notwendigem Prozess der Distanzierung des Subjekt von der Natur entsprungenes Produkt bestimmt wird, das sich von der Herrschaft nur post festum angeeignet werde, und es nicht als ein systematisch herrschaftlich erzwungenes, erpresstes Mehrprodukt aus Freiheit, das aus der Arbeit am Naturgegenstand selbst nicht ,automatisch' entspringt bestimmt wird, entspringt das Mehrprodukt in der Dialektik der Aufklärung damit - anders als bei Marx! - einer „der menschli-

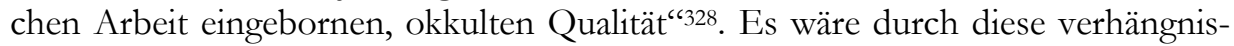
volle Verbindung von Naturbearbeitung und gesellschaftlicher Herrschaft auch zweckfrei, eine Kritik an der systematischen kapitalistischen Mehrproduktion als Form einer erzwungenen Mehrproduktion zu formulieren; höchstens eine verzweifelte Kritik an der Verteilungsfrage wäre noch möglich.

Für Marx hingegen ist der Fortschritt in der Distanz zur Natur einer, der erst durch anderes aktualisiert wird, nämlich durch äußeren Zwang: „Die Gunst der Naturbedingungen liefert immer nur die Möglichkeit, niemals die Wirklichkeit der Mehrarbeit, also des Mehrwerts oder des Mehrprodukts.““329 Dieser äußere Zwang zur Mehrproduktion erpresst von den Subjekten erst die entsprechende Arbeitszeit für andere: „Damit er [in diesem Fall der ostasiatischer Brotschneider, B.E.B.] diese [die Mußezeit, B.E.B.] produktiv für sich selbst verwende, ist eine ganze Reihe geschichtlicher Umstände, damit er sie in Mehrarbeit für fremde Personen

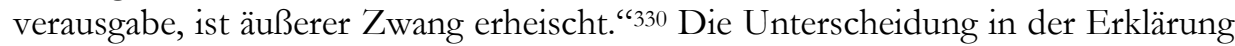
von Mehrproduktion bei Marx und Adorno/Horkheimer scheint zunächst zwar marginal zu sein, doch die Differenz von notwendiger gesellschaftlicher Arbeit des praktischen lebendigen Subjekts und herrschaftlicher Mehrarbeit wird um den gesellschaftstheoretisch höchsten Preis eingezogen, wenn man diese dem naturbearbeitenden Subjekt selbst entspringen lässt: den des kritischen, freiheitlichen Maßstabs der Denunziation von Mehrarbeit durch gesellschaftlich realisierten Zwang. Weil Horkheimer und Adorno in der Dialektik der Aufklärung die notwendige ratio bei der gesellschaftlichen Naturbeherrschung durch die Subjekte zu gesellschaftlicher Herrschaft fortführen, können sie ihren Maßstab der Kritik nicht ausreichend ausweisen. Darum bekommt die Dialektik der Aufklärung jenen bereits

\footnotetext{
327 Ebd., S. 29 f.

328 Marx: Das Kapital, Bd. 1, S. 538.

329 Ebd., S. 537.

330 Ebd., S. 538.
} 
von Claussen bemerkten „merkwürdig finalistische[n] Charakter“331 von einer ontologischen Vorherbestimmtheit gesellschaftlicher Herrschaft. Ohne jede freiheitliche Diskontinuität verewigt sich Herrschaft damit in Geschichte und durch Geschichte als kontinuierlich. Die mögliche Aufbrechbarkeit von gesellschaftlicher Herrschaft und Herrschaftsstrukturen wird durch die Anthropologisierung von Mehrarbeit zur pfadlosen Utopie, zu einer Gesellschaftskritik ohne freiheitlich herausweisenden Maßstab. Weil Horkheimer und Adorno die Vernunft damit auch eindimensional an eine verdinglichte, instrumentelle Vernunft heften, muss, wenn denn die Logik aus der Dialektik der Aufklärung konsequent weitergesponnen wird, die gesellschaftliche Emanzipation bis auf weiteres ausbleiben.

Diesen aporetischen Mangel bei Adorno/Horkheimer akzeptiert Habermas nicht. Seine Revision der traditionellen Kritischen Theorie löst deshalb insbesondere diese Aporie auf: „,Wenn man vom Spätwerk Adornos auf die Intention zurückschaut, denen die Kritische Theorie anfänglich gefolgt ist, kann man den Preis ermessen, den die Kritik der instrumentellen Vernunft für ihre konsequent eingestandenen Aporien entrichten muß." ${ }^{\text {"332 }}$ Mit der kommunikationstheoretischen Wende soll die Aporie aufgelöst werden, denn für Habermas garantiere allein die zwanglose, intersubjektive Kommunikation eine mögliche Befreiung von heteronomen, gesellschaftlichen Zwängen. Die Kritik am normativen Maßstab der traditionellen Kritischen Theorie ist, wenn die von Habermas übernommene „Reduktion des Selbsterzeugungsaktes der Menschengattung auf Arbeit“"333 gilt, tatsächlich berechtigt, weil die gesellschaftliche Herrschaft in ihr unmittelbar aus der Naturbeherrschung folgen muss. Gesellschaftliche Herrschaft von Menschen über Menschen wäre demnach ein unvermeidliches, notwendiges Resultat der Subjektkonstitution. Sie wäre demzufolge ein Akt aus immer notwendiger Naturbeherrschung und nicht erst ein Resultat subjektiver Freibeit gegen die Naturzwecke, die in Herrschaft mündet.

In Adornos Subjekttheorie bleibt dieses Verhältnis von Natur und Herrschaft allerdings ambivalent - und bis zuletzt ungeklärt. ${ }^{334}$ Bereits in der Dialektik der Aufklärung hätte Habermas deshalb auch eine alternative Erklärung von gesellschaftlicher Herrschaft, nämlich eine aus Zwang, finden können: „Die Distanz des Subjekts zum Objekt, Voraussetzung der Abstraktion, gründet in der Distanz der Sache, die der Herr durch den Beherrschten gewinnt. "335 Ein weiterer angebotener Maßstab für die Kritik ist auch die nichttheoretisierbare Spontaneität der Vernunft (vgl. dazu 2.6.4).

\footnotetext{
331 Claussen: Grenzen der Aufklärung, S. 43.

332 Habermas: Theorie des kommunikativen Handelns, Bd. 1, S. 516.

333 Habermas: Erkenntnis und Interesse, S. 58.

334 Vgl. Weyand: Adornos Kritische Theorie des Subjekts, S. 43 ff.

335 Adorno/Horkheimer: Dialektik der Aufklärung, S. 29 f.
} 


\subsection{Die negative Dialektik Adornos als Voraussetzung emphatischer Kritik}

„Denken, das an Identität irre ward, kapituliert leicht vor dem Unauflöslichen und bereitet aus der Unauflöslichkeit des Objekts ein Tabu fürs Subjekt.“"336

Adornos negative Dialektik ist ein Resultat aus seinen Reflexionen zu Gesellschaft und Subjekt bzw. zu Subjekt und Objekt. Besonders die Kritik der Philosophie Hegels erweist sich als ihr in konzeptioneller Hinsicht archimedischer Punkt. Mit einer kritisch angeeigneten Dialektik Hegels zielt Adornos Kritik auf Gesellschaft und ihre Phänomene, weshalb eine Beschäftigung mit der Dialektik Hegels hier zentral wird. Adornos negative Dialektik nimmt Hegels Dialektik in sich auf, hebt sie aber sogleich auch auf eine höhere Stufe: „Das Buch [gemeint ist die Negative Dialektik, B.E.B.] möchte Dialektik von (...) affirmativem Wesen befreien, ohne an Bestimmtheit etwas nachzulassen." "337 Die Notwendigkeit der Dialektik Hegels für Adornos negative Dialektik ist deshalb sowohl logisch, weil Denken aus sich heraus notwendig schon zur Dialektik treibe ${ }^{338}$, als auch gesellschaftstheoretisch begründet. Der Methode Hegels bleibe nach Adorno nämlich ein realistisches, ein überragendes analytisches Moment ${ }^{339}$ immanent: „Solange also Hegel einfach den Weltlauf konstruiert, ist er, indem er den Vorrang des Allgemeinen vorm Besonderen konstruiert, ja, lassen Sie's mich ganz vulgär ausrücken: realistisch; so geht's wirklich in der Welt zu. “340 Hegels Philosophie interveniert ihrerseits wiederum am entschiedensten gegen die noch ontologischen Überlegungen Kants (vgl. 2.2. ff.). ${ }^{341}$ Hegel tritt an, diesen ,Fehler ${ }^{6}$ Kants zu überwinden. Dafür verabsolutiert er in seiner spezifischen Systemphilosophie ${ }^{342}$ System und Vernunft. Sein Subjekt entpuppt sich darum nicht nur als ein Absolutes, das sich von keiner Transzendenz mehr etwas vorschreiben lassen will, es entpuppt sich auch noch als ein schon antagonistisches Allgemeinsubjekt, das die bedürftigen Subjekte der Praxis

\footnotetext{
336 Adorno: Negative Dialektik, S. 163.

337 Vgl. ebd., S. 9.

338 Vgl. bspw. Adorno: Philosophische Terminologie, Band 1, S. 40 ff.

339 „Erst der absolute Idealismus gibt, paradox genug, historisch die Methode frei, welche in der Einleitung der Phänomenologie das ,bloße Zusehen“ heißt.“ (Adorno: Drei Studien zu Hegel,

S. 258.)

340 Adorno: Zur Lehre von der Geschichte und von der Freiheit, S. 65.

${ }^{341}$ In Hegels Frühwerk finden sich dagegen konsequente Negationen des Bestehenden, auch schon des bürgerlichen Staates: „Die Idee der Menschheit voran, will ich zeigen, daß es keine Idee vom Staat gibt, weil der Staat etwas Mechanisches ist, so wenig als es eine Idee von einer Maschine gibt. Nur was Gegenstand der Freiheit ist, heißt Idee. Wir müssen also über den Staat hinaus! - Denn jeder Staat muß freie Menschen als mechanisches Räderwerk behandeln; und das soll er nicht; also soll er aufhören.“ (Hegel: Das älteste Systemprogramm des deutschen Idealismus, S. 234 f.)

342 „Hegel hat zweifellos die differenzierteste Systemkonzeption vorgelegt, die wir kennen“.

(Krijnen: Selbsterkenntnis und Systemgliederung, S. 113.)
} 
unter sich begräbt. Hegel degradiert dabei selbst noch die Natur zur reinen substanzlosen Funktionalität des antagonistisch Allgemeinen, wodurch er die mit ihr nur verfahrende instrumentelle Vernunft (vgl. 2.3.2) verabsolutiert. Diese letztendlich hypostasierte instrumentelle Vernunft Hegels wird in 2.4.1 als das Resultat einer affirmativ gedachten Dialektik, als Kritik an dem unbekanntem Ding an sich Begriffs überführt: Es ist die Dialektik als konsequente Methode gegen den transzendentalen Idealismus Kants gedacht, die deshalb ohne Kantisches Unmittelbares, nicht jedoch ohne Unmittelbarkeit, gedacht wird.

Diese affirmative Dialektik des Hegelschen Idealismus wird auf Geschichte und Gesellschaft übertragen. In 2.4 .2 wird deshalb auf die sich aus dem System Hegels ergebende Problematik bei einer gesellschaftstheoretischen Betrachtung hingewiesen. Das antagonistisch Allgemeine bei Hegel stellt eine Widerspiegelung der Herrschaftsgeschichte dar, um diese zu rechtfertigen.

Adornos Kritik am Hegelschen Absolutismus, wie in 2.4.3 untersucht, wendet sich insbesondere gegen die Hegelsche Dialektik als Methode. Diese verschlinge jeden Inhalt mahlstromartig, weshalb sie mit „keinem methodischen oder ontologischen Prinzip“343 vergleichbar sei. Adornos Kritik an Hegels zum Inhalt gepeitschter Methode nimmt dabei Kantische, aber auch Marxsche Motive für die Kritik des idealistischen Subjektivismus auf. Die von Adorno reflektierte Marxsche Kritik an der Dialektik Hegels wird zwar allgemein noch nicht als eine negative Dialektik bezeichnet. Bei Marx aber erhalten sich schon bestimmte Negationen im Gegensatz zur positiven Dialektik Hegels, die methodisch-idealistisch alles in Affirmation überträgt. ${ }^{344}$ So tauchen bereits bei Marx wieder vermittelt Kantische Motive auf, die auf den oben kennengelernten Begriff vom Ding an sich, allerdings kritisch verwandelt, zurückgreifen. Das registriert Adorno.

Die negative Dialektik Adornos, die das Unmittelbare als Moment der Vermittlung von Subjekt und Objekt zu retten versucht, ist dabei auch nicht mit einer wiedereingeführten Ontologie zu verwechseln, wie man aufgrund der strengen Kritik am Idealismus meinen könnte. Trotz oder gerade durch ihre notwendigen restontologischen Momente ist sie gerade keine Renaissance ontologischer Positionen. Das macht 2.4.4 deutlich.

2.4.5 beschäftigt sich dann noch mit einer kritischen Begründung der negativen Dialektik gegen subjektivistische Positionen.

\footnotetext{
343 Adorno: Drei Studien zu Hegel, S. 258.

344 Die materialistische Dialektik von Marx lässt sich ohne spezifischen Inhalt nicht denken. Georg Lukács unterstellt der Marxschen Dialektik diese Formalität in Gescbichte und Klassenbewußtsein; indem er sie zur Methode macht, verabsolutiert er sie als stillgestellte Dialektik: „Sie ist die wissenschaftliche Überzeugung, daß im dialektischen Marxismus die richtige Forschungsmethode gefunden wurde, daß diese Methode nur im Sinne ihrer Begründer ausgebaut, weitergeführt und vertieft werden kann.“ (Lukács: Was ist orthodoxer Marxismus?, S. 59.)
} 


\subsubsection{Hegels System: (Positive) Dialektik als Methode}

Um die negative Dialektik als möglichen Maßstab der Kritik in ihrer gesellschaftstheoretischen Konstellation zu verstehen, muss also zunächst einmal die methodische Begriffsdialektik Hegels zum Gegenstand werden. Erst dieser ,Umweg' über Hegels Logik kann ein profundes Urteil darüber liefern, ob zum einen die gesellschaftstheoretische, negativ-dialektische Kritik Adornos an Hegel ihre Berechtigung hat; zum anderen aber kann auch dann erst wirklich nachvollzogen werden, ob die Kritik von Gesellschaft mit der negativen Dialektik einen wirklich erschöpfenden Maßstab hat. Dann erst kann auch beantwortet werden, ob die kritischdialektische Negation von Gesellschaft und sozialen Phänomenen nicht vielleicht doch nur eine Fortführung von philosophischer Spielerei mit Sprache und Theorie ist. Eine solche Substanzlosigkeit unterstellt unter anderem Botho Strauß der Dialektik. 345

Hegel blickt mit einer die Philosophiegeschichte systematisch reflektierenden Brille des objektiven Idealismus auf das Subjekt-Objekt-Verhältnis. Vor allem die in-sich-Bestimmtheit eines autonomen Gegenstands, das Kantsche Ding an sich als unbekannte Ursache aller Erscheinungen, verfällt deshalb seiner Kritik. Hegel erschließt die Voraussetzungen von wahrer Erkenntnis nun nicht aus einer Differenz von Geist und Nicht-Geist, sondern für ihn wird sie überhaupt erst aus Geist hervorgebracht. ${ }^{346}$ Damit will er dem transzendentalen Idealismus eine Art Selbstbetrug bezüglich der Autonomie des Objekts nachweisen. Das unerkennbare Objekt ist für Hegel insofern durch nichts anderes als das Subjekt als derart autonom bestimmt. Diese Konsequenz des verabsolutierten Selbstbewusstseins war zwar Ansatzweise schon bei Kant zu finden (vgl. 2.2.3), der eigentlich auch erst durch seine idealistischen Funktionsbegriffe, die jeden substanziellen Realismus des Dings an sich verneinen, als Idealist bezeichnet werden kann: „Hegel hat den Kantischen Kritizismus zu seinem Recht gebracht, indem er den Kantischen Dualismus von Form und Inhalt selber kritisierte, die starren Differenzbestimmungen von Kant und, Hegels Interpretation zufolge, auch noch von Fichte in die Dynamik hineinzog, ohne doch die Unauflöslichkeit der Momente einer unmittelbaren planen Identität zu opfern.“"347 Hegel hat Kant, wie Adorno schreibt, insofern erst zu seinem vollen Recht gebracht, gerade weil dieser in der Kritik der reinen Vernunft idealistisch und selbstwidersprüchlich sein bereits entfaltetes ontologisches Moment revidiert und den Vorrang des Objekts wieder kassiert: „,[W]as die Dinge an sich sein mögen, weiß ich nicht, und brauche es auch nicht zu wissen, weil mir doch niemals ein Ding anders, als in der Erscheinung vorkommen kann. "“348 Diese von Kant formulierten Selbstwidersprüche greift Hegel auf und überantwortet die Kritiken Kants einem

\footnotetext{
${ }^{345}$ Vgl. hierzu Reus: Unglückliches Bewußtsein, S. 11 ff.

346 Vgl. Hegel: Wissenschaft der Logik I.

347 Adorno: Drei Studien zu Hegel, S. 257.

348 Kant: Kritik der reinen Vernunft, A 277 / B 333.
} 
adäquaten, philosophischen Selbstbewusstsein: „Hegel“, so Adorno, sei „in sehr vielem Betracht ein zu sich selbst gekommener Kant".349

Über den dialektisch-synthetisch kassierten Widerspruch bei Kant verabsolutiert Hegel dann auch die Widerspruchslosigkeit überhaupt. Hegel vollzieht damit einen selbstbewussten, gleichsam konsequenten Schritt gegen alles Nichtidentische. Sein methodisches Vorgehen ist insoweit logisch kompromisslos. Für ihn existiert die logische Grenze des Dings an sich nicht, der absolute Idealismus hat sich zum Ziel gesteckt, ontologische Überlegungen systematisch, oder besser gesagt: in ein mit sich identisches, stringentes System, aufzulösen. Der terminus ad quem der Hegelschen Philosophie realisiert sich dabei, indem sich das reine, unbestimmte Sein durch seine Entsubstantialisierung selbst negiert. Es löst sich im Seienden auf. Wenn man so will, lässt Hegel dadurch also das Kantische, noch negativ transzendente, autonome Ding an sich im als absolut bestimmten affirmativen Begriff gänzlich - in der geschichtlich vermittelten Selbstentsubstantialisierung des Absoluten - aufgehen: „Der konsequenter durchgeführte transzendentale Idealismus hat die Nichtigkeit des von der kritischen Philosophie noch übriggelassenen Gespensts des Ding-an-sich, dieses abstrakten, von allem Inhalt abgeschiedenen Schattens erkannt und den Zweck gehabt, ihn vollends zu zerstören. “350 Jede restontologisch bestimmte Transzendenz sei damit auch „,verhaucht“351. Jede Form des Dings an sich, als kritisches Moment des Vorrangs des Objekts, sei dadurch in der Immanenz des Subjekts und seiner Logik aufgehoben, jede im Ding an sich auffindbare Substanz wird nun funktionalisiert. So existiert durch die positiv-dialektische Vermittlung Hegels auch kein irgend unbestimmt bleibender Hiatus zwischen Subjekt und Objekt mehr. Substantiell Unmittelbares, also über Subjekt hinaus Seiendes, gibt es für Hegel nicht mehr. Ein über subjektives Wissen und damit auch über subjektive Begriffe Hinausgehendes, dem Systemgedanken als unerkennbar querstehendes Etwas, das „Gespenst des Ding an sich“352, duldet Hegel, ganz identitätsphilosophischer Positivist, nicht mehr. Jede restontologische Überlegung löst sich deshalb im stringenten, konsistenten (Begriffs-)System ohne jedes nichtidentische Außen auf: Er „gewahrt im reinen Sein die Abstraktion und will mit dem Denken anfangen, das sich die Gestalt der einfachen Unmittelbarkeit gegeben hat.“"353 „Wie Denken von allem abstrahieren konnte, so soll es, indem es die Gestalt des Seins annimmt, aus sich auch alles Seiende entlassen können. “354

Indem Hegel also die logischen Konsequenzen aus dem Begriff des Dings an sich zieht, versucht er zugleich noch nachzuweisen, dass die unbekannte Ursache aller Erscheinungen, die transzendentale Einheit der Apperzeption, eine unvermit-

\footnotetext{
349 Adorno: Drei Studien zu Hegel, S. 255.

${ }^{350}$ Hegel: Wissenschaft der Logik I, S. 41.

${ }^{351}$ Haag: Der Fortschritt in der Philosophie, S. 97.

352 Hegel: Wissenschaft der Logik I, S. 41.

${ }^{353}$ Haag: Der Fortschritt in der Philsophie, S. 97.

354 Ebd.
} 
telt bleibende Funktion sei. Da sie deshalb, als instrumentalisiertes Sein für Anderes, keine dialektische Beziehung zu irgendeinem bestimmten Inhalt der Erkenntnis mehr habe, sei sie leer. Und da die Erscheinung, das Material der Erkenntnis, bei Kant auch nicht mit ihrem Substrat, d.h. dem Ding an sich vermittelt sei, gerate diese unbekannte Ursache aller Erscheinungen für Hegel zu jener bereits zitierten begriffslosen (und damit unsystematischen), widersprüchlich bleibenden Schattenwelt. Ähnlich dem späteren positivistischen Angriff Nietzsches auf die verstaubte philosophische Hinterwelt ${ }^{355}$, worunter für Nietzsche auch der transzendentale Idealismus Kants fällt, zieht Hegel - allerdings stärker dialektisch vermittelt als Nietzsche (und den Satz des zu vermeidenden Widerspruchs und damit den absoluten Wahrheitsgedanken ${ }^{356}$, nicht aufgebend ${ }^{357}$ ) - den objektiven Existenzgrund der Dinge in den subjektiven Bestimmungsgrund des Geistes. Weil mit der Negation des Hiatus die Bewegung des identifizierenden Denkens positivistisch die Bewegung der ,nichtidentischen' Dinge ist, zieht Hegel nun mit jener systembedingten Identifikation von Subjekt und Objekt als Identität der Identität und Nichtidentität die bei Kant noch restontologisch unbekannte und unbestimmte Ursache aller Erscheinungen als deren Existenzgrund unmittelbar ins Subjekt und dessen logische Kategorien. Er verabsolutiert mit dem Beweis von der Unmöglichkeit einer dem Subjekt nichtidentischen Ursache, das Identitätsprinzip - denn ,[w] as nicht bestimmt ist, ist nicht.“" ${ }^{\text {"35 }}$ Deswegen gilt Hegels Position als das adäquateste Modell eines positivistischen Idealismus, das den widerspruchsfreien Absolutheitsanspruch des Subjekts gegenüber der transzendenten Natur hypostasiert. 359

Die Philosophie Hegels spiegelt dadurch auch den Absolutheitsanspruch des bürgerlichen Denkens wider, das sich die Natur zu seinen (kapitalistischen) Zwecken funktionalisiert (vgl. 2.3.3). Demnach komponiert Hegel den absoluten Geist als kompatibles Moment einer kapitalistischen Naturbeherrschung; als das absolute Subjekt. Dieses ist allerdings nicht mit einem einzelseienden Subjekt als physisches, sich reproduzierendem Naturwesen zu verwechseln. Selbst wenn der absolute Geist dialektisch mit Einzelsubjektivem immer auch vermittelt bleibt - und auch Hegel fällt wie schon Kant nicht hinter die nominalistische Wende aufs Sub-

\footnotetext{
355 Das Denken in den überholten Termini der Metaphysik wird von Nietzsche als antiquiertes Denken ungebildeter Hinterwäldler begriffen. (Vgl. Nietzsche: Also sprach Zarathustra, S. 30 ff.) 356 Z.B. in Friedrich Nietzsche: Morgenröte, S. 252: „Vielleicht folgt aus alledem der Satz, daß die Wahrheit als Ganzes und Zusammenhängendes nur für die zugleich mächtigen und harmlosen, freud- und friedvollen Seelen (wie es die des Aristoteles war) da ist, ebenso wie diese wohl auch nur imstande sein werden, sie zu suchen“.

357 „Nietzsches Philosophie schließlich negiert sowohl den Wahrheitsanspruch der modernen Wissenschaft als auch die Geltung absoluter Werte und Normen." (Hösle: Die Krise der Gegenwart, S. 64.)

358 Knahl: Die Steine schreien nicht selbst, S. 78.

${ }^{359}$ Versuche, den Absolutheitsanspruch des Subjekts zu formulieren, hat es dabei viele gegeben. Man denke nur einmal an die Philosophien Fichtes oder Schellings.
} 
jekt zurück -, er also nicht von den vielen einzelseienden Subjekten als ein rein theoretisches Moment getrennt wird, ist Hegels reiner Geist bloß noch antagonistisch mit den einzelnen Subjekten verbunden. Die idealistisch verabsolutierten Zwecke des Subjekts oder des Geists werden insofern zu allgemeinen Zwecken eines jedem einzelnen Subjekt feindlich gegenüberstehendem Allgemeinen: zu Zwecken eines dem einzelnen Subjekt gegenüber fremden, heteronomen Objekts als Geist. Das ist die Folge des methodisch-dialektisch angemeldeten Absolutheitsanspruchs des reinen, absoluten Geists, der sich selbst negiert und die Welt dabei aus sich heraus entlässt - und alle ihm nichtidentischen Gegenstände als objektiv letztlich vollkommen Gegenstandslos rationalisiert.

Das hat Konsequenzen auch noch auf höherer Ebene: Der Hegelsche Geist kann sich, weil methodisch realisierte Absolutheit, nur noch funktionell um die eigene Achse drehen. Wo der objektive Geist hinschaut, war er als synthetisch die Nichtidentität bestimmender schon am Werke. Was er begrifflich nicht bestimmt hat, hat er nicht gesehen und was er nicht gesehen hat, ist nicht (oder kann und darf nicht sein). So schaut er nur auf das von ihm als selbstbewusste Identität willentlich produzierte Material, das er aus sich mittels der dialektischen Methode herausnegierte: „Das Wesentliche für die Wissenschaft ist nicht so sehr, daß ein rein Unmittelbares der Anfang sei, sondern daß das Ganze derselben ein Kreislauf in sich selbst ist, worin das Erste auch das Letzte und das Letzte auch das Erste wird.“'360 Jedem Anderen gegenüber ist der Geist insoweit blind, der konsequent durchgeführten, positiv dialektischen Methode ist ein Anderes inexistent. Alles gegen sich selbst Seiende ist dem absoluten Geist deshalb ein Nichtseiendes. Mit dieser Synthese des eigentlichen Widerspruchs versöhnt der absolute Geist den in der Philosophie bis dato vorherrschenden dualistischen Gegensatz von Subjekt und Objekt, Hegel glättet damit den Hiatus von Geist und Nicht-Geist. Als dialektisch absolut in sich vermittelte Momente werden beide als Momente von Hegel in sich miteinander absolut identifiziert; das Eine sei das Andere, das Andere sei das Eine.

Weil seine synthetische Vermittlung von Subjekt und Objekt in sich zu dieser absoluten Vermittlung der beiden dialektisch zu vermittelnden Momente von Subjekt und Objekt wird, weil sie im reinen Geist sowohl mündet wie beginnt, restituiert Hegel dann trotz seiner für den Idealismus typisch tätigen Vermittlung von Subjekt und Objekt den von Kant in der Kritik der reinen Vermunft mittels des Dings an sich angegriffenen Rationalismus: „Das vernichtende Verdikt Hegels setzt sich jedoch über Kants Kritik des dogmatischen Rationalismus spekulativ hinweg, das rational nicht Auflösbare terminologisch zu bezeichnen. Sein eigenes rationalistisches proton pseudos registriert Hegel an Kant.“361 Der durch Hegel kritisch wiederholte ontologische Gottesbeweis Anselms ${ }^{362}$ zeugt noch einmal mehr von

\footnotetext{
${ }^{360}$ Hegel: Wissenschaft der Logik I, S. 70.

361 Krahl: Konstitution und Klassenkampf, S. 73.

362 Vgl. Anselm von Canterbury: Proslogion/Anrede.
} 
seiner Anlehnung an den Rationalismus. ${ }^{363}$ Hegel säkularisiert jedoch die traditionelle Bedeutung Gottes und geht deshalb die rationalistische Zwei-SubstanzenLehre aus Gründen der eigenen dialektischen Vermittlung dieser beiden ,Substanzen' in sich nicht mit: „War das Hegelsche Absolute Säkularisation der Gottheit, so eben doch deren Säkularisation. “364 Hegel säkularisiert die Gottheit insofern als Idee. Und die säkularisierte Gottidee als absolutes Subjekt Hegels hat Konsequenzen: Das absolute Subjekt, Hegels selbstbewusster absoluter, antagonistisch physisloser Geist, wird durch die dialektische Methode zum logisch wie ontologisch Ersten seiner systematischen Philosophie oder besser: zum Ersten seiner spezifischen Systemphilosophie. 365 Weil Geist damit der wirklichen dialektischen Reflexion enthoben ist und sich in den Dingen nur noch selbst erkennt, werden damit alle Bestimmungen - ja selbst die Bestimmtheit des Objekts! - aus dem hypostasierten, verabsolutierten Subjekt methodisch widerspruchsfrei hervorgebracht. Die Formen des Seienden schlechthin entpuppen sich für Hegel als allein aus den Denkformen entsprungene Negationen des reinen Seins. Das Seiende wird zum den Dingen durchs logisch und ontologisch primäre identische Bewusstsein nur übergestülpten Resultat. Hegels methodische Reflexion des ,absolute[n] Wis$\operatorname{sen}[\mathrm{s}]$ "366 des absoluten Geists wird dadurch zum analytischen Urteil.

Mithilfe des absoluten Wissens und Handelns entlastet Hegel den nichtphysischen Geist in Form einer verabsolutierten adaequatio auch von seiner Differenz zur nichtidentischen Natur, oder: Der selbstbewusste Geist entlastet sich von seiner eigenen Natur wie den anderen heteronomen, materiellen Naturdingen selbst. Natur wird durch die identitätsphilosophische Konsequenz zum identisch Anderen des reinen Geistes. Als absoluter Geist, der sich durch Negationen materialisiert, ist er der Differenz zwischen sich und seinem anderen entledigt. Eine Nichterkannte, unmittelbar transzendente Natur kann in der Folge auch nur eine sich selbst noch nicht bewusste Vernunft sein. Die Vernunft erscheint in der physischen Natur insofern in von sich selbst entfremdeter Gestalt: „Was vernünftig ist, das ist wirklich; und was wirklich ist, das ist vernünftig." ${ }^{\text {"367 }}$ Noch unbestimmte

\footnotetext{
363 Am traditionellen ontologischen Gottesbeweis kritisiert Hegel, dass dieser das Sein Gottes bereits voraussetze, ohne diese Voraussetzung jedoch beweisen zu können: „Der Mangel aber in der Argumentation Anselms, den übrigens Cartesius und Spinoza so wie das Prinzip des unmittelbaren Wissens mit ihr teilen, ist, daß diese Einheit, die als das Vollkommenste oder auch subjektiv als das wahre Wissen ausgesprochen wird, vorausgesetət, d.i. nur als an sich angenommen wird.“ (Hegel: Enzyklopädie der philosophischen Wissenschaften I, \193, S. 349.)

364 Adorno: Negative Dialektik, S. 397.

365 Die absolut-idealistische Systemphilosophie Hegels hat weder mit der späteren positivistischen Systemtheorie Niklas Luhmanns, noch mit der positivistischen Handlungstheorie Talcott Parsons etwas entscheidend gemeinsam. Es sind deshalb zwischen systematischer Philosophie, Systemtheorie und Systemphilosophie spezifische Differenzen, die bei genauerer Betrachtung Unterschiede ums Ganze sind, zu konstatieren. (Vgl. gegen Hegels Philosophie des Systems etwa Luhmann: Soziale Systeme; Parsons: Social Systems and the Evolution of Action Theory.)

366 Hegel: Enzyklopädie der philosophischen Wissenschaften III, S. 31.

${ }^{367}$ Hegel: Grundlinien der Philosophie des Rechts, S. 24.
} 
Natur ist für Hegel wie das „qualitätslose Sein“368 nichts, und „reine[s] Nichts“369 kann es für sich betrachtet genau so wenig geben wie qualitätsloses Sein.

Alles besonders Seiende, alles Besondere, geht für Hegel insofern in der Indifferenz gegen den Unterschied von Besonderem und Besonderheit unter. Über die Sprachlogik vermittelt zieht Hegel durch den bestimmten Zusatz -heit für alles ,Besondere', alles Nichtidentische geschickt in den dialektischen Begriff. Alles unmittelbar Nichtidentische schleift er dadurch im Strudel idealistisch dialektischer Logik rund: „Anstelle des Besonderen schiebt er den allgemeinen Begriff von Besonderung schlechthin, etwa von ,Existenz', in dem es kein Besonderes mehr gibt. Er restauriert die Verfahrensweise des Denkens, welche Kant am älteren Rationalismus als Amphibolie der Reflexionsbegriffe mit Grund tadelt. "370 So bleibt die nichtidentische Natur bei Hegel an das Logische und somit an den selbstbewussten Geist und seine Methode dialektisch absolut rückgebunden. Als Anderes des absoluten Geistes bleibt Natur durch Geist als dessen eigene Negation bestimmt. Die Natur sei nur ihrer äußeren Erscheinung nach unbestimmbar, ihrem Wesen nach von der Vernunft allerdings ununterscheidbar. ${ }^{371}$ In den allgemeinen Naturgesetzen, die darum auch nur Setzungen des absoluten Geistes als entfremdete Entsubstanzialisierung aus sich selbst sein können, drückt sich für Hegel das an sich logische Wesen der Natur aus. Die Gesetze der Natur liegen den Erscheinungen der Natur zugrunde und bestimmen insofern ihr Verhalten, ohne dabei jedoch selbst Erscheinung der Natur zu sein. Als Naturgesetze sind sie deshalb auch nicht sinnlich wahrnehmbar, sondern haben ihrerseits eine logische Existenz, einen noumenalen Charakter. Sie existieren ausschließlich im Denken des gottähnlich die Natur (er-)kennenden und produzierenden absoluten Geistes. Weil die Natur nur als mit ihm identisch als Anderes des rationalen Geistes ist, identifiziert Hegel sie absolut mit Geist, womit an ihr selbst nun auch nichts unmittelbar Nichtidentisches mehr bleibe: „Der absolute Geist erfaßt sich selber das Sein setzend, als selber sein Anderes, die Natur und den endlichen Geist hervorbringend, so daß dies Andere jeden Schein der Selbstständigkeit gegen ihn verliert, vollkommen aufhört, eine Schranke für ihn zu sein, und nur als das Mittel erscheint, durch welches der Geist zum absoluten Fürsichsein, zur absoluten Einheit seines Ansichseins und seines Fürsichseins, seines Begriffs und seiner Wirklichkeit gelangt." 372 So entwickelt sich für Hegel alles Besondere und überhaupt alles irgend Bestimmte erst aus dem logischen Begriff des Allgemeinen, als eine Selbstentäußerung oder Entfremdung des Allgemeinen, durch den absoluten Geist repräsentiert. Alles Besondere, alles Individuierte verkommt damit zum unweigerlichen Resultat der antagonistisch-methodischen Selbstbewegung des dialektischen Be-

\footnotetext{
368 Hegel: Wissenschaft der Logik I, S. 82.

${ }^{369}$ Ebd., S. 83.

370 Adorno: Negative Dialektik, S. 175.

371 Vgl. Hegel: Enzyklopädie der philosophischen Wissenschaften II, S. 13 ff.

372 Hegel: Enzyklopädie der philosophischen Wissenschaften III, S. 31.
} 
griffs. Indem er also alles Nichtsystematische mit sich absolut identifiziert, schafft der Begriff das mit Geist (und damit mit sich selbst, nichtidentische Material) als seinen eigenen Mangel ab: „Die Herleitung des Reellen aus ihm, wenn man es Herleitung nennen will, besteht zunächst wesentlich darin, daß der Begriff in seiner formellen Abstraktion sich als unvollendet zeigt und durch die in ihm selbst gegründete Dialektik zur Realität so übergeht, daß er sie aus sich erzeugt, aber nicht, daß er zu einer fertigen, ihm gegenüber gefundenen Realität wieder zurückfällt und zu etwas, das sich als das Unwesentliche der Erscheinung kundgetan, seine Zuflucht nimmt, weil er, nachdem er sich um ein Besseres umgesehn, doch dergleichen nicht gefunden habe." ${ }^{\text {"373 }}$ Die tatsächlich seiende Natur kann für Hegel insofern auch nur ein Abhub des Geistes sein und das Besondere demnach nur ein Abfall des Begriffs der Besonderheit: ein Resultat dialektischer Sprachlogik, die damit erst zur Wirklichkeit konstruiert wird.

Durch das im Resultat analytische Urteil gleicht Hegels System einem supponierten Kreislauf. Dieser bereits methodisch vorgefertigte, alles Auswendige identifizierende Kreislauf, mit dem Hegel auf das Material losgeht, ist ein synthetisierender Sog des Bewusstseins, in dem der Geist durch die geschichtliche Bewegung hindurch sich als absoluter negierend wieder zu sich selbst komme. Für Hegel wird die wissenschaftliche „Fortbewegung (...) zu einem Kreis.“" 374 Bloch beschreibt die Hegelsche Dialektik deshalb als ,,vor allem (...) Theorie der Bewegung ““375 seiende. Doch die affizierende Dynamik von Hegels synthetischem Denken erinnert mehr noch an eine festgeklopfte Statik als an Dynamik. Denn das dialektische Denken des Inhalts durch Methode hat ein absolut festes, starres Fundament in der sich realisierenden „Idee“ als „Einheit des Begriffs und der Objektivität“"376. Der Strudel des Hegelschen Denkens ist deshalb nicht mit einer wirklichen Dynamik des Denkens von autonomen Gegenständen zu verwechseln. Die absolute Vermittlung Hegels, die dynamische Bewegung von synthetischer Identität der Identität und Nichtidentität, täuscht den dynamischen Prozess des Denkens deshalb auch bloß vor. Im Kern nämlich enthält die Dialektik Hegels extrem starre, bereits vorgefertigte Begriffe, die in Form einer allgemeinen Idee dialektisch immer nur durch das Material hindurch, durch den Entfremdungsprozess des absoluten Geistes hindurch, zu sich selbst kommen. So ist die dynamische Prozesshaftigkeit Hegels eine Supposition und Deduktion aus dem hypostasierten allgemeinen und antagonistischen Begriff, und die Bewegung des Systems gleicht einer Bewegung unter einer starren Glocke, über deren Richtung immer bereits entschieden war. Denn zu Anfang der prozessualen dialektischen Bewegung steht für Hegel implizit auch immer schon fest, was sich aus dem allgemeinen Begriff der absoluten Idee, aus dem absoluten Geist, schicksalsgleich realisiert/synthe-

\footnotetext{
${ }^{373}$ Hegel: Wissenschaft der Logik II, S. 264.

${ }^{374}$ Hegel: Wissenschaft der Logik I, S. 71. (Herv. i. Original)

375 Bloch: Subjekt-Objekt, S. 65.

376 Hegel: Wissenschaft der Logik II, S. 464.
} 
tisiert/entsubstantialisiert: „Soll das System tatsächlich geschlossen sein, nichts außerhalb seines Bannkreises dulden, so wird es, sei es noch so dynamisch konzipiert, als positive Unendlichkeit endlich, statisch." 377 Das ist der Inbegriff der idealistischen Dialektik als Methode überhaupt, die ein Unmittelbares nur als Unmittelbarkeit, nicht aber als eine Bestimmtheit vor Subjekt, ernst nimmt. Dasselbe logifizierende Verfahren wendet Hegel nun auch auf die Geschichte an. Auch dort tritt die säkularisierte Gottesidee als Antagonismus entscheidend zutage.

\subsubsection{Logik und Geschichte bei Hegel. Idealistische Widerspiegelungstheorie oder Geschichte als Methode}

Ein (philosophisches) System tangiert schon der Bedeutung nach jeden Bereich der Wissenschaft durch die immanente, exerzierte Stringenz, durch die die Korrelate zugerichtet werden. Hegel verrät sein System nicht, die systematische Denkbewegung der Identität von Identität und Nichtidentität beschränkt sich bei Hegel insofern auch nicht auf die dialektische (Sprach-)Logik. Seine systematische Methode reicht deshalb weit in den Bereich der Gesellschaftswissenschaften hinein. Über den Hegelschen Begriff der Geschichte lässt sich dabei besonders gut nachvollziehen, wie sein systematischer, absoluter Idealismus mit allem Gesellschaftlichen, Raumzeitlichen, geschichtlich in der Welt Seienden logisch verfährt. Dass Geschichtsphilosophie und Gesellschaftstheorie als Momente in sich dialektisch vermittelt seien, macht Hegel in seinen Grundlinien der Philosophie des Rechts deutlich. Seine Darstellung des Staates geht hier darum nicht grundlos in das Kapitel ,Die Weltgeschichte“ über. ${ }^{378}$

Auch in der Geschichtsphilosophie lässt sich seine zunächst selbstentfremdende Entsubstantialisierung des antagonistischen Weltgeists in die Welt feststellen. Die entsprechende Frage nach dem Zweck des Weltgeists führt Hegel in den Vorlesungen über die Philosophie der Geschichte aus: „Aber auch, indem wir die Geschichte als diese Schlachtbank betrachten, auf welcher das Glück der Völker, die Weisheit der Staaten und die Tugend der Individuen zum Opfer gebracht worden, so entsteht dem Gedanken notwendig die Frage, wem, welchem Endzwecke diese ungeheuersten Opfer gebracht worden sind. Von hier aus geht gewöhnlich die Frage nach dem, was wir zum allgemeinen Anfange unserer Betrachtung gemacht; von demselben aus haben wir die Begebenheiten, die uns jenes Gemälde für die trübe Empfindung und für die darüber sinnende Reflexion darbieten, sogleich als das Feld bestimmt, in welchem wir nur die Mittel sehen wollen für das, was wir behaupten, daß es die substantielle Bestimmung, der absolute Endzweck oder, was dasselbe ist, daß es das wahrhafte Resultat der Weltgeschichte sei. “379 Die Systematik Hegels objektiviert die Geschichte insofern zur reinen Widerspiegelung der

\footnotetext{
377 Adorno: Negative Dialektik, S. 37.

378 Hegel: Grundlinien der Philosophie des Rechts, S. 503.

379 Hegel: Vorlesungen über die Philosophie der Geschichte, S. 35.
} 
Zwecke des absoluten Geistes. Die in ihr handelnden, lebendigen Subjekte werden zur Kontemplation gezwungen. ${ }^{380}$ Sie werden dadurch zu praktischen Marionetten des absoluten Weltgeists, der sich durch sie und ihre Praxis in die raumzeitliche Welt entlässt - unter anderem manifestiere er sich modellhaft in Napoleon, jener „Weltseele zu Pferde“ 381.

Es ist diese Hegelsche Konzeption der Idee des Weltgeists, die ihn als allgemeines und körperloses Subjekt der systematischen geschichtlichen Bewegung herausstellt. Durch die selbstentfremdende Entsubstantialisierung hindurch erreiche er sein Telos, und der Weltgeist sei deshalb Voraussetzung wie Resultat der weltgeschichtlichen Bewegung: „Die Weltgeschichte fängt mit ihrem allgemeinen Zwecke, daß der Begriff des Geistes befriedigt werde, nur an sich an, d.h. als Natur; er ist der innere, der innerste bewußtlose Trieb, und das ganze Geschäft der Weltgeschichte ist, wie schon überhaupt erinnert, die Arbeit, ihn zum Bewußtsein zu bringen. "382 Durch die damit schicksalhafte Vorherbestimmtheit der Weltgeschichte ${ }^{383}$ deutet Hegel jedes dem nichtphysischen Geist heteronome Moment, alles, was als negativ-nichtidentisches in die Statik des geschichtlichen Systems nicht passt, zum schlechthin Positiven um. Die raumzeitliche Kontingenz der

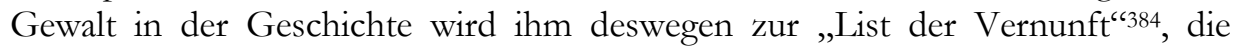
spontane Freiheit der Subjekte, die diese listige Gewalt ausüben, wird dadurch zum bloßen Mittel des sich in ihnen negierenden Weltgeists zu seinem Zwecke: die praktisch handelnden „Individuen“ seien immer bloß „Mittel und Werkzeuge eines Höheren und weiteren" 385 . Durch das funktionelle, dynamische Handeln der zu Marionetten bestimmten Individuen hindurch realisiere der Weltgeist erst seine präformierten, allgemeinen geschichtlichen und gesellschaftlichen Zwecke. Er vermittele sich mit seinen Zwecken durch die einzelnen, lebendigen Subjekte der Praxis hindurch: „Einfach und abstrakt ist es die Tätigkeit der Subjekte, in welchen die Vernunft als ihr an sich seiendes substantielles Wesen vorhanden, aber ihr zunächst noch dunkler, in ihnen verborgener Grund ist.“"386 Ausschließlich der Weltgeist, die „göttliche Idee“"387 als logisch wie ontologisch Erstes gedacht, weiß darum selbstbewusst, wohin die teleologisch konzipierte Reise der Weltgeschichte überhaupt geht - sein Mittel ist, verdinglicht allemal, nur funktionell zu diesem

\footnotetext{
380 Als ästhetisches, recht parodistisches Modell für die Kontemplation von Subjekten gilt das Theaterstück Warten auf Godot von Samuel Beckett. (Beckett: Warten auf Godot.)

381 Vgl. Hegel: Brief an F.I. Niethammer vom 13. Oktober 1806, S. 119.

382 Hegel: Vorlesungen über die Philosophie der Geschichte, S. 39 f.

383 „Die Weltgeschichte zeigt nur, wie der Geist allmählich zum Bewußtsein und zum Wollen der Wahrheit kommt; es dämmert in ihm, er findet Hauptpunkte, am Ende gelangt er zum vollen Bewußtsein.“ (Ebd., S. 74). Vgl. auch: „Die Weltgeschichte stellt nun den Stufengang der Entwicklung des Prinzips, dessen Gehalt das Bewußtsein der Freiheit ist, dar.“ (Ebd., S. 77.)

384 Ebd., S. 49.

385 Ebd., S. 40.

386 Ebd., S. 54.

387 Ebd., S. 53.
} 
Zweck: „Aus dem Prinzip der Freiheit des Geistes konstruiert Hegel auch die Geschichte der Welt im Hinblick auf ein erfülltes Ende.“"388

Die Zwecke des empirischen Subjekts sind demnach allein funktionale Zwecke eines ihm vorgeordnet Allgemeinen in Form der Idee des Weltgeists. Die einzelnen Subjekte sind damit verdinglicht, ohne jede wirkliche Aussicht auf selbstbewusste Emanzipation; sie bleiben Mittel der Realisation der Zwecke des Weltgeistes: der Vernunft in der Geschichte. Alles von Hegel Aufgebotene dient insoweit dem methodisch präsupponierten Beweis, „daß es also auch in der Weltgeschichte vernünftig zugegangen sei. “389 Ein letzter Ort von Freiheit gegen diese allgemeinen Zwecke des Weltgeists sei allein das bewusstlose, geistlose Handeln einzelner physischer Subjekte. Diese ,Querulanten“ werden jedoch zur „faule(n) Existenz“ ${ }^{\prime 2} 390$ erklärt, die keine „Wirklichkeit“391 haben können. Auch sie sind dadurch ebenso verdinglicht und können deshalb keine wirklich widerständigen Subjekte sein. In ihrem autozweckbezogenen Vollzug der Vernunft ist die Weltgeschichte vom endlichen Subjekt insofern nicht freiheitlich handelnd zu verändern.

In ihrem Fortgang sei die Weltgeschichte jedoch als Notwendigkeit zu erkennen. Das endliche selbstbewusste Subjekt habe dabei der Realisation der allgemeinen Weltgeschichte durch die determinierende Freiheit des ideellen Weltgeistes kontemplativ, funktionell zum Mittel der Weltgeschichte verdinglicht, zuzusehen. Die Weltgeschichte erweist sich für Hegel als „,der Fortschritt im Bewußtsein der

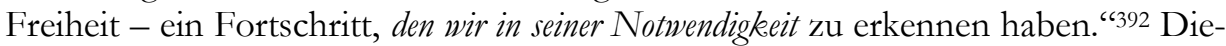
ses Bewusstsein der Freiheit setze das Sein als sich negierendes aus sich heraus und im geschichtlichen Sein spiegele sich das autonome Bewusstsein des Weltgeists als der säkularisierten göttlichen Idee wider. Diese autonome Freiheit des nichtphysischen, ideellen Weltgeists als Zwecke realisierendes Subjekt bei Hegel ist jedoch nicht mit der Freiheit des Einzelnen, lebendigen und selbstbewussten Subjekts zu verwechseln. Jedes einzelne Subjekt verbleibt als lediglich verdinglichter Erfüllungsgehilfe des Weltgeists in der Geschichte. Die physischen Subjekte leiden in der durch den Weltgeist vorherbestimmten allgemeinen Geschichte, indem sie ihre eigenen, subjektiven Zwecke als herabgesetzte Mittel zum Zwecke der säkularisierten göttlichen Idee periodisch entweder gar nicht oder bloß funktional erfüllt finden.

Allerdings sieht Hegel den Antagonismus des Allgemeinen gegenüber dem Besonderen, wenn er schreibt: „Aber auch, indem wir die Geschichte als diese Schlachtbank betrachten, auf welcher das Glück der Völker, die Weisheit der Staaten und die Tugend der Individuen zum Opfer gebracht worden, so entsteht dem Gedanken notwendig die Frage, wem, welchem Endzwecke diese ungeheuersten

\footnotetext{
388 Löwith: Von Hegel zu Nietzsche, S. 45.

${ }^{389}$ Hegel: Vorlesungen über die Philosophie der Geschichte, S. 20.

390 Ebd., S. 53.

${ }^{391}$ Ebd.

392 Ebd., S. 32. (Herv. von mir)
} 
Opfer gebracht worden sind. Von hier aus geht gewöhnlich die Frage nach dem, was wir zum allgemeinen Anfange unserer Betrachtung gemacht; von demselben aus haben wir die Begebenheiten, die uns jenes Gemälde für die trübe Empfindung und für die darüber sinnende Reflexion darbieten, sogleich als das Feld bestimmt, in welchem wir nur die Mittel sehen wollen für das, was wir behaupten, daß es die substantielle Bestimmung, der absolute Endzweck oder, was dasselbe ist, daß es das wahrhafte Resultat der Weltgeschichte sei.““393 Dieser Antagonismus ist Hegel in der Konstellation, insofern es dem eigenen teleologischen terminus ad quem der antagonistischen Konzeption der Weltgeschichte geschuldet ist, nichts wirklich Unangenehmes. Er ist das methodisch-dialektisch bestimmte Ziel seiner idealistischen Philosophie, die die logische Selbstentwicklung der Realität nur begreifend darstellen möchte. Von daher ist der Antagonismus nicht einmal ein zähneknirschend akzeptiertes Nebenprodukt seines Systems, sondern dessen unumstößlicher Teil: „Die Weltgeschichte ist nicht der Boden des Glücks. Die Perioden des Glücks sind leere Blätter in ihr.“"394

Für Hegel geht nun auch die Geschichte, wie alles positiv Seiende, aus der logischen Bewegung der Negation der Negation hervor. Alles Sein, alle raumzeitliche Welt, jede Gesellschaftsform etc. sei das affirmative Resultat der negativen Bewegung des zum absoluten und allgemeinen stilisierten Geistes als der sich entsubstantialisierenden, dem empirischen Subjekt antagonistischen Idee. Sie komme durch diese Funktionalisierung des raumzeitlich Seienden - in dem Fall durch die einzelnen, nach den Zwecken des Weltgeists handelnden Subjekte - zu sich selbst. Dieser idealistische Konstruktivismus der erscheinenden gesellschaftlichen Welt durchs physische Subjekt hindurch, der noch jedes irgend autonome Material als völlig uneigenständiges in den sich entsubstantialisierenden Geist zieht, erklärt jedoch wie jede Identitätsphilosophie des Idealismus nicht, was denn die Materie als an sich seiende für sich selbst sei, weil sie nicht autonom für sich sein -, oder besser ausgedrückt: bleiben darf.

Hegel konzipiert trotz seiner beständigen Negationen jeder affirmativen Position im Prozess der Synthetisierung allerdings keine negative, kritische Dialektik. Immer wieder erschafft er mit der momentanen Negation der affirmativen Position nur die nächsthöhere positive Synthese der Subjekt-Objekt-Bewegung, die dann alles und jedes Daseiende mit sich, mit Begriff als seines Ursprungs, affirmiert: „Das ist Hegels dialektische creatio ex nihilo. Welt entsteht aus der Selbstverneinung des Negativen und soll in ihr ,aufgehen“."3955 Diese Hegelsche Geschichtsphilosophie muss, frei nach Marx’ Kritik des Hegelschen Staatsrechts ${ }^{396}$, entsprechend kritisiert werden: nicht die Geschichtsphilosophie, sondern allein die Logik des eigenen Systems sei ihr wahres Interesse: „Nicht die Logik der Sache,

\footnotetext{
393 Ebd., S. 35.

394 Ebd., S. 42.

395 Haag, Der Fortschritt in der Philosophie, S. 98.

396 Vgl. Marx: Kritik des Hegelschen Staatsrechts, S. 216.
} 
sondern die Sache der Logik ist das philosophische Moment.“"397 Das Denken Hegels ist insofern eine Form des positivistischen Immanenzdenkens. ${ }^{398}$

\subsubsection{Adornos Rettung des restontologisch Unmittelbaren}

„Hegels vermessen idealistische Präsupposition, das Subjekt könne darum dem Objekt, der Sache selbst, rein, vorbehaltlos sich überlassen, weil jene Sache im Prozeß als das sich enthüllte, was sie an sich schon sei, Subjekt, notiert wider den Idealismus ein Wahres über die denkende Verhaltensweise des Subjekts: es muß wirklich dem Objekt ,zusehen', weil es das Objekt nicht schafft, und die Maxime von Erkenntnis ist, dem beizustehen." 399

„Mag auch die Hegelsche Logik gleich der Kantischen am transzendentalen Subjekt ,festgemacht', mag sie vollkommener Idealismus sein, so weist sie doch, wie nach Goethes dialektischem Diktum alles Vollkommene, über sich hinaus." 400

Adornos negative Dialektik denkt die Vermittlung von selbstbewusstem Subjekt und Objekt insbesondere mit und gegen Hegel. Sie eröffnet dadurch eine moderne, emanzipative Perspektive auf die Überwindung der subjektivistischen Tautologie Hegels, die sich immanent gar nicht wirklich konsistent kritisieren lässt. Es ist die an Hegels Dialektik gewonnene Perspektive auf eine unsubsumierbare Negativität des das einzelne Subjekt der Praxis unterdrückenden Allgemeinen, das der Gesellschaftstheorie erst eine ganz neue Möglichkeit von Gesellschaftskritik eröffnet, die nicht aus einer Hypostasierung des Subjekts heraus über den gesellschaftlichen Gegenstand als tautologisch supponierten urteilt. ${ }^{401}$ Die begriffslogische Supposition Hegels als eines sich im Material entsubstantialisierenden absoluten Geists, der dem Materiellen seinen Inhalt überstülpt, wird von Adorno deshalb entscheidend kritisiert. Er kritisiert dabei vor allem die positive Synthese von

\footnotetext{
397 Ebd.

398 Die Immanenzphilosophie ist die philosophische Richtung, „die Wirklichkeit und Bewußtsein gleichsetzte, in Berkeley, Hume u.a. ihre Vorläufer sah und sich als antimetaphysisch und positivistisch verstand." (Halder: Philosophisches Wörterbuch, S. 155.) Auch Richard Avenarius und Ernst Mach könnten sich ,in manchen Zügen“ (ebd.) darunter subsumieren lassen.

399 Adorno: Negative Dialektik, S. 189.

400 Adorno: Zur Metakritik der Erkenntnistheorie, S. 12.

401 Adornos negativ dialektische Antwort auf den absoluten Idealismus, seine Ideologie und Verdinglichung des einzelnen Subjekts, das beim Vollzug der eigenen Geschichte zum Zusehen verdammt ist, nimmt dabei Bezug auf die Marxsche Hegelkritik. (Vgl. Schweppenhäuser: Theodor W. Adorno zur Einführung, S. 29 ff.) Auf jene sich gegen die idealistischen Suppositionen richtende Hegelkritik von Marx kann ich hier leider nicht näher eingehen. Ein Blick aber auf die theoretischen Überschneidungen von Adorno und Marx lohnt sich - vor allem was die Form und den Inhalt der Kritik der Ideologie Hegels angeht. Insbesondere die Kritik an der Hegelschen Rechtsphilosophie von Adorno weist Parallelen zu Marx' Kritik auf. (Vgl. dazu ebd., S. 32 ff.)
} 
Hegels Negation der Negation, die sich in der Geschichtsphilosophie als idealistische Widerspiegelungstheorie des gesellschaftlichen Antagonismus geltend macht (vgl. 2.4.2). Dabei sieht er in der nominalistischen Supposition des antagonistisch Allgemeinen, besser der Allgemeinheit, trotzdem noch ein gewisses progressives Moment. Er übernimmt deshalb die Hegelsche Präformation des einzelnen Subjekts, die Verdinglichung des endlichen Subjekts durchs gesellschaftliche Allgemeine (vgl. ebd.). Dieser Gedanke Hegels sei dem „Zeitalter subjektiver Ohnmacht" ${ }^{402}$ adäquat. Denn die idealistische Vormachtstellung des Allgemeinen beschreibe bereits ganz richtig, wie das Allgemeine in der modernen Gesellschaft das Besondere und Einzelne unterdrücke. Deshalb gebe der absolute Idealismus Hegels ein adäquat reelles, präzises Bild von Gesellschaft und Subjekt wider. Diesen Gedanken aus Hegels dialektischer Weltgeisttheorie variiert Adorno für seine Gesellschaftstheorie: „Der Mensch als fessellos Produzierender erscheint der bürgerlichen Gesellschaft als autonom, Erbe des göttlichen Gesetzgebers, virtuell allmächtig. Das Einzelindividuum aber, in dieser Gesellschaft in Wahrheit bloßer Agent des gesellschaftlichen Produktionsprozesses, dessen eigene Bedürfnisse von diesem Prozeß gleichsam nur mitgeschleift werden, gilt darum zugleich auch als ganz ohnmächtig und nichtig." "403 Adorno hält damit an der Hegelschen realistischen, analytischen Darstellung des Weltlaufs als dem einzelnen Subjekt Heteronomen fest: „Solange also Hegel einfach den Weltlauf konstruiert, ist er, indem er den Vorrang des Allgemeinen vor dem Besonderen konstruiert, ja, lassen Sie's mich ganz vulgär ausdrücken: realistisch; so geht's wirklich in der Welt zu.“"404

Hegels Realismus überzeugt Adorno jedoch nicht, jene unterdrückende und das Subjekt verdinglichende Ideologie einfach hinzunehmen, geschweige denn sie zu übernehmen. ${ }^{405}$ Das adäquat realistische Moment des objektiven Idealismus reflektiert er kritisch, auch wenn für ihn das dialektische Denken unabkömmlich wird, um die gesellschaftliche Realität als eine das Subjekt antagonistisch verdinglichende adäquat darzustellen. Allein dialektisches Denken besitze für Adorno die entsprechende „Bestimmtheit“" ${ }^{\text {"406, }}$, erkenntnistheoretische und gesellschaftstheoretische Dinge adäquat benennen zu können. Neben dieser Fähigkeit, Seiendes analytisch beschreiben zu können, trage es nun auch noch andere, entscheidend emanzipative Momente in sich; namentlich dasjenige, sich aus innersten eigenen Voraussetzungen negativ gegen sich selbst und gegen die eigenen Affirmationen stellen zu können: „Mit konsequenzlogischen Mitteln trachtet sie [die Negative Dialektik, B.E.B.], anstelle des Einheitsprinzips und der Allherrschaft des übergeordneten Begriffs [Hegels, B.E.B.] die Idee dessen zu rücken, was außerhalb des

\footnotetext{
402 Adorno: Zu Subjekt und Objekt, S. 750.

403 Adorno: Drei Studien zu Hegel, S. 290.

404 Adorno: Zur Lehre von der Geschichte und von der Freiheit, S. 65.

405Vgl. Adorno: Drei Studien zu Hegel, S. 266 ff.

406 Adorno: Negative Dialektik, S. 9.
} 
Banns solcher Einheit wäre."407 Die negative Dialektik ist für Adorno deswegen, weil sie reflektierend ihrer eigenen Voraussetzungen gewahr wird, eine konsequent (selbst-)reflektierte Dialektik. Hegels dialektischer Absolutismus wird mit ihr kritisch gewendet, gerade weil das Bewusstsein ohne positiv dialektische, idealistische Begrenzung auch gegen sich selbst kritisch umschlägt (vgl. auch 2.3.1). Ex negativo soll mit der negativen Dialektik die gesellschaftliche, antagonistische Allgemeinheit, die die physischen Subjekte zu kontemplativen Funktionsträgern und verdinglichten Befehlsempfängern herabdrückt, gegen den objektiven Idealismus und die idealistische Widerspiegelung des Bewusstseins des Weltgeists in der Welt gewendet werden: „Die Kraft des Bewußtseins reicht an seinen eigenen Trug heran. “408 Die unterdrückende Allgemeinheit soll somit zur falschen, zu kritisierenden antagonistischen Allgemeinheit werden, weil sie das Subjekt heteronom bestimme - und keine notwendig zwingende Allgemeinheit, die wie bei Hegel einen Fortschritt im Bewusstsein von Freiheit bewirke (vgl. 2.4.2).

Adorno kritisiert an Hegels absolutem (Welt-)Geist deshalb nicht, dass dieser den Antagonismus der modernen gesellschaftlichen Herrschaft dialektisch adäquat, realistisch, darstellt - sondern, dass Hegel den konsequenten Umschlag der Dialektik gegen sich selbst und ihre autonomen Setzungen wie die des absoluten Geists einfach unterlasse, er ihn einfach abschneide. Dadurch bleibe beim objektiven Idealismus der realistische Antagonismus von Subjekt und Objekt jedoch bestehen. Hegels idealistische Dialektik bleibe deshalb, weil er die gesellschaftliche Realität mit ihr verdinglicht, eine verdinglichte Dialektik. Sie missachte ihre eigenen negativen Konsequenzen, die in ihr jedoch bereits angelegt sind. Zwar taste sich Hegel bis dicht an diesen selbstreflexiven Umschlag der eigenen Dialektik heran, seine idealistische Philosophie bleibe jedoch weiterhin vom Mangel an subjektiver, selbstreflexiver Kritik geprägt: „Die Hegelsche Synthesis ist durchweg Einsicht in die Insuffizienz jener Bewegung, gleichsam in ihre Gestehungskosten. Er gelangt dicht bis ans Bewußtsein vom negativen Wesen der von ihm ausgeführten dialektischen Logik so früh wie in der Einleitung zur Phänomenologie.“409

Gesellschaftstheoretisch hat diese Hegelsche Selbstzensur durch den idealistischen Abbruch der Dialektik Folgen: Die Inkonsequenz der Dialektik des Allgemeinen führt beispielsweise dazu, dass Hegel den bürgerlichen Staat gänzlich unkritisch als den einzigen Garanten der Bedingung der materiellen ,Fürsorge' und der moralischen ,Persönlichkeitsentfaltung' der individuellen Subjekte sieht. Der Staat wird ihm deshalb zum notwendigen Moment des sich durchsetzenden absoluten Weltgeists, und die funktionalisierten Subjekte der Geschichte affirmieren ihn als Garanten ihres sittlichen Zusammenhangs. Sie sehen im bürgerlichen Staat die teleologische Verwirklichung der allgemeinen Freiheit als Idee. ${ }^{410}$ Diese teleo-

\footnotetext{
407 Ebd., S. 10.

408 Ebd., S. 152.

${ }^{409}$ Ebd., S. 159.

${ }^{410}$ Vgl. Hegel: Grundlinien der Philosophie des Rechts, S. 398.
} 
logisch konzipierte Ideologie Hegels, die die Affirmation des bürgerlichen Staates philosophisch, idealistisch-dialektisch betreibt, kritisiert Adorno mit seiner negativen Dialektik vehement. Das macht er schon aus logischen Gründen, um damit einen normativen Maßstab der Kritik gesellschaftstheoretisch zu begründen. Hegel kann diesen kritischen Maßstab durch seine Funktionalisierung, Kontemplation und Verdinglichung nicht haben (vgl. 2.4.1; 2.4.2).

Adornos materialistische Antwort auf die idealistische Supposition, den Deduktionismus und die Hegelsche Affirmation des Allgemeinen, wird als eine dialektisch vermittelte Rückbindung der als Idee hypostasierten Weltgeschichte an das vernünftige, lebendige Subjekt ausgeführt. Abgezielt wird auf das dem Bewusstsein Verschiedene und notwendig verschieden bleiben Müssende. Dieses Nichtidentische bleibt ein notwendiges und allgemeines Denkmoment, das sich in einer konsequent ausgeführten Dialektik zeigt. Es ist ein materielles Moment der Transzendenz, das nach Peter Bulthaup nicht mit Selbstbewusstsein oder Denken identifiziert werden kann: „Damit Denken sei, bedarf es seiner Beziehung auf ein von ihm Unterschiedenes, das, damit es zu denken sei, dem Denken doch adäquat sein muß.“411 Das verweist auf das notwendig Unmittelbare genauso wie auf die notwendige Identität des Seienden mit Denken im Erkenntnisprozess. Folglich kann es nur eine genuine dialektische Vermittlung von Subjekt und Objekt geben, wenn Unmittelbares, Substantielles, ein allgemein erst denkvermittelndes Etwas vorausgesetzt ist. Dieses negative, nichtidentische Moment kann insofern nicht gleich im logisch-dialektischen Wortwitz der Hegelschen Unmittelbarkeit untergehen (vgl. dazu 2.4.1). Ohne das unmittelbare Etwas kann die dialektische „Kommunikation des Unterschiedenen“412, die Kommunikation von selbstbewusstem Subjekt und nichtidentischem Objekt, gar nicht erst stattfinden. Die Kommunikation des Subjekts wäre als verabsolutiert gedachte keine Kommunikation, weil kein anderes selbständiges, intelligibles nichtidentisches Gegenüber mehr ist, mit dem es seiner selbst bewusst überhaupt kommunizieren könnte. Das kommunizierende autonome Subjekt fände also kein transzendentes, dialektisches Korrelat als Anderes der Vermittlung, das nicht Hegelianisch tautologisch es selbst als selbstbewusstes Subjekt im Spiegel sei. In allen Bestimmungen des Materials würde das Subjekt nur sich selbst und die dem Material übergestülpten Bestimmungen als im Material gespiegelte intersubjektive Kommunikation finden. Ohne das zu bestimmende, ohne das unmittelbare und in sich rational zu erkennende ontologische Etwas als autonomes, würde die Kommunikation deshalb auch bloß tautologisch bei sich bleiben. Eine wahre Erkenntnis der Dinge könnte es demnach nicht geben. Das kommunizierende Subjekt würde insofern in lediglichem ,Anschmiegen' seines Denkens an sich selbst verharren und nur noch und ewig um sich selbst rotieren was wiederum dem analytischen Urteil Hegels gliche. Anders als noch der Kantische transzendentale Idealismus erkennt der objektive Idealismus Hegels deshalb

411 Bulthaup: Möglichkeiten und Grenzen philosophischer Naturerkenntnis, S. 150.

412 Adorno: Zu Subjekt und Objekt, S. 743. 
auch keinen transzendenten Gegenstand der Wirklichkeit mehr an: „Ohne Beziehung auf ein dem Denken transzendentes Objekt wäre dieses Denken ein Denken von Nichts, also kein Denken, und nicht einmal ein Bewußtsein seiner selbst wäre möglich. Damit ein seiner selbst gewisses Denken möglich sei, muß dies Denken eine Beziehung auf mögliche Gegenstände der Erfahrung haben." ${ }^{413}$ Für Adorno jedoch bleibt, um diese Inkonsequenz zu vermeiden, „keine Vermittlung ohne das Etwas. In Unmittelbarkeit liegt nicht ebenso deren Vermitteltsein wie in der Vermittlung ein Unmittelbares, welches vermittelt würde. Den Unterschied hat Hegel vernachlässigt.““414

Warum kann Adorno jedoch überaupt davon ausgehen, dass dieses Unmittelbare nicht doch wieder nur ein, wie Hegel es gegen Kants Ding an sich formuliert, „Von allem Inhalt abgeschieden[er] Schatten“415 ist? Mit der bis an die Grenze des Subjekts kritisch herangeführten und mittels der Reflexion über es hinaus durchgeführten negativen Subjekt-Objekt-Dialektik, die die transzendente Autonomie des Objekts als anderes Extrem der Vermittlung nicht nur ernst nimmt, sondern auch als notwendiges Moment der Vermittlung bestimmt, gibt Adorno auf diese Frage eine kritische Antwort. Die Vermittlung beider Extreme als Momente in sich und durch sich hindurch soll demnach auch kein versuchter Mittel- oder Sonderweg zwischen Nominalismus und Realismus sein. Die Vermittlung von selbstbewusstem Subjekt und Objekt in sich und durch sich hindurch ziehe das Subjekt zudem ohne jede supponierte Sonderrolle in die negative Dialektik dieser beiden Momente hinein. So führe erst die ernstgemeinte konsequente Dialektik als Negative zum besagten selbstkritischen, nichtidentischen Vorrang des Objekts: durch die Vermittlung beider Momente in sich, ohne dabei das eine im anderen, ohne das Objekt in Subjekt, zu absorbieren. Diese genuine Vermittlung in sich und durch sich hindurch, ohne die Momente absolut miteinander identisch werden zu lassen, sei eine genuine Dialektik wider jede Ideologie, eine Dialektik, die das Transzendente erkenntnistheoretisch zuallererst einmal ernst nimmt. Erst so könne die Ideologie des subjektivistischen Konstruktivismus durchs verabsolutierte Identitätsprinzips vermieden werden: „Aus Subjekt, gleichgültig, wie es bestimmt werde, läßt ein Seiendes nicht sich eskamotieren.“416

Indem Adorno die bisherige Erkenntnistheorie reflektiert, insbesondere die Hegelsche idealistische Dialektik, setzt er sich also ex negativo kritisch mit der inhaltlichen Wahrheit der Vermittlung von Subjekt und Objekt auseinander: „Durchgeführte Kritik an der Identität tastet nach der Präponderanz des Objekts." ${ }^{417}$ Die Erkenntnis von der Präponderanz des Objekts durch die Kritik an

\footnotetext{
${ }^{413}$ Bulthaup: Möglichkeiten und Grenzen philosophischer Naturerkenntnis, in: ders., Das Gesetz der Befreiung, S. 149.

414 Adorno: Negative Dialektik, S. 173.

415 Hegel: Wissenschaft der Logik I, S. 41.

416 Adorno: Zu Subjekt und Objekt, S. 747.

417 Theodor W. Adorno, Negative Dialektik, a.a.O., S. 184.
} 
der identitätsphilosophischen Methode drücke sich ihm im „Vorrang des Objekts" 418 aus. Jener Vorrang bleibe in der konsequenten erkenntnistheoretischen Reflexion als negativer, ungewollter Rest wider die traditionellen, positivistischen Suppositionen der Philosophiegeschichte gültig. ${ }^{419}$ Auch hinsichtlich sinnlicher Erfahrung bleibe ein solcher Rest bestehen. Im Prozess der genuinen dialektischen Vermittlung von Subjekt und Objekt nimmt Adorno darum das nichtidentische Unmittelbare in Form einer transzendenten, primären Erfahrung ${ }^{420}$ des selbstbewussten Subjekts ernst. Es gebe also eine erste subjektive Erfahrung von nichtidentisch Heteronomem: „Ich möchte nämlich nicht leugnen, daß es so etwas gibt wie solche primären Erfahrungen. “421 Diese erste Erfahrung von Nichtidentischem sei jedoch nicht gleich eine unmittelbar wahre Erkenntnis des Objekts. Es könne daraus keine ontologische Aussage im Stile einer unreflektierten intentio recta resultieren. Die primäre Erfahrung sei deshalb auch bloß der erste Kontakt des selbstbewussten, empirischen Subjekts mit Nichtidentischem. Sie sei eine „ursprüngliche Erfahrung“422 des lebendigen Subjekts von heteronomen, äußeren Dingen, die auf das endliche lebendige Subjekt als Naturwesen unmittelbar und heteronom einwirken. Die primäre Erfahrung sei dabei so wenig als Erstes wie als Letztes bestimmt. Sie sei die Vermittlung von subjektiven und objektiven Momenten in sich, also immer dialektisch ,in sich Vermitteltes“423: „Sie kann ebensowenig ohne das Moment des Subjekts wie ohne das diesem entgegenstehende Moment gedacht werden, die ineinander sich verschränken. “424 Die primäre Erfahrung des Fremden, Nichtidentischen, ist demnach also eine individuelle Erfahrung von unmittelbar heteronomen Dingen. Das empirische Subjekt besitze überhaupt erst kraft seines individuellen Bewusstseins die besondere Fähigkeit, ein reflexives Subjekt zu sein: „Zum Subjekt wird das Individuum, insofern es kraft seines individuellen Bewußtseins sich objektiviert, in der Einheit seiner selbst wie in der seiner Erfahrungen. “" ${ }^{\circ 25}$ Weil die erfahrene Faktizität auf keine unmittelbar

\footnotetext{
418 Ebd., S. 187.

${ }^{419}$ Vgl. Karl Heinz Haag, Der Fortschritt, a.a.O., S. 9 ff.

${ }^{420}$ Vgl. zur primären Erfahrung Adorno: Philosophische Terminologie, Bd. 1, S. 85.

421 Ebd.

422 Ebd., S. 85 f.

${ }^{423}$ Ebd., S. 85.

${ }^{424}$ Ebd.

425 Adorno, Negative Dialektik, S. 56. Für Hegel ist eine primäre Erfahrung ohne jede notwendige Vermittlung des Bewusstseins, der subjektiven Kategorien, ,sinnliche Gewißheit“. (Hegel: Phänomenologie des Geistes, S. 82.) Auf diesem Bewusstseinsstand kann es für das Subjekt keinen selbstbewussten Begriff von Etwas geben: „Der konkrete Inhalt der sinnlichen Gewißheit läßt sie unmittelbar als die reichste Erkenntnis, ja als eine Erkenntnis von unendlichem Reichtum erscheinen“. (Ebd.) Die sinnliche Gewissheit wird bei Hegel im Prozess der Erkenntnis deshalb auch nicht als unmittelbar primäre Erfahrung der Transzendenz erhalten, sondern wird notwendig in die Immanenz des Geistes gezogen, der sie ausformt: „Diese Gewißheit [die sinnliche, B.E.B.] aber gibt in der Tat sich selbst für die abstrakteste und ärmste Wabrheit aus. Sie sagt von dem, was sie weiß, nur dies aus: es ist.“ (Ebd.)
} 
wahre Aussage von Seiendem schließen kann, geht sie für Adorno auch notwendig vermittelt in den überindividuellen, notwendigen und allgemeinen Urteilen des überhistorischen Subjekts auf: „Durch ihre Teilhabe am diskursiven Medium ist sie [die individuelle Erfahrung, B.E.B.] der eigenen Bestimmung nach immer zugleich mehr als nur individuell." 426 Jede individuelle Erfahrung sei insofern zugleich überindividuell und deshalb verallgemeinerbar: „Weil sie in sich allgemein ist, und soweit sie es ist, reicht individuelle Erfahrung auch ans Allgemeine heran. ${ }^{*} 427$

Eine Vermittlung des Objekts im Denken hat durch die notwendigen Verallgemeinerungen zum notwendigen Resultat, dass das Objekt sich dadurch verändert, anders wird, als es primär zunächst erfahren wurde. Die primäre Erfahrung des empirischen Subjekts bleibe jedoch trotzdem als die ein Stück weit unmittelbare Erfahrung erhalten, selbst wenn bei ihr nicht stehengeblieben werden könne. An der Identität bleibe deshalb immer auch ein Nichtidentisches haften. Mit der primären Erfahrung des selbstbewussten Subjekts hält sich darum ein unmittelbares Moment noch vor jeder verallgemeinernden Vermittlung der Erfahrung, vor jedem subjektiv vermittelten Denken. Was sich eigentlich der Erfahrung immanent zeige und von Gesellschaft untrennbar ist, erhalte sich zwecks genuiner Dialektik durch ihre Vermittlung von Identischem und Nichtidentischem als Momente in sich. Diese Unterstellung von Unmittelbarem, nicht gleich in vernünftiger Vermittlung absolut aufgehend, bleibt insofern das notwendige Moment präformierter Objektivität der subjektiven Erkenntnis. Der aus der konsequenten Dialektik negativ resultierende Vorrang des Objekts als Ausdruck subjektiver Abhängigkeit von Nichtidentischem ist also selbst Resultat von subjektiver Vernunft. Es ist darum auch nichts installiert Ontologisches, mit dem nur versucht wird, dem Subjekt ein mythisches Objekt gegenüberzustellen. Die negative Dialektik versucht insofern nicht, den Hiatus von Subjekt und Objekt künstlich (wieder-) herzustellen. Das wird im nächsten Abschnitt deutlich.

\subsubsection{Negative Dialektik: eine Ontologie?}

„Objekt kann nur durch Subjekt gedacht werden, erhält sich aber diesem gegenüber immer als Anderes.““28

Adorno gibt mit der negativen Dialektik also eine materialistische, kritische Antwort auf den vernunftverabsolutierenden objektiven Idealismus Hegels. Mit dem aufrechterhaltenen Identitätsprinzip macht Adorno dabei jedoch notwendige Anleihen beim Idealismus. Als aus nominalistischen Reflexionen gewonnene Voraus-

\footnotetext{
${ }^{426}$ Adorno: Negative Dialektik, S. 56.

427 Ebd.

428 Adorno: Negative Dialektik, S. 184.
} 
setzung objektiver Erkenntnis ${ }^{429}$ behält Adorno die Widerspruchslosigkeit bei der Bestimmung der nichtgeistigen Materie bei. Objektiv real ist insofern auch für Adorno nur, was sich in Form des rationalen, widerspruchsfreien Systems identischer Begriffe unter der Kantischen transzendentalen Einheit der Apperzeption wiedergeben lässt: „, $[\mathrm{N}]$ icht aber kann ohne Identifikation gedacht werden, jede Bestimmung ist Identifikation.“430 Am Ausgang des Begriffs, durch nominalistische Reflexionen gewonnen, hält er also weiterhin fest: „Weil das Seiende nicht unmittelbar sondern nur durch den Begriff hindurch ist, wäre beim Begriff anzuheben, nicht bei der bloßen Gegebenheit.“"431

Ohne Identitätsprinzip, das zweifellos immer unter den logischen Satz des zu vermeidenden Widerspruchs fällt, sei überhaupt keine rationale und damit widerspruchsfreie Reflexion über das Nichtidentische der primären Erfahrung möglich; genau so wenig wie die Kritik desselben. Der negativ dialektisch gefasste Begriff ist deshalb von den Vernunftprinzipien nicht zu trennen (vgl. auch 2.1). Das selbstbewusst denkende Subjekt bleibe für Adorno deswegen auch der Inbegriff der negativ dialektischen Vermittlung des autonomen Subjekts und autonomen Objekts: „Noch die selbstkritische Wendung des Einheitsdenkens ist auf Begriffe, geronnene Synthesen angewiesen.“"432 Das vernünftige Subjekt bleibt insofern die Voraussetzung auch der materialistischen Auflösung einer Hegelschen positiven Dialektik als Methode und ist die Voraussetzung dafür, einen normativen Maßstab der Kritik überhaupt in der Hand zu haben: „Weil aber der Vorrang des Objekts der Reflexion bedarf, wird Subjektivität, anders als im primitiven Materialismus, der Dialektik eigentlich nicht zuläßt, zum festgehaltenen Moment.“433 Die Dialektik wird insofern bloß als Methode überwunden, ohne dass dabei Logik und System einfach abstrakt negiert werden.

Durch ihre logischen Anleihen beim identitätsphilosophischen Idealismus klingt die negative Dialektik zunächst nach einem klassischen Paradoxon. Sie erinnert an den emanzipativ gedachten, dann aber hinter seine Ziele zurückfallenden Versuch Lenins aus Materialismus und Empiriokritizismus. ${ }^{434}$ Lenin tritt dort mit einer Polemik gegen den Subjektivismus in den Wissenschaften an und will dadurch das Festhalten an wissenschaftlicher Objektivität einfordern. Weil Lenin jedoch durch die identitätsphilosophische Widerspiegelungstheorie die Objektivität dann wiederum selbst subjektivistisch auflöst, fällt er dadurch auf eine Position der von ihm kritisierten Subjektivisten/Idealisten zurück: „Wie bei Ernst Mach besteht auch in seiner [Lenins, B.E.B.] Theorie ein Chorismos zwischen rein materiellem constituens und dessen constitutum, der objektiven Welt, die in jenem nicht aufgeht. (...)

\footnotetext{
${ }^{429}$ Vgl. Kant: Kritik der reinen Vernunft, A 280 ff.

430 Adorno: Negative Dialektik, S. 152.

431 Ebd., S. 156.

432 Ebd., S. 160.

433 Adorno: Zu Subjekt und Objekt, S. 749.

434 Vgl. Lenin: Materialismus und Empiriokritizismus.
} 
Das war die Position eines um seine Prämissen verkürzten Idealismus: einer Dialektik, die alle erkennbaren Phänomene für autonome Setzungen der Materie hielt.، "435

Solche Fehler, wie sie Lenin unterlaufen, vermeidet Adorno. Der Widerspruch in der negativen Dialektik ist ein Resultat der von Adorno reflektierten ideologischen Subjekt-Objekt-Dialektik, die ohne reflexives Subjekt als in sich mit Objekt vermitteltes Moment nicht stattfinden könnte. Die emphatische Kritik der adaequatio ist insofern überhaupt nur über die konsequente, dialektische adaequatio möglich (vgl. 2.4.3). Sie ist Resultat einer Reflexion, die sich den eigenen materiellen und damit nichtidentischen Widersprüchen in den positiven Synthesen bewusst ist. Wider jeden tautologischen Subjektivismus soll deshalb der „Vorrang des Objekts“"436 das bestehen bleibende heteronome Moment des seiner selbst bewussten, aber nicht absoluten Subjekts vermitteln. Der präjudizierte Vorrang des Objekts stellt sich dadurch als das unbedingte momentum heraus, dass das Subjekt, obwohl Selbstbewusstes, vom äußeren Material auch weiterhin abhängig bleibt - ganz gleichgültig, wie sehr das selbstbewusste Subjekt die begriffliche Identität auch vorantreibe: „Das hat zur Konsequenz: ein in Kategorien der Wissenschaften bestimmtes Objekt kann niemals reines Objekt sein, sondern es umfaßt sich und das erkennende Subjekt, aus dessen geschichtlich vermittelter Perspektive es fixiert wurde. “437

Das nichtidentische Objekt lässt sich insofern niemals mit Mitteln der Logik oder der Abbildtheorie in ein mit sich identisches Subjekt auflösen. Eine solche Position wäre wider jede selbstkritische Reflexion des Subjekts auf seine eigenen, materiellen Voraussetzungen (vgl. 2.3.1). In der negativ dialektischen Vermittlung von Subjekt und Objekt steckt deshalb die vernünftige Kritik des selbstbewussten, notwendig identifizierenden Subjekts an der tautologischen Selbstverabsolutierung im analytischen Urteil - aus einer Kritik am nichtsdestotrotz im Erkenntnisprozess aktuell bleibenden Identitätsprinzip. Trotz der Hegel durch Adorno zugestandenen in-sich-Vermitteltheit von Subjekt und Objekt, trotz der notwendigen Vermittlung und notwendigen subjektiven Identifikationen des Materials der vormals unumgänglichen Standpunkte der Philosophiegeschichte, gibt er, in Anlehnung an das Kantische Ding an sich und die Kausalität der Dinge in sich, dem unmittelbaren, nichtidentischen Objekt aus der Subjekt-Objekt-Vermittlung heraus damit einen zwar kleinen, aber sachlich notwendigen Vorsprung gegenüber der verallgemeinerten, supponierten Identifikation. Das ist ein Resultat des dialektisch reflektierten Materialismus, der sich eines restontologischen Moments aus Gründen der positivistischen Ideologiekritik nicht entledigt.

Die materialistische Antwort Adornos auf Hegel und die tautologische Philosophiegeschichte insgesamt hängt sich damit an genau der Stelle einer vorausge-

\footnotetext{
435 Haag: Der Fortschritt in der Philosophie, S. 128.

436 Adorno: Negative Dialektik, S. 187.

${ }^{437}$ Haag: Der Fortschritt in der Philosophie, S. 113.
} 
setzten gewissen Selbständigkeit des dem identifizierenden, selbstbewusst denkenden Subjekt gegenüberstehenden disparaten, aber in sich rationalem, selbst intelligiblen Materials - auch dem der eigenen Körperlichkeit des seiner selbst bewussten Subjekts und der Gesellschaft - auf. Subjekt war für Adorno ohne ein ihm nichtidentisch eigenständiges, an sich seiendes Objekt im Sinne der Voraussetzung von Vermittlung überhaupt durch ein schon daseiendes Unmittelbares genau so wenig wie auch ohne die eigene verletzliche Körperlichkeit zu denken; nicht hinsichtlich des einzelnen Subjekts, und auch nicht des überindividuellen Subjekts, das ohne endliches Subjekt unmöglich zu denken ist (vgl. 2.3.1). Adornos materialistische Antwort beschreibt deshalb den unmittelbaren, realistischen „Überschuß an Welt über bloßes Subjekt “438. Dieser Vorrang des Objektiven geht jedoch nicht so weit, dass sich die Erkenntnis in einen mythologischen oder kritischen Realismus ${ }^{439}$ des transzendenten Ansichseins ohne jede mögliche Aufbruchs- oder Veränderungsmöglichkeit auflöst: „Derlei Realismus ist unrealistisch.“440 Adorno tappt deshalb nicht in die Falle einer wiederum subjektivistischen Ontologiekonzeption: „Entscheidend ist es zu bemerken“, so Michael Städtler, „daß Adorno mit dem ,Vorrang des Objekts' keinen naiven Materialismus oder Empirismus vertritt, in dem sich ein Subjekt und ein Objekt substantiiert gegenüberstünden und womöglich das Bewußtsein seine Bestimmungen vom Sein empfinge." "441 Adorno sei sich „der erkenntnistheoretischen Gratwanderung bewußt" ${ }^{\text {"442 }}$. Diese Gratwanderung ist ein Resultat seiner bewussten Vermittlung von notwendigem Identitätsprinzip und denknotwendigem, unmittelbar Nichtidentischen (vgl. auch 2.4.3). Adornos kritische Reflexion auf Subjekt und Objekt ist insofern Resultat der dialektischen Vermittlung des philosophiegeschichtlich überbrachten Universalienstreits, der bereits auf die Überwindung von traditionellen und unrealistischen Subjektivismen drängt. Adorno gibt auf die traditionelle Frage nach der Existenz von universalia oder die Auffassung der Universalien als bloße flatus voci eine dialektisch kritische Antwort. Er entscheidet sich für keinen der traditionell eingenommenen Standpunkte, sondern geht mit der negativen Vermittlung beider selbst auf Form und Inhalt jenseits des Standpunktdenkens: auf die dialektisch vermittelte Wahrheit. Die dialektische Subjekt-Objekt-Vermittlung richtet sich aus ihrer eigenen Konsequenz selbst heraus gegen die ideologische Favorisierung von erkenntnistheoretischen Standpunkten, weil diese immer noch etwas vermessen Positives an sich haben, indem sie sich positiv auf etwas beziehen. Positiv bezieht sich Adorno bei seiner Reflexion der Subjekt-Objekt-Vermittlung einzig auf den

\footnotetext{
438 Adorno: Philosophische Terminologie, Band II, S. 138.

${ }^{439}$ Den Realismus in der Erkenntnistheorie kritisiert Schopenhauer schon zurecht als unmöglich, auch wenn er ihn unreflektiert mit dem Materialismus identifiziert. (Vgl. Schopenhauer: Die Welt als Wille und Vorstellung, S. 57 ff.) Zu den Vertretern des kritischen Realismus siehe Albert: Kritischer Rationalismus; Bohnen/Musgrave (Hrsg.): Wege der Vernunft.

440 Adorno: Gesellschaft, S. 10.

441 Städtler: Kant und die Aporetik moderner Subjektivität, S. 32.

${ }_{442}$ Ebd., S. 33, Fn. 50.
} 
ontologischen Wahrheitsbegriff, was jedoch nicht heißt, dass er deswegen einen ontologischen Standpunkt vertritt. Zwar könnte man nun angesichts des gefahrenen Angriffs auf den Subjektivismus in den Wissenschaften meinen, dass Adorno gegen Subjekt und jegliches Identitätsdenken versucht, einen ontologischen Objektivismus zu restituieren. Doch die negative Dialektik formuliert keine Gegenposition gegen die sich als subjektivistisch erweisende Philosophiegeschichte, genau so wenig wie mit ihr eine vermeintlich wirkliche, wasserdichte Ontologie - und damit wieder etwas Positives! - ausgearbeitet wird. Sie erweist sich über die Kritik der Philosophie- und Wissenschaftsgeschichte als in sich reflektierte ,erkenntnistheoretische Gratwanderung, die solche Theorien, insofern diese vermittelte Notwendigkeit der Dialektik von Subjekt und Objekt nicht reflektieren, kritisiert. Nach Adorno ist die moderne Ontologie, entgegen ihrer eigentlichen Intention von gegenständlicher Objektivität, wiederum selbst alles andere als frei von subjektivistischen und nominalistischen Momenten. Das zeigt sich am Beispiel seiner Kritik der Fundamentalontologie Heideggers: „Bei Heidegger überschlägt sich Sachlichkeit: er ist darauf aus, gleichsam ohne Form, rein aus den Sachen zu philosophieren, und damit verflüchtigen diese sich ihm. Der Überdruß an dem subjektiven Gefängnis der Erkenntnis veranlaßt zur Überzeugung, das der Subjektivität Transzendente sei für sie unmittelbar, ohne daß sie durch den Begriff es befleckte. (...) Weil aber Subjektivität ihre Vermittlungen nicht aus der Welt denken kann, wünscht sie Stufen des Bewußtseins zurück, die vor der Reflexion auf Subjektivität und Vermittlung liegen. Das mißlingt.“"443 Es misslinge insofern die in Sein und Zeit beabsichtigte Regression auf irrational Vorvernünftiges, Präsubjektives, um Subjekt und Ideologie zu meiden - zumal bei Heidegger subjektivistischkonstruktivistisch das „Sein nur im Dasein [also letztendlich Subjekt, B.E.B.] erscheint" ${ }^{\text {"444 }}$. So sei und bleibe dessen fundamentalontologische Philosophie paradox und notwendig ,subjektiv gerichtete[s] Denken“445. In Sein und Zeit heißt es: „Daraus entspringt die Einsicht: Realität hat weder innerhalb der Seinsmodi des innerweltlichen Seienden einen Vorrang, noch kann gar diese Seinsart so etwas wie Welt und Dasein ontologisch angemessen charakterisieren. (...) Allerdings nur solange Dasein ist, das heißt die ontische Möglichkeit von Seinsverständnis, ,gibt es' Sein. Wenn Dasein nicht existiert, dann ,ist' auch nicht ,Unabhängigkeit' und ,ist "auch nicht ,An-sich'." "446 Das untermauert die These Adornos von der subjektiven Konstruktion der materiellen Wirklichkeit bei Heidegger. In Heideggers Fundamentalontologie bleibt das Identitätsprinzip darum, gerade durch ihre nominalistische Konzeption und trotz seiner „Wendung zu einer im weiteren Sinne des Wortes realistischen Philosophie“447, unbewusst existent. Jede ontologische

\footnotetext{
443 Adorno: Negative Dialektik, S. 86.

${ }_{444}$ Adorno: Ontologie und Dialektik, S. 142.

${ }^{445}$ Ebd., S. 143.

446 Heidegger: Sein und Zeit, S. 211 f.

447 Hösle: Die Krise der Gegenwart, S. 93.
} 
Position, die das Subjekt schicksalsgetrieben aus der Verantwortung für sein eigenes Handeln und Tun nehmen will, so wie z.B., neben den (Fundamental)Ontologien im Stile Heideggers ${ }^{448}$, auch der naturalistische Materialismus der Hirnforschung, erweist sich als ihrer selbst unbewusst; und sie leistet zudem die Reflexion der eigenen Bedingungen nicht. Wenn die Neurowissenschaft das Bewusstsein mit physiologischen Vorgängen im Gehirn einfach identifiziert, erklärt sie zwar ,objektiv‘ tatsächlich alles Seiende aus einem Prinzip der Materie: „Für sie [Neurophilosophie als Sparte der Neurowissenschaften, B.E.B.] ist das Ich aus der Physiologie des ,Seelenorganes', des Hirns, zu begreifen. "449 Das neurowissenschaftliche Prinzip der Erklärung alles Seienden aus Materie ist jedoch nicht anders als aus dem mit sich identischen, vernünftigen Subjekt Kommendem und dieses aus Prinzip erst Identifizierendem erklärbar. Die Konzeption eines bewusst konzipierten Hiatus von Subjekt und Objekt widerspricht sich insofern schon deshalb, weil dieser Hiatus ein Konstrukt des Subjekts ist. Gerade diese Erklärung aus dem zugrundegelegten Prinæip überführt die Neurowissenschaft deshalb des Subjektivismus - und ihre Theorie damit des Widerspruchs. Jedes principium verweist unmittelbar auf ein rationales Denken; und damit auf das Subjekt identitätsstiftender Begriffsbildung: „Das identifizierende Prinzip, das alles vereinheitlicht und alles, was da ist, sich selbst gleichsetzt, ist aber immer auf der Subjektseite. " ${ }^{450}$ Selbst wenn sich der naturalistische Materialismus den eigenen idealistischen Subjektivismus nicht eingestehen mag, verrät dieser sich durch das Identitätsdenken des naturalistischen Materialismus implizit: „Identitätsdenken ist, auch wenn es das bestreitet, subjektivistisch. " 451 Durch die im Resultat durchscheinende Identität von Bewusstsein und Sein erschlägt der naturalistische Materialismus der Neurowissenschaft deshalb den eigenen vermeintlich radikalen Materialismus mit niemals losgelassenen Mitteln des subjektivistischen Idealismus. Der naturalistische Materialismus reflektiert dadurch, wider die eigene Intention, die Vorrangigkeit des dem subjektiven Prinzip entgegenstehendem Objektiven nicht adäquat. Der naturalistische Materialismus der Neurowissenschaften wird insofern zur Ideologie, weil er die eigenen subjektiven Bedingungen bei der Konzeption des vermeintlich radikalen Materialismus verleugnet.

\footnotetext{
${ }^{448}$ Vgl. Adorno: Negative Dialektik, S. 69: „Die Ontologien in Deutschland, zumal die Heideggersche, wirken stets noch weiter, ohne daß die Spuren der politischen Vergangenheit schreckten. Stillschweigend wird Ontologie verstanden als Bereitschaft, eine heteronome, der Rechtfertigung vorm Bewußtsein enthobene Ordnung zu sanktionieren. “So schreibt auch Hösle, „daß sein [Heideggers, B.E.B.] schicksalsgläubiger Ansatz Europa und besonders Deutschland von einer Verantwortung für die Verbrechen und Katastrophen freisprach, die es zu Heideggers Lebzeit über die Welt gebracht hatte.“ (Hösle: Die Krise der Gegenwart, S. 93.)

${ }^{449}$ Breidbach: Die Materialisierung des Ichs, S. 16.

450 Adorno: Philosophische Terminologie, Bd. II, S. 82.

451 Adorno: Negative Dialektik, S. 184.
} 


\subsubsection{Die verdoppelte intentione obliqua als Kritik subjektivistischer Suppositionen}

Mithilfe von philosophiegeschichtlichen Begriffen, intentio recta und intentio obliqua, lassen sich die Grenzen subjektivistischer Tautologien aufzeigen. Anders als in der vornominalistischen antiken und mittelalterlichen Philosophie, in der Ontologie und Metaphysik noch zusammenfallen, geht für Adorno, wie schon für Kant und Hegel etc., das Subjekt nicht mehr intentione recta, also direkt und unvermittelt, auf Gegenstand und Wahrheit. Hinter die vom Nominalismus gemachte Einsicht vom selbstbewussten Subjekt als Subjekt der Erkenntnis geht auch Adorno nicht wieder zurück (vgl. etwa 2.3.1): „Durch die Einsicht in den Vorrang des Objekts wird nicht die alte intentio recta restauriert, das hörige Vertrauen auf die so seiende Außenwelt, wie sie diesseits von Kritik erscheint, ein anthropologischer Stand bar des Selbstbewußtseins, welches erst im Kontext der Rückbeziehung von Erkenntnis auf das erkennende sich kristallisiert." $" 452$

Ohne die Reflexion auf das Subjekt würde die Aussage über Seiendes deshalb nur ein unvermittelter Rückfall auf eine längst überholte, vorkritische Metaphysik sein. Der Universalienrealismus der vorkritischen Metaphysik ist darum, weil er Erkennendes und Erkanntes identifiziert, auch schon ohne eine ausgearbeitete Subjekttheorie ,subjektivistisch'. Auch sie akzeptiert das zu erkennende Objekt nicht als der Erkenntnis und dem Subjekt gegenüber autonom: „Richtig war ihre Erkenntnis, daß es formae rerum geben: Natur als Gegenstand physikalischer Forschung aus geformten Entitäten bestehen muß. Auf ein falsches Gleis hat dann jedoch der Versuch geführt, das Ansichsein der empirischen Dinge positiv zu bestimmen.“" 453

Der metaphysische Universalienrealismus leuchtet dem Nominalismus nun durch die eigenen erkenntnistheoretischen Mängel den entsprechend kritischen Pfad: ,Jener [Universalienrealismus, B.E.B] impliziert diesen [Universaliennominalismus, B.E.B.]: ist nämlich [von Haag an Thomas von Aquin ausgeführt, B.E.B.] die erscheindende res nur durch Akzidentien von der essentia unterschieden, die essentia also nur die ihrer Hülle entkleidete res, so ergibt sich die nominalistische Konsequenz, daß die essentia rei bloßer flatus vocis sei.“"454 Die nominalistische Kritik am Universalienrealismus durch die Installation des Subjekts ist insofern zwar fundamental, deshalb aber auch nicht gleich hinreichend. Auch die nominalistische intentio obliqua, die nominalistische Stellung des (Selbst-)Bewusstseins zu den Gegenständen, lässt wiederum erkenntnistheoretische Mängel erkennen. Auch der subjektiv-nominalistische Modus akzeptiert das Objekt der Erkenntnis nicht als ein Autonomes, Widerständiges: „Die von der traditionellen Erkenntniskritik am Objekt ausgemerzten und dem Subjekt gutgeschriebenen Qualitäten verdan-

\footnotetext{
452 Adorno: Zu Subjekt und Objekt, S. 746.

453 Vgl. Haag: Der Fortschritt in der Philosophie, S. 11.

${ }^{454}$ Ebd., S. 54.
} 
ken in der subjektiven Erfahrung sich dem Vorrang des Objekts; darüber betrog die Herrschaft der intentio obliqua [d.h. des Idealismus, des Rationalismus B.E.B.]." ${ }^{455}$

An genau jener Stelle des subjektiv-nominalistischen ,Betrugs' greift Adornos Kritik an. Das nichtidentische Objekt hat für Adorno, wider den subjektiven Nominalismus und deshalb scheinbar zunächst in Anlehnung an die traditionelle Metaphysik und ihre formae rerum, ein autonomes intelligibles Substrat. Dies mache das Objekt als ein Stück weit transzendentes Ding überhaupt erst durch das Subjekt bestimmbar: „In den Bestimmungen, die scheinbar bloß das Subjekt ihm anheftet, setzt dessen eigene [sic!] Objektivität sich durch: sie alle sind der Objektivität der intentio recta entlehnt. “" ${ }^{56}$ Das widerständige Objekt sei durch das Subjekt und seinem individuierten Allgemeinvermögen in sich und in seinen Strukturzusammenhängen als in seinem funktionalen Verhalten nur deshalb bestimmbar (und dadurch zweckmäßig bearbeitbar), weil es ein auf den allgemeinen, objektiv und notwendigen Begriff gebrachtes, ein wahres, ontologisches Urteil über ein an sich seiendes Objekt als dem Subjekt widerständig transzendentes gibt: „Will man indessen das Objekt erlangen, so sind seine subjektiven Bestimmungen oder Qualitäten nicht zu eliminieren: eben das wäre dem Vorrang von Objekt entgegen. Hat Subjekt einen Kern von Objekt, so sind die subjektiven Qualitäten am Objekt erst recht ein Moment des Objektiven. Denn einzig als Bestimmtes wird Objekt zu etwas." "457 Intentio recta und intentio obliqua zeigen sich insofern für Adorno dialektisch als Momente in sich vermittelt. Beide Wege der Stellung des Bewusstseins zur Objekterkenntnis sind dialektisch miteinander vermittelt.

Diese dialektische Vermittlung zu erkennen kann jedoch erst ein Resultat einer konsequenten dialektischen Logik sein. Bei Adorno verdoppelt sich die Reflexion des selbstbewussten Subjekts auf das Objekt, womit die tautologischen Fehler der traditionellen und nominalistischen Philosophie dialektisch reflektierend überwunden werden sollen. Und der Verweis auf den unmittelbar subjektiven Reflexionsprozess bei der Anerkennung der Präponderanz des Objekts deutete dies auch nicht nur implizit an. Die in 2.4.4 angeführte autonome Subjektleistung im objektiven Erkenntnisprozess sei die entscheidende Voraussetzung auch einer Verdopplung der Reflexion aufs Objekt, der verdoppelten intentio obliqua. Die Vermittlung von Subjekt und Objekt unterziehe sich dabei nochmals einer notwendigen kritischen Reflexion auf das selbstbewusste Erkennen der transzendenten, nichtidentischen Materie. So doppele sich der dialektische Vermittlungsprozess von Subjekt-Objekt selbstreflexiv. Dies ist die kritische Reflexion des bereits seiner selbst bewussten Subjekts, das sich als solches selbstkritisch der inkonsequenten nominalistischen Verabsolutierung entzieht. Erst diese Verdoppelung der des durch den Nominalismus herausgehobenen unbedingten Subjektbezugs der Er-

\footnotetext{
455 Adorno: Zu Subjekt und Objekt, S. 747.

456 Ebd.

${ }^{457}$ Ebd.
} 
kenntnis führe für Adorno zu einer wahren Aussage über das Objekt. Ein ontologisch wahres Urteil lässt sich insofern immer erst nach der entsprechenden kritischen Selbstreflexion des Subjekts formulieren: „Der Vorrang von Objekt ist die intentio obliqua der intentio obliqua, nicht die aufgewärmte intentio recta; das Korrektiv der subjektiven Reduktion, nicht die Verleugnung eines subjektiven Anteils. Vermittelt ist auch Objekt, nur nicht dem eigenen Begriff nach so durchaus auf Subjekt verwiesen wie Subjekt auf Objekt. “458 Diese selbstkritische Verdopplung der nominalistischen intentio obliqua sei insofern die einzig gelungene, konsequente dialektische Reflexion des Objekts durchs selbstbewusste Subjekt. Die Verdopplung der intentio obliqua ist dabei als ein Korrektiv der philosophiegeschichtlichen tautologischen Subjektivierungen der Erkenntnis zu sehen. Sie ist Resultat der selbstkritischen Relation von Subjekt und Objekt, die die notwendige Identität von Subjekt und Objekt als notwendigen Prozess der Erkenntnis bei gleichzeitiger, weil notwendiger Anerkennung der transzendenten Präponderanz des Objekts reflektiert - der an sich seienden Nichtidentität des Objekts. Die Verdopplung der intentione obliqua kann den entscheidend kritischen Maßstab der Erkenntnis von außersubjektiven Dingen begründen, weil sie die traditionellen subjektivistischen Tautologien der Erkenntnis reflektiert und den Gegenstand als Autonomen erkennt.

Mit der selbstkritisch verdoppelten intentio obliqua als Kritik der reductio ad hominem restituiert Adorno also keinen bloß realistischen Standpunkt, wie man oberflächlich betrachtet meinen könnte; ein solcher würde auch nur eine oben bereits kritisierte ontologische Verleugnung von Subjektivität wiederholen. Der fürs Subjekt uneinholbar bleibende Vorsprung des Objekts liegt für Adorno im intelligiblen Substrat der Erscheinungen. Solch ein erst zu vermittelndes, immer nichtidentisch bleibendes, transzendentes Unmittelbares existiere gegen den objektiven Idealismus Hegels und die gesamte subjektivistische Identitätsphilosophie schon deswegen, weil jede „Reflexionsbestimmung, sinnvoll nur in bezug auf das ihr Entgegengesetzte, Unmittelbare“ ${ }^{459}$ sei. Die negative Subjekt-Objekt-Dialektik, die beide Momente, Subjekt und Objekt, als Momente in sich und durch sich hindurch vermittelt, als selbständige und doch ohne einander Nichtseiende ernst nimmt, löse die intelligibel in sich erkennbare Außenwelt dabei nicht vollständig in subjektiver Reflexion auf. Der transzendente Rest der Objektivität bleibt deshalb Voraussetzung wie Resultat einer durchgeführten negativen Dialektik, negativer Rest der Dialektik in Form einer unauflöslichen bestimmten Negation, der wider jede Versöhnung von vernunftbegabtem Subjekt und Objekt immer bestehen bleibt. Der negative Rest bleibt für Adorno insoweit unmittelbares Moment der Voraussetzung einer Subjekt-Objekt-Vermittlung überhaupt: „Umgekehrt bliebe keine Vermittlung ohne das Etwas.“460

\footnotetext{
458 Ebd.

459 Adorno: Negative Dialektik, S. 173.

${ }^{460}$ Ebd.
} 
Dadurch wird die Dialektik also nicht wieder zur systematisch Positiven wie noch bei Hegel, die alles nur in den allgemeinen Begriff - am Ende von sich selbst! zieht. Die negative Dialektik lässt die Reflexion auch nicht, wie beispielsweise in der Naturalistischen oder dem Diamat, einfach objektivistisch aus der Realität entspringen (vgl. etwa 2.4.4). Das wiederum würde die eigentliche Qualität des Subjekts auch nur zu einem bloßen Reflex machen und die Widerständigkeit des vernünftigen Subjekts verleugnen. Selbst die Erkenntnis von sich als zeitliches, unmittelbares Subjekts kann immer erst dann stattfinden, wenn das Subjekt sich selbst als Naturwesen, als ein Stück weit nichtautonomes, nichtidentisches Individuum, als körperliches, auch nicht geistiges Subjekt reflektiert. Die negative Subjekt-Objekt-Dialektik mit dem im Resultat reflektierten Realismus pocht mit dem transzendenten Unmittelbaren auf die entscheidende Voraussetzung der Durchführbarkeit von dialektischer Vermittlung.

Vor dem Hintergrund dieser Ausführungen zur Präponderanz des Objekts bleibt auch für die Zukunft die Möglichkeit eines versöhnlichen Aufbrechens des restontologischen Vorrangs des Objekts verstellt. Die Versöhnungsromantik, die beispielsweise Habermas in der Theorie des kommunikativen Handelns Adorno unterstellt, kann es darum mit einer negativen Dialektik nicht geben (vgl. 2.3.1). Habermas unterstellt der negativen Dialektik jedoch das zu sein, was sie selbstbewusst nicht ist, eine idealistische Dialektik: „Allein, wie soll sich die Idee der Versöhnung, in deren Licht Adorno die Verfehlungen der idealistischen Dialektik doch nur sichtbar machen kann, explizieren lassen, wenn sich die Negative Dialektik als der einzig mögliche, eben diskursiv nicht begehbare [sic!] Weg der Rekonstruktion anbietet?“461 Die der negativen Dialektik von Habermas anempfohlenen romantisierende Abschaffung des Nichtidentischen wäre deshalb bloß ein Rückfall in eine intersubjektive Tautologie. Jeder Versuch der Versöhnung von Subjekt und Objekt fällt nämlich auf einen positivistisch und romantisch gespickten Idealismus zurück, ohne jede sich trotz der Arbeit des Subjekts erhaltende bestimmte Negation. Aus der Romantik und dem Idealismus kennt man diese identitätsbehaftete Versöhnung von Subjekt und Objekt bereits. Die zwei Denkepochen stehen sich zwar eigentlich, wie Walter Benjamin in Der Begriff der Kunstkritik in der deutschen Romantik nachweist ${ }^{462}$, ablehnend gegenüber, aber der Versuch der Versöhnung von Subjekt und Objekt ist ihnen wesentlich gemeinsam. Jener romantische, versöhnliche Hölderlineffekt ${ }^{463}$ steht dabei völlig wider eine negative Dialektik. Habermas kann deshalb mit Adorno entgegnet werden: „Das Bild eines zeitlich oder außerzeitlich ursprünglichen Zustands glücklicher Identität

\footnotetext{
461 Habermas: Theorie des kommunikativen Handelns, Band 1, S. 500.

462 Vgl. hierzu die Kritik der erkenntnistheoretischen Voraussetzungen der Romantiker durch Benjamin: Der Begriff der Kunstkritik in der deutschen Romantik.

${ }^{463}$ Vgl. z.B. Hölderlin: Vorrede, S. 163: ,Wir sind zerfallen mit der Natur, und was einst, wie man glauben kann, Eins war, widerstreitet sich jetzt, und Herrschaft und Knechtschaft wechselt auf beiden Seiten.“,Wir“ sollen „uns mit der Natur (...) vereinigen zu einem unendlichen Ganzen, das ist das Ziel all’ unseren Strebens.“
} 
von Subjekt und Objekt aber ist romantisch; zuzeiten Projektion der Sehnsucht [wie bei Hölderlin, B.E.B.], heute nur noch Lüge." 464

Der Versöhnungsgedanke findet sich jedoch auch noch in weiteren Werken der kritischen Philosophie, wie beispielsweise bei Georg Lukács. Dieser kritisiert seine Theorie des Romans später, gerade weil sein Hauptgedanke hier noch auf einen Idealismus-Romantizismus zurückfalle. Er bezeichnet sein Frühwerk darum auch als kryptoidealistisch, das eine unvermittelte Identifikation von Subjekt und Objekt vornehme und aus dem Grund auf die idealistisch dialektische Methode Hegels zurückfalle, die Subjekt und Objekt gegenüber indifferent sei: „,(..) nicht einmal auf der Ebene der abstraktesten Gedanklichkeit gab es damals bei mir Vermittlungen von der subjektiven Stellungnahme zur objektiven Wirklichkeit."465 Lukács folgt in der Theorie des Romans tatsächlich stellenweise einer strengen Hölderlinschen Interpretation von romantizistischer Versöhnung. Versöhnung sei im Urzustand des Denkens einmal gewesen, sie sei dann jedoch durch die verdinglichende Moderne entfremdet verloren gegangen: „Deshalb ist Philosophie als Lebensform sowohl wie als das Formbestimmende und das Inhaltgebende der Dichtung immer ein Symptom des Risses zwischen Innen und Außen, ein Zeichen der Wesensverschiedenheit von Ich und Welt, der Inkongruenz von Seele und Tat. Deshalb haben die seligen Zeiten keine Philosophie, oder, was dasselbe besagt, alle Menschen dieser Zeit sind Philosophen, Inhaber des utopischen Zieles jeder Philosophie. “466

Auch Detlev Claussen optiert in Grenzen der Aufklärung fürs versöhnliche Aufbrechen der Subjekt-Objekt-Schranke: „Logisch muß auf die Entmachtung der Ökonomie in der Wirklichkeit auch die Entmachtung der Ökonomie in der Gesellschaftskritik folgen. Das heißt jedoch nicht, daß alle ökonomischen Motive verschwunden oder gegenstandslos geworden sind. Der Geschichtsverlauf subjektiviert sich, gerade weil der Vorrang des Objektiven nicht gebrochen werden konnte. " ${ }^{667}$ Auch das suggeriert, dass der Vorrang des Objekts, die nicht nur denknotwendige Transzendenz des Objekts, wirklich einmal aufgebrochen werden könne. Adornos reflektierter Realismus der negativen Dialektik, der die selbstbewusste Reflexion aufs Objekt, die intentione obliqua, verdoppelt und dieses damit eben nicht in zweiter Unmittelbarkeit restituiert, löst die Dialektik von Sein und Bewusstsein dagegen eben nicht romantizistisch-versöhnlich auf. Denn eine Versöhnung entließe beide Momente, Subjekt und Objekt, doch nur wieder in eine schon an Hegels Idealismus kritisierte absolute Vermittlung. Die negative Dialektik, die das Unmittelbare zur Voraussetzung wie zum Resultat hat, würde so wieder nur ihrer eigenen Voraussetzungen beraubt.

\footnotetext{
464 Adorno: Zu Subjekt und Objekt, S. 742.

465 Vgl. Lukács: Die Theorie des Romans, S. 6.

466 Ebd., S. 21.

${ }^{467}$ Claussen: Grenzen der Aufklärung, S. 72.
} 
Die Reflexionen des Vorrangs des Objekts führen direkt auf Gesellschaftstheoretisches. Claussen spricht bereits die derzeitige über das sich selbsterhaltende Subjekt herrschende „Vormacht von Ökonomie“468 an. Diese ökonomische Vormacht solle Claussen zufolge mit dem Subjekt versöhnt werden. ${ }^{469}$ Für Adorno bleibe Gesellschaft hingegen - dem Durkheimschen Credo ähnlich, dessen soziologische Tatbestände, in besonderen Arten des Handelns, Denkens und Fühlens [bestehen, B.E.B.], die außerhalb der Einzelnen stehen und mit zwingender Gewalt ausgestattet sind, kraft derer sie sich ihnen aufdrängen“ ${ }^{* 470}$ - in ihren verhärteten Strukturen dem einzelnen Subjekt der Praxis immer transzendent vorausgesetzt. Erst mithilfe der subjektiven Anerkennung einer Präponderanz auch von gesellschaftlichem Objekt könne überhaupt etwas wie eine wirklich fruchtbare Kommunikation von Subjekt und Gesellschaft stattfinden, die nicht gleich wieder im subjektivistischen Identitätsdenken und blinder Versöhnung resultiere, sondern die Verhärtungen des Gegenstands der Gesellschaft reflektierend auflöst: „Wäre Spekulation über den Stand der Versöhnung erlaubt, so ließe in ihm weder die ununterschiedene Einheit von Subjekt und Objekt noch ihre feindselige Antithetik sich vorstellen; eher die Kommunikation des Unterschiedenen. Dann erst käme der Begriff von Kommunikation, als objektiver, an seine Stelle. Der gegenwärtige ist so schmählich, weil er das Beste, das Potential eines Einverständnisses von Dingen, an die Mitteilung zwischen Subjekten nach den Erfordernissen subjektiver Vernunft verrät.“" ${ }^{771}$ Insofern begreift Adorno Versöhnung also nicht als die absolute, unterschiedslose Identität von Subjekt und Objekt, sondern als zweckbezogene Versöhnung von, auch nach dem Erkenntnisprozess, weiterhin Unterschiedenem. Selbst potentiell denkbare, freieste gesellschaftlichen Bedingungen, unter denen das Subjekt seine Zwecke selbst und herrschaftsfrei für sich wählen kann, entledigten sich nicht jener ontologischen Vorrangigkeit des Objektiven. Selbst wenn Gesellschaft dem Subjekt nicht mehr als feindlich gesonnene, sondern als freiheitlich zweckbestimmte gegenübersteht, gelte immer noch: „Friede ist der Stand eines Unterschiedenen ohne Herrschaft, in dem das Unterschiedene teilhat aneinander.“ ${ }^{472}$ So fungiert der Begriff der Versöhnung bei Adorno als unorthodox Kantisch gedachte regulative Idee; als Begriff, dem kein Material und keine Erfahrung korrespondiert, der aber deshalb, weil denknotwendig, angenommen werden muss, wenn Befreiung von nichtnotwendig Heteronomen überhaupt gedacht werden soll. 473

\footnotetext{
468 Adorno: Negative Dialektik, S. 190 f.

469 Vgl. Claussen: Grenzen der Aufklärung, S. 72.

470 Durkheim: Die Regeln der soziologischen Methode, S. 107.

471 Adorno: Zu Subjekt und Objekt, S. 743

472 Ebd.

473 Die regulative Idee meint, dass dem Begriff keine Erfahrung korrespondiert, dieser aber, weil denknotwendig, angenommen werden muss. (Vgl. Kant: Kritik der reinen Vernunft, A 642/ B 670 ff.)
} 


\subsection{Das Gesellschaftsphänomen im Kontext}

2.5.1 ordnet zunächst am Gegenstand des Antisemitismus das soziale Phänomen ein. Dargestellt werden eine das soziale Phänomen ontologisierende Variante, eine das soziale Phänomen intersubjektivierende Variante.

Abschnitt 2.5.2 beschäftigt sich dann mit dem Wesensbegriff bei Marx und Adorno.

Das Wesen des gesellschaftlichen Phänomens ist von Natur und insbesondere der Naturbearbeitung nicht streng zu trennen. Der Zusammenhang von Natur- und Gesellschaftsphänomen wird in 2.5 .3 beleuchtet.

\subsubsection{Zu Ontologisierung und Subjektivierung des modernen Antisemitismus}

Als Erscheinungen der zweiten Natur sind Gesellschaftsphänomene etwas anderes als Naturphänomene. Darüber jedoch, warum diese Phänomene wie erscheinen und ob sich Wesentliches hinter ihnen überhaupt finden lässt, wird in den Gesellschaftswissenschaften kontrovers diskutiert. Die Frage, wie mit sozialen Phänomenen zu verfahren ist, gilt hier als ebenso ungelöst wie die nach der wahren Erkenntnis von den Dingen der ersten Natur in der Philosophie. Dabei kristallisieren sich insbesondere zwei Fragen heraus: Ist das soziale Phänomen ,szientifisch', wie bei Comte (vgl. Einleitung), gleich dem Phänomen der ersten Natur zu behandeln? Oder ist es doch nur ein intersubjektiver Ausdruck gesellschaftlichen Handelns oder eines Diskurses, wie es beispielsweise Foucault unterstreichen würde (Vgl. 2.1)?

Die gesellschaftstheoretische Kontroverse um die sozialen Phänomene ist also eine um ihre adäquate erkenntnistheoretische Einordnung. Als primäre Erfahrung des individuellen Bewusstseins (vgl. 2.4.3) ist das soziale Phänomen für das Subjekt zunächst genauso wie das Naturphänomen sinnlich wahrnehmbar. Anders als die meisten physikalischen Naturphänomene lassen sich soziale Phänomene jedoch nicht anfassen, nicht mikroskopisch bestimmen etc. Das Verhalten sozialer Phänomene kann insofern nicht unter experimentellen Bedingungen, von geregelten Versuchsanordnungen ausgehend, mit bestimmten Messmethoden etc. irgend positiv (quantitativ) bestimmt werden. Ihr funktionales Verhalten bezieht sich nämlich ausschließlich auf Gesellschaftliches.

Es erscheint insofern als undinglicher, gesellschaftlich vermittelter Gegenstand, der auch demgemäß untersucht werden muss. Innerhalb des gesellschaftlichen Kontexts bleibt das soziale Phänomen deshalb auch an bestimmte raumzeitliche, gesellschaftliche Zusammenhänge gebunden. Es ist ein nur mit und durch die jeweilige raumzeitlich geprägte Gesellschaft als sie wesentlich konstituierende vermitteltes Phänomen. Es wird ausschließlich durch subjektives Handeln erst zum Faktum in der Welt - wie vermittelt auch immer. Es sind demnach subjektive Handlungen, die unter einen bestimmten allgemeinen Begriff, der sich vermittelt auf gesellschaftlich Wesentliches bezieht, theoretisch subsumiert werden. Diese erscheinen 
innerhalb eines bestimmten allgemeinen, totalen gesellschaftlichen Zusammenhangs in der Zeit und innerhalb eines bestimmten Raums. Sie haben ihre Substanz jedoch nicht in der sozialen Faktizität selbst, weshalb die gesellschaftlichen Phänomene immer nur als ein vermittelter Ausdruck von allgemeiner, wesentlicher Vergesellschaftung zu sehen sind. Das für soziale Phänomene ebenso geltende intelligible Substrat hinter der Erscheinung ist deshalb keines von an sich seiender, erkennbarer Natur, sondern ein mit den gesellschaftlichen Zusammenhängen vermitteltes, nur begrifflich zu beschreibendes intelligibles Substrat. Die wesentliche Rationalität hinter den sozialen Erscheinungen ist deswegen eine im unmittelbaren Zusammenhang mit der sich reproduzierenden Gesellschaft stehende Rationalität - die aber eben auch nicht anders als vernünftig begrifflich bestimmt werden kann: „Weil Gesellschaft weder als Begriff nach der gängigen Logik sich definieren noch ,deiktisch' sich demonstrieren läßt, während doch die sozialen Phänomene unabweislich ihren Begriff fordern, ist dessen Organ die Theorie. “474 Dabei ist die jeweilige Gesellschaft die jeweils konkrete, raumzeitliche Form der rationalen Organisation der allgemeinen Reproduktion. Vom gesellschaftlichen Phänomen lässt sich insofern nichts bestimmen, was fernab von den objektiven, intelligiblen Strukturgesetzen der Gesellschaft als zweiter Natur überhaupt Objektivität oder ein an sich Sein besäße. Soziale Phänomene gehen insofern auch nie in ihrer Wirklichkeit auf, sondern sind immer wesentlich vermittelte Handlungen, die theoretisch, begrifflich ergründet werden müssen. Der sinnlich wahrnehmbare soziale Sachverhalt, die primäre Erfahrung des gesellschaftlichen Faktums (vgl. 2.4.3), verweist deshalb immer auf ein nur begrifflich bestimmbares, wesentlich Allgemeines hinter jedem sozialen Faktum als das Konstituens seiner Manifestation. Die Gesellschaft ist deshalb eine sich im sozialen Phänomen immer auch selbst jeweils zweckmäßig abzeichnende: „In den faktischen sozialen Situationen“, schreibt Adorno, „,erscheint die Gesellschaft.“475

Es gibt nun jedoch zwei einander widersprechende populäre Herangehensweisen an das soziale Phänomen in den Sozialwissenschaften. Die gegensätzlichen Positionen, in diesem Fall am modernen Antisemitismus dargestellt, verdeutlichen dabei die Problematik bei der Bestimmung gesellschaftlich vermittelter Phänomene. Zunächst wird (1.) eine das soziale Phänomen Antisemitismus ontologisierende Herangehensweise vorgestellt und kritisiert. Im Anschluss daran wird (2.) die gegenteilige Position vorgestellt und kritisiert, die den modernen Antisemitismus allein aus dem Subjekt und dessen praktischem gesellschaftlichen Handeln entspringen lässt.

(1.) Die das soziale Phänomen ontologisierende Variante nimmt bei der Bestimmung des sozialen Phänomens den Begriff der zweiten Natur sehr ernst. Es wird von der tatsächlichen (gesellschaftlichen) Verdinglichung sozialer Phänomene

474 Adorno: Gesellschaft, S. 11.

475 Ebd., S. 10. 
ausgegangen, und an Gesellschaft und ihre Phänomene wird mit naturwissenschaftlichen Methoden herangetreten. Das soziale Phänomen wird hier wie ein zu erkennendes physikalisches Naturding behandelt. Es bleibt dabei zwar wesentlich noch mit der verhärteten Gesellschaft, der zweiten Natur, vermittelt, aber die Ontologisierung macht das offensichtlich aus subjektivem Handeln entstehende Phänomen ferner zu einem substantiell Unkritisierbaren, immer schon notwendigem gesellschaftlichen Phänomen - gleichgültig in welcher Gesellschaftsform. Das Phänomen wie auch das Handeln werden darum mit der konkreten Gesellschaftsform wenig bis gar nicht zusammengebracht; subjektives Handeln scheint einem Naturzwang zu folgen. Das verewigt das soziale Phänomen, das damit nicht als sich funktional verhaltende Erscheinung in der Welt bestimmt wird, die immer auch auf ein konkretes und bestimmbares, veränderliches gesellschaftliches Wesen hinter ihm verweist.

Ein entsprechendes Modell für die Ontologisierung von Gesellschaft findet sich in der Bestimmung des Antisemitismus als eines angeblich, ewigen Antisemitismus'. ${ }^{476}$ Auch Ernst Simmel, ein der Kritischen Theorie nahestehender Autor, geht von der geschichtlichen Ewigkeit des Antisemitismus aus: „Die Geschichte zeigt, daß der Antisemitismus, wie immer sich seine Manifestationen im Laufe der Zeiten gewandelt haben, im Grunde in allen Epochen der gleiche blieb, ungeachtet wechselnder Gesellschaftsstrukturen und der Veränderungen, die die Juden selber durchmachten. “477 Juden würden ,in eine teleologische Opferrolle“478 gezwungen.

\footnotetext{
476 Der ,ewige Antisemitismus' ist ein Begriff, der die gesellschaftlichen Bedingungen, unter denen der Antisemitismus auftritt, ob als traditioneller, moderner, sekundärer etc., nicht reflektiert. Die qualitativen Unterschiede in der Ausprägung des Judenhasses werden nicht mehr mit konkreten und sich ebenfalls qualitativ verändernden gesellschaftlichen Herrschaftsverhältnissen zusammengebracht. Die Reflexionen fallen deshalb zurück auf den kleinsten gemeinsamen Nenner des Antisemitismus, der relativ nichtssagend, weil abstrakt, zum ahistorischen Prinzip des sozialen Phänomens auserkoren wird: dem Judenhass: „Es ist keineswegs so, wie heute oft behauptet wird, Antijudaismus der Kirchen und biologischer Rassenantisemitismus kämen aus grundsätzlich verschiedenen Quellen. Dieser ist die Fortsetzung des anderen, und beide konnten dann auch, wie die Judenpolitik der ,Deutschen Christen' zeigt, harmonisch verbunden werden." (Ehrlich: Luther und die Juden, S. 63.) Dieses Zitat, das die gemeinsame Substanz von Judenhass und Antisemitismus völlig richtig als in der gesellschaftlichen Herrschaft liegend sieht, bezieht sich jedoch auf diese gemeinsame Substanz der Herrschaft nicht wirklich, sondern bloß abstrakt. Für Ehrlich unterliegen die zu registrierenden Veränderungen des Antisemitismus nicht in erster Linie dem Form- und Qualitätswechsel von gesellschaftlicher Herrschaft, sondern der Judenhass ist etwas sich raumzeitlich substantiell nicht oder nur marginal veränderndes, etwas mythisch immergleiches: Ein in der christlichen Ablehnung von Juden liegendes Motiv. Gegen den Antisemitismus helfe deshalb auch nur ein auf die Hoffnung seines Verschwindens setzendes „Besinnen“, um dadurch den „eigenen Standort besser [sic!] zu bestimmen.“ (Ebd., S. 64.) Von einer Ewigkeit des Antisemitismus, weil er in den Wurzeln der Menschheit liege, geht auch Henryk M. Broder aus: „Der Antisemitismus gehört zur abendländischen Kultur wie der Glaube an den ewigen Kampf zwischen Gut und Böse, er ist Teil und Erbe der christlichen Tradition“. (Broder: Der ewige Antisemit, S. 56, vgl. aber auch von Braun/Heid: Der ewige Judenhass.)

477 Simmel: Antisemitismus und Massen-Psychopathologie, S. 60.

478 Benz: Was ist Antisemitismus, S. 241.
} 
Damit ignoriert Simmel allerdings konkrete Gesellschaftsstrukturen und der Antisemitismus wirft, als anthropologische Konstante gedacht, auch einen langen Schatten voraus. Diesen langen Schatten bekommt der moderne Antisemitismus jedoch nur, weil man auf einen langen historischen Schatten des Antisemitismus zurückblicken kann. Das verleitet geradewegs dazu, ihn zu ontologisieren: „Die Rede vom, ewigen Antisemitismus' bedeutet deshalb nichts anderes als eine intellektuell-politische Kapitulation vor dem Sachverhalt: Man isoliert den Antisemitismus aus seinem jeweiligen gesellschaftlich-geschichtlichen Kontext und verwandelt ihn in eine anthropologische Konstante."“479

Durch die verewigte Verhärtung wird jedoch noch jede Möglichkeit der Befreiung vom Antisemitismus hinfällig - und seine Überwindung wird dadurch unausweisbar. Die wesentliche Kritik der Konstituentien des verewigten Phänomens wird demnach außer Acht gelassen. Es wird somit nicht die Überwindung herrschaftlicher Strukturen und der negativen Phänomene zum Gegenstand, womit diese und jene zum Unvermeidlichen der Geschichte gemacht werden. Die gesellschaftliche Herrschaft wird deshalb auch einfach nur verewigt, weil sie nicht substantiell theoretisch reflektiert und kritisiert wird. Die gesellschaftliche Struktur wird als naturgleich aufgefasst und soziale Phänomene werden deswegen wie Naturphänomene behandelt. Darauf macht Adorno aufmerksam: „Das Verlangen, Gesellschaft durch Theorie zu bestimmen (...), exponiert sich weiter dem Bedenken, es sei hinter dem stillschweigend als verbindlich supponierten Vorbild der Naturwissenschaften zurückgeblieben. (...) Der Einwand mißt den Begriff der Gesellschaft am Kriterium ihrer unmittelbaren Gegebenheit, dem sie gerade als Vermittlung wesentlich sich entzieht." 480

Dieser gesellschaftswissenschaftliche Naturalismus, der von Gesellschaftsdingen ohne die vermittelt freiheitlichen Möglichkeiten seiner eigenen Existenz spricht - dem vermittelt freien Handeln der lebendigen, selbstbewussten Subjekte bspw. - schlägt dabei auch noch jeden wesentlich vermittelten Gesellschaftsbezug als Konstituens sozialer Phänomene aus. Deren Existenz wird gar nicht mit dem wesentlich über den Köpfen transzendent sich realisierenden Allgemeinen, der nur begrifflich in ihrer Totalität bestimmbaren Gesellschaft, ihrem emphatischen, nicht statischen Begriff, vermittelt. Mittels der Ewigkeitsformel durch die Anthropologisierung von sozialen Phänomenen als vermeintlich natürliche Phänomene verdinglicht man diese realistisch. ${ }^{481}$ Die in Zeit und Raum seiende allgemeine

\footnotetext{
${ }^{479}$ Claussen: Vom Judenhass zum Antisemitismus, S. 66.

480 Adorno, Gesellschaft, S. 11.

${ }^{481}$ Das Argument vom, immerwährenden Sachzwang“, die ausweglose „Sachgesetzlichkeif“ Schelskys, ist ein Beispiel für die Verewigung gesellschaftlicher Strukturen. (Schelsky, Die Arbeit tun die anderen. Klassenkampf und Priesterherrschaft der Intellektuellen, S. 65.) Das Argument des immerwährenden Sachzwangs beschreibt eine angebliche Ausweglosigkeit des sogleich ontologisierten gesellschaftlichen Zwangs - als ob gesellschaftliche Zwänge natürliche Zwänge seien und nicht aus einer falschen, der Möglichkeit aufbrechbaren Vergesellschaftung herrühren. Dass der Sachzwang ontologisiert wird, ist dabei offensichtlich einer Affirmation der bürgerlichen Gesellschaft geschuldet.
} 
Gesellschaftsform wird nicht als durch ihre immanente Strukturgesetzlichkeit die vergänglichen sozialen Phänomene erst faktisch Verdinglichende dargestellt. Die Existenz von sozialen Phänomenen, wie dem modernen Antisemitismus, wird in den sich an naturwissenschaftliche Erklärungsmodelle anbiedernden gesellschaftsontologischen Konzeptionen dadurch gewaltsam von Zeit und konkreter Gesellschaft abgelöst. 482

(2.) Die Antwort auf die Ontologisierung gesellschaftlicher Phänomene fällt nun jedoch nicht weniger problematisch aus: Die Deduktion sozialer Phänomene aus dem vernünftigen Subjekt und dem freien Handeln unterstellt die Deduktion der Gesellschaft als Begriff von reiner, handelnder Intersubjektivität in der Zeit. Weil sich so betrachtet die Gesellschaft aus der Vielzahl der freien Handlungen einzelner vernünftiger Subjekte entspinnen soll, liegt hier ein offensichtlich intersubjektiver Gesellschaftsbegriff vor. Dieser intersubjektive Gesellschaftsbegriff spart die wesentlichen Bedingungen hinter den zweckbestimmten Handlungen der Subjekte aus. In der Soziologie findet sich ein solch strenger Nominalismus/Positivismus bereits in statu nascendi. Schon Max Weber will nur noch mit der Untersuchung des sozialen Handelns die bürgerliche Gesellschaft verstehen, weswegen er die bürgerliche Gesellschaft als bloßes Konglomerat subjektiven Handelns bestimmt. Hinter den Handlungen der Subjekte stünde deshalb auch kein begrifflich bestimmbares Wesen, welches diese Handlungen überhaupt erst zweckmäßig bestimme. Gesellschaft sei einfach nur subjektives Handeln, also Praxis schlechthin: „Soziologie (...) soll heißen: eine Wissenschaft, welche soziales Handeln deutend verstehen und dadurch in seinem Ablauf und seinen Wirkungen ursächlich [sic!] erklären will. ,Handeln' soll dabei ein menschliches Verhalten (...) heißen, wenn und insofern als der oder die Handelnden mit ihm einen subjektiven Sinn verbinden. ,Soziales ${ }^{c}$ Handeln aber soll ein solches Handeln heißen, welches seinem von dem oder den Handelnden gemeinten Sinn nach auf das Verhalten anderer bezogen wird und daran in seinem Ablauf orientiert ist. “" 483

Die Webersche Auffassung hat nun in der Soziologie Karriere gemacht. Auch Jürgen Habermas beschreibt die bürgerliche Gesellschaft als ein bloß additives Resultat individuellen Handelns nach intersubjektiven Richtlinien und Zwecken. Das heißt letztendlich, dass sich für Habermas die bürgerliche Gesellschaft aus völlig herrschaftsfrei entstandenen Gesellschaftskonzepten entspinne: „In Zusammenhängen kommunikativen Handelns darf als zurechnungsfähig nur gelten, wer als Angehöriger einer Kommunikationsgemeinschaft [sic!] sein Handeln an

Wenn der Zwang einmal als anthropologisch unüberwindlich gilt, ist er versöhnlich gerechtfertigt, weil er als ewig so seiender Zwang bestimmt ist.

482 Ähnlich, wenn auch mit anderem Verve und ohne Antisemitismusbezug, ist die späte Gesell-

schaftsontologie von Georg Lukács konzipiert. (Vgl. etwa Lukács: Zur Ontologie des gesellschaftlichen Seins.)

483 Weber: Wirtschaft und Gesellschaft, S. 3. 
intersubjektiv anerkannten Geltungsansprüchen orientieren kann. “484 Die Subjekte seien demnach Subjekte freier Praxis und die bürgerliche Gesellschaft wäre das freiheitliche Resultat ihres intersubjektiven Handelns. Diese von Habermas unterstellte autonom-freiheitlich gedachte Intersubjektivität bezüglich der gesellschaftlichen Geltungsansprüche, nach denen das lebendige Subjekt, um zu überleben, handeln muss, führt auf das bereits in 2.3.1 angesprochene entscheidende Problem ihrer Begrenzung als subjektive Freiheit des Handelns zurück: die entscheidende Heteronomie der Gesellschaft. Habermas wie Weber unterstellen damit eine intersubjektive Zweckbestimmtheit des Handelns und übersehen dabei allerdings, neben dem gesellschaftlichen Antagonismus, Wesentliches: die notwendig dialektische Vermittlung von subjektiven Handlungen und der real verhärteten gesellschaftlichen Objektivität als ihre allgemeinen, wesentlichen Bedingungen der Möglichkeit. Denn „,[d]ie Vorstellung absoluter Freiheit zur Entscheidung ist so illusionär wie je die vom absoluten Ich, das die Welt aus sich heraus entläßt. "485 Nach Adorno wird das zweckbestimmte Handeln der lebendigen Subjekte deshalb wesentlich negativ erst durchs substantiell Allgemeine, durch die konkrete und antagonistische bürgerliche Gesellschaft bestimmt; nicht aber umgekehrt Gesellschaft durch Subjekt/Intersubjektivität: „Eher ist jetzt Subjektivität das Vermittelte als Objektivität, und solche Vermittlung dringender der Analyse bedürftig denn die herkömmliche." ${ }^{\text {"486 }}$

Auch gegenwärtige Theorien über den modernen Antisemitismus erklären den Antisemitismus nun nur noch als aus dem vernünftigen Subjekt und dessen vermeintlich völlig freien, autonomen Handlungen stammend. Damit geben auch Theorien über den modernen Antisemitismus das konstituierende Wesen hinter der Erscheinung als notwendig substantielles Moment der Erklärung des Antisemitismus auf. Solch substanzlose Form der Erklärung des modernen Antisemitismus findet sich beispielsweise bei Ulrich Enderwitz ${ }^{487}$ : Antisemitische Urteile seien ,per definitionem [in] ihrer Vorurteilsstruktur nicht Reaktion auf eine äußere, reale Erfahrung (...), sondern Projektionen eines inneren, intentionalen Konflikts, nicht empirisches Produkt eines Wahrnehmungs- und Erkenntnisprozesses, sondern symptomatischer Ausdruck eines Zwiespalts und Widerstands im wahrnehmenden und erkennenden Subjekt selbst [sic!]." "488 Damit legt Enderwitz die Erklärung des modernen Antisemitismus ins Subjekt, und aus jenem werde dieser gestiftet. So wird das gesellschaftliche Phänomen Antisemitismus einerseits nominalistisch aus dem scheinbar vollkommen autonomen und vernünftigen, urteilendem Subjekt deduziert, das dann aber trotzdem irrational urteilen, schließen und

\footnotetext{
${ }^{484}$ Habermas: Theorie des kommunikativen Handelns, Band 1, S. 34.

485 Adorno, Negative Dialektik, S. 60.

486 Ebd., S. 173.

487 Ulrich Enderwitz, Antisemitismus und Volksstaat. Zur Pathologie kapitalistischer Krisenbewältigung, Freiburg 1998.

488 Ebd., S. 11.
} 
handeln soll: indem es sich den Antisemitismus völlig autonom (und warum und wodurch auch immer) als unsinnigen Zweck setzt. Diese widersprüchliche Interpretation von der autonomen Freiwilligkeit des Subjekts auf der einen und der intentionslosen subjektiven Irrationalität auf der anderen Seite führt Enderwitz parallel. Das vernachlässigt das in allen seinen vermeintlich willkürlichen Handlungen durch das gesellschaftlich Allgemeine vergesellschaftete und gesellschaftlich präformierte vernünftige Subjekt, das ein sich selbst in bürgerlicher Gesellschaft erhalten müssendes Individuum ist (vgl. bspw. 2.3.1). Ohne wesentliche, allgemeine gesellschaftliche Bestimmungen, die über das vereinzelte selbstbewusste Subjekt und seine autonome Freiwilligkeit hinausgehen, bestimmt Enderwitz den modernen Antisemitismus als das Resultat von reiner Intersubjektivität. Dadurch spart er jedoch jede wesentliche Vermittlung mit der dem Subjekt transzendent vorgeordneten heteronomen bürgerlichen Gesellschaft aus. Weil die bürgerliche Gesellschaft für ihn nur ein Resultat von Intersubjektivität und nicht von begrifflich bestimmbaren Strukturgesetzen hinter den intersubjektiven Zwecksetzungen sei, müssen auch die gesellschaftlichen Phänomene für ihn Ausdruck dieser (inter-)subjektiven Freiheit sein. Dergleichen frei, als aus dem Subjekt stammend, bestimmt er dann deshalb auch den faschistischen Staat: „Und wie die gesellschaftlichen Kräfte sich dieser ihrer Widersprüchlichkeit in eine objektive Einheit bannende Identität eben deshalb, weil es ihre eigene [!] ist, fügen müssen, wie sie dem faschistischen Staat eben deshalb, weil er die von ihnen bevollmächtigte Macht [!] ist, ohnmächtig ausgeliefert sind." ${ }^{489}$

Weil der Enderwitzsche moderne Antisemitismus also keinerlei ,Erscheinungsdruck von Außen' kenne, kann dieser für ihn, wenn der moderne Antisemitismus nicht Erscheinung von Nichts sein soll, auch nur aus dem intentionslos irrationalen, lebendigen Subjekt selbst herrühren. Diese Internalisierung des Antisemitismus baut Enderwitz deshalb auch konsequent zu einer Psychologisierung des Antisemitismus aus: „Der entscheidende Punkt ist, daß sich der Antisemitismus kraft seiner Vorurteilsstruktur einer symptomatischen Verschiebungsleistung verdankt, die an die Stelle der Wirklichkeit, auf die er mit seinen Urteilen primär reagiert, eine Ersatz- und Alibirealität treten läßt, auf die er seine Urteile sekundär projiziert. “" ${ }^{\circ 90}$ Wird der Antisemitismus jedoch dergleichen mit einer psychologisch gewendeten Internalisierung ins vergesellschaftete, gesellschaftlich präformierte Subjekt der Praxis gelegt und das Phänomen dann aus jenem in Form einer rein vermittelten Intersubjektivität des Gegenstands erklärt, müssen für Enderwitz die entscheidenden, objektiven Bedingungen des intersubjektiven Handelns der Antisemiten damit ein blinder Fleck bleiben. Weil es keinen wirklich heteronomen, allgemeinen gesellschaftlichen Zwang auf das Subjekt gibt, der seinem der Möglichkeit nach freiheitlichen Handeln einen begrenzenden Rahmen setzt, sondern nur den selbstverschuldeten Zwangszusammenhang eines jeden Subjekts, ent- 
springt der moderne Antisemitismus für Enderwitz nur aus dem intersubjektiven Zusammenhang von Subjekten und deren eigens kreierter bürgerlicher Gesellschaft. Der Antisemitismus wird somit konsequent nur aus dem Subjekt erklärt, weil er allein als aus der Psyche der Subjekte vermittelt und über ihre intersubjektive Praxis gestiftet begriffen wird. Diese Substanzlosigkeit verengt und relativiert seine Erklärung als soziales Phänomen. So wird der moderne Antisemitismus, wie auch die gesellschaftliche Herrschaft, bloß als ein Resultat falscher, intersubjektiver Vergesellschaftung von in ihrer Zwecksetzung anscheinend völlig freien Subjekten gedacht. Diese autonomen Subjekte würden auf zwischenmenschlicher Ebene falsch handeln, weil sie aus ihrer Psyche heraus falsch über das eigens praktisch kreierte gesellschaftliche Allgemeine urteilen würden. Eine solche Unterstellung, dass dieses eigens und völlig autonom Kreierte falsch sei, muss jedoch immer schon auf einer mehr als nur intersubjektiv gedachten Objektivität eines vernünftigen Urteils beruhen. Ein rationales Urteil über richtig und falsch kann es aber gar nicht geben, wenn aus der autonomen Vernünftigkeit sogleich ein Irrationales entspringen soll. Deshalb hat Enderwitz für die eigene Erklärung der Irrationalität des Antisemitismus auch keinen kritischen Maßstab; oder besser: hätte ihn nicht haben dürfen. Seine Erklärung führt deshalb auch zu keiner adäquaten Antwort auf die wirklichen, wesentlichen Voraussetzungen der Phänomene und das wesentlich gesellschaftlich präformierte Handeln der Subjekte der Praxis in der bürgerlichen Gesellschaft. Das soziale Phänomen wäre demnach wie die gesellschaftliche Herrschaft kein Ergebnis einer dialektischen Kommunikation von Verschiedenem, sondern bloß eine tautologische Bestimmung von antisemitischen Zwecken rein aus dem Subjekt. Rational ist diese Tautologie dann aber nicht mehr erklärbar.

Diese subjektivistische Argumentation, dass das soziale Phänomen ein Phänomen der Vergesellschaftung und ausschließlich der Intersubjektivität des Handelns unterliege, objektiv also nicht erklärbar sei, entlässt noch jedes gesellschaftliche Phänomen aus dem dialektischen Versuch der rationalen Bestimmung von Phänomenen durch das somit unkommunikativ bestimmte Subjekt. Die Erklärung des modernen Antisemitismus insbesondere wird damit vollkommen substanzlos und fällt auch hinter die Linien eines rationalen Denkens zurück, das der dialektischen Vermittlung von rationalem Subjekt und allgemeinem gesellschaftlichen Objekt bedarf. Enderwitz kann deshalb, weil er den Begriff von bürgerlicher Gesellschaft dergleichen intersubjektivistisch-positivistisch interpretiert, auch keinen rationalen Begriff vom Antisemitismus mehr haben. Ein solch positivistisches Urteil vom sinnlich wahrnehmbaren sozialen Phänomen ohne jeden (gesellschaftlich) vermittelten, begrifflich bestimmbaren Grund ist jedoch problematisch, weil, bedingt durch die reine Intersubjektivierung der Handlungen die Negation subjektiver Handlungen als aus einer gesellschaftlichen Präformation heraus entstehende Handlungen folgt, wodurch allgemeine, wesentliche Bedingungen der Existenz des sozialen Phänomens nicht mehr zum Gegenstand werden. So wird allein im 
Schein des Unmittelbaren der sozialen Phänomene steckengeblieben. Selbst wenn die sozialen Phänomene nun funktional beschrieben und durchdekliniert werden, ja sogar noch die intendierten Absichten der handelnden vergesellschafteten Akteure richtig eingeschätzt werden können: die wesentliche Begründung der erfahrbaren Fakten des sozialen Gegenstands, das, was nicht unmittelbar faktisch mit dem Phänomen und dem Handeln der Subjekte erscheint oder sichtbar, sondern nur vermittels der begrifflichen Reflexion auch als Transzendenz einer totalen Gesellschaft deutlich wird, ist nicht derart belanglos (vgl. 1, Ausführungen zu Comte).

Ein subjektivistischer Verlust der wesentlich transzendenten Objektivität des im gesellschaftlichen Zusammenhang erscheinenden Phänomens durch die unkommunikative Internalisierung des Phänomens hat dabei jedoch noch weitere Konsequenzen: Die intersubjektivistische Konventionalisierung der Gesellschaft, ihrer Prozesse und ihrer Phänomene resultiert notwendig in einem subjektivistischen Sozialkonstruktivismus. Durch die konstruktivistische Konzeption eines sich unbedingt frei für sein gesellschaftliches Handeln und frei fürs soziale Phänomen entscheidenden Subjekts werden die tatsächlichen gesellschaftlichen Herrschaftsverhältnisse immer nur als rein intersubjektiv begriffen. Dadurch wird die substantielle Kritik des sozialen Phänomens fernab von moralistischer oder skeptischer Kritik unmöglich, weil das Phänomen einer freiheitlichen Zwecksetzung entspricht und die Zwecksetzung selbst nicht mit einem aus heteronomer Gesellschaft folgenden, vermittelten Zwang kritisiert wird. Der soziale Gegenstand kann jedoch nicht dergleichen von allem wesentlich Objektiven, von aller verdinglichten intelligiblen Nichtidentität und vorrangig transzendenten, objektiven Wesentlichkeit, sprich: aus der negativen Totalität und dem Zwang der Gesellschaft auf das Subjekt gelöst werden.

Enderwitz' vorgestellte konstruktivistische Position ist jedoch keine isolierte. Schon Jean-Paul Sartre vertritt in den Überlegungen zur Judenfrage eine strenge (sozial-)konstruktivistische Position hinsichtlich des modernen Antisemitismus, die eine Konsequenz des in seinem Oewvre systematischen Dezisionismus ist. ${ }^{491}$ Dadurch tritt auch Sartre in sich widersprüchlich, subjektivistisch an die Gegenstände heran. Sartre argumentiert dabei aus einer radikal nominalistischen Position, die sich, durchaus ambivalent, dem idealistischen Credo der freien Tathandlung des Subjekts verschreibt. Adorno fasst Sartres theoretischen Widerspruch

\footnotetext{
${ }^{491}$ Schon oben wurde Sartres Begriff von Freiheit angeführt, der sich aufs einzelne Subjekt beschränkt. Freiheit selbst meint bei Sartre eine Autonomie des Subjekts zur völlig freien Wahl des subjektiven Handelns: „Tatsächlich sind wir eine Freiheit, die wählt, aber wir wählen nicht, frei zu sein: wir sind zur Freiheit verurteilt (...), in die Freiheit geworfen“. (Sartre: Das Sein und das Nichts, S. 838.) Adorno schreibt bezüglich Sartres Dezisionismus: „Je weniger objektiv Chancen ihr die gesellschaftliche Machtverteilung bot, desto ausschließlicher hat er die Kierkegaardsche Kategorie der Entscheidung urgiert. Bei jenem empfing sie ihren Sinn vom teminus ad quem, der Christologie; bei Sartre wird sie zu dem Absoluten, dem sie einmal dienen sollte.“ (Adorno: Negative Dialektik, S. 59.)
} 
recht gut zusammen: „Trotz seines extremen Nominalismus organisierte sich Sartres Philosophie in ihrer wirksamsten Phase nach der alten idealistischen Kategorie der freien Tathandlung des Subjekts. Wie für Fichte ist für den Existentialismus jegliche Objektivität gleichgültig. Folgerecht wurden in Sartres Stücken die gesellschaftlichen Verhältnisse und Bedingungen allenfalls aktueller Zusatz, strukturell jedoch kaum mehr als Anlässe für die Aktion. Diese ward von Sartres philosophischer Objektlosigkeit zu einer Irrationalität verurteilt, die der unbeirrbare Aufklärer gewiß am wenigsten meinte. Die Vorstellung absoluter Freiheit zur Entscheidung ist so illusionär wie je die vom absoluten Ich, das die Welt aus sich heraus entläßt." 492

Weil Sartre also seinen philosophischen Subjektivismus und dessen entsprechendes Resultat von absoluter Freiheit zur Entscheidung auf die Gesellschaftstheorie überträgt, wird ihm der moderne Antisemitismus zur völlig ,freie[n] und totale[n] Wahl“"493 eines unbedingt autonom bestimmten Subjekts. Zwar lässt sich der moderne Antisemitismus auch nicht einfach als ein notwendiger, objektiver Zwang aus den Institutionen der bürgerlichen Gesellschaft herleiten (das haben vor allem bereits die obigen Bestimmungen des reflexiven Subjektbegriffs deutlich gemacht (vgl. 2.3.1); doch es kann die offensichtlich dialektische Verwiesenheit des modernen Antisemitismus auf den objektiven Zwang des transzendent Allgemeinen nicht herausgearbeitet werden, wenn über die Fokussierung auf die ,freie und totale Wahl' alles hinter dem sozialen Faktum Antisemitismus Stehende, all sein gesellschaftlich Wesentliches einfach negiert wird. Sartres dezisionistischer Sozialkonstruktivismus geht deshalb von nur intersubjektiv konstruierten Phänomenen der gesellschaftlichen Wirklichkeit aus, ohne dass dabei auf die notwendig transzendente (gesellschaftliche) Substanz gesellschaftlicher Erscheinungen reflektiert wird. 494

Aber nicht nur Sartres (Sozial-)Konstruktivismus steht damit dem strengen Dezisionismus Carl Schmitts ${ }^{495}$, der einen unbändigen Subjektivismus voraussetzt,

\footnotetext{
492 Ebd., S. 59 f.

${ }^{493}$ Sartre: Überlegungen zur Judenfrage, S. 14. Auch Ingo Elbe sieht den „Sartreschen Dezisionismus", der sich aus der Verbindung der systematischen Überlegungen aus Das Sein und das Nichts mit der Judenfrage ergibt. (Elbe: Angst vor der Freiheit, S. 21.)

494 Die Antisemitismustheorie Sartres hat allerdings auch viele richtige, emanzipative Momente. Sie kann deshalb auch nicht ignoriert werden. Sartres Portrait des Antisemiten nimmt nämlich erstmals eine nahezu komplette psychologische Beschreibung des Antisemiten vor. Auf diese Beschreibung des Denken und Fühlens des Antisemiten wird in den nach Sartre nachfolgenden Antisemitismustheorien aufgebaut. (Vgl. Samuel Salzborn, Antisemitismus als negative Leitidee der Moderne, S. 62 ff.)

${ }^{495}$ Schmitts strenger Subjektivismus setzt die Möglichkeit der Veränderung von Strukturen allein durch die Autorität eines einzelnen Subjekts, des souveränen Führers, voraus: „Der Führer schützt das Recht vor dem schlimmsten Mißbrauch, wenn er im Augenblick der Gefahr kraft seines Fuhrertums als oberster Gerichtsherr unmittelbar Recht schafft: ,In dieser Stunde war ich verantwortlich für das Schicksal der deutschen Nation und damit des Deutschen Volkes oberster Gerichtsherr.
} 
viel näher als es das Selbstverständnis der sich politisch-praktisch von rechten Denkern distanzierenden Theorien wahrhaben möchte. ${ }^{496}$ Der Konstruktivismus macht, wie es Berger und Luckmann in ihrem grundlegenden Werk, Die gesellschaftliche Konstruktion der Wirklichkeit ${ }^{497}$, durchführen, die gesellschaftlichen Herrschaftsverhältnisse, wie auch Enderwitz, immer zu nur scheinbar verdinglichten Herrschaftsverhältnissen. Bei Berger und Luckmann vemisst man, wie bereits bei Sartre, jegliche notwendig reale Substanz gesellschaftlicher Selbständigkeit, die über das entscheidende Subjekt und die Intersubjektivität hinausgeht. Deswegen erübrigt sich für sie auch der Begriff des Korrelats als eines der Möglichkeit nach reflektierten Objekts. Die Herrschaftsverhältnisse erscheinen konstruktivistischen Verdinglichungskonzepten insofern konsequent als dem unbedingt freien Subjekt nur entglittene gesellschaftliche Verhältnisse. Diese könnten deshalb jederzeit auch wieder aufgebrochen werden, sich also einfach - weil ja eigene, wenn auch intersubjektiv verdinglichten Verhältnisse - zurückgeholt werden. Demnach muss den Subjekten die eigentliche Position der Macht ihres eigenen Handelns erst mit der Zeit unbewusst geworden sein. Die offensichtliche Machtlosigkeit des einzelnen vergesellschafteten Subjekts wird insofern nur als bloß vorübergehende Position der Entscheidungsschwäche in der subjektiven bzw. intersubjektiven, verblendeten Zwecksetzung gedeutet.

Damit spricht der Konstruktivismus den Begriffen der subjektiven Beschreibung der objektiven sozialen Wirklichkeit - konsequenterweise auch dem modernen Antisemitismusbegriff - ein jegliches Eigensein oder Eigenleben ab. Es wird nicht über das vereinzelte, denkende und freie Subjekt objektiv hinausgedacht, um damit gesellschaftliche Totalität emphatisch zu denken. Alle gesellschaftlichen Prozesse, alle Strukturgesetze der zweiten Natur, die die sozialen Erscheinungen als Handlungsweisen der Subjekte erst hervorbringen, scheinen sich durch die Internalisierung von Gesellschaft und deren Prozesse doch noch irgendwo sicher, versöhnt in der führenden Hand der einzelnen, handelnden, aber zeitweilig schwachen Subjekte zu befinden. Transzendente, den Subjekten übergeordnete reale gesellschaftliche Prozesse kennt der Sozialkonstruktivismus darum genauso wenig wie gesellschaftliche Strukturgesetze, die die vergesellschafteten Subjekte in ihren zweckgerichteten Handlungen über den objektiven Zwang zur eigenen Selbsterhaltung präformieren und damit heteronom bestimmen. So beruhen die Bedingungen der allgemeinen Reproduktion der Gesellschaft auf einem, wie und wodurch auch immer, falsch bestimmten intersubjektiven Konsens der Zwecksetzung, und nicht aus dem fürs einzelne Subjekt heteronomen, objektiv herrschaftlichem Zwang.

\footnotetext{
Der wahre Führer ist immer auch Richter. Aus dem Fuhrertum fließt das Richtertum.“ (Schmitt: Der Führer schützt das Recht, vgl. auch Schmitt, Carl: Politische Theologie, S. 11 ff.) 496 Vgl. zum kritischen linken Selbstverständnis bei Sartre etwa Heter: Sartre's Political Philosophy. 497 Vgl. Berger/Luckmann: Die gesellschaftliche Konstruktion der Wirklichkeit.
} 
Lässt man die vorgestellten subjektivistischen Lesarten von gesellschaftlichen Phänomenen einmal Revue passieren, wird auch schnell deutlich, dass all die Konzeptionen der Erkenntnis von Objektivität reductione ad hominem ohne den entscheidenden Begriff vom erkennbaren gesellschaftlichen Wesen als der objektiv vorrangigen Wahrheit hinter sozialen Erscheinungen arbeiten. Diese Wesensfeindlichkeit ist das entscheidende Problem: Weil Wesen, Substanz und Wahrheit immer emphatische Begriffe des objektiven Erkennens der Transzendenz bleiben, sind diese Begriffe notwendig. Kein soziales Phänomen wie der Antisemitismus lässt sich ohne dieses die Erscheinung konstituierende Wesen, die Substanz o.ä. erschließen. Anders als dem antikantianisch gedachten und offensiven positivistische Credo aus dem Tractatus Wittgensteins entsprechend - „Worüber man nicht sprechen kann, darüber muss man schweigen. “498 - muss gerade das, was hinter der gesellschaftlichen Erscheinung strukturell als ihr zweckbestimmendes, nur begrifflich bestimmbares Wesen, als objektive Möglichkeit der Erscheinung verborgen liegt, vernünftig begriffen werden, um darüber zu sprechen: „Und insofern muß man wohl auch sagen, daß der Begriff der Philosophie selber die widerspruchsvolle Anstrengung sei, durch ihren Zusammenhang und durch ihre Vermittlung das zu sagen, was unmittelbar, hic et nunc nicht sich sagen lasse; daß insofern die Philosophie ihrem eigenen Begriff nach widerspruchsvoll, also in sich selbst dialektisch sei. “499 Nur ohne die positivistische Philosophiefeindlichkeit kann sich dann auch von gefährlichen gesellschaftlichen Erscheinungen wie dem Antisemitismus nachhaltig verabschiedet werden. Die Überwindung des Antisemitismus ist also nur dann denkbar, wenn sich von seinen wesentlichen Bedingungen, die nicht aus seiner Erscheinung heraus offensichtlich sind, verabschiedet wird. Um das soziale Phänomen als Manifestation des gesellschaftlichen Wesens abzuschaffen, um die Zwecke des sozialen Phänomens in vermitteltem Bezug aufs Allgemeine abzuschaffen, muss das gesellschaftliche Wesen der sozialen Erscheinung als eine vermittelte Besonderung eines falschen, wesentlich Allgemeinen zunächst theoretisch denunziert, danach dann praktisch abgeschafft werden. Deshalb muss über das Wesen des sozialen Phänomens gesprochen werden, was eben nicht aus dem sozialen Phänomen unmittelbar herausschaut, sondern der reflektierten, begrifflichen Arbeit bedarf.

\subsubsection{Die gesellschaftstheoretische Vermittlung von Wesen und Phänomen}

Gegen die allgemeine subjektivistisch-konstruktivistische Trennung von begrifflich bestimmbarem Wesen und sozialer (oder sonstiger wissenschaftlich zu ergründender) Erscheinung lässt sich mit gesellschaftstheoretischen Überlegungen von Marx und Adorno argumentieren. Im dritten Band des Kapitals schreibt Marx, dass ,alle Wissenschaft (...) überflüssig“ sei, ,,wenn die Erscheinungsform und das

\footnotetext{
498 Wittgenstein, Tractatus logico-philosophicus, S. 7.

${ }^{499}$ Adorno: Vorlesung über Negative Dialektik, S. 112.
} 
Wesen der Dinge unmittelbar zusammenfielen. “500 Wahr sei demnach, in der Folge eines Zusammenfallens von Wesen und Erscheinung, nur noch, was dem selbstbewussten Subjekt ohne Reflexion aufs Selbstbewusstsein und notwendig in Begriffen explizierte Wahrheit hinter den Dingen unmittelbar als Faktum erscheine. Wenn dergestalt nichts intelligibles, durch das vernünftige Subjekt nur begrifflich Bestimmbares als das Wesen hinter den Phänomenen und als diese in ihren Zwecken Bestimmendes walten würde, wäre die wissenschaftliche Ausbreitung von Gegenständen auch nicht nur überflüssig, sondern albern. Darum hält Marx gegen jeden Positivismus ${ }^{501}$ am Wesensbegriff fest. Für ihn bekommt deshalb auch die Wahrheit über Gesellschaft einen noumenalen Charakter, womit auch sie der unmittelbaren Decodierung durchs Subjekt entzogen ist. Auch durch den erscheinenden sozialen Gegenstand wirke deshalb eine zwar nicht unmittelbar erscheinende, aber begrifflich vernünftig zu begreifende gesellschaftliche Totalität, deren adäquate Bestimmung für ein objektiv richtiges Urteil über die sozialen Dinge wesentlich wird. Aus der Erscheinung selbst sei das gesellschaftliche Wesen den Subjekten so wenig ersichtlich, wie das Wesen als objektive Möglichkeit der Erscheinungen nicht aus den Erscheinungen unmittelbar herausschaut - oder es nicht tautologisch als petitio principii im Subjekt verborgen liegt. Damit hält Marx an der vernünftigen Denkleistung des selbstbewussten Subjekts gegen die angebliche Offensichtlichkeit von Fakten und Sinnen fest. Dieses kritische Festhalten von Marx am Wesensbegriff ist mit der Entscheidung für die Reflexionsleistung eines selbstbewussten Subjekts auch eine Entscheidung für eine allgemeine und notwendige Objektivität der subjektiven Urteile von den Dingen. Marx verzichte demnach auf die Tautologie des positivistischen Denkens und gehe darum, so Haag,

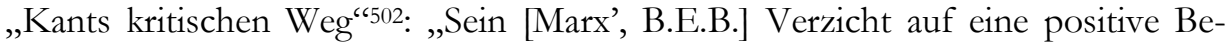
stimmung, also auf die Ernennung von ,Abstraktionen von Naturbestimmungen zu metaphysischen Wesenheiten, war der Verzicht auf tautologisches Denken. “503

Auch Adorno hält an der auf den Begriff gebrachten Wahrheit hinter den erscheinenden Tatsachen/Fakten/Handlungen fest. Mit seinem Wesensbegriff orientiert er sich offensichtlich an Marx, ohne ihn dabei jedoch als entscheidende Referenzquelle zu nennen: „Wenn Adorno die Negativität des gesellschaftlichen Wesens benennt, dann tut er das zunächst mit Marxschen Mitteln.“504 Ein hinter den Gesellschaftsphänomenen waltendes Wesen, das jedes soziale Faktum erst in seiner Erscheinung bedinge, ist insofern auch für Adorno essenziell: „Eine dialektische Theorie der Gesellschaft geht auf Strukturgesetze, welche die Fakten bedingen, in ihnen sich manifestieren und von ihnen modifiziert werden. Unter Struk-

\footnotetext{
${ }^{500}$ Marx: Das Kapital, Bd. 3, S. 825.

501 Marx formuliert an der oben zitierten Stelle gegen die „Vulgärökonomie“ - aber im Kapital setzt er sich auch schon mit dem Frühsozialisten Saint-Simon auseinander, der ein Vorreiter der positivistischen Soziologie Comtes ist. (Vgl. Ebd., S. 618 ff.)

${ }^{502}$ Haag, Der Fortschritt in der Philosophie, S. 110.

503 Ebd.

504 Schweppenhäuser: Theodor W. Adorno zur Einführung, S. 74.
} 
turgesetzen versteht sie Tendenzen, die mehr oder minder stringent aus historischen Konstituentien des Gesamtsystems folgen. “505 Die hinter den sozialen Erscheinungen wirkenden allgemeinen Wesens- oder Strukturgesetze seien, gegen jeden sozialwissenschaftlichen Positivismus gedacht, ,wirklicher als das Faktische, in dem sie erscheinen und das über sie betrügt. (...) Zu benennen wären sie als die auf ihren Begriff gebrachte Negativität, welche die Welt so macht, wie sie ist.“"506 Und zu „bestreiten, daß ein Wesen sei, heißt sich auf die Seite des Scheins, der totalen Ideologie schlagen, zu der mittlerweile das Dasein wurde.“507 Deswegen müsse der Wesensbegriff, nicht nur gegen den erweiterten positivistisch operierenden Wiener Kreis ${ }^{508}$ um Wittgenstein und Popper, sondern auch gegen den sukzessive sich durchsetzenden Positivismus in den Wissenschaften, ein notwendiger Begriff in der Gesellschaftstheorie bleiben. Nur dann könne überhaupt noch kritisch am sozialen Phänomen gearbeitet werden: Denn „Positivismus wird zur Ideologie, indem er erst die objektive Kategorie des Wesens ausschaltet und dann, folgerecht, das Interesse an Wesentlichem. “509 Als auf den „Begriff gebrachte Negativität" ${ }^{\text {" } 510}$ wird der Wesensbegriff für Adorno in der dialektischen, kritischen Unterscheidung von gesellschaftlichem Wesen und Erscheinung zum „Unwesen" ${ }^{\text {“511. }}$.

Das Unwesen ist ein von Adorno für das falsche gesellschaftliche Wesen gewählter Terminus, der die wesentlich antagonistische, die dem Subjekt gegenüberstehende heteronom zwingende totale Gesellschaft beschreibt, die sich auch für die Hervorbringung der, falschen' sozialen Fakten verantwortlich zeigt. Die antagonistische Gesellschaft ist dem Subjekt dabei immer transzendent und wesentliches Konstituens des sozialen Faktums. Sie ist für Adorno die negativ gedachte „herrschende Allgemeinheit “ 512 einer totalen Gesellschaft, die mit dem Unwesenbegriff auf den dialektisch adäquaten Begriff gebracht wird. So steht der Unwesensbegriff im Zusammenhang einer beißenden Kritik dessen, was als sinnlich wahrnehmbare gesellschaftliche Erscheinung des nur begrifflich bestimmbaren Unwesens existiert. Auch Marx verwendet den Begriff des Unwesens bereits, allerdings noch in einem ganz anderen Kontext: Er kritisiert damit den idealistischen Wesensbegriff Hegels: Weil Wesen bei Hegel völlig ungegenständlich gedacht werde, sei dieser idealistische Wesensbegriff ein völlig substanzloser Begriff. Der Hegelsche Wesensbegriff repräsentiere insofern ein nur abstrakt gedachtes, ein unwirkliches geistiges Gebilde, ein reines Gedankenkonstrukt: „Aber ein ungegenständliches Wesen ist ein unwirkliches, unsinnliches, nur gedachtes, d.h. nur

\footnotetext{
505 Adorno: Spätkapitalismus oder Industriegesellschaft?, S. 356.

506 Adorno: Negative Dialektik, S. 171.

507 Ebd.

508 Vgl. Geier: Der Wiener Kreis.

509 Adorno: Negative Dialektik, S. 172.

510 Ebd.

511 Ebd.

512 Ebd.
} 
eingebildetes Wesen, ein Wesen der Abstraktion.“"513 Ein ,Wesen der Abstraktion“ sei für den frühen Marx demnach metaphysisch verstaubt, weil eben nicht bei Sinnen: „Ein ungegenständliches Wesen ist ein Unwesen.“514

Das ist eine noch streng nominalistische Kritik an Hegels Idealismus durch den jungen Marx. Diesen frühschriftlichen Nominalismus gibt Marx dann im Kapital aber nicht zuletzt mittels des objektiven Arbeitsbegriffs auf. 515 Doch nicht nur der Arbeitsbegriff könnte von einer unter nominalistischen Prämissen stehenden Theorie noch nicht formuliert werden, auch die Marxschen Begriffe von Klasse, Mehrwert etc. wären dergleichen unmöglich zu formulieren. Denn wenn nur gelten soll, was gegenständlich und bei Sinnen ist, könnte den genannten Begriffen sowie auch den politisch-ökonomischen Gesetzen nicht wirklich beizukommen sein. Marx sieht diese eigene nominalistische Aporie im Kapital, weswegen er dort die Substanz einer wesentlich richtigen Aussage von der Übereinstimmung mit der offensichtlichen Sinnlichkeit in den Begriff von der Sache legt - die Substanz wird hier zum Material begrifflichen Denkens.

Adornos Unwesensbegriff ist nun, anders als bei Marx, von Beginn an kein pejorativer Begriff, sondern ein emphatisch-kritischer Begriff. Das verweist auf einen spezifischen, inhaltlichen Unterschied im Umgang mit dem Unwesensbegriff von Marx und Adorno. Adorno versucht nicht nominalistisch - mittels des Unwesensbegriffs - geistige Gebilde als bloß reine subjektive Konstruktionen zu überführen. Gesellschaft ist ihm als Allgemeinbegriff deswegen beispielsweise nie ein nominalistischer flatus vocis, nur weil sie nicht unmittelbar angeschaut werden könne: „Gesellschaft ist in der Kritischen Theorie kein bloßer Funktions-, sondern vor allem Strukturbegriff." ${ }^{16}$

Der Unwesensbegriff Adornos verknüpft sich gesellschaftstheoretisch nun mit dem Begriff des falschen Wesens. Das Wesen der bürgerlichen Gesellschaft sei ihr Unwesen, was wiederum die herrschende Allgemeinheit bezeichne. ${ }^{517}$ Das Unwesen kann deshalb als eine Metapher für die gesamtgesellschaftliche Irrationalität der bürgerlichen Gesellschaft gelesen werden. Wenn Adorno nun auch an den spezifischen Begriff des Unwesens aus Marx' Frühschriften anknüpft, so aber doch nur noch formell-sprachlich. Das falsche Allgemeine ist für ihn nicht deshalb gleich falsch, weil es für ihn wie schon für Marx ungegenständlich ist; Adorno möchte den Wesensbegriff nicht, wie der frühe Marx in diesem Fall, positivistisch mit gegenständlichen, in den Sinnen seienden Erscheinungen gleichsetzen, obgleich der Begriff des (Un-)Wesens auf sinnliche Erscheinungen, Manifestationen als Beweis seiner Existenz - auch was soziale Phänomene wie den Anti-

\footnotetext{
513 Marx: Kritik der Hegelschen Dialektik und Philosophie überhaupt, S. 579.

${ }^{514}$ Ebd., S. 578.

515 Vgl. hierzu Mensching: Nominalistische und realistische Momente des Marxschen Arbeitsbegriffs, S. $60 \mathrm{ff}$.

516 Schweppenhäuser: Theodor W. Adorno zur Einführung, S. 72.

517 Vgl. Adorno: Negative Dialektik, S. 172.
} 
semitismus angeht -, immer angewiesen bleibt: „Aber diese objektiven Bewegungsgesetze [als allgemeines Wesen hinter den Erscheinungen, B.E.B.] haben Gültigkeit nur so weit, wie sie tatsächlich in sozialen Phänomenen sich ausdrücken und nicht, wenn sie im Sinn einer bloß deduktiven Ableitung aus reinen Begriffen, und mögen diese Ableitungen noch so tief in gesellschaftlicher Erkenntnis verwurzelt sein, sich erschöpfen. “518 Streng antinominalistisch bleibt Adornos Kritik der antagonistischen, totalen Gesellschaft als Unwesen also auf vernünftige Begriffe angewiesen, weil das Unwesen nicht unmittelbar erscheinen kann. Auch die Bestimmung des Unwesens hinter den sozialen Erscheinungen bleibt darum aufs selbstbewusste Subjekt und auf dessen adäquate Reflexion angewiesen, weil auch diesem nur mit dem rationalen, selbstbewussten Subjekt kritisch beizukommen ist. Die sinnlich wahrnehmbaren sozialen Phänomene verweisen als Manifestationen der gesellschaftlichen Totalität erst auf jenes hinter ihnen wirkende, objektiv vorrängige gesellschaftliche (Un-)Wesen, das sie nicht selber sind - und das sich der unmittelbaren Identifikation auch immer entzieht. Die jeweilige Manifestation als soziale Erscheinung ist eine Manifestation des dem Subjekt gegenüber feindlichen, heteronomen Wesens. Dieses antagonistisch falsche, feindliche gesellschaftliche Allgemeine setzt und verwirklicht falsche, das Subjekt verdinglichende Zwecke. ${ }^{519}$ Nicht nur brandmarkt der Unwesensbegriff die Wahrheit hinter den sozialen Phänomenen dialektisch als unwahr, weil das, was hinter der Erscheinung liegt, sich gemäß seiner reflektierten Zwecksetzungen als irrational und unwahr erweist. Die (un-)wesentliche Wahrheit hinter den Fakten ist deshalb auch ambivalent: wahr und unwahr zugleich: Wahr, eben weil tatsächlich gesellschaftliche Fakten hervorbringend, unwahr jedoch, weil Gesellschaft eine antagonistische, feindliche Gesellschaft ist und Herrschaft über die unter sie befassten Subjekte ausübt.

Der Unwesensbegriff Adornos formuliert nun auch eine deutliche Kritik am verwässerten oder aufgegebenen Wesensbegriff, der sich (wie nicht nur bei den Protagonisten des Wiener Kreises deutlich wird ${ }^{520}$ ) auf die Gesellschaftstheorie überträgt. Allein das Festhalten am Wesensbegriff impliziert dabei schon eine deutliche Kritik an subjektivistischen und positivistischen Gesellschaftstheorien. Diese schaffen, wie an Enderwitz, Berger, Luckmann, Sartre etc. bereits herausgearbeitet (vgl. 2.5.1), den vorgestellten emphatischen (Un-)Wesensbegriff über ihre gewaltsame Reduktion alles Auswendigen auf das unbedingt frei gedachte Subjekt konstruktivistisch/positivistisch ab. Zwar bekommt die Transzendenz der heteronomen Gesellschaft durch die begrifflichen Bestimmungen - was da hinter den Fakten und den eigenen Handlungen waltet - notwendig auch immer ein Stück von Immanenz, die der Subjektivismus dann verabsolutiert. Diese Immanenz ist jedoch allein schon durch die Begrifflichkeit nicht positivistisch mit einer Identität von Subjekt und Nichtidentität zu verwechseln. Die gesellschaftliche Transzen-

\footnotetext{
518 Adorno: Vorlesung zur Einleitung in die Soziologie, S. 23.

519 Vgl. Adorno: Negative Dialektik, S. 172.

${ }^{520}$ Vgl. Cassirer: Substanzbegriff und Funktionsbegriff.
} 
denz geht auch nach Adorno nicht reduktionistisch in einem konstruktivistisch gedachten Subjekt auf: „Was die Tatsachen vermittelt, ist gar nicht so sehr der subjektive Mechanismus, der sie präformiert und auffaßt, als die dem Subjekt heteronome Objektivität hinter dem, was es erfahren kann." ${ }^{521}$ Der subjektivistischen Gesellschaftstheorie sind solche Reflexionsbegriffe, die auf eine heteronome, in sich autonome Objektivität gehen, jedoch apokryph. Sie lehnen mit dem Wesensbegriff deshalb auch die Objektivität und vice versa Wesentliches und Substantielles ab: „Positivismus wird zur Ideologie, indem er erst die objektive Kategorie des Wesens ausschaltet und dann, folgerecht, das Interesse am Wesentlichen." ${ }^{\circ 22}$

Adornos antisubjektivistischer Unwesensbegriff ist als Reflexionsbegriff nun nicht nur als eine Kritik an der Substanzlosigkeit der subjektivistischen Gesellschaftstheorie zu verstehen, sondern auch als eine Kritik am alten metaphysischen Wesensbegriff. Der traditionelle, metaphysische Wesensbegriff stelle die Welt immer als wesenhaft sinnvolle, gemäß ihren allgemeinen Zwecken richtige Welt, dar. Diese Affirmation des Bestehenden lasse sich, vor allem mit Blick auf die antagonistische Gesellschaft, logisch und historisch jedoch nicht aufrechterhalten: „Das Wesen selbst ist nicht eines mit Sinn, es ist nicht eine Positivität ,sui generis‘, sondern es ist viel eher der Verstrickungszusammenhang und der Schuldzusammenhang, in den alles Einzelne verflochten ist, und der in allem Einzelnen sich manifestiert. " ${ }^{\text {5 } 23}$ Das Wesen verliere sich deshalb nicht in einer unvermittelt ontologischen metaphysischen Wesenheit hinter den Dingen, wie schon der frühe Marx an Hegel kritisiert. ${ }^{224}$ Alles Erscheinende erscheint in der Tradition insofern nur als identische Manifestation des ontologisch hinter diesem wirkenden und vom Subjekt abgetrennten Rationalen. Das moderne Wesen falle dagegen, wie Krahl herausarbeitet, in „die Sphäre endlicher Seinsbestimmungen, in die der

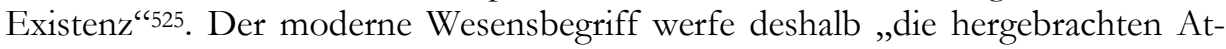
tribute ihrer Wesenhaftigkeit ab." ${ }^{526}$ Krahl verdeutlicht, dass, gegen die Tradition

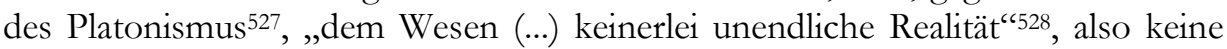

\footnotetext{
521 Adorno: Negative Dialektik, S. 172.

522 Ebd.

523 Adorno: Vorlesung zur Einleitung in die Soziologie, S. 22.

${ }^{524}$ Das ist ein früher positivistischer, Platonismusvorwurf' an Hegel, der Marx dann wiederum von Popper gemacht wird: „Die ganze Idee - sie ist keine Erfindung [!] von Marx -, daß es etwas binter den Preisen gibt, einen objektiven oder wirklichen oder wahren Wert, zu dem sich die Preise nur wie ,Erscheinungsformen' verhalten, zeigt klar genug den Einfluß des platonischen Idealismus mit seiner Unterscheidung zwischen einer verborgenen wesentlichen oder wahren Realität und einer zufälligen oder trügerischen Erscheinung.“ (Popper: Die offene Gesellschaft und ihre Feinde, Bd. II, S. 206.) 525 Krahl: Konstitution und Klassenkampf, S. 35.

526 Adorno: Negative Dialektik, S. 171.

527 „Von der Scheidung beider, des Ansichseienden und des sinnlichen Phänomens, geht seit Platon die Faszination aus, durch welche die große europäische Philosophie sich konstituierte." (Haag: Der Fortschritt in der Philosophie, S. 21.)

${ }^{528}$ Krahl: Konstitution und Klassenkampf, S. 35.
} 
idealisierte (zeitlose) Konstanz zukomme. Der moderne Wesensbegriff wird deshalb vom Denken des lebendigen Subjekts nicht abgespalten und auch nicht ins subjektive, damit es verabsolutierende Denken hineingezogen, sondern inzwischen als vom Subjekt erschlossener Denkzusammenhang der (gesellschaftlichen) Totalität aufgefasst. Die Kritik am traditionellen Wesensbegriff verträgt sich aber, weil negativ vermittelt, trotzdem mit dem intellektuellen Festhalten an seinem metaphysischen Kerngedanken. Für eine emphatische Kritik der Gesellschaft, die auf die unscheinbare Totalität der bürgerlichen Gesellschaft hinter den sozialen Phänomenen geht, wird dieser Gedanke sogar notwendig. Wesen und Erscheinung ,entstammen der philosophischen Tradition, werden festgehalten, aber ihrer Richtungstendenz nach umgewendet.“ ${ }^{\circ 529}$

Die Kritik Adornos und Krahls am traditionellen Wesensbegriff zeigt sich dabei als eine spätestens mit Marx' Kapital ins Leben gerufene materialistische Kritik der philosophischen Tradition. Die historischen Ergebnisse des Denkens werden mit der Kritik nun nicht einfach irrational über Bord geworfen, sondern es werden mit ihr, die Tradition reflektierend aufhebend, gesellschaftstheoretische Implikationen angegangen. Die Reflexion der gesellschaftlichen Totalität bleibt dabei eine entscheidende Denknotwendigkeit und Voraussetzung von Gesellschaftskritik überhaupt. Dass diese dem Subjekt überhaupt erkenntnistheoretisch zugänglich ist, liegt dabei an der immanenten Intelligibilität gesellschaftlicher Bewegungsgesetze, die allesamt Gesetze aus der zweiten Natur sind. Die intelligiblen Strukturgesetze des rational erkennbaren gesellschaftlichen Wesens entziehen sich zwar auch als ein Stück weit widerständig selbsttätig Seiende dem denkenden Subjekt, weil das richtige Denken, auch über Gesellschaft, nicht unverlierbar ist (vgl. 2.3.1). Bei der Arbeit mit dem Begriff der gesellschaftlichen Totalität muss dieses als rational erkennbares, hinter den Fakten liegendes Prinzip/Konstituens der Existenz der sozialen Phänomene angenommen werden, das sich durch seine automatisierte Selbständigkeit als zweite Natur auch immer wieder seiner absoluten Erkenntnis als Nichtidentität entzieht. Auch die Gesellschaft hat demnach als zweite Natur eine innere Form, die der Möglichkeit nach für das vernünftige Subjekt und seine Reflexion der gesellschaftlichen Totale erkennbar und veränderbar ist (vgl. hierzu dann 2.5.3). Diese intelligible gesellschaftliche Totalität ist insofern die objektiv erkennbare, allgemeine Gesetzmäßigkeit hinter den sich relativ zu ihr funktional verhaltenden sozialen Erscheinungen. Diese gesellschaftliche Totalität ist insofern die in sich erkennbare metaphysische Grundlage aller sozialen Phänomene: deren gesellschaftliches (Un-)Wesen: „Und gerade darum geht es Marx: den Vorrang des Gesichtspunktes der Totalität behaupten heißt, die dem Menschen gegebene Möglichkeit anerkennen, sich praktisch wie theoretisch die Wahrheit des Ganzen anzueignen. “530

\footnotetext{
529 Adorno: Negative Dialektik, S. 169.

${ }^{530}$ Sebag: Marxismus und Strukturalismus, S. 68 f.
} 
Die von allen vernünftigen Einzelsubjekten und ihrem je individuellen Bewusstsein erfahrbaren sozialen Fakten können deshalb auch nicht zugunsten einer hypostasierten, tautologischen Vermittlung einer intersubjektiven Bedingtheit aller Unmittelbarkeit aufgegeben werden. Sie müssen immer auf ihre relative Stellung innerhalb der gesellschaftlichen Totalität untersucht werden. Die gesellschaftliche Totalität als Reflexionsbegriff des gesellschaftlichen (Un-)Wesens ist insofern auch nicht extensional zu bestimmen, sie ist keine positivistische Agglomeration von all den sozialen Phänomenen und subjektiven Handlungen, die einfach nur unter sie subsumiert werden. Die gesellschaftliche Totalität ist immer mehr als eine nur umfangslogische Bestimmung des positivistisch Daseienden, weshalb sie intensional bestimmt werden muss. Diese intensionale Bestimmung der gesellschaftlichen Totalität macht erst den wirkmächtigen Strukturbegriff von Gesellschaft als allgemeinem Begriff zu mehr als die subsumtionslogische Addition der faktisch zusammengetragenen sozialen Phänomene oder subjektiven Handlungen. Der Allgemeinbegriff verweist auf die objektive Bedingung der Möglichkeit der Erscheinung, die sich aus den einzelnen zusammengefassten Bezeichnungen von sozialen Phänomenen nicht erkennen lässt. So wird der Begriff von Gesellschaft auch erst zu einem emphatischen Begriff, der sich mit all seinen Zusammenhängen, Auswirkungen etc. als dem Subjekt gegenüber Transzendentem trotzdem subjektiv reflektieren und wesentlich kritisieren lässt. Die sozialen Phänomene, faktische Handlungen lebendiger Subjekte ausdrückend, müssen, weil sie ansonsten auch nur Erscheinungen von Nichts und damit substanzlos wären, auf ihr allgemeines gesellschaftliches Wesen hinter ihnen hin untersucht werden. Sie müssen insofern immer auf ihren konstellativen ${ }^{531}$ Begriff, auf den wesentlichen Zusammenhang innerhalb der gesellschaftlichen Totalität gebracht werden. Wenn sich nun allerdings positivistisch gegen dieses objektive, substantielle Moment der Erkenntnis von Phänomen der Vergesellschaftung in der Theorie ausgesprochen wird, dann gehen genau an der Stelle, unreflektiert, die wesentlichen Bedingungen der Erscheinung des Phänomens verloren. Dadurch geht, neben der Substanz der Phänomene, auch die Möglichkeit einer substantiellen Kritik der sozialen Phänomene verloren.

\subsubsection{Zur Dialektik von Naturgesetzen, Naturbearbeitung und Gesellschaftsphänomenen}

Die Vermittlung von gesellschaftlichem Unwesen und sozialem Phänomen verweist nun immer auch auf die Natur bearbeitende totale Gesellschaft. Deshalb wird an dieser Stelle auf den spezifischen dialektischen Zusammenhang von Naturbearbeitung unter der Anwendung von Naturgesetzen und den Gesellschaftsphänomenen Bezug genommen. Es besteht, soviel zunächst vorweg, ein

531 „Der Konstellation gewahr werden, in der die Sache steht, heißt soviel wie diejenige entziffern, die es als Gewordenes in sich trägt." (Adorno: Negative Dialektik, S. 165.) 
Unterschied zwischen Natur- und Gesellschaftsgesetzen. Naturgesetze werden sich mithilfe der rationalen Ausnutzung ihrer intelligiblen, ihrer in sich erkennbaren und deshalb zu erkennenden Gesetzmäßigkeit rational handhabbar gemacht (vgl. 2.2.3 ff.). ${ }^{532}$ Die Sinnesimplikaten zugrundeliegende immanente Rationalität der Naturdinge identifiziert das selbstbewusste Subjekt der Möglichkeit nach via das Identitätsprinzip (vgl. 2.2.1 ff.).

Den sozialen Phänomenen liegen dagegen, im Unterschied zu den Naturphänomenen, wesentlich dynamische, der Möglichkeit nach immer auch veränderbare Gesetze der kapitalistischen Reproduktion zugrunde. Diese sind allerdings genauso statisch, selbst wenn sie sich nicht zu einem ontologischen Grund zusammenschließen lassen. Auch dieses Moment der Dynamik einer möglichen Veränderbarkeit des gesellschaftlich organisierten Eingriffs in den Naturzusammenhang steht der Statik und der eigenen rationalen Erkennbarkeit deshalb nicht quer, weil nun alles andere als blind, vielmehr durchaus zweckbestimmt von der jeweiligen Gesellschaft in den Naturzusammenhang eingegriffen wird. Die Dialektik von Statik und Dynamik ist dementsprechend eine von theoretisch-praktischer subjektiver Emanzipation und trotzdem objektiver, der Möglichkeit nach allerdings veränderbarer Struktur. Die Gesetze der Gesellschaft sind, um es anders auszudrücken, aufgrund der möglichen Freiheit bei der Organisation des Eingriffs in den Naturzusammenhang nicht derart alternativlos wie die Naturgesetze. Sie enthalten, wie Lukács schreibt, ,immer die (...) reale Möglichkeit der Änderung des wählenden Subjekts in sich. " 533

Trotz der ausgemachten Differenz in der Dynamik des hinter den Phänomenen waltenden Wesens lässt sich das soziale Phänomen, als vermittelt aus den gesellschaftlichen Gesetzen der allgemeinen Reproduktion kommendes, allerdings auch nicht grundsätzlich vom Naturphänomen und seiner vermittelten Naturgesetzlichkeit unterscheiden. Die hinter den sozialen Phänomenen wirksamen gesellschaftlichen Prozesse sind von gleicher verhärteter Struktur wie Naturprozesse, die das Naturphänomen in seiner Festigkeit hervorbringen. Sie sind dabei jedoch nicht wirklich von derselben unmittelbaren verbärteten Struktur wie die Naturgesetze erster Natur, sondern sie besitzen diese Festigkeit immer nur scheinbar. Deshalb sind sie vermittelt verhärtete gesellschaftliche Gesetze der zweiten Natur: „Das aber gibt dem gesellschaftlichen Prozeß die Objektivität, die Härte blinder Notwendigkeit, die als die der zweiten Natur der der ersten gleicht. Der Mythos ist der erste subjektive Reflex auf die den Menschen undurchdringliche, feindliche Natur, und die Aufklärung dessen Kritik, auf die die Härte des Kritisierten zurückschlägt. "534

\footnotetext{
532 Vgl. Haag: Der Fortschritt in der Philosophie, S. 14.

533 Lukács: Zur Ontologie des gesellschaftlichen Seins, S. 86. Es stellt sich die Frage, wie sich diese Möglichkeit der Veränderung praktisch aktualisieren lässt. Die Antwort darauf ist in diesem Unterabschnitt unmöglich zu liefern - wenn sie sich denn überhaupt rein theoretisch herleiten lässt.

534 Bulthaup: Herrschaft, Sprache und Revolution, S. 53.
} 
Wie die Naturerscheinungen bleiben nun auch gesellschaftliche Erscheinungen strukturell in in sich rationale Gesetzmäßigkeiten, nämlich die konkrete und rationale Organisation des Eingriffs in den transzendenten Naturzusammenhang mit dem Anspruch auf deren Beherrschung, eingebettet. Im Kapital spricht Marx deshalb vom zum „Naturgesetz mystifizierten Gesetz der kapitalistischen Akkumulation“"535. Die hinter dem sozialen Phänomen stehenden strukturellen Gesetze der gesellschaftlichen Reproduktion, die Gesetze der zweiten Natur, wirken zunächst einmal auch wie ein „sogenannte[s] Naturgesetz“536. Diesem so unmittelbaren Gesetz müsse, weil durch die Prozesshaftigkeit der kapitalistischen Produktion mystifiziert ${ }^{537}$, Rechnung getragen werden. Das verweist ganz offensichtlich auf die Übereinstimmung der beiden verhärteten Strukturen, bzw. auf eine entsprechende Ähnlichkeit von Natur- und Gesellschaftsphänomen im Erkenntnisprozess. Die Verhärtung der gesellschaftlichen Gesetze des Eingriffs in den Naturzusammenhang verweist insofern sogleich auf die hinter den Gesellschaftsphänomenen wirksamen, wesentlich gesellschaftlichen Strukturgesetze, die die sozialen Phänomene überhaupt erst vermittelt hervorbringen. Auch in den sozialen Phänomenen kommen darum, wie im Naturphänomen, konstitutiv objektive, intelligible, allgemein erkennbare Gesetze als ein scheinbar statischer Plan ihrer Genesis zur Erscheinung, die die vermittelt dynamischen Gesetze von der zur zweiten Natur gewordenen verhärteten bürgerlichen Gesellschaft sind. Die bürgerliche Gesellschaft greift insofern mittels der gesetzmäßig organisierten kapitalistischen Produktionsweise rational in den Naturzusammenhang ein, und diese Organisation der gesellschaftlichen Reproduktion wird demnach als zweite Natur vermittelt unmittelbar - und die Gesellschaft erscheint dem Subjekt darum wie ein naturgesetzlicher Zusammenhang. Der Begriff von Gesellschaft als einer vernünftig und damit allgemein und notwendig nachvollziehbar in den heteronomen Naturzusammenhang eingreifenden ${ }^{538}$ setzt dabei auch voraus, dass es diese vernünftig erkennbaren, in sich rationalen Gesetze der gesellschaftlichen Reproduktion, nach denen Gesellschaft sich bewegt und verändert, als erkennbare Gesetze, die in einem Prinzip gründen, auch gibt. Der erscheinenden sozialen Mannigfaltigkeit, den sozialen Tatsachen, liegen demnach konstitutiv intelligible gesellschaftliche Gesetze des kooperativen, kapitalistischen Eingriffs in den Naturzusammenhang zugrunde. Diese gesellschaftlichen Gesetze der allgemeinen Reproduktion kommen als wesentliche Strukturgesetze in den sozialen Phänomenen, weil sie Manifestationen des gesellschaftlichen (Un-)Wesens sind, vermittelt und nicht unmittelbar zur Erscheinung. Das soziale Phänomen ist insofern nicht einfach von den

\footnotetext{
535 Marx, Das Kapital, Bd. 1, S. 649.

536 Adorno: Negative Dialektik, S. 347.

${ }^{537}$ Vgl. Marx, Das Kapital, Bd. 1, S. 649.

538 Vgl. die Ausführungen oben, denn: „Alle Tätigkeiten der Gattung verweisen auf ihren physischen Fortbestand, mögen sie es auch verkennen, sich organisatorisch verselbständigen und ihr Geschäft nur noch beiher besorgen.“ (Adorno: Negative Dialektik, S. 203.)
} 
wesentlich gesellschaftlichen Gesetzen der Naturbearbeitung, die es konstituieren und die ihrerseits den kapitalistisch organisierten Eingriff in den Naturzusammenhang bedeuten, zu trennen.

Dass das soziale Phänomen in die Konstellation rational erkennbarer Gegenstände eingeordnet werden muss, ist aufgrund der intelligiblen Rationalität der begrifflich vermittelten, in den Naturzusammenhang kooperativ eingreifenden Gesellschaft, möglich. Die intelligiblen gesellschaftlichen Gesetze des Eingriffs in den Naturzusammenhang können sich nun als zunächst statische Gesetze der zweiten Natur durch die erkennenden Subjekte qualitativ und grundlegend immer verändern lassen, wie mit Lukács oben bereits verdeutlicht wurde. Das bleibt auch weiterhin die entscheidende Differenz zu den Gesetzen der ersten Natur, deren Dinge zwar funktional in ihrem Verhalten bestimmt werden können, deren ontologischer Grund dabei jedoch auch immer statisch bleibt. Die immanente Rationalität von transzendenter, kapitalistischer Gesellschaft als allgemeine Reproduktionsbedingung der handelnden Subjekte verweist also gerade durch die Organisation der gesellschaftlichen Naturbearbeitung auf den notwendig dialektischen Zusammenhang von vergesellschafteter Naturbearbeitung und Gesellschaftsphänomen. An dieser Stelle der reproduktionsbedingten Vergesellschaftung von Naturprodukten wird also der dialektische Zusammenhang von rationaler Naturbearbeitung und in sich rationalen Gesellschaftsphänomenen offenbar. Denn ohne die sich über den Eingriff in den Naturzusammenhang reproduzierende Gesellschaft als Bedingung ihrer Möglichkeit werden soziale Phänomene gar nicht erst manifest. Auch darum sind sie Ausdruck des Eingriffs in den Naturzusammenhang.

Alles, was sich den Subjekten als vermittelt unmittelbares gesellschaftliches Phänomen zeigt, ist insofern das Resultat einer kapitalistisch rational vollzogenen „Distanz zur Natur“539. Das soziale Phänomen ist der mittelbare Ausdruck tätig eingreifender Gesellschaft in den Naturzusammenhang zu kapitalistischen Reproduktionszwecken. Weil jede Distanzierung des Subjekts von Natur in Kultur resultiert, ${ }^{540}$ ist deshalb auch jedes soziale Phänomen ein vermittelter Kulturgegenstand der kapitalistischen Gesellschaft, der sich aus diesen allgemein objektiven, an sich seienden Naturzusammenhängen und der rationalen Bearbeitung von dieser nicht lösen lässt; es sei denn mit theoretischer Gewalt. Als Kulturprodukte verbergen also alle gesellschaftlichen Erscheinungen ihren Seins- oder Realgrund in der über

\footnotetext{
${ }^{539}$ Bensch: Vom Reichtum der Gesellschaften, S. 20.

${ }^{540}$ An dieser Stelle ist der umgangssprachlich gebrauchte Begriff der Kultur als Synonym für Gesellschaft adäquat. Die differente Bezeichnung des der Sache nach Selben hat einen besonderen Grund: Es klingt unverfänglicher, die Integration von Zuwanderern in eine Kultur zu fordern, als die Integration des neuen ,Humankapitals ' in die kapitalistisch organisierte Gesellschaft zu fordern und fördern. Der positiv besetzte Kulturbegriff ist mit Walter Benjamin jedoch abzulehnen, da Kultur ohne mit gesellschaftlicher Herrschaft vermittelt nicht zu denken ist: „Es ist niemals ein Dokument der Kultur, ohne zugleich ein solches der Barbarei zu sein.“ (Benjamin: Über den Begriff der Geschichte, S. 145.) Die gesellschaftliche Herrschaft, die den Eingriff in den Naturzusammenhang organisiert, ist insofern notwendige Voraussetzung von daraus erst Entstehendem: Kultur.
} 
den Arbeitsprozess vermittelten Reproduktion der kapitalistischen Gesellschaft. ${ }^{541}$ Auch der moderne Antisemitismus muss deshalb ein vermittelter Ausdruck der kapitalistisch organisierten gesellschaftlichen Distanzierung von der Natur sein, eine bestimmte Manifestation der rational in die transzendente Natur eingreifenden Gesellschaft. Auch der Antisemitismus ist demnach ein Kulturprodukt der totalen bürgerlichen Gesellschaft, ist mit ihr also verhängnisvoll als Manifestation ihres Wesens vermittelt. Der Antisemitismus ist insofern, als undinglicher Gegenstand der bürgerlichen Gesellschaft, ein mal mehr, mal weniger offen zutage tretendes soziales Faktum kapitalistischer Kultur. Er ist deswegen auch keine bodenlose Chimäre.

Weil Gesellschaft vom Anspruch und von der Realisierung der gesellschaftlichen Naturbeherrschung, der gesellschaftlichen Kultivierung, nicht unvermittelt getrennt ist, kann also jede Trennung von sozialem Phänomen und wesentlichen, gesellschaftlichen Strukturgesetzen auch nur ein gewaltsames Aufbrechen von Dialektik sein. Nur über den gemeinschaftlichen Eingriff der individuellen Subjekte in den Naturzusammenhang vermittelt kann Gesellschaft und damit Kultur überhaupt bestehen. Jede Gesellschaft ausnahmslos greift demnach in Form eines tätigen, allgemein rational organisierten Arbeitsprozesses in den Naturzusammenhang mit dem Ziel der Realisation der allgemeinen, gesellschaftlichen Reproduktion ein. Die vergesellschafteten Subjekte sind deshalb für die rationale Realisation ihrer eigenen Reproduktion immer auf die Zweckmäßigkeit ihrer Tätigkeit, die Arbeitsmittel und den Naturgegenstand ihrer Arbeit im Arbeitsprozess angewiesen. Sie müssen sich, Marx zufolge, beständig „,gewisser Dinge der Außenwelt (...) durch die Tat" ${ }^{\text {"542 }}$ bemächtigen, um so, subjektiv-zweckmäßig, ,ihr Bedürfnis“543 also ihre eigene Reproduktion, ihre eigene Selbsterhaltung in der Gesellschaft - zu realisieren. Weil nun das vereinzelte Individuum für seine eigene Reproduktion historisch nie alleine habe sorgen können, ist die Kooperation der Subjekte bei

\footnotetext{
541 Ohne als mit der in den Naturzusammenhang rational eingreifenden Gesellschaft vermittelt kann selbst die Kunst nicht gedacht werden. Noch die sich aller gesellschaftlichen Einflüsse erhaben glaubende kreative Ästhetik der l'art pour l'art, als ultimative Freiheit der Kunst und des Künstlers von allen Zwängen gefeiert, bleibt mit ihren eigenen gesellschaftlichen Voraussetzungen, mit den vermittelten kapitalistischen Bedingungen ihrer Existenz, verbunden. (Nietzsche sieht die gesellschaftlichen Zwecke in der Kunst des ästhetizistischen l'art pour l'art und spricht sich gegen den falschen Kunstbegriff einiger Künstler aus: „Wenn man den Zweck des Moralpredigens und Menschen-Verbesserns von der Kunst ausgeschlossen hat, so folgt daraus noch lange nicht, daß die Kunst überhaupt zwecklos, ziellos, sinnlos, kurz l'art pour l'art - ein Wurm, der sich in den Schwanz beißt - ist.“ (Nietzsche: Götzen-Dämmerung, S. 322.) Das unterscheidet die Ästhetik der Kunst um der Kunst willen auch nicht von der offensiv kritischsten Ästhetik: „Die Ausdehnung der bürgerlichen Verkehrsformen produziert nicht nur die neue Notwendigkeit der Kunst, setzt sie, als die ästhetische Aufhebung der entstehenden und verbleibenden Rätsel, nicht nur als Antithese zur Verbürgerlichung der Welt, sondern evoziert ihre neuen Formen und Gestalten auch als Ausdruck und Konsequenz eben dieser Verbürgerlichung.“ (Menasse: Phänomenologie der Entgeisterung, S. 26.)

542 Marx: Randglossen zu A. Wagners ,Lehrbuch der politischen Ökonomie‘, S. 363.

543 Ebd.
} 
Marx auch eine allgemeine Bestimmung der Reproduktion: „Daß jede Nation verrecken würde, die (...) für ein paar Wochen die Arbeit einstellte, weiß jedes Kind." ${ }^{544}$ Die individuelle Reproduktion realisiert sich demnach ausschließlich im Verein, weshalb die Möglichkeit der Selbsterhaltung der Subjekte immer auf Seiten der Gattung und nur bedingt auf Seiten des einzelnen, individuellen Subjekts liegt.

Noch zu Anfang des Kapitals abstrahiert Marx diesen in sich vernünftig und nachvollziehbar organisierten praktischen Eingriff in den Naturzusammenhang zur Kultivierung, den menschlichen Arbeitsprozess, von jeder konkreten, auch der kapitalistischen Gesellschaftsform: „Der Arbeitsprozeß ist daher zunächst unabhängig von jeder bestimmten gesellschaftlichen Form zu betrachten. “"545 Weil sich, zunächst einmal völlig abstrakt besehen, „das Leben der Menschen“ unmittelbar dieser bereits organisierten gesellschaftlichen Vermittlung mit der Natur „verdankt ${ }^{\text {“546 }}$, bleibe demnach der praktische Eingriff überhaupt die natürliche Grundlage aller sinnlichen Erscheinungen - und deshalb auch der sozialen Erscheinungen. Ohne die in den nichtidentischen Naturzusammenhang eingreifende Gesellschaft vermittelt wäre insofern kein soziales Phänomen denkbar, weil nach der statischen Kategorie des notwendigen Eingriffs in den Naturzusammenhang keine Gesellschaft (und somit keine konkrete soziale Erscheinung) ohne diesen denkbar sein kann. Alles gesellschaftliche, menschliche Leben verdankt sich insofern erst jenem zweckmäßigen, willentlich-vernünftig und gesellschaftlich/kooperativ organisierten Eingriff in den Naturzusammenhang. Arbeit ist insofern immer gleich vergesellschaftete Arbeit und auf den gesellschaftlichen Arbeitsprozess geht darum noch jede historische gesellschaftliche Reproduktion und Kultur zurück.

Der rationale, willentliche, sich im Material Zwecke setzende Eingriff in den Naturzusammenhang macht bei Marx demnach also wesentlich Gesellschaft, Kultur und die Vergesellschaftung der Subjekte aus. Dermaßen abstrakt, durch die Marxsche statische Kategorie der historisch immer zur gesellschaftlichen Reproduktion notwendigen Naturbeherrschung, ohne das Moment der konkreten Dynamik des Eingriffs in den Naturzusammenhang mit anzuführen, ohne konkret organisierte Arbeitsprozesse also, kann sich der Arbeitsprozess jedoch bloß einem abstrahierenden, vernünftigen Bewusstsein der Reflexion, darstellen. In der konkreten Realität verweist die erzwungene Verwiesenheit des individuellen Einzelnen mit seinem Willen zur eigenen Reproduktion immer schon auf konkrete gesellschaftliche Arbeitsprozesse, die in der Geschichte mit den Produktionsverhältnissen variieren. Die überlebenswichtige Eingebundenheit des Subjekts in die kooperative Gesellschaft verweist deshalb auch auf die jeweils konkrete gesellschaftliche Organisation des Arbeitsprozesses, der über jedes einzelne Subjekt wiederum hinausgeht. Im heute realpolitisch vorherrschenden Fall ist der kooperativ organi-

\footnotetext{
${ }^{544}$ Marx/Engels: Briefwechsel, zitiert nach Kuhne: Begriff und Zitat, S. 9.

545 Marx, Das Kapital, Bd. 1, S. 192.

${ }^{546}$ Krahl: Konstitution und Klassenkampf, S. 115.
} 
sierte Arbeitsprozess der der bürgerlichen, kapitalistischen Gesellschaft. ${ }^{547}$ Insofern muss also auch jedes in der bürgerlichen Gesellschaft erscheinende soziale Phänomen mit dem kapitalistischen Eingriff in den Naturzusammenhang dialektisch vermittelt sein. Die Phänomene der Vergesellschaftung und seine Zwecke sind deshalb mit dem Kapitalismus wesentlich vermittelt. Auch das soziale Phänomen des modernen Antisemitismus bleibt demzufolge auf die bürgerliche Gesellschaft und ihre kapitalistische Form der gesellschaftlichen Reproduktion verwiesen. Der moderne Antisemitismus ist, wie auch Leo Löwenthal schreibt, ,in der Dynamik moderner Zivilisation und besonders moderner Wirtschaftsorganisation verwurzelt.“" 548

Der gesellschaftliche, rationale, kooperative Zusammenhang der Individuen macht die kapitalistische Organisation der Ökonomie dabei selbst zum Subjekt. Adorno beschreibt diesen Zusammenhang von Subjekt und antagonistischer Gesellschaft deshalb als rationalen Zwangszusammenhang von allgemeinem und besonderem, zur Kooperation im Kapitalismus gezwungenen Subjekt: „Subjekt als Feind des Subjekts. “" ${ }^{“ 49}$ Die rational organisierte antagonistische Gesellschaft werde demnach zum transzendenten Subjekt individueller Selbsterhaltung vergesellschafteter Subjekte - und weil diese kapitalistische Kooperation antagonistisch ist, sei es ein feindliches Subjekt. Dem feindlichen Subjekt, der kapitalistisch organisierten gesellschaftlichen Reproduktion, habe sich das um die eigene Selbsterhaltung bemühte Subjekt immer zu fügen. In dem heteronomen, in sich rationalen Zusammenhang der gesellschaftlichen Totalität bleibe deshalb auch völlig gleichgültig, ob sich der Einzelne mit der konkreten kapitalistischen Organisation der Kulturprodukte anfreunde oder nicht. Die Gefühle des Subjekts für oder wider den rational organisierten Eingriff in die erste Natur werden insofern vollkommen zweitrangig. Das Subjekt wird dadurch als eigentlich Seiendes und seine Geschicke selbst lenkendes beständig infrage gestellt. Adorno schreibt dazu in der Negativen Dialektik: „Die Abschaffung des Leidens, oder dessen Milderung hin bis zu einem Grad, der theoretisch nicht vorwegzunehmen, dem keine Grenze anzubefehlen ist, steht nicht bei dem Einzelnen, der das Leid empfindet, sondern allein bei der Gattung, der er dort noch zugehört, wo er subjektiv von ihr sich lossagt und objektiv in die absolute Einsamkeit des hilflosen Objekts gedrängt wird.““550

Der allgemeine Antiindividualismus der bürgerlichen Gesellschaft, gegen den sich nur mithilfe von individualistischen und subjektivistischen Ideologien ${ }^{51}$ und

\footnotetext{
547 Die alternativen Möglichkeiten bei der Organisation der Reproduktion, wie oben bereits angeführt, dynamisieren die Statik des ahistorischen Eingriffs in den Naturzusammenhang als Grundlage der allgemeinen Reproduktion.

548 Löwenthal, Individuum und Terror, S. 163.

549 Adorno: Negative Dialektik, S. 22.

${ }^{550}$ Vgl. ebd., S. 203.

${ }^{551}$ Individualistische Ideologien nehmen Subjekte dabei einseitig für gesellschaftliche Dinge wie z.B. Gewalt, Kriege etc. in die Pflicht, weshalb sie sich sehr gut mit den Werten und den Forderungen der modernen kapitalistischen Gesellschaft in Einklang bringen lassen. Sie bieten als Erklärung von
} 
dabei auch nur scheinbar gewehrt werden kann, erweist sich somit notwendig als Resultat des notwendig kooperativen Sozialisierungsprozesses des Subjekts in der kapitalistischen Gesellschaft selbst. Die einzelsubjektive Selbsterhaltung bleibt von der allgemeinen Gattung und deren rationaler Organisation des Stoffwechsels mit der Natur, von der bürgerlichen Gesellschaft als dem gesellschaftlich übergeordneten Allgemeinen, abhängig. So verweist auch der erscheinende undingliche soziale Gegenstand gerade durch seine Bedingungen der Möglichkeit auf die Dimension der ihn konstituierenden Grundlage notwendig zurück: die rational organisiert in den heteronomen Naturzusammenhang eingreifende kapitalistische Gesellschaft als feindliches Subjekt. Deshalb gibt es nach Adorno, der bereits angeführten gesellschaftlichen Totalität das Wort redend, auch „kein soziales Faktum, das nicht durch Gesellschaft determiniert wäre." ${ }^{552}$ Ein Begriff von kapitalistischer Gesellschaft wird für die Erkenntnis und Arbeit mit dem sozialen Phänomen deshalb zu einer der wichtigsten Voraussetzungen.

\subsection{Zum Handeln der Subjekte in Gesellschaft}

Die nächsten vier Unterabschnitte beschäftigen sich mit dem Handeln der Subjekte in der bürgerlichen Gesellschaft.

In 2.6.1 ist vor allem die allgemeine Heteronomie des subjektiven Handelns Gegenstand, während sich 2.6.2 dann mit dem Geschichtsbegriff und verschiedenen Interpretationen der Integration des selbstbewussten Subjekts in die Gesellschaft beschäftigt. Dazu werden der Geschichtsbegriff von Marx im Wandel seiner eigenen Interpretation und der Begriff der Naturgeschichte von Adorno näher betrachtet. 2.6.3 stellt die Integration des bürgerlichen Subjekts in den Naturzusammenhang als systematische, universale Integration dar. Diese Integration in die heteronome Gesellschaft hat Auswirkungen auch auf die Psyche des Subjekts. Diese Auswirkungen werden in Abschnitt 2.6.4 thematisiert, der sich mit der Sozialpsychologie und dem dialektischen Ich-Begriff als vorauszusetzendes Moment der gesellschaftlichen Emanzipation, der Realisationsmöglichkeit von Freiheit, befasst.

persönlichem Leid und gesellschaftlichem Versagen eine die eigentlichen Ursachen verschleiernde Erklärung an: das Subjekt selbst. Bestes Beispiel dafür ist die Lehre von Scientology, nach der das empirische Subjekt nach bestimmten Vorgaben an sich arbeiten soll, um dadurch ein besseres Leben führen zu können, was dann wiederum der Gesellschaft zu gute käme.

(Vgl. dazu Willms: Scientology. Kulturbeobachtungen jenseits der Devianz.)

552 Theodor W. Adorno, Gesellschaft, GS 8, a.a.O., S. 10. 
2.6.1 Integration: Die bürgerliche Gesellschaft im subjektiven Handeln

„Die Gleichgültigkeit gegen die Freiheit, ihren Begriff und die Sache selbst, wird gezeitigt von der Integration der Gesellschaft, die den Subjekten widerfährt, als wäre sie unwiderstehlich.“" 553

„Noch wo die Menschen am ehesten sich frei von der Gesellschaft fühlen, in der Stärke ihres Ichs, sind sie zugleich deren Agenten: das Ichprinzip ist ihnen von der Gesellschaft eingepflanzt, und sie honoriert es, obwohl sie es eindämmt. “汭4

Nur durch subjektives Handeln, durch Praxis, entsteht eine dynamische gesellschaftliche Faktizität, die die Sinnlichkeit der vergesellschafteten Subjekte der Praxis im Rahmen einer primären Erfahrung (vgl. 2.4.3) affiziert. Weil die sozialen Phänomene vom subjektiven Handeln innerhalb der antagonistischen Gesellschaft nicht getrennt werden können, muss auch die Intention des Handelns der Subjekte, die sich aufs heteronome Allgemeine vermittelt bezieht, konkret zum Gegenstand werden. Damit erst wird auch die Heteronomie des Subjekts bei der eigenen Selbsterhaltung in der antagonistischen Gesellschaft deutlich. Das Handeln innerhalb des kooperativen, heteronomen Allgemeinen der bürgerlichen Gesellschaft ist selbsterhaltend zweckbezogen. Vom großen heteronomen Ganzen, von politischer Ökonomie und Totalität im Konkreten unabhängig, also vom wesentlichen gesellschaftlichen Konstituens unberührt, ist subjektives Handeln nicht zu denken. Das Subjekt wird in seinem Handeln dabei durch das soziale Umfeld oder das „Milieu“ ${ }^{\circ 55}$ mikrokosmisch geprägt.

Studien wie die Bourdieus ${ }^{556}$, die sich mit dem subjektiven Handeln in Gesellschaft befassen, können dabei immer nur eindimensional zum Ausdruck bringen, wie und warum es zu jenen Mikrokosmen und spezifisch bestimmbaren sozialen Umfeldern innerhalb des großen Ganzen, um weiter in der Sprache der modernen Soziologie zu sprechen: innerhalb des Makrokosmos, kommt. Die Kritik an gesellschaftlichen Verhältnissen, die lediglich bestimmte Verhaltensweisen des Subjekts in Gesellschaft untersucht, bricht die Reflexion des gesellschaftlich Wesentlichen, das für das Verhalten der Subjekte ursächlich ist, an wesentlichen Stellen einfach unkritisch ab. Der Milieubegriff lässt sich jedoch nicht als von seinen eigenen

\footnotetext{
553 Adorno, Negative Dialektik, S. 215.

${ }^{554}$ Ebd., S. 292.

555 Vgl. etwa Vester (Hrsg.): Neue soziale Milieus und pluralisierte Klassengesellschaft; Vester (Hrsg.): Soziale Milieus im gesellschaftlichen Strukturwandel; Bremer/Lange-Vester: Soziale Milieus und Wandel der Sozialstruktur.

556 So zum Beispiel in Pierre Bourdieu: Die feinen Unterschiede. Hierin kommt zwar die gesellschaftliche Prägung der Subjekte zur Sprache, doch warum und zu welchem Zweck Gesellschaft individuelles Handeln bestimmt, bleibt wage und in der Studie relativ weit ausgeklammert. Bourdieus Kritik bricht dort ab, wo konkrete gesellschaftliche Bedingungen des subjektiven Handelns auftauchen müssten.
} 
momentanen Voraussetzungen unabhängig verselbständigen. Das Milieu ist das Sinnbild eines gesellschaftlich eingeschränkten Handelns der Subjekte. ${ }^{557}$ Kein Milieu, keine Schicht, Klasse, peer group etc. kann dabei ohne den dialektischen Bezug auf die bürgerliche Gesellschaft und ihre kapitalistische Organisation der allgemeinen Reproduktion existent, bzw. von ihr abgelöst denkbar sein. Als allgemeine Begriffe bleiben sie deshalb auf die konkrete Gesellschaftsform, in der sie ihre Geltung erst bekommen, verwiesen: Kein Milieu-, Schicht- oder Klassenmodell existiert deshalb je ohne Bezug auf die Totalität der Gesellschaftsform für sich oder durch sich allein. All diese soziologischen Modelle sind deshalb in Relation auf das ihnen heteronom Allgemeine, die bürgerliche Gesellschaft in ihrer systematischen Totalität, zu setzen - was jedoch gerne missachtet wird. Dadurch werden Begriffe wie Milieu etc. zu eigenständigen Begriffen umgemünzt, denen dann auch Substanz aus sich zukomme. Das würde jedoch das Subjekt und sein gesellschaftliches Handeln von der heteronomen bürgerlichen Gesellschaft und der kapitalistischen Produktionsweise trennen. Dadurch bekommt es einen ihm zugesprochenen Machtfaktor gegen Gesellschaft, die Milieuzugehörigkeit an sich scheint dabei auch nicht mehr wirklich zu stören.

Dadurch, dass nur das Subjekt zum Gegenstand der Forschung gemacht wird, wird es bei der Erklärung von Gesellschaft jedoch verabsolutiert. Entscheidende Modelle der Verabsolutierung des Subjekts sind klassischerweise Ludwig Feuerbachs anthropologischer Materialismus ${ }^{558}$ und aktuell Richard Dawkins Evolutionsbiologie ${ }^{559}$. Weil das Subjekt jedoch um seines Überlebens Willen in seinem Handeln auf das Gesamte, die kooperative totale Gesellschaft und die allgemeine Reproduktion, verwiesen ist, bleibt die Bestimmung des Individuums als des ei-

\footnotetext{
${ }^{557}$ Im Roman Berlin Alexanderplatz lässt Döblin seinen Protagonisten Franz Biberkopf an den äußeren gesellschaftlichen Bedingungen scheitern. Döblin möchte nach eigenem Selbstverständnis zwar verdeutlichen, dass Biberkopf an seinem eigenen Untergang, durch die eigene Verhaftung im Milieu, schuld sei: „Es wird ihm aufs deutlichste klargemacht, woran alles lag. Und zwar an ihm selbst, man sieht es schon, an seinem Lebensplan." (Döblin: Berlin Alexanderplatz, S. 9) Die Entscheidungsmöglichkeiten Biberkopfs, der nach einer Gefängnisstrafe anständig durchs Leben gehen wollte, erweisen sich jedoch aus gesellschaftlichen Gründen als sehr limitiert.

558 Vgl. Engels: Feuerbach, S. 541.

559 Richard Dawkins naturalistische Begründungen des Subjekts verlieren vor Anthropologisierung und Naturalisierung der kapitalistischen Gesellschaft die Klassengesellschaft und das Prinzip der Erscheinung der Konkurrenz völlig aus den Augen. Er kann die Erscheinung kapitalistischer Konkurrenz nicht mehr etwa auf begrifflich erkennbare objektive gesellschaftliche Gesetzmäßigkeiten der politischen Ökonomie zurückführen. Diese gesellschaftlichen Komponenten von Konkurrenz und Missgunst führt er umgekehrt auf anthropologische Naturgesetze, genetische Determiniertheit etc., zurück. Deshalb entsteht die bürgerliche Gesellschaft für ihn aus anthropologisch bestimmten subjektiven Bedürfnissen. Die reale, aber nur scheinbare Naturwüchsigkeit der kapitalistischen Gesellschaftsform verkehrt sich so zu einer nicht veränderbaren Abhängigkeit der Subjekte von angeblichen Naturgesetzen. Diesen subjektiven Naturgesetzen, die ihren adäquaten Ausdruck in der bürgerlichen Gesellschaft haben, unterliegt das Subjekt auch noch in Zukunft. Damit wird die bürgerliche Gesellschaft unveränderbar und die zweite Natur all zu menschlich. (Vgl. Dawkins: The Selfish Gene.)
} 
gentlich Seienden oder zu Untersuchenden verkürzt. Bei Adorno heißt es, dass „[w]as der Mensch sei, (...) sich nicht angeben [läßt]. Der heute ist Funktion, unfrei, regrediert hinter alles, was als invariant ihm zugeschlagen wird, es sei denn die schutzlose Bedürftigkeit, an der manche Anthropologien sich weiden. " ${ }^{560}$ Ein unberührtes, völlig autonomes und in seinem praktischen Handeln von Gesellschaft und Umwelt unbeeindrucktes Subjekt kann es dabei auch schon aufgrund der erzwungenen Integration in den transzendenten heteronomen Strukturzusammenhang Gesellschaft nicht geben. Die rationale politisch-ökonomische Gesellschaft hat, weil selbst Subjekt (vgl. 2.5.3), einen solch integralen und das einzelne Subjekt zwingenden Charakter, wodurch neben dem selbstbezogenen Denken des lebendigen Subjekts hinsichtlich der eigenen Reproduktion, dem instrumentellen Denken, auch das Handeln als das Resultat des Willens geprägt wird und dem deshalb nachzugehen ist. Das zwangsläufig in das falsche, kooperative Allgemeine eingebundene individuelle Subjekt ist mit all seinen (auch theoretischen) Erfahrungen und Handlungen ein akzidentelles Bündel der auf es einwirkenden allgemeinen, gesellschaftlichen Gesetzmäßigkeit: „In der individualistischen Gesellschaft jedoch verwirklicht nicht nur das Allgemeine sich durchs Zusammenspiel der Einzelnen hindurch, sondern die Gesellschaft ist wesentlich die Substanz des Individuums. “561

Selbst wenn man also ganz bewusst nur über das empirische Subjekt sprechen wollte, hätte man dann niemals mehr einen dialektisch vermittelten und sachhaltigen Gegenstand, der die Bestimmung von Subjekten als Individuen überhaupt erst rechtfertigen würde. Das zeigt auch die oben beschriebene Äquivokation im Subjektbegriff bereits auf (vgl. 2.3.1). Auch deshalb kann nicht bei der Beschreibung der verallgemeinerten peer group stehen geblieben werden ohne die Zwecke der Gesellschaft, in deren Zusammenhang diese auftritt und zu denken ist, zum Gegenstand zu machen. Das daseiende, lebendige Subjekt, zunächst gleichgültig ob es als ein Klassenmitglied, als Mitglied einer peer group, als einer bestimmten Schicht zugehörig begriffen wird, hat sich den nur scheinbar naturwüchsig auf es einwirkenden allgemeinen Gesetzmäßigkeiten der Gesellschaft in seinem Handeln und Wollen im Zuge seiner Realisation der eigenen Selbsterhaltung unterzuordnen. Es hat äußeren gesellschaftlichen Bedürfnissen, die vorausgesetzte Bedingungen seiner eigenen Existenz sind, zu parieren: „Die sogenannten Oberflächenbedürfnisse spiegeln den Arbeitsprozeß wider, der die Menschen zu ,Anhängseln der Maschine' macht und sie nötigt, außerbalb der Arbeit sich auf die Reproduktion der Ware Arbeitskraft zu reduzieren. Jene Bedürfnisse sind die Male eines Zustandes, der seine Opfer zur Flucht zwingt und zugleich so fest in der Gewalt hält, daß die Flucht stets in die krampfhafte Wiederholung des Zustandes ausartet, vor dem geflohen wird.“" ${ }^{62}$ Diese äußeren Bedürfnisse der Gesellschaft finden sich nun im

\footnotetext{
560 Adorno: Negative Dialektik, S. 130.

561 Adorno: Minima Moralia, S. 16.

562 Adorno: Thesen über Bedürfnis, S. 392. (Herv. von mir, B.E.B.)
} 
Bedürfnis des Subjekts, selbst im instrumentellen Denken über eigene Bedürfnisse, wieder ${ }^{563}$, weshalb es auch die anthropologische Bestimmung eines subjektiven Bedürfnisses nicht geben kann. ${ }^{564}$ Das Bedürfnis des lebendigen Subjekts ist mit dem objektiven Bedürfnis der Gesellschaft dialektisch immer vermittelt. Auch kann Bedürfnis nicht aus einem unbewussten Trieb des Subjekts erklärt werden, einem anthropologischen Trieb beispielsweise, der irgend aus sich heraus agiert und das Subjekt zum Handeln und realisieren des eigenen Bedürfnisses in Gesellschaft anstiftet.

Das subjektive Bedürfnis verweist demnach also allein auf die gesellschaftliche Totalität und nicht etwa auf ein unbewusstes Moment, beispielsweise aus körperlicher Heteronomie heraus: „Bedürfnis ist eine gesellschaftliche Kategorie.“565 Selbst der Hunger ist in der Weise, wie er als ein natürliches Bedürfnis dann vom Subjekt gestillt wird, gesellschaftlich vermittelt, weshalb jede Frage nach dem subjektiven Bedürfnis auf den gesamten, totalen Bedürfniszusammenhang der kooperativ vergesellschafteten Subjekte, den „konkreten Zusammenhang mit dem Ganzen des gesellschaftlichen Prozesses"566, verweist. Durch diese Einbindung in die Kooperation wird das vereinzelte, selbstbewusste Subjekt zum sekundären Moment heruntergedrückt, es wird zum bloßen Exemplar der Gattung Mensch. Es wird zur bloßen quantité negiliable erniedrigt und als Individuum von der totalen Gesellschaft übergangen. Das empirische Subjekt wird deshalb von der vorgeordneten Gesellschaft als Subjekt negiert, insbesondere, wenn es nicht den subjektgleichen Maßstäben der Gesellschaft entsprechend praktisch handelt: „Das heißt also, daß man Gesellschaft (...) auf der Haut zu spüren bekommt, wenn man auf irgendwelche kollektiven Verhaltensweisen stößt, die das Moment der Unansprechbarkeit haben und vor allem das, daß sie unvergleichlich viel stärker sind, als die einzelnen Individuen es sind, die diese Verhaltensweisen an den Tag legen, so daß man geradezu und mit einer leichten Übertreibung sagen kann, daß im Sinn von Durkheim Gesellschaft unmittelbar da fühlbar wird, wo es wehtut.“567 Lukács stellt nun in seiner Aufsatzsammlung Geschicbte und Klassenbewußtsein fest, dass jede qualitative Veränderung der Gesellschaftsform dialektisch immer auch eine qualitative Veränderung im praktischen Verhalten der Subjekte mit sich bringe. Das parierende Verhalten der vereinzelten Subjekte in der Gesellschaft wird

\footnotetext{
563 Vgl. ebd., S. 394: „Der Gedanke etwa, das Kino sei neben Wohnung und Nahrung zur Reproduktion notwendig, ist ,wahr' nur in einer Welt, die die Menschen auf die Reproduktion der Arbeitskraft zurichtet, und ihre Bedürfnisse zur Harmonie mit dem Profit- und Herrschaftsinteresse der Unternehmer zwingt."

${ }^{564}$ Ein anthropologisches Bedürfnis, das im Kapitalismus sukzessive durch herrschaftlichen Zwang verlorengehe, unterstellt u.a. auch Pohrt: Theorie des Gebrauchswerts, S. 22: „Die Regression der Bedürfnisstruktur war die Plattform, auf der sich der Kulturimperialismus von Coca-Cola, Dosenbier und Hamburgern etablieren konnte.“

565 Adorno, Thesen über Bedürfnis, S. 392.

566 Ebd., S. 393.

${ }^{567}$ Adorno: Vorlesung zur Einleitung in die Soziologie, S. 38.
} 
für ihn damit zum offensichtlichen Spiegel der objektiven gesellschaftlichen Verhältnisse. Heteronome gesellschaftliche Verhältnisse hielten das Subjekt dabei überhaupt auch erst zum Parieren an: „Der Unterschied zwischen einer Gesellschaft, in der die Warenform die herrschende, alle Lebensäußerungen entscheidend beeinflussende Form ist, und zwischen einer, in der sie nur episodisch auftritt, ist vielmehr ein qualitativer Unterschied." ${ }^{668}$ In jedem vereinzelten, vergesellschafteten und seiner selbst bewussten Subjekt würden sich deshalb die wesentlich objektiven, gesellschaftlichen Einflüsse ausdrücken: als gesellschaftliche Prägung/Präformation des vergesellschafteten, reflexiven Subjekts: „Dazu muß sie [die kapitalistische Warenform, B.E.B] sämtliche Lebensäußerungen der Gesellschaft durchdringen und nach ihrem Ebenbilde umformen, nicht bloß an sich von ihr unabhängige, auf Produktion von Gebrauchswerten gerichtete Prozesse äußerlich verbinden. “569 Der Schwenk auf die gesetzmäßig verfasste und transzendente objektive Gesellschaft, die das erfahrende, vergesellschaftete Subjekt unmittelbar als sein Erfahrungsmaterial in seinen Vorstellungen präformiert, kann darum auch nicht als ein unberechtigter Gegenstandswechsel begriffen werden. Adorno schreibt darauf bezogen: „Denn Gesellschaft ist der Erfahrung immanent, kein

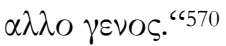

Dementsprechend sind auch empirisches Subjekt und kapitalistische Gesellschaft als Momente ineinander. Soziales ,Umfeld‘ und gemeinschaftliche Ausdrücke des Handelns sind demnach von der kapitalistischen, totalen Gesellschaft nicht einfach zu trennen. Deshalb verweist die Bestimmung des handelnden Individuums auf das dem Individuum als seiner selbst bewusstes Subjekt gesellschaftlich Zugrundeliegende, das in sich rationale „Ensemble der gesellschaftlichen Verhältnisse“ "571, das sich in Handeln und Denken des Subjekts zeigende objektive, allgemeine Ensemble der Integrität. In dieses Ensemble bleibt jedes noch so selbstbewusste und autonome Subjekt als sich selbst reproduzierendes Individuum zwangsläufig integrativ und verdinglicht eingebunden. Das verweist insofern auf die konkreten Zusammenhänge des in sich vernünftig organisierten gesellschaftlichen Eingriffs in den Naturzusammenhang: Produktivkräfte, Produktions- und Eigentumsverhältnisse heißen die direkten wie indirekten impacts auf die Dinge der Natur in der kontemporären, konkreten Form der gesellschaftlichen Reproduktion: der kapitalistischen, bürgerlichen Gesellschaft. Wie die Subjekte bereits in der vorbürgerlichen Gesellschaft um die mannigfaltigen Dinge der Natur zwecks ihrer eigenen Reproduktion kämpfen, so kämpfen auch die inzwischen in der bürgerlichen Gesellschaft integrativ vergesellschafteten Subjekte bloß als Vereinzelte um ihr jeweiliges Überleben. Die selbstbewussten Subjekte haben also weiterhin „im

\footnotetext{
568 Lukács: Geschichte und Klassenbewußtsein, S. 171.

${ }^{569}$ Ebd., S. 172 f.

570 Adorno: Zu Subjekt und Objekt, S. 748.

571 Marx: Thesen über Feuerbach, S. 534.
} 
Kampf mit anderen [zu] ringen“572. Ihr einzelsubjektives Handeln und Denken dreht sich deshalb vor allem um die eigene Selbsterhaltung innerhalb der heteronomen kapitalistischen Gesellschaft. Weil der Kampf um die eigene Reproduktion in der Geschichte fortbestehe, ist die kapitalistische Gesellschaft auch nicht stellvertretend schon das messianische, versöhnte ,Ende der Geschichte‘. Die bürgerliche Gesellschaft habe mit der kapitalistischen Produktionsweise das Leiden der Individuen demnach nicht „bis zu einem erträglichen Grad“ 573 gemildert, sondern sie erzwinge, so Adorno, weiterhin und in besonderer, qualitativ veränderten Schärfe das Leiden der Subjekte. Der antagonistische Kampf ums Überleben in der kapitalistischen Gesellschaft ist insofern nicht frei von der fortgeführten „verwilderte(n) Selbsterhaltung “5774. Die Selbsterhaltung gilt deshalb als „stets noch

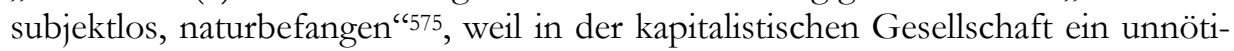
ger „Kampf ums Dasein fortgesetzt“ ${ }^{\text {‘576 }}$ werde.

Damit denunziert Adorno die transzendenten allgemeinen Zwecke der bürgerlichen Gesellschaft als jeweils falsche gesellschaftliche Zwecke, ihr gesellschaftliches Wesen sei deshalb das antagonistische, in sich rationale Unwesen (vgl. auch 2.5.2), das die autonomen Subjekte als integrierte Masse in ihrer gesellschaftlich möglichen Freiheit massiv einschränkt. Gesellschaft degradiert die Subjekte demnach als Mittel zum gesellschaftlichen Zweck. Das offenbart die gesellschaftliche Reproduktion über den konkreten Eingriff in den Naturzusammenhang als eine falsche gesellschaftliche Reproduktion. Das Handeln der Subjekte wird dadurch ebenfalls, aus der totalen Perspektive, als ein instrumentelles Handeln in der antagonistischen Gesellschaft kritisiert. Das in die Gesellschaft integrierte, vergesellschaftete Subjekt wird gezwungen, unter den unfreien, ihm transzendenten gesellschaftlichen Bedingungen zu handeln - weshalb sich wiederum die unfreien gesellschaftlichen Zwecke der bürgerlichen Gesellschaft in seinem Handeln ausdrücken.

\subsubsection{Integration und Differenzierung. Subjektives Handeln und Geschichte}

Adorno geht es nun unter anderem darum, den unmittelbar auf das Subjekt wirkenden objektiven Integrationszwang in die Gesellschaft aufzuzeigen. Der gesellschaftstheoretisch gedachte transzendente Vorrang des Objekts wurde oben bereits als notwendig übrigbleibendes restontologisches, gegen jede idealistische Versöhnungsromantik seiendes Moment gekennzeichnet. Dadurch, dass die gesellschaftliche Herrschaft eine so lange Geschichte hat und sie den Einzelnen bislang immer unter sich begraben hat, bekommt sie ein statisches Moment. Weil gesellschaftliche Herrschaft jedoch auch ihre jeweils besondere Geschichte hat, ist

\footnotetext{
572 Marx, Randglossen zu A. Wagners, Lehrbuch der politischen Ökonomie‘, S. 363.

573 Adorno: Negative Dialektik, S. 203.

574 Ebd., S. 285.

575 Adorno: Einleitung zu Emile Durkheim, ,Soziologie und Philosophie‘, S. 251.

576 Ebd.
} 
sie nun nicht als statisch oder ewig zu ontologisieren. Die jeweils konkrete Form der Vergesellschaftung darf trotz aller zu konstatierender Ahistorizität der Vergesellschaftung durch gesellschaftliche Herrschaft in der Menschheitsgeschichte bei der Gesellschaftsbildung zu Reproduktionszwecken nicht aus den Augen verloren werden. Jede Diskussion über eine wirkmächtige ahistorische Statik von gesellschaftlicher Herrschaft durch den heteronomen Naturzwang aber rechtfertigt letztendlich nur die gesellschaftliche Herrschaft, indem sie die Reflexion auf ihre eigenen Bedingungen nicht leistet. Sie ließe die dynamischen historischen Differenzen als in der Zeit seiende ideologisch ausgespart. Gerne wird deshalb von einer notwendig gesellschaftlichen Herrschaft gesprochen, weil ohne diese angeblich die Organisation des ansonsten chaotischen Eingriffs in den Naturzusammenhang unmöglich wäre; Hobbes beispielsweise möchte den möglichen Rückfall in den anarchischen Naturzustand nur über die Implementierung staatlich zentrierter gesellschaftliche Herrschaft verhindern. ${ }^{577}$ Diese Anthropologie mit dem Ziel der Verteidigung gesellschaftlicher Herrschaft macht jede mögliche Organisation von Reproduktion undifferenziert und ideologisch zu Herrschaft. Herrschaft wird mit der bloßen Organisation des Eingriffs in den Naturzusammenhang identifiziert, womit die gegenwärtige Gesellschaft und ihre Herrschaft von jeder ,Schuld' befreit ist. Weil jedoch die ,Naturbeherrschung' nicht gleich notwendig in Herrschaft von Menschen über Menschen übergeht (vgl. 2.3.3), ist Herrschaft nicht mit der bloßen Organisation der Reproduktion der Gattung zu verwechseln. ${ }^{578}$

Das Moment einer Organisation von gesellschaftlicher Reproduktion ist nach Adorno auch weiterhin notwendig, auch wenn die antagonistische, herrschaftliche Organisation der Gesellschaft überwunden ist. Die Aneignung der Natur zur Befriedigung menschlicher Bedürfnisse bleibt die unmittelbare Bedingung des menschlichen Überlebens; von der Gesellschaftsform und auch gesellschaftlicher Herrschaft ist diese Aneignung unabhängig 579 : „Eine rational durchsichtige, wahrhaft freie Gesellschaft könnte so wenig der Verwaltung entraten wie der Arbeitsteilung überhaupt.“580 Der Möglichkeit nach können also in einer vom gesellschaftlich-herrschaftlichen Zwang befreiten, aber reproduktionstechnisch organisierten Gesellschaft die Zwecke des einzelnen Subjekts trotzdem verwirklicht werden. Die gesellschaftliche Organisation des reproduktionstechnischen Eingriffs in den Naturzusammenhang ist zwar nie als absolute Vermittlung, als Ver-

\footnotetext{
577 Vgl. Hobbes: Leviathan.

578 So wenn, wie in 2.3.3 nachgewiesen wird, Naturbeherrschung bei Adorno und Horkheimer in der Dialektik der Aufklärung unreflektiert in Herrschaft von Menschen über Menschen übergeht, dann reproduziert sich das Problem der angeblich immerwährenden Ausweglosigkeit aus gesellschaftlicher Herrschaft.

579 „Die Arbeit ist zunächst ein Prozeß zwischen Mensch und Natur, ein Prozeß, worin der Mensch seinen Stoffwechsel mit der Natur durch seine eigene Tat vermittelt, regelt und kontrolliert.“ (Marx: Das Kapital, Bd. 1, S. 192.)

580 Adorno: Gesellschaft, S. 17.
} 
söhnung von in Gesellschaft handelndem Subjekt und gesellschaftlichem Objekt zu denken, sehr wohl aber ohne Herrschaft. Ein Stück nichtversöhntes, transzendentes Unmittelbares oder Unterschiedenes bleibt insofern selbst in jeder den Eingriff in den Naturzusammenhang freiheitlich organisierenden Gesellschaft übrig, weil auch sie, vermittelt über das Handeln der Subjekte, weiterhin in den Naturzwang eingreifen muss. Der Tod herrschaftlich gesellschaftlicher Zwänge bedeutet deshalb auch nicht den Tod von inhaltsschweren Begriffen, weil der Tod der Dialektik von selbstbewusstem, kritischen Subjekt und heteronomer Gesellschaft nicht aufgehoben werden kann. Beide unterschiedenen Momente bleiben insofern auch in der befreiten Gesellschaft durch sich hindurch vermittelt, selbst wenn der herrschaftliche Antagonismus der Vergesellschaftung längst aufgehoben sein sollte. Das Subjekt ist gegenüber dem Naturzwang und der gesellschaftlichen Organisation seiner Abschwächung ein nicht absolutes, negativ bestimmtes. Der Möglichkeit nach muss gesellschaftliche Freiheit jedoch trotz beständig bleibender gemeinschaftlicher Organisation und Naturzwang erreicht werden können: „Ich glaube also, daß man das doch zunächst einmal sagen muß und daß der mögliche Ansatzpunkt einer richtigen Praxis darin liegt, daß man nun allerdings neu durchdenkt, wie eine Gesellschaft denn doch ins Richtige kommen könnte, die zwar nach der Seite der in ihr geronnenen Verhältnisse und des nach ihr gemodelten Bewußtseins stationär zu werden droht, die aber auf der anderen Seite unablässig Kräfte produziert, die zwar einstweilen wesentlich der Vernichtung dienen, durch die aber - wenn ich es einmal ganz kraß sagen soll - das Paradies auf Erden heute oder morgen tatsächlich möglich wäre.“"581

Nach der Überwerfung der feudalen Traditionen durch die „ursprüngliche Akkumulation" ${ }^{\prime 582}$ wird das kooperativ handeln müssende Subjekt gezwungen, sich in die ökonomischen Gepflogenheiten der bürgerlichen Gesellschaft zu integrieren. Die eigene Reproduktion muss das bürgerliche Subjekt danach in der für es konkreten, gegenwärtigen bürgerlichen Gesellschaft handelnd realisieren, was im Vergleich zur feudalen Gesellschaft Änderungen mit sich bringt: Als der feudale Knecht nach den ersten bürgerlichen Revolutionen von 1776 in Amerika und 1789 in Frankreich gewaltsam von seinen Reproduktionsbedingungen befreit wird, hat er sich dem „Handelskrieg der europäischen Nationen“"583 durch den sich ausbreitenden Kapitalismus als Lohnarbeiter zu unterwerfen. Denn durch die bürgerliche Revolution wird er seinen subsistenzwirtschaftlichen Möglichkeiten enthoben. Es bleibt ihm zur Realisierung der eigenen Reproduktion dehalb bloß noch die Integration in den kapitalistisch organisierten Arbeitsprozess. Seitdem hat das bürgerliche Subjekt den inzwischen ökonomisch vermittelten gesellschaftlichen und nicht mehr persönlichen Zwängen zu folgen, um sich reproduzieren zu können. Das im Gesellschaftszusammenhang handelnde Subjekt wird jetzt als ein

\footnotetext{
581 Adorno: Vorlesung über Negative Dialektik, S. 76.

582 Marx: Das Kapital, Bd. 1, S. 741.

583 Ebd., S. 779.
} 
Vergesellschaftetes mit Haut und Haaren in den integralen gesellschaftlichen, kooperativen Zusammenhang der totalen bürgerlichen Gesellschaft eingebunden, wobei es durch die antagonistische Gesellschaft zu einem gesellschaftlich vermittelten Willen und bestimmten gesellschaftlichen Handeln in dieser gezwungen wird. Zu Gunsten seiner eigenen Reproduktion, die die einzige Zwecksetzung des Subjekts ist, muss es jetzt instrumentell im Rahmen der bürgerlichen Gesellschaft handeln. Die formell betonte Freiwilligkeit in der bürgerlichen Gesellschaft beruht deshalb auf einem gesellschaftlichen, integrativen Zwang der vorerst formellen, dann aber auch einem historisch fortlaufenden Prozess der reellen Subsumtion der Arbeit unters Kapital. ${ }^{584}$ Im subjektiven Handeln selbst drückt sich insofern der heteronome gesellschaftliche Zwang auf den Willen des Subjekts aus. In den durchs subjektive Handeln erscheinenden sozialen Phänomenen drückt sich deshalb vermittelt auch der allgemeine gesellschaftliche Zwang der bürgerlichen Gesellschaft aus: „Da würde ich nun allerdings sagen, das Wesentliche sind die objektiven Bewegungsgesetze der Gesellschaft, die über das Schicksal entscheiden, und die ihr Verständnis sind, und die andererseits aber auch die Möglichkeit enthalten, daß es anders wird, daß die Gesellschaft aufhört, ein Zwangsverband zu sein, in den man nun einmal hineingeraten ist. Aber diese objektiven Bewegungsgesetze haben Gültigkeit nur so weit, wie sie tatsächlich in sozialen Phänomenen sich ausdrücken und nicht, wenn sie im Sinn einer bloß deduktiven Ableitung aus reinen Begriffen, und mögen diese Ableitungen noch so tief in gesellschaftlicher Erkenntnis verwurzelt sein, sich erschöpfen.“"585

Der Zwang wird in der bürgerlichen Gesellschaft insbesondere über die Organisation der allgemeinen Reproduktion vermittelt und wirkt sich, dabei formell ganz anders als im Feudalismus, auf das Wollen und damit unmittelbar auch auf das Handeln jedes sich selbsterhaltenden, daseienden Subjekts aus. Jedes Subjekt muss sich über den konkreten, gesellschaftlich organisierten Arbeitsprozess selbst in die strukturell organisierte bürgerliche Gesellschaft integrieren, um so sein Überleben durch Unterwerfung unter die objektiven Bewegungsgesetze der allgemeinen Reproduktion zu sichern. Diese Selbstorganisation der eigenen Ausbeutung gehört, als gesellschaftlich positiv besetzte, in den ideologischen Rahmen der Freiwilligkeit der eigenen Reproduktion. Der kapitalistische Arbeitsprozess der bürgerlichen Gesellschaft, dem sich jedes Subjekt um seines Überlebens Willen zu unterwerfen hat, ist dabei kooperativ arbeitsteilig organisiert: „Die kapitalistische Produktion beginnt (...) in der Tat erst, wo dasselbe individuelle Kapital eine größere Anzahl Arbeiter gleichzeitig beschäftigt, der Arbeitsprozeß also seinen Umfang erweitert und Produkt auf größerer quantitativer Stufenleiter liefert.““586 „Die

\footnotetext{
${ }^{584}$ Ebd.: „Die verschiedenen Momente der ursprünglichen Akkumulation verteilen sich nun, mehr oder minder in zeitlicher Reihenfolge, namentlich auf Spanien, Portugal, Holland, Frankreich und England.“

585 Adorno: Vorlesung zur Einleitung in die Soziologie, S. 23.

586 Marx: Das Kapital, Bd. 1, S. 341.
} 
Form der Arbeit vieler, die in demselben Produktionsprozeß oder in verschiednen, aber aber zusammenhängenden Produktionsprozessen planmäßig neben- und miteinander arbeiten, heißt Kooperation." "587 Jedes Subjekt ausnahmslos wird durch die in der kapitalistischen Produktionsweise erforderte gesellschaftliche Arbeitsteilung in den gesellschaftlichen Zusammenhang der bürgerlichen Gesellschaft integriert und hat somit in ihm entsprechend zu handeln. Zwangsläufig trägt so also auch jedes Subjekt zum kapitalistischen Fortkommen, zur allgemeinen gesellschaftlichen Reproduktion bei. Diesen dialektischen Zwangszusammenhang der Gesellschaft über die die Subjekte einbindende kooperative Arbeitsteilung präzisiert Durkheim in Über die Teilung der sozialen Arbeit mit dem Begriff der „organischen Solidarität“588. Damit spricht Durkheim die erzwungene Integration in den allgemeinen gesellschaftlichen Zusammenhang als das Resultat moderner Arbeitsteilung in der bürgerlichen Gesellschaft an. ${ }^{589}$

Ähnlich wie bei Durkheim wird der das Subjekt integrativ einbindende allgemeine Zwang, der das subjektive Wollen und Handeln in der bürgerlichen Gesellschaft bestimmt, von Marx beschrieben - allerdings mit anderen Intentionen: Marx beschreibt den Zwang der Integration in die Gesellschaft zunächst an der Stelle, wo er von einer die Subjekte notwendig einbindenden objektiven Geschichte spricht. Dies ist noch eine dem Hegelschen absoluten Geist nachgebildete, allerdings bereits negativ gewendete links- oder junghegelianische Position, die Marx in seinen Frühschriften durchgängig vertritt (vgl. 2.6.2.1). Im Kapital überwirft er seine idealistische, frühschriftliche Geschichtsposition dann. Mit dem Ausdruck des ,automatische[n] Subjekt[s]“"590 bekommt die kapitalistische Gesellschaft, als inzwischen wertproduzierende kapitalistische Gesellschaft, als eine dem Subjekt gegenübertretende Objektivität, ihr zwingend ökonomisches, wirklich materialistisches Moment. Hier bezieht sich der integrative Zwangszusammenhang des automatischen Subjekts auf die ökonomische Arbeitsteilung des kapitalistisch organisierten Arbeitsprozesses und die in sie zwangsläufig integrierten, weil sich reproduzieren müssenden handelnden Subjekte (vgl. 2.6.2.2). Anhand dieses Schritts aus der vom einzelnen Subjekt abgespaltenen idealistischen Geschichtskonzeption macht Marx deutlich, dass die allgemeine transzendente Objektivität der totalen Gesellschaft gegenüber dem seiner selbst bewussten und reflektierten Subjekt nicht einfach Halt macht, bzw. das empirische Subjekt nicht einfach eingedenken kann und sich für eine Alternative autonom handelnd entscheiden kann. Als weitestgehend autonomes Subjekt wird es in die schon vorrangige Objektivität nahezu ohnmächtig integriert.

\footnotetext{
587 Ebd., S. 344.

588 Vgl. Durkheim: Über die Teilung der sozialen Arbeit, S. 152 ff.

589 Über die spezifischen Inhalte der Arbeitsteilung bei Durkheim siehe Habermas: Theorie des kommunikativen Handelns, Band 2, S. $173 \mathrm{ff}$.

590 Marx: Das Kapital, Bd. 1, 23, S. 169.
} 


\subsubsection{Der frühe Marx und das subjektive Handeln in der Gescbicbte}

Vor allem im Achtzehnten Brumaire nimmt sich Marx der Reflexion freiheitlicher Handlungen der empirischen Subjekte in der Geschichte an. Dort steht der inzwischen zum geflügelten Wort gewordene Satz, dass die Subjekte die Geschichte „selbst“"591 machen würden. Die Subjekte sollen in der Geschichte der Möglichkeit demnach frei, ganz nach ihrem spezifischen Wollen handeln können. Dieses ,selbst' verweist an ein notwendiges Moment der Autonomie des Subjekts, sich zu realisierende Zwecke im äußeren Material auch als instrumentell Denkendes und Handelndes suchen zu können (vgl. etwa 2.3.2). Doch diese Zwecke, zunächst als eigens realisierte angeführt, sind dann auch für Marx nicht wirklich eigene Zwecke des Subjekts, weil deren Realisation kein wirklich autonomes Handeln des Subjekts repräsentiere. Ihre Zwecke würden sich die Subjekte dann doch „nicht unter selbstgewählten, sondern unter unmittelbar vorgefundenen, gegebenen und überlieferten Umständen“"592 suchen.

Das ist eine ambivalente Bestimmung der Geschichte durch Marx. Auf der einen Seite ist es eine subjektive und keine vollkommen transzendente, wirkmächtige Geschichte eines abgespaltenen, metaphysisch anmutenden Außen, die durch gemeinschaftliche Handlungen der Subjekte realisiert wird - wie schon bei Hegel (vgl. 2.4.2). Auf der anderen Seite bewirkt, die Geschichte‘ jedoch ein deterministisches subjektives Handeln, was die Subjekte zur Kontemplation anhalte. Dieser doppeldeutige geschichtsphilosophische Teil des Achtzehnten Brumaire ist als ein früher, junghegelianischer Versuch einer Ausformulierung einer materialistisch mit und gegen Hegel gedachten transzendenten Präponderanz des gesellschaftlichen Objekts gegenüber dem in Gesellschaft handelnden Subjekt zu lesen. Die heteronome Präponderanz des Objekts gegenüber dem Subjekt nimmt bei Marx in seinen noch junghegelianischen Frühschriften einen hohen Stellenwert ein, da dieses Moment sich auch schon in Hegels idealistischer Geschichtsschreibung findet (vgl. 2.4.2), von der sich Marx an der Stelle noch nicht emanzipiert hat. Weil die selbstbewussten Subjekte neben ihrer notwendigen Autonomie derart heteronom bestimmt sind und in den ihnen und ihren eigenen Zwecken vorgeordneten Sedimentierungen der Geschichte Rollengerecht mitzuspielen haben, spricht Marx an anderer Stelle von einer bislang noch unbefriedet gebliebenen „Vorgeschichte" ${ }^{\text {“593. }}$ Diese bleibe als Vorgeschichte solange aktuell, wie eine befreite Gesellschaft noch unrealisiert sei. Bis dahin seien die Subjekte zu handelnden Mitteln heteronomer, ihnen transzendenter Zwecke der Gesellschaft herabgedrückt, bloße Exemplare der Gattung: „Was einmal bei Marx, mit schwermütiger Hoffnung, Vorgeschichte heißt, ist nicht weniger als der Inbegriff aller bisher bekannten Geschichte, das Reich der Unfreiheit.“"594 Der Begriff der zwingenden ,Vorgeschichte' verweist

\footnotetext{
${ }^{591}$ Marx: Der achtzehnte Brumaire des Louis Bonaparte, S. 115.

592 Ebd., S. 115.

593 Marx: Zur Kritik der Politischen Ökonomie, S. 9.

594 Adorno: Über Statik und Dynamik als soziologische Kategorien, S. 234.
} 
insofern auf ein zukünftig Kommendes, was die Subjekte schließlich aus ihrer heteronomen Umklammerung und in ihrem Handeln befreien würde. Diese dem Begriff immanente teleologische Notwendigkeit rückt den Begriff nicht bloß in die Nähe des ,historischen Materialismus', der frühschriftliche Geschichtsbegriff nährt sich dadurch auch der teleologischen Befreiungslehre an. Das Handeln der Subjekte weise nämlich durch das teleologische Moment ,automatisch' auf etwas in der Zeit noch Kommendes hin. Mit dieser , materialistischen' Teleologie wird das endliche Subjekt zu einem ohnmächtigen, auf ein unveränderbares Objektives, Gesellschaft/Geschichte, nur reagierendem. Geschichte werde für das individuelle Subjekt damit, ähnlich wie bei Hegel, zu einer unveränderlichen und unerkennbaren Naturgewalt. Diese Naturgewalt bekomme selber wiederum einen feindlichen Subjektcharakter, der das Subjekt durch seine Undurchsichtigkeit als bloße quantité negliable bestätigt. Diese Logik des nahezu messianischen Geschichtsverlaufs, auf etwas hin als aus sich selbst heraus, wird in der Sowjetunion nun zur offiziellen Auslegung der Geschichte, die auch nicht ganz zu Unrecht an Marx’ Frühschriften angelegt ist. Im Resultat dieser Interpretationen der teleologischen Geschichtsbewegung kennt man im Sowjetmarxismus keine der Möglichkeit nach mit ihrem Handeln in den Geschichtszusammenhang eingreifenden Subjekte mehr. Der sowjetmarxistische Histomat wird, weil derart subjektlos gedacht, jedoch zu einer Farce, zu einer stumpfen Wiederholung von Messianismus und Parusie: „Darum wachet! Denn ihr wisst weder Tag noch Stunde, (in welcher des Menschen Sohn kommen wird).“ “595

Die jeder konkreten (Jetzt-)Zeit enthobene Geschichte wird nun auch noch vom junghegelianischen Marx dergleichen negativ Hegelianisch als prozessuale Heilsbringerin materialisiert. Zeit werde dabei zu einer, wie Walter Benjamin hinsichtlich des Sowjetmarxismus bemerkt, abstrakt fortlaufenden „homogene[n] und

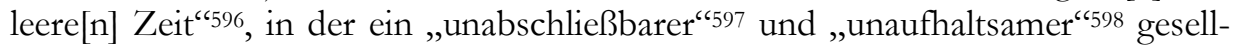
schaftlicher Fortschritt unkritisch, zu einer Naturnotwendigkeit hypostasiert wird, indem er Gesellschaft förmlich übergestülpt werde. Kontemplatives Warten auf die eigene Befreiung von gesellschaftlichen Zwängen durch die Geschichte wird dem Subjekt deshalb wie in Becketts Godot zur Tugend. ${ }^{599}$ Konstadinow schreibt in den Grundlagen der marxistischen Pbilosophie: „Die Grundbedingung für die Entwicklung der Produktion sind die von der Gesellschaft bereits geschaffenen Produktivkräfte, und die hauptsächlichen Quellen der Entwicklung der Produktion sind in der Produktion selbst und nicht außerhalb der Produktion zu suchen. Diese Quellen sind die dialektische Wechselwirkung der Elemente der Produktion, insbesondere der Elemente der Produktivkräfte, ihre inneren Widersprüche und

\footnotetext{
595 Matthäus 25, 13.

596 Benjamin: Sprache und Geschichte, S. 150.

597 Ebd., S. 149.

598 Ebd., S. 150.

${ }^{599}$ Vgl. Beckett: Warten auf Godot.
} 
hauptsächlich die Wechselwirkung zwischen den Produktivkräften und den Produktionsverhältnissen." ${ }^{600}$ Durch die teleologische Entwicklung der Produktivkräfte würden, nicht nur nach Konstadinow ${ }^{601}$, die Produktionsverhältnisse zur gegebenen, abstrakt bleibenden Zeit, die Vorgeschichte als dialektisch in sich selbst verschlungene aus sich selbst heraus auf eine höhere Stufe heben. Beim noch junghegelianisch geprägten Marx lautet dieser von Konstadinow aufgenommene Widerspruch von den Produktivkräften und Produktionsverhältnissen, der letztendlich in gesellschaftlicher Emanzipation resultieren soll: „Auf einer gewissen Stufe ihrer Entwicklung geraten die materiellen Produktivkräfte der Gesellschaft in Widerspruch mit den vorhandenen Produktionsverhältnissen oder, was nur ein juristischer Ausdruck dafür ist, mit den Eigentumsverhältnissen, innerhalb deren sie sich bisher bewegt haben. (...) Eine Gesellschaftsformation geht nie unter, bevor alle Produktivkräfte entwickelt sind, für die sie weit genug ist, und neue höhere Produktionsverhältnisse treten nie an die Stelle, bevor die materiellen Existenzbedingungen derselben im Schoß der alten Gesellschaft selbst ausgebrütet worden sind." "602

Dieses Prinzip der sich dialektisch widersprechenden bürgerlichen Ökonomie, die sich deswegen aus sich selbst herausarbeitet hin auf eine Befreiung von Herrschaft, ist eine Antezedensbedingung gesellschaftlicher Befreiung. Entscheidende Fragen nach dem Ort des Anstoßes der logischen Bewegung und der Zeit bleiben dabei konkret unbeantwortet. Die geschichtsphilosophische Teleologie und das Resultat in den Marxschen Frühschriften ist auch deshalb problematisch, weil der Geschichtsverlauf hier, recht widersprüchlich, außerhalb der Reichweite der Subjekte liegt. Damit wird nicht nur das empirische Subjekt aus dem Zusammenhang von allgemeiner Geschichte und Fortschritt herausgehoben, sondern das Subjekt wird generell idealistisch aus dem dialektischen Zusammenhang von Allgemeinem und Besonderem herausgehoben und dadurch zum völlig unmündigen Opfer dialektischer Geschichtsmethodik gemacht (vgl. 2.4.1; 2.4.2). Diese objektivistischen Automatisierungen im Kontext von Vorgeschichte und emanzipativer Befreiung lassen den Marxschen Geschichtsbegriff der Frühschriften, vor allem durch die Rezeption des Marxschen Geschichtsbegriffs im Marxismus, kritisch erscheinen. Doch auf den zweiten Blick lässt er auch einen allgemein objektiven, tatsächlich naturwüchsigen Zwang von Gesellschaft aufs autonome Subjekt, das tatsächlich durch die gesellschaftliche Zwangsintegration in seiner Autonomie

\footnotetext{
${ }^{600}$ Vgl. Konstadinow: Grundlagen der marxistischen Philosophie, S. 448.

${ }^{601}$ Vgl. zu den verschiedenen Autoren des sogenannten Diamat den Abschnitt „Dialektischer Materialismus" in Historisch-Kritisches Wörterbuch des Marxismus, Band 2, S. 694-703. Auch die Sozialdemokraten haben stets auf die Geschichtsteleologie gebaut. Deshalb fiel es einigen von ihnen von Beginn an auch leicht, sich positiv in den bürgerlichen Demokratien zu engagieren und nicht kritisch gegen diese revolutionär zu intervenieren. So bezeichneten sie sich weiterhin als Sozialisten und sahen sich nicht entsprechend als Revisionisten. Den Revisionismus hat die sozialdemokratische Partei bekanntlich bis heute nicht mehr abgelegt.

${ }^{602}$ Marx: Zur Kritik der politischen Ökonomie, S. 9.
} 
eingeschränkt wird, erkennen. Dieser von Marx als das Subjekt zum Handeln zwingende ausgemachte gesellschaftliche Zusammenhang wird nicht in der Darstellung als ein solcher gesellschaftlicher Zwang komplett falsch, nur weil die Darstellung noch in eine weitgehend subjektlose Theorie der Marxschen Frühschriften eingebettet bleibt. Die Ideologie der Geschichtsbewegung trifft durch die dargestellte Ohnmacht des empirischen Subjekts auch gesellschaftlich Richtiges, Wahres.

\subsubsection{Der späte Marx und das subjektive Handeln in der Geschichte}

Der Geschichtsbegriff von Marx im Kapital ist gegenüber den in den junghegelianischen Frühschriften konzipierten Begriffen von Geschichte und emanzipativer Befreiung implizit selbstkritisch. Hier begreift Marx die erzwungene Integration des in der bürgerlichen Gesellschaft handelnden Subjekts anders: Er macht sie konkret an den zeitgenössischen gesellschaftlichen Begebenheiten fest. Sie wird mit dem objektiv ökonomischen Zwang auf das Subjekt sichtbar. Das verdeutlicht die Heteronomie des Subjekts, das zwar gegen seine eigenen Voraussetzungen denken, aber als Einzelnes nicht dagegen handeln kann, solange es in der präformierten Gesellschaft überleben will.

Einer der entscheidenden Faktoren des negativen, zwangvollen Integrationsprozesses unter die gesellschaftlichen Herrschaftsverhältnisse und den kapitalistischen Arbeitsprozess ist für Marx die gesellschaftlich organisierte Arbeitsteilung. Im Resultat bringe die Arbeitsteilung im kapitalistisch organisierten Produktionsprozess die tendenzielle Angleichung der Arbeitsprozesse bei weiterem Fortschreiten der tendenziellen Kapitalisierung der Produktionszweige mit sich: „Da Warenproduktion und Warenzirkulation die allgemeine Voraussetzung der kapitalistischen Produktionsweise, erheischt manufakturmäßige Teilung der Arbeit eine schon bis zu gewissem Entwicklungsgrad gereifte Teilung der Arbeit im Innern der Gesellschaft. Umgekehrt entwickelt und vervielfältigt die manufakturmäßige Teilung der Arbeit rückwirkend jene gesellschaftliche Teilung der Arbeit. Mit der Differenzierung der Arbeitsinstrumente differenzieren sich mehr und mehr die Gewerbe, welche diese Instrumente produzieren." ${ }^{603}$ Weil sich Kapital nicht nur sukzessive in die verschiedenen Zweige der Produktion differenziere, so dass sich Haupt- und Nebengewerbe ein und derselben Produzenten sukzessive in eigene Gewerbe verselbstständigen, sondern die mit der Produktivkraftsteigerung möglich gewordene Teilung der Arbeit in verschiedene Gewerbe die einheitliche Produktion einer Ware in in sich verschiedene vereinzelte Produktionsschritte zerfallen lasse, differenziere sich die Produktion für Marx zudem in „verschiedne, zum Teil ganz neue Manufakturen“"604. Durch die Vereinfachung der Arbeit als Resultat der kooperativen kapitalistischen Produktion und dem ökonomischen Konkur-

\footnotetext{
${ }^{603}$ Marx: Das Kapital, Bd. 1, S. 374.

${ }^{604}$ Ebd.
} 
renzmodell der erzwungenen Produktivkraftsteigerung werde die fortschreitende Kapitalisierung dann auch zum entscheidenden Motor einer Vereinfachung des Arbeitsprozesses. Die vormals kompliziert geltende Arbeit werde durch den systematischen Zwang zur Produktivkraftsteigerung tendenziell zur einfachen Arbeit. ${ }^{605}$ Die Produktivkraftsteigerung nivelliere damit sukzessive die Unterschiede subjektiver Geschicklichkeit. Durch die Produktivkraftsteigerung glichen sich die Subjekte deshalb in ihrer möglichen Verwertbarkeit fürs Kapital als körperliche Subjekte mit gleichen Voraussetzungen einander an. Jeder Arbeiter auf dem Arbeitsmarkt werde deswegen jetzt auch immer viel schneller ersetzbar, weshalb jeder Arbeiter beim Verkauf seiner Ware Arbeitskraft dem Anderen dadurch viel schneller zur Konkurrenz werde: „Sofern die Maschinerie Muskelkraft entbehrlich macht, wird sie zum Mittel, Arbeiter ohne Muskelkraft oder von unreifer Körperentwicklung, aber größerer Geschmeidigkeit der Glieder anzuwenden." "606 Die tendenzielle Angleichung der gesellschaftlichen Arbeitsprozesse durch die Differenzierung der Arbeitszweige habe insofern eine verschärfte Konkurrenz um die individuelle Selbsterhaltung zur Folge. Es kommt dadurch zu einer verschärften integralen Einbindung der lohnarbeitenden, die Produktionsmittel anwendenden Subjekte und ihres Handelns in und unter die Gesetze der Gesellschaft. Der graduell erhöhte Konkurrenzdruck „zwischen Arbeiter und Arbeiter“607 wirkt sich dementsprechend lähmend auf die potentiellen Möglichkeiten aus, die eigene Selbsterhaltung als Arbeiter und selbstbewusst handelndes Subjekt in der integralen, allgemeinen Gesellschaft zu realisieren. Mit dieser durch die ökonomischen Prozesse hindurch vermittelten schnelleren Ersetzbarkeit jedes Einzelnen drohe nun jedem Arbeiter die der Möglichkeit nach existente und sich sukzessive fortführende Entziehung der Lebensgrundlage, sollte er sich nicht ordnungsgemäß in den gesellschaftlichen Zwangszusammenhang integrieren.

Adorno spricht deshalb, um diesen notwendig objektiven, naturwüchsig wirkenden Zwang des integralen Geschichtsprozesses auf alle selbstbewusst handelnden Subjekte zu benennen, viel präziser als Marx, von der Naturgeschichte, die das Handeln der Subjekte bislang und noch immer bestimme. Die Naturgeschichte sei auf zunächst unbestimmte Zeit verlängert und verfalle schon deswegen nicht einer idealistisch-objektivistischen Geschichtsdialektik wie der Marxsche Begriff der Vorgeschichte. Doch auch der späte Marx teilt schon nicht mehr die Inhalte des Begriffs der Vorgeschichte, wie Adorno in der Negativen Dialektik. feststellt: „Die Objektivität des geschichtlichen Lebens ist die von Naturgeschichte. Marx hat das gegen Hegel erkannt, und zwar streng im Zusammenhang mit dem über die Köpfe der Subjekte sich realisierenden Allgemeinen. “608

\footnotetext{
${ }^{605}$ Vgl. ebd., S. 59 ff. $/ 211$ f.

606 Ebd., S. 416.

${ }^{607}$ Marx: Grundrisse der Kritik der politischen Ökonomie, S. 457.

608 Adorno: Negative Dialektik, S. 347.
} 


\subsubsection{Gesellschaftliche Integration als universaler Zwang, konform zu handeln}

Die These von der Universalität des objektiven Zwangs auf die Subjekte und ihr Handeln muss noch präziser begründet werden, um sie zu verifizieren. Die scheinbar naturwüchsige Differenzierung und Verdinglichung durch die verallgemeinerte Konkurrenz um die adäquate Integration in die gesellschaftlichen Prozesse lastet nun nicht, wie man meinen könnte, einseitig auf den Proletariern. Wenn das Allgemeine die Subjekte universal als unbefreite, gezwungene präformiere, kann sich der Zwangszusammenhang nicht partikular und primär auf nur eine Klasse auswirken. Damit würde nur die allgemeine, wirkmächtige und systematische Gesetzmäßigkeit hinter den Erscheinungen verkannt. Der heteronome Zwang ist jedoch ein allgemein objektiver Zwang auf jedes Subjekt ausnahmslos. Der antagonistische gesellschaftliche Zwangszusammenhang zieht alles Produzierte und auch jedes Subjekt in seinen Bann. Einem naturwüchsigen Zwang gleich saugt die Gesellschaft alle Subjekte integrativ in sich hinein. Alle Subjekte werden demnach durch Gesellschaft als Mittel unter ihren besonderen Zweck integriert. ${ }^{609}$

Weil universaler Zwang auf die Subjekte, machen die Differenzierung und ihre Folgen also auch nicht vor den Eigentümern an Produktionsmitteln nicht Halt. Die Eigentümer an Produktionsmitteln, die nicht mehr unmittelbar in den Naturzusammenhang eingreifen müssen, sondern von ihrem Privateigentum an Produktionsmitteln leben, sind genauso den strukturellen Gesetzen der kapitalistischen Produktion in ihrem Handeln unterworfen wie die Produktionsmittellosen. Auch Produktionsmitteleigentümer sind dementsprechend individuelle Subjekte der Selbsterhaltung, die diese nur über die Integration in den gesellschaftlichen Verein und die konkrete Organisation der allgemeinen Selbsterhaltung realisieren können. Als vereinzelte, atomisierte individuelle Subjekte der Selbsterhaltung sind sie nicht diejenigen Subjekte, die die Geschicke der bürgerlichen Gesellschaft autonom und durch ihr persönliches Handeln bestimmen. ${ }^{610}$ Das zu behaupten käme einer subjektivistischen Personalisierung von objektiven Gesetzen der bürgerlichen Gesellschaft gleich. Die bürgerliche Gesellschaft kann jedoch gerade deshalb als eine totale Gesellschaft bestimmt werden, weil sich auch die Produktionsmitteleigentümer in die Gesellschaft integrieren müssen. Zum einen bleiben die Eigentümer an Produktionsmitteln durch die der kapitalistischen Produktivkraftsteigerung entspringenden Differenzierung technisch auf die anderen Produktionszweige angewiesen, was ihre affirmative Beziehung in der kapitalistischen Gesellschaft aufeinander verdeutlicht. Zum anderen beziehen sie sich durch die Konkurrenz um die gesellschaftliche Profitmasse negativ aufeinander. Die Konkurrenz um den allgemeinen kapitalistischen Marktmagen führt auch in der vermeintlich herr-

\footnotetext{
${ }^{609}$ Konkret werden die Begründungen des Zwangs und seine Vermittlungen erst im nächsten Kapitel.

${ }^{610}$ Solch ein Urteil von der herrschaftlichen Autonomie der Kapitalisten führt vielleicht zu mehr Wählern der Sozialdemokratie und mehr ausgestellten Mitgliedsbüchern von Gewerkschaften. Näher an die Wahrheit rückt man damit aber nicht.
} 
schenden Klasse der Bourgeoisie zu einem entsprechenden Differenzierungsprozess, weil der Marktmagen der kapitalistischen Gesellschaft nicht alle Kapitalisten und jedes Eigentum an Produktionsmitteln gleichermaßen verträgt.

Der integrale Zusammenhang der Einzelkapitale lässt sich dabei gut mit dem Begriff des Gesamtkapitals ${ }^{611}$ verdeutlichen. Der Begriff vom Gesamtkapital ist bei Marx nicht die bloße zusammengefasste Summe der Einzelkapitale oder womöglich die Summe aller Einzelkapitalisten. Er stellt die vernünftig begriffene, begrifflich bestimmte Totalität der kapitalistischen Produktionsweise dar, die sich auch negativ gegen die Einzelkapitale oder Einzelkapitalisten äußert. Als ein wirklich Ganzes ist das Gesamtkapital darum bei Marx auch als viel mehr bestimmt, als wenn es nur die Summe seiner Teile wäre. Die beschriebene Konkurrenz der Einzelkapitale um den Marktmagen schließt insofern die negative Beziehung der Einzelkapitale aufeinander sogleich mit ein: Sie steckt zumindest ökonomisch den Rahmen der kapitalistischen Konkurrenz innerhalb der einzelnen Produktionssphären ab. Im Rahmen einer Entwicklung des Totalitätsbegriffs von Gesellschaft stellt sich die dringende Frage nach der Beziehung der verschiedenen Sphären der Einzelkapitale mit unterschiedlicher „organischer Zusammensetzung des Kapitals“"612 zueinander. Was zunächst wie ein logischer Widerspruch anmutet, beantwortet Marx im Kapital mit der gesellschaftlichen Durchschnittsprofitrate. ${ }^{613}$ Diese als Schnittmenge klassifizierte Rate des Profits realisieren hier alle Einzelkapitale durchschnittlich, was bedeutet, dass die Profite aller Einzelkapitale um diese eine objektive „allgemeine Profitrate“614 oszillieren. Der Begriff des gesellschaftlichen Gesamtkapitals vermittelt deshalb, rein ökonomisch betrachtet, die allseits integrale Abhängigkeit der jeweiligen Einzelkapitale - sowohl als affirmative wie negative Abhängigkeit - sowie, in 2.6.2 beschrieben, die integrale Abhängigkeit der Lohnarbeiter unter den Bedingungen der allgemeinen Arbeitsteilung: „Zum ersten Mal in der Geschichte stehen sich daher zwei Klassen gegenüber: das gesellschaftliche

\footnotetext{
${ }^{611}$ Der Physiokrat Quesnay 1758 formuliert mit dem Tableau économique in Form eines Kreislaufmodells den ersten Gesamtzusammenhang des (noch semi-feudalen) Gesamtkapitals. (Quesnay: Tableau économique.) Engels befasst sich im Anti-Dübring mit dem Tableau und Marx findet in seinen Theorien über den Mehrwert, dass, ,den ganzen Produktionsprozeß des Kapitals als Reproduktionsprozeß darzustellen, die Zirkulation bloß als die Form dieses Reproduktionsprozesses, die Geldzirkulation nur als ein Moment der Zirkulation des Kapitals“, ein genialer Einfall sei, ,, unstreitig der genialste, dessen sich die politische Ökonomie bisher schuldig gemacht hat.“ (Marx: Theorien über den Mehrwert, S. 319.) Marx selbst weist im 2. Band des Kapitals nach, wie sich das Gesamtkapital konstituiert. Dabei stellt er die Dynamik heraus, wie das die allgemeine Reproduktion aller und alle gesellschaftlichen Klassen in die kapitalistische Produktionsweise eingeschlossen sind: „Das Kapital als sich verwertender Wert umschließt nicht nur Klassenverhältnisse, einen bestimmten gesellschaftlichen Charakter, der auf dem Dasein der Arbeit auf Lohnarbeit ruht. Es ist eine Bewegung, ein Kreislaufprozeß durch verschiedene Stadien, der selbst wieder drei verschiedene Formen des Kreislaufprozesses einschließt. Es kann daher nur als Bewegung und nicht als ruhendes Ding begriffen werden.“ (Marx: Das Kapital, Bd. 2, S. 109.)

612 Marx: Das Kapital, Bd. 1, S. 640.

${ }^{613}$ Marx: Das Kapital, Bd. 3, S. 167.

${ }^{614} \mathrm{Ebd}$
} 
Gesamtkapital setzt die Klasse der Kapitalisten zu der der Lohnarbeiter in Beziehung." "615 Diese sich ökonomisch-objektiv durchsetzende Prozesshaftigkeit realisiert das Verhältnis der Klassen zueinander wie untereinander.

Diese allgemeine Differenzierung durch den strukturellen Zwang der objektiven Gesetze der Produktion bringt Marx im Kapital deshalb auch dazu, die Kapitalisten wie auch die Arbeiter als Personen ein Stück weit aus der vollen Verantwortung für ihr persönliches, individuelles Handeln innerhalb der naturwüchsigen Zwänge der bürgerlichen Gesellschaft zu nehmen. Den Eigentümern an Produktionsmitteln, der Bourgeoisie, wird deshalb von Marx, anders als beispielsweise von Proudhon ${ }^{616}$, als gesellschaftlich verdinglichte Subjekte moralisch kein Vorwurf für ihr persönliches Handeln gemacht, weil jedes Subjekt unter dem Zwang objektiver Gesetzmäßigkeiten der allgemeinen Reproduktion stehe: „Die Gestalten von Kapitalist und Grundeigentümer zeichne ich keineswegs in rosigem Licht. Aber es handelt sich um die Personen nur, soweit sie die Personifikation ökonomischer Kategorien sind, Träger von bestimmten Klassenverhältnissen und Interessen. Weniger als jeder andere kann mein Standpunkt, der die Entwicklung der ökonomischen Gesellschaftsformation als einen naturgeschichtlichen Prozeß auffaßt, den einzelnen verantwortlich machen für Verhältnisse, deren Geschöpf er sozial bleibt, sosehr er sich auch subjektiv über sie erheben mag. (...) Nur als Personifikation des Kapitals ist der Kapitalist respektabel. Als solche teilt er mit dem Schatzbildner den absoluten Bereicherungstrieb. Was aber bei diesem als individuelle Manie erscheint, ist beim Kapitalisten Wirkung des gesellschaftlichen Mechanismus, worin er nur Triebrad ist. Außerdem macht die Entwicklung der kapitalistischen Produktion eine fortwährende Steigerung des in einem industriellen Unternehmen angelegten Kapitals zur Notwendigkeit, und die Konkurrenz herrscht jedem individuellen Kapitalisten die immanenten Gesetze der kapitalistischen Produktionsweise als äußere Zwangsgesetze auf. Sie zwingt ihn, sein Kapital fortwährend auszudehnen, um es zu erhalten, und ausdehnen kann er es nur vermittelst progressiver Akkumulation." ${ }^{\prime 617}$

Jedes sich selbst erhaltende Subjekt wird demnach durch den systematischen, naturgleichen Zwang der Integration in die Gesellschaft und ihre Zwangsgesetze ergriffen. Der totalitäre Zwang ist demnach ein Prozess. Dieser integrative, nur begrifflich zu beschreibende ökonomische Prozess affiziert und verdinglicht das vereinzelt handelnde Subjekt als selbstbewusstes Klassensubjekt der bürgerlichen Gesellschaft nahezu vollständig. Die bürgerliche Gesellschaft präformiert die einzelnen Subjekte durch den ihnen abgerungenen Willen, innerhalb der heterono-

\footnotetext{
${ }^{615}$ Weyand: Stummer Zwang oder innere Stimmen?, S. 102.

${ }^{616}$ So kritisiert Marx an Proudhon dessen kleinbürgerliche Art des Denkens, die diesen dann auch immer wieder zu falschen Schlüssen kommen lässt. Proudhon wollte nach Marx zwar Dialektik betreiben, konnte aber immer nur Sophisterei betreiben. (Vgl. Karl Marx, Über P.J. Proudhon, S. 25 ff.)

${ }^{617}$ Marx: Das Kapital, Bd. 1, S. 618.
} 
men und antagonistischen gesellschaftlichen Verhältnisse zu überleben. Die Gesellschaft bindet somit jedes individuelle selbstbewusste Subjekt aus Gründen der Selbsterhaltung systematisch in ihren strukturell organisierten und integralen, reflexiven Prozess von Produktion und Reproduktion ein. Nach Marx sei es „,die Zwickmühle des Prozesses selbst" ${ }^{\text {"618 }}$, der die Subjekte in den unmittelbaren Bann zieht und diese nach seinen Bedingungen forme. Jedes Subjekt, ganz gleich ob Bourgeois oder Proletarier, wird in dieser integralen Gesellschaft deshalb ausnahmslos zum funktionalen Gegenstand kapitalistischer Produktion. Die notwendig gesellschaftliche Integration jedes bürgerlichen Subjekts - also jedes selbstbewussten Individuums - in die kapitalistische Gesellschaft schlägt damit immanent dialektisch, wie schon die Aufspaltung des Produktionsprozesses in einzelne Teilproduktionen, - und zwar vermittels des gesellschaftlichen Prozesses der Vereinheitlichung selbst - in eine Differenzierung des individuellen Subjekts der Selbsterhaltung um.

In den systematischen Prozess von Konkurrenz und verwilderter Selbsterhaltung wird also ein jedes individuelle, seiner selbst bewusste Subjekt scheinbar naturwüchsig geworfen. Dadurch wird das individuelle Subjekt als individuell handelndes zum Mittel des zweckmäßigen Prozesses der allgemeinen gesellschaftlichen Reproduktion in der bürgerlichen Gesellschaft herabgedrückt. Weil das so ist, erweist sich auch die mit Moralansprüchen an das einzelne Subjekt herantretende Kritik als offensichtlicher Rückfall hinter die kennengelernten Ausführungen von Marx. Denn von Moralisten wird die treibende Substanz dessen, was das vereinzelte Subjekt erst zu seinem individuellen Handeln zwingt, nicht reflektiert bzw. kritisiert. Der Zeigefingermoralist ${ }^{619}$ liegt insofern immer falsch, weil seine Kritik, die bloß individuelle Handlungen von Subjekten, ohne das gesellschaftliche Wesen hinter Handlungen, sozialen Erscheinungen etc. kritisiert, vollkommen unzureichend ist. Einzelne Subjekte können deshalb, bei gleichzeitiger Reflexion ihrer Funktion, nur bedingt kritisiert werden. Jede als vermeintlich substantiell vorgetragene Kritik verpufft darum, auch weil sich von den gesellschaftlichen Bürden durch die Zwangsintegration in die Gesellschaft kein handelndes Subjekt je freimachen kann. ${ }^{620}$ Dem vorgeordneten Ganzen, als das Subjekt in seinem Handeln präformierendes, korrespondiert die Auffassung von der Gesellschaft nicht nur als dynamischer, sondern eben auch als funktionaler Kategorie. Das Ganze der Gesellschaft erhält sich ,vermöge der Einheit der von seinen Mitgliedern erfüllten Funktionen“, also nur und gerade durch die Konkurrenz und durch die einzelnen Funktionsträger als Personifikation ihrer sachlichen Aufgaben hindurch: „Generell

\footnotetext{
618 Ebd., S. 603.

619 ..., der damit ein Ethiker ist. Vgl. zur Differenz von Moral und Ethik, Sitte, Gesetz und sich davon abhebender Theorie: Adorno: Probleme der Moralphilosophie, S. 26 ff.

${ }^{620}$ Vgl. dazu tagesspiegel.de: Veganer und Drogen. Hört erstmal auf zu koksen!
} 
muß jeder Einzelne, um sein Leben zu fristen, eine Funktion auf sich nehmen und wird gelehrt, zu danken, solange er eine hat."621

\subsubsection{Das sozialpsychologische Moment der Integration. Selbstdifferenzierung und Ich-Dialektik}

„An der Psychoanalyse ist nichts wahr als ihre Übertreibungen.“622

Der Prozess der in der bürgerlichen Totalität vergesellschafteten Selbsterhaltung dringt selbstverständlich auch in die Psyche des selbstbewussten, lebendigen Subjekts ein. Vor allem, weil das selbstbewusste Subjekt nicht nur um die äußeren heteronomen natürlichen, sondern auch um die transzendenten gesellschaftlichen Zwänge auf es selbst als somatisches und damit leidendes Individuum weiß. Physis und Psyche sind dialektisch ineinander als durch sich hindurch vermittelte Momente. In der Psyche des Subjekts findet Gesellschaftliches insofern immer seinen Ausdruck: „Man kann wohl bestimmte Typen geistiger Erkrankung selber nach dem Modell einer erkrankten Gesellschaft konstruieren." 623

Die konkreten Auswirkungen der Gesellschaft auf die Psyche untersucht, als Teildisziplin der Psychologie, die Sozialpsychologie. Sie arbeitet mit der komplexen, auch auf gesellschaftstheoretischem Boden fruchtbaren Psychologie Sigmund Freuds. ${ }^{624}$ Dessen elaborierte Psychologie am gesellschaftlichen Gegenstand konnte die Sozialpsychologie erst begründen. ${ }^{625}$ Eine fundierte Psychologie kann sich

\footnotetext{
${ }^{621}$ Adorno: Gesellschaft, S. 10.

622 Adorno: Minima Moralia, S. 54.

623 Adorno: Zum Verhältnis von Soziologie und Psychologie, S. 53.

${ }^{624}$ Begründer einer Sozialpsychologie ist deswegen Sigmund Freud und nicht etwa der eher feldtheoretisch arbeitenden Kurt Lewin: Resolving social conflicts: selected papers on group dynamics) und/oder Gordon W. Allport: The Nature of Prejudice); Freuds Sozialpsychologie wird hier deshalb gegen die populäre Meinung der methodisch ausgebildeten sozialpsychologischen Vorurteilsforscher Gegenstand. Parsons: Der Beitrag der Psychoanalyse zu den Sozialwissenschaften, S. 96-106, beschreibt den entscheidenden Beitrag Freuds zur Gesellschaftswissenschaft adäquat.

${ }^{625}$ Die Spaltungen der Psychologie in Spezial- bzw. Teildisziplinen, u.a. die Individualpsychologie, Sozialpsychologie etc., bringen Probleme mit sich: Einer Individualpsychologie bspw. wird die konkrete Gesellschaft nur abstrakt zum Gegenstand. Der Mensch ginge ihr, subjektivistisch/ positivistisch gedacht, voraus: ,Jeder Gedanke des Menschen mußte so beschaffen sein, daß er einer Gemeinschaft gerecht werden konnte.“ (Adler: Menschenkenntnis, S. 40.) Eine solche Eindimensionalität der Psychologie verfolgte Freud nun nicht. Freuds offene Differenzen zu Adler lassen sich vor seiner triebdualistischen, Wende von 1920' (vgl. Freud: Jenseits des Lustprinzips) an der Interpretation vor allem des Aggressionstriebs festmachen; anders als für Adler sei der Aggressionstrieb für den Sozialpsychologen Freud kein eigenständiger Trieb ,neben und gleichberechtigt mit den uns vertrauten Selbsterhaltungs- und Sexualtrieben“. So gebühre hier noch ,jedem Triebe sein eigenes Vermögen, aggressiv zu werden“". (Freud: Zwei Kinderneurosen, S. 117 f.). So verfolgt Freud zunächst auch eine ganz andere Stoßrichtung: die der (Sozial-)Psychologie, die Gesellschaft in ihrer konkreten Beschaffenheit als Totalität nicht ausklammert. Heute erfährt die Sozialpsychologie durch die Zerschlagung auch des Freudschen Systemzusammenhangs immer mehr Einschränkungen, was seine Theorie durchaus problematisch, weil subjektivistisch, monadenartig in Kleinstbereiche zer-
} 
von Sozialpsychologischem generell so wenig sinnvoll abspalten wie sich die Theorie einer Gesellschaft einfach von sozialpsychologischen Reflexionen freimachen kann.

Den oben angestellten Reflexionen zur ökonomischen Differenzierung entspricht der von Freud festgestellten und in seiner zweiten Topik, vor allem in den Schriften Trauer und Melancholie und Das Ich und das Es, untersuchten Differenzierung der gesellschaftlich handelnden Subjekte in sich selbst. Freud liefert hier tiefgreifende Untersuchungen über die innere Zerrissenheit des bürgerlichen Subjekts (als Ich). Die moralische Instanz des Freudschen Über-Ich erweist sich dabei als untrennbar in den gesetzmäßig verfassten allgemeinen Reproduktionszusammenhang der kapitalistischen Gesellschaft eingebundene gesellschaftliche Instanz, „die ein Gesetz verkörpert und verbietet, es zu überschreiten. “626 Sie ist deshalb von gesellschaftlicher Herrschaft nicht zu trennen. Durch die in Gesellschaft und ihre Institutionen eingebundenen Eltern dringt der gesellschaftliche Antagonismus auch schon in das kindliche Individuum ein. Die Elterninstanz ${ }^{627}$ ist diejenige Instanz des Über-Ich, die sich durch die kindliche Verinnerlichung der äußeren, gesellschaftlichen Konflikte der vergesellschafteten Eltern bildet. Durch sie „verinnerlicht [das Kind, B.E.B.] das Verbot" ${ }^{\text {"628 }}$ der Eltern. Die äußere, objektive Gewalt der bürgerlichen Gesellschaft, die das elterliche Subjekt verdinglicht an sich selbst erfährt, verinnerlicht sich demnach im kindlichen Subjekt und dessen ÜberIch. Das elterliche Über-Ich ist insofern die von der bürgerlichen Gesellschaft bereits geprägte Instanz, die sich psychisch vermittelt auf das kindliche Über-Ich auswirkt bzw. überträgt. Freud beschreibt den gesellschaftlichen Kontext des Über-Ich, in dem das Über-Ich als Elterninstanz wesentlich (ent-)steht: „So wird das Über-Ich des Kindes eigentlich nicht nach dem Vorbild der Eltern, sondern des elterlichen Über-Ichs aufgebaut; es erfüllt sich mit dem gleichen Inhalt, es wird zum Träger der Tradition, all der zeitbeständigen Wertungen, die sich auf diesem Wege über Generationen fortgepflanzt haben." ${ }^{\prime 29}$ Das zeigt auf, wie der

splittert. Die gesellschaftliche Totalität wird in diesen Konzepten nicht reflektiert, Gesellschaft und Realität werden generell als reine subjektive Konstruktion aufgefasst. Alles Verhalten und Erleben werde von sozialen Beziehungen, von der freiheitlichen Intersubjektivität zumal, beeinflusst.

(Smith/Mackie: Social Psychology, S. 5: „Social psychology is the scientific study of the effects of social and cognitive processes on the way individuals perceive, influence, and relate to others.")

${ }^{626}$ Laplanche/Pontalis: Das Vokabular der Psychoanalyse, S. 541.

${ }^{627}$ Vgl. Freud: Die Zerlegung der psychischen Persönlichkeit, S. 505.

${ }^{628}$ Laplanche/Pontalis: Das Vokabular der Psychoanalyse, a.a.O., S. 541.

${ }^{629}$ Sigmund Freud: Die Zerlegung der psychischen Persönlichkeit, S. 505. Mit den „zeitbeständigen Wertungen“" spielt Freud allerdings auch auf etwas mythisch über der Ökonomie Stehendes an. Er bricht dabei nicht nur mit dem Verhältnis von gesellschaftlichen Erscheinungen und gesellschaftlicher Reproduktion, sondern Freud besetzt dabei auch Begriffe wie Volk und Rasse positiv: „Die Menschheit lebt nie ganz in der Gegenwart, in den Ideologien des Über-Ichs lebt die Vergangenheit, die Tradition der Rasse und des Volkes fort, die den Einflüssen der Gegenwart, neuen Veränderungen, nur langsam weicht, und solange sie durch das Über-Ich wirkt, eine mächtige, von den ökonomischen Verhältnissen unabhängige Rolle im Menschenleben spielt.“ (Ebd.) 
transzendente gesellschaftliche Antagonismus der kapitalistischen Gesellschaft in das noch nicht erwachsene Subjekt und dessen Psyche gelangt. Die gesellschaftliche Transzendenz ist insofern keine einfach nur abgespaltene, sondern eine in die psychische Immanenz des Subjekts dialektisch über die Schnittstelle des elterlichen Über-Ichs bereits hineinverlegte. Das führt bereits im Kindesalter zu einer Zerrissenheit des Subjekts - durch die über-ichlich vermittelten gesellschaftlichen Erfahrungen der kapitalistischen Gesellschaft.

Die Zerrissenheit des bürgerlichen Subjekts als Ich durch die Forderung nach der Befolgung von gesellschaftlichen Werten und Normen entspricht der Differenzierung durch Integration in die bürgerliche Gesellschaft und ihre allgemeinen ökonomischen und sonstigen herrschaftlichen Prozesse. Das vernünftige, in der bürgerlichen Gesellschaft handelnde selbstbewusste Subjekt erkennt sich nicht bloß zugleich als Objekt. Es macht sich auch zum gesellschaftlichen Objekt, weil es in der bürgerlichen Gesellschaft immer nur das Objekt kapitalistischer Verwertung sein darf und seiner Autonomie durch die eigene Selbsterhaltung in der kapitalistischen Gesellschaft größtenteils beraubt ist: „Verweilen wir einen Moment lang bei dem Einblick, den uns die Affektion des Melancholikers in die Konstitution des menschlichen Ichs gewährt. Wir sehen bei ihm, wie sich ein Teil des Ichs dem anderen gegenüberstellt, es kritisch wertet, es gleichsam zum Objekt nimmt." "630 Dergestalt verdinglicht sich das Subjekt selbst als ein in der transzendenten Gesellschaft handelndes, weil es gesellschaftlich bereits zum funktionellen Mittel für Anderes degradiert ist. Diese verdinglichende Degradierung hinterfragt die Existenz jedes Einzelnen beständig. Dadurch wird das vergesellschaftete Subjekt, sozialpsychologisch gesprochen, weil es sich in innerhalb und durch die verhärtete kapitalistische Gesellschaft selbst zum Objekt degradieren muss und ständig existentiell kritisiert wird, zu einem melancholischen Subjekt. ${ }^{631}$

Dieser existenziellen Hinterfragung seines Daseins setzt sich das vernünftige, lebendige Subjekt auch nicht nur in bestimmten Phasen seines Lebens aus (zum Beispiel, wenn es gerade arbeitslos ist etc.); es wird ständig, immerzu am besonderen Wert fürs kapitalistische System gemessen. Jedes Subjekt muss deshalb um diesen seinen eigenen besonderen Wert in der kapitalistischen Gesellschaft auch notgedrungen wissen - und es weiß um ihn, wenn es sich in dieser Gesellschaft reproduzieren möchte. Das einzelne Subjekt wird deshalb als in der bürgerlichen Gesellschaft handeln müssendes nicht etwa nur am Bodensatz der Gesellschaft bezüglich seiner Existenz hinterfragt, sondern die Funktionalität des einzelnen Subjekts im gesellschaftlichen Rahmen wird hinsichtlich seines Werts für die kapitalistische Gesellschaft beständig hinterfragt. Diese Hinterfragung geschieht auch nicht (nur) gut versteckt oder hinter verschlossenen Türen, sondern ganz offen und im Rahmen der Legalität wird nach der gesellschaftlichen Wertigkeit von

\footnotetext{
${ }^{630}$ Freud: Trauer und Melancholie, S. 201.

${ }^{631}$ Vgl. Lepenies: Melancholie und Gesellschaft.
} 
subjektivem Leben gefragt. ${ }^{632}$ Der damit einhergehende lebensbedrohliche Stress, der im Zusammenhang mit der kapitalistischen Selbstverwertung steht, hat dabei selbstverständlich eklatante Auswirkungen auf die Psyche des Subjekts. Auch wenn sich diese Invektiven der totalen Gesellschaft in den einzelnen Subjekten durchaus jeweils dispositionell in den Subjekten verschieden auswirken können, kann sich doch kein Subjekt davon befreien. Das vergesellschaftete Subjekt differenziert sich darum ausnahmslos deshalb von sich selbst, um den äußeren gesellschaftlichen Antagonismus besser parieren zu können. Diese Selbstdifferenzierung reflektiert Adorno, der die fruchtbaren sozialpsychologischen Überlegungen Freuds in seiner Gesellschaftstheorie gesellschaftstheoretisch noch zugespitzter konkretisiert: „Durch äußerste Abstraktion verschafft sich, im Indifferenzbegriff der Persönlichkeit, der nach traditionell-logischer Argumentationsweise tabuierte, aber desto realere dialektische Sachverhalt sein Recht, daß in der antagonistischen Welt die einzelnen Subjekte auch in sich antagonistisch sind, frei und unfrei."“633 Diese von Adorno ausgemachte Ich-Schwäche des vergesellschafteten Subjekts ist ein Resultat einer konkretisierenden Reflexion dieser Selbstdifferenzierung und Verdinglichung aus der Psychoanalyse. Die Ich-Schwäche des Subjekts ist demzufolge der psychische Ausdruck von gesellschaftlicher Herrschaft.

Der auf Adorno in diesem Rahmen Eindruck machende (Sozial-)Psychologe David Riesman spricht in seinen Studien zum Verhältnis von bürgerlichem Subjekt und bürgerlicher Gesellschaft vom outer directed character im Gegensatz zum inner directed character. Der überwiegende Sozialcharakter des modernen bürgerlichen Subjekts sei der outer directed character: "The type of character I shall describe as other-directed seems to be emerging in very recent years in the upper middle class of our larger cities". ${ }^{634}$ Diesem heteronomen, von kapitalistischer Gesellschaft determinierten Sozialcharakter fehle, anders als dem inner directed character, die Fähigkeit zur selbstbewussten Dialektik seiner inneren und äußeren Kräfte.

\footnotetext{
${ }^{632}$ Nota bene: Was sozialrechtlich Behinderung heißt, ist Resultat einer Einteilung der offen zum Sachverhalt degradierten, zu funktionellen Objekten verdinglichten Menschen: nämlich nach ihrer arbeitsmarkttauglichen (Voll-)Wertigkeit. Es wird noch graduell abgestuft, mit wie viel Prozent die körperlich oder geistig eingeschränkten Subjekte dem kapitalistischen Arbeitsmarkt trotz ihrer körperlichen oder seelischen Einschränkung noch zur Verfügung stehen müssen. Wenn man also die eigene Selbsterhaltung nicht (mehr) oder nur noch schwer, selbst' organisieren kann, gilt man als in seinem selbstbewussten Handeln behindertes, ökonomisch verhindertes, nicht vollwertiges Subjekt, was sich den für die eigene Selbsterhaltung entsprechenden Arbeitsplatz nicht mehr selbst organisieren oder auf einem solchen nur noch eingeschränkt arbeiten kann. Die soziale Kategorie Behinderung ist nichts als ein relativer Gradmesser der Arbeitstauglichkeit des Menschen im kapitalistisch organisierten Arbeitsmarkt: „Schwerbehinderten Menschen gleichgestellt werden sollen behinderte Menschen mit einem Grad der Behinderung von weniger als 50, aber wenigstens 30, bei denen die übrigen Voraussetzungen des Absatzes 2 vorliegen, wenn sie infolge ihrer Behinderung ohne die Gleichstellung einen geeigneten Arbeitsplatz im Sinne des $\$ 73$ nicht erlangen oder nicht behalten können (gleichgestellte behinderte Menschen).“ (Neuntes Buch Sozialgesetzbuch, \2, 3). 633 Adorno: Negative Dialektik, S. 290.

${ }^{634}$ Riesman/Glazer/Denney: The Lonely Crowd, S. 19. (zitiert nach Adorno: Zur Lehre von der Geschichte und von der Freiheit, S. 13.)
} 
Resultat sei deshalb die komplette Anpassung einer großen Anzahl von Subjekten an gegenwärtige gesellschaftliche Herrschaftsstrukturen. Adorno nimmt in einer Vorlesung direkten Bezug auf Riesmans Anpassungsthese: „In seinem Falle [dem des outer directed characters, B.E.B.] wird die Disproportion zwischen der Ausbildung des eigenen Ich und der Gewalt der Kräfte, die auf ihm herumarbeiten, so gelöst, daß das Ich zur Dialektik seiner inneren und äußeren Kräfte nicht kommt und sich anpasst."635 Die Anpassungsthese reflektiert die psychische Ohnmacht des eigentlich reflexiven, zeitlichen und selbstbewussten Subjekts innerhalb der zum Zwecke der eigenen Selbsterhaltung verlangten Integration in den objektiven Zwangszusammenhang der bürgerlichen Gesellschaft. Durch die gesellschaftliche Übermacht drohe dem schwachen Ich deshalb immer die vollkommene Beraubung der selbstbewussten Reflexionskraft: „Unterm Bann der zähen Irrationalität des Ganzen ist normal auch die Irrationalität des Menschen. Sie und die Zweckrationalität ihres praktischen Handelns klaffen weit auseinander, aber Irrationalität ist stets auf dem Sprung, auch diese Zweckrationalität, im politischen Verhalten, zu überfluten." ${ }^{636}$ Die selbsterhaltende Zweckrationalität des lebendigen Subjekts sei insofern die gesellschaftlich geforderte und gleichermaßen konforme Handlungsweise der integrativen Anpassung an die Irrationalität des transzendenten, heteronomen Ganzen. Dabei reflektiere das schwache Subjekt die gesellschaftlichen Lebensbedingungen unterm Bann nicht mehr, weil es dies nicht mehr schaffe. Durch die erforderte Zweckrationalität könne das Subjekt seine eigenen gesellschaftlichen Bedingungen gar nicht reflektieren, was den Bann letztlich auch verlängert.

Die zwei Sozialcharaktere Riesmans bleiben für Adorno aber nicht dergestalt wie für diesen in einem krass dualistischen Entweder-Oder stehen. Der Dualismus der zwei Sozialcharaktere sei nämlich ein Resultat eines noch weitestgehend undialektisch gedachten Subjektbegriffs: Entweder das Subjekt ist ein starkes, sich gegen die eigene Funktionalisierung wehrendes, oder aber es lässt sich als schwaches von der antagonistischen Gesellschaft deterministisch tranquilisieren. Diese dualistische Typisierung von Subjekten löst Adorno deshalb dialektisch auf, um eine gesellschaftliche Befreiung realistisch im Rahmen einer Subjekttheorie überhaupt denken zu können. Durch die Riesmansche Gegenüberstellung der zwei Sozialcharaktere werde die Gesellschaft in ihren Strukturen auch nicht mehr subjektiv aufbrechbar. Denn unter Beibehaltung eines sozialpsychologischen Dualismus kann eine gesellschaftliche Emanzipation nicht gedacht werden, weil die Befreiung der schwachen Sozialcharaktere mit ihm unmöglich wird. Kein emanzipatives Moment lässt das Gegenteil wahr werden und das Subjekt zum starken Subjekt werden. Das Subjekt bleibt immer in seinem Charakter gefangen. Um die Möglichkeit von Emanzipation zu wahren, begreift Adorno beide Momente, Freiheit und Determinismus, als in einem Ich dialektisch vermittelt: „Das Ich ist (...) ein

635 Adorno: Zur Lehre von der Geschichte und von der Freiheit, S. 13.

636 Adorno: Meinung, Wahn, Gesellschaft, S. 587. 
Ich (...), ihm kommen die beiden Seiten des dialektischen Begriffs des Ichs zu.““637 Damit bricht Adorno entsprechende Grenzen des Denkens gesellschaftlicher Freiheit auf. Das Ich bestimmt er dialektisch als psychologisches wie nichtpsychologisches. Der tranquilisierenden Domination des deterministischen Banns, die einen Begriff von Freiheit durch die unvermittelte Kausalität des Ichs nicht mehr zuließe, wird dadurch Einhalt geboten. Auch im psychologisch bestimmten Subjekt, das einer sozialen Kausalität unterwürfig gehorcht, kann der Möglichkeit nach immer eine gesellschaftstheoretische Reflexion statthaben und damit von ihm eine mögliche, potentielle Befreiung von Herrschaft ausgehen. Jedes Subjekt trägt dementsprechend immer auch die Möglichkeit von freiheitlicher Veränderung, vom Aufbrechen auch der eigenen ichpsychologischen Grenzen, in sich. ${ }^{638}$ Somit bleibt das Subjekt, selbst unter dem noch so objektiven gesellschaftlichen Bann, der Möglichkeit nach ein vernünftiges Subjekt - ganz egal wie beschädigt es durch den gesellschaftlichen Antagonismus ist. Die bewusste Reflexion, auch auf die eigene Triebökonomie, ist für jedes Subjekt damit ausnahmslos und jederzeit möglich.

Theoretisch jedoch, das heißt systematisch, lässt sich die freiheitliche Selbstreflexion der unter gesellschaftlichem Bann stehenden Subjekte nicht bestimmen. Sie ist spontan, womit auch die reelle Möglichkeit der Realisation der gesellschaftlichen Freiheit, die gesellschaftliche Emanzipation ein Moment der Spontaneität bekommt. Auf wissenschaftlichen Kausalitäten oder Antezendensbedingungen lasse sie sich nicht reduzieren, weil sie ein Akt aus Freiheit sei: „Selbstreflexion ist ein Akt aus Freiheit (...), sie ist spontan. Weil Selbstreflexion spontan ist, kann sie nicht auf anderes zurückgeführt werden. ${ }^{(639}$ Der Möglichkeit nach muss also jedes reflexive, vernünftige Subjekt ein starkes vernünftiges Subjekt sein, das potentiell schon für seine eigene und auch die gesellschaftliche Befreiung steht. Trotz erzwungener Integration in die antagonistischen gesellschaftlichen Verhältnisse können die totalen, antagonistischen Verhältnisse potentiell durchs Subjekt aufgebrochen werden. Die Integration des Subjekts in den gesellschaftlichen Zusammenhang sei dabei sogar mehr als nur notwendig zu seinem Überleben. Die erzwungene Integration bilde sogar erst die negative Grundlage, um die eigenen wie gesellschaftlichen Schranken überhaupt spontan aufbrechen zu können: „Nur dadurch, daß der Einzelne die Objektivität in sich hineinnimmt und in gewissem Sinn, nämlich bewußt, ihr sich anpaßt, vermag er den Widerstand gegen sie auszubilden. “640 Dass der Widerstand des Subjekts gegen die verhärtete Gesellschaft

\footnotetext{
${ }^{637}$ Weyand: Adornos Kritische Theorie des Subjekts, S. 119.

${ }^{638}$ Eine Möglichkeit von subjektiver Freiheit sieht Jacques Lacan nicht, weil er sich vom selbstbewussten, lebendigen und kritischen Subjekt verabschiedet. Das ist nicht nur logisch problematisch, sondern auch jedwede Möglichkeit gesellschaftlicher Emanzipation wird damit verbaut. Diese Desillusionstheorie verbaut Befreiung mittels der eigenen Freiheit der Reflexion. (Vgl. zur These der Verabschiedung Lacans vom traditionellen Subjektbegriff etwa Pagel: Jacques Lacan, S. 32 f.) ${ }^{639}$ Weyand: Adornos Kritische Theorie des Subjekts, S. 118 f.

640 Adorno: Glosse über Persönlichkeit, S. 644.
} 
notwendig und potentiell möglich sei, vermittelt für Adorno die leise dialektische Hoffnung darauf, dass es ,spontan` einmal anders werde. Theoretisch aber lässt sich diese Freiheit aufgrund der Spontaneität des psychologisch bestimmten Subjekts nicht einmal annähernd konkret bestimmen. In der Bestimmung der Unfreiheit des Subjekts liegt dialektisch jedoch zumindest auch immer ein reelles Moment von Freiheit verborgen: das der Reflexion. 


\title{
3 Gesellschaft, Staat und Kapital. Reflexionen zu Totalität und Herrschaft
}

\subsection{Aller Anfang ist Gewalt. Historische Voraussetzungen gesellschaftlicher Totalität}

\begin{abstract}
„Dieses abstrakte Ding Eigentumsverhältnis als in unserer Gesellschaft umfassend vorgefundenes Phänomen gibt also Rätsel auf: $W$ as es in seiner Abstraktheit (...) als Tun der Menschen umfasst und weiter ausmacht, kann einen schon neugierig machen. Mehr noch: Warum es existiert und gilt, d.h. warum und wie die Menschen - die für sich ja mehr als nur abstrakte Eigentümer sind und sein wollen - es praktizieren; warum nur, wo sie es doch als individuelles Verhältnis zu den materiellen Dingen gar nicht benötigen."“641
\end{abstract}

In der bürgerlichen Gesellschaft ist der Eingriff in den Naturzusammenhang kapitalistisch organisiert. Die bürgerliche Gesellschaft hat einen historisch zu bestimmenden Beginn. Erst mit den bürgerlichen Revolutionen der Neuzeit, der Amerikanischen 1776 und der Französischen 1789, beginnt ein sich qualitativ wie quantitativ von allen vorangegangenen Gesellschaftsformationen abzeichnender Weg. Dieser verweist auf das, was ihm wesentlich ist und was sich mit ihm verlängert:

${ }^{641}$ Haslbauer: Eigentum und Person, S. 44. 
Gewalt. Um diese Gewalt geht es in den kommenden zwei Unterabschnitten. Zunächst wird die Gewalt der Implementierung der bürgerlichen Gesellschaft in 3.1.1 Gegenstand.

Bevor sich in $3.2 \mathrm{ff}$. mit der gewaltsamen Befriedung durch die Garantie des Eigentumstitels beschäftigt wird, folgt in 3.1.2 eine Interpretation des Begriffs der ursprünglichen Akkumulation bei Marx. Damit soll auf die Notwendigkeit der aneignenden, willkürlichen Gewalt der bürgerlichen Revolution für den sich daraus ergebenden systematischen Kapitalkreislauf hingewiesen werden. Damit wird auch deutlich, dass das Resultat der historischen, revolutionären Gewalt die conditio sine qua non für eine Totalität der bürgerlichen Gesellschaft ist.

\subsubsection{Vor Staat und Eigentum. Rationalität und Irrationalität des gesellschaftlichen Umbruchs}

„Oft sprießt ein frommes Recht empor aus schnödem Raub.“642

„Die Frage quid iuris an das Recht zu stellen, scheint so widersinnig wie die Forderung nach einer Begründung der Logik, denn die Frage nach dem Rechtsgrund läßt nur innerhalb des Rechts sich beantworten, und führte, an das Recht selbst gestellt, ebenso auf eine petitio principii wie die Forderung nach einer Begründung der Logik, die, Organon aller Begründung, eben darum selbst nicht zu begründen ist, bliebe für das Recht immerhin noch die Möglichkeit einer Begründung ab aliud, einer Begründung aus Prinzipien, die selbst keine Rechtsbegriffe sind." ${ }^{“ 643}$

Jede formelle, saubere logische Herleitung der bürgerlichen Gesellschaft aus Deduktionen stößt sich sogleich an bestimmten inhaltlichen, historischen Bedingungen ihrer Existenz. Poulantzas macht deshalb gegen den „hegelianischmarxistischen Historizismus" 644 deutlich, dass der bürgerliche Staat keine dezidierte, systematische Realisierung einer Idee von totaler Freiheit sei, die durch die Materialisierung in ihm (wieder ein Stück weit) zu sich selbst komme: „Man kann die allgemeinen Aussagen über den Staat nicht ausgehend vom kapitalistischen Staat selbst entwickeln, so als ob er die perfekte Materialisierung eines Urstaates darstellte, der sich schrittweise in der historischen Realität durchsetzt - eine Konzeption, die immer noch zahlreiche Theoretiker der Macht verfolgen" ${ }^{645}$ Der bürgerliche Staat objektiviere sich demnach nicht einfach (deduktiv) aus sich selbst, kein allgemeiner Begriff des Urstaats liege an seinem Grund, und er materialisiert sich nicht teleologisch notwendig aus einem solchen heraus. Der bürgerliche Staat sei insofern kein Resultat einer ihm zugrunde gelegten Hegelschen Idee

\footnotetext{
${ }^{642}$ Carl Spitteler, Olympischer Frühling.

643 Bulthaup: Das Recht der Logik, S. 92.

644 Poulantzas: Staatstheorie, S. 50.

645 Ebd.
} 
der Staatlichkeit, die dann vom Marxismus-Leninismus übernommen und weitergeführt wurde. 646 Wider jede ideelle Systematisierung von Staat und Kapital müssen der vom bürgerlichen Staat nicht zu trennenden bürgerlichen Gesellschaft deshalb kontingente Voraussetzungen in der Geschichte zugrunde liegen.

Auch erklärt sich die Existenz der kapitalistischen Produktionsweise nicht induktiv aus einer systematisch anthropologisierten Konkurrenz der Subjekte um ihre eigene Lebenserhaltung, die die Menschheit nun erst zu den die historische Gewalt befriedenden allgemeinen Gesetzen der bürgerlichen Gesellschaft treibe und die die kapitalistische Produktionsweise erst ermöglichen. In den Grundrissen schreibt Marx deshalb, dass die „Konkurrenz zwischen Arbeiter und Arbeiter"“647 nicht mit der anthropologisch gesetzten Konkurrenz den natürlichen Arbeitslohn der kapitalistischen Gesellschaft erkläre. Einen solch natürlichen Lohn aus klasseninterner Konkurrenz der Lohnarbeiter würde es nicht geben, womit Marx den systematisch-positiven Rückgriff auf den natürlichen Lohn durch die klassische Nationalökonomie, insbesondere Smith und Ricardo, kritisiert. Die Kategorie der klassischen Nationalökonomie klammere gerade durch die anthropologisierte Konkurrenz jedes gesellschaftliche Gewaltverhältnis einfach aus. ${ }^{648}$ Die Konkurrenz der Arbeiter könne jedoch ,nur aus dem ursprünglichen Verhältnis zwischen Kapital und Arbeit" ${ }^{\prime 649}$ erklärt werden, das wesentlich erst Resultat der kapitalistischen Gesellschaftsform sei, die ihrerseits wiederum ein Resultat aus historischer Gewalt ist, wie dann insbesondere der Marxsche Abschnitt über die ,ursprüngliche Akkumulation"650 im Kapital zeigt (vgl. auch 3.1.2). Die Konkurrenz innerhalb der Klasse der Lohnarbeiter selbst sei dabei genauso gesellschaftliches, historisches Resultat wie die Klassengesellschaft überhaupt: „Die Konkurrenz überhaupt, dieser wesentliche Lokomotor der bürgerlichen Ökonomie, etabliert nicht ihre Gesetze, sondern ist deren Exekutor."651 In den Grundrissen heißt es weiter: „Illimited competition ist darum nicht die Voraussetzung für die Wahrheit der ökonomischen Gesetze, sondern die Folge - die Erscheinungsform, worin sich ihre Notwendigkeit realisiert." 652

Die hemmungslose Konkurrenz der lohnarbeitenden Subjekte gegeneinander lässt sich insofern nicht systematisch anthropologisch aus dem Subjekt erklären, die kapitalistische Ökonomie folgt also nicht aus einer einfach zugrunde gelegten Konkurrenz der Subjekte, sondern sie ist erst eine historische, gewaltvolle Folgeerscheinung. Das ,ursprüngliche Verhältnis‘ von Kapital und Arbeit verweist inso-

\footnotetext{
${ }^{646}$ Vgl. Hegel: Grundlinien der Philosophie des Rechts, S. 339: „Die Schöpfung der bürgerlichen Gesellschaft gehört übrigens der modernen Welt an, welche allen Bestimmungen der Idee erst ihr Recht widerfahren lässt.“"

${ }^{647}$ Marx: Grundrisse der Kritik der politischen Ökonomie, S. 457.

${ }^{648}$ Vgl. hierzu auch Euchner: Karl Marx, S. 82 ff.

${ }^{649}$ Marx: Grundrisse der Kritik der politischen Ökonomie, S. 457.

${ }^{650}$ Vgl. Marx: Das Kapital, Bd. 1, S. 741 ff.

${ }^{651}$ Marx: Grundrisse der Kritik der politischen Ökonomie, S. 457.

652 Ebd.
} 
fern auf eine das Verhältnis der Konkurrenz der Subjekte erst voraussetzende Geschichte der Entstehung von politischer Ökonomie. Die Konkurrenz wird somit erst durch die installierten, wesentlichen Gesetze der Ökonomie in ihren allgemeinen Auswüchsen real, weil erst diese Gesetze die Subjekte in ökonomische Klassen aufspalten, wie auch in den internen Konkurrenzzusammenhang stellen. Die Setzung der allgemeinen Konkurrenz ist deswegen für Marx erst ein Resultat der historischen Konstitution der bürgerlichen Gesellschaft: „Die Konkurrenz erklärt daher nicht diese Gesetze [der bürgerlichen Ökonomie, B.E.B.]; sondern sie läßt sie sehn, produziert sie aber nicht."“653 So lässt sich auch nicht erst mit Marx’ zentralem Kapitel des Kapitals zur ,ursprünglichen Akkumulation“654 zeigen, dass die Konkurrenz der Klassen untereinander (vgl. auch 2.6.3) aus einem historisch-gesellschaftlichen Gewaltakt - und nicht etwa systematisch aus Begriff ${ }^{655}$ - oder aus einem die gesellschaftlichen Verhältnisse anthropologisierenden Menschsein entspringt. Schon in Vorarbeiten zum Kapital verweist Marx also auf die unbedingten, nicht-begrifflichen, historischen Bezüge der kapitalistischen Gesellschaftsform. Im Kapital führt er die bürgerliche Gesellschaft dann jedoch deutlich auf ihren historisch ursprünglichen Gewaltakt, auf historische Willkür, zurück: „In der wirklichen Geschichte [der Eigentumsfrage, B.E.B.] spielen bekanntlich Eroberung, Unterjochung, Raubmord, kurz Gewalt die große Rolle.“"656 Die willkürliche Aneignung von Dingen als Voraussetzung des Kapitalismus beschreibt insofern eine unsystematische, nicht-begriffliche und herrschaftliche Bedingung der Existenz der kapitalistischen Produktionsweise. Das heftet die bürgerliche, kapitalistische Gesellschaft deshalb an die ihr vorausgehende, systematisch unbegründbare und unmittelbare Gewalt im gesellschaftlichen Akt ihres Entstehens.

Auch die heute rechtlich und rational durch den bürgerlichen Staat abgesicherten reziproken Eigentumstitel, Form der Realisation der kapitalistischen Produktionsweise, verweisen auf die blutige Geschichte, aus der sie folgen: die historisch gewaltsame Aneignung von Produktionsmitteln während der kurzen Zeit der bürgerlichen Revolutionen. Dieser durch erzwungene Expropriationen, durch kontingente, materielle Akte gesellschaftlicher Gewalt gegen Subjekte und deren Besitz geprägte Zeitraum verweist aber auch auf noch mehr: Dialektisch betrachtet sind die Gewaltakte willkürliche, freiheitliche Akte des subjektiven Handelns in der Geschichte. Deshalb sind sie selbst nicht schon das, was historisch aus ihnen entsteht: „Der Grund, der das Verhältnis von Lohnarbeit und Kapital, den Kapitalismus, zur Folge hatte, kann nicht der Kapitalismus selbst sein, wenn auf teleologische Konstruktionen zu verzichten ist. Die historische Abfolge ist nicht an sich

\footnotetext{
${ }^{653}$ Marx: Grundrisse der Kritik der politischen Ökonomie, S. 457.

${ }^{654}$ Marx: Das Kapital, Bd. 1, S. 741 ff.

${ }^{655}$ Vgl. Marx: Grundrisse der Kritik der politischen Ökonomie, S. 203: „Es ist zu bedenken, daß die neuen Produktivkräfte und Produktionsverhältnisse sich nicht aus Nichts entwickeln noch aus der Luft, noch aus dem Schoß der sich selbst setzenden Idee“. Das Verhältnis zum Junghegelianismus des frühen Marx ist allerdings ambivalent und keineswegs eindeutig.

${ }^{656}$ Marx: Das Kapital, Bd. 1, S. 742.
} 
ein Grund-Folge-Verhältnis.“"657 Der Eigentumsbegriff ist der bürgerlichen Gesellschaft und ihrer Produktionsweise zwar logisch vorgeordnet, historisch entsteht er jedoch erst aus dem gesellschaftlichen Gewaltverhältnis als Mittel zum Zweck der Rationalisierung der historischen, willkürlichen Gewalt: „Die Schwierigkeit der Begründung des rechtlichen Zustands besteht darin, daß seine reziproke Eigentumsgarantie das Eigentum schon voraussetzt als Resultat einer Aneignung, die unmöglich selbst reziprok gedacht werden kann. Sie kann nicht durch Vertrag erfolgt sein, weil jeder Vertrag über Eigentum dieses schon voraussetzt.“"658 Die systematischen Gesetze der kapitalistischen Produktionsweise verweisen insofern auf eine sie begründende historische Irrationalität der Willkür bürgerlicher Revolutionen. Die systematischen Rechtsbegriffe verweisen auf eine diskontinuierlich nicht-begriffliche, willkürliche Gewalt in der Geschichte, die zu ihrer Konstitution notwendig gewesen ist. Das rechtslose Verhältnis ist deswegen ein ursprüngliches Moment des eigentümlichen Rechts. Die historisch späteren, logischen Prinzipien des Rechts fehlen bei der im Entstehen begriffenen bürgerlichen Gesellschaft. Aus der reinen Immanenz der in sich rationalen bürgerlichen Gesellschaft selbst, aus einem prinzipiellen Eigentumsbegriff zumal, ließe sich die sie konstituierende historische Gewalt der Revolutionsperiode, die zum Resultat die materielle Differenz der ökonomischen Voraussetzungen hat, allerdings so wenig wie die Konkurrenz der Subjekte als ,Lokomotor der bürgerlichen Gesellschaft' begründen. Die bürgerliche Gesellschaft wäre, würde ihre eigene Expropriationsgeschichte in ihre bereits konstituierte kategoriale Form überführt werden, würde mit ihr also über ihre eigene Geschichte geurteilt werden, in sich widersprüchlich: Ihre eigene Expropriationsgeschichte wäre aufgrund der räuberischen Aneignung fremder Dinge durch Dritte nach den eigenen, dadurch erst geschaffenen Maßstäben illegal. Das Recht resultiert also offensichtlich aus der willkürlichen, irrationalen gesellschaftlichen Gewalt einer historisch spezifischen Epoche der revolutionären Expropriation. Adorno und Horkheimer schreiben deshalb: „Die Binde über den Augen der Justitia bedeutet nicht bloß, daß ins Recht nicht eingegriffen werden soll, sondern daß es nicht aus Freiheit stammt.“"659

Aus freiheitlicher Willkür stammt das Recht allerdings. Der willkürliche Akt der Aneignung von Produktionsmitteln im noch prinzipienlosen Vakuum revolutionärer Gewalt ist mit Mitteln der bürgerlichen Gesellschaft jedoch nicht post festum als bereits illegaler Akt zu jenem Zeitpunkt seiner Durchführung zu ahnden. Vor allem das meint die von Adorno und Horkheimer beschriebene Binde über den Augen der Justitia: Recht und Gesetz seien hinsichtlich ihrer eigenen Geschichte blind. Das bürgerliche Gesetz geht also erst aus den willkürlichen Aneignungen der Revolutionsepoche hervor, weshalb es auch nicht gegen seine eigene unmittelbare Entstehungsgeschichte und die eigenen Zwecke gewendet bzw. ge-

\footnotetext{
${ }^{657}$ Bulthaup: Zum Problem des Übergangs vom Feudalismus zum Kapitalismus, S. 51.

${ }^{658}$ Städtler: Kant und die Aporetik moderner Subjektivität, S. 181.

${ }^{659}$ Adorno/Horkheimer, Dialektik der Aufklärung, S. 33.
} 
dacht werden kann. Historische Gewaltakte vor der eigenen Entstehung fallen gar nicht erst in den Zuständigkeitsbereich des einmal installierten bürgerlichen Rechts. Einen entsprechenden Begriff des Eigentums, der die damalige revolutionäre Aneignung als Raub klassifizieren würde, gibt es zu Zeiten der Expropriationen noch gar nicht. Der prinzipielle, grundlegende juristische Begriff von Person, Gleichheit etc. existiert noch nicht, weshalb es in diesem Fall heißt: nulla poena sine lege. Auch das deutsche Strafgesetzbuch kennt keine Straftat ohne ein zu jenem Zeitpunkt der Tat existierendes Gesetz, das diese Tat überhaupt erst unter Strafe stellen würde: „Eine Tat kann nur bestraft werden, wenn die Strafbarkeit gesetzlich bestimmt war, bevor die Tat begangen wurde.“660 Das führt allerdings zu rechtsphilosophischen Problemen, die hier leider nicht ausreichend behandelt werden können. Nur ein Naturrechtsansatz kann die Verurteilung von Personen rechtfertigen, deren Handlungen zum Tatzeitpunkt gegen kein geltendes Recht verstießen, weshalb es auch nur mit der naturrechtlich argumentierenden Radbruchschen Formel ${ }^{661}$ in der BRD möglich gewesen ist, allen rechtsphilosophischen Bedenken zum Trotz, Prozesse gegen Nationalsozialisten und DDRMauerschützen zu führen. Erst mit der entsprechenden Formel Radbruchs von der ,Unerträglichkeit des geltenden allgemeinen Rechts' zur entsprechenden Tatzeit können Personen für Handlungen verurteilt werden, die zum Zeitpunkt der Tat allerdings gegen kein geltendes Recht verstoßen haben, sondern die geltendes Recht ganz pflicht- und rechtsgemäß anwendeten. Nach streng rechtspositivistischer Auslegung hätte es solche Verurteilungen durch post festum für unerträglich erklärte Gesetze nicht geben dürfen. ${ }^{662}$

Auch die revolutionäre Aneignung der ursprünglichen Produktionsmittel der kapitalistischen Produktionsweise geschieht nun noch im bürgerlich rechtsfreien Raum. Es wird sich mit diesen gewaltsamen Aktionen auf keine rationale Ordnung nach Prinzipien bezogen. Die willkürliche Aneignung steht insofern in einem rational-irrationalen geschicbtlichen Zusammenhang, der mit der entwickelten bürgerlichen Produktionsweise bloß bedingt etwas zu tun hat. Adorno schreibt deshalb in der Negativen Dialektik auf das bürgerliche Recht bezogen, und sehr viel kryptischer als der im Eingangszitat genannte Spitteler: „Recht ist das Urphänomen irrationaler Rationalität." "663 Auch für Adorno begründet die expropriierende revolutionäre Gewalt als ihre notwendige Voraussetzung erst die spätere rechtliche Rationalität der bürgerlichen Gesellschaft.

\footnotetext{
${ }^{660}$ Strafgesetzbuch, $\int 1$.

${ }^{661}$ Vgl. Radbruch: Gesetzliches Unrecht und übergesetzliches Recht.

${ }^{662}$ Der Rechtspositivist H.L.A. Hart widerspricht seinem eigenen Rechtspositivismus aus durchaus hehren Gründen, wenn er, ähnlich wie auch aus der Radbruchschen Formel bekannt, davon ausgeht, dass einem ungerechten Gesetz der Gehorsam zu verweigern ist. Das aber solle nach Hart selber wieder Recht sein, womit die Schwierigkeiten der juristischen Definition von Rechtsprechung dann auch wirklich beginnen. (Vgl. Hart: The Concept of Law, S. 183 ff.)

${ }^{663}$ Adorno: Negative Dialektik, S. 304.
} 
Das heißt jedoch nicht, dass die gewaltsame Aneignung zu Zeiten der Revolution vollkommen irrational sei, nur weil sie noch unter keinem prinzipiellen Deckmantel der Legalität stehe. Wenn der immanent rationalen bürgerlichen Gesellschaft eine entsprechende Irrationalität des Gewaltakts bürgerlicher Revolution historisch gegenüber gestellt wird, dann bedeutet das nicht, dass die revolutionäre Gewalt als Mittel der geschichtlichen Aneignung von Reproduktionsmitteln aufgrund ihrer systematischen Unordnung kein vernünftig bestimmtes Ziel und keinen der Vernunft entsprechenden rationalen Zweck hatte. Das vernünftige Subjekt des Handelns würde ansonsten, wie bei Hegel, wieder nur verdinglicht werden, weil sein praktisches Handeln absolut Mittel zum Zweck wird. Erneut wären die Subjekte zum Objekt der eigenen Geschichte degradiert (vgl. 2.4.2). Der Gewaltakt der Aneignung ist deshalb auch nur deswegen irrational, weil er sich nicht systematisch, mit den begrifflichen Mitteln bzw. aus den Prinzipien der bürgerlichen Gesellschaft selbst begreifen, geschweige denn rechtfertigen lässt. Diese angeführte Dialektik von Rationalität und Irrationalität im willkürlichen Gewaltakt der revolutionären Expropriation ist offenbar. Selbst der handfesten, aneignenden Gewalt der Revolutionsperiode ist demnach also ein rationales Mittel zum Zweck immanent: Der negativ bestimmte Zweck der Aneignung ist die gegen die alte feudale Gesellschaftsordnung gedachte Freiheit. Die revolutionäre Gewalt hat mit ihrem Handeln insofern sehr wohl schon einen bestimmten emanzipativen Zweck, dessen rationales Mittel sie zweifelsohne ist. Deshalb kann sich die Gewalt der Revolution auch nicht von einer systematisch sie erst erklärenden Intention freimachen. Durch dieses immanent rationale Handeln aus Vernunft lässt sie sich auch erst in ihrer Existenz wissenschaftlich erklären. Erst der Intentionszusammenhang macht den willkürlichen Akt der historischen Gewalt post festum vernünftig erklärbar, weshalb der Gewaltakt nicht vollkommen irrational und damit gegenstandslos ist. ${ }^{664}$ Verständlich, rational und nachvollziehbar zeigt sich das gewaltsame Handeln der Revolutionäre anhand der objektiven gesellschaftlichen Zwecke, der Überwerfung der alten Privilegiengesellschaft. Dem revolutionären Gewaltakt bleibt damit dialektisch betrachtet, wie auch jedem anderen gesellschaftlichen Gewaltakt, ein rationales Moment immanent. Gesellschaftliche Reproduktionsmittel wie Grund und Boden werden sich nicht aus einem blinden, unerklärlichen Hass auf Adel, Kirche und Privilegienrechte angeeignet, sondern die Intention des aneigenenden Gewaltakts liegt in der reproduktionstechnischen Motivation eines gewalttätigen, als negativem Zweck gesetzten Versuchs der Umformung der gesellschaftlichen Produktionsverhältnisse: „Auf der anderen Seite aber ist durch die ökonomische Vormacht des Bürgertums bereits zu jener Epoche [gemeint ist der Vorabend der Französischen Revolution, B.E.B.] (...) diese Ausgabenwirtschaft des Feudalabsolutismus selber etwas Zurückgebliebenes; sie ist zurückgeblieben gegenüber dem Stand der Rationalisierung der Produktivkräf-

${ }^{664}$ Vgl. dazu auch Städtler: Geschichte oder Tendenz, S. 119 ff. 
te, sie ist zurückgeblieben als ein ihm gegenüber Irrationales und ist infolgedessen selber eine Funktion der Gesamttendenz." "665 Die Bezeichnung der revolutionären Gewaltperiode als irrationale Willkür beruft sich deshalb nicht auf eine anarchische oder chaotische Freiheit des subjektiven Handelns zu jener Zeit, denn allein schon im Begriff der Willkür steckt neben dem Freiheitsbegriff ein Wollen, das wiederum vom Vernunftbegriff nicht zu trennen ist.

Wenn sich nun das feudale Willkürrecht auf noch kein allgemeines, rational nachvollziehbares Gesetz als Moment eines für alle Personen gleichermaßen geltenden Rechtsprinzips beruft, so beruft es sich allerdings trotzdem schon auf ein zweckbestimmtes Wollen, nämlich dem der das feudale Recht sprechenden Personen. Die wollenden Personen können noch einen partikularen Willen als Mittel zu einem partikularen Zweck durchsetzen. ${ }^{666}$ Diese partikularen Privilegien der vorbürgerlichen Gesellschaft sind es, die mit den ersten bürgerlichen Revolutionen, zunächst in den amerikanischen Kolonien 1776, dann 1789 im monarchistischen Frankreich, abgeschafft werden. Weil ,einfache‘ Bürger zum Zeitpunkt der Revolution und auch bereits kurz zuvor die ökonomischen Schaltstellen der feudalen Gesellschaft unlängst übernehmen, tritt das revolutionäre Bürgertum bereits ziel- und zweckgerichtet mit dem revolutionären Plan an, durch die Demokratisierung der Verhältnisse die feudale Privilegiengesellschaft politisch wie ökonomisch zu ihrem eigenen Vorteil aufzubrechen. Die bürgerliche Revolution soll endlich partikulare ökonomische Möglichkeiten zur Entfaltung bringen und die einschränkende Privilegien für das Bürgertum abschaffen: „Sie [die Französische Revolution, B.E.B.] wäre weder möglich gewesen noch gelungen, hätte es [das Bürgertum, B.E.B.] nicht 1789 die Schlüsselstellungen wirtschaftlicher Produktion bereits okkupiert und den Feudalismus und seine absolutistische Spitze, die zuzeiten mit dem bürgerlichen Interesse koaliert war, überflügelt." "667 Das von der feudalen Herrschaft befreiende, gewaltsame Ziel des praktischen Handelns der Revolutionäre liegt zunächst aber auch noch gänzlich außerhalb der prozessualen Systematik der kapitalistischen Produktionsweise. Die historisch-revolutionäre Zwecksetzung hat deshalb noch nicht die kapitalistische Produktionsweise zum Ziel, geschweige denn wird die kapitalistische Produktionsweise mit den revolutionären Gewaltakten gleich realisiert: „The French Revolution was not made or led by a formed party or movement in the modern sense, nor by man attempting to carry out a systematic programme. "668 Zunächst soll die Gewalt der bürgerlichen Revolutionäre also nur von den Fesseln der noch vorkapitalistischen Ständegesellschaft befreien, die ihnen der Adel vor 1789 durch seine spezifischen Privilegien

\footnotetext{
665 Adorno: Zur Lehre von der Geschichte und von der Freiheit, S. 57.

666 „Das Recht ist also der Inbegriff der Bedingungen, unter denen die Willkür des einen mit der Willkür des anderen nach einem allgemeinen Gesetze der Freiheit zusammen vereinigt werden kann.“ (Kant: Die Metaphysik der Sitten, AA VI.)

667 Adorno: Negative Dialektik, S. 296.

668 Hobsbawm: The Age of Revolution, S. 58.
} 
noch anlegen kann. Die angewendete Gewalt soll die bloß negative Zwecksetzung des feudalistischen Bürgertums/Bürgerstands realisieren und damit die bisherige Privilegiengesellschaft des Ancien Régime nachhaltig überwerfen, um somit jeden vorbürgerlichen Partikularismus der Privilegiengesellschaft nachhaltig zu zerstören, der das Handeln der bürgerlichen Revolutionäre im Sinne ibrer eigenen Selbsterhaltung derzeit noch einschränkt. Das Ziel des revolutionären Wegs blieb somit also ein zunächst rein negativer Zweck der revoltierenden Subjekte: Die negativ gedachte Freiheit von feudalen Zwängen soll die Abschaffung gesellschaftlicher Defizite bei der Organisation der Selbsterhaltung der bürgerlichen Revolutionäre einleiten. Die Bürger laufen insofern nicht völlig sinn- und intentionslos gegen die Bataillone des Ancien Régime Sturm. Die revolutionäre Gewalt der Revolutionsepoche ist deshalb auch kein bloßer Selbstzweck, also keine Irrationalität per se. Sie ist nicht als ein unfunktioneller Akt allein aus sich selbst heraus zu bestimmen, weil sich das Handeln der Revolutionäre nicht allein um sich selbst dreht, weswegen Mittel und Zweck während der Revolution auch nicht zusammenfallen. Die gesellschaftliche Gewalt als reiner Selbstzweck gedacht, als Gewalt ohne jeden Bezug auf ein bestimmtes Ziel würde dementsprechend nichts außer sich selbst kennen und wäre darum tautologisch bestimmt. ${ }^{699}$ Gegenstand und Zweck von Gewalt ließen sich dann jedoch nicht mehr rational bestimmen. Wenn der gesellschaftlichen Gewalt jedoch dieser rationale Gegenstand fehlte, so könnte man sie höchstens noch psychopathologisch erklären. Als psychopathologisch bestimmte Gewalt muss die revolutionäre, Gesellschaft verändern wollende Gewalt als gesellschaftliches Mittel wissenschaftlich unbestimmt bleiben. Sie wäre demnach auch vollkommen hinfällig und Subjekte, die sie ausüben, wären irrational handelnde Subjekte. ${ }^{670}$

Das heißt aber nicht, dass der revolutionären Gewalt dialektisch nicht doch auch ein irrationales, willkürliches Moment von Freiheit zukommt. Neben der

\footnotetext{
${ }^{669}$ Vgl. auch Claussen: List der Gewalt, S. 13 ff.

${ }^{670}$ Die Erklärung von Gewalt als sinnloser Selbstzweck wird angesichts einer auf die Straße getragenen gerne gewählt. Vgl. die dürftigen Thesen des Artikels: ,Extremisten haben vor allem Lust auf Gewalt'. (welt.de: Extremisten haben vor allem Lust auf Gewalt.) Wenn eine Begründung von der gesellschaftlichen Gewalt als Selbstzweck nicht aus unbeabsichtigter, intellektueller Unfähigkeit geschieht, gesellschaftliche Vorgänge zu erklären, handelt es sich um eine Apologie des Bestehenden. Ein Artikel über die Gewalt in den Banlieus von Paris 2005, vernachlässigt die wesentliche Erklärung der Ursachen der Gewalt. (deutschlandradiokultur.de: Zehn Jahre nach den Unruhen.) Die Gewalt hätte kein bestimmtes Ziel gehabt und sei auch nicht Mittel eines, durchaus zu kritisierenden, Versuchs gewesen, soziale Probleme mit Gewalt auf die Straße zu tragen, um sich Gehör zu verschaffen. Die riots in London von 2011 eröffnen z.B. den Blick auf eine längere Tradition der riots als auf die Straße getragene Kritik: „In der Regel verliefen ,riots“ nicht chaotisch und undiszipliniert. Sie waren zumeist gut organisiert, verfolgten überwiegend sehr präzise Ziele, wollten etwas Bestimmtes erreichen oder verhindern." (Schröder: Englische Geschichte, S. 48.) Die Akteure der riots waren insofern nicht nur selbstgefällige, egozentrische Gewalttäter. Als solche denunziert man sie entsprechend nur, wenn man von den wesentlichen Begründungen ihres Tuns nichts wissen möchte. Wenn nämlich der Grund der Gewalt keinen Sinn oder Zweck haben soll, sondern einzig die Lust auf Gewalt als ihr Grund gilt, kann man damit das gewalttätige Subjekt zum neurotischen Täter, das politisch kein Gehör finden darf, abstempeln - das im Gegenzug einfach nur weggesperrt gehöre.
} 
Irrationalität der gesellschaftlichen Verhältnisse zu Zeiten des subjektiven Handelns behält die Rede von der Irrationalität der Gewalt trotzdem ihr Recht. Der entsprechende Gewaltakt der Aneignung selbst, und hier kommt ein in sich vermitteltes Moment von Irrationalität in Form der geschichtlichen Diskontinuität ins Spiel, ist in seiner Dynamik und seiner eventuellen Schärfe durch die Revolutionäre nicht vernünftig, d.h. rational, planbar. Die Revolution, ihre mitunter überflüssige Brutalität und auch der spontane Verlauf der Aktionen, die vom eigentlich vernunftgeleiteten Ziel ablenken können, bleibt zeitgleich immer ungewiss. Das ist eine notwendige Dialektik von systematischer Rationalität und nicht-begrifflicher Irrationalität/Spontaneität gesellschaftlicher Gewaltakte. Aus dem Gewaltakt der Revolution entstehen deshalb auch nicht notwendig die bürgerliche Gesellschaft und ihre kapitalistische Organisation der Naturaneignung: Sie entstanden 1776 und 1789; es hätte an diesem Scheidepunkt der Geschichte aber auch anders kommen können.

\subsubsection{Die ,ursprüngliche Akkumulation` bei Marx als irrationale Rationalisierung der kapitalistischen Produktionsweise}

Im Kapital ist der revolutionäre Gewaltakt der Expropriation der Bauern der entscheidende Dreh- und Angelpunkt für die im Entstehen begriffene kapitalistische Gesellschaftsform. Die ,Voraussetzung für die Wahrheit der ökonomischen Gesetze $^{6}$ (s.o.) ist die aneignende, willkürliche Gewalt, durch die erst spezifische, qualitativ veränderte, materielle, ökonomische Unterschiede der Bürger geschaffen werden. Mit der „ursprüngliche(n) Akkumulation“ 671 bezeichnet Marx den gesamten Prozess der revolutionär-historischen Periode des gewaltsamen, gesellschaftlichen Scheidungsprozesses von Proletariern und Eigentümern an Produktionsmitteln. Die Expropriationen leibeigener Bauern von ihren Möglichkeiten der Subsistenzwirtschaft bringen dabei auch erst die kapitalistische Akkumulation als prozessuale Reichtumsproduktion der bürgerlichen Gesellschaftsform hervor: „Und die Geschichte dieser ihrer Expropriation ist in die Annalen der Menschheit eingeschrieben mit Zügen von Blut und Feuer." ${ }^{\text {"672 }}$

Auf die ursprüngliche Akkumulation folgt insofern auch erst post festum die neue Qualität der gesellschaftlichen Naturbearbeitung, nämlich die Akkumulation von Reichtum auf einer erhöhten Stufe der gesellschaftlichen Reproduktion. Zwar bleibt die ursprüngliche Akkumulation dabei nicht peinlichst auf die exakten Daten der jeweiligen bürgerlichen Revolutionen beschränkt, sondern sie ist durchaus ein längerwährender historischer Prozess, doch die bürgerliche Revolution allein vermittelt den sauberen Beginn des neuen, kapitalistischen Produktionsprozesses. ${ }^{673}$ Erst jetzt kommt es durch die Implementierung des bürgerlichen Staates

\footnotetext{
671 Marx: Das Kapital, Bd. 1, S. 741.

672 Ebd., S. 743.

673 Vgl. Marx: Das Kapital, Bd. 1, S. 741 ff.
} 
zur juristischen Absicherung der Voraussetzungen der kapitalistischen Produktionsweise (vgl. dazu insbesondere 3.2.1). Die der bürgerlichen Gesellschaft äußeren, gewaltsamen Voraussetzungen bedingen die juristisch geregelte Rationalität der ökonomischen Verhältnisse demnach also erst. Die institutionelle Rationalisierung der totalen bürgerlichen Gesellschaft verlässt dann den Boden der ursprünglichen Akkumulation, eine Institutionalisierung ihrer prozessualen Resultate lässt den noch rechtslosen Zeitraum der Revolutionsperiode hinter sich. Mit der Institutionalisierung wird auch erst die systematische kapitalistische Produktionsweise durchgesetzt. Mit den bürgerlichen Revolutionen realisiert sich deshalb auch erst der Begriff von bürgerlicher Gesellschaft, die kapitalistisch produziert. Weil durch die ursprüngliche Akkumulation des Kapitals systematisch und historisch nun auch nur die Möglichkeiten einer ersten kapitalistischen Akkumulation des Reichtums hervorgebracht werden, ist die ursprüngliche Akkumulation also nicht schon als die Realisation der kapitalistischen Akkumulation zu verstehen (s.o.). Als ein prozessualer Gewaltakt begriffen ist die ursprüngliche Akkumulation keine kapitalistische Akkumulation, genau so wenig wie sich aus ihr die bürgerliche Gesellschaft realisiert. Die ursprüngliche Akkumulation behält schon deswegen ihr noch irrationales, unsystematisches Moment von Willkür in der Geschichte.

Die von Marx als gewaltsamer „Sündenfall“ 674 beschriebene ursprüngliche Akkumulation bietet dementsprechend einfach nur die historische Voraussetzung für eine tatsächliche, besondere kapitalistische Akkumulation auf. Ohne die ursprüngliche Akkumulation, die in ein historisches Vakuum von Feudalismus und Kapitalismus fällt, würde insofern jede vorauszusetzende Grundlage jeder weiteren kapitalistischen Akkumulation in der Geschichte fehlen: „Vor der Akkumulation durch das Kapital ist eine Akkumulation vorausgesetzt, die das Kapital konstituiert, die zu seiner Begriffsbestimmung gehört. "675 Die kapitalistische Akkumulation selbst braucht dann auch nichts mehr vom ursprünglichen Sündenfall zu wissen: „Diese Ganze Bewegung scheint sich also in einem fehlerhaften Kreislauf herumzudrehen, aus dem wir nur herauskommen, indem wir eine der kapitalistischen Akkumulation vorausgehende ,ursprüngliche' Akkumulation (...) unterstellen, eine Akkumulation, welche nicht das Resultat der kapitalistischen Produktionsweise ist, sondern ihr Ausgangspunkt.“"676 Deshalb ist, paradoxerweise, die gewaltsame, kontingente Aneignung und Expropriation der Bauern die systematisch notwendige Voraussetzung der rationalen, mit Eigentumstiteln geregelten kapitalistischen Produktionsweise: „Die Expropriation und Verjagung eines Teils des Landvolks setzt mit den Arbeitern nicht nur ihre Lebensmittel und ihr Arbeitsmaterial für das industrielle Kapital frei. “677 Oder: Die systematische Irrationalität des Gewaltakts der Aneignung materiell unterschiedlicher Dinge durch die

\footnotetext{
${ }^{674}$ Ebd., S. 741.

675 Marx: Grundrisse der Kritik der politischen Ökonomie, S. 492.

${ }^{676}$ Marx: Das Kapital, Bd. 1, S. 741.

677 Ebd., S. 775.
} 
Subjekte ist die historische Voraussetzung der logischen, gesetzlich allgemein geregelten Rationalität der bürgerlichen Gesellschaft.

Weil also die ursprüngliche Akkumulation noch keine kapitalistische Akkumulation ist, ist die rationale kapitalistische Akkumulation in diesem Abschnitt über ihre Initialisierung auch kein Gegenstand. Weil aber ohne die ursprüngliche Akkumulation die hinreichende Bedingung jeder einzelnen kapitalistischen Akkumulation fehlt, bleibt sie bei Marx in den ökonomischen Zusammenhang der kapitalistischen Produktionsweise als ,ökonomische[r] Sündenfall“ ${ }^{\text {(678 }}$ eingebunden. Der ,Sündenfall` ist nun offensichtlich nicht vom über ihn Hinausweisenden, noch Kommenden zu trennen. Diese Dialektik von Systematischem und Nichtsystematischem, von Rationalem und Irrationalem, von Notwendigem und Historischem, muss gedacht werden, wenn man vom Ursprung des rationalen, gesellschaftlichen Gewaltverhältnis der Moderne spricht. Das rationalisierte Gewaltverhältnis der bürgerlichen Gesellschaft ebnet die ökonomischen Differenzen aus dem Gewaltverhältnis nach der Expropriation prinzipiell ein. Sie befriedet sie, wie die bürgerliche Ideologie veranschlagt, jedoch nicht. Wie die unterschiedliche ökonomische Potentialität der materiellen Dinge nach der Phase der Gewalt, Entreissung, Expropriation etc. objektiv rationalisiert wird und die Konkurrenz der Subjekte dadurch auch auf die eigene Klasse beschränkt bleibt, behandelt deshalb der nächste Abschnitt.

\subsection{Postrevolution, Gewalt und Zwang. Die Garantie von Eigentum als entscheidendes Moment der bürgerlichen Totalität}

Weil oben herausgearbeitet wurde, dass die bürgerliche Gesellschaft auf historischer Gewalt beruht, die rational verlängert wird, fragt dieser in fünf Unterabschnitte aufgeteilte Abschnitt nach dem entsprechenden Wie dieser rationalen Verlängerung. In 3.2.1 wird dafür zunächst der Begriff des Eigentums, der Eigentumstitel der bürgerlichen Gesellschaft, vorgestellt.

Der kapitalistische Warentausch ist dann in 3.2.2 Thema. Hier wird auch die Gewalt und die Ideologisierung von Gewalt durch Recht und Gesetz untersucht.

In 3.2.3 wird dann der für den Schutz des Warentauschs zuständige Staat Gegenstand. Mittels der immanenten Widersprüche eines konsequenten Liberalismus wird untersucht, was passieren würde, wenn der bürgerliche Staat im Warentausch keine Funktion mehr hätte. Der konsequente Liberalismus oder Anarchokapitalismus ist nicht zu unterschätzen, auch nicht hinsichtlich großer Unterstützerzahlen zum Beispiel in den USA, wo die entsprechende Libertarian Party gegenwärtig die drittgrößte Partei (Third Party) nach den Democrats und den Republicans ist. Da

${ }^{678}$ Marx: Das Kapital, Bd. 1, S. 741. 
der Eigentumstitel Subjekte konsequent von Material ausschließt, handelt 3.2.4 von der entsprechenden Entfremdung der Subjekte. Sie ist auch genau in diesem Zusammenhang zu sehen: als Entfremdung von Material, gerade auch dem Material an Produktionsmitteln, durch den Eigentumstitel.

Daran anschließend geht es im Unterabschnitt 3.2.5 um die Verdinglichung des bürgerlichen Subjekts in der bürgerlichen Gesellschaft. Der Zwang zur eigenen Verdinglichung zeigt sich als ein wesentlicher Faktor innerhalb des Reproduktionsprozesses des lebendigen Subjekts der Praxis.

\subsubsection{Die Systematisierung der revolutionären Gewalt. Zum Begriff des Eigentums}

Durch die verfassungsmäßige Installation eines allgemeinen bürgerlichen Rechts grenzt sich die bürgerliche Gesellschaft von historischen Willkürrechtszuständen entscheidend ab. Das ist eine ihrer großen Errungenschaften. ${ }^{679}$ In seinen Vorarbeiten zum Kapital verordnet Marx das allgemeine Recht der bürgerlichen Gesellschaft als entscheidendes Moment des geistigen „Überbau[s] “680, das über dem gesamten ökonomischen Unterbau schwebt. Der juristische Überbau, Teil der „geistigen Produktion“"681, bleibt für ihn jedoch auch in den späteren, im vierten Band des Kapitals verhandelten Theorien über den Mehrwert682, ein von der Zirkulationssphäre untrennbares, wichtiges Moment bei der Bestimmung der Totalität der kapitalistischen Produktionsweise. Als überbauliches Moment ist das Recht für die wichtige Organisation des Warenumschlags der kapitalistischen Produktionsweise verantwortlich. Unter den allgemeinen Rechtsbegriffen ist dafür der Eigentumstitel entscheidend. ${ }^{683}$ Über diesen vollzieht sich nicht nur die prinzipielle, juristische Rationalisierung von noch revolutionärer, unmittelbarer Gewalt, er wird nach der Revolution auch zum zentralen Prinzip des Funktionierens der Zirkulationssphäre. Mit ihm wird insbesondere der Rückfall in den Feudalismus und das Willkürrecht verhindert. ${ }^{684}$

Der juristische Eigentumstitel gibt den Bürgern gewisse Sicherheiten gegen die noch vorbürgerliche Willkür. Mit ihm können sich die Bürger positiv auf materiel-

\footnotetext{
${ }^{679}$ Das bürgerliche Recht, das sich verfassungsmäßig realisiert, wurde wiederum aus der Erklärung der Menschen- und Bürgerrechte ableitet, die bereits am 26.08.1789 artikuliert wurden.

(Vgl. Hartmann: Geschichte Frankreichs, S. 39.)

${ }^{680}$ Marx: Zur Kritik der Politischen Ökonomie, S. 9.

${ }^{681}$ Marx: Theorien über den Mehrwert, S. 257.

${ }^{682}$ So auch der Untertitel der MEW 26.1, 26.2, 26.3. Vgl. auch Heinrich: Die Marxschen Texte zur Ökonomiekritik.

${ }^{683}$ Der in der bürgerlichen Gesellschaft entscheidende Gegenstand des Eigentumsrechts wird in den Rechtswissenschaften unter den Bereich Privatrecht/Bürgerliches Recht/Zivilrecht subsumiert. ${ }^{684} \mathrm{Vgl}$. Hobsbawm: The Age of Revolution, S. 59: „More specifically, the demands of the bourgeois of 1789 are laid down in the famous Declaration of the Rights of Man and Citizens of that year. This document is a manifesto against the hierarchial society of noble privilege, but not one in favour of democratic or egalitarian society.“
} 
le Dinge als ibr Eigentum berufen, sollte ihr Recht auf Eigentum missachtet werden. Doch die Reflexion auf den Eigentumstitel muss noch tiefer gehen, weil ein Rechtsbegriff auf einem Stück Papier dem Subjekt noch lange nichts garantiert. Erst der bürgerliche Staat garantiert seinen Staatsbürgern praktisch, mittels seiner Macht und Gewalt, Eigentum. Es ist die objektive Gewalt des Staats, die die Eigentumstitel auf Waren wie auch allgemeines Recht garantiert. Im Grundgesetz der Bundesrepublik Deutscbland lässt sich im Artikel 14 diese ausnahmslose Garantie des formellen Eigentums für jedermann durch die Staatsgewalt explizit nachlesen: „Das Eigentum und das Erbrecht werden gewährleistet. Inhalt und Schranken werden durch die Gesetze bestimmt. " 685 Vorm Staat können die Bürger als Personen des Rechts ihr postrevolutionär erworbenes Recht auf Gleichheit und Eigentum habende Personen geltend machen - ohne jede privilegienrechtliche Einschränkung: „Men were equal before the law.“686

Diese Universalisierung des Rechts drückt jedoch ambivalent auch einen allgemeinen Zwang auf die bürgerlichen Subjekte aus. Dieser Zwang ist durch die allgemeine Garantie des Eigentums durch den Staat kein willkürlich persönlicher mehr, sondern inzwischen ist er ein systematischer Zwang eines Rechtssystems. Jede Form, z.B. von gewaltsamer persönlicher Willkür bei der Aneignung von Eigentum durch Dritte, wird durch die legitimierte Staatsgewalt im Hinblick auf das allgemeine Recht und den garantierten Eigentumstitel unterbunden. Um den Tausch von Waren zu regeln und eine Anarchie in der Warenaneignung zu verhindern, existieren deshalb Eigentumstitel. Der Eigentumsbegriff und seine materiallose Formalität realisiert dadurch erst die moderne kapitalistische Ökonomie. Nicos Poulantzas stellt in seiner Staatstheorie darum die gewaltsame Periode der ursprünglichen Akkumulation in den Zusammenhang einer Hervorbringung des die kapitalistische Ökonomie ordnenden, staatlich-juristischen Eigentumsbegriffs: „Im Kapitalismus stehen die unmittelbaren Produzenten in einem Verhältnis der vollständigen Besitzllosigkeit zu Arbeitsgegenstand und Produktionsmittel, und zwar nicht nur in Bezug auf das ökonomische Eigentum, sondern auch auf den Besitz. Es entsteht der, freie Arbeiter, der nur die Arbeitskraft besitzt und den Arbeitsprozess nicht ohne die Intervention des Eigentümers in Gang setzen kann, die sich juristisch als Vertrag über den Kauf und Verkauf der Arbeitskraft darstellt.“"687

Mithilfe des Rechtsprinzips Eigentum werden also die mit der revolutionären Gewalt der ursprünglichen Akkumulation willkürlich angeeigneten Besitztümer legalisiert und abgesichert. Sie werden als Eigentum von jemandem (einer Person) unters allgemeine Recht der bürgerlichen Gesellschaft gestellt und dadurch als von Dritten nicht mehr anzueignende Dinge geschützt. Der vormals feudale (Grund-) Besitz geht nun in den juristischen Eigentumstiteln auf und wird infolgedessen zum Privateigentum einer bestimmten Person. In der postrevolutionären kapitalis-

\footnotetext{
${ }^{685}$ Grundgesetz für die Bundesrepublik Deutschland, Artikel 14.

${ }^{686}$ Hobsbawm: The Age of Revolution, S. 59.

${ }^{687}$ Poulantzas: Staatstheorie, S. 46 f.
} 
tischen, auf Warentausch beruhenden Gesellschaft darf sich nun niemand mehr ungestraft materielle Dinge zum eigenen Gebrauch aneignen, die nicht sein festgeschriebenes Eigentum sind. Solch eine Aneignung fremden Materials wären immer ein unlauterer, partikularer Wettbewerbsvorteil, weshalb die „mächtige Instanz des Staates“"688 willkürliche Aneignungen von fremden Waren im Kapitalismus unverzüglich unterbindet. In der Bundesrepublik regelt \903 des BGB den gültigen, allgemeinen Ausschluss von Dritten an fremdem Eigentum, an fremder Ware: „Der Eigentümer einer Sache kann, soweit nicht das Gesetz oder Rechte Dritter entgegenstehen, mit der Sache nach Belieben verfahren und andere von jeder Einwirkung ausschließen." 689 Schon im revolutionären Erwachen der bürgerlichen Gesellschaft schiebt der bürgerliche Staat jeder willkürlichen, gewaltsamen Aneignung von Waren durch die allgemein rechtliche Form der Setzung von Eigentumstiteln einen zwingenden Riegel vor. Robespierre spricht beispielsweise in einer Rede vom 24.04.1793 vor dem französischen Nationalkonvent die entscheidende Garantie der Einschränkung der Willkürrechte aus: „Das Eigentum ist das Recht eines jeden Bürgers, über den Teil der Güter frei zu verfügen, der ihm durch das Gesetz garantiert wird. " 690

Insofern wird der bürgerliche Staat nach den bürgerlichen Revolutionen und seiner Konstituierung der alleinige, konstitutive Bezugspunkt der Garantie der Rechtmäßigkeit von Aneignung und Veräußerung von Dingen. Diese geschützte Gleichheit von Eigentum und Person hat einen sachlichen, historisch-materiellen Hintergrund, ein fundamentum in re in der bürgerlichen Gesellschaft und ihrer kapitalistischen Produktionsweise. Die zunächst nur abstrakte Garantie, vor dem Gesetz als Eigentum habende Personen gleich zu sein, ist ohne den relationalen Inhalt des Eigentumstitels, ohne entsprechendes durch den Staat zu schützendes Material, allerdings nicht denkbar: „Das Eigentum-Haben ohne eine solche nähere Bestimmung kürzt sich tautologisch darauf zusammen, dass da ein Subjekt, etwa ein Mensch, überhaupt ein Eigentumsverhältnis zu etwas, egal zu was, praktiziert." 691 Deshalb verweist der Eigentumsbegriff als Mittel auf die rationalen Zwecke eines gesellschaftlichen (Produktions-)Verhältnisses, das „ohne den Hinweis, was man da sein Eigen nennt" 692 nicht funktioniert. ${ }^{693}$ Über den von allem besonderen Inhalt immer abstrahierenden Eigentumsbegriff wird historisch zunächst das zu Revolutionszeiten gewaltsam Expropriierte als inhaltliches Eigentum einer beliebigen Person, eines Bürgers abgesichert - auch und gerade als materiell unter-

\footnotetext{
${ }^{688}$ Haslbauer: Eigentum und Person, S. 34.

${ }^{689}$ Bürgerliches Gesetzbuch, $\ 903$.

${ }^{690}$ Robespierre, zit. nach Haslbauer: Eigentum und Person, S. 41, Fn.

${ }^{691}$ Haslbauer: Eigentum und Person, S. 15 f.

${ }^{692}$ Ebd., S. 15.

${ }^{693}$ Auch bei Kant ist die Trennung mit dem Begriff vom intelligiblen Besitz Gegenstand: „Die

Trennung des Titels vom Gegenstand täuscht ein intelligibles Besitzverhältnis an einem Gegenstand an sich vor, tatsächlich bleibt der Titel immer auf empirische Gegenstände bezogen.“ (Städtler: Kant und die Aporetik, S. 180.)
} 
schiedliches Eigentum. Wie das Eigentum jedoch in den Besitz der Person gekommen ist, interessiert dabei nicht: „Indem er [der Staat, B.E.B.] seine Gewalt dafür einsetzt, daß von keiner Seite Übergriffe auf die Person und das ihr gehörige Eigentum stattfinden, sorgt er für die Bewahrung der Unterschiede, die er im ökonomischen Leben vorfindet, und für eine Austragung der darin enthaltenen Gegensätze, deren Resultat von vornherein feststeht. Daß die gleiche Behandlung der mit unterschiedlichen Mitteln ausgestatteten Kontrahenten die beste Gewähr dafür bietet, daß die Ungleichheit fortbesteht und wächst, will den Fanatikern der Gleichheit nicht in den Kopf." $"$ "694

Deshalb begründet die mit dem Rechtsprinzip Eigentum überwundene willkürliche Gewalt der Revolution die materiellen Unterschiede im formell jeder Person garantierten Eigentum. Der offensichtlich materielle Unterschied des gewaltsam Angeeigneten verschwindet dabei aus Prinzip in der rationalen, bürgerlichen Rechtsprechung. Der Gewaltakt ist in der bürgerlichen, Rechtsprechung tatsächlich - hegelianisch gesprochen - aufgehoben. Mit dem juristischen Begriff des Eigentums unterwirft man die jeweils mit Gewalt angeeigneten, unterschiedlichen Dinge dem allgemeinen bürgerlichen Recht. Damit objektiviert sich der vorbürgerliche Besitz, der zu juristischem Eigentum einer Person umfunktioniert wird, durch die ihn garantierende Rechtsform hindurch zu einem mit objektiver Gewalt geschützten allgemeinrechtlichen Eigentumstitel.

Die Begriffe Eigentum und Besitz können deshalb auch nicht einfach konfundiert werden. Sie bezeichnen zwar der Sache nach nichts unterschiedliches, der gesellschaftlichen Seite nach bezeichnen sie jedoch nach den Revolutionen entscheidend juristisch zu unterscheidendes. Zugleich repräsentieren die Unterschiede von Eigentum und Besitz auch die qualitative Differenz von Feudalismus und Kapitalismus: „Die Unterscheidung von Eigentum und Besitz in Bezug auf ihre rechtliche Wertigkeit und Rangfolge ist andererseits jedem geläufig, der nur eine Wohnung mietet oder sich mal ein Auto leiht." ${ }^{" 695}$ Das gewaltsam initiierte juristische Eigentumsverhältnis klärt jene postrevolutionäre Verfügungsmacht einer konkreten Person über eine Sache, über ein Ding tatsächlich und eindeutig: „Im Allgemeinen wird das Eigentumsverhältnis durchaus (...) sogar wörtlich als Verfügungsgewalt über Gegenstände gewusst.“" ${ }^{\text {"996 }}$ Der Besitz ist und bleibt innerhalb dieses Verhältnisses, wie im Feudalismus, kein Ausdruck von einer letzten Verfügungsgewalt über die Dinge. Er ist Ausdruck von einer nur vorübergehenden, nicht rechtlich fixen Verfügung über ein entsprechendes Material. ${ }^{697}$ Erst der Eigentumsbegriff regelt rational jede postrevolutionäre Beziehung von Subjekten

${ }^{694}$ Resultate Bd. 3: Der bürgerliche Staat, S. 27.

${ }^{695}$ Haslbauer: Eigentum und Person, S. 26 f.

${ }^{696}$ Ebd., S. 25.

${ }^{697}$ „Gemäß dieser Unterscheidung beider Begriffe kann der Eigentümer einer Sache bestohlen werden - sein Eigentumsrecht bleibt trotzdem bestehen. Der Dieb wird zum Besitzer dieser Sache keinesfalls jedoch zum Eigentümer derselben.“ (Held: Eigentum und Herrschaft bei John Locke und Immanuel Kant, S. 17.) 
untereinander und auch ihre Beziehung auf Objekte im Hinblick auf das antagonistische gesellschaftliche Verhältnis der „Individuen zueinander in Beziehung auf

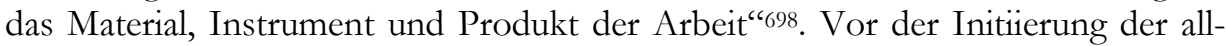
gemeinen bürgerlichen Gesellschaft konnte es den ökonomischen Eigentumstitel mit seiner besonderen juristischen Stellung in der kapitalistischen bürgerlichen Gesellschaftsform nicht geben, weil es erst innerhalb der kapitalistischen Produktionsweise zu jener entscheidenden ,eigentümliche(n) Charakteristik“699 des Produktionsverhältnisses kommt: „Der Rechtsakt, der Besitz zu Eigentum aufteilt, bringt die Akkumulationskraft der Wirtschaft hervor." "700 Diese Besonderheit, den juristischen Eigentumstitel als materielles Regulationsmoment der politischen, kapitalistischen Ökonomie zu reflektieren, geht zuweilen auch Marx verloren. Wenn er in der Deutschen Ideologie schreibt, dass den „verschiedenen Entwicklungsstufen der Teilung der Arbeit (...) ebensoviel verschiedene Formen des Eigentums "701 zugrunde lägen, gehen auch ihm die juristisch zu trennenden Begriffe Besitz und Eigentum durcheinander. Damit legt Marx den Eigentumsbegriff weit in die vorbürgerlichen Gesellschaftsformen zurück, weshalb dieser dadurch gerade nicht in seiner Besonderheit nach und durch die bürgerliche Revolution und dem aus ihr zweckmäßig hervorgehenden juristischen Staatsapparat reflektiert wird: „Gegen die Vorstellung, Eigentum wäre etwas zeitloses, etwa dem Wesen Mensch an sich erwachsendes, kann sich die häufig gut dokumentierte Argumentation wenden, dass Eigentum doch etwas völlig neues in der Geschichte der Menschheit sei, das nichts gemein habe mit etwa den römischen Formen von dominium und propietas oder den mittelalterlichen Verfügungsformen. "702 Auch Marx begreift an der Stelle noch nicht, dass wirklich erst der juristische Kontext des Begriffs den Schlüssel auch des Verständnisses gesellschaftlicher, produktiver Veränderungen in die Hand gibt. Die historisch mittels Gewalt gewonnenen juristischen Eigentumstitel lassen sich insofern von der Geschichte der bürgerlichen Vergesellschaftung und ihrer konkreten kapitalistischen Warendistribution nicht einfach abstrahieren. Erst innerhalb der totalen Gesellschaft, die kapitalistisch Waren produziert und diese vermittels Eigentumsbestimmungen herstellt und auch tauscht, bekommen sie nun den bestimmten, die Dinge gesellschaftlich ordnenden Zweck. Deshalb lassen sie sich auch erst auf diese bestimmte Gesellschaftsform zurückführen: „Eigentum ist ein gesellschaftliches Verhältnis.“703

Deswegen kann es auch kein gottgegebenes oder sonst wie axiomatisch oder apodiktisch begründetes Naturrecht als Rechtfertigung für personelles Eigentum geben. Kein jus naturae rechtfertigt die erst mittels revolutionärer Gewalt gewon-

\footnotetext{
698 Marx: Die deutsche Ideologie, S. 22.

699 Poulantzas: Staatstheorie, S. 47.

700 Gernalzick: Medium Geld, S. 95.

701 Marx: Die deutsche Ideologie, S. 22.

702 Haslbauer: Eigentum und Person, S. 43. Vgl. auch den von Haslbauer empfohlenen Michael Villey: Das römische Recht in Hegels Rechtsphilosophie.

703 Bulthaup: Rechtspragmatik oder von der Zwangsläufigkeit des sittlichen Verfalls der Justiz, S. 75.
} 
nenen Eigentumstitel. Das hielt Philosophen jedoch nicht davon ab, einen solchen Begründungsversuch zu unternehmen. John Locke schreibt: „Whether we consider natural reason, which tells us, that men, being once born, have a right to their preservation, and consequently to meat and drink, and such other things as nature affords for their subsistence, or ,revelation,' which gives us an account of those grants God made of the world to Adam, and to Noah and his sons, it is very clear that God, as king David says (Psalm 115:16), ,has given the earth to the children of men, given it to mankind in common. "704 Den Eigentumsbegriff stellt Locke deshalb auch nicht in den gesellschaftlichen Zusammenhang von Gewalt, Herrschaft und bürgerlicher Revolution. Mit Eigentum wird ihm zufolge nicht das rational abgesichert, was materiell aus der Englischen Revolution ${ }^{705}$ bzw. den Cromwellschen Bodenreformen ${ }^{706}$ hervorging. Für Locke ist Eigentum einzig Resultat eines theologisch begründeten überpositiven Naturrechts. ${ }^{707}$ Bei einer konkreten Begründung der Unterschiede im Eigentum stößt Locke dadurch auch an entsprechende logische Grenzen. Als Naturrechtler rechtfertigt er die offensichtlich materiellen Unterschiede im Eigentum allein mit der fleißigen Arbeit von Einzelnen an dadurch proportional übermäßig angeeigneter Natur. Seinen Ursprung habe das Eigentum deshalb allein in Arbeit und Fleiß des die Natur selbständig bearbeitenden Subjekts. ${ }^{708}$ Das unterstellt die gleichen Voraussetzungen der Subjekte, das unterstellt gleiche gesellschaftliche Ausgangsbedingungen für jedermann. Die vorgefundene Natur müsse demnach allen Menschen gleichermaBen gehören, und nur das könne den Unterschied in ihrer Aneignung begründen. Diese ursprünglich gleiche Voraussetzung aller Menschen, ihren gleichen ursprünglichen Besitz an Land, rechtfertigt Locke mit Bibel und „God, who hath

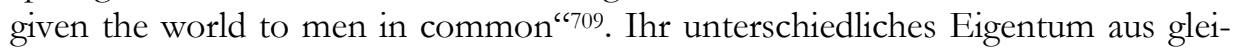
chen Voraussetzungen könnten sich einzelne Menschen gegen andere nur darum fleißig aneignen, weil Gott allen Menschen die gleiche Verfügungsmacht über Grund und Boden zugeteilt habe und ,hath also given them reason to make use of it to the best advantage of life and convenience. ${ }^{\text {"7 }} 10$ Jeder Mensch, der sich sein Stück Natur mit seiner eigenen Arbeit(-skraft) Untertan mache sei deshalb berechtigt, jenen Teil der von ihm fleißig bearbeiteten Natur auch als sein Eigentum auszugeben. So hat die Aneignung von Natur für Locke nichts mit willkürlichen,

\footnotetext{
${ }^{704}$ Locke: Two Treatises of Government, Book II (Of Property), $\$ 24, S. 87.

${ }^{705}$ Vgl. Schröder: Englische Geschichte, S. 29.

706 Wobei die Idee, Bodenreformen in England durchzuführen, wohl auch schon auf Thomas Morus zurückgeht. (Vgl. von Alemann (Hrsg.): René König Schriften, Zur Konstitution moderner Gesellschaften, S. 147.)

${ }^{707}$ Es gibt daneben auch eine das Naturrecht rechtsphilosophisch begründe Schule. Für die Bundesrepublik ist hier zweifelsohne der oben schon einmal angesprochene Gustav Radbruch zu nennen.

(Vgl. Radbruch, Rechtsphilosophie I.

${ }^{708}$ Vgl. bspw. Locke: Two Treatises of Government, Book II (Of Property), \27, S. 87 f.

${ }^{709}$ Ebd., \25, S. 87.

${ }^{710}$ Ebd.
} 
aus Gewaltzusammenhängen kommenden Bezeichnungen der Sachen mit besitzanzeigenden Fürwörtern zu tun, sondern bloß mit eingeflossener Arbeit an auch nur deshalb rechtmäßig eigentümlich von einem Subjekt beanspruchten Dingen: „As much land as a man tills, plants, improves, cultivates, and can use the product of, so much is his property." ${ }^{\circ 711}$ Von der revolutionär-gewaltsamen Aneignung, von erst post festum rationalisiertem Eigentum ohne vorher eingeflossenes Arbeitspensum will der Naturrechtler Locke deshalb auch nichts wissen: Gesellschaften würden ihm zufolge ganz intersubjektiv-konsensuell die Frage des Eigentums klären: „by compact and agreement“"712. Locke kann deshalb das gesellschaftlichgewaltvolle Verhältnis des Eigentums auch nicht adäquat begreifen, weil er den intelligiblen Besitz des Eigentums, vor allem eben des Privateigentums an Produktionsmitteln, nicht in seiner entscheidenden Wichtigkeit reflektiert. Lockes Darstellungen verlieren dadurch die spezifische Differenz von Eigentum zum privaten Gebrauch und dem Privateigentum an Produktionsmitteln aus den Augen. Der für die kapitalistische Produktionsweise und ihr Funktionieren so wichtige Boden, den die Menschen zur eigenen Selbsterhaltung bei ihm allesamt gleichermaßen bearbeiten dürfen, hat für Locke keinen -, und wenn doch, dann jedoch nur geringen Wert.

Der Boden ist für Locke insofern nicht das „ursprüngliche Produktionsmittel ${ }^{\text {‘ } 713}$, das sich mittels der gewaltsamen Bodenreformen durch Wenige angeeignet wird. Wert bekomme der Boden für Locke allein aufgrund seiner Verknappung, die eine Folge von gesellschaftlicher Übervölkerung sei - aber nicht als die attraktive Möglichkeit von kapitalistischer Wertschöpfung, als kapitalistische Wertschöpfungsquelle überhaupt: „,The one of these being the food and raiment which unassisted Nature furnishes us with; the other provisions which our industry and pains prepare for us, which how much they exceed the other in value, when any one has computed, he will then see how much labour makes the far greatest part of the value of things we enjoy in this world; and the ground which produces the materials is scarce to be reckoned in as any, or at most, but a very small part of it; so little, that even amongst us, land that is left wholly to nature, that hath no improvement of pasturage, tillage, or planting, is called, as indeed it is, waste; and we shall find the benefit of it amount to little more than nothing. ${ }^{\text {"7 }} 14$ Auch der Wert des Bodens sei also größtenteils nur Resultat fleißiger Arbeit. ${ }^{715}$ So funktioniert Lockes naturrechtliche Legitimation des Eigentums. Seine Argumentation, so Bulthaup, sei jedoch ,nicht stichhaltig für das durch Vertrag an Grund und Bo-

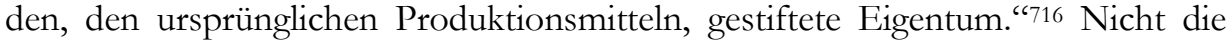

\footnotetext{
711 Ebd., \$31, S. 89.

712 Ebd., \$ 45, S. 93.

${ }^{713}$ Berger: Arbeit, Selbstbewusstsein und Selbstbestimmung bei Hegel, S. 91.

${ }^{714}$ Locke: Two Treatises of Government, Book II (Of Property), \42, S. 92.

715 Ebd., \43, S. 92: „It is labour, then, which puts the greatest part of value upon land“.

716 Bulthaup: Rechtspragmatik oder von der Zwangsläufigkeit des sittlichen Verfalls der Justiz, S. 74.
} 
Arbeit, sondern das staatlich geschützte Gesetz sichert der Person zunächst das juristische Eigentum auch an Boden zu - und gibt damit die gesellschaftlichen Voraussetzungen von kapitalistischer Produktionsweise an die Hand. Kants systematische Konzeption des intelligiblen Besitzes ${ }^{717}$ erklärt das Eigentumsverhältnis hingegen besser als Locke ${ }^{718}$, „Kants apriorische Konstruktion des intelligiblen Besitzes geht in intentione recta auf das Eigentum an Produktionsmitteln und steht damit in Widerspruch zu den zunächst plausiblen sozialgeschichtlichen Erklärungen [Locke et al., B.E.B.] der Trennung von physischem und intelligiblen Besitz." "719 Das liegt jedoch auch an den ökonomischen Fortschritten der Gesellschaft zu Kants Zeiten gegenüber der Zeit Lockes.

Auch der Klassenantagonismus zeigt sich als ein Resultat der historischen Gewalt, und mit dem bürgerlichen Recht wird er erst rationalisiert: „Diesen historischen Prozess beschreibt Marx als die Enteignung der ProduzentInnen von ihren Überlebensmitteln, wodurch eine Klasse geschaffen wird, die nichts besitzt, außer ihre Arbeitskraft." ${ }^{\text {"720 }}$ Durch den gewaltsamen Akt der Schaffung kapitalistischer Verhältnisse mittels der den Feudalismus zersprengenden Gewalt der Landnahme werden die juristisch als Personen gleichgemachten Bürger insofern erst in zwei ökonomischen Klassen ${ }^{721}$ gespalten. Der Gewaltakt der Schaffung der bürgerlichen, kapitalistischen Gesellschaft bringt mittels der damit einhergehenden juristischen Absicherung des Angeeigneten durch die post festum durch den Staat garantierten Eigentumstitel einen rational reflexiven, mythisch immergleich anmutenden ökonomischen Prozess von auf der einen Seite Eigentumslosen an Produktionsmitteln, auf der anderen Seite Eigentümern in Gang: „Durch den Antagonismus sind die Klassen aufeinander bezogen." ${ }^{\prime 722}$

Der Klassenantagonismus bezieht die Klassen als materiell unterschiedene dabei nicht nur aufeinander, sondern erhält sie auch durch sich hindurch. Er ist für die kapitalistische Produktionsweise wesentlich. Mit dem Kapitalismus ist deshalb auch der historisch offensichtliche Verlust von lebenserhaltenden Reprodukti-

\footnotetext{
717 Vgl. zum intelligiblen Besitz auch Held: Eigentum und Herrschaft bei John Locke und Immanuel Kant, S. 126 ff.

718 „Deshalb ist allem empirischen Besitz die Vorstellung des intelligiblen Besitzes vorgeordnet. So verweist Kant auf den Erwerb eines Bodens durch erste Aneignung, mithin auf die historische Bedingtheit der Unterscheidung von empirischem und intelligiblen Besitz." (Städtler: Kant und die Aporetik, S. 180.)

${ }^{719}$ Bulthaup: Rechtspragmatik oder von der Zwangsläufigkeit des sittlichen Verfalls der Justiz, S. 74.

${ }^{720}$ Hanloser/Reitter: Der bewegte Marx, S. 6.

721 „Bourgeoisie und Proletariat sind die einzigen, reinen Klassen der bürgerlichen Gesellschaft.“ (Lukács: Geschichte und Klassenbewusstsein, S. 139.) Das schreibt Lukács, weil Marx im dritten Band des Kapitals eigentlich drei Klassen der bürgerlichen Gesellschaft bestimmt: „Die Eigentümer von bloßer Arbeitskraft, die Eigentümer von Kapital und die Grundeigentümer, deren respektive Einkommensquellen Arbeitslohn, Profit und Grundrente sind, also Lohnarbeiter, Kapitalisten und Grundeigentümer, bilden die drei großen Klassen der modernen, auf der kapitalistischen Produktionsweise beruhenden Gesellschaft." (Marx: Das Kapital, Bd. 3, S. 892.)

722 Buthaup: Herrschaft, Sprache, Revolution, S. 51.
} 
onsmitteln einer ganzen verdinglichten Klasse verbunden: „Das Kapitalverhältnis setzt die Scheidung zwischen den Arbeitern und dem Eigentum an den Verwirklichungsbedingungen der Arbeit voraus. Sobald die kapitalistische Produktion einmal auf eignen Füßen steht, erhält sie nicht nur jene Scheidung, sondern reproduziert sie auf stets wachsender Stufenleiter." 723 Der Eigentumsbegriff verlängert somit die Eigentumslosigkeit an Produktionsmitteln der Proletarier durch den kapitalistischen Produktionsprozess hindurch. Dabei verliert die historische Offensichtlichkeit des gewaltsamen Verlusts von Reproduktionsbedingungen einer Klasse ihre Sichtbarkeit. Die gesetzlich garantierte juristische Gleichheit der vernünftigen Subjekte als Eigentümer, „in der die Differenzen untergehen“724, verlängert die Gewalt der willkürlichen Aneignung im in sich rationalen Gesetz. Zur Durchsetzung der kapitalistischen Produktionsweise durch die Initiierung von Recht, Gesetz und Eigentum gehört mehr Herrschaft und Gewalt als bloß die sie initiierende sinnlich wahrnehmbare Gewalt der bürgerlichen Revolution. Die offensichtliche Gewalt im Akt der Entreißung von Subsistenzmöglichkeiten verschwindet in der bürgerlichen Gesellschaft. Durch die allgemeinen Gesetze fast zur Unkenntlichkeit vermittelt, gehört das gesellschaftliche Gewaltverhältnis weiterhin zur bürgerlichen Gesellschaft. Darum beruht auch für Hannah Arendt die „Existenz des Staates (...) auf Gewalt" ${ }^{6725}$, was auf das in den staatlichen Institutionen verlängerte Gewaltverhältnis hinweist.

Die willkürliche, gewaltsame Expropriation eines großen Bevölkerungsteils ist zudem, neben der Hervorbringung des oben beschriebenen Klassenantagonismus’, auch die hervorgebrachte Voraussetzung des ,inneren Marktes“726 der kapitalistischen Produktionsweise. Es ist der doppelt freie Lohnarbeiter ohne jede weitere selbsterhaltende Möglichkeit, der als unerlässliches Opfer aus dem Prozess der Expropriation hervorgeht. Der Lohnarbeiter kann sich inzwischen nicht mehr, wie früher noch der Knecht, subsistenzwirtschaftlich selbst versorgen. Er wird dadurch zur „historische[n] Existenzbedingung ${ }^{6727}$ der kapitalistischen Produktion: „Historisch epochemachend in der Geschichte der ursprünglichen Akkumulation sind alle Umwälzungen, die der sich bildenden Kapitalistenklasse zum Hebel dienen; vor allem aber die Momente, worin große Menschenmassen plötzlich und gewaltsam von ihren Subsistenzmitteln losgerissen und als vogelfreie Proletarier

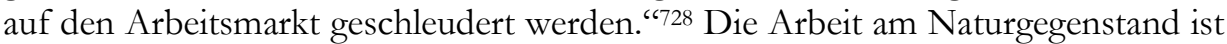
nun, postrevolutionär, sogleich unters Kapital subsumiert, und alle noch besitzbasierten Gebrauchsdinge der feudalen Bauern/Knechte, wie Lebensmittel und

\footnotetext{
${ }^{723}$ Marx: Das Kapital, Bd. 1, S. 742.

${ }^{724}$ Adorno: Negative Dialektik, S. 304.

725 Arendt: Macht und Gewalt, S. 37.

726 „Und nur die Vernichtung des ländlichen Hausgewerbes kann dem innern Markt eines Landes die Ausdehnung und den festen Bestand geben, deren die kapitalistische Produktionsweise bedarf.“

(Marx: Das Kapital, Bd. 1, S. 776.

727 Ebd., S. 184.

728 Ebd., S. 744.
} 
Rohstoffe, sind mit der Durchsetzung des inneren Marktes auch schon in „sachliche Elemente des Kapitals“729 verwandelt. Jene warenförmigen, sachlichen Elemente dürfen die freigesetzten Bauern als juristisch befreite Lohnarbeiter deshalb nicht mehr subsistenzwirtschaftlich zur eigenen Reproduktion benutzen. Diese Möglichkeit wird ihnen durch die revolutionäre Gewalt und den diese rationalisierenden Eigentumstitel entrissen. So erst wird das Kapitalverhältnis, als gesellschaftliches Herrschaftsverhältnis zwischen den Personen, nach der Herstellung des inneren Marktes durch die Expropriation von zuvor in der vorbürgerlichen Gesellschaft auf dem einfachen Besitz basierenden Sachen antagonistisch durch die Klassen hindurch vermittelt. Nur jener gewaltsam vonstatten gehende Verlust von subsistenzwirtschaftlichen Möglichkeiten der Reproduktion einer ganzen Klasse und deren Abhängigkeit von Lohnarbeit nach der Landnahme garantiert die kapitalistische Gesellschaftsform. So ist die kontingente Expropriation von Vielen jene beschriebene Schaffung der kapitalistischen Eigentumsvoraussetzungen gegen den intersubjektiven Konsens Lockes und gegen jede soziologische, subjektivistische Handlungstheorie. Die Auffassung von autonomen Subjekten, die angeblich in friedlicher Koexistenz ihre Selbsterhaltung als Eigentümer in der bürgerlichen Gesellschaft realisieren können, ist schon deshalb falsch.

\subsubsection{Das Verhältnis von Eigentum und Gewalt}

„Zweierlei sehr verschiedne Sorten von Warenbesitzer müssen sich gegenüber und in Kontakt treten, einerseits Eigner von Geld, Produktionsund Lebensmitteln, denen es gilt, die von ihnen geeignete Wertsumme zu verwerten durch Ankauf fremder Arbeitskraft; andrerseits freie Arbeiter, Verkäufer der eignen Arbeitskraft und daher Verkäufer von Arbeit. Freie Arbeiter in dem Doppelsinn, daß weder sie selbst unmittelbar zu den Produktionsmitteln gehören, wie Sklaven, Leibeigene usw., noch auch die Produktionsmittel ihnen gehören, wie beim selbstwirtschaftenden Bauer usw., sie davon vielmehr frei, los und ledig sind. Mit dieser Polarisation des Warenmarkts sind die Grundbedingungen der kapitalistischen Produktion gegeben." ${ }^{\prime c 730}$

Das Urteil von der Existenz des Staates, der das Gewaltverhältnis über seine Rechtsbegriffe nur verlängert, lässt sich allein mittels der tiefergreifenden Reflexion der gesellschaftlichen Verhältnisse begreifen. Denn selbst das an keinem Subjekt vorbeigehende Bewusstsein vom staatlichen Gewaltmonopol ändert wenig an der Ideologie der Gewaltlosigkeit von bürgerlicher Gesellschaft und Staat. Diese Ideologie ist das adäquate Selbstbewusstsein der bürgerlichen Gesellschaft, das sich im Bewusstsein der vergesellschafteten Subjekte nur adäquat ausdrückt. Dass

\footnotetext{
${ }^{729}$ Ebd., S. 775.

${ }^{730}$ Ebd., S. 742.
} 
diese Ideologie existiert, hat auch einen Grund in der Sache, ein fundamentum in re in der bürgerlichen Gesellschaft. Zum einen kann sie nämlich darauf zurückgeführt werden, dass weil alle Staatsgewalt vom Volke ausgehe ${ }^{731}$, diese von den Rechtssubjekten auch als richtig, eben als die Ihrige, anerkannt wird. Es wird sich mit der Staatsgewalt insofern als eigens geschaffene, demokratische Macht identifiziert. Selbst im Zweifel wird sich deshalb noch mit ihr als der notwendigen Gewalt des Volkes für seine Interessen identifiziert. Vor allem aber, weil die bürgerliche Gesellschaft tatsächlich von ungerechtfertigter, sprich persönlicher Gewalt abstrahiert, hält sich die Ideologie der Gewaltlosigkeit so hartnäckig. Die gegenwärtige, vermittelte Gewalt der gesellschaftlichen Herrschaft wird dem Subjekt jedoch auch deshalb nicht als historisch vermittelte, rationalisierte Gewalt offenbar, weil sich „der kapitalistische Staat (...) niemals als Klassenstaat “"732 zu erkennen gibt.

Der bürgerlichen Gesellschaft diese Gewaltlosigkeit zu unterstellen ist nun auch nicht einfach nur falsch, weil Ideologie nie einfach nur falsch ist. So werden den feudalen Knechten nach ihrer juristischen Freisetzung in der bürgerlichen Gesellschaft die allgemeinen, nicht weniger intensiven gesellschaftliche Zwänge der neuen, kapitalistischen Produktionsweise auferlegt, die allerdings gewaltfrei zu sein scheinen: „Die Bourgeoisie, wo sie zur Herrschaft gekommen, hat alle feudalen, patriarchalischen, idyllischen Verhältnisse zerstört. Sie hat die buntscheckigen Feudalbande, die den Menschen an seinen natürlichen Vorgesetzten knüpften, unbarmherzig zerrissen und kein anderes Band zwischen Mensch und Mensch übriggelassen als das nackte Interesse, als die gefühllose, ,bare Zahlung. ." ${ }^{\prime} 33$ Das fundamentum der so erfolgreichen Ideologie der Gewalt- und Herrschaftslosigkeit liegt in der inzwischen tatsächlichen „Gleichstellung auf dem Gebiet der Ökonomie ${ }^{\text {‘734 }}$ und im allgemein garantierten gleichen (Eigentums-)Recht für alle Bürger ausnahmslos. Darum scheint die bürgerliche Gesellschaft auch keine gesellschaftliche Herrschaft mehr zu kennen: „In der modernen Form, dem Schein der unpersönlichen Geldmacht, scheint Herrschaft zunächst ganz verschwunden zu sein. “"735 Denn jene Herrschaft wird, ideologisch, immer nur noch mit persönlicher oder willkürlicher Gewaltausübung von politischen Gruppen gegen allgemeine Gesetze identifiziert. ${ }^{736}$

Die Gewalt des staatlich geschützten Gesetzes gilt dagegen eben immer schon als völlig gerechtes Herrschaftsprinzip im Sinne aller Bürger - weil jede Person die gleichen Rechte hat und Ausnahmen von der Regel des allgemeinen Zwangs, wie

\footnotetext{
731 „Alle Staatsgewalt geht vom Volke aus. Sie wird vom Volke in Wahlen und Abstimmungen und durch besondere Organe der Gesetzgebung, der vollziehenden Gewalt und der Rechtsprechung ausgeübt." Grundgesetz für die Bundesrepublik Deutschland, Artikel 20.

732 Poulantzas: Staatstheorie, S. 93.

${ }^{733}$ Marx/Engels: Das Kommunistische Manifest, S. 464.

${ }^{734}$ Claussen: Grenzen der Aufklärung, S. 125.

735 Claussen: Grenzen der Aufklärung, S. 109.

736 Vgl. die Interpretationen von der Herrschaft der Banker, des Finanzkapitals, der Bilderberger etc.
} 
vorbürgerliche Privilegien, aus seinem (Rechts-)Prinzip heraus nicht mehr gelten. Wahrgenommen wird der bürgerliche Staat also nur als ein über der Sphäre von persönlicher Gewalt und Klassen schwebender objektiver Schlichter von verschiedenen Bürgerinteressen. Er vereinige dabei, so die Ideologie, alle Einzelinteressen im Interesse aller. Jede offen sichtbare staatliche Gewalt der bürgerlichen Gesellschaft rechtfertigt sich vor allem post festum immer als im Sinne des Einzelinteresses gewesene - beispielsweise als notwendige Gewalt des staatlichen Gewaltmonopols, die die Gesellschaft gegen die Feinde von Demokratie und Gleichheit verteidigt.

Die bürgerliche Gesellschaft ist, über die in der Verfassung verbrieften allgemeinen Rechte, ein allgemeiner Rechtsstaat. ${ }^{737}$ Im Bewusstsein der Staatsbürger wird der gewaltsam konstituierte Rechtsstaat deswegen auch ,als Gegensatz zur

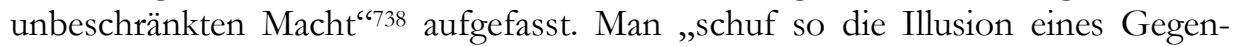
satzpaares Gesetz/Terror.“"739 Das juristische Eigentum, weil jedem Staatsbürger als Person ausnahmslos garantiert und vom Staat gegen jede Willkür verteidigt, tut hinsichtlich der Pazifizierung der gesellschaftlichen Herrschaft noch sein Übriges. Von den über das Gesetz nur verlängerten materiellen Unterschieden nach der Revolution ist im Eigentumsrecht selbst nämlich selbstverständlich keine Rede mehr. Diesen allgemeinen Gesetzen des bürgerlichen Rechtstaates muss sich jedes Subjekt als vergesellschaftet handelndes nun unterwerfen, wenn es in der bürgerli-

\footnotetext{
${ }^{737}$ Ein Zustand, der für jeden Staat, der nach allgemeingültigen und einsichtigen Gesetzen handelt, gilt. Bezüglich der DDR und den nationalsozialistischen, faschistischen deutschen Staat wird das gerne vergessen. Beide Staaten werden voluntaristisch als Unrechtsstaaten abqualifiziert. Keine Rede ist hinsichtlich des Nationalsozialismus vom Notverordnungsrecht, dem berühmten Artikel 48 der Weimarer Verfassung, das juristisch erst sicherstellte, dass die allgemeine Verfassung der Weimarer Republik bis zum Ende des Faschismus galt: „Als die Nazis die Macht ergriffen und am 28.Februar 1933 die ,Verordnung zum Schutz von Volk und Staat' erließen, die auf unbestimmte Zeit die Artikel aufhob, welche persönliche Freiheit, die freie Meinungsäußerung, das Versammlungsrecht, die Unverletzlichkeit der Wohnung und das Brief-, Post-., Telegraph- und Fernsprechgeheimnis betrafen, haben sie eigentlich nur eine bereits von den vorangehenden Regierungen gefestigte Praxis weiterverfolgt.“ (Agamben: Homo Sacer, S. 176 f.) Diese Möglichkeiten, das allgemeine Recht zu partikularen Zwecken notverordnungsrechtlich zu nutzen, gibt es nahezu ausnahmslos in jedem bürgerlichen Staat. Die derzeitigen NDAA-Gesetze in den USA bilden da eben so wenig eine Ausnahme wie die Notstandsverfassung der BRD oder der zum Zeitpunkt des Verfassens dieser Zeilen aktive französische État d'urgence. - Auch in der DDR galten allgemeine Gesetze und Verfassung. Vor der Enquete Kommission zur Aufarbeitung der ,SED-Diktatur'versuchte Roman Herzog, damals Bundespräsident, den nationalsozialistischen deutschen Staat mit der DDR anhand seines Begriffs vom Unrechtsstaat zu vergleichen. Er kommt dabei zu dem offensichtlich falschen Ergebnis, das die Bedingungen von Recht und deshalb den Rechtsbegriff nicht als rein Zweckbezogenen reflektiert: „Sie [die DDR, B.E.B.] war ein Unrechtsstaat!“ Den Grund für dieses Unrecht sieht Herzog in dem de-facto-Einparteiensystem (das es de jure nicht einmal war) der DDR, was er recht abenteuerlich mit den Verhältnissen im Nationalsozialismus verbindet: „NSDAP und SED hatten sich gleichermaßen des Staates und der gesellschaftlichen Organisationen bemächtigt.“ (archive.org: Rede von Bundespräsident Roman Herzog vor der Enquete-Kommission „SED-Diktatur“ in Berlin.)

738 Poulantzas: Staatstheorie, S. 104.

${ }^{739}$ Ebd.
} 
chen Gesellschaft, zumindest problemloser, überleben will. Während des Vollzugs seiner eigenen Selbsterhaltung hat jedes Subjekt dabei das Recht darauf, durch sein subjektives Gegenüber unversehrt zu bleiben. Aus Gründen des reziproken Tauschs von Eigentum ist die unmittelbare, willkürliche Gewalt gegen Personen also tatsächlich abgeschafft. Durch den Staat und seine kategorial universalen Gesetze soll sie möglichst erfolgreich verhindert werden: „In der modernen Gesellschaft ist die vorherrschende Verkehrsform die Tauschbeziehung geworden: Sie erfordert Verzicht auf unmittelbare Gewalt." ${ }^{\text {"7 }} 40$

Durch die allgemeinen Gesetze herrscht deshalb ein formell recht friedvoller Tausch von eigentümlichen Waren auf dem kapitalistischen Markt. Die bürgerliche Gesellschaft kennt die unmittelbare, sprich persönliche Gewalt nur noch als eine grenzüberschreitende, illegale Gewalt: Das beweist bereits la Grande Terreur ${ }^{741}$. Im bürgerlichen Staat ist die persönliche Konfrontation in einen solch streng funktionalisierten, streng institutionalisierten Rahmen eingebettet, dass die persönliche Gewalt im Rahmen des Gesetzes demnach auch unbegründbar wird. Selbst der Polizist, der Demonstranten prügelt, prügelt diese nicht, weil es ihm als Person der Exekutive unmittelbar erlaubt ist, Gewalt gegen andere Personen anzuwenden, sondern es ist das allgemeine, objektiv gültige Recht, dass sich hier bloß über seine Person vermittelt realisiert. In seiner Funktion als Subjekt der Exekutivorgane werden ihm vom Gesetz die dafür zwingenden Maßnahmen, ideologisch allesamt zum Wohle der Allgemeinheit, zugesprochen. Als juristische Person ist der Polizist vor dem Gesetz demnach so gleich wie jeder andere Staatsbürger. Gegen jede Form der Willkür der Staatsorgane gegen seine Staatsbürger formuliert heißt es deshalb auch schon im deutschen Grundgesetz: „Die Gesetzgebung ist an die verfassungsmäßige Ordnung, die vollziehende Gewalt und die Rechtsprechung sind an Gesetz und Recht gebunden." "742

Das Recht am eigenen Eigentum wird dabei aber eben nur jedem Staatsbürger ausnahmslos durch den ,eigenen“ Staat garantiert: „Er [der bürgerliche Staat, B.E.B.] verleiht seinen Gesetzen allgemeine Gültigkeit, bezieht alle Handlungen auf sich und verlangt keinem Interesse besondere $\mathrm{ab}$ - außer eben die, welche sich aus dessen ökonomischen Mitteln ergeben." "743 Insofern die Mitgliedschaft im Staat über ein entsprechendes Dokument bestätigt ist, sind dem idealen bürgerli-

\footnotetext{
740 Claussen: Vom Judenhass zum Antisemitismus, S. 93.

${ }^{741}$ Der Beginn des berühmten postrevolutionären, bürgerlichen Terreurs wird durch den Eintritt Robespierres in den Wohlfahrtsausschuß markiert. Historisch ist er eine von Staatswegen durchgeführte und legitimierte wie legalisierte Gewalt, also ein erstes Resultat republikanischer Durchsetzungskraft. Der Terreur hat deshalb einen unpersönlichen, ,systematisch-institutionalisierten Charakter", wie Hans-Ulrich Thamer schreibt. (Thamer: Die Französische Revolution, S. 76.) Spätestens 1793 wird er zum offiziellen „Regierungsprinzip“ (Ebd., S. 80) der französischen Republik. Vgl. zum Begriff des Terrors auch die phänomenologische Studie Ulrich Schneckeners: Transnationaler Terrorismus, S. $21 \mathrm{ff}$.

742 Grundgesetz für die Bundesrepublik Deutschland, Artikel 20, 3.

${ }^{743}$ Resultate Bd. 3: Der bürgerliche Staat, S. 22.
} 
chen Staat laut Grundgesetz/Verfassung Religion, Rasse, Geschlecht usw. gleichgültig. Es gelten jedoch für Subjekte dann andere Gesetze, wenn sie keine entsprechenden Staatsbürger sind. Neben dem offensichtlichen Ausländer- oder Fremdenrecht, das für die Staatsbürger logischerweise hinfällig ist, wird die Unterscheidung von Staatsbürgern und den Menschen ohne das entsprechende Dokument in der Bundesrepublik vor allem anhand des Widerstandsrechts, Teil des deutschen Grundgesetzes, offensichtlich. Artikel 20, Abs. 4 lautet: „Gegen jeden, der es unternimmt, diese Ordnung zu beseitigen, haben alle Deutschen [sic!] das Recht zum Widerstand, wenn andere Abhilfe [sic!] nicht möglich ist.“" ${ }^{\text {“74 }}$ Ungeachtet der völlig offengelassenen Frage, wann und wie Widerstand auch für die Staatsbürger möglich sein soll - wenn, andere Abhilfe' schon nicht mehr möglich sei, sprich der Staat bereits völlig am Boden ist - macht gerade dieser Punkt der bürgerlichen Rechtsprechung die gesetzliche Differenzierung von Staatsbürgern und Ausländern deutlich.

Der wirklichen Gleichheit aller auf dem Staatsgebiet lebenden Personen vor dem Gesetz, unabhängig ihres Passes, tut das jedoch trotzdem keinen Abbruch. Diese Gleichheit ist keine Illusion, wenn auch Ideologie. In Gänze wird sie zwar ausschließlich den dokumentierten Staatsbürgern garantiert, aber die Exklusion von Subjekten aus der Allgemeinheit fällt bei näherer Betrachtung immer auch gleich unter die Spielregeln der juristischen Gleichheit. Das weist der Rechtspositivist Kelsen bei seiner Antwort auf die Frage nach der bürgerlichen Gerechtigkeit nach: „Und nun gar das besondere Prinzip der sogenannten Gleichheit vor dem Gesetz! Es bedeutet nichts anderes, als daß die rechtsanwendenden Organe keine Unterschiede machen sollen, die das anzuwendende Recht nicht selbst macht. Gewährt das Recht nur Männern, nicht aber Frauen, nur Staatsbürgern, nicht aber Staatsfremden, nur Angehörigen einer bestimmten Religion oder Rasse, nicht aber Angehörigen anderer Religionen oder Rassen, politische Rechte, dann ist der Grundsatz der Gleichheit vor dem Gesetz durchaus gewahrt, wenn die rechtsanwendenden Organe in konkreten Fällen entscheiden, daß eine Frau, ein Staatsfremder, der Angehörige einer bestimmten Religion oder Rasse keine politische Rechte habe. ${ }^{\text {‘7 } 45}$

Die Ideologie der Gewaltlosigkeit durch Universalität ist demnach genauso falsch wie adäquat. Adäquat ist sie, weil eine Ideologie ihr fundamentum bekanntlich in der Gesellschaft selbst hat. Falsch aber ist sie, weil das Selbstbewusstsein der bürgerlichen Gesellschaft nicht darüber hinwegtäuschen kann, dass nur, weil die persönlich motivierte Gewalt zu Gunsten der rationalen Organisation der Ökonomie aufgehoben wird, die postfeudale Gesellschaft auch wirklich gewaltfrei wird. Allein schon die Entscheidung über die Existenz des postrevolutionären bürgerlichen und nationalen Staat ist historisch nie Gegenstand einer freien, willentlichen Entscheidung der republikanisch post festum vergesellschafteten Staats-

\footnotetext{
${ }^{744}$ Grundgesetz für die Bundesrepublik Deutschland, Artikel 20, 4.
}

745 Kelsen: Was ist Gerechtigkeit?, S. 35 f. 
bürgersubjekte gewesen: „Ob Staat sein soll, ist nie Gegenstand einer freien Entscheidung, sondern durch Gewalt entschieden. “746 Dass Staat überhaupt ist, fällt heute nicht negativ als Gewaltakt auf, sondern dies wird ideologisch noch unter den besonders achtenswerten historischen Errungenschaften verbucht - Errungenschaften, die notwendig gewesen seien, um allgemeines Recht und Menschlichkeit zu garantieren und damit Willkür oder Chaos zu verhindern. Die Errungenschaften der bürgerlichen Revolution sind von der akuten Permanenz der historischen Gewalt der willkürlichen Aneignung im verfassungsrechtlich verbrieften Eigentumsrecht jedoch nicht zu trennen (s.o.).

Um die perennierende Gewalt des Gewaltmonopols als wirkliche Gewalt und gesellschaftliche Herrschaft zu entlarven, müssen sich aber insbesondere die kapitalistisch organisierten Tauschverhältnisse näher angeschaut werden. Ganz rational, allgemein, notwendig und ohne sichtbaren Zwang werden in der kapitalistischen Gesellschaftsform die zur Reproduktion des Einzelnen nützlichen Dinge, als Waren und Eigentumstitel nachvollziehbar, auf dem Markt getauscht. Die allgemeine Reproduktion der bürgerlichen Gesellschaft macht sich deshalb auf der Erscheinungsebene durch die garantierten Eigentumstitel des jeweiligen Staats zunächst als eine ubiquitär Waren tauschende Gesellschaft geltend. Alles, was sich in der wertverwertenden Gesellschaft der bürgerlichen Produktionsweise verwerten will, muss deshalb die Form eines geschützten Eigentums, von Ware annehmen: „Die Ökonomie, ein rationales, über Sachen und sachliche Verhältnisse (Eigentum und Tausch) vermitteltes Machtverhältnis, erfasst alle menschlichen Beziehungen." "747 So erst werden die Dinge den Voraussetzungen des rationalen und persönlich gewaltfreien Tauschs zu ihren jeweiligen Werten gerecht. Äquivalent lässt sich ein gesellschaftliche Bedürfnisse befriedigendes Ding gegen andere Dinge auf dem Markt einzig noch als das entsprechend warenförmiges, eigentümliches tauschen. Heinrich schreibt hinsichtlich dieser gewaltlosen Ubiquität der eigentümlichen Warenbeziehungen in der bürgerlichen Gesellschaft: „In einer Gesellschaft, die auf Warentausch beruht, muss jede und jeder der Logik des Tausches folgen, wenn er oder sie überleben will.“"748

Alle zum Tausch bestimmten Waren sind geschütztes Eigentum eines Staatsbürgers bzw. einer Rechtsperson. Deshalb gilt Adorno das gewaltlose kapitalistische Tauschgesetz als die „maßgebende Struktur" "749 der bürgerlichen Gesellschaft, was allerdings nur oberflächlich richtig ist (vgl. dagegen 4.1.4). Jeder tauschbaren Ware auf dem Markt ist ein bestimmter, immer schon mit einem bestimmten Wert bezifferter Eigentumstitel immanent. Wie und warum dieser Wert des Eigentums-

\footnotetext{
746 Resultate Bd. 3: Der bürgerliche Staat, S. 17. Dass der Staat allerdings wirklich nie Gegenstand der freien Entscheidung von Subjekten war, muss historisch zumindest verneint werden. Diese Verabsolutierung ist in der Form unzulässig, denn sie lässt eine tatsächliche Naturwüchsigkeit des Staates vermuten.

747 Claussen: Vom Judenhass zum Antisemitismus, S. 91.

748 Heinrich: Kritik der politischen Ökonomie, S. 43.

749 Adorno: Zu Subjekt und Objekt, S. 745.
} 
titels überhaupt objektiv beziffert werden kann, interessiert an dieser Stelle zunächst noch nicht. Als unter die Bestimmungen der Gleichheit fallendes Subjekt, ganz gleich ob Arbeiter oder Kapitalist, hat jeder den gewaltfreien Regeln des eigentümlichen kapitalistischen Tauschs Folge zu leisten, sofern man sich in der Gesellschaft legal und problemlos reproduzieren möchte. ${ }^{750}$ Der ,Logik des Tauschs' der bedürfnisbefriedigenden Dinge als Waren/Eigentum in der bürgerlichen Gesellschaft, die allerdings ein ziemlich manifestes Verhältnis der produzierten Dinge in der bürgerlichen Gesellschaft zueinander beschreibt, muss sich jedes Subjekt unterwerfen. Die Unterwerfung ist ein nicht sichtbarer Akt der Gewalt der subjektiven Integration, wiegt dadurch aber nicht minder schwer: „Der totale [gesellschaftliche, B.E.B.] Zusammenhang hat die Gestalt", so Adorno, „daß alle dem Tauschgesetz sich unterwerfen müssen, wenn sie nicht zugrunde gehen wollen, gleichgültig, ob sie subjektiv von einem ,Profitmotiv ${ }^{`}$ geleitet werden oder nicht. “751

So kommt es aus ganz persönlichen Gründen, dem Ziel der Selbsterhaltung in der bürgerlichen Gesellschaft, zur willentlich erzwungenen Anerkennung der objektiven Instanz der eigenen materiellen Reproduktionsgarantie, dem Staat. Es kommt deshalb zur ideologischen Identifikation der die kapitalistische Produktionsweise organisierenden Herrschaft, die aus historischer Gewalt hervorging und die sich in der bürgerlichen Gesellschaft perennierend verlängert hat: „Sie können sich das vielleicht am einfachsten daran klar machen, daß sie sich vergegenwärtigen, daß ja das ganze Leben in der entfalteten bürgerlichen Gesellschaft unter dem Tauschprinzip steht und gleichzeitig unter der - und zwar den Individuen aufgezwungenen - Notwendigkeit, möglichst viel, einen möglichst großen Teil des Sozialprodukts, für sich im Kampf aller gegen alle zu ergattern." ${ }^{\text {" } 752}$ Zur Realisierung ihres Willens der Verfügung über ihre eigentümlichen Sachen benötigen die sich vergesellschaftet selbsterhaltenden Subjekte diese rechtliche Garantie als ihre jeweils individuelle Sicherheit gegen die Willkür der freiheitlichen, persönlich gewaltsamen Aneignung ihrer Reproduktionsmittel. Sie benötigen dafür eine gültige Garantie des Eigentums an ihrer Ware, so dass ihr besonderer Wille als selbstbewusstes Subjekt letztendlich im abgeschlossenen Tauschvertrag repräsentiert und auch vom anderen Subjekt als autonomer Wille anerkannt wird. Nur von einer mit legalen Kompetenzen zu zwingen ausgestatteten mächtigen Instanz, dem Staat, kann den Subjekten insofern objektiv die Garantie gegen eine persönliche Willkür der Aneignung ihrer Sachen durch Dritte gegeben werden. Als allgemeine und notwendige Instanz ist der Staat allen besonderen Staatsbürgern der bürgerlichen

\footnotetext{
750 „Die Individuen wurden in mehrfacher Hinsicht einer Vergesellschaftung unterzogen: durch die Totalität der Warenproduktion und das sie Begründende und in ihr gründende Klassenverhältnis, durch die neuen Formen der Kooperation in der großen Industrie, durch die erzwungenen neuen Lebensweisen in den Städten, die veränderten Familienstrukturen.“ (Hofmann: Anmerkungen zur klassischen Soziologie, S. 45.)

751 Adorno: Gesellschaft, S. 14.

752 Adorno: Zur Lehre von der Geschichte und von der Freiheit, S. 75.
} 
Gesellschaft übergeordnet. Er erzwingt dialektisch die Anerkennung des freien Willens eines jeden Mitglieds durch die Anderen. Mit seiner Gewalt erzwingt er insofern die Anerkennung der persönlichen Gewaltlosigkeit im intersubjektiven Verkehr: „Die legitime Gewalt des Staates unterwirft die Bürger dem Gesetz. Der Staat verschafft dem Recht Geltung und zwingt sie dadurch zur wechselseitigen Anerkennung ihres freien Willens.“753 Die objektive Machtinstanz Staat erkennt insofern die Willen der miteinander in ihrem Handeln um ihre Lebensbedingungen konkurrierenden Staatsbürger als ihren besonderen freien Willen gleich dem jedes anderen Staatsbürgers als Person an: „Weil die Mitglieder der kapitalistischen Gesellschaft in der Verfolgung ihres individuellen Nutzens die Schädigung der anderen betreiben, sind sie auf eine Macht angewiesen, die getrennt vom ökonomischen Leben die Anerkennung von Eigentum und Person garantiert. (...) [D]er Staat anerkennt die Besonderheit aller Privatpersonen, die er dem Gesetz unterwirft. “754 Um nun die eigene Schädigung bei der Verfolgung ihres individuellen Nutzens gering zu halten, müssen die Staatsbürger die Dinge deshalb als die Ihren mittels der objektiven Rechtsgrundsätze auch sichern wollen: „Das bürgerliche Recht hält die Subjekte in ihrer Konkurrenz zueinander und in ihrer Abhängigkeit voneinander. Es fördert die Verfolgung einander entgegengesetzter Partikularinteressen dadurch, daß die materiellen Bedingungen dieser Interessen vor den zerstörerischen Wirkungen regelloser Konkurrenz geschützt werden." "755 Die Bürger wollen deshalb den gegebenen allgemeinen und notwendigen Rechtsstatus als Personen gegen sich und die anderen Subjekte geltend machen können, um sich darüber ihre eigene Reproduktion in der Waren tauschenden Gesellschaft zu sichern. Nur so haben sie gegen eine womöglich vertragswidrige, willkürliche Aneignung ihrer Reproduktionsmittel oder Waren durch Dritte überhaupt etwas in der Hand. Die ökonomischen Eigentumsverhältnisse und die persönliche Gewaltlosigkeit gehen demzufolge aus ihren besonderen Willensakten als reflexive, selbstbewusste Subjekte hervor.

Das untermauert die geschichtsvergessene Wahrnehmung von der Gewaltlosigkeit in der bürgerlichen Gesellschaft. Diese Ambivalenz in der willentlichen Anerkennung von anderen Subjekten und Staat ist erst die Konsequenz aus der gesellschaftlichen Vermittlung der Interessen von Allgemeinem, Besonderem und Individuum in der postrevolutionären kapitalistischen Produktionsform. Allein der Staat bietet den einzelnen Subjekten den entsprechenden Schutz gegen die Freiheit der Willkür der beliebigen Aneignung von ihrem Eigentum durch Andere an, weswegen sie ihn um ihrer selbst Willen als die Gesellschaft regelnde Gewalt akzeptieren. So erwächst aus der Form der staatlich garantierten Eigentumstitel zu Reproduktionszwecken neben der persönlichen Gewaltlosigkeit auch der abstrakte Anspruch eines jeden Staatsbürgers auf die Anerkennung von Eigentum über-

\footnotetext{
753 Resultate Bd. 3: Der bürgerliche Staat, S. 27.

754 Ebd., S. 11 u. 22.

755 Städtler: Kant und die Aporetik, S. 183.
} 
haupt zum Zweck der eigenen Reproduktion, die wiederum allein über den staatlich erzwungenen Tausch von Dingen als Ware überhaupt realisiert wird. Die Subjekte werden nach dem qualitativen Sprung der feudalen Gesellschaftsform in die kapitalistisch organisierten Gesellschaftsform auch ,als Austauschende, daher Gleiche gesetzt." "756 Damit entsteht erst jene formelle allgemeine Konkurrenz Aller gegen Alle um die Verwertung ihrer jeweiligen Ware(n) als Eigentum. Es ist dieser formelle, jeweils die Subjekte als Gleiche allgemein in Konkurrenz setzende Zwang - der Zwang um die jeweils eigene Reproduktion unter den Voraussetzungen des allgemeinen Bezugs Aller auf das gesellschaftliche Gesamtkapital -, der sich als Rivalität oben schon zeigte und sich dort in Bezug auf das Gesamtkapital reell als ökonomische Scheinkonkurrenz der zwei Klassen gegeneinander erwies. Den Subjekten wird deshalb aus Gründen der allgemeinen, kapitalistisch organisierten Reproduktion, der daraus entstehenden Konkurrenz durch Freiheit etc., zugestanden, freiheitliche Autonomie zu realisieren. Ohne den juristischen Tauschvertrag von Eigentum als Ausdruck des gemeinsamen, freiheitlichen Willens zur Erhaltung ihres Rechts und damit den gesicherten Möglichkeiten der eigenen Reproduktion könnte der kapitalistische Tausch von Eigentum in der Zirkulationssphäre nicht stattfinden. Im objektiv garantierten (Tausch-)Vertrag realisiert sich deswegen auch, weil reproduktionsnotwendiger Wille, der ,gemeinsame Wille ${ }^{6}$ von miteinander konkurrierenden Staatsbürgersubjekten. Dieser zeigt sich als die reziproke Anerkennung von jeweils freiem Willen im Handeln auf dem Markt. Das unlängst historisch fixierte Machtgefüge der Klassen zueinander findet insofern unter der Voraussetzung der Respektierung der staatlich geschützten Eigentumstitel als kapitalistisch produzierte Waren statt, indem mittels der juristischen Verträge über den Tausch der Eigentumstitel diese als Eigentumstitel eines anderen zugleich willentlich anerkannt werden. Der Verzicht auf die persönliche Gewalt ist also ein Verzicht auf den eigenen Vorteil aus Zwang, dessen Einhalten bei der Organisation der eigenen Selbsterhaltung entscheidende Vorteile bringt: indem er das eigene, nackte Überleben garantiert. Die Anerkennung des bürgerlichen Staates ist dafür notwendig. Auch wenn dieser die persönliche Gewaltlosigkeit nur bei gleichzeitiger Realisierung von historisch gewaltsam angeeigneten materiellen Unterschieden durchsetzt und deswegen für die Verlängerung der historischen Gewalt verantwortlich ist.

\subsubsection{Kapitalistisches Eigentum ohne Staat? Gedanken zum konsequenten Liberalismus}

Wenn Dinge bzw. Waren willkürlich und durch persönliche Gewalt angeeignet würden, dann gäbe es keine rational objektiven Regeln des Tauschs von Eigentum. Die subjektive Aneignung der Dinge unterläge dann allein der freiheitlichen Willkür. Kein allgemeiner und vernünftig nachvollziehbarer, nach rationalen Re-

${ }^{756}$ Marx: Urtext ,Zur Kritik‘. 
geln der Logik ablaufender Tausch von materiellen Dingen könnte stattfinden. Das würde den kapitalistischen Tausch jedoch torpedieren. Gegen diese Form von Willkür sichert der bürgerliche Staat als objektive Instanz des herrschaftlichen Zusammenhalts den kapitalistischen Tausch mit entsprechender Gewaltkompetenz ab. Allein der staatlich garantierte Eigentumstitel an Ware ist das entscheidende Herrschaftsrecht einer juristischen Person über die eigene kapitalistische Ware oder Sache. Bloß der Eigentümer darf, vermittelt über den legalen Vertrag - und auch das Vertragsrecht ist Privatrecht, bei Hegel interessanterweise als das „abstrakte Recht“ ${ }^{\star 7757}$ bezeichnet - die Sache auf dem Markt veräußern: „Ihre an sich seiende Identität erhält Existenz durch das Übergehen des Eigentums des einen in das des anderen mit gemeinsamen Willen und Erhaltung ihres Rechts im Vertrag." ${ }^{\prime \prime} 758$

Erst der Eigentumstitel auf eine (tauschbare) Sache als Ware schließt andere Subjekte von der freien Verfügung über die juristisch gesicherte eigene dingliche Ware überhaupt aus. Dafür bedarf es noch nicht einmal des physischen Besitzes der zum Eigentum bestimmten Ware: „Der intelligible Besitz, unabhängig - und deshalb der Möglichkeit nach getrennt - vom physischen Besitz, ist der Gegenstand des von Pflicht und Gesetz bestimmten Willens, als Eigentumstitel ist er Gegenstand des Vertrags." "759 Über den intelligiblen Besitz bestimmt schon Kant die „Trennung des Titels vom Gegenstand“"760. Mit dem staatlich gesicherten Eigentumstitel lässt sich insofern also der Geistige vom unmittelbar physischen Besitz trennen. Das macht die kapitalistische Ware auch dann noch gegen andere Waren auf dem Markt austauschbar, wenn ihr Eigentümer hier nicht persönlich anwesend ist. Das deutet auf objektive staatliche Regeln des Tauschs hin, der mit denen staatlich geschützten Eigentumsrecht zweckmäßig abgesichert wird.

Es gibt allerdings liberalökonomische Konzepte, die der Auffassung widersprechen, dass der Staat die notwendige objektive Überwachungsinstanz der Regeln des Eigentumstauschs ist. Verhandelt wird in diesen, wie weit die Aufgaben und Rechte des Staats in der kapitalistischen Ökonomie überhaupt gehen sollen und müssen - und wann die bürgerliche Gesellschaft an zu viel Staat,erkranke': „Here, libertarians, past an present, have differed considerably." ${ }^{\text {"761 }}$ Der Anarchokapitalismus, dem der zitierte Rothbard angehört, ist ein derart konsequenter Liberalismus, der den Staat deshalb genau so wie dessen Regelung der Ökonomie ablehnt. Diese Denkrichtung ist deswegen so interessant, weil sich mit ihr aufzeigen lässt, wie schnell man sich doch in eklatante Widersprüche verstrickt, wenn die Autarkie des Marktes gegen das allgemeine Ordnungsmoment Staat absolut gedacht wird. Gesellschaft soll im konsequenten Liberalismus sogar noch als rein

\footnotetext{
${ }^{757}$ Hegel: Grundlinien der Philosophie des Rechts, S. 92.

${ }^{758}$ Ebd., S. 98.

759 Bulthaup: Rechtspragmatik oder von der Zwangsläufigkeit des sittlichen Verfalls der Justiz, S. 72.

760 Städtler: Kant und die Aporetik, S. 180.

${ }^{761}$ Rothbard: For a New Liberty, S. 30.
} 
privatrechtliche Einheit gedacht werden, ohne staatliche Zwangsmaßnahmen sollen Gesellschaft, Tausch, Aneignung etc. funktionieren. Als ökonomische und politische Theorie, die konsequent gegen die Herrschaft des Staats und deshalb umso mehr für den freien kapitalistischen Markt eintritt, soll der Tausch von Gütern insoweit auf freiwilligen Übereinkünften wie freiwilligen vertraglichen Bindungen beruhen. Ohne den Zwang staatlicher Institutionen soll der kapitalistische Tausch der Waren ein Resultat der selbstbestimmten Willkür des selbstbewussten Subjekts sein. Die Selbstbestimmung des Individuums wird hier insofern radikal gegen den herrschenden bürgerlichen Staat gedacht, was den Anarchokapitalismus an dieser Stelle entsprechend auf eine Stufenleiter mit anarchistischen Überlegungen, vorwiegend den Kropotkinschen Überlegungen zur individualistischen Freiheit gegen den staatlichen Zwang und für die freiheitliche Kooperation, in Einklang bringt. ${ }^{72}$ Der Anarchokapitalismus ist eine Variante des Anarchismus: „Anarchistische Denker“ machen, so Salzborn, „mit der liberalen Staatsfeindlichkeit ernst ${ }^{6763.764}$ Der Anarchokapitalismus übernimmt den anarchistischen Ruf nach freiheitlicher Staatslosigkeit, die er allerdings auf eine ökonomisch völlig freiheitliche Aneignung des Eigentums Dritter ohne jegliche staatliche Eingriffe bezieht. Der Anarchokapitalismus emanzipiert sich demnach vom ideellen Kopf der gesellschaftlichen Produktionsform, indem er dessen Herrschaftsrecht und Kompetenz bezüglich der kapitalistischen Ökonomie offen in Frage stellt. Die akephale Gesellschaft des Anarchokapitalismus soll mit einer uneingeschränkten Marktfreiheit realisiert werden. Jene sei der Ausdruck von subjektiver, menschlicher Freiheit überhaupt, von der die Gesellschaft dann auch den größten Nutzen hätte: „Anarcho-capitalism is a form of anarchism whose prime tenet is that the free market, unhampered by government intervention, can coordinate all the functions of society currently carried out by the state, including systems of justice and

\footnotetext{
762 Vgl. Kropotkin: Gegenseitige Hilfe in der Tier- und Menschenwelt, S. 219 ff. Alle von Kropotkin angeführten Beispiele für angeblich schon realisierte freie Kooperationen bleiben auf eine ökonomische Zweckmäßigkeit innerhalb der kapitalistischen Produktionsweise (die Fröbelvereine mit seiner Einführung des Kindergartens, Alpenvereine, Kegelbrüder, Jagdschutzvereine etc.), bezogen. Das macht das gesamte Buch zu einem starken Glaubensbekenntnis an eine bessere Welt, nicht aber zu einer wissenschaftlich starken Auseinandersetzung mit dem ausgemachten Aggressor Staat, der die Natur des Menschen unterdrücke.

763 Salzborn: Kampf der Ideen, S. 61.

${ }^{764}$ Was allen Anarchisten auch gemeinsam ist, ist dass sie alle die kapitalistische Ökonomie und ihre zweckmäßige Organisation nicht reflektieren. Deshalb z.B. attakiert Bakunin die gesellschaftliche Herrschaft, die er allein klassenbezogen in der Bourgeoisie sieht, so scharf. Er reflektiert die gesellschaftliche Herrschaft nicht als in der gesellschaftlichen Totalität liegende, von der sich kein Subjekt in seinem Handeln wirklich freimachen kann, sondern macht dabei einzelnen Subjekten kleinbürgerliche Vorwürfe: „Man muß wirklich sehr naiv sein, um zu glauben, ein bürgerliches Parlament könne aus freien Stücken für eine geistige, materielle und politische Befreiung des Volkes [sic!] stimmen. Hat man jemals in der Geschichte gesehen, daß eine politische Körperschaft, eine bevorrechtete Klasse [sic!], sich aus Liebe zur Gerechtigkeit und zum Menschentum [sic!] aufgegeben und das Geringste von ihren Interessen und so genannten Rechten geopfert hat?" (Bakunin: Gott und der Staat, S. 122.) Auch Bakunin identifiziert Bourgeoisie mit Staat.
} 
national defense [sic!]. Anarcho-capitalists believe that a system of private property based on individual rights is the only moral system - a system that implies a free

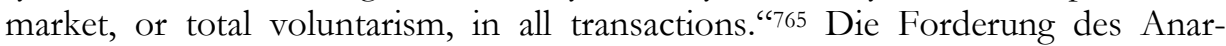
chokapitalismus nach dem subjektiv willkürlichen Tausch ohne staatliche Spielregeln fordert dabei nun genau das positiv ein, was sich negativ beispielsweise in Jürgen Trittins Äußerungen von der, Anarchie des Marktes ${ }^{6766}$ als angeblich bereits existentem Element der kapitalistischen Gesellschaft zeigt: die objektiv unkontrollierte Aneignung fremder Waren durch Dritte. Gegen Trittin sieht der Anarchokapitalismus allerdings tatsächliche Beschränkungen und Auflagen gegen Kapital und Subjekt durch den Staat. Der auch fremdes Eigentum schützende und Steuern eintreibende bürgerliche Staat betreibt nach Rothbard deshalb eins: „forcible theft" ${ }^{\text {" } 767}$.

Aller Kritik am Staat zum Trotz offenbart die anarchokapitalistische Forderung nach uneingeschränkter Marktfreiheit einen recht paradoxen, positiven Bezug auf das vom bürgerlichen Staat durchgesetzte Rechts- und Ordnungsprinzip. Die gegenseitige Respektierung von den vorausgesetzten bürgerlichen Grundfreiheiten wird durch den Anarchokapitalismus einfach mal unterstellt. ${ }^{768}$ Positiv bezieht er sich auf die vom bürgerlichen Staat objektiv mit Gewalt geschützten Titel wie ,private property ${ }^{6}$ und ,individual rights', die er dabei jedoch von ihrer objektiven Schutzinstanz bürgerlicher Staat einfach abstrakt löst. Die staatlichgesetzlichen Mittel zur Regelung des reziproken Tauschs des Eigentums affirmiert der Anarchokapitalismus deshalb, und er übernimmt das Ordnungsprinzip der bürgerlichen Gesellschaft und ihrer kapitalistischen Produktionsweise gar nicht so freigeistig als adäquates Mittel zum Zweck des Warentauschs. ${ }^{769}$ Durch die von ihm kritisierten staatlichen Eingriffe in den freien Tausch über den Eigentumstitel kann die Freiheit des Tauschs der Waren jedoch generell erst nach objektiv gesicherten, individual rights' und ,private properties' gegen jede Willkür stattfinden. Der Anarchokapitalismus muss demnach weiterhin, weil auch er weiterhin den kapitalistischen Warentausch voraussetzt, auf die entscheidende conditio sine qua non der bürgerlichen Gesellschaft setzen, weil ohne die Prinzipien der bürgerlichen Gesellschaft die Voraussetzungen des Kapitalismus wie das Eigentumsverhältnis obsolet würden. Den bürgerlichen Staat aber, der von bürgerlichen Gesellschaft nicht undialektisch zu trennen ist, will er dabei nicht als das objektive Instrument der Bedingung der aktiven Durchsetzung von Bürger- und Eigentumsrechten akzeptieren.

\footnotetext{
765 Brown: The Free Market as Salvation from Government, S. 99 (zitiert nach wikiquote.org: Anarcho-capitalism.).

${ }^{766}$ Jürgen Trittin unterstellt in der Rede die ungesetzliche, gewaltsame Anarchie des ,Marktes` - was immer ,der Markt' vom Kapitalismus unterschiedenes sein soll (Trittin: Finanzmarkt.)

${ }^{767}$ Rothbard: For a New Liberty, S. 29.

768 Vgl. Rothbard: Law, Property Rights, and Air Pollution.

${ }^{769}$ Vgl. Rothbard: For a New Liberty, S. 30 ff.
} 
Deswegen greift Rothbard dann auch auf angeblich natürliche Regelungen des Austauschs von Eigentum aus naturrechtlichen Bestimmungen zurück, die jenem unnatürlichen, dem unbedingt freien Subjekt oktroyierten Gebilde Staat scheinbar entgegenstünden. Rothbard ist davon überzeugt, dass die Freiheit des Marktes und der Austausch von Waren ohne staatlichen Zwang möglich ist, weil ja das Individuum den eigentümlichen Warenaustausch auch ,natürlich' vollziehen würde: „That prime reason is moral and is rooted in the natural-rights defense of private property ${ }^{4770}$. Der Anarchokapitalismus sieht dabei zwar, wie schon Hegel ${ }^{771}$, dass es den regellosen Austausch gar nicht geben kann. Er legt den kapitalistischen Austausch und seine Regeln jedoch anthropologisch in die Natur des Menschen, wodurch er den durch den Staat geschützten Warenverkehr als ein menschliches Bedürfnis anthropologisiert. Diesen dadurch immanenten Widerspruch von Freiheit und Ordnung formuliert Salzborn schon hinsichtlich des Anarchismus: „Gustav Landauer (...) mit seiner bündisch-romantischen Gemeinschafts- und Gemeinwesenorientierung, die als Regulativ gegenüber einer vollständigen Anarchie fungieren sollte, zeigte aber auch, dass in anarchistischen Vorstellungen nicht nur eine radikale Staatsablehnung, sondern auch ein liberalen Ansätzen angenäherter instrumenteller Ordnungsbegriff formuliert wurde." ${ }^{\text {"772 }}$ Anarchistische und anarchokapitalistische Konzepte der Staatsablehnung behalten insofern prinzipielle und in ihren gesellschaftlichen Zwecken unreflektierten Ordnungsmomente der kapitalistischen Produktionsform bei, die sie dann aber mittels einer Anthropologisierung zu verstecken versuchen. Beide Positionen nähern sich damit auch durch ihre unreflektierte Übernahme von Herrschaftsmomenten einander prinzipiell an. Wie der Anarchismus votiert deshalb auch der Anarchokapitalismus unbewusst und in Form einer „Realumkehr" ${ }^{\text {‘73 }}$ für eine privatisierte, inoffizielle Herrschaft: „Der Liberalismus proklamiert die faktische Machtausübung in der Anarchie des Marktes, der Anarchismus die informelle Herrschaft der deregulierten Bünde und Räte." "774

Die anarchistische Rebellion gegen den Staat ist somit unbewusst oder versteckt doch nur eine Affirmation seiner Ordnungsprinzipien, deren objektiver Absicherung man sich nicht entledigen kann, wenn man, wie vor allem der Anar-

\footnotetext{
770 Vgl. ebd., S. 48.

771 Mit Hegel kann von einer solchen wirklich schrankenlosen ,absoluten Freiheit“ (Hegel: Phänomenologie des Geistes, S. 431) bezüglich des Kapitalismus, ohne die passive objektive Instanz Staat, der in den Produktionsprozess zumindest noch passiv über Recht und Gesetz eingreift, nicht gesprochen werden. Die vom Anarchokapitalismus verabsolutierte Freiheit der Willkür ohne ordnende praktische Eingriffe der objektiv staatlichen Instanz ist für Hegel nichts weiter als ein chaotischer „Schrecken“ (Ebd.) und die totale Willkür bei Vertragsverhandlungen ohne parteiinteressenlose Staatlichkeit die „sich selbst zerstörende Wirklichkeit“ (Ebd., S. 441). Eine solche Freiheit der Willkür würden Vertreter des liberalistischen Anarchokapitalismus mit ihrem Interesse am Weiterleben der kapitalistischen Ökonomie nicht wollen können.

772 Salzborn: Kampf der Ideen, S. 61.

773 Ebd., S. 62.

${ }^{774}$ Ebd., S. 62 f.
} 
chokapitalismus, die kapitalistische Gesellschaftsform weiterhin aufrechterhalten will. Eine völlige Vertragsfreiheit würde beispielsweise nicht gerade zum ,sozialen Frieden' beitragen; und letzten Endes auch den Kapitalismus zerstören: „Schrankenlose Vertragsfreiheit zerstört sich selbst. Eine fürchterliche Waffe in der Hand des Starken, ein stumpfes Werkzeug in der Hand des Schwachen, wird sie zum Mittel der Unterdrückung des Einen durch den Anderen, der schonungslosen Ausbeutung geistiger und wirtschaftlicher Übermacht.“"775 Keine objektive Instanz der Rechtssicherheit und Vertragssicherheit könnte unter den Voraussetzungen der völligen Vertragsfreiheit dem Kapitalisten noch garantieren, dass ihm sein Eigentum nicht doch einmal gewaltsam enteignet wird; und auch keine objektive Instanz könnte dem Kapitalisten garantieren, dass die Arbeiterklasse über allgemeine Arbeitsschutzgesetze ausbeutbar bleibt.

Um den Kapitalismus auf seinem Staatsgebiet gewährleisten zu können, greift der bürgerliche Staat über die Exekutive immer auch aktiv in die Ökonomie ein. Er setzt sich dabei auch mit Gewalt gegen jene Staatsbürgersubjekte durch, die den allgemeinen Regeln des reziproken Tauschs zu ihrem eigenen Vorteil widersprechen und den Willen des Anderen missachten. ${ }^{776}$ Jene disziplinierende Gewalt des Staates spiegelt sich bei Foucault in dem, vor allem in Überwachen und Strafen entwickelten, Begriff der Disziplinargesellschaft wider. ${ }^{777}$ Mithilfe eines Abstraktionsprozesses wäre zwar denkbar - wie beim anarchokapitalistischen Vordenker de Molinari ${ }^{778}$ ausgeführt - dass alle grundlegenden objektiven und allgemeinen Prinzipien eines Nationalstaats einfach privatisiert werden und es deshalb den Staat und seine objektive Gewalt nicht mehr braucht. Dafür müsste man diese nicht objektiv interessierten Gewaltinstanzen des bürgerlichen Staates wie Polizei und Staatsanwaltschaft selbstbezogen arbeitenden Dienstleistern in die Hand geben: „Aus welchem besonderen Grund kann die Sicherheitsproduktion nicht dem freien Wettbewerb ausgesetzt werden?“779 $\mathrm{Da}$ die Gesellschaft wie bei Rothbard auch bei de Molinari auf einem Naturgesetz beruht ${ }^{780}$, das der Staat als Institution künstlich behindere, und es eigentlich keines Zwangs bedarf, Gesellschaft zu organisieren, sich also alles wie durch die Smithsche invisible Hand ${ }^{711}$ ordne, dürfe es

775 Wesel: Geschichte des Rechts in Europa, S. 487. Das allein wäre zunächst kein Kriterium für die Abschaffung einer unbedingten Vertragsfreiheit. Weil aber der totale Staat ein totaler ist, hat er an der Arbeiterklasse als Arbeiterklasse auch ein eigenes Interesse. Physische Schranken stehen der Ausbeutung der Arbeiterklasse im Hinblick auf deren grenzenlose Ausbeutungsfähigkeit zu Ungunsten der allgemeinen gesellschaftlichen Reproduktion entgegen.

776 „Insofern sich der Staat in all seinen Handlungen dem von ihm selbst gesetzten Recht unterwirft, sich als Rechtssubjekt beurteilt, wenn er seine Gesetze erläßt (Legislative), Recht spricht (Judikative) und ausführt (Exekutive), eröffnet sich der gewaltige Nutzen der wechselseitigen Kontrolle der Staatsgewalten: Ideologie der Gewaltenteilung." (Resultate Bd. 3: Der bürgerliche Staat, S. 31.)

777 Vgl. Foucault: Überwachen und Strafen.

778 Vgl. de Molinari: Produktion der Sicherheit.

779 Ebd., S. 18.

${ }^{780}$ Vgl. ebd., S. 14 f.

${ }^{781}$ Vgl. Smith: Der Wohlstand der Nationen. 
auch bezüglich der Sicherheitsfragen keine Ausnahmen von dieser Regel geben: „Ein Naturgesetz gilt überall und immer, oder es gilt nicht.“" ${ }^{\text {" } 82}$ Trotzdem spielt de Molinari dann doch, recht inkonsequent, Ausnahmen von seiner Regel durch. Garantiert werden soll die gegenwärtig durch den bürgerlichen Staat garantierte Sicherheit dann, falls es doch einmal gegen die naturgesetzlichen Bestimmungen laufe, durch die jeweiligen privaten Produzenten. Der jeweilige Produzent soll in seinem jeweiligen Zuständigkeitsbereich ,gewisse Strafen gegen Körperverletzung und den Raub von Eigentum“"783 einführen können und „die Konsumenten es akzeptieren, sich diesen Strafen zu unterwerfen, falls sie sich selbst an Personen oder Eigentum vergehen." ${ }^{\text {"784 }}$ So sollen die Produzenten bzw. die Kapitalisten Auftraggeber eines privaten, nur für sie arbeitenden Sicherheitsdienstes werden, den de Molinari dann allerdings, wiederum recht ambivalent, als „Polizei“ ${ }^{\text {‘785 be- }}$ zeichnet. Die einzelnen Produzenten sollen mit ihren jeweils verschiedenen Sicherheitskonzepten zudem auch noch um die „Konsumenten“786 werbend konkurrieren. Diese Konkurrenz der Produzenten in Sicherheitsfragen würde sich entsprechend ausgleichen und deshalb auch nicht zu einer Machtkonzentration eines Produzenten führen, weil insgesamt ,ein dauernder Wettstreit“ ${ }^{6787}$ herrsche, der die Produzenten beständig zwinge, mit besseren bzw. angenehmeren Sicherheitskonzepten an die ,Konsumenten' heranzutreten. ${ }^{788}$

Diese naturgesetzliche Überlegung der Selbstregulierung kann jedoch in der Praxis, die dem kapitalistischen Gesetz der historisch initiierten Konkurrenz unterliegt, nicht wirklich funktionieren. Wenn keine objektive und damit subjektivinteresselose Instanz die Vergabe und die Einhaltung von objektiven Regeln zum Zweck kapitalistischer Produktion tätigen würde, ginge auch die vermeintlich naturgesetzliche Selbstregulierung nicht mehr auf. Die freiheitlichen Abstraktionen des Anarchokapitalismus von jedem Erfahrungsmaterial drücken nun zwar sehr wohl eine Autonomie des Denkens gegenüber allen objektiven Schranken des Bewusstseins aus. Doch diese Abstraktionen vom Wesentlichen gehen hier so weit, dass die reflektierende Vernunft auf keiner wirklichkeitsbezogenen Rationalität mehr fußt und der Anarchokapitalismus mit keinem Existenzialurteil die adäquate Beziehung der Reflexion auf irgendein materiales Gehalt beweisen könnte. Die Reflexionsleistung geht deshalb so weit über das materielle Erfahrungsmaterial hinaus, dass die Begriffe anfangen zu schillern. Die gesellschaftliche Totalität der bürgerlichen Gesellschaft, ihre Produktionsweise insbesondere, wird über die Anthropologisierung abstrakt negiert. Eine vollkommene Privatisierung des Si-

\footnotetext{
782 de Molinari: Produktion der Sicherheit, S. 19.

${ }^{783}$ Ebd., S. 41.

784 Ebd.

${ }^{785}$ Ebd., S. 42.

786 Ebd.

${ }^{787}$ Ebd., S. 43.

788 Vgl. ebd.
} 
cherheitssektors erweist sich insofern sowohl praktisch wie rational als undurchführbar. 789

\subsubsection{Entfremdung: Das Resultat des abstrahierenden Eigentumstitels}

„Die Eigentumslosigkeit des Arbeiters und das Eigentum der vergegenständlichten Arbeit an der lebendigen oder die Aneignung fremder Arbeit durch das Kapital - beides nur auf zwei entgegengesetzten Polen dasselbe Verhältnis ausdrückend - sind Grundbedingungen der bürgerlichen Produktionsweise, keineswegs ihr gleichgültige Zufälle. ${ }^{\text {‘790 }}$

Verfolgt man den Entfremdungsbegriff bis in die Anfänge seiner philosophiegeschichtlichen Rezeption, stößt man mit ihm sowohl auf Versuche der Darstellung eines etwas veräußernden Subjekts als auch die Veräußerung des Subjekts von sich selbst: „Der Begriff lässt sich bis auf ARISTOTELES ( $\alpha \lambda \lambda \alpha \gamma \eta$ Tausch), SENECA, CICERO und AUGUSTINUS (alienato) zurückverfolgen, bei denen mit E[ntfremdung] entweder ökonomisch-juristische Vorgänge der Übertragung bzw. Veräußerung von Eigentum oder Zustände geistiger Entrückung und Verwirrung sowie Geisteskrankheit genannt werden. “791

Auch der objektive Idealist Hegel arbeitet mit dem Entfremdungsbegriff: Als bereits nominalistisch geprägter Philosoph fasst er unter Entfremdung die (Selbst-)Entäußerung des Geistes, die Entäußerung des Selbstbewusstseins des Weltgeistes in die Welt. Der durch einzelne Subjekte agierende Geist werde sich demnach selbst fremd, um dann um eine (letztendlich tautologische, vgl. 2.4.1 und 2.4.2) Selbsterfahrung des Anderen reicher wieder zurück zu sich selbst zu kommen. ${ }^{792}$ In einer nur vermeintlichen Anlehnung an Hegel wird Entfremdung dann oftmals als bloße Selbstentfremdung des einzelnen Subjekts von sich selbst, eben nicht einmal des Hegelschen absoluten Subjekts der selbstentfremdenden Entsubstanzialisierung (wie in 2.4.1 und 2.4.2 beschrieben), im kapitalistischen, monotonen Arbeitsprozess interpretiert. Weil das einzelne Subjekt also nicht selbstbestimmt und sich selbstverwirklichend in den Arbeitsprozess integriert sei, sondern nur monoton und ziellos für andere arbeite, sei es im Kapitalismus deshalb vom

\footnotetext{
${ }^{789}$ Die private Söldnertruppe Blackwater, heute Academi, ist ohne US-amerikanischen Staat und dessen Interessen undenkbar. Die privat geführte Organisation wird insbesondere zur Entlastung des Staatshaushalts in Krisengebieten eingesetzt; sei es außenpolitisch nach dem Irakkrieg oder innenpolitisch nach dem Hurricane Katrina in New Orleans. Es ist ein rationales, zielführendes Unterfangen, Gelder für militärische Auslandseinsätze im Haushaltsbericht gering zu rechnen. (Vgl. Scahill: Blackwater.) Scahill beleuchtet eindrucksvoll in The Nation die innenpolitische Bedeutung Blackwaters nach dem Hurricane Katrina in New Orleans (thenation.com: In the (Black)water.)

790 Marx: Grundrisse der Kritik der politischen Ökonomie, S. 723.

${ }^{791}$ Historisch-Kritisches Wörterbuch des Marxismus, Bd. 3, S. 459.

${ }^{792}$ Hegel: Phänomenologie des Geistes, S. 359 ff.
} 
eigentlichen menschlichen Gattungsleben, was immer das sein soll, entfremdet ${ }^{793}$ : „Die schöpferische Arbeit ist entfremdet [!], der Mensch erkennt sich nicht in seinem eigenen Produkt, und all seine zermürbende Mühsal erscheint ihm wie [sic!] eine feindliche Gewalt."“794 Oder als eine weiter gefasste Variante der Hegelschen Entfremdung: Durch die moderne Gesellschaft und ihre ganzen Anforderungen, die sie inzwischen an das einzelne Subjekt stelle, sei es inzwischen von sich selbst und seinem eigentlichen Gattungsleben entfremdet. ${ }^{795}$ Das entspricht dem Durkheimschen Begriff der Anomie ${ }^{796}$ oder der Simmelschen Differenzierung ${ }^{797}$.

Dass die manufakturperiodisch bedingte Arbeitsteilung im modernen Arbeitsprozess für die Entfremdung des Subjekts von den eigens hergestellten Dingen verantwortlich ist, unterstellt auch Marx noch in seinen junghegelianischen Frühschriften: „In seinem Frühwerk sah Marx die Entfremdung noch als Entfremdung

793 Vor allem in der Theologie beschäftigt man sich mit dem Entfremdungsbegriff. Vgl. beispielsweise Kreutzer: Arbeit und Muße, S. 23: „Viele Symptome des Leidens unter Arbeit werden mit einem von Karl Marx profilierten Begriff als Entfremdung bezeichnet. Entfremdung meint die genaue Kehrseite der Selbstverwirklichung durch Arbeit [sic!]. Entfremdete Arbeit ist durch schlechte Arbeitsbedingungen [sic!] vorenthaltenes Menschsein, ist verhinderte Selbstverwirklichung in der Berufsarbeit [sic!]. Solche Entfremdungssymptome sind zum Beispiel die Monotonie automatisierter Tätigkeiten, die Entfremdung vom Produkt der eigenen Arbeit, die fehlende Zeitsouveränität, mangelnde soziale Integration [sic!] am Arbeitsplatz. Wird Arbeit jedoch theologisch und ethisch als Erfüllung des Menschseins begriffen, wie dies bei Sölle und Johannes Paul II. geschieht, dann muss sich gegen diese Entfremdungsmechanismen theologischer Einspruch erheben." Das ist entweder ein sehr unglücklicher oder aber gerade geschickter Versuch Kreutzers, die Marxsche Position der Frühschriften auf eine Versöhnung mit ,richtig gemachter ' bürgerlicher Gesellschaft zu bringen. Dies Versöhnungsmoment wird jedoch selbst dem noch idealistischen Marx der Frühschriften nicht gerecht. Auch in der Kritischen Theorie kommt es zu problematischen Interpretationen einer Entfremdung vom Gattungsleben. So erfordere „die moderne Vergesellschaftung die totale Anpassung des Subjekts unter die Ideologie der Selbsterhaltung. [...] Alles wird austauschbar und erhält Warencharakter. Was scheinbar keinen Wert mehr hat, fällt heraus. Auch die sozialen Beziehungen werden verdinglicht. Das bürgerliche Subjekt verliert seine Autonomie.“ Jaecker: Politische Psychologie des Antisemitismus.). Was eine Paraphrase der Position Adornos sein soll, ist aus zwei Gründen problematisch. Zum einen wird die Existenz einer (womöglich vorbürgerlichen) Gesellschaft unterstellt, in der Subjekte wirklich autonome Subjekte ohne jegliche Heteronomie entweder waren oder es sein können (Vgl. hierzu zum Problem des hölderlinschen Romantizismus Unterabschnitt 2.4.5); zum anderen wird proklamiert, dass allein der gesellschaftliche Warencharakter an der Verdinglichung/Entfremdung des Subjekts schuld sei. Keine Rede ist von Geschichte, gesellschaftlicher Herrschaft, Kapitalismus oder Gewalt.

${ }^{794}$ Sartre: Marxismus und Existentialismus, S. 15.

${ }^{795}$ Vgl. z.B. Alfred A. Oppolzer, der schreibt, dass der Mensch ,von den anderen Menschen und von der menschlichen Gattung“" entfremdet sei. (Oppolzer: Entfremdung und Industriearbeit, S. 69.) ${ }^{796}$ Das Konzept der Anomie soll alle impacts der modernen Gesellschaft auf das Subjekt einbeziehen. Es beschreibt die erzwungene Integration in den gesellschaftlichen Zusammenhang, der die Subjekte auf der Strecke bleiben lässt: „Diesem Konzept der Anomie liegt die Vorstellung zugrunde, daß das menschliche Zusammenleben in der Gesellschaft nur dann funktionieren kann, wenn menschliche Bedürfnisse, Wünsche und Hoffnungen im Zaum gehalten werden.“ (Ludz: Ideologiebegriff und marxistische Theorie, S. 61.) Auch Ëmile Durkheim spricht von der durch die Arbeitsteilung bedingten Entfremdung, so in: Über die Teilung der sozialen Arbeit.

${ }^{797}$ Simmel: Aufsätze 1887-1890. 
des Menschen von seinem Gattungsleben.“798 Diese junghegelianische Interpretation lässt sich auch noch heute finden. Auf den modernen Produktionsprozess als Resultat der Entfremdung schauen theoretische Versuche, die die Entfremdung in der bürgerlichen Gesellschaft anhand der Hegelschen Herrschafts-KnechtschaftsDialektik untersuchen ${ }^{799}$ : kein Subjekt arbeite heute für sich selbstbestimmt, weil kein Subjekt die jeweiligen Dinge zu seiner eigenen Reproduktion herstelle. Der Kapitalist lasse selbstentfremdet in den Naturzusammenhang eingreifen, der Arbeiter greife nur vermittelt für diesen in ihn ein, weshalb er die hergestellten Produkte hinterher nicht für sich hat. Der Kapitalist jedoch kann die Produkte nicht selbstständig herstellen, was ihn in eine Abhängigkeit des für ihn produzierenden Arbeiters bringe. Ohne Arbeiter sei der Kapitalist insofern nichts.

Die Anspielungen auf Hegels Herrschaft-Knechtschaft-Dialektik sind dabei so offensichtlich wie problematisch, denn sie sind anachronistisch aus der Warte der kapitalistischen Gesellschaft gemacht, quasi ex post. Übersehen wird dabei, dass der Herr bei Hegel noch recht unvermittelt und unversöhnt die vom Knecht bearbeiteten Dinge der Natur „rein “800 genießt. Das trennt jenen qualitativ vom Kapitalisten, wie mit der Konkurrenz der Produktionsmitteleigentümer untereinander deutlich wurde (vgl. 2.6.3). Der Versuch, mit einer HerrschaftsKnechtschafts-Dialektik Hegels die Entfremdung in der modernen bürgerlichen Gesellschaft zu kritisieren ist insofern nicht nur anachronistisch, sondern obsolet. Dieser Versuch hat aber doch den Vorteil, recht nah an einer juristischökonomischen Kritik der allgemeinen Entfremdung zu sein, die hier in dieser Untersuchung zum Gegenstand wird. Der komplexe Zusammenhang des Entfremdungsbegriffs mit der totalen bürgerlichen Gesellschaft darf nicht übersehen werden.

Auch wertkritische, sich an Marx orientierende Arbeiten übernehmen die These des expliziten Mangels an subjektiver Selbstverwirklichung im inzwischen kapitalistischen Arbeits- und Verwertungsprozess. Dieser Mangel sei demnach das Resultat eines Zwangs der anonymen Anforderungen der kapitalistischen Gesellschaft und ihrer Warenproduktion, der heute für alle selbstbewussten Subjekte ausnahmslos gelte. Die Entfremdung werde deshalb zu einem die antagonistischen Klassen übergreifenden Moment der bürgerlichen Produktionsweise. ${ }^{801}$ Ein Autor, der die These des durch die moderne Warenbeziehung entfremdeten Subjekts

\footnotetext{
${ }^{798}$ Grigat: Fetisch und Freiheit, S. 69. Siehe auch Marx: Die deutsche Ideologie, S. 69.

${ }^{799}$ Vgl. Sayers: Marx und Entfremdung. Vgl. z.B. auch Negt: Lebendige Arbeit, enteignete Zeit. Oskar Negt beschreibt den Kampf um freie Zeit für die Arbeiter, die auch den „Unternehmern“ (bspw. S. 35) helfe. Aufgestellt wird ein Konzept gegenseitiger Anerkennung und ,Wertschätzung،, was sehr an Hegels Anerkennungskapitel aus der Phänomenologie erinnert. Diese versöhnlichen Töne von Anerkennung, Sozialpartnerschaft etc. sind auch bei Gewerkschaften und SPD zu finden. ${ }^{800}$ Hegel: Phänomenologie des Geistes, S. 151.

801 So auch im Begriff der „,autonome[n] Entfremdung“ in Hardt/Negri: Empire, S. 38. Vgl. zur sich an Marx orientierenden Bestimmung von Entfremdung durch Warenform auch Pfreundschuh: Entfremdung.
} 
zuerst formuliert, ist Georg Lukács: „Gerade weil in ihnen die in der unmittelbaren Warenbeziehung verborgenen Beziehungen der Menschen zueinander und zu den wirklichen Objekten ihrer realen Bedürfnisbefriedigung zur vollen Unwahrnehmbarkeit und Unkenntlichkeit verblassen, müssen sie für das verdinglichte Bewußtsein zu den wahren Repräsentanten seines gesellschaftlichen Lebens werden.“" 802 Es ist jedoch, anders als bei Lukács und den Wertkritikern, nicht die Warenförmigkeit der im Arbeitsprozess eigens hergestellten Produkte, die das Bewusstsein des lohnarbeitenden Subjekts von diesen oder auch die Menschen in ihren Beziehungen voneinander entfremdet ${ }^{803}$, sondern das lohnarbeitende Subjekt wird von den eigens im Produktionsprozess hergestellten Dingen juristisch entfremdet. Das Subjekt wird in der bürgerlichen, kapitalistischen Gesellschaft genötigt, ihm fremde Waren mit ihm juristisch fremden, eigentumstechnisch fremden Produktionsmitteln zu produzieren. Die in der bürgerlichen Gesellschaft zum Zwecke des Tauschs produzierte Ware bleibt deshalb immer Eigentum des Eigentümers der Produktionsmittel, selbst wenn der unmittelbare Produzent ihr Besitzer ist. Juristisch muss der unmittelbare Produzent der Ware nicht ihr Eigentümer sein, selbst wenn er es in Ausnahmefällen sein kann. Für den an Produktionsmitteln eigentumslosen unmittelbaren Produzenten der Sache wird das Produkt seiner eigenen Arbeit als Mittel zum Zweck seiner eigenen Reproduktion, vermittelt über das ihn der Sache der eigenen Arbeit entfremdende Eigentumsrecht, deshalb zu einem ihm juristisch völlig fremden Gegenstand. Über die formelle, allgemeine Rechtsform der bürgerlichen Gesellschaft ist und bleibt jedes hergestellte Ding deshalb, trotz der aktiven oder passiven Veränderung des Materials durch einen unmittelbaren Produzenten, weiterhin juristisches Eigentum des gesetzmäßigen Eigentümers der Produktionsmittel der Ware. Das entfremdet den tätigen Hersteller also ganz legal von den eigens hergestellten Produkten. Das durch den Produzenten hergestellte Produkt bleibt deswegen juristisch auch immer Eigentum eines Anderen, der es selbst nicht tätig hergestellt hat. Der unmittelbare Produzent der Dinge bleibt verlängert an den eigens hergestellten Dingen entrechtet. Vom Ausdruck des gesellschaftlichen Reichtums, der Ware, bleiben die unmittelbaren Produzenten insofern juristisch entfremdet. ${ }^{804}$ Aufgrund der Trennung von physischem Besitz und Eigentum hat der unmittelbare Produzent also

\footnotetext{
802 Lukács: Geschichte und Klassenbewußtsein, S. 184.

803 „Im Arbeitsprozess bedeutet dies eine immer stärkere Ausschaltung der qualitativen, menschlichindividuellen Eigenschaften der Arbeitenden durch Zerlegung des Arbeitsprozesses, Objektivierung des Arbeitspensums, sogar eine Objektivierung von für die Produktion nützlichen psychologischen Eigenschaften gegenüber der Gesamtpersönlichkeit.“ (Brunner: Entfremdete Menschen, verdinglichte Verhältnisse.)

804 „Dabei wird die Art der Verfügungsrechte über ein Gut in vier Einzelrechte unterteilt: (1) Die Nutzung des Gutes (usus), (2) das Recht der Veränderung des Gutes, in Form und Substanz (abusus), (3) das Recht, die entstehenden Gewinne einzubehalten bzw. die Verluste zu tragen (usus fructus), (4) das Recht, das Gut zu veräußern und den Liquidationserlös zu vereinnahmen (ius abutendi).“ (wirtschaftslexikon24.com: Property Rights.)
} 
keinerlei Verwendungsrecht am hergestellten Gegenstand, weil er vermittels der herrschenden Gesetze keine Rechte an den von ihm erzeugten Dingen und den für deren Herstellung benutzten Materialien hat. Diese innergesellschaftlich prozessierende ,Automatik' des Entfremdungsprozesses beschreibt Marx in Lohnarbeit und Kapital: „Das Kapital setzt also die Lohnarbeit, die Lohnarbeit setzt das Kapital voraus. Sie bedingen sich wechselseitig; sie bringen sich wechselseitig hervor." “805

Die dafür vorausgesetzte bürgerlich-rechtliche Dimension hinsichtlich der Entfremdung, und damit die juristische Ökonomisierung des Entfremdungsbegriffs, reflektiert Marx dann spätestens im Kapital. Diese Reflexionen sind implizit auch gegen seine Versuche in den Frühschriften zu lesen, in denen die Entfremdung ja tatsächlich noch als eine Entfremdung des Subjekts vom Gattungsleben bestimmt wird. Im Kapital heißt es dagegen: „Das Produkt ist Eigentum des Kapitalisten, nicht des unmittelbaren Produzenten. “806 Marx kann deshalb nicht als der Philosoph der Entfremdung des Subjekts von sich selbst und seines Gattungswesens als Resultat manufaktureller Arbeitsteilung gelten. ${ }^{807}$ Die Entfremdung bekommt auch für ihn die wesentlich juristisch-ökonomische Dimension, die nur noch über den juristischen Eigentumsbegriff zu denken ist. Sie ist insofern kein Resultat des hinter den Möglichkeiten der modernen Produktion zurückgebliebenen menschlichen Bewusstseins und der daraus resultierenden Entfremdung von seinem Gattungsleben mehr. Im Kapital liegt die Entfremdung darum in der formellen, von jedem Inhalt abstrahierenden Sphäre des dem Subjekt transzendent seienden Rechts begründet - und nicht im falschen Handeln der Menschen in Gesellschaft, das ihr Bewusstsein für die sie umgebende Realität verschwinden lässt. Nach dem Produktionsprozess ist formell-juristisch auch immer, nicht nur für Marx, sondern auch für das bürgerliche Recht, vor dem Produktionsprozess. Der Entfremdungsbegriff bekommt deshalb seine entscheidend juristischökonomische Qualität. Die Entfremdung von den materiellen Produkten ist das ökonomische Resultat des spezifischen Rechtsverhältnisses der bürgerlichen Gesellschaft: „Das Eigentum an den Produktionsmitteln ist der Grund des Eigentums am Produzierten." ${ }^{008}$ Die Entfremdung reproduziert sich darum durch die juristischen Voraussetzungen hindurch beständig. Beide Sphären, Recht und Ökonomie, sind nicht voneinander zu trennen. ${ }^{809}$

\footnotetext{
${ }^{805}$ Marx, Lohnarbeit und Kapital, S. 410.

${ }^{806}$ Marx: Das Kapital, Bd. 1, S. 200. Der Stellenwert des Entfremdungsbegriffs im Marxschen Gesamtwerk gilt deshalb zu Recht als umstritten: „Welchen Stellenwert die Entfremdungstheorie im Marxschen CEuvre einnimmt, war und ist durchaus umstritten." (Zehnpfennig: Rousseau und Marx oder: Das Ende der Entfremdung, S. 184. Vgl. auch Lefebvre: Der dialektische Materialismus;

Ollman: Alienation.

807 „Nicht die Arbeitsteilung, sondern die Unterordnung der Individuen unter sie ist aufzuheben.“

(Haug: Vorlesungen zur Einführung ins ,Kapital', S. 117.)

808 Bulthaup, Rechtspragmatik oder von der Zwangsläufigkeit des sittlichen Verfalls der Justiz, S. 76.

${ }^{809}$ Vgl. dazu Gegenstandpunkt: Der bürgerliche Staat, S. 27 f.
} 
Die Früchte der eigenen entfremdeten Anwendung im Produktionsprozess lassen sich für den unmittelbaren Hersteller der Produkte nur bedingt, nur vermittelt ernten: über den Umweg des ihm ausbezahlten Lohns für seine Ware Arbeitskraft. Der eigentumstechnische Lohn ist das Resultat eines rechtlich abgesicherten und ante festum willentlich durchs selbstbewusste Subjekt abgeschlossenen juristischen Arbeitsvertrags. Er ist das eigentümliche Äquivalent der Ware Arbeitskraft für die geleistete Tätigkeit am fremden Material in bestimmter Zeit. Der Lohn ist also ein aus dem Arbeitsprozess gewonnenes Eigentum des Produzenten, das ideologisch den Entfremdungsprozess im Bewusstsein der entfremdeten Subjekte dabei noch pazifiziert. Die juristisch gerechte Entlohnung gilt als ein scheinbarer Ausgleich für den unmittelbaren Produzenten, wodurch er ideologisch als gleichwertig in das entfremdete Verhältnis vom Eigentumstausch integriert wird. ${ }^{810}$

Diese Ideologie hat einen wahren Kern. Denn selbst wenn der Produzent an der eigens hergestellten Sache kein Eigentumsrecht hat, geht er in der auf ubiquitärem Eigentum beruhenden Gesellschaft dann doch nicht völlig ohne im Arbeitsprozess erworbenes Eigentum, dem Lohn, nach Hause. Der Lohnarbeiter kommt insofern, waren- und eigentumstechnisch gesprochen, als Eigentümer an ihm äußerlichen Material aus dem Produktionsprozess: Der ihm ausbezahlte Lohn ist sein äquivalentes Eigentum für die zeitliche Einbringung seiner Ware Arbeitskraft in den Produktionsprozess. Die für die Herstellung des Produkts aufgewendete Arbeitskraft wird tatsächlich als geleistete Arbeit in der Zeit entsprechend mit dem vertraglich festgelegten Lohn abgegolten. Mit diesem mit der Ware Geld ausbezahlten Lohn gilt die gesamte geleistete Arbeit juristisch als eigentumstechnisch abgegolten, was die juristische Entfremdung von den Produktionsmitteln an der Stelle verschleiert: „Was auf den Markt gebracht wird, ist in der Tat nicht Arbeit, sondern der Arbeiter. Was er dem Kapitalisten verkauft, ist nicht seine Arbeit, sondern der zeitweilige Gebrauch seiner selbst als Arbeitskraft." ${ }^{\text {"811 Auch der }}$ Arbeiter bleibt damit Eigentümer an etwas vermittelt aus dem Produktionsprozess Kommendem, an dem er (Eigentums-)Rechte hat und das auch nicht nur seine weiterhin existente Ware Arbeitskraft ist. Er hat sogar einen objektiven Rechtsanspruch auf dieses jeweilige, über seine eigentümliche Ware hinausgehende Eigentum: „Durch den Dienstvertrag wird derjenige, welcher Dienste zusagt, zur Leistung der versprochenen Dienste, der andere Teil zur Gewährung der vereinbarten Vergütung verpflichtet.“"812

Diese Seite der rationalen Logik des Eigentumsrechts und der staatlich abgesicherten Verträge beleuchtet insofern die praktische Ausschließung des unmittelbaren Produzenten vom Material gesellschaftlicher Reichtumsproduktion, weil mit dem Eigentumsrecht die ausschließende Verfügung Dritter an staatlich garantier-

\footnotetext{
${ }^{810}$ Vgl. von Nell-Breuning: Der Lohn als Erwerbsmittel und Eigentumsquelle, S. 51 ff. Vgl. auch Marx: Das Kapital, Bd.1, S. 562.

811 Marx: Theorien über den Mehrwert, S. 109.

812 BGB $\$ 611$.
} 
ten Eigentumstiteln gesetzt ist. Was für die formelle Rechtsprechung im bürgerlichen Staat einzig zählt, ist das formelle und damit abstrakte Eigentum einer juristischen Person an einer beliebigen Sache. ${ }^{813}$ Das verweist sogleich auf den bürgerlichen Staat als Kommandomacht der Subsumtion der Staatsbürger unter das Kapital. Das dem Staat dafür in die Hand gelegte Werkzeug sind die allgemeinen Eigentumsrechte, die die Freiheit der Person und die Abstraktheit des Inhalts jedes Eigentums voraussetzen sowie seine objektive Gewalt der Verfügung darüber. Die Entfremdung ist jedoch dadurch, gerade weil der bürgerliche Staat mit seinen allgemeinen Gesetzen die objektive Bezugsinstanz bleibt, universal. Sie macht selbst vor den Eigentümern an Produktionsmitteln nicht halt. Auch diese werden in die Gesellschaft zwangsintegriert und mit ihrem Privateigentum an Produktionsmitteln unters Eigentumsrecht subsumiert. Juristisch haben auch sie nur so viel an Eigentum an Produktionsmitteln, wie ihnen gesetzlich zugestanden wird: Steuern, die ihnen auferlegt werden können, weil sie Eigentum an Produktionsmitteln haben, entfremden auch die Produktionsmitteleigentümer von ihren gesetzlich garantierten Produkten. ${ }^{814}$ Über die Steuergesetzgebung meldet der Staat als Ausgleich für die Garantie ihres Eigentums einen Besitz an diesem an: „Da die proportionale Besteuerung des Einkommens bei weitem nicht der Vergrößerung des privaten Eigentums entspricht, deren Beförderung dem Staat immer mehr Leistungen aufnötigt, gibt es einerseits die Steuerprogression, durch die der Staat die handfesten Einkommensunterschiede für sich ausnützt und beweist, wieviel Geld manche Leute übrig haben, andererseits auch noch andere Besitzsteuern: die Einkommen juristischer Personen werden in der Körperschaftssteuer erfaßt, und auch der nicht in den Konsum unmittelbar eingehende Besitz ist entsprechend seiner Größe steuerpflichtig: Ertrags- und Vermögenssteuer." ${ }^{\text {"B15 }}$

\subsubsection{Verdinglichung durch Vereigentümlichung. Ware Arbeitskraft und Privateigentum}

Die formellen Voraussetzungen des kapitalistischen Produktionsprozess bringen beide Klassen wiederholt - scheinbar mythisch immergleich - durch die institutionalisierte Garantie von Eigentum in ihrer ökonomischen Funktion hervor: „Die ökonomischen Grundprozesse der Gesellschaft, die Klassen hervorbringen“, schreibt Adorno zu jener systematischen Hervorbringung von Voraussetzungen als Resultat, „haben aller Integration der Subjekte zum Trotz sich nicht geändert. “816 Die ,ausschließende Verfügung über den Reichtum der Gesellschaft"817, das die zwei Klassen der bürgerlichen Gesellschaft als perennierendes gesellschaft-

\footnotetext{
813 Vgl. Haslbauer: Eigentum und Person, S. 31 ff.

${ }^{814}$ Das sieht Murray Rothbard richtig, wenn er vom forcible theft durch den bürgerlichen Staat spricht (vgl. 3.2.3).

815 Resultate Bd. 3 : Der bürgerliche Staat, S. 82.

816 Adorno: Anmerkungen zum sozialen Konflikt heute, S. 184.

817 Resultate Bd. 3: Der bürgerliche Staat, S. 13.
} 
liches Gewaltverhältnis erweitert hervorbringt, ist ein Resultat der Abstraktion des Eigentumsrechts als bloße Form vom eigenen Inhalt. Es ist insofern das den Eigentümern an Produktionsmitteln staatlich garantierte Privateigentum an diesen, worüber sie sich, weil sie darüber vermittelt als Klasse Eigentümer an den Produktionsmitteln bleiben, das materielle Eigentum am gesellschaftlichen Reichtum verlängert sichern. Diejenigen Subjekte, die in der Geschichte ohne jedes konkrete Material der möglichen eigenen Reproduktion stehengelassen werden, als Eigentümer an nichts als an ihrer Ware Arbeitskraft, werden dagegen durch die staatliche Garantie der abstrakten Eigentumsverhältnisse hindurch von diesem materiellen Reichtum in der entwickelten kapitalistischen Produktionsweise verlängert ausgeschlossen: entfremdet (vgl. 3.2.3). Durch diese systematische Reflexivität in der prozessualen Verwertung des Kapitalverhältnisses, die ihre Voraussetzung in der juristischen Sphäre hat, scheint der kapitalistische Verwertungsprozess wie ein sich selbst aus sich heraus setzendes Subjekt zu wirken. Im Kapital bezeichnet Marx ihn deshalb, in Anlehnung an die Philosophie Hegels, als „automatisches Subjekt.“" 818 Diese starke Metapher des Absoluten, die ein vermeintlich göttliches, körperloses Subjekt Kapital assoziiert, bleibt bei Marx jedoch kein in sich subsistierender Prozess des Absoluten, weil das Kapital auf transzendent Äußeres, auf Objektives immer verwiesen bleibt.

Durch die oben bereits angeführte Abstraktion des spezifisch kapitalistischen Eigentumsbegriffs von vorausgesetzten Inhalten kann er überhaupt erst in einer formellen Ubiquität erscheinen. Erst durch diese sachbezogene Inhaltslosigkeit kann jedem Staatsbürger das uneingeschränkte Recht auf Privateigentum an etwas zukommen. Die Subjekte können auch nur deshalb als Eigentümer an Lohn aus dem Arbeitsprozess hervorgehen, weil sie als Eigentümer, nämlich an der Ware Arbeitskraft, in ihn eintreten. Jeder Besitz wird nach dem ,historische[n] Scheidungsprozeß von Produzent und Produktionsmittel“"819 ausnahmslos rechtlich ,vereigentümlicht', selbst noch die eigene physis. Den besonderen Eigentumstitel an der Ware Arbeitskraft, der die eigene physis ist, führt deshalb auch jedes selbstbewusste Subjekt als rechtliche Person in der bürgerlichen Gesellschaft mit sich. Allen körperlichen, biologischen Wesen kommt also der Eigentumstitel an der Ware Arbeitskraft aufgrund dieser abstrakten Potentialität, Eigentumstitel zu besitzen, zu. Das Subjekt muss insofern, um in den allgemeinen Tausch von Eigentum integriert $\mathrm{zu}$ werden, als ein individuelles, materielles und selbstbewusstes Subjekt, auch keine entsprechend sachlichen Gegenstände zum Tausch anbieten. Über dieses eine, objektiv garantierte Eigentum an Ware verfügt es frei, darüber vermittelt kann es sich selbst als Material auf dem Markt anbieten. Diese Möglichkeit und Realität der Anpreisung steht dementsprechend allen Rechtssubjekten ausnahmslos frei. Über den allgemein garantierten Eigentumstitel vermittelt wird deshalb auch jedes bürgerliche Subjekt (alle selbstbewussten Subjekte der Recht-

818 Marx: Das Kapital, Bd. 1, S. 169.

${ }^{819}$ Ebd., S. 742. 
sprechung) in den gesellschaftlichen Zusammenhang systematisch und universell (zwangs-)integriert, und die Arbeitskraft wird vom Staat als eigentümliche Ware jeder Person, jedes Staatsbürgers, garantiert und geschützt. Als Rechtspersonen kommt allen selbstbewussten Subjekten insofern universell die Möglichkeit zu, sich in der bürgerlichen Gesellschaft als Eigentümer zu reproduzieren, weil sie, wider Heidegger ${ }^{820}$, als Individuen körperliche Wesen, materielle Dinge in der Welt sind - und eben nicht bloß geistige. Gerade weil die selbstbewnssten Subjekte immer auch körperliche Individuen sind, macht der Vereigentümlichungsprozess vor ihnen keinen Halt. Wenn das staatsbürgerliche Subjekt keine anderen hochwertigen Waren oder Produktionsmittel als sein Eigentum juristisch nennen und verwerten kann, dann muss es sich mit seiner physis willentlich als Mittel zum Zweck der Produktionsmitteleigentümer veräußern. Ob der eigenen sachlichen Eigentumslosigkeit hat der Produktionsmittellose immer nur sich selbst zum einzigen sachlichen Eigentum ${ }^{821}$, weil er eben nur jenes verdinglichte Eigentum an seiner Ware Arbeitskraft hat. Produktionsmittellose werden dadurch im gesellschaftlichen Reproduktionsprozess der kapitalistischen Gesellschaft, weil sie politischökonomisch betrachtet auf ihre bloße Körperlichkeit reduzierte Subjekte sind, zu res extensae oder Exemplaren der Gattung. ${ }^{822}$ Die vormals Leibeigenen, noch vom Feudalherren besessenen Bauern, werden in der bürgerlichen Gesellschaft nun, als von allen feudalen Zwängen gewaltsam befreite Lohnarbeiter, gezwungen, sich als eigentümliche Waren ,selbst freiwillig zu verkaufen', um fremdes Eigentum mit Werten auszustatten, Waren als Ware, Gleiches mit Gleichem, herzustellen. Deshalb stellt sich ihre Freiheit in der bürgerlichen Gesellschaft auch nicht als nur einfache Freiheit von den persönlichen Zwängen des Feudalismus dar. Juristisch sind die Subjekte in ihr zwar von persönlicher Herrschaft und Willkür befreit, ökonomisch werden sie dadurch aber auch von allen subsistenzwirtschaftlichen Produktionsmitteln freigesetzt, was ihre Freiheit an der Stelle verdoppelt. Der Preis der Befreiung ist demnach, sich damit zugleich in ein verdinglichtes Produktionsmittel zur Produktion von Eigentum der Klasse der Produktionsmitteleigentümer zu verwandeln. In der bürgerlichen Gesellschaft wird also selbst die sachliche Eigentumslosigkeit an Dingen durch die objektiv geforderte eigene Verdinglichung kein Hindernis für die Rechtssubjekte, im Konzert des Tauschs von Eigentumstiteln unter Gleichen, unter Warenbesitzern, mitzuspielen. ${ }^{823}$ Alle Subjekte ohne entsprechendes Produktionsmitteleigentum sind jetzt rein funktionalistisches Sein für fremdes Eigentum: „Andrerseits aber werden diese Neubefreiten erst Verkäufer ihrer selbst, nachdem ihnen alle ihre Produktionsmittel und alle durch

\footnotetext{
820 „Die Person ist kein Ding, keine Substanz, kein Gegenstand.“ (Heidegger: Sein und Zeit, S. 47.) ${ }^{821}$ In Max Stirners Werk Der Einそige und sein Eigentum wird dieser objektive Zwang des Eigentumsbesitzes in der bürgerlichen Gesellschaft nicht reflektiert. (Vgl. Stirner: Der Einzige und sein Eigentum.)

822 Vgl. Adorno: Negative Dialektik, S. 254.

823 „Though the earth and all inferior creatures be common to all men, yet every man has a proper-

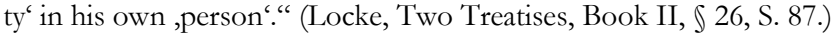


die alten feudalen Einrichtungen gebotnen Garantien ihrer Existenz geraubt sind." ${ }^{2} 24$ Ihre Reproduktion als juristisch Gleiche kann sich überhaupt nur realisie-

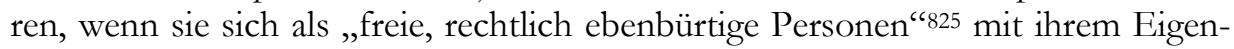
tum gegen einen gewissen Lohn an Produktionsmitteleigentümer verkaufen, sich selbst als Ware gegen Lohn veräußern und ihr vorausgesetztes körperliches Eigentum zweckmäßig einsetzen. Nur noch vermittelt über ihre individuelle, besondere Körperlichkeit, die als extramentales Besonderes zur allgemeinen Ware gemacht wird, können sie noch als Subjekte in der Welt des Tausches von objektiv garantierten Eigentumstiteln bestehen. Dergleichen in ein instrumentum vocale verdinglicht werden die Subjekte in den ökonomischen Prozess von Warentausch und Reichtumsproduktion integriert. Dabei wird ihnen als Eigentümern an sich selbst garantiert, dass ihre individuelle Ware Arbeitskraft durch objektive, allgemeingültige Vertragsbedingungen bei ihrer Veräußerung durch den Staat geschützt wird. Diese Garantie bindet den Produktionsmittellosen deshalb an die Instanz der Garantie der juristischen ,Unversehrtheit ${ }^{`}$ der Ware Arbeitskraft zum ,selbstbestimmten Gebrauch, also den bürgerlichen Staat: „Mit dem Schutz von Person und Eigentum sichert der Staat dem einzelnen eine Sphäre der Freiheit, die ihm bei der Verfolgung seiner besonderen Anliegen Grenzen setzt. “826 Die eigene, willentliche Verdinglichung zum lebendigen Produktionsmittel ist deswegen im Zusammenhang mit der Garantie der Sicherung ihrer Existenz durch den Staat, der ihnen ihre Selbsterhaltung dann garantiert, zu sehen (vgl. 3.2.2).

Selbst die Eigentümer an Produktionsmitteln sind nun von den heteronomen Zwängen der staatlich abgesicherten Eigentumsverträge nicht einfach auszunehmen. Auch sie unterliegen dem allgemeinen Zwang des gesellschaftlichen Vereigentümlichungsprozess. Sie müssen sowohl untereinander wie mit den Lohnarbeitern rechtskräftige Verträge abschließen: „Als Agenten ihres Kapitals sind sie nicht frei. “" ${ }^{\text {(27 }}$ Nach der bürgerlichen revolutionären Befreiung sind die Produktionsmitteleigentümer funktional auf das Gesamtkapital bezogen, so dass auch ihr Dasein zum funktionellen Dasein des Erhalts ihres Privateigentums an Produktionsmitteln wird (vgl. 2.6.2). Zwar müssen sich die Kapitalisten in der bürgerlichen Gesellschaft nun auch nicht wie die Proletarier unmittelbar selbst als sachliche, biologische Wesen verdinglichen. Aber sie haben dem objektiven Bezug der Verträge zur allgemeinen Instanz der Garantie der Rechtsverhältnisse ebenfalls Folge zu leisten. Auch sie sind einzig in diesem verdinglichten Zusammenhang der gesellschaftlichen Totalität Subjekte. Auch sie müssen ihrer gesellschaftlichen Rolle um ihres Überlebens Willen gerecht werden und sind im objektiven Recht nichts anderes als von herrschaftlichen, ihnen heteronomen gesellschaftlichen Zwecken abhängige res extensae. Bei etwaigen Vertragsbrüchen drohen den Eigentümern an

\footnotetext{
${ }^{824}$ Marx: Das Kapital, Bd. 1, S. 743.

825 Ebd., S. 190.

826 Resultate Bd. 3: Der bürgerliche Staat, S. 28.

${ }^{827}$ Kuhne: Marx’ Ideologiebegriff im Kapital, S. 20, Fn. 2.
} 
Produktionsmitteln empfindliche Strafen, die ihre Person betreffen. Ihre äußeren Dinge wie Produktionsmittel etc. sind deshalb, wenn auch vermittelt, ebenfalls nicht von ihrer Körperlichkeit zu trennen. Die Produktionsmittel beziehen sich insofern, als gesellschaftliche Dinge, immer auf für sie verantwortliche Subjekte.

Diese Affirmation der Selbstverdinglichung als Mittel zum fremden, gesellschaftlichen Zweck ist eine erzwungene Bejahung der objektiv eingerichteten Sicherung der eigenen Reproduktion und muss nicht unbedingt die persönliche Zustimmung des Einzelnen zur bürgerlichen Gesellschaft sein. Denn das selbstbewusste Subjekt wird nicht erst durch einen persönlichen Zustimmungsvertrag zum staatsbürgerlichen Rechtssubjekt, sondern es ist mit bürgerlichen Rechten und Pflichten immer schon ausgestattet. Verdinglichtes Rechtssubjekt ist es darum schon von Geburt an, weil es biologisches und geistiges Wesen ist. Der Einzelne wird deshalb gezwungenermaßen in das ordnende Rechtsverhältnis inkludiert: „Die Rekrutierung der Staatsbürger erfolgt, ohne diese nach ihrem Einverständnis zu fragen. “828 Auch dies ist ein unvermittelter Akt gesellschaftlicher Herrschaft, der nochmals eindrucksvoll auf die heteronome Objektivität des gesellschaftlichen Herrschaftsverhältnisses hinweist. Wie schon in Rousseaus ${ }^{829}$ contrat social wird also die willentliche Zustimmung jedes bürgerlichen Subjekts zur Gesellschaft schon als absolut, gleich der volonté générale, vorausgesetzt. Diese tiefe Einsicht Rousseaus in die volonté generale zeigt, auch wenn er diesen Zusammenhang von Willen und Gesellschaft affirmativ konzipiert, seinen bereits tiefen Einblick in Gesellschaft und Herrschaft.

Auch heute noch ist der die bürgerliche Gesellschaft bejahende Gemeinwille mehr als nur die einfache Zusammenfassung aller Einzelwillen zu einem allgemeinen, gesellschaftlichen Willen. ${ }^{830} \mathrm{Er}$ ist der unvermittelte Zwang, der auf jedes einzelne körperliche, verdinglichte Subjekt beständig einwirkt. Als individuelles biologisches Wesen ist jedes Subjekt in der bürgerlichen Gesellschaft, noch vor jeder individuellen Subjektkonstitution, vor der Ausprägung des Selbstbewusstseins, Träger von Rechten und Pflichten. Bereits pränatal wirkt die Gesellschaft auf das im entstehen begriffene Subjekt, wodurch die bürgerliche Gesellschaft bereits auf das Ungeborene, bevor es überhaupt zum Staatsbürger in ihr wird, über es bestimmt. Dieser pränatale gesellschaftliche Zwang wird mit dem Abtreibungsrecht besonders deutlich. Das Familienministerium der BRD formuliert: „Ein Schwangerschaftsabbruch ist in Deutschland zwar grundsätzlich rechtswidrig, bleibt aber unter bestimmten Voraussetzungen straffrei $(\$ 218$ a Abs. $1, \$ 219$ StGB)." "831 Den Zeitpunkt, zu dem das im entstehen begriffene Subjekt Staatsmaterial ist, über das dann auch nicht mehr die schwangere Frau als die körperliche

\footnotetext{
828 Grigat: Fetisch und Freiheit, S. 254.

${ }^{829}$ Vgl. Rousseau: Vom Gesellschaftsvertrag oder Prinzipien des Staatsrechtes.

${ }^{830}$ Vgl. Engels: Ludwig Feuerbach und der Ausgang der klassischen deutschen Philosophie, S. $296 \mathrm{ff}$.

831 bmfsfj.de: Schwangerschaftsabbruch nach $₫ 218$ Strafgesetzbuch.
} 
Trägerin des Materials entscheiden und verfügen darf, bestimmt insofern das Strafgesetzbuch. Der Staat greift damit in die körperliche Integrität der Frau ein, die als Schwangere ab dem bestimmten Zeitpunkt auch nicht mehr über ihren eigenen Körper bestimmen darf.

Der Zwang auf ein Neugeborenes drückt sich dagegen im BGB, $\$ 1$, aus. Jener Paragraph bestimmt den Beginn der Rechtsfähigkeit eines Staatsbürgers mit dem Abschluss des Geburtsvorgangs: „Die Rechtsfähigkeit des Menschen beginnt mit der Vollendung der Geburt." ${ }^{332}$ Diese außersubjektive, unwillentliche objektive Bestimmung als Rechtssubjekt ist dafür verantwortlich, dass Neugeborene und Kinder in Zukunft die Möglichkeit der Veräußerung von Eigentum an Ware bekommen. Nur eine juristisch klar definierte Person nämlich darf in der bürgerlichen Gesellschaft verdinglichter Eigentümer von etwas sein - oder zumindest die Aussicht darauf haben: „Die (...) Bevölkerungsgruppe, die (...) nicht notwendiger Weise Person - im (...) genuinen Begriff, also Eigentümer von Einkommensquellen - sind, sind die Kinder und Heranwachsenden. Aus dem einfachen Grund, dass sie sich eben erst in der Vorbereitung auf das Eigentümer-Dasein befinden, dieses eben noch nicht - in eben dieser Abstraktion von sich - ausfüllen. “833

Auf den juristischen Begriff der Person als objektiv garantierter Begriff des Rechts sind überhaupt alle individuellen Subjekte angewiesen, um sich durch ihr jeweiliges Eigentum hindurch in der bürgerlichen Gesellschaft zu reproduzieren. Aus ganz eigenem, persönlichem Interesse geben sich die juristischen Personen der bürgerlichen Gesellschaft dem, wie Marx im Kapital schreibt, ,stummen Zwang der ökonomischen Verhältnisse ${ }^{\text {c } 834}$ hin. Nur so kann der allgemeine, reziproke Eigentumstausch überhaupt funktionieren. Bereits Hegel beschreibt den Austausch von Warendingen als Eigentum, der auf der juristischen Gleichheit in der bürgerlichen Gesellschaft und dem freien Eigentümer beruht, als einen wesentlichen Akt, der auf der Grundlage der formellen, objektiv garantierten Freiheit für alle Bürger aufbaut. Die Bürger als gleichwertige Eigentümer und rechtliche Personen in der formell allgemeinen Sphäre der ökonomischen Konkurrenz entäußern sich dabei wechselseitig ihres objektiv durch den Staat garantierten Eigentums - ganz gleich welcher Ware sie sich entäußern - zu ihren Gunsten, indem sie als Revenuequellenbesitzer ihren freien Willen darein legen, ,so daß ich meine Sache überhaupt von mir als herrenlos lasse (delinquiere) oder sie dem Willen eines anderen zum Besitzen überlasse, - aber nur insofern die Sache ibrer Natur nach ein Äußerliches ist. ${ }^{\text {“835 }}$ Die allgemeine Garantie von Eigentum durch den bür-

\footnotetext{
${ }_{832}$ BGB, \1, Beginn der Rechtsfähigkeit. Vgl. hierzu \1 BGB Beginn der Rechtsfähigkeit (Kommentar): „Die Rechtsfähigkeit beginnt mit der Vollendung der Geburt. Darunter ist die vollständige Trennung, also der vollständige Austritt des Kindes vom Mutterleib zu verstehen. Unerheblich ist, ob dies auf natürlichem oder künstlichem Wege geschieht. Auch kommt es auf den Zeitpunkt der Durchtrennung der Nabelschnur nicht an."

833 Haslbauer: Eigentum und Person, S. 192 f.

834 Marx: Das Kapital, Band 1, S. 765.

${ }^{835}$ Hegel: Grundlinien der Philosophie des Rechts, S. 140.
} 
gerlichen Staat, durch die alle Sachen überhaupt erst eigentümliche Dinge werden, in die man seinen freien Willen hineinlegen kann, meint also, dass ausscbließlich der Wille des Eigentümers bezüglich der Veräußerung seines Eigentums gilt. Keine dritte juristische Person darf ein willentliches Verfügungsrecht über fremdes Eigentum, Eigentum einer anderen Person, haben oder dem anderen Rechtssubjekt willkürliche Pflichten zu seinen alleinigen Gunsten auferlegen. Aufgrund des Axioms der formellen Gleichheit aller inzwischen freien Bürger als Personen des Rechts wird durch die Abstraktion von jeglichen materiellen Unterschieden durch und nach der bürgerlichen Revolution die Handlung des Vertragsabschlusses nach geltendem Recht auch ideologisch als unbedingt freiwillige Handlung bestimmt: „Geschäftsunfähig ist: 1. wer nicht das siebente Lebensjahr vollendet hat, 2 . wer sich in einem die freie Willensbestimmung [sic!] ausschließenden Zustand krankhafter Störung der Geistestätigkeit befindet, sofern nicht der Zustand seiner Natur nach ein vorübergehender ist. “836

\subsection{Zur praktischen Diskussion des abstrakten Eigentumstitels. Die Allgemeine Erklärung der Menschenrechte von 1948}

Der befriedete Wohlstand der Gesellschaften wird oftmals durch das durchgesetzte Recht an Eigentum unterstellt. ${ }^{837}$ Menschenrechtsgruppen möchten mithilfe der Forderung nach einem allgemeinen ,Menschenrecht auf Eigentum ' der Befriedung der Welt und der Gerechtigkeit für alle näherkommen ${ }^{838}$; wenn im Rahmen des allgemeinen Menschenrechts flächendeckend Eigentumstitel durchgesetzt seien, dann lasse sich auch der Wohlstand aller Einzelnen realisieren. Die Grundlage dieser Forderung ist der Artikel $17 \mathrm{der}$ Allgemeinen Erklärung der Menschenrechte von $1948^{839}$ aus der UN-Menschenrechtskonvention, und in Anlehnung an diese Erklärung fordert man ein weltweites Recht auf Eigentum ein: „Jeder hat das Recht, sowohl allein als auch in Gemeinschaft mit anderen Eigentum innezuhaben." ${ }^{840}$ Gegen jede Form von Willkür sollen Eigentum, Freiheit und Gleichheit garantiert werden: „Niemand darf willkürlich seines Eigentums beraubt werden.“"841 Auch schon Hannah Arendt unterstellt, dass die Durchsetzung von allgemeinen Menschenrechten zur Realisierung von Eigentum, Gleichheit, Freiheit und Frieden in der Welt führe: „Wir sahen bereits, daß Eigentum im Unterschied zu Besitz,

\footnotetext{
836 BGB, \ 104.

${ }^{837}$ So z.B. Rothfritz: Die Konvention der Vereinten Nationen zum Schutz der Rechte der Menschen mit Behinderungen.

838 youthforhumanrights.org: Jugend für Menschenrechte; amnesty.de: Menschenrechte sind grenzenlos.

839 ohchr.org: Allgemeine Erklärung der Menschenrechte.

${ }^{840}$ Ebd.

${ }^{841}$ Ebd.
} 
Reichtum und dem Prozeß der Aneignung, ein weltliches Phänomen ist, bzw. den Teil der uns gemeinsamen Welt anzeigt, der uns privat zu eigen ist; Vorhandensein und Schutz von Privateigentum gehören daher zu den elementarsten politischen Bedingungen für die Entfaltung der Weltlichkeit menschlichen Daseins." ${ }^{\text {"842 }}$ Reell bleibt diese ideelle Forderung nach dem Menschenrecht auf Eigentum jedoch abstrakt und wirkungslos. Die Erklärung der Menschenrechte von 1948 ist bis heute kein durchgesetztes, objektiv gültiges und bindendes Recht für Nationalstaaten. Weil nationale Interessen mit der Universalität eines bürgerlichen Weltrechts immer kollidieren werden, wird sie wohl auch zukünftig eine unrealisierbare Idee eines Weltrechts bleiben. Eine zukünftige Aufgabe der Länderautonomie bürgerlicher Staaten in Rechtsfragen ist kaum vorstellbar.

Es gibt aber noch weitere, theoretisch tiefergreifendere Probleme, die mit einer Durchsetzung der Allgemeinen Erklärung der Menschenrechte einhergehen würden: Materielle Unterschiede im Eigentum würden dadurch nämlich doch wieder nur bestätigt. Eigentumsunterschiede werden durch die Garantie des Eigentums nicht etwa beseitigt, gerade weil sich das allgemeine, durchgesetzte Recht für die Schaffung und Aufrechterhaltung der Klassenunterschiede nach den Gewaltakten der Aneignung verantwortlich zeigt. Denn mithilfe der allgemeinen Rechtsform konnte das gewaltsam angeeignete Privateigentum an Produktionsmitteln für wenige historisch ja erst erhärtet werden (vgl. hierzu 3.2 ff.). Auch ein Allgemeines Menschenrecht würde das Recht auf Eigentum an Produktionsmitteln etc. insofern nur setzen, schützen und verlängern. Es würde in der Konsequenz also erst zu einem Instrument dessen, was man mit Artikel 17 eigentlich meinte bekämpfen zu können: Die offensichtlichen Reichtumsunterschiede innerhalb wie zwischen den Staaten. ${ }^{843}$ Die Klassenunterschiede in der bürgerlichen Gesellschaft sind ja nun immer erst das Resultat der scheinbar interesselosen Abstraktion der Eigentumstitel von allem Material. Das wird deshalb auch hinsichtlich der Allgemeinen Menschenrechte und deren Forderung nach Eigentum für den Fall nicht anders sein, sollten sie denn einmal universal durchgesetzt sein: „Gerade die formelle Gleichheit aller als Warenbesitzer macht dieses Verhältnis zu einem Herrschaftsverhältnis, in dem die Eigentümer der Produktionsmittel die beherrschen, die als einzige Ware ihre Arbeitskraft zu verkaufen haben. " 844 Ohne entscheidenden kritischen Hinweis darauf, wovon denn die rechtliche Form Eigentum überhaupt Form ist, auf welches materielle Etwas sie geht, welche ökonomischen Zwecke die juristische Form verfolgt etc., ist Recht deshalb auch nicht zu denken (vgl. 3.2.1). Form ohne Inhalt ist undenkbar, und das nicht zu reflektieren, ist der entscheidend blin-

\footnotetext{
842 Arendt: Vita activa oder vom tätigen Leben, S. 324.

${ }^{843}$ Das soll nicht bestreiten, dass es in Teilen der Welt keine Möglichkeit gibt, infrastrukturell das allgemeine Recht durchzusetzen und das vielen Leuten geholfen ist, wenn sie sich auf ein solches gegen völlige Willkür berufen könnten. Mir geht es hier jedoch um eine systematische Darstellung und Kritik.

${ }^{844}$ Bulthaup: Herrschaft, Sprache und Revolution, S. 51.
} 
de Fleck in der politischen Diskussion um die Forderung von allgemeinem Eigentum, Gleichheit etc.

Die abstrakte Garantie der Eigentumstitel und die einhergehende juristische Logik des verlängerten Ausschlusses sind daneben auch noch dafür verantwortlich, dass beide historisch entstandene Klassen nicht, wie ideologisch behauptet, klassenübergreifend gegeneinander und um die Aneignung des gesellschaftlichen Reichtums ,friedlich` konkurrieren können (s.o.). Eine friedliche Koexistenz von Kapitalisten und Proletariern ist aufgrund des abstrakten Eigentumsrechts und dessen Folgen ausgeschlossen. Die an Produktionsmitteln Eigentumslosen Eigentümer ihrer Ware Arbeitskraft können ja auch nur klassenintern um die vertragliche Veräußerung ihres einzigen Eigentums konkurrieren, das unmittelbar an ihrer Körperlichkeit hängt (s.o.). Die Arbeiterklasse erteilt nun durch ihr unvermeidliches Handeln dem eigenen Verlust der Subsistenzmittel im kapitalistischen Prozess auch immer wieder die Absolution. Das geschieht über die erzwungene Anerkennung des Vertrages nach der gewaltsamen historischen Expropriation. ${ }^{845}$ Der Lohnarbeiter wird durch die danach initiierten, rechtlichen Eigentumsverhältnisse also überhaupt erst zu jener Person, die „sich selbst freiwillig zu verkaufen ge-

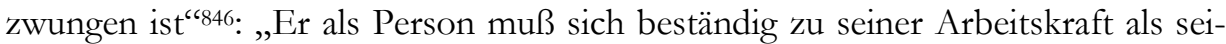
nem Eigentum und daher seiner eignen Ware verhalten, und das kann er nur, soweit er sie dem Käufer stets nur vorübergehend, für einen bestimmten Zeittermin, zur Verfügung stellt, zum Verbrauch überläßt, also durch ihre Veräußerung nicht auf sein Eigentum an ihr verzichtet. “847 Da der Eigentümer an Ware Arbeitskraft mit seiner Ware Arbeitskraft plus Lohn zur Selbstversorgung aus dem Prozess hervorgeht, ist zum einen die Ideologie des Schaffens und der Erfüllung des Glücks durch Arbeit, zumindest für den Einzelnen, hinfällig. Genauso ist es systematisch schwer bis unmöglich für den Lohnarbeiter und sein allein gesichertes Dasein als Eigentümer seiner eigenen Körperlichkeit, die eigene Klasse zu verlassen und gesellschaftlich, aufzusteigen'.

Die Eigentümer an Produktionsmitteln hingegen konkurrieren ebenfalls nur untereinander um ihre Reproduktion, indem sie jeweils gegeneinander um ihren Platz im kapitalistischen Marktmagen kämpfen. Auch sie dürfen und können erst nach der allgemeinen Rechtsetzung und der staatsgewaltlichen Garantie der Eigentumstitel um den Marktmagen und damit um die Aneignung von gesellschaftlichem Reichtum konkurrieren. So wird auch der Produktionsmitteleigentümer zu jenem Konkurrenzsubjekt innerhalb der Gesellschaft, das mithilfe seiner durch Lohnarbeiter angewendeten Produktionsmittel den Konkurrenten ausstechen muss. Damit sind die Produktionsmitteleigentümer also ebenfalls von einer autonomen Selbstbestimmung ausgeschlossen, denn auch sie unterliegen als Eigentümer einem Entfremdungsprozess, weil sie auf die rechtliche Sphäre der Garantie

\footnotetext{
$845 \mathrm{Vgl}$. dazu auch die Unterabschnitte $3.6 \mathrm{ff}$.

846 Marx: Das Kapital, Bd. 1, S. 793.

847 Ebd., S. 182.
} 
ihrer Rechte als Eigentümer, die staatliches Seite also, angewiesen sind (vgl. 3.2.1). Die lebensfeindliche Konkurrenz in der kapitalistischen Eigentümergesellschaft ist somit universell, weshalb sie nicht nur von der einen Klasse an Produktionsmitteln Eigentumslosen erfahren wird. Jeder Eigentümer ausnahmslos hat sich dieser lebensfeindlichen Konkurrenz immer um seine eigene Selbsterhaltung willen zu stellen und sich gegen andere zu behaupten: „Er [der bürgerliche Staat, B.E.B.] verpflichtet sie [seine Staatsbürger, B.E.B.], die ökonomische Konkurrenz unter Respektierung des Privateigentums abzuwickeln: jeder wird gezwungen, die ausschließende Verfügung über den Reichtum der Gesellschaft anzuerkennen [als ein Resultat der ursprünglichen Akkumulation, B.E.B.] und zum Prinzip seines ökonomischen Handelns zu machen. "848 Beide Klassen halten insofern an ihrem formell objektiv gesicherten und historisch zugesprochenen Eigentum notwendig fest, weil sie daran festhalten müssen: „Es findet also eine Konkurrenz unter den Verkäufern statt, die den Preis der von ihnen angebotenen Ware herabdrückt. "849 Solange also die Klassenmitglieder als Eigentümer ihr Eigentum an Waren behalten wollen, um sich zu reproduzieren, haben sie die objektiven Rechtsgrundsätze der Garantie des eigenen Eigentums als Garant ihrer eigenen weiteren Reproduktion $\mathrm{zu}$ affirmieren.

Diese dialektischen Zusammenhänge bleiben von Verfechtern der Allgemeinen Erklärung allerdings unreflektiert. Garantiere man einfach nur die gleichen Rechte als allgemeine Menschenrechte, wieder ganz gleich der Ideologie, als ob alle Subjekte von Geburt an materiell die gleichen Voraussetzungen haben und sich die bürgerliche Gesellschaft historisch ohne willkürliche Akte der Aneignung von Produktionsmitteln konstituierte, übersieht man die Konkurrenz aller Subjekte untereinander als „fundamental konkurrierende Rechtspersonen“850 nach der Konstituierung von Eigentumsverhältnissen. Diese Notwendigkeit der materiellen Unterschiede im Eigentum würde sich jedoch selbst mit einer von den Menschenrechtsgruppen geforderten bürgerlichen, kapitalistischen Weltgesellschaft mit universal garantierten Eigentumstiteln nicht auflösen. So wird sich von den Verfechtern der Menschenrechte des Scheins des Eigentums und der Gleichheit hingegeben, weil man die durch Eigentum verlängerten ökonomischen Unterschiede nicht als den kapitalistischen Zweck der Setzung von Eigentumstiteln reflektiert.

Durch die Prozesshaftigkeit der durch die formelle Eigentumsfrage hindurch stattfindenden allgemeinen Reproduktion der bürgerlichen, kapitalistischen Gesellschaft erstarrt nun auch die ideologisch formell allgemeine Konkurrenz, die ideologische Koexistenz der Sozialpartnerschaft, zur Unwirklichkeit. Denn die Stellung der einzelnen Eigentümer zum gesellschaftlichen Gesamtkapital ist eine historisch längst entschiedene Frage gewesen, die sich mittels der Rechtsform auf unbestimmte Zeit nur verlängert hat: „Scheidung zwischen dem Arbeitsprodukt

\footnotetext{
848 Resultate Bd. 3: Der bürgerliche Staat, S. 11.

${ }^{849}$ Marx, Lohnarbeit und Kapital, S. 402.

${ }^{850}$ Mensching: Das Allgemeine und das Besondere, S. 9.
} 
und der Arbeit selbst, zwischen den objektiven Arbeitsbedingungen und der subjektiven Arbeitskraft, war also die tatsächlich gegebne Grundlage, der Ausgangspunkt des kapitalistischen Produktionsprozesses. Was aber anfangs nur Ausgangspunkt war, wird vermittelst der bloßen Kontinuität des Prozesses, der einfachen Reproduktion, stets aufs neue produziert und verewigt als eignes Resultat der kapitalistischen Produktion." "851 Die alleinige Intention der historischen Setzung von Eigentumstiteln ist deshalb die Schaffung und Verlängerung von elitärem Privateigentum an Produktionsmitteln für die zur herrschenden Klasse gewordenen Klasse von Produktionsmitteleigentümern - und nicht der Schutz von gesellschaftlich Schwächeren (vgl. dazu auch 3.2.1). Denn rechtlich gilt nun auch jedes Eigentum an Produktionsmitteln aufgrund der abstrakten Formalität des Schutzes genauso als Eigentum wie belangloseres: Schuhe oder Haarspray: „Daß die gleiche Behandlung der mit unterschiedlichen Mitteln ausgestatteten Kontrahenten die beste Gewähr dafür bietet, daß die Ungleichheit fortbesteht und wächst, will den Fanatikern der Gleichheit nicht in den Kopf. In der Gleichheit sehen sie kein Gewaltverhältnis, sondern ein Ideal, an dem sie die gesellschaftlichen Unterschiede messen." ${ }^{852}$

Somit wird die politische Forderung nach dem Allgemeinen Menschenrecht an Eigentum nach der Reflexion der Zwecke des bürgerlichen Rechts als politische Forderung ob der Dialektik von Recht und Ökonomie, von Staat und Kapital, obsolet. Möchte man mit Artikel 17 die materiell ungleiche Besitzverteilung nach den Expropriationen substantiell kritisieren, sitzt man also bloß dem gesellschaftlichen Schein des allgemeinen Rechts auf. Die Forderung von Eigentum und allgemeinem Recht durch die blinden Verfechter der Menschenrechte würde deshalb entweder nur helfen, historisch bereits vorhandene Besitzverhältnisse als objektivierte Eigentumsverhältnisse zu affirmieren. Die Geschichte wiederholend würden damit wieder willkürlich angeeignete Güter zur gesellschaftlichen Reichtumsproduktion post festum unter den legalen Schutz des Privateigentums als Privateigentum an Produktionsmitteln des gesellschaftlichen Reichtums gestellt. Oder aber, die abstrakte Gleichgültigkeit gegenüber jedem Inhalt des Eigentums würde mit Gewalt inhaltlich verschiedene Eigentumsverhältnisse erst setzen. Diese Setzung ermöglicht unter kapitalistischen Verhältnissen, unter denen der Eigentumsbegriff systematisch auch einzig seinen Sinn hat, den unterschiedlichen Zugang zum gesellschaftlichen Reichtum. Nur dadurch bekommt der objektiv geschützte Eigentumstitel auch seinen entsprechenden Zweck in der kapitalistisch organisierten allgemeinen Reproduktion. Indem die allem Material enthobenen formellen Eigentumstitel als mit der Freiheit des Individuums als unabdingbar über ihre wichtigste Formel verbunden angepriesen werden, sind beide Varianten der Enteignung zum Zweck der kapitalistischen Produktion in allen Teilen der Welt möglich.

\footnotetext{
851 Marx: Das Kapital, Bd. 1, S. 595.

852 Resultate Bd. 3: Der bürgerliche Staat, S. 27.
} 


\subsection{Form als reales Versprechen. Die Realität der Marxschen fictio juris im Kontext}

Der Ausdruck der juristischen Gleichheit aller freien (Rechts-)Bürger als Eigentum habende Personen existiert erst seit der Formulierung der amerikanischen equality $1776^{853}$ und der französischen egalité $1789^{854}$. Die formelle Gleichheit der Personen vor dem bürgerlichen Gesetz ist deshalb nicht als ambivalent zu betrachten, sondern als bereits realisiert: „Die Sphäre der Zirkulation oder des Warenaustausches, innerhalb deren Schranken Kauf und Verkauf der Arbeitskraft sich bewegt, war in der Tat ein wahres Eden der angebornen Menschenrechte. Was allein hier herrscht, ist Freiheit, Gleichheit, Eigentum und Bentham. “855

Selbst wenn sich selbstverständlich durchweg Beispiele anführen lassen ${ }^{856}$, die die These von der Ungleichheit der Personen auch vor dem Gesetz nur scheinbar wahr werden lassen, konnte bereits mit dem obigen Kelsen-Zitat verdeutlicht werden, dass die vermeintliche Ungleichheit eine Form der juristischen Gleichheit ist (vgl. dazu 3.2.2). Die juristische Gleichheit erwies sich deshalb nicht als eine potentiell mögliche, aber noch nicht realisierte Rechtsform. ${ }^{857}$ Mit dem bürgerlichen Gesetzbuch ist die juristische Gleichheit der Personen vor dem Gesetz also bereits durchgesetzt. Feudale oder sonstige Privilegien zurückgreifende Unterschiede zwischen Personen kennt nun das allgemeine bürgerliche Gesetz auch nicht mehr (vgl. auch 3.2.2). Die Gleichheit ist insofern keine Fiktion. Das aus den republikanischen Prinzipien stammende Rechtssystem ist deswegen auch für Adorno real, denn es ,übt reale Gewalt aus. “858 Anatole France parodiert diese Formulierung der juristischen Gleichheit der Personen vor dem Gesetz besonders treffend als eine offensichtliche Absurdität. Egal ob Bettler oder Millionär, es bleibe beiden Personen des Rechts per Gesetz verboten, unter Brücken zu schlafen: „Das Gesetz in seiner majestätischen Gleichheit verbietet dem Reichen wie

\footnotetext{
853 ,We hold these truths to be self-evident, that all men are created equal, that they are endowed by their Creator with certain unalienable Rights, that among these are Life, Liberty and the pursuit of Happiness." (Declaration of Independence.)

854 „Les hommes naissent et demeurent libres et égaux en droits. Les distinctions sociales ne peuvent être fondées que sur l'utilité commune." (Déclaration des Droits de l'Homme et du Citoyen de 1789.)

${ }^{855}$ Marx: Das Kapital, Bd. 1, S. 189.

856 Tatsächlicher Rassismus in den Südstaaten der USA, Südafrika etc., das Zensuswahlrecht, kein gleiches Recht für Minderheiten etc. sind Beispiele für Ungerechtigkeit und Diskriminierung, die der bürgerlichen Gesellschaft nicht immer nur Feind oder abträglich waren. (Vgl. Gegenstandpunkt: Anti-Rassismus Konferenz in Südafrika: Vom feinen demokratischen Unterschied zwischen achtensund verachtenswerten Diskriminierungen.)

${ }^{857}$ So ist auch das Urteil Adornos falsch: „Gleiches Recht und gleiche Chance (...) ist weithin fiktiv." (Adorno: Reflexionen zur Klassentheorie, S. 378.

858 Adorno: Negative Dialektik, S. 304.
} 
dem Armen, unter den Brücken zu schlafen, auf den Straßen zu betteln und Brot zu stehlen“" 859 .

Diese vorausgesetzte formelle Gleichheit der Personen vor dem Gesetz beschreibt die Marxsche fictio juris. Mit ihr lässt sich die Rechtsprechung aber nicht etwa als bloße Fiktion im Sinne einer Einbildung von Recht und Gerechtigkeit aufdecken, wie man zunächst meinen könnte. Sondern die Formulierung erfasst die reale Rechtsprechung in ihrer Wirkung. Marx spricht im Kapital deshalb von der fictio juris des allgemeinen bürgerlichen Rechts, um damit die allgemeine Setzung und Verlängerung von Gewalt im Recht über die Setzung von Eigentumstiteln zu verdeutlichen. ${ }^{860}$ Dadurch verdeutlicht er die Heteronomie des Lohnarbeiters als bürgerliches Rechtssubjekt. Nur dem Schein nach kontrahiere das an Produktionsmitteln eigentumslose Subjekt beim Tausch seines materiellen, körperlichen Eigentums freiwillig: „Der römische Sklave war durch Ketten, der Lohnarbeiter ist durch unsichtbare Fäden an seinen Eigentümer gebunden. Der Schein seiner Unabhängigkeit wird durch den beständigen Wechsel der individuellen Lohnherren und die fictio juris des Kontrakts aufrechterhalten. “861 Der Zwang der eigenen Selbsterhaltung lasse das Rechtssubjekt überhaupt erst ,frei' kontrahieren. Dieser Zwang ergebe sich erst aus der garantierten juristischen Gleichheit. Die juristische Fiktion sei deshalb eine Folge des bürgerlichen Rechtsprinzips der Egalität, der personellen Gleichheit vor dem Gesetz. Ihr Gegenstand sei die ideologische Nichtnennung des existentiellen Zwangs auf das Subjekt durch die Abstraktion von jeglichem Inhalt: „Auf dem Arbeitsmarkt treten die Agenten des Kapitals und die Verkäufer der Ware Lohnarbeit als getrennte Parteien auf, die Arbeitsverträge aushandeln. Die Rechtslage, in der die beiden Akteure als Tauschpartner in Verhandlung treten, sieht von den ungleichen Ausgangsbedingungen ab, unter denen die Kontrahenten die Arbeitsverträge schließen." "862

In einer seiner populärsten ,Frühschriften', der Deutschen Ideologie, fasst Marx den Inhalt der ungleichen materiellen Vertragsbedingungen bezüglich des Eigentums, die den Willen des an Produktionsmitteln Eigentumslosen erst zum Vertragsabschluss zwingen, zunächst noch unter dem Terminus der ,juristischen Illusion“"803 zusammen: „Aus derselben Illusion der Juristen erklärt es sich, daß es für sie und für jeden Kodex überhaupt zufällig ist, daß Individuen in Verhältnisse untereinander treten, z.B. Verträge, und daß ihm diese Verhältnisse für solche gelten, die man nach Belieben eingehen oder nicht eingehen kann und deren Inhalt ganz auf der individuellen Willkür der Kontrahenten beruht." "864 Die juristische Illusion sei insofern der adäquate ideologische Ausdruck des bürgerlichen

859 Zitiert nach Radbruch: Rechtsphilosophie I, S. 304.

${ }^{860}$ Erstmals formuliert in Marx: Das Kapital, Bd. 1, S. 50: „In der bürgerlichen Gesellschaft herrscht die fictio juris, daß jeder Mensch als Warenkäufer eine enzyklopädische Warenkenntnis besitzt.“

861 Ebd., S. 599.

862 Becker-Schmidt: Adornos Gesellschaftstheorie, S. 77.

863 Marx/Engels: Die deutsche Ideologie, S. 63.

864 Ebd., S. 64. 
Rechts, das wesentlich von allen konkreten, inhaltlichen Unterschieden im Eigentum mittels der Abstraktion von jeglichen konkreten Inhalten großzügig absehe wenn auch nicht von Inhaltlichkeit überhaupt (vgl. 3.2.1): „Die Fiktion, der Vertrag sei die Übereinstimmung des freien Willens derjenigen, die ihn schließen, setzt voraus, daß keiner, um die Bedingungen seiner Existenz zu sichern, den Vertrag wegen der Notwendigkeiten der Selbsterhaltung zu schließen gezwungen sei und ihn nicht aus freien Stücken schließe." ${ }^{865}$ Die juristische Fiktion denunziere deshalb, unter gesamtaspektlichen Gesichtspunkten der bürgerlichen Produktionsweise, den blanken Euphemismus bei der Beschreibung der vorausgesetzten Gleichheit der bürgerlichen Verhältnisse nach der ursprünglichen Akkumulation. Als jeweils gleiche Eigentümer haben sich die Rechtssubjekte der bürgerlichen Gesellschaft auf objektiv abgesicherte und rechtsgültige Verträge berufen. Diese Verträge anzuerkennen sind sie alle als Personen gezwungen, wenn sie denn überhaupt miteinander kontrahieren wollen, um ihre eigene Reproduktion, ihr sese conservare, zu sichern. Die juristische Gleichheit unterliege deshalb auch keiner hinterhältigen List, selbst wenn Vertragsabschlüsse aus heteronomen, dem einzelnen Subjekt transzendenten materiellen Bedingungen resultieren. Die Egalität betrügt das Rechtssubjekt nicht etwa um sein eigentliches, wirkliches Recht, sondern sie steht ganz im Sinne der allgemeinen Rechtsgrundlage der bürgerlichen Gesellschaft.

Die Egalitätsformel des bürgerlichen Rechts bereitet deshalb gegenüber der materiellen, historischen Ungleichheit der bürgerlichen Rechtssubjekte keinerlei Illusionen. Dem Gesetz ist beispielsweise die historische, materielle Ungleichheit der gewaltsamen Aneignung von Produktionsmitteln, die Expropriation, gar kein Gegenstand. Nur weil es den spürbaren materiellen Unterschied bezüglich der historisch gewordenen Voraussetzungen der Bürger gibt, ist die wirkliche Gleichheit vor dem Gesetz nicht anzweifelbar und schon gar keine fiktive Illusion im Sinne einer Einbildung von juristischer Gleichheit. Insofern hat die Bezeichnung der bürgerlichen Gleichheit vor dem Gesetz als fictio juris nach der historischen Aneignung der Produktionsmittel durch eine Klasse ihren konkreten Gegenstand: als Bezeichnung der garantierten allgemeinen Gleichheit vor dem Gesetz, der Egalitätsformel der bürgerlichen Gesellschaft. Die Realität der Gleichheit vor dem Gesetz verlängert erst die materielle Ungleichheit der Eigentumsverhältnisse als Voraussetzung der kapitalistischen Produktionsweise. Aus der bürgerlichen Egalität heraus folgt also prozessual materiell Unterschiedliches. Gerade weil aus den Rechtsbegriffen dialektisch etwas bestimmtes Materielles folgt und ihnen in der Realität damit etwas korrespondiert, scheitern die Rechtsbegriffe der bürgerlichen Gesellschaft nicht als nur idealistische Formel an den eigenen materiellen Grenzen, sondern sie setzen der bürgerlichen Produktionsweise nach der ursprünglichen Akkumulation dialektisch erst ihre Grenzen. Die wesentlichen Losungen der

${ }^{865}$ Bulthaup: Rechtspragmatik oder von der Zwangsläufigkeit des sittlichen Verfalls der Justiz, S. 78. 
bürgerlichen Gesellschaft von Freiheit (libertê) und Gleichheit (egalité) vermitteln die materiellen, historisch gesetzten Voraussetzungen der bürgerlichen Gesellschaft deshalb adäquat: „Gerade in diesem abstrakten Begriff [gemeint ist der Bezug aller Rechtssubjekte auf den die Gleichheit und damit die Voraussetzungen der Reproduktion jedes Einzelnen garantierenden Staates, B.E.B.] wird deutlich, daß die Realisierung von Freiheit und Gleichheit eine ungemütliche Sache ist, weil sie sich erstens ökonomischen Gegensätzen verdankt und zweitens eine mittels Gewaltmonopol erzwungene Aufrechterhaltung dieser Gegensätze zum Zweck hat." "866 Oder wie es Hobsbawm, zugegeben ein wenig verklausulierter, ausdrückt: „Men were equal before the law and careers were equally open to talent; but if the race started without handicaps, it was equally assumed that the runners would not finish together." ${ }^{\text {"867 }}$

So also kann die juristische Fiktion nicht eine reine Einbildung sein, vielmehr liegt in der materiellen und historischen Voraussetzung der bürgerlichen Gesellschaft ihre Begründung. Sie verweist dabei nicht zuletzt auf die gewaltsame Geschichte ihrer Schaffung. Die materielle Ungleichheit der Subjekte ist das konsequente Resultat der historischen, materiellen Voraussetzungen in der postrevolutionären Gesellschaft. Diese materielle Ungleichheit aus den revolutionären Bodenreformen etc. existiert deshalb gerade durch die entscheidenden Rechtsprinzipien der bürgerlichen Gesellschaft weiter, ja sie kann sogar erst durch die staatlich durchgesetzten Begriffen von Gleichheit und Freiheit hindurch weiter existieren (vgl. dazu 3.2.1). Insofern ist die juristische Fiktion als Beschreibung der juristischen Gleichheit auch nach Marx nicht als bloße Einbildung von lediglich verblendeten oder gesellschaftlich bereits verblödeten Subjekten zu sehen, der als Einbildung keinerlei Realität korrespondiere: „Er [der Lohnarbeiter, B.E.B.] und der Geldbesitzer begegnen sich auf dem Markt und treten in Verhältnis zueinander als ebenbürtige Warenbesitzer, nur dadurch unterschieden, daß der eine Käufer, der andere Verkäufer, beide also juristisch gleiche Personen sind.“" ${ }^{868}$ Die wesentlichen Losungen der bürgerlichen Revolution von Freiheit und Gleichheit erweisen sich damit als mit den materiellen Voraussetzungen in sich vermittelte Momente der bürgerlichen Gesellschaft: Sie erfüllen ihren intendierten Zweck, gerade indem sie über die Abstraktion von jedem Inhalt die voraussetzende Konkurrenz der Eigentümer bei der Gewinnung des gesellschaftlichen Reichtums setzen. Für Marx und auch Adorno ist das allgemeine Gesetz deshalb keine Täuschung oder Illusion, eben weil es reelle Gewalt ausübt. Ihrem immanenten Zweck der Absicherung der kapitalistischen Warenproduktion und -distribution zeigt sich die juristische Form der bürgerlichen Gesellschaft damit adäquat. Der objektive Rechtsrahmen garantiert erst den adäquaten Verlauf der bürgerlichen Ökonomie im Sinne ihrer historischen Implementierung. Der objektive Rechts-

\footnotetext{
866 Resultate Bd. 3: Der bürgerliche Staat, S. 11.

867 Hobsbawm: The Age of Revolution, S. 59.

868 Marx: Das Kapital, Bd. 1, S. 182.
} 
rahmen der Egalität wird vom bürgerlichen Staat mit all seiner Macht und Gewalt allen Rechtssubjekten gleichermaßen garantiert. Jeder wechselseitige Austausch vom warendinglichen Eigentum als eines formell freiwilligen Akts der Bürger ist insofern das objektiv implementierte, subjektive Recht eines jeden Revenuequellenbesitzers.

Die Einbeziehung dieses abstrakten Moments personeller Gleichheit als Zweck der kapitalistischen Produktionsweise zur Schaffung gesellschaftlichen Reichtums bleibt jedoch so häufig ein blinder Fleck in gesellschaftswissenschaftlichen Theorien. Es gibt nun nicht wenige Theoretiker, die die juristische formelle Gleichheit der bürgerlichen Gesellschaft verfechten und nur in der angeblich mangelhaften praktischen Umsetzung von Gleichheit den entscheidenden Stichund Kritikpunkt an der gegenwärtigen bürgerlichen Gesellschaft sehen. Die richtige Umsetzung, eine Realisation der schlummernden Gleichheit würde die bürgerliche Gesellschaft demzufolge zum Guten verändern. ${ }^{869}$ An der Stelle wird den Theoretikern die juristische Gleichheit zur reinen, noch unverwirklichten Einbildung. Unterstellt wird deshalb idealistisch, dass die fictio juris im Marxschen Sinne, als durchgesetzte reale Abstraktion von juristischen Inhalten, (noch) nicht existiert. ${ }^{870}$ Weil jedoch die verlängerte historische Ungleichheit das Resultat des bürgerlichen Rechts ist, wird eine Interpretation der fictio juris wie die Joachim Bruhns - dass die Realfiktion des Rechts als Illusion oder Einbildung des Gegenstands nur ein Als ob des Rechts sei - inadäquat: „,Fictio juris' will sagen: tatsächliche, reelle Fiktion, Realfiktion, ein Als ob, das von Staats wegen und von Kapitals wegen den Individuen, die Subjekte sein müssen [!], mit aller Gewalt untergeschoben [!] wird“671. Demnach würde das Gesetz mit seinen allgemein durchgesetzten Rechtsbegriffen einer nur reellen Täuschung unterliegen, die es ja nach der Interpretation der fictio juris gerade nicht ist. Dass das reale Recht den Subjekten mit aller Gewalt, wie Bruhn schreibt, „untergeschoben“ wird, indem es sie zu heteronomen Subjekten macht, muss dabei nicht bestritten werden. Alle Subjekte unterliegen der heteronomen gesellschaftlichen Transzendenz, die beständig verdinglichende Invektiven gegen sie fährt. Das aber macht das Recht als Moment gesellschaftlicher Herrschaft gerade nicht zur Täuschung, zur Illusion, sondern zur Realität und nicht zur Realfiktion. Keine Partikularität der Freiheit einer Klasse etc. lässt sich ausmachen, weshalb die fictio juris kein Mittel zum Zweck ist, mit dem sich etwa die Bourgeoisie nur die Arbeiterklasse gefügig macht.

\footnotetext{
${ }^{869}$ Vgl. etwa in der gegenwärtigen Diskussion Piketty: Das Kapital im 21. Jahrhundert.

870 Vgl. z.B. Abendroth: Das Grundgesetz, S. 12. Abendroth spricht davon, dass erst die sozialistische Gesellschaft „allen gleiche Rechte“ gewähre, anders als die aktuelle bürgerliche Gesellschaft. Als Nachfolger von Abendroth gilt Joachim Perels. (Vgl. Perels: Demokratie und soziale Emanzipation.) Generell geben die Artikel in der von Perels gegründeten und mit herausgegebenen Kritischen Justiz einen guten Überblick über die aktuellen Positionen der Verteidigung des idealen bürgerlichen Rechtsprinzips gegen angeblich unlautere kapitalistische Interessenpolitik.

871 Bruhn: Studentenfutter. Über die Transformation der materialistischen Kritik im akademischen Marxismus.
} 
Der reale Zwang des Rechts ist tatsächlich universell. Auch die Kapitalisten haben sich, als Klasse, bereits als interne Konkurrenten um die Mittel der Reproduktion erwiesen. Als Agenten ihres Kapitals sind auch sie keine frei über dem Recht stehenden Privatpersonen. Das hält Marx bereits in seinen Frühschriften fest: „In der Praxis hat das abuti sehr bestimmte ökonomische Grenzen für den Privateigentümer, wenn er nicht sein Eigentum und damit sein jus abutendi in andre Hände übergehn sehen will." ${ }^{872}$ Die Privateigentümer an Produktionsmitteln können den Rahmen der juristisch definierten Freiheit und Gleichheit nur in dem Maße ausschöpfen, wie es ihnen durch den auch ihnen gesetzten objektiven Rechtsrahmen gewährleistet wird. Diese Durchsetzung des allgemeingültigen Gesetzes ist durchaus ein Fortschritt gegenüber den feudalen Willkürverhältnissen, die noch rein auf persönlicher Gewalt beruhen. Bei genauerem Hinschauen wird jedoch die Dialektik dieses Fortschritts offenbar: Die Verhältnisse sind insofern nicht, wie bei den oben genannten Autoren, als mangelhafte Praxis der Gleichheit zu kritisieren, sondern es muss eine Kritik am historischen und aktuellen Zweck von durchgesetzter Gleichheit, Freiheit und Brüderlichkeit überhaupt formuliert werden. So viel autonomer wie das Handeln in der bürgerlichen Gesellschaft ohne den noch persönlich zwingenden Feudalherren auch sein mag, die Begriffe von Recht, Freiheit, Gleichheit und Brüderlichkeit (liberté, egalité, fraternitê) haben ihre in sich vermittelten materiellen Zwecksetzungen, die sich innerhalb der kapitalistischen Produktionsweise durch sie hindurch realisieren sollen.

Mit der juristischen Fiktion nimmt Marx deshalb genau diese ökonomischen Zwecke der formellen und tatsächlichen Egalität ins Visier. Die Autonomie freier Entscheidungen durch mit freiem Willen begabte Bürger sei demnach keine. Die Entscheidungen bleiben der transzendenten Heteronomie der geschichtlichen Verhältnisse unterworfen. Durch die gewaltvolle Geschichte der Aneignung von Produktionsmitteln und der ausschließenden Verfügung darüber vermittels des Eigentumsbegriffs wird eine entscheidende Heteronomie des Subjekts gesetzt. Der eigentlich autonome Wille des Subjekts hat sich danach mit den juristisch verlängerten Willkürakten der Eigentumssetzung und -sicherung zu arrangieren. Die Rede von der unbedingt freiwilligen Handlung des Subjekts und der formell gleichen Konkurrenz um die Reproduktionsmittel bekommt deshalb bei der Betrachtung ihrer materiellen Voraussetzung entscheidende Risse. Denn der historische Verlust ihres grunddeckenden Besitzes zwingt die produktionsmittellosen Rechtssubjekte erst, im bürgerlich gesetzlichen Rahmen willentlich frei als Eigentümer von nichts als ihrer Ware Arbeitskraft miteinander zu kontrahieren. Durch das geschaffene Eigentum an Produktionsmitteln und ihrem garantierten Eigentum an der Ware Arbeitskraft als ihr subjektives Recht bleibt den bürgerlich emanzipierten Subjekten, die von ihrem Besitz gewaltsam getrennt und jetzt über das allgemeine Eigentumsrecht vermittelt freigesetzt bleiben, nichts weiter übrig,

${ }^{872}$ Marx/Engels: Die Deutsche Ideologie, S. 63. 
als ihre besondere Reproduktion auf dem kapitalistisch eingebundenen inneren Markt für sich selbst als atomisierte Individuen zu organisieren. Das alles impliziert der Ausdruck der juristischen Fiktion, der damit die juristische Gleichheit, die Egalität, nicht etwa als nicht durchgesetzte, und damit idealistisch als reell fiktive kritisiert (wie bspw. Bruhn), sondern im Gegenteil: als durchgesetzte, dialektisch eine materielle Ungleichheit erst realisierende bzw. reproduzierende. Erst diese übergreifende Perspektive auf die gesamtgesellschaftlichen, materiellen Zwecke der Egalität der totalen bürgerlichen Gesellschaft lässt von einer juristischen Fiktion sprechen. Die fictio juris steht insofern auch für die Heteronomie des Subjekts aus System in der bürgerlichen Gesellschaft.

\subsection{Zur Diskussion des permanenten Staatseingriffs in die Ökonomie in der Kritischen Theorie}

Der Gedanke, dass sich der bürgerliche Staat mit seinen objektiven Rechtsprinzipien aus den konkreten, alltäglichen ökonomischen Geschäften heraushalten solle und die kapitalistische Produktionsweise nur dann und deshalb gut funktioniere, ist als ein ,neoliberales' Konstrukt von Staat und Ökonomie bekannt. ${ }^{873}$ An dieses neoliberale Konstrukt knüpfen Theoretiker an, die davon ausgehen, dass es illegal oder zumindest ökonomisch fragwürdig sei, wenn der Staat in den kontemporären ökonomischen Prozess aktiv eingreife. ${ }^{874}$ Auch eine Leugnung des Staates als für die kapitalistische Ökonomie unabdingbare Voraussetzung kann in diesen Kontext gestellt werden.

Es wird dabei jedoch übersehen, dass Staat und Kapital in der bürgerlichen Gesellschaft eine unzertrennliche, dialektisch vermittelte Symbiose eingehen. Dass die inhaltslose Formalität der Rechtsgrundsätze aufgrund der unterschiedlichen Eigentumsverteilung in der bürgerlichen Gesellschaft dialektisch der Grund für die inhaltliche kapitalistische Produktion und die daraus folgende interne Konkurrenz der antagonistischen Klassen ist, konnte bereits gezeigt werden (vgl. $3.2 \mathrm{ff}$.). Die Prinzipien des Rechts wurden dabei als Geburtshelfer des ökonomischen Inhalts überführt. Als Mittel zum Zweck zeigten sich dabei jene in diesen un-

\footnotetext{
${ }^{873} \mathrm{Im}$ von Milton Friedman formulierten Selbstverständnis der Chicago School heißt es, dass man gegenüber permanenten Staatseingriffen in ökonomische Geschäfte generell skeptisch sei: „In discussions of economic policy, ,Chicago' stands for belief in the efficiency of the free market as a means of organizing resources, for skepticism about government intervention into economic affairs, and for emphasis on the quantity theory of money as a key factor in producing inflation." (Friedman: School of Chicago, S. 11, zitiert nach Martin: Remembrance of Things Past: Antitrust, Ideology, and the Development of Industrial Economics, S. 12.) Angesichts des historischen Hintergrunds und praktischen Versuchsfelds der Chicago School klingt Friedmans Aussage zynisch. Die Experimente der ,Chicago Boys' im Chile Pinochets brauchten den faschistoiden Militärstaat, um den freien Markt durchzusetzen. (Vgl. zur Verbindung der Schule mit der Geschichte Chiles: Valdés: Pinochet's Economists. Gegenwärtige Vertreter der Schule sind Richard Posner und Steven Levitt.)

${ }^{874}$ Dieses Argument findet sich auch bei Misik: Kaputtalismus.
} 
trennbar verwoben. Bürgerliches Recht und kapitalistische Ökonomie sind insofern in sich vermittelte Momente kapitalistischer Produktionsweise. Der bürgerliche Rechtstaat mitsamt seinen Institutionen wurde also bereits als ein entscheidendes Moment der das Subjekt zwingenden totalen Systematik dargestellt. Dass sich aus der allgemeinen Formalität ein inhaltliches Verhältnis ergibt, lässt jedoch noch kein hinreichendes Urteil von der notwendigen Immanenz eines permanenten staatlichen Eingriffs in die kapitalistische Produktionsweise, als Notwendigkeit im Rahmen der gesellschaftlichen Totalität, zu. Mittels des Abschnitts zum Anarchokapitalismus und dem darin geführten apagogischen Beweis von der Notwendigkeit des Staates für die kapitalistische Produktionsweise ist zwar die dialektische Vermittlung beider Momente bereits offenbar geworden: Ein zwingender Staat mit allgemeinen Rechtsprinzipien wurde hier als objektiv notwendig für den reibungslosen Ablauf der kapitalistischen Reproduktion dargestellt (vgl. 3.2.3).

Neben dieser indirekten, formellen Gewalt der Egalität behält sich der bürgerliche Staat als Totalität gedacht aber eben auch ganz konkrete Eingriffe in den Produktionszusammenhang vor. Mit ihnen garantiert er erst den reibungslosen Ablauf der kapitalistischen Produktionsweise. Diesen permanenten und aktiven Staatseingriff in die kapitalistische Produktionsweise möchte dieser Abschnitt deshalb fernab der offensichtlichen zwingenden Sicherung der Formalität der bürgerlichen Produktionsweise als einen Notwendigen zur Aufrechterhaltung der kapitalistischen Produktionsweise begründen. Er möchte jenen, auf raumzeitliche Veränderungen des ökonomischen Produktionsprozesses Einfluss nehmenden, reaktiv-direkten Staatseingriff in die kapitalistische Produktionsweise nachweisen, um den Staat wirklich auch als totalen Staat überführen zu können. Dafür könnten nun zunächst entsprechende Subventionsleistungen des bürgerlichen Staates für ein Unternehmen oder einen Unternehmenszweig, erkenntlich in der BRD beispielsweise über den \264 STGB zum Subventionsbetrug, als ein entscheidender Hinweis des direkten Staatseingriffs in die Ökonomie genannt werden. Darüber wird zumindest ein rechtmäßig aktiver Eingriff des Staates in die kapitalistische Produktionsweise nachweisbar. Subventionen können jedoch immer als bloß staatliches Hilfsprogramm in der Not begründet werden, und sie sind auch tatsächlich als Ausnahmen im Umgang mit einzelnen Unternehmen von der kanonischen Regel zu sehen. Zur bestimmten Zeit hat der Staat als Subventionierer offensichtlich ein besonderes Interesse am Weiterbestehen des subventionierten Unternehmens. Das hat er an anderer Stelle und zu anderer Zeit nicht, was auf die spezielle Auswahl von Unternehmen als subventionswürdig hinweist. Darum ist der Hinweis auf Subventionen kein hinreichender Beweis für einen permanenten, aktiven Staatseingriffs in die kapitalistische Produktionsweise.

In den 30er und 40er Jahren des letzten Jahrhunderts kommt es im Institut für Sorialforscbung zu einer vielbeachteten Debatte um den aktiven Staatseingriff in die kapitalistische Produktionsweise. Sie hat hauptsächlich die objektive Stellung des Staates in der bürgerlichen, kapitalistischen Produktionsweise im Vergleich mit 
dem aufkommenden Faschismus zum Gegenstand. Der Streit unter den Mitarbeitern dreht sich wesentlich darum, ob es erst im Faschismus zu einem die Gesellschaft qualitativ verändernden Staatseingriff komme, oder ob dieser nicht doch schon ein wesentliches Merkmal der bürgerlichen Gesellschaft sei. Vor dem Faschismus ins amerikanische Exil geflohen stellt sich den Theoretikern der ,Frankfurter Schule ${ }^{6}$ wie anderen Intellektuellen ${ }^{875}$ jener Zeit die Frage, ob ein direkter Staatseingriff in die kapitalistische Produktionsweise gegenüber dem von ihnen zeitlich früher angesetzten liberalen Kapitalismus das entscheidende Merkmal des aufkommenden Faschismus und amerikanischen Monopolkapitalismus ist, der inzwischen den liberalen Kapitalismus ablöst. Sind also Faschismus und Monopolkapitalismus die entscheidend raumzeitlich besondere, qualitative Veränderung des liberalen Kapitalismus?

Wesentlich für die Beantwortung der Frage wird dabei auch, ob der nachweisbare direkte Staatseingriff in den Produktionszusammenhang ein qualitativ die kapitalistische Produktionsweise veränderndes Moment ist oder ob er seit jeher besteht und die kapitalistische Produktionsweise sich zu Beginn des 20. Jahrhunderts nur quantitativ verändert. Denn ein für den Staat wesentlicher, aktiver und permanenter Eingriff jenseits der ,drei (un-)abhängigen Gewalten ${ }^{6876}$ kann, wenn der permanente Staatseingriff nun einmal nachgewiesen wird, kein qualitativ anderes Moment der sich verändernden kapitalistischen Produktionsweise sein, wenn er sich denn als allgemeines, bereits historisches Moment der Aufrechterhaltung der kapitalistischen Produktionsweise erweist. Wenn also der Staatseingriff als ein permanenter Eingriff nachgewiesen ist, können sich auch die sozialen Phänome der monopolkapitalistischen/faschistischen Zeit nicht qualitativ ändern - weil wesentliche Bedingungen des Phänomens gleich bleiben und die Totalität, in die es eingebunden bleibt, lediglich quantitativ verändert fortbesteht. Das schließt gewisse phänomenale Diskontinuitäten und dessen quantitative Veränderungen nicht aus - aber diese Veränderungen können unter diesen Umständen dann nicht einfach zu eigenständigen Qualitäten umformuliert werden.

Adornos Position hinsichtlich des aktiven Staatseingriffs als qualitativ neues Merkmal des Monopolkapitalismus gegenüber dem klassischen Liberalismus ist

\footnotetext{
875 Vom internationalen Konsens der Intellektuellen, dass es zu einer monopolkapitalistischen Ökonomie gekommen sei, zeugt auch eine Stelle aus Peter Weiss' Roman Die Ästhetik des Widerstands: „Höglund und Ström wollten, zur Herstellung einer gemeinsamen Front, mit dem sozialdemokratischen Vorstand zusammenarbeiten, die Komintern jedoch verordnete parteipolitische Trennung. Die Einheitsfront, um zu einer effektiven Front gegen das Monopolkapital zu werden, mußte unter der Leitung der Kommunistischen Partei stehn." (Peter Weiss, Die Ästhetik des Widerstands, S. 293.)

876 „Insofern sich der Staat in all seinen Handlungen dem von ihm selbst gesetzten Recht unterwirft, sich als Rechtssubjekt beurteilt, wenn er seine Gesetze erläßt (Legislative), Recht spricht (Judikative) und ausführt (Exekutive), eröffnet sich die sinnreiche Frage nach dem gewaltigen Nutzen der wechselseitigen Kontrolle der Staatsgewalten: Ideologie der Gewaltenteilung.“ (Resultate Bd. 3: Der bürgerliche Staat, S. 31.)
} 
zunächst einmal unmissverständlich: Während die gesellschaftliche Herrschaft im liberalen Kapitalismus noch strikt durch das System vermittelt sei, trete im gegenwärtigen Monopolkapitalismus nun eine ganz neue Qualität gesellschaftlicher Herrschaft zutage. Es komme hier zur qualitativen Umänderung von gesellschaftlichen Strukturen, die sich ubiquitär durchsetzten. In allen Bereichen würde Gesellschaft, auch was die sozialen Phänomene anginge, dadurch grundlegend wie nachhaltig verändert. In einem frühen Text, Zur gesellschaftlichen Lage der Musik, von 1932, beschreibt Adorno dieses scheinbar neue qualitative Moment der kapitalistischen Produktionsweise mithilfe eines anschaulichen ästhetischen Modells: In der musikalischen Reproduktion finde sich bereits ein Hinweis auf eine sich verändert habende Qualität der gesellschaftlichen Totalität: „Es ist die entscheidende Veränderung, die die gegenwärtige musikalische Reproduktion dem 19. Jahrhundert gegenüber erfuhr, daß das Gleichgewicht von individualistischer Gesellschaft und individualistischer Produktion vernichtet, die Freiheit der Reproduktion vollends problematisch geworden ist und nirgends besser als hier mag an musikalischen Phänomenen der Übergang vom Konkurrenz- zum Monopolkapitalismus sich erkennen lassen.“"877

Vor allem aber Anfang der 40er Jahre spricht Adorno in Bezug auf die kapitalistische Produktionsweise dann vom liberalen ,Konkurrenzkapitalismus ' versus dem gegenwärtigen, durch den Staatseingriff Bestand habenden ,Monopolkapitalismus', wie Weyand feststellt: „Die Veränderung in der ökonomischen Struktur der Gesellschaft drückt Adorno in den 30er und 40er Jahren in der These vom ,Übergang vom Konkurrenz- zum Monopolkapitalismus', in den späteren Schriften in der These vom Übergang vom frühen zum späten Kapitalismus aus. “878 Auch in den 1942 entstandenen Reflexionen zur Klassentheorie vertritt Adorno die Auffassung, dass es mit dem Monopolkapitalismus zu einer qualitativen Überwindung des laissez-faire-Prinzips des Liberalismus gekommen sei. Die Überwindung der liberalkapitalistischen Phase dränge deshalb zu einem den Kapitalismus qualitativ verändernden Monopolkapitalismus, der dann wiederum in den Faschismus führe: „Die jüngste Phase der Klassengesellschaft wird von den Monopolen beherrscht; sie drängt zum Faschismus, der ihrer würdigen Form politischer Organisation. “879 In Adornos Nachkriegsschriften firmiert dasselbe Phänomen des Monopolkapitalismus dann unter dem Terminus ,Spätkapitalismus', was eine gewisse Kontinuität der Gedanken zum Monopolkapitalismus in Adornos Ouevre erkennen lässt. Selbst noch in seiner letzten Veröffentlichung, der Ästhetischen Theorie ${ }^{880}$, findet sich jene These von der Monopolisierung des Kapitals.

Adorno argumentiert im gleichen Atemzug immer auch, dass die Veränderung in der gesellschaftlichen Struktur wesentliche gesellschaftstheoretische Konse-

\footnotetext{
877 Adorno: Zur gesellschaftlichen Lage der Musik, S. 755.

878 Weyand: Adornos Kritische Theorie des Subjekts, S. 83.

879 Adorno: Reflexionen zur Klassentheorie, S. 376.

880 Vgl. Adorno: Ästhetische Theorie, S. 372.
} 
quenzen habe, die er insbesondere in den Reflexionen zur Klassentheorie am sich verändernden Klassenbegriff aufzeigt. Die im Liberalkapitalismus noch systematisch bedingte unpersönliche, ökonomisch bestimmte herrschende Klasse sei inzwischen nicht mehr so anonym und personell gleichgültig: Als personifizierte Klasse werde ihre Herrschaft über agierende, andere Subjekte zwingende Personen sichtbar. Die Bourgeoisie sei, durch die Veränderung in der gesellschaftlichen Struktur, mittlerweile auch in personam Beherrscher der Arbeiterklasse. Sie herrsche inzwischen durch das System, ohne selbst noch durch dieses beherrscht zu werden. Die ökonomischen Fesseln ihrer eigenen Beherrschung, ihre wechselseitige Kontrolle durch Konkurrenz, habe sie inzwischen weitestgehend abgeworfen. So sei sie ein Stück weit selbst zum herrschenden System geworden: „Aber die herrschende Klasse wird nicht nur vom System beherrscht, sie herrscht durchs System und beherrscht es schließlich selber. Die modifizierenden Umstände stehen extraterritorial zum System der politischen Ökonomie, aber zentral in der Geschichte der Herrschaft. “881 Diese Interpretation von Klasse und Herrschaft hat nun entscheidende Auswirkungen auf den Klassenbegriff. Die Klasse im Faschismus und Monopolkapitalismus kann nun nicht mehr mit dem Marxschen objektiven Klassenbegriff bestimmt werden, weil dieser sich ausschließlich auf den Liberalismus bezog. Die Klasse ist zu einer modernen herrschenden Klasse geworden, die sich von ihrem klassischen liberalkapitalistischen Pendant auch, aber nicht nur, durch ihre offene Sichtbarkeit unterscheide. Wird die Bourgeoisie als selbst zum System gewordene personifizierte Herrschaft interpretiert, überführt man den klassisch objektiven Begriff der Bourgeoisie, der sich nur in Bezug auf das gesellschaftliche Gesamtkapital darstellt (vgl. 2.6.3), zugleich als antiquiert. Unter dem Eindruck gesellschaftlicher Transformation wird die Bourgeoisie anders als zuvor begriffen, wodurch auch die Klassengesellschaft anders begriffen wird. Deshalb wird die Marxsche Klassentheorie von Adorno konsequent durch seine Rackettheorie abgelöst. 882

Mit der Rackettheorie verliert der objektive Klassenbegriff jedoch seine gesamte Substanz, weil sich das, was bei Marx die Objektivität des Klassenbegriffs ausmacht, bei Adorno ins Subjekt verschiebt. ${ }^{883}$ Starke Subjekte würden demzufolge Geschichte, auch Klassengeschichte machen: „Die Geschichte ist, nach dem Bilde der letzten ökonomischen Phase, die Geschichte von Monopolen. Nach dem Bilde der manifesten Usurpation, die von einträchtigen Führern von Kapital und Arbeit heute verübt wird, ist sie die Geschichte von Bandenkämpfen, Gangs und

\footnotetext{
881 Adorno: Reflexionen zur Klassentheorie, S. 385.

882 Adorno übernimmt den Racketbegriff von Max Horkheimer. (Vgl. etwa Horkheimer: Zur Soziologie der Klassenverhältnisse, S. 104.)

${ }^{883}$ Das kritisiert Adorno an anderen Theorien vehement. In seiner Antrittsvorlesung sagt er: „So hat man etwa den Begriff der Klasse aufgehoben und durch zahllose Deskriptionen einzelner Gruppen ersetzt, ohne sie mehr zu übergreifenden Einheiten anordnen zu können, wiewohl sie doch in der Empirie als solche in Erscheinung treten“. (Adorno: Die Aktualität der Philosophie, S. 340.)
} 
Rackets.“884 Der Rackettheorie zufolge werde die Bourgeoisie als vormals systemimmanente Klasse von den kriminellen und monopolbildenden racketeers zunächst okkupiert, dann übernommen. 885 Aus „der Dialektik der Klasse“ werde so „am

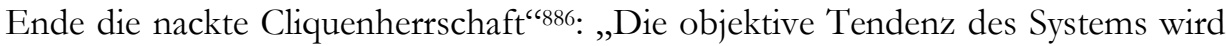
immer vom bewußten Willen derer verdoppelt, gestempelt, legitimiert, die darüber verfügen. "887 Deshalb machten sich die rackets den vormals objektiven, liberalen Staat zu ihren persönlichen Zwecken zu eigen. Sie würden sich ihren eigenen persönlichen Vorteil aus den für sich selbst vorteilhaft zugeschnittenen ökonomischen Verhältnissen schaffen, allein weil sie es können. Diese zugeschnittenen ökonomischen Verhältnisse seien Resultat der Veränderung der Produktionsverhältnisse: „Diese sind nicht länger mehr allein solche des Eigentums, sondern der Administration, bis hinauf zur Rolle des Staates als des Gesamtkapitalisten. " 888 In Deutschland insbesondere sei diese Herrschaft der Rackets dann in den Faschismus übergegangen.

Adorno geht somit von einem direkten, politischen und willkürlichen Eingriff zur Modifikation der politischen Ökonomie durch das „Primat der Administration"889 aus, das nur durch Fortschritt in der Produktion ermöglicht werde. Jener administrative Eingriff in den Produktionszusammenhang mache den entsprechenden, entscheidend qualitativen Unterschied zum liberalen, bürgerlichen Kapitalismus aus. Die kapitalistische Produktionsweise werde deshalb inzwischen nur noch gewaltsam konserviert, obwohl sie eigentlich, aus ihrer eigenen reflexiven Dynamik des Klassenverhältnisses heraustretend, bereits am Ende sei: „Die Macht der Produktionsverhältnisse, die nicht umgewälzt wurden, ist größer als je, aber zugleich sind sie, als objektiv anachronistisch, allerorten erkrankt, beschädigt, durchlöchert. Sie funktionieren nicht mehr selbsttätig. " ${ }^{\circ 90}$

Diese Interpretationen lassen sich durchaus an den zu jener Zeit populären Marxismus-Leninismus anschließen. Adornos Thesen zur Rackettheorie gleichen der entsprechenden Auffassung des Histomats (historischer Materialismus), der aus dem Diamat (dialektischer Materialismus) die gesellschaftliche Komponente herausarbeitet: dass der Widerspruch zwischen Produktivkräften und Produktionsverhältnissen dialektisch in eine gesellschaftliche Emanzipation umschlage. ${ }^{891}$

\footnotetext{
884 Adorno: Reflexionen zur Klassentheorie, S. 381.

885 Vgl. zu dieser Interpretation bei Adorno etwa Türcke/Bolte: Einführung in die Kritische Theorie, S. 49.

886 Adorno: Reflexionen zur Klassentheorie, S. 383.

887 Ebd., S. 387.

888 Adorno: Spätkapitalismus oder Industriegesellschaft?, S. 363.

889 Adorno: Ästhetische Theorie, S. 372.

890 Adorno: Spätkapitalismus oder Industriegesellschaft?, S. 367.

${ }^{891}$ Die These des notwendigen dialektischen Umschlags durch die Widersprüche von Produktivkräften und Produktionsverhältnissen findet sich ausschließlich in Marx' Frühschriften. Vor allem im Vorwort zur Kritik der politischen Ökonomie heißt es bei ihm: „Aus Entwicklungsformen der Produktivkräfte schlagen diese Verhältnisse [Eigentums- und Produktionsverhältnisse, B.E.B.] in Fesseln derselben um. Es tritt dann eine Epoche sozialer Revolution ein.“ (Marx: Zur Kritik der
} 
Adorno geht diesen teleologischen movens der Geschichte also zunächst mit. Allein der qualitative Umschlag in Emanzipation bleibe für ihn, wie schon für Lukács ${ }^{892}$, obwohl er hätte unlängst an der Zeit sein müssen, aus. Er offenbart sich stattdessen negativ als ein Umschlag in Regression und nicht als tendenzielle Aufsprengung des repressiven Klassenantagonismus aus sich heraus: Regression statt Revolution, rackets statt befreiter Subjekte und Gesellschaft. Wenn Adorno von der „letzten ökonomischen Phase“"893, als der „Geschichte von den Monopolen“"894 spricht ${ }^{895}$, wird auch hier eine Übereinstimmung mit Lenins Thesen aus Der Imperialismus als dem höchsten Stadium des Kapitalismus ${ }^{896}$ offenbar. Lenin formuliert dort eine an Hilferding ${ }^{897}$ angelehnte These: Zum notwendigen Imperialismus als höchstem Stadium der „Weiterentwicklung und direkte[n] Fortsetzung der Grundeigenschaften des Kapitalismus überhaupt ${ }^{\text {“898 }}$ oder der allerletzten Stufe vor dem Umschlag in gesellschaftliche Emanzipation schreibt Lenin: „1. Konzentration der Produktion und des Kapitals, die eine so hohe Entwicklungsstufe erreicht hat, daß sie Monopole schafft, die im Wirtschaftsleben die entscheidende Rolle spielen; 2. Verschmelzung des Bankkapitals mit dem Industriekapital und Entstehung einer Finanzoligarchie auf der Basis des ,Finanzkapitals'; 3. der Kapitalexport, zum Unterschied vom Warenexport, gewinnt besonders wichtige Bedeutung; 4. es bilden sich internationale monopolistische Kapitalistenverbände, die die Welt unter sich teilen, und 5. die territoriale Aufteilung der Erde unter die kapitalistischen Großmächte ist beendet. Der Imperialismus ist der Kapitalismus auf jener Entwicklungsstufe, wo die Herrschaft der Monopole und des Finanzkapitals sich herausgebildet, der Kapitalexport hervorragende Bedeutung gewonnen, die Aufteilung der Welt durch die internationalen Trusts begonnen hat und die Aufteilung des gesamten Territoriums der Erde durch die größten kapitalistischen Länder abgeschlossen ist." "899 Dieses Urteil der Imperialismusschrift bezüglich der persönlichen Vorteilsnahme der Kapitalistenklasse veranlasst Lenin in Staat und Revolution

politischen Ökonomie, S. 9; vgl. auch: Das Elend der Philosophie, S. 140; Klassenkämpfe in Frankreich, S. 98.) Ausgearbeitet hat den historischen Materialismus Engels. (Vgl. Historisch-Kritisches Wörterbuch des Marxismus: Band 6/I, S. 319 f.)

892 Georg Lukács versucht die Frage nach dem Ausbleiben der Revolution mit der Verdinglichung des Bewusstseins der Arbeiterklasse, resultierend aus der Warenförmigkeit des Kapitalismus, zu erklären. „Die Selbsterkenntnis des Proletariats“ sei deshalb ,zugleich die objektive Erkenntnis des Wesens der Gesellschaft.“ (Lukács: Geschichte und Klassenbewußtsein, S. 267.)

${ }^{893}$ Adorno: Reflexionen zur Klassentheorie, S. 381.

${ }^{894}$ Ebd.

895 Ebd.

896 Lenin: Der Imperialismus als höchstes Stadium des Kapitalismus.

${ }^{897}$ Hilferding: Das Finanzkapital, S. 17: „Das Charakteristische des ,modernen“ Kapitalismus bilden aber jene Konzentrationsvorgänge, die einerseits in der ,Aufhebung der freien Konkurrenz' durch die Bildung von Kartellen und Trusts, andererseits in einer immer innigeren Beziehung zwischen Bankkapital und industriellem Kapital erscheinen.“

898 Lenin: Der Imperialismus als höchstes Stadium des Kapitalismus, S. 98.

899 Ebd., S. 99 f. 
dazu, den Staat der Bourgeoisie, „das Organ der Herrschaft einer bestimmten Klasse", 900 nach der kommunistischen Revolution unter die Kontrolle der KP zu stellen. Der Bourgeoisie, so Lenin, solle gewaltsam „im Namen der Gesellschaft ${ }^{\text {" }}{ }^{01}$ der ihren Interessen funktionelle Staat entrissen werden. ${ }^{902}$ Auch bei Lenin hat der objektive Klassenbegriff Marx' aus dem Kapital deshalb längst seine Substanz verloren.

Adornos Analyse von Personalisierung und Subjektivierung der ökonomischen Herrschaft geht aber nicht nur auf sich seinerzeit durchsetzende intellektuelle Konzepte ein. In seinen Schriften finden auch gesellschaftliche Erscheinungen der 30er und 40er Jahre, die diesen Schluss empirisch zulassen, entsprechenden Niederschlag. Seit Beginn des 20. Jahrhunderts buhlen organisierte Banden in den USA um die ökonomische und politische Vorherrschaft. Ein gewisses Rackettum wird durch soziale Veränderungen, besonders zu Zeiten der Prohibition in den USA (1918-1933), auch empirisch nachweisbar. Mit exzessiver Gewalt versuchen viele sogenannte misfits den sozialen und ökonomischen Aufstieg. ${ }^{903}$ Neben der Prohibition bringt die heftige Armut, besonders unter Neueinwanderern und auch noch vor dem berühmten Immigration Act von 1924904, sehr kreative kriminelle Modelle hervor. Diese Kriminalität garantiert vielen misfits in den USA erst ihren Lebensunterhalt. Nach dem New Deal unter Roosevelt, nach der Krise 1929, kommt es deshalb zu durchaus spezifischen Eigenheiten bei der phänomenalen Ausprägung des Kapitalismus.

Aber nicht nur die offensichtlichen kriminellen Machenschaften z.B. der International Brotherhood of Teamsters unter Jimmy Hoffa ${ }^{905}$, die sich wie die Mafia um $\mathrm{Al}$ Capone die ihnen bietenden ökonomischen Chancen nicht entgehen lassen wollen, spielen bei der Wahrnehmung gesellschaftlicher Veränderungen eine Rolle. $\mathrm{Zu}$ dieser veränderten Wahrnehmung trägt nun auch der zeitgleich in Europa aufkommende Faschismus mit seinem exzessiven Personen- und Führerkult bei. Von Adorno wird gesellschaftliche Herrschaft deswegen, gegen die Marxsche Analyse, aus der ökonomischen Sphäre gehoben und deshalb dann auch personalisiert. Zwar verliert Adorno die dialektischen gesellschaftlichen Vermittlungen dabei nicht ganz aus den Augen ${ }^{906}$, doch die Personalisierungen bleiben bei ihm ambivalent. In seinem Gesamtwerk, unabhängig der Jahreszahlen der Veröffentli-

\footnotetext{
${ }^{900}$ Lenin: Staat und Revolution, S. 10.

${ }^{901}$ Ebd., S. 22.

902 Vgl. zu jener These generell Ebd., S. 19 ff.

903 Vgl. Raab: Five Families; Katcher: The Big Bankroll; vgl. dazu auch den Roman F. Scott Fitzgeralds: The Great Gatsby. Dieser beschreibt Amerika zu Zeiten des so genannten ,Jazz Age' der Zwanzigerjahre des 20. Jahrhunderts.

${ }^{904}$ Der Immigration Act of 1924 war die Reaktion auf die hohe Arbeitslosenquote, der man meinte, durch eine Quote für unerwünschte Einwanderer - die rassistisch begründet wurde - Herr zu werden.

905 Vgl. Witwer: The Most Racketeer-Ridden Union in America.

906 Vgl. etwa Adorno/Horkheimer: Dialektik der Aufklärung, S. 209 f.
} 
chung, lassen sich darum zwei widersprüchliche Stränge finden. Wie in der oben schon zitierten Schrift, der Ästhetischen Theorie, findet sich auch in späteren Schriften noch die These von der qualitativen Veränderung in den Produktionsverhältnissen. Herrschaft gilt ihm im 1968 entstandenen Text Spätkapitalismus oder Industriegesellschaft? allerdings als ökonomisch vermittelt und nicht mehr nur als politisch von Rackets oktroyierte. Die Differenz wird in der systemimmanenten politischadministrativen Absicherung des Produktionsverhältnisses durch den Staat gesehen.

Das kann als ein Abwenden Adornos von Lenins Thesen aus der berühmten Imperialismustheorie gesehen werden: „Der wirtschaftliche Interventionismus ist nicht, wie die ältere liberale Schule meint, systemfremd aufgepfropft, sondern

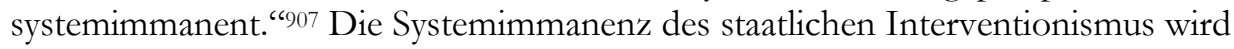
als Resultat der spezifischen Dialektik, als Folge eines „Umschlag[s] “908 von Quantität in Qualität begriffen. Die Zunahme der Staatseingriffe in die kapitalistische Produktionsweise begründe deshalb nicht nur eine quantitative, sondern auch eine qualitative Differenz des Spätkapitalismus gegenüber der liberalkapitalistischen Phase: „Konstituens des Systems“ sei das vormals „Systemfremde" "909, die das System scheinbar äußerlich aufrechterhaltende politische Gewalt, die jetzt dialektisch ins System integriert wurde. Das sei deshalb im Resultat die offensichtliche „Rückbildung des liberalen Kapitalismus“, der inzwischen „,nicht mehr selbsttätig ${ }^{\text {“"910 }}$ wie der von Marx als ,automatisches Subjekt“"911 begriffene Kapitalismus funktioniere. Die Frage, ob ein Staatseingriff in die kapitalistische Produktionsweise äußerliche oder logisch immanente, eine das System immer schon konstituierende und nicht nur phänomenale Gewalt ist, beschäftigt Adorno insofern sein gesamtes Werk hindurch. Sie bleibt allerdings ungelöst.

Adorno wirft damit jedoch die entscheidende Frage auf, ob denn der Prozess der Gewinnung gesellschaftlichen Reichtums nach liberalkapitalistischen Prämissen, wie in Spätkapitalismus oder Industriegesellschaft?, inzwischen einfach als substanzlos in Frage gestellt werden kann? Ist der aktive Eingriff in den ökonomischen Zusammenhang der bürgerlichen Gesellschaft als Folge der inzwischen scheinbar administrativ verwalteten Welt nun Merkmal einer qualitativen Differenz, die den Liberalkapitalismus zur Geschichte macht, oder werden hier nur phänomenale Veränderungen im Zusammenhang von Politik und Ökonomie einfach als wesentliche Veränderung der kapitalistischen Produktionsweise begriffen? Adornos im Rahmen seiner Untersuchungen dazu gemachten Anspielungen auf Lenin sind dabei vermutlich nur vermittelt in seine Gesellschaftstheorie eingeflossen; zumal Adorno Lenin nicht zitiert.

\footnotetext{
907 Adorno: Spätkapitalismus oder Industriegesellschaft, S. 367.

908 Ebd., S. 368.

909 Ebd.

910 Ebd., S. 367 f.

911 Marx: Das Kapital, Bd. 1, S. 169.
} 
Es ist Pollock, der Lenins Thesen, ebenfalls implizit, in die Debatten der Kritischen Theorie bringt. ${ }^{912}$ In erster Linie sind es dessen in den 30er und 40er Jahren geschriebenen Beiträge für die Zeitschrift für Sozialforschung, die dann auch eine Grundsatzdebatte um den entweder permanenten oder doch historisch neuen Staatseingriff in die kapitalistische Produktionsweise auslösen: „Die ökonomische Begründung der Differenz zwischen liberalem und monopolistischem bzw. später zwischen frühem und spätem Kapitalismus geht wesentlich auf die Analysen Friedrich Pollocks zurück.“"913 Pollock unterstellt als erster aus dem Kreis des Instituts eine qualitative Differenz zwischen den einzelnen kapitalistischen Entwicklungsphasen, der bürgerlichen und der monopolkapitalistischen Phase, was der Leninschen Imperialismustheorie gleicht. Pollock behauptet eine angeblich ganz neue Qualität des Kapitalismus gegenüber der liberalen Phase: „Was zu Ende geht ist nicht der Kapitalismus, sondern nur seine liberale Phase. "914 Diese qualitative Differenz resultiere für ihn im Faschismus bzw. Monopolkapitalismus. Pollock registriert zwar in einem 1933 erschienenen Beitrag für die Zeitschrift für Sozialforschung „Geburtshelferdienste“915 der Staatsgewalt für die kapitalistische Produktionsweise, diese sie konstituierenden, interessengeleiteten staatlichen Eingriffe zur Gewährleistung der kapitalistischen Produktion würden in der sich daraus entwickelnden liberalen Phase des Kapitalismus dann jedoch „,beiseite geschoben“916. Erst in Folge der Weltwirtschaftskrise von 1929 greife der Staat wieder in „die durch den Liberalismus postulierte Vertragsfreiheit“"917 ein. Deshalb sei der monopolkapitalistische Kapitalismus auch nicht mehr mit den Kategorien der klassischen politischen Ökonomie zu begreifen. Er zeichne sich inzwischen durch ineinander verschmolzene politische und ökonomische Machtbereiche aus. In State Capitalism, 1941 in der Zeitschrift für Sozialforschung erschienen, heißt es: „Under private capitalism greater profits signify greater power and less dependence upon the commands of others. The difference, however, is not only that the profit motive is a mediated form of the power motive, but that the latter is essentially bound up with the power position of the ruling group while former pertains to the individual only. "918 Deshalb habe der New Deal Roosevelts nach 1929 nicht nur die Karten neu gemischt. Er habe auch eine qualitativ neue Form der Gewinnung von

\footnotetext{
912 Pollock selbst nimmt in Bemerkungen zur Wirtschaftskrise zwar nicht positiv auf Lenin Bezug, schreibt aber bezüglich der krisentheoretischen Debatten sehr an Lenin erinnernd: „Was man heute ,Selbstdeflation“ nennt und was einen Hauptgegenstand des krisentheoretischen Streites bildet, lässt sich auch in den früheren Krisen beobachten (wenngleich nicht in der heutigen Schärfe): der ,Reinigungsprozess ${ }^{`}$ bewirkt stärkste Preissenkungen, die Bankrotte verursachen und damit weitere Zwangsverkäufe und neue Zusammenbrüche, so dass man in einen fehlerhaften Zirkel gerät.“ (Pollock: Bemerkungen zur Wirtschaftskrise, S. 323.)

913 Weyand: Adornos Kritische Theorie des Subjekts, S. 83.

914 Pollock: Bemerkungen zur Wirtschaftskrise, S. 350.

915 Ebd., S. 346.

916 Ebd.

917 Ebd.

918 Pollock: State Capitalism, S. 207.
} 
gesellschaftlichem Reichtum, eben über den monopolorientierten Staatskapitalismus, geschaffen: „Under state capitalism“, so Pollock, „this power has been transferred to the government which is still limited by certain ,natural' restrictions but free from the tyranny of an uncontrolled market. “"919

Die Thesen Pollocks werden im Kreise des Instituts allerdings kontrovers diskutiert, denn auch wenn sich Adorno zeitweise Pollocks Überlegungen anschließt, so kritisiert Franz Neumann die nicht ganz grundlos an Lenins Krisentheorie ${ }^{920}$ erinnernden Überlegungen zur spezifischen, qualitativen Differenz von liberalem Kapitalismus und Monopolkapitalismus: Er hält sie für konstruiert. Das weist er im 1944 verfassten Behemoth systematisch am Beispiel der Ökonomie des Nationalsozialismus nach. Gegen die „wachsende Tendenz, den kapitalistischen Charakter des Nationalsozialismus zu leugnen" "921, womit er Pollocks Primatthese angreift, schreibt er, dass die Argumentation von der Spezifizität der faschistischen Ökonomie notwendig auf „eine Ökonomie ohne Ökonomie“"222 hinauslaufe. Im Nationalsozialismus sei der traditionelle, liberale Kapitalismus nicht deshalb gleich abgeschafft, weil der Staat und Partei in ihn eingreifen würden und die Konkurrenz jetzt vermeintlich politisch und nicht ökonomisch von oberster Stelle entschieden werde; im Gegenteil: die „Widersprüche des Kapitalismus“923 seien inzwischen auf einem sehr viel „,höheren und deshalb auch gefährlicherem Niveau wirksam (...), auch wenn diese Widersprüche durch einen bürokratischen Apparat

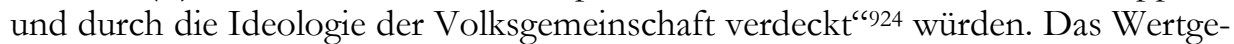
setz, das Herzstück der bürgerlich-kapitalistischen Ökonomie, sei durch den aktiven, nationalsozialistischen Staatseingriff und seine politische Regelung der Konkurrenz deshalb auch nur vermeintlich abgeschafft. Die politische Entscheidung der Konkurrenz durch die Monopolisierungen der Wirtschaftszweige verbleibe nach Neumann in der ökonomischen Sphäre verhaftet, weshalb nicht aus der Totalität einer historischen Kontinuität der kapitalistischen Gesellschaft herausgefallen werde. Nichts spreche daher für die qualitative Veränderung des kapitalistischen Produktionsverhältnisses in der monopolkapitalistischen Phase. Mehr noch: Für Neumann erweist sich der dafür herangezogene aktive Staatseingriff in den ökonomischen Prozess, auch des nationalsozialistischen Staates, wie im bürgerlichen, liberalkapitalistischen Staat als ein weiterhin allgemein beständiges, notwendiges Moment der Existenz des Kapitalismus. Durch alle objektiv realisierten

\footnotetext{
919 Ebd.

${ }^{920}$ Lenin wird im Historisch-Kritischen Wörterbuch des Marxismus unter dem Lemma Krisentheorie als expliziter sowie vor allem impliziter Ideengeber für viele Krisentheoretiker vernachlässigt. Selbst in Schriften, in denen man einen Leninismus nicht unbedingt vermutet, tauchen seine Thesen jedoch vermittelt wieder auf. (Vgl. bspw. Misik: Kaputtalismus, S. 20 ff.)

${ }^{921}$ Neumann, Behemoth, S. 272.

922 Vgl. Ebd., S. 273.

923 Vgl. Ebd., S. 278.

924 Ebd.
} 
Begriffe wie Freiheit, Gleichheit und Eigentum hindurch erweise sich der Eingriff des kapitalistischen, bürgerlichen Staates auch für ihn als praktisch notwendig. ${ }^{925}$

Auch Marx beschreibt im Kapital bereits eine systematische Voraussetzung des aktiven Staatseingriffs in die kapitalistische Produktionsweise zu ihrem Funktionieren. ${ }^{926}$ Mit der Fabrikgesetzgebung im England des 19. Jahrhunderts verweist er auf die beständige Notwendigkeit des direkten, aktiv staatlichen Eingriffs in die kapitalistische Ökonomie: die Regulation der (Mehr-)Produktion durch den liberalen, bürgerlichen Staat: „Die Fabrikgesetzgebung, diese erste bewußte und planmäßige Rückwirkung der Gesellschaft auf die naturwüchsige Gestalt ihres Produktionsprozesses, ist, wie man gesehn, ebensosehr ein notwendiges Produkt der großen Industrie als Baumwollgarn, Selfactors und der elektrische Telegraph.“927 Daneben kann die Einführung der Schulpflicht in der Weimarer Republik $1919^{928}$ genauso wie die Fabrikgesetzgebung als das korrigierende Mittel des bürgerlichen Staates zum politisch-ökonomischen Zweck gesehen werden, der Aufrechterhaltung der kapitalistischen Produktionsweise als politisches Eigeninteresse im Rahmen der gesellschaftlichen Totalität: „Was also in dieser englischen Gesetzgebung von 1867 auffällt, ist einerseits die dem Parlament der herrschenden Klasse aufgezwungene Notwendigkeit, so außerordentliche und ausgedehnte Maßregeln gegen die Übergriffe der kapitalistischen Exploitation im Prinzip anzunehmen; anderer-

${ }^{225}$ Auch Jan Weyand kritisiert in seiner Dissertation den entscheidenden „Irrtum Pollocks“ bei der Bestimmung der Totalität der kapitalistischen Produktionsweise: er bestehe „darin, daß er [Pollock, B.E.B] Veränderungen im Verhältnis von Politik und Ökonomie als wesentliche Veränderung der kapitalistischen Produktionsweise begreift. Die aus seiner These eines Umschlags von einem Primat der Ökonomie in einen Primat der Politik entfalteten Widersprüche haben gezeigt, daß das, was Pollock als Primat der Politik erscheint, die ungebrochene Funktion der kapitalistischen Produktionsweise unterstellt." (Weyand: Adornos Kritische Theorie des Subjekts, S. 87.)

926 Von Überlegungen Keynes hin bis zu den französischen Regulationstheoretikern um Michel Aglietta, Louis Althusser, Alain Lipietz, Nicos Poulantzas u.a. kommt es immer wieder mit unterschiedlichen Schwerpunkten zur Beschäftigung des Einflusses des Staates auf die Produktionsweise. Poulantzas sieht, dass die dialektische Vermittlung von Staat und Ökonomie unbedingt gedacht werden muss, wenn man die politische Ökonomie ernst nehmen möchte. In der Staatstheorie heißt es: „Diese Trennung [von Staat und Ökonomie, B.E.B.] darf nicht im Sinne einer wirklichen Äußerlichkeit von Staat und Ökonomie verstanden werden, als Intervention des Staates von außen in die Ökonomie. Diese Trennung ist nur die bestimmte Form, die im Kapitalismus die konstitutive Präsenz des Politischen in den Produktionsverbältnissen und ibrer Reproduktion annimmt." (Poulanzas: Staatstheorie, S. 47, kursiv i. Orig.) Die von Poulantzas beschriebene Dialektik von Staat und Ökonomie ist die entscheidende gesellschaftstheoretische Dialektik vom Standpunkt einer gesellschaftlichen Totalität aus, mit der alle in sich vermittelten Momente adäquat zu begreifen versucht werden. Ohne diese Dialektik wäre die Rationalität und damit auch das Überleben des Kapitalismus in Frage gestellt. Diese sollen hier aber kein Gegenstand sein.

${ }_{927}$ Marx: Das Kapital, Bd. 1, S. 504.

928 Vgl. tagesspiegel.de: Schulpflicht. Erst mit der Weimarer Republik galt sie in ganz Deutschland.. Mit der Einführung der Schulpflicht wird nun zugunsten der Aufrechterhaltung des inzwischen großflächig rekrutierenden stehenden Militärs die Kinderarbeit abgeschafft. Damit wird Kindern aus staatlichen, die Aufrechterhaltung der gesellschaftlichen Totalität betreffenden Intentionen heraus die Möglichkeit genommen, als Personen ihre Ware Arbeitskraft vor Vollendung der Schulpflicht zu verkaufen. 
seits die Halbheit, der Widerwille und die mala fides, womit es diese Maßregeln dann wirklich ins Leben rief." "929 Neumann nimmt diese Analysen Marx' zum notwendigen Staatseingriff als einer der wenigen Intellektuellen jener Zeit ernst. ${ }^{930}$

Die Kritik Neumanns an Pollocks Thesen überzeugt Horkheimer allerdings nicht. Obwohl sich Horkheimer nicht dezidiert mit der Frage nach dem Staatseingriff beschäftigt, geht die Debatte unter den Mitarbeitern der Zeitschrift für Sozialforschung um den direkten Staatseingriff auch an ihm nicht spurlos vorbei. Er bestreitet Neumanns Kritik an den Thesen Pollocks dabei implizit. Seine Analysen des spätbürgerlichen Kapitalismus bzw. des Faschismus halten das kapitalistische Wertgesetz im Faschismus und monopolistischen Spätkapitalismus für korrumpiert. In seinem zentralen Text der 40er Jahre, Die Juden und Europa, spricht er deshalb von der inzwischen ,zerfallenden Marktwirtschaft [sic!]“"931. Daraus würde nun das Ende freier marktwirtschaftlicher Verträge resultieren, womit der Verlust der liberalen Sicherheiten und demokratischen Prinzipien einhergehe. ${ }^{932}$ Wie Pollock unterstellt er damit den vertikalen Bruch in der Organisation der allgemeinen Reproduktion, die qualitative Differenz von liberalem Kapitalismus und späterem, monopolkapitalistischem Faschismus. Die Gewinnung gesellschaftlichen Reichtums werde im Monopolkapitalismus/Faschismus allein noch durch eine unbändige, staatliche Autorität realisiert. Zwar habe der liberale Kapitalismus, wie schon bei Pollock, bereits entscheidende Vorarbeit für Faschismus und Spätkapitalismus geliefert, er wurde jedoch, nahezu teleologisch, mithilfe seiner eigenen Voraussetzungen ausgekontert: „Er [der Faschismus, B.E.B.] fixiert die extremen Unterschiede, die das Wertgesetz am Ende [sic!] produzierte." "933 In einer späteren, 1942 veröffentlichten Schrift, Autoritärer Staat, bekräftigt Horkheimer dann nochmals: „Eine Periode mit eigener gesellschaftlicher Struktur [sic!] hat die freie Wirtschaft abgelöst.“"934

In ihrem sogar Pollock gewidmeten Werk, der Dialektik der Aufklärung (geschrieben 1939-1944), sprechen Adorno und Horkheimer dann auch noch einmal gemeinsam von einem staatlich konstruierten Verlust der Konkurrenz im faschistischen sowie im nachbürgerlichen Monopolkapitalismus. Im Monopolkapitalismus herrsche im Gegensatz zur liberalkapitalistischen Phase auch lediglich ein „Schein der Konkurrenz ${ }^{“ 935}$, weil es zur politischen Entscheidung für oder wider

\footnotetext{
${ }_{929}$ Marx: Das Kapital, Bd. 1, S. 519.

${ }^{930}$ Poulantzas sieht in den 70er Jahren des 20. Jahrhunderts ebenfalls den immer notwendigen Staatseingriff in den ökonomischen Zusammenhang: „Genausowenig wie im vormonopolistischen Stadium der Staat sich wirklich außerhalb des Raums der Reproduktion des Kapitals befand, führt die Tätigkeit des Staates im monopolistischen Stadium (...) umgekehrt zu einer Aufhebung der Trennung von Staat und Ökonomie." (Poulantzas: Staatstheorie, S. 47.)

${ }^{931}$ Horkheimer: Die Juden und Europa, S. 117.

932 Vgl. ebd., S. 116.

933 Ebd.

934 Horkheimer: Autoritärer Staat, S. 295.

935 Horkheimer/Adorno: Dialektik der Aufklärung, S. 144.
} 
die ökonomischen Konkurrenten komme, weswegen in der Konsequenz der „freie Markt zu Ende“"936 gehe. Aus dem neuen gesellschaftlichen Prinzip der autoritären staatlichen Kontrolle heraus mache der Schein der Konkurrenz alles zu einem Gleichen, was auch die Gleichschaltung im Nationalsozialismus erkläre. Weil bloß noch scheinbar auf dem Markt konkurriert werde, treibe die durch den autoritären Staat exerzierte politische Monopolisierung der Ökonomie zur die

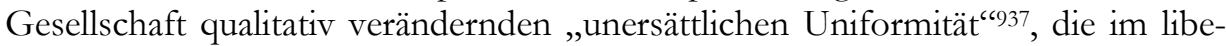
ralkapitalistischen Staat nun ihresgleichen suche. Damit gleicht das Urteil der Dialektik der Aufklärung dem Pollockschen Primat der Politik unter staatskapitalistischen Prämissen.

Adorno, Horkheimer und Pollock begeben sich damit jedoch auf recht unwegsames theoretisches Terrain: Das Argument vom monopolistischen Staatskapitalismus hat aporetische Konsequenzen, denn sollte die Konkurrenz im Monopolkapitalismus wirklich außer Kraft gesetzt sein, so unterlägen die Warenpreise einzig noch einem politisch motivierten Diktat. Durch die politischen Eingriffe würde der vormals kapitalistische Markt gleichgeschaltet und die Preise der Waren könnten nicht mehr, wie im liberalen Kapitalismus, durch die interne Konkurrenz der Einzelkapitale gebildet werden - also nicht mehr durch Kostpreis plus Durchschnittsprofit. Diesen allgemeinen Durchschnittsprofit bezeichnet Marx jedoch noch als den entscheidenden Oszillationspunkt der Profitrate. Die Profitrate, die sich aus dem Verhältnis des erzwungenen Mehrwerts zum Gesamtkapital ergibt, signalisiert nun, dass die mit Eigentumstiteln bestückten Waren nicht zu ihren jeweiligen Werten, sondern ihren jeweiligen Produktionspreisen verkauft werden. So ist die Durchschnittsprofitrate auch Marx' Antwort auf den sich ergebenden Widerspruch der unterschiedlich realisierten Mehrwertraten in den unterschiedlichen Produktionszweigen mit ihrer jeweils unterschiedlichen organischen $\mathrm{Zu}$ sammensetzung. Seine Werttheorie würde nämlich, weil sie immer nur den Verkauf der Waren als Eigentumstitel zu ihren Werten unterstellt, in einen aporetischen Selbstwiderspruch geraten, wenn verschiedene Produktionszweige mit unterschiedlichen Mehrwertmassen nebeneinander existieren würden. In Produktionszweigen mit niedriger organischer Zusammensetzung, in denen der Produktionsprozess einen höheren Anteil an Arbeitskräften bei niedrigerem Anteil an technischen Produktionsmitteln bedarf, müsste demnach also auch der meiste Mehrwert realisiert werden: „Wir haben also gezeigt: daß in verschiedenden Industriezweigen, entsprechend der verschiednen organischen Zusammensetzung der Kapitale, und innerhalb der angegebenen Grenzen auch entsprechend ihren verschiedenen Umschlagszeiten, ungleiche Profitraten herrschen.“938 Weil unterschiedliche organische Zusammensetzungen zwischen den unterschiedlichen Produktionszweigen existieren und die Produktionszweige mit niedriger organischer

\footnotetext{
936 Ebd., S. 185.

937 Ebd., S. 145.

938 Marx: Das Kapital, Bd. 3, S. 162.
} 
Zusammensetzung laut Werttheorie dann auch den meisten Mehrwert realisieren, würde sich deshalb auf ihrer Grundlage ergeben, dass dem Kapitalismus eine Tendenz zur Steigerung der angewandten Arbeitskräfte in Relation zu den angewandten Produktionsmitteln immanent wäre. Das wäre jedoch eine Entwicklung wider den ökonomischen und gesellschaftlichen Fortschritt, der zwar nicht notwendig dem Kapitalismus immanent ist ${ }^{939}$, zu dem es jedoch aus Gründen der

${ }^{939} \mathrm{Im}$ Kapital werden die Zwecke der Realisierbarkeit des möglichen Fortschritts im Kontext der ökonomischen Konkurrenz reflektiert, um einen allgemeinen Fortschritt in der Produktion überhaupt stattfinden zu lassen. (Vgl. Marx: Das Kapital, Bd. 3, S. 123 f.) Die Produktivkraftsteigerung findet immer nur dann statt, wenn sich der Fortschritt für ein Privatunternehmen auch ökonomisch realisieren lässt: „Das Kriterium hat die Bedingung, daß der Wert der neuen Maschinerie durch das $\mathrm{Maß}$ der für sie aufgewendeten Arbeit, genauer: der für sie aufgewendeten Arbeitszeit bestimmt ist. Dieses Maß existiert nur dann, wenn die Maschinerie selbst nach einem methodisch geregelten Verfahren produziert ist. Das methodisch geregelte Verfahren der Produktion technologisch neuartiger Maschinerie ist aber selbst Resultat eines Prozesses, der nicht methodisch geregelt ist, und das gilt sowohl für die Erfindung wie für deren Umsetzung in ein industrielles Produktionsverfahren. Daß selbst geniale Erfinder nur wenig von ihrer Erfindung profitieren oder sogar mit ihr Bankrott machen, erklärt sich aus dieser Diskrepanz.“ (Bulthaup: Von der Freiheit im ökonomischen Verstande, S. 29.) Selbst die emanzipiertesten Ideen haben insofern ihr materielles Korrelat. Und selbst nützlichste Erfindungen sind zum Scheitern verdammt, sobald sie im ökonomischen Konkurrenzkampf rational nicht mehr bestehen können. In Form einer Kosten-Nutzen-Rechnung kreist das Damoklesschwert deshalb auch immer über allen noch so emanzipativen gesellschaftlichen Erfindungen. Jede nützliche Erfindung kann insofern unbrauchbar werden, was dem naiven Fortschrittsglauben sogleich eine Absage erteilt. Vor allem die Forschung im Bereich der Kinderkrebsmedizin führt drastisch vor Augen, wie wichtig die rationale Berechnung von realisierbaren Gewinnen im Kapitalismus für eine Bereitstellung von Forschungsgeldern ist. Obwohl eine Herstellung von spezifisch auf Kinder zugeschnittenen Medikamenten möglich wäre, wird aufgrund mangelnder Nachfrage auf die Herstellung von wirksamen Mitteln gegen den Kinderkrebs wegen zu hoher Herstellungskosten verzichtet. Das klingt so nüchtern wie brutal, ist aber deshalb nicht gesellschaftlich irrational. Der Zweck heiligt in diesem Fall nicht die Mittel, sondern im Kapitalismus bestimmen die Mittel den ökonomisch rational-realisierbaren Zweck. Ein bloß gutmütig gesetzter Zweck schlägt sogleich in ökonomische Irrationalität um, wenn die Entwicklung von Medikamenten dem systematisch gesetzten Streben nach Profit der einzelnen Pharmaunternehmen entgegensteht: „Für eigens entwickelte Kinderkrebsmedikamente sind allerdings weder von Pharmaindustrie noch öffentlicher Hand ausreichend finanzielle Mittel zu gewinnen.“ (pressemeldungen.com: Treffpunkt Medizin.) Mit den mangelnden öffentlichen Mittel ist es bereits angesprochen: Auch dem Staat liegt als langfristigem Planer ökonomischer Rationalität am Kurieren der medizinisch sehr spezifischen Tumore bei Kindern nichts. Die Stiftung Deutsche KinderKrebshilfe e.V. meldet beispielsweise: „Die Deutsche Krebshilfe finanziert ihre Aktivitäten ausschließlich aus freiwilligen Zuwendungen der Bevölkerung. Sie erhält keine öffentlichen Mittel.“ (krebshilfe.de: Krebshilfe.) Auch der Staat springt nun nicht mit Steuergeldern ein, weil ein spezifisches, nur Kinder betreffendes Krankheitsbild die nationale Durchschnittsprofitrate langfristig nicht kostenungünstig korrigieren würde. Das mag zynisch klingen, ist aber, weil instrumentell, der rationale Zynismus des Kapitalismus: Zu wenige Kinder sterben an den sehr spezifischen, nur bei Kindern in dieser Art vorkommenden Tumoren, so dass die gesellschaftlichen Auswirkungen, beispielsweise der Mangel an zukünftigen Lohnarbeitern, für den Staat nicht gravierend werden würde. Deshalb ist auch die Dringlichkeit, sich von Staats wegen der Sache finanziell anzunehmen, nicht gegeben. Solch rationale Entscheidungen gegen die mögliche Forschung werden also im Zuge des allgemeinen Zwecks der kapitalistischen Profitmaximierung gefällt und Realisierbares wird insofern nur bei rationalen Rechnungen der Mittel realisiert. Adorno spricht den nicht realisierten, obwohl gesellschaftlich möglichen Fortschritt, in einer Vorlesung kritisch an: 
Profitsteigerung im Konkurrenzkampf kommt. Die Theorie von der Monopolisierung als qualitativ differente, neue Form der Gewinnung von gesellschaftlichem Reichtum zu bestimmen, muss insofern in einer Aporie münden. Unterstellt, Monopole hätten in wichtigen Produktionszweigen längeren Bestand, bestimmen die Preise und zwingen Staaten auch noch, diese willkürlich festgelegten Preise zu schützen, ergeben sich daraus notwendig Fehlinvestitionen. Das sieht Pollock und löst den Widerspruch trotzdem nicht systematisch auf: „Every investment, wheter it serves replacement or expansion, is subject to plan, and neither oversaving nor overexpansion, neither an ,investment strike nor ,Fehlinvestitionen' can create large-scale disturbances. “940

Sofern Folgen der Fehlinvestitionen nicht politisch bekämpft werden, würden sich allerdings nur noch heftigere Konkurrenzkämpfe auf dem Weltmarkt als zu Zeiten des status quo der kapitalistischen Produktionsweise ergeben. Denn ein willkürlich festgesetzter Monopolpreis würde es dem Monopolisten auch erlauben, längerfristig Profite über dem allgemeinen,Durchschnittsprofit ${ }^{`} \mathrm{zu}$ realisieren, um seine Konkurrenz dadurch nachhaltig auszuhebeln. Ohne den Staat als den Organisator der Voraussetzungen von kapitalistischer Ökonomie würde die Konkurrenz untereinander sowie die Stellung der Klassen zueinander zu einem die allgemeine Reproduktion zerstörenden Konglomerat aus sich selbst immer widersprechenden und selbst zerstörenden Interessen. Die aktiven, regulierenden Eingriffe von Seiten des Staates in die Ökonomie erweisen sich deshalb als zum weiteren Fortbestehen der kapitalistischen Produktionsweise notwendig und sind deshalb nicht erst ein Zeichen des Zerfalls des bürgerlichen Staates. Ohne diese handfeste Praxis durch staatliche Organe wäre insofern kein Staat mehr zu machen. Der New Deal in den USA nach der Weltwirtschaftskrise 1929 unter Franklin D. Roosevelt ist als ein solch zweckmäßiger Eingriff zur Rettung von Kapital und Arbeiterklasse, Staat und Kapital zu sehen; so wie sich auch der aktive Staatseingriff zum Zwecke der sogenannten ,Bankenrettung' in der gegenwärtigen Krise eine unumgängliche Aktion des Staats zur Aufrechterhaltung des Gesellschaftsmodells Kapitalismus erweist. Hätte der Staat diese aktiv korrigierenden Mittel zu seinen ökonomischen Zwecken jemals aus der Hand gelegt und wäre einfach nur kontemplativ bei seinen Gesetzen und der Bestrafung der Delinquenten verblieben, die mannigfaltigen und willkürlichen Sonderinteressen hätten das allgemeine Interesse des Staates als politische Gewalt der kapitalistischen Gesellschaft nachhaltig torpediert. Das würde sich für diesen, als objektive, allgemeine Instanz des Produktionsverhältnisses nur negativ auswirken, weil sich für die allgemeine kapitalistische

\footnotetext{
„Ich halte es für eine Absurdität, daß also so elementare Bedürfnisse und Probleme, die den Menschen so unmittelbar ans Leben gehen [gemeint ist die Bekämpfung des Krebs, B.E.B.], wie mögliche Heilung angeblich unheilbarer Krankheiten - die wie ich mir von verschiedenen Medizinern habe sagen lassen, prinzipiell sich lösen ließen -, daß die aus gesellschaftlichen Gründen nicht gelöst werden." (Adorno: Vorlesung zur Einleitung in die Soziologie, S. 17.)

940 Pollock: State Capitalism, S. 208.
} 
Reproduktion der Gesellschaft und damit unmittelbar für die allgemeine Reproduktion ungeahnte Einbußen an Produktivkraft ergäben. Als ungezügelte kapitalistische Produktion ohne jede Regulation würden die Voraussetzungen der kapitalistischen Produktionsweise - Erde und Arbeiter - insofern sukzessive durch Naturzerstörung, Überarbeitung der lohnarbeitenden Subjekte etc. zerstört. Das würde das Resultat und die Voraussetzung kapitalistischer Akkumulation - vorausgesetztes Eigentum - zerstören.

Jede reelle Subsumtion der Arbeit unters Kapital erfordert also einen aktiv eingreifenden bürgerlichen Staat neben seiner scheinbaren Passivität als oberste objektive Instanz. Dabei verfolgt der Staat den einen hauptsächlichen Zweck: die Zerstörung von Naturbedingungen und Arbeiterklasse so gut es geht zu verhindern, um dadurch den allgemeinen Zweck der Produktionsweise, die weitere Ausbeutung der befreiten Lohnarbeiter als Eigentümer und das Eigentum an Produktionsmitteln zu verlängern. Denn welchen Nutzen hätte ein staatlich geschützter Eigentumstitel, wenn es bald schon keine Subjekte mehr geben würde, die diesen beanspruchen und das fremde Eigentum funktional zum eigenen Überleben bedienen müssen? Indem durch staatliche Eingriffe Einzelkapitalisten deshalb ein Teil ihres Gewinns gestrichen wird, schränkt der Staat die Exploitation der Arbeiter ein und gebietet der selbstzerstörerischen Konkurrenz im Kapitalismus Einhalt. Gewerkschaften und linke Verbände feiern solche Sozialverträglichkeitsmaßnahmen als ein positives Zeichen des Staates für gesellschaftlichen Frieden und Einsicht; und gegen das raubende Kapital. Ihre dadurch entstehende ideologische Staatsaffirmation reflektiert jedoch den eigentlichen Grund der Implementierung von direkten Staatseingriffen nicht. Durch den Eingriff werden entscheidende Voraussetzungen und Ressourcen der kapitalistischen Reichtumsproduktion gesichert, wodurch die Eigentumsverhältnisse auch weiterhin antagonistisch fixiert bleiben. Die kapitalistische Konkurrenz wird insofern durch sozialverträgliche Gesetze nicht etwa entschärft oder abgeschafft, sondern nur rationalisiert: Zum Zweck der Verlängerung der Konkurrenz wird der Klassenantagonismus gegen seine konsequente Abschaffung durch eine mögliche Zugrunderichtung der Arbeiterklasse als produktive Arbeiterklasse aufrechterhalten. Der Einzelkapitalist (,Unternehmer/Arbeitgeber) erleidet gesellschaftlich verträgliche Verluste und die Ausbeutung der doppelt freien Lohnarbeiter (,Arbeitnehmer) wird damit auch gleich immer wieder an sich verändernde objektive Verhältnisse angepasst. Sozialverträglichkeit heißt insofern, dass der Staat die kapitalistische Produktionsweise seinen Interessen entsprechend aufrecht erhält.

Demnach bleibt der bürgerliche Staat nie als äußere, organisierende Instanz der Produktionsweise außerhalb der inneren Prozesse der Ökonomie, wie es Pollock für die liberale Phase jedoch veranschlagt. Der Staat ist mehr, er erweist sich als das Innen und Außen ökonomischer Prozesse. Dadurch erst wird er seiner 
expliziten „Rolle (...) als des Gesamtkapitalisten“941 gerecht. Der bürgerliche Staat ist zweifellos, wie Engels es als erster substantiell zusammenfasst, der „ideelle Gesamtkapitalist “942. Er ist tatsächlich eine von jedem daseienden Einzelkapital als raumzeitlicher Gegebenheit abgezogene ideelle Einheit. Er vertritt deshalb auch nicht das Interesse aller konkreten Einzelkapitalisten und damit der Privateigentümer an Produktionsmitteln, wie Lenin vermutet (s.o.). Wäre der bürgerliche Staat nicht über diese positivistische Bestimmung einer Funktionalität schon hinaus, wäre er also bloß die Summe an einzelkapitalistischen Interessen, dann wäre er auch bloß die subsumtionslogische Agglomeration aller Einzelkapitale. Der Staat wäre insofern nicht die objektiv wirkliche, konkrete Einheit als ideeller Gesamtkapitalist. Ihren Gegenstand hat die konkrete Einheit des Staates jedoch gerade daran, dass sie als konkrete Einheit mehr als nur die Agglomeration ihrer Teile ist, mehr als eine nur positivistische Funktionseinheit ist. Diese wirkliche, emphatische Einheit ist durch objektive Strukturgesetze geprägt, nach denen sie sich bewegt und die sie als klassenübergreifende Gesetze auch erst wirksam macht. Gegen die Interessen aller einzelnen Kapitalisten und aller Einzelkapitale und ihrer bloß summierten Interessen vertritt der ideelle Gesamtkapitalist insofern wirklich die objektive Totalität der kapitalistischen Produktionsweise und abstrahiert deshalb als eine Art Metainstanz von allen konkreten materiellen Begebenheiten, die ihm gleichgültig bleiben.

Das bestätigt das objektive, heteronome Moment der gesellschaftlichen Herrschaft. Weil der Staat jene klassenübergreifende, objektive Totalität bei der Organisation der kapitalistischen Produktionsweise ist, können die allgemeinen Gesetze vom Staat und seinem Handeln auch nicht als ein Ideal transzendiert werden, das es nun (endlich) einmal zu erreichen gelte. Die Gesetze des Staates können insofern nicht als gesellschaftlich nicht zur Geltung kommende Prinzipien bestimmt werden, bloß weil der Staat weiterhin aktiv in den kapitalistischen Produktionsprozess eingreife. Der Grund des gesellschaftlichen Abgehängtseins der großen Masse kann dabei genauso wenig in einer scheinbar so ungerechten, weil von der großen Ökonomie erpressten Steuergesetzgebung des Staates gegen ,den kleinen Mann' und ,für die große Industrie', bzw. im Steuerbetrug durch Wenige liegen (vgl. etwa die Argumente in der Hoeneß-Affäre" ${ }^{943}$ ). In diesem Urteil vom angeblich schwachen bürgerlichen Staat gegen das ,große, übermächtige‘ Kapital soll demnach die ,Ungerechtigkeit ${ }^{`}$ des differierenden Reichtums der Bürger liegen. Solch ein Urteil trennt die Ökonomie vom Staatsinteresse sauber. Damit wird eine unreflektierte, aber unmittelbar auf der Hand liegende Lösung des Problems der Ungerechtigkeit konstruiert, die ein starker Staat aufheben würde. Jenes Modell taucht beispielsweise im Rahmen der verkürzten Definition bzw. Kritik des Finanzkapitals durch die SPD als zentraler Lösungsvorschlag für gesellschaftliche

\footnotetext{
941 Adorno: Spätkapitalismus oder Industriegesellschaft?, S. 363.

942 Friedrich Engels, Herrn Eugen Dühring's Umwälzung der Wissenschaft, S. 260.

943 Vgl. Posor: Der Fall Hoeneß als Skandal in den Medien.
} 
Probleme auf: „Finanzmärkte brauchen Regeln, die das Gemeinwohl sichern und verhindern, dass die Demokratien der Welt von Banken und Börsen erpressbar gemacht werden. Auch durch Steuerbetrug wird dem Gemeinwesen erheblicher Schaden zugefügt. "944 Jene Forderung nach dem starken bürgerlichen Staat durch die SPD wird jedoch gegenstandslos, weil ihr dabei die dialektisch vermittelten Momente der gesellschaftlichen Totalität, von Staat und Kapital als in sich vermittelte Zwecke der kapitalistischen Produktionsweise und Gesellschaftsform, nicht zum Gegenstand werden. Das sich durch die Setzung von Recht und Eigentum reproduzierende und auch erweiternde Kapitalverhältnis bleibt den revisionistischen Kritikern deshalb undeutlich: Ihnen gelten Recht und Eigentum abstrakt als ungemein positive Momente des Rechtsstaates, mit denen sich die gesellschaftliche Ungerechtigkeit bekämpfen lassen würde. Die Abstraktion von jedem Inhalt des Eigentums durch den Staat gilt für den Revisionismus deshalb als eine zu affirmierende Wertneutralität. Jenes Argument eines starken Staats für die gesellschaftlich Schwachen ist jedoch nur formell, durch anders gemeinte Vorzeichen, von der faschistischen Theorie des gegen alle Widerstände durchgreifenden (Volks-)Staats zu trennen. ${ }^{945}$

Affirmationen von Staat und Staatlichkeit gegen die ,böse' Ökonomie finden sich nun auch in modernen soziologischen Theorien, die sich selber allerdings der gesellschaftskritischen, linken Strömung zuschreiben. Thomas Piketty beispielweise bejaht über die Affirmation des Staates die gesellschaftliche Totalität bzw. Herrschaft der bürgerlichen Gesellschaft. In Das Kapital im 21. Jabrbundert registriert er zunächst einmal die offensichtliche Zunahme in der Ungleichheit der Vermögensverteilung im 21. Jahrhundert: „Seit den 1970er Jahren hat die Ungleichheit in den reichen Ländern wieder stark zugenommen“"946. Das hält er, gar nicht zu unrecht, für eine große Gefahr für die bürgerliche Demokratie. Piketty hat jedoch mit der bürgerlichen Gesellschaft, d.h. der kapitalistischen Produktionsweise, die diese ,Ungleichheit' in der Vermögensverteilung erst wesentlich hervorbringt, kein Problem. Von Kapitalismus und bürgerlicher Gesellschaft spricht er recht positiv, wenn er z.B. Maßnahmen von „Wohnraumbeschaffung ${ }^{\text {‘ } 947}$ etc. beschreibt. Piketty sieht lediglich ein Problem in den immer krasser werdenden Auswirkungen eines Moments der gesellschaftlichen Totalität: der kapitalistischen Ökonomie. Ihre Auswüchse, nicht das System, gehören deshalb für ihn eingeschränkt und der Kapitalismus bzw. die Demokratie deswegen reformiert. Er reflektiert dabei so wenig wie Wilhelm Heitmeyer, Professor für Er-

\footnotetext{
944 spd.de: Finanzmärkte steuern.

945 Vgl. Resultate Bd. 3: Der bürgerliche Staat, S. 22 ff. In der positiven Fokussierung auf Recht und Gesetz stimmen sie mit der oben kennengelernten Abendroth-Schule überein (vgl. 3.4). Diese sah allerdings nicht den bürgerlichen Rechtstaat unter Zugzwang, sondern war der Überzeugung, dass das Grundgesetz erst im Sozialismus wirklich zur Geltung kommen könne. (Vgl. z.B. Abendroth: Das Grundgesetz.) 946 Vgl. Piketty: Das Kapital im 21. Jahrhundert, S. 31. ${ }^{947}$ Vgl. Ebd., S. 283.
} 
ziehungswissenschaft in Bielefeld, ebenfalls Kritiker der ,Ungleichheit', dass ,die Politik', d.h. der Staat, dialektisch notwendig vermitteltes Moment der kapitalistischen Produktionsweise und deshalb vermittelt auch für alle sozialen Erscheinungen mitverantwortlich ist. Bei Heitmeyer klingt die Eindimensionalität des soziologischen Denkens wie folgt: „Der Grund dafür [für Zukunftsängste, B.E.B.] liegt darin, daß bislang überhaupt nicht öffentlich darüber diskutiert wurde, wie es zu diesem massiven Kontrollverlust der Politik zugunsten eines zunehmend autoritären Kapitalismus kommen konnte, und daß niemand garantieren kann, daß so etwas nicht noch einmal passiert."“948

Man kann der SPD, Piketty und Heitmeyer nun zwar zugutehalten, dass sie den allgegenwärtigen Schein des bürgerlichen Staates als mögliche Versöhnungsund Schlichtungsinstanz benennen, weil sie diese Kompetenzen ausbauen wollen. ${ }^{949}$ Die positiv unterstellte Schlichterfunktion des bürgerlichen Staates ist jedoch immer nur ein scheinbares, nur funktionelles Moment des bürgerlichen Staates, weil er eine klassenübergreifende, totale Instanz der kapitalistischen Produktionsweise/Gesellschaftsform ist, das selbst aktiv zur Wahrung seiner Interessen in den wesentlichen Zusammenhang der Ökonomie eingreift. Zwar tritt der bürgerliche Staat zunächst einmal, prima facie, tatsächlich immer wie ein objektiver Schlichter gegensätzlicher Interessen von antagonistischen Eigentümerklassen, also Klassenantagonisten, auf. ${ }^{950}$ Weil er als objektive Instanz der Organisation der Gesellschaft vom Einzelkapitalisten wie vom Arbeiter unterschieden ist, ist er deshalb tatsächlich die entscheidende Instanz von potentieller gesellschaftlicher Gerechtigkeit. Als die allgemeine Regelungsinstanz des Kapitalismus versöhnt er gewissermaßen beide antagonistischen Klassen der bürgerlichen Gesellschaft miteinander, auch indem er beide Klassen gleichermaßen unter sich und seine formellen Gesetze zwingt. Weil sich dadurch jedes einzelne Subjekt der Praxis zu Gunsten seiner eigenen Reproduktion positiv auf ihn zu beziehen hat, will es den bürgerlichen Staat und handelt deshalb auch nach seinen formellen Maßgaben (s.o.).

Auch bei Marx zeigt sich der Staat als der entscheidende Schlichter im „Kampf zwischen dem Gesamtkapitalisten, d.h. der Klasse der Kapitalisten, und dem Gesamtarbeiter, oder der Arbeiterklasse“"951. Schlichter ist der Staat jedoch immer nur zum bestimmten Zweck: der Aufrechterhaltung der kapitalistischen Produktionsweise. Gegen seine positivistische Affirmation als Schlichter der Ungerechtigkeit zeigt sich der Staat aber auch als entscheidender Konstrukteur des (internen) Konkurrenzverhältnisses der Subjekte. Es darf also insofern nicht übersehen wer-

\footnotetext{
948 Heitmeyer (Hrsg.): Deutsche Zustände, S. 15.

${ }^{949}$ Lenin bezeichnet diese Auffassung vom Staat als Schlichter als „Entstellung des Marxismus“. (Lenin: Staat und Revolution, S. 9.

${ }^{950}$ Einigen Historikern gilt der bürgerliche Staat als der Schlichter historischer Klassenkämpfe. Darauf bezogen schreibt auch Nicos Poulantzas: „Es gibt keine Geschichte von Klassenkämpfen, deren Resultat zu einem gegebenen Zeitpunkt der Staat wäre: diese Geschichte ist ohne Staat nicht denkbar." (Poulantzas: Staatstheorie, S. 69.)

951 Marx: Das Kapital, Bd. 1, S. 249.
} 
den, dass er die eigens hervorgebrachten gesellschaftlichen Widersprüche nicht schlichtet, sondern der bürgerliche Staat erst als der Konstrukteur und Sicherungsinstanz des gesellschaftlichen Antagonismus auftritt. Der kapitalistische Staat greift immer regulierend in die Ökonomie ein und jede kapitalistische Produktionsweise würde sich ohne die aktive staatliche Interventionsmöglichkeit und Reorganisationsmöglichkeit sogleich vernichten. Als objektive, staatliche Metainstanz der kapitalistischen Produktionsweise greift der bürgerliche Staat also als ideeller Gesamtkapitalist direkt in die Produktionsweise zur Schlichtung der antagonistischen Interessen ein. Nicht nur, weil sich ohne seine Garantien und die aktiven Veränderungen im Produktionsprozess die allgemeine Konkurrenz der Subjekte so grenzenlos und unberechenbar gegeneinander verhalten würde, wie Hobbes ${ }^{952}$ es schon für den Naturzustand konzipierte. Ohne objektive Regelungsinstanz des bürgerlichen Staates würde um die Produktionsmittel vertragslos und willkürlich gekämpft, wodurch der Schutz des Eigentums wegfiele. Durch die direkten, aktiven Eingriffe, die der Aufrechterhaltung der kapitalistischen Produktionsweise und der internen Konkurrenz dienen, ist der Staat ,die politische Gewalt der kapitalistischen Gesellschaft. “"953 $\mathrm{Er}$ ist die aktive, objektiv korrigierend eingreifen könnende, totale Instanz der bürgerlichen Gesellschaft und ihrer kapitalistischen Ökonomie, die sich auch nur dadurch reproduzieren kann.

Diese objektive Instanz ist er demnach nicht erst als faschistischer, autoritärer Staat, sondern bereits als bürgerlicher. Der bürgerliche Staat ist deshalb bereits ein autoritärer, regulierender Staat. So erweist sich die qualitative Differenz von liberalem und Monopolkapitalismus bzw. Faschismus nicht als qualitative, sondern, wie Neumann herausarbeitet, als eine bloß quantitative Differenz. Auch gesellschaftliche Phänomene wie der moderne Antisemitismus etc. müssten, wenn der Monopolkapitalismus eine gegenüber dem alten Liberalkapitalismus wesentlich unterschiedene Gesellschaftsform sein soll, auf einer neuen, wesentlich veränderten Qualität beruhen. Wenn sich das ökonomische Wesen des Antisemitismus also grundlegend verändern würde, hätte dies auch auf die soziale Erscheinung entscheidende Auswirkungen. Diese Gedanken zu Wesen und Phänomen lassen sich mit Horkheimers Überlegungen zum Antisemitismus spezifizieren.

Horkheimer bestimmt in Die Juden und Europa den Faschismus als ohne die wesentliche kapitalistische Ökonomie generell undenkbar: „Wer aber vom Kapitalismus nicht reden will, sollte auch vom Faschismus schweigen.“954 Er sei „die Wahrheit der modernen Gesellschaft, die von der Theorie von Anfang an getroffen war.“"955 Deshalb sei der Faschismus tatsächlich „die alternative Form bürgerli-

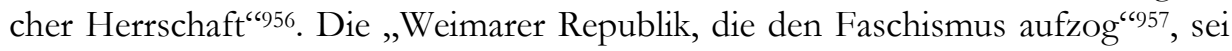

\footnotetext{
952 Vgl. Hobbes, Leviathan.

953 Resultate Bd. 3: Der bürgerliche Staat, S. 11.

954 Horkheimer: Die Juden und Europa, S. 115.

955 Ebd., S. 116.

956 Resultate Bd. 3: Der bürgerliche Staat, S. 24.
} 
im Wesentlichen für den Umschlag von Liberalismus in Faschismus verantwortlich, was allerdings von Horkheimer ganz systematisch, nicht etwa als politische Besonderung ${ }^{958}$ durch Elitenbildung etc. begriffen wird: Der Faschismus gehe aus „dem kapitalistischen Prinzip“959 wesentlich hervor: „Die Ordnung, die 1789 als fortschrittliche ihren Weg antrat, trug von Beginn an die Tendenz zum Nationalsozialismus in sich. " ${ }^{600}$ Die Erscheinungsweise des Antisemitismus im Faschismus grenzt Horkheimer dabei ebenfalls nicht konkret vom modernen Antisemitismus der bürgerlichen Gesellschaft ab, sondern fasst ihn hegelianisch als konsequent zu sich selbst gekommenem Antisemitismus. Wie die bürgerliche Gesellschaft im Faschismus zu sich selbst gekommen sei, so sei der moderne Antisemitismus im Faschismus zu sich selbst gekommen. Von Beginn der bürgerlichen Gesellschaft und des modernen Antisemitismus an sei die gesellschaftliche Lage der Juden jedoch bereits mehr als prekär gewesen: „Selbst die französische Revolution, die der bürgerlichen Wirtschaft politisch zum Sieg verhalf und den Juden die Gleichheit gab, war zweideutiger, als sie [die Juden, die der bürgerlichen Gesellschaft ,hinterherweinen', B.E.B.] sich heute träumen lassen." "961 Aus der zunächst liberalen Konkurrenz, in der man sich unter geregelten Bedingungen behaupten musste, erwachse im Faschismus dann eine viel heftigere Konkurrenz, die zunächst im Wunsch und später der Realität der zügellosen Eliminierung von Konkurrenten, denen man beikommt, resultiere - den Juden: „Dieselbe Rationalität, nach der unterlegene Konkurrenten schon immer ins Proletariat versanken und um ihr Leben betrogen waren, diese ökonomische Zweckmässigkeit hat jetzt auch den Juden das Urteil gesprochen." “962 Selbst in den bürgerlichen Staaten, in die die Juden hilfesuchend vor dem Faschismus fliehen, werden sie zur unliebsamen ökonomischen Konkurrenz erklärt, der man sich deshalb am liebsten schnell wieder entledigen möchte: „In Kontinenten, von deren Ertrag die Menschheit sich ernähren könnte, fürchtet jeder Bettler, dass der jüdische Einwanderer ihn um seine Nahrung bringt.“963 Der Unterschied des modernen Antisemitismus der bürgerlichen Gesellschaft zum Faschismus sei deshalb in der Entfesselung der

\footnotetext{
${ }^{957}$ Horkheimer: Die Juden und Europa, S. 122. Kapitalismus, S. S. 478 ff.)

${ }^{959}$ Horkheimer: Die Juden und Europa, S. 119.

${ }^{960}$ Ebd., S. 129.

961 Ebd.

962 Ebd., S. 130.

963 Ebd., S. 133.
}

${ }^{958}$ Das Argument Horkheimers widerspricht deshalb auch immer wieder vorgebrachten Thesen des spezifisch, deutschen' Sonderwegs in den Faschismus. Das Sonderwegsargument geht von einer aus historischen Gründen ,falschen Elitenbildung' in Deutschland aus, die dann zum Faschismus geführt habe: „In der Sonderwegsdebatte bildete die ,Feudalisierungsthese‘ einen der wichtigsten Stützpfeiler für das Argument der mangelnden Durchsetzung bürgerlich-liberaler Wertvorstellungen, Normen und Lebensstile innerhalb der bürgerlichen Eliten selber.“ (Ziegler: Das wirtschaftliche Großbürgertum, S. 114. Vgl. zu den Thesen des angeblich deutschen Sonderwegs auch Dahrendorf: Gesellschaft und Freiheit, S. 269 f.; Wehler: Deutscher Sonderweg oder allgemeine Probleme des westlichen 
Produktivkräfte zu sehen, die Neumann mit der entsprechenden Entfesselung des Wertgesetzes im Faschismus ausmacht (s.o.).

Wenn Horkheimer jedoch von den zu sich selbst gekommenen Phänomenen im Faschismus spricht, widerspricht er damit seinen an anderer Stelle gemachten systematischen Analysen der kapitalistischen Produktionsweise, die auf eine qualitative Differenz von liberalem Kapitalismus und Monopolkapitalismus hinausliefen. Auch in der Dialektik der Aufklärung, in den gemeinsamen ,Elementen des Antisemitismus', setzen Adorno und Horkheimer das Phänomen Antisemitismus nicht mit dem Aufkommen des Faschismus und dem Monopolkapitalismus völlig neu an, sondern sie stellen in der Erscheinungsweise des Antisemitismus im Faschismus und Monopolkapitalismus zwar verschiedenes, aber auch nicht unterschiedenes fest. Minimal seien die Differenzen, weshalb sie prinzipiell ineinander überführbar seien: „Die das Bürgerrecht, das ihnen die Qualität der Menschheit zusprechen sollte, nie ganz ohne Sorge besitzen durften, heißen wieder Der Jude, ohne Unterschied." "964 Im modernen Antisemitismus der Faschisten lasse sich darum auch kein wesentlicher Unterschied zum liberalkapitalistischen Antisemitismus ausmachen: „Das Bündnis von Aufklärung und Herrschaft hat dem Moment ihrer Wahrheit den Zugang zum Bewußtsein abgeschnitten und ihre verdinglichten Formen konserviert. Beides kommt zuletzt dem Faschismus zugute: die unbeherrschte Sehnsucht wird als völkische Rebellion kanalisiert, die Nachfahren der evangelistischen Schwarmgeister werden nach dem Modell der Wagnerschen Gralsritter in Verschworene der Blutsgemeinschaft und Elitegarden verkehrt, die Religion als Institution teils unmittelbar mit dem System verfilzt, teils ins Gepränge von Massenkultur und Aufmärschen transponiert.“965 Der Antisemitismus der Faschisten, der völkische Antisemitismus, wird damit zum festgehaltenen Moment des modernen Antisemitismus. Auch weil sich, durchaus problematisch, in der Dialektik der Aufklärung, der moderne Antisemitismus aus dem Tausch, der hier mit kapitalistischer politischer Ökonomie gleichgesetzt wird, ergibt, bleibt er von Adorno und Horkheimer weiterhin in wesentliche Prinzipien der bürgerlichen Gesellschaft eingebettet. Die Autoren der Dialektik der Aufklärung verlassen an dieser Stelle deshalb den zunächst noch mit Pollock gemeinsam beschrittenen Weg vom qualitativen Sprung der Gesellschaftsform, indem sie an der Stelle der gesellschaftstheoretischen Analyse des Phänomens Antisemitismus einen entscheidend qualitativen Unterschied zwischen liberalem Kapitalismus und Monopolkapitalismus/Faschismus nicht mehr ausmachen.

\footnotetext{
964 Adorno/Horkheimer: Dialektik der Aufklärung, S. 200.

965 Ebd., S. 200 f.
} 


\subsection{Wille und Staat. Zur Dialektik von Subjekt und totaler, heteronomer Gesellschaft}

Mit dem erzwungenen Willen des Subjekts in der heteronomen Gesellschaft wurde sich noch nicht beschäftigt. In 3.6.1 ff. wird zunächst gesellschaftstheoretisch ganz allgemein der Wille als erzwungener Wille, sich positiv auf die Zwecke der Gesellschaft zu beziehen, dargestellt. Hier verweist die Reflexion schon auf den Zwang des lebendigen Subjekts, sich zu Reproduktionszwecken auf den die eigene Reproduktion in der gesellschaftlichen Totalität sichernden bürgerlichen Staat zu berufen. Dieser wird durch einen bürgerlichen Nationalstaat repräsentiert, in dem sich das Subjekt zu sozialisieren hat.

Weil das lebendige Subjekt in der kapitalistischen Gesellschaft notwendig auf einen Nationalstaat verwiesen ist, wird in 3.6.2 der Nationalismus reflektiert. Das ist zugleich die Reflexion eines Moments der Sozialisation, die sich dadurch als recht ungemütlich erweist.

Ein weiteres Moment der Sozialisation ist die erzwungene Mehrwertproduktion, die das lebendige Subjekt immer zu leisten hat. Diese erzwungene Mehrwertproduktion ist deshalb in 3.6.3 Gegenstand.

In 3.6.4 ist dann der Zwang zur Produktion von Allgemeinwohl Gegenstand. Dieser Zwang erweist sich als über die erzwungene Mehrwertproduktion realisierter Zwang.

\subsubsection{Zur unfreiwilligen Freiwilligkeit der eigenen Reproduktion. Zur Dialektik von Körper und Geist}

Die Subjekte können ihre dinglichen Waren nicht telepathisch miteinander austauschen. Sie tauschen diese Eigentumstitel als körperliche Wesen zum Zweck der gesellschaftlichen und individuellen Selbsterhaltung aus, denn die durch Tätigkeit erst hergestellten „Waren können nicht selbst zum Markte gehen“966. Zu ihrem Austausch werden bedürftige Subjekte als Vermittler benötigt.

Auch für die Ware Arbeitskraft ist es unmöglich, selbsttätig, als vom Körper ihres Trägers losgelöste Ware, zum kapitalistischen Markt und ihrer eigenen Verwertung zu schreiten. Die Ware Arbeitskraft kann, medizinisch generell unmöglich, von ihrem physischen Träger nicht als ein ihm äußerliches Ding abgetrennt werden. Als zugleich physischer Träger seiner spezifischen Ware als Eigentum kann der doppelt freie Lohnarbeiter seine einzige Ware, Arbeitskraft, deshalb auch nicht am Fabriktor abgeben und sich anschließend, während sein Eigentum in der Fabrik arbeitet, beispielsweise zum Sonnen in den Park legen oder dergleichen. Im Rahmen der Realisation der eigenen Reproduktion spielt also die individuelle Physis des Verkäufers der Ware Arbeitskraft eine entscheidende Rolle, nicht nur im Kontext der dinglichen Warenzirkulation. Die Dialektik von Zirkulations- und

966 Bulthaup: Elemente des Antisemitismus, S. 124. 
Produktionssphäre, ihr dialektisch momentanes Ineinander, wird jedoch im Falle der Ware Arbeitskraft besonders offensichtlich: Ohne die Körperlichkeit könnte das lohnarbeitende Subjekt die ihm rechtlich einzig garantierte Ware bei der Realisation der eigenen Reproduktion im äquivalenten Eigentumstiteltausch nicht benutzen.967 Während der fremdbestimmten Anwendungszeit seines Eigentums durch ein fremdes Eigentum - vermittels eines abgeschlossenen Vertrags - kann der Träger der Ware Arbeitskraft nicht einfach aus seinem Körper fahren.968 Weil er ein biologisches, lebendiges Wesen ist, lässt sich das Arbeitsvermögen des Trägers der Ware Arbeitskraft also nur durch die direkte Vernutzung seiner eigenen Körperlichkeit aktualisieren. Marx’ Urteil im Kapital lautet entsprechend: „Die Arbeitskraft existiert nur als Anlage des lebendigen Individuums. “969

Über den Tausch der an die physis unmittelbar gebundenen Ware kommt das körperliche Moment des Subjekts demnach überlebenswichtig zum Tragen. Somit wird das entscheidende Moment des objektiv Allgemeinen bei der Verwertung des Eigentums durch das Individuum offenbar. Bloß noch vermittelt über den subjektiv autonom getätigten Abschluss des gesetzlich garantierten Vertrages kann das allem Grund und Boden entledigte Subjekt die eigene Selbsterhaltung als körperliches Individuum sichern: dem staatlich garantierten Arbeitsvertrag. Diesen darf, kann und muss es als frei und autonom bestimmtes, seiner selbst bewusstes Rechtssubjekt jederzeit abschließen wollen. Im bürgerlichen Vertrag liegt deshalb der Zwang - die Unfreiwilligkeit - der freiwilligen Reproduktion des an Produktionsmitteleigentumslosen..$^{970}$

Der Produktionsmitteleigentümer hingegen muss mit den Arbeitern den Arbeitsvertrag abschließen und dabei auch wieder die objektiven Regeln des jeweiligen bürgerlichen Staates respektieren. In den erzwungenen Vertragsabschlüssen zum Zweck der eigenen Reproduktion liegt deshalb das klassenübergreifend gemeinsame Moment der gesellschaftlich bedingten Heteronomie bei der Sicherung der eigenen Reproduktion als Individuen. Diesen Vertrag über den reziproken Eigentumstausch schließt jedes Subjekt der bürgerlichen Gesellschaft zu Zwecken der eigenen Reproduktion willentlich als Person des Rechts ab, um für sich jeweils ,lukrativ ${ }^{`}$ die eigenen Zwecke der Selbsterhaltung zu realisieren. Über das allgemein garantierte bürgerliche Vertragsrecht von freien Eigentümern realisiert sich insofern der systematische und herrschaftliche Zwang gegen jedes der bürgerlichen Herrschaftsform unterworfene, willensbegabte Subjekt. Die Verfolgung des

\footnotetext{
967 Zum Subjektbegriff und seinem nichtidentischen, körperlichen Objekt als Korrelat vgl. auch Adorno: Negative Dialektik, S. 178 f.

968 Das stellt sich aber immer als Problem dar.

969 Marx: Das Kapital, Bd. 1, S. 185.

970 Dieses Verhältnis übersieht die bürgerliche Rechtswissenschaft. Walter Jellinek z.B. schreibt: „daß jener Zustand [gemeint ist der Staat, B.E.B.] in Wahrheit stets eine unbegrenzte Vielheit von Willensverhältnissen ist, die niemals etwas bloß Objektives sind, daß er kein Konkretum, sondern eine Abstraktion aus zahllosen individualisierten Willensverhältnissen ist." (Jellinek: Allgemeine Staatslehre, S. 143.) Dass ohne Willensverhältnis kein Vertrag sei, ist die Wahrheit der Ideologie Jellineks.
} 
eigenen Willens zu Reproduktionszwecken muss das Subjekt in der kapitalistischen Konkurrenzgesellschaft gegen andere sich diesen Zweck setzende Subjekte realisieren. Dieser Zwang des erfolgreichen Vertragsabschlusses aller biologischen, sich reproduzieren müssender Subjekte ist ein allgemeiner. Die Subjekte müssen sich willentlich gegen alle anderen verhalten, um den Vertragsabschluss zu realisieren. Die autonome Vertragsgebundenheit zu individuellen Reproduktionszwecken erweist sich insofern auch als ein klassenübergreifendes Zwangsmoment der Subjekte. Sich selbst erhalten, oder umgangssprachlicher formuliert: überleben, kann in der totalen bürgerlichen Gesellschaft nur der persönliche Eigentümer oder Revenuequellenbesitzer, der den besonderen, allgemeingültigen Vertrag willentlich akzeptiert. Der erzwungene Abschluss des Vertrags zu Reproduktionszwecken denunziert deshalb die Heteronomie der gesellschaftlichen Verhältnisse: „Die Personen, die ihren Willen in die Dinge legen, sind in Wahrheit nicht frei, sondern realisieren die diesen Dingen objektiv inhärierenden ökonomischen Bestimmungen. ${ }^{\text {“971 }}$ Der Zwang des transzendent Allgemeinen, das eine in den objektiven Gesetzen geronnene gesellschaftliche Herrschaft ist, ist deswegen auch größer als dass er ein aus allen Subjekten zusammengenommener, nur intersubjektiver Zwang ist. Es ist ein größerer Zwang auf das Subjekt, als sich ,nur ${ }^{6}$ einer bloß atomistisch zusammengefassten Intersubjektivität unterzuordnen. Der gesellschaftliche Vorrang des Objekts nimmt jedes Subjekt und seinen Willen gleichermaßen in seinen heteronomen Bann. Jedes Subjekt hat sich über die Heteronomie der gesellschaftlichen Verhältnisse, als diese anerkennendes und gleichzeitig anerkanntes Staatsbürgersubjekt, zu sozialisieren: „Die Lebensnot erzwingt die Anerkennung. “"972

Über das allgemein garantierte bürgerliche Vertragsrecht von freien Eigentümern realisiert sich also ein systematischer und herrschaftlicher Zwang gegen jedes der bürgerlichen Herrschaftsform unterworfene, willensbegabte Subjekt. Die Verfolgung des eigenen Willens zur Reproduktion muss jedes Subjekt in der kapitalistischen Konkurrenzgesellschaft notwendig gegen andere zwecksetzende Subjekte realisieren. Die Konkurrenz um die Verträge erweist sich als ein nackter Kampf der Subjekte ums Überleben. Das Subjekt muss sich dabei gegen andere erfolgreich handelnd verhalten, um den Vertragsabschluss für sich zu realisieren. Dieses Verhältnis von Affirmation und Negation, von Anerkennung und Konkurrenz lässt sich systematisch verdeutlichen: Beide antagonistisch aufs Gesamtkapital bezogene Klassen haben den allgemeinen und vertraglichen Zwängen der kapitalistischen Produktion innerhalb des Staates jeweils unterschiedlich als Klassenmitglieder zu parieren. Alle Subjekte der Klassen bleiben dabei in sich, sowohl an Produktionsmitteln Eigentumslose (3.6.1.1) wie Eigentümer an diesen (3.6.1.2), negativ wie affirmativ aufeinander bezogen.

971 Kuhne: Begriff und Zitat bei Marx, S. $86 \mathrm{f}$.

972 Weyand: Stummer Zwang oder innere Stimmen?, S. 100. 


\subsubsection{Die unfreiwillige Freiwilligkeit der an Produktionsmitteln Eigentumslosen}

Der an Produktionsmitteln Eigentumslose erkennt mit seinem vor dem Staat getätigten Arbeitsvertragsabschluss willentlich die eigene Versachlichung als Kostenrechnungsfaktor im kapitalistischen Produktionsprozess an. Er muss sich für die Realisation seiner eigenen Zwecke der Realisation seiner Lebensbedingungen als variables Kapital im Kostenrechnungsprozess als biologisches Individuum zur Verfügung stellen. Damit wird er, als körperliches Wesen, zum Produktionsmittel für andere, zum Produktionsmittel von ihm heteronomen, allgemeinen Zwecken. Durch den kapitalistischen Produktionsprozess hindurch produziert er darum fremdes, juristisch ihm entfremdetes Eigentum an Ware. Der Eigentümer von Produktionsmitteln erlaubt ihm dabei, via reziprokem und anerkanntem, weil beide Willen realisierenden, Vertrag die Verwendung dieser Produktionsmittel zur Beförderung der ihm fremden Zwecke. Diese willige Kooperation des Produktionsmittellosen bei eigener Verdinglichung als Produktionsmittel ist deshalb eine erzwungene Kooperation im Zuge der eigenen Sozialisation. Als körperliches, selbstbewusstes Wesen hat er sich, bzw. vermittelt seine Physis, meistbietend zu verkaufen, ohne dass er dabei jedoch von der klasseneigenen Konkurrenz ausgebootet wird.

Jene paradox anmutende heteronome, erzwungene Kooperation kann überhaupt erst aufgrund der allgemeinen Freiheit des Vertragsabschlusses, garantiert durch den bürgerlichen Staat, stattfinden: „Denn Käufer und Verkäufer einer Ware, z.B. der Arbeitskraft, sind nur durch ihren freien Willen bestimmt. Sie kontrahieren als freie, rechtlich ebenbürtige Personen. Der Kontrakt ist das Endresultat, worin sich ihre Willen einen gemeinsamen Rechtsausdruck geben. “973 Deshalb sind die an Produktionsmitteln Eigentumslosen bei der Realisation ihrer Selbsterhaltung durch ihre ständige interne Konkurrenz um die eigene Reproduktion nun vor allem negativ aufeinander bezogen. Das findet besonders im Kampf um systematisch begrenzte Arbeitsplätze in der kapitalistischen Gesellschaft Ausdruck, deren subjektive Sicherung die Vertragsunterzeichnung mit dem Produktionsmitteleigentümer gilt. Dieser Kampf um Arbeitsplätze, um lukrative Arbeitsverträge vielmehr, erregt, wie Marx ironisch schreibt, „den Wetteifer der einzelnen und [spanne] ihre Lebensgeister ${ }^{\text {(977 }}$. An anderer Stelle des Kapitals beschreibt Marx dieses ständige Konkurrenzverhältnis systematisch mit dem so genannten ,Populationsgesetz ${ }^{6}$ der kapitalistischen Produktionsweise: „Mit der durch sie selbst produzierten Akkumulation des Kapitals produziert die Arbeiterbevölkerung (...) in wachsendem Umfang die Mittel ihrer eignen relativen Überzähligmachung. Es ist dies ein der kapitalistischen Produktionsweise eigentümliches Populationsgesetz, wie in der Tat jede besondre historische Produktionsweise ihre besondren, histo-

\footnotetext{
973 Marx: Das Kapital, Bd. 1, S. 189 f.

${ }^{974}$ Ebd., S. 348.
} 
risch gültigen Populationsgesetze hat. "“975 Die Lohnarbeiter, die sich gegen ihre eigene Überzähligmachung ständig wehren müssen, werden „zu Konkurrenten um den Arbeitsplatz, das heißt um ihre Lebensbedingungen. "976 Sie wollen den Konkurrenten um die Arbeitsverträge die Lebensbedingungen dabei streitig machen, weil sie es müssen. Hier zeigt sich die entscheidende Problematik der systematischen ökonomischen Konkurrenz der Subjekte - auf die hinsichtlich der Phänomene wie Antisemitismus, Rassismus etc. dann entsprechend zurückgekommen wird.

Diese Konkurrenz bleibt aber nicht, als negative Bezogenheit der Arbeiter aufeinander, der einzige Faktor im Prozess der Realisation der eigenen Reproduktion innerhalb der kapitalistischen Produktionsweise. Es zeigen sich dabei auch zwei Stränge einer gesellschaftlich erzwungenen positiven Kooperation der Arbeiterklasse. Die Eigentumslosen haben immer auch gemeinsame Klasseninteressen. Zum einen ist das das Interesse daran, den exponentiell wachsenden Ausbeutungsgrad der gesellschaftlichen Gesamtarbeit zu senken.977 Das ist vor allem ein intellektuelles Resultat aus dem Klassenbewusstsein heraus, das sich für das Subjekt aus der integrativen Eingebundenheit der Subjekte in die Gesellschaft und den lebensfeindlichen materiellen Zwängen in ihr ergibt. Zudem sind die Eigentumslosen vermittels der durchgesetzten, kooperativen Arbeitsteilung innerhalb der reellen Subsumtion der Arbeit unters Kapital auch wirklich, reell affirmativ aufeinander bezogen. ${ }^{978}$ Deswegen kann von einer doppelt affirmativen Bezogenheit der Eigentumslosen an Produktionsmitteln aufeinander zum Zweck der Realisation der eigenen Reproduktion gesprochen werden. Diese doppelte Affirmation ist jedoch lediglich ein momentaner, systematisch einzuordnender Bestandteil jener existentiell entscheidend bleibenden negativen Bezogenheit der Lohnarbeiter aufeinander.

\subsubsection{Die unfreiwillige Freiwilligkeit der Eigentümer an Produktionsmitteln}

Auch der Eigentümer an Produktionsmitteln muss sich willentlich dem Zwang des legalen Vertragsabschlusses in der Zirkulationssphäre zu seinen Reproduktionszwecken fügen. Er kann nicht, nur weil er wichtiges Eigentum an Produktionsmitteln besitzt, das Recht einfach willkürlich zu seinen Gunsten beugen, das ihm die Ausbeutung der Produktionsmittellosen über die Garantie seines Eigentums an Produktionsmitteln garantiert. Oben erwies sich der Agent seines eigenen produktiven Kapitals bereits nicht als unbedingt frei, was die Fabrikgesetzgebung

\footnotetext{
975 Ebd., S. 660.

976 Bulthaup: Herrschaft, Sprache und Revolution, S. 52.

977 „Zum ,Schutz‘ gegen die Schlange ihrer Qualen müssen die Arbeiter ihre Köpfe zusammenrotten und als Klasse ein Staatsgesetz erzwingen, ein übermächtiges gesellschaftliches Hindernis, das sie selbst verhindert, durch freiwilligen Kontrakt mit dem Kapital sich und ihr Geschlecht in Tod und Sklaverei zu verkaufen.“ (Marx: Das Kapital, Bd. 1, S. 320.)

978 Vgl. Weyand: Stummer Zwang oder innere Stimmen?, S. 102.
} 
von 1867 verdeutlichte (vgl. 3.5). Aber nicht nur Arbeiterschutzgesetze lassen sich zu seinem persönlichen Nachteil anführen. Auch schon, als die notwendigen Staatseingriffe des ideellen Gesamtkapitalisten in die kapitalistische Produktionsweise um ihrer selbst willen thematisch Gegenstand waren, wurde die systematische Heteronomie auch des Kapitalisten im Kapitalismus deutlich (vgl. 2.6.3): Der ideelle Gesamtkapitalist Staat ist der totale, klassenübergreifende ideelle Kapitalist und Arbeiter zugleich, der mit den Einzelkapitalisten wie den einzelnen Arbeitern jedoch nichts gemeinsam hat, sondern der nur die subjektlose objektive Instanz des antagonistischen Kapitalverhältnisses ist: als bürgerlicher Staat (vgl. 3.3).

Nun sind aber auch die Eigentümer an Produktionsmitteln als Klasse, wie schon die Eigentumslosen, doppelt affirmativ aufeinander bezogen. Ihrem Begriff nach hat die Klasse der Eigentümer an Produktionsmitteln in der bürgerlichen Gesellschaft ein der Arbeiterklasse entgegengesetztes, fortwährendes und generelles Interesse an der Steigerung des Ausbeutungsgrades der Klasse der freien Lohnarbeiter. Durch dieses gemeinsame, ebenfalls intellektuell klassenbewusste Interesse an der Erhöhung des Ausbeutungsgrades der gesellschaftlichen Gesamtarbeit - geleistet durch die antagonistische Klasse der Lohnarbeiter - sind also die Eigentümer an Produktionsmitteln wie die Klasse der Proletarier affirmativ aufeinander bezogen. Diese intellektuelle Bindung der Eigentümer aneinander ergibt sich ebenfalls erst aus ihrer integrativen Eingebundenheit in die kapitalistische Gesellschaft. Zudem sind sie noch aufgrund der technischen Abhängigkeit der einzelnen Produktionszweige auch wirklich, reell affirmativ, weil kooperativ, aufeinander bezogen. Auch die Eigentümer an Produktionsmitteln sind als Klasse also doppelt affirmativ aufeinander bezogen, oder, adäquat ausgedrückt: auch sie haben sich gezwungenermaßen doppelt affirmativ aufeinander zu beziehen: „Da Warenproduktion und Warenzirkulation die allgemeine Voraussetzung der kapitalistischen Produktionsweise, erheischt manufakturmäßige Teilung der Arbeit eine schon bis zu gewissem Entwicklungsgrad gereifte Teilung der Arbeit im Innern der Gesellschaft. Umgekehrt entwickelt und vervielfältigt die manufakturmäßige Teilung der Arbeit rückwirkend jene gesellschaftliche Teilung der Arbeit. Mit der Differenzierung der Arbeitsinstrumente differenzieren sich mehr und mehr die Gewerbe, welche diese Instrumente produzieren. “979

Doch auch die Eigentümer der mehrwertgenerierenden Produktionsmittel sind durch ihre klasseninterne Konkurrenz um die gesellschaftliche Profitmasse, vermittelt über die Anwendung von eigentumslosen Lohnarbeitern als Klassenmitglieder, entscheidend negativ aufeinander bezogen. Diese Negativität drückt vor allem das universale Moment des objektiven systematischen Zwangs aus, der auf alle Subjekte der kapitalistischen Produktionsweise gleichermaßen über den objektiv gesicherten Zwang wirkt: weil aufgrund der Motivation ihrerseits, Profit zu machen, auch die Eigentümer an Produktionsmitteln vor allem branchenintern

${ }^{979}$ Marx: Das Kapital, Bd. 1, S. 374. 
miteinander konkurrieren. Auch hier macht sich deshalb ein ,Populationsgesetz der totalen kapitalistischen Produktionsweise gegen die jeweiligen Klassenmitglieder geltend. Die entsprechende Motivation des willensbegabten Subjekts, den Privateigentümerkonkurrenten zu seinem Vorteil auszubooten, lässt sich dabei wiederum auch mit den objektiven Gesetzmäßigkeiten der materiellen Verfasstheit der wertverwertenden Gesellschaft belegen. Auch die Eigentümer an Produktionsmitteln wollen den klasseninternen Konkurrenten die Lebensbedingungen nur deswegen streitig machen, weil sie es systematisch müssen. So erweist sich das gesellschaftliche Gesamtkapital auch für den totalen Zwangszusammenhang der gesellschaftlichen Einzelkapitale in toto verantwortlich: „Als Totalität der Bedingungen der Reproduktion aller Einzelkapitale zwingt es diese hinsichtlich ihrer arbeitsteiligen affirmativen Beziehung aufeinander in quantitativ und qualitativ bestimmte Relationen, hinsichtlich ihrer negativen Beziehung aufeinander in einen qualitativ bestimmten und quantitativ begrenzten Marktmagen. "980

Es kommt dadurch auch noch augenscheinlicher zur Geltung, was oben bereits kritisiert wurde: Mit einer biologisierten Anthropologie, Evolutionsbiologie etc. lässt sich die Konkurrenz aller gegen alle nicht erklären, sondern sie kann nur als ein Resultat der bürgerlichen Vergesellschaftung aufgefasst werden. Nur oberflächlich betrachtet lässt sich die ökonomische Konkurrenz um die Verwertung von Eigentumstiteln als eine Frage von biologischen, egoistischen Charakterzügen der Subjekte abtun. Die wahren Bedingungen der Konkurrenz liegen in den ökonomischen Verhältnissen begründet, ursprünglich sind sie ein institutionell verlängertes Resultat der Geschichte der revolutionären Expropriation. Das lässt das heteronome Handeln der Subjekte in der Gesellschaft erklären und das begründet auch die unfreiwillige Freiwilligkeit der Subjekte.

So bekommt also mit der als klassenübergreifend dargestellten erzwungen, heteronomen Kooperation der an sich freien Willensäußerung der Subjekte im Vertrag, die sich mit der oben angesprochenen fictio juris vermitteln lässt (vgl. 3.4), auch jedes Urteil der Freiwilligkeit des praktischen Tuns der individuellen Eigentümer - auch und insbesondere zu nennen das der gewerblichen, sexuellen Prostitution - ein unwahres Moment. Das willensbegabte Subjekt des Vertragsabschlusses kann sich als Eigentümer, ob an Ware Arbeitskraft oder an Produktionsmitteln, nicht etwa freiwillig sozialisieren. Die formell freiwillige Kooperation des sozialisierten Subjekts innerhalb des reziproken Eigentumsaustauschs erweist sich im Resultat immer als eine Kooperation des Subjekts mit kapitalistischer Gesellschaft aus der gesellschaftlichen Oppression des Subjekts heraus. Die formell freiwillige Kooperation über die Vertragsfreiheit muss demnach vom Subjekt immer der eigenen, individuellen Reproduktion zuliebe gewählt werden. Durch dieses entscheidende Moment der Sozialisation wird die gesellschaftliche Totalität der kapitalistischen Produktionsweise erst erhalten und (erweitert) reproduziert, indem

980 Weyand: Adornos Kritische Theorie des Subjekts, S. 72 
das Subjekt seine eigene Selbsterhaltung als physisches Individuum - eben als mit dem Subjekt in sich vermitteltes körperliches Moment - innerhalb dieser ihm gegenüberstehenden und es integrativ einbeziehenden Totalität als atomisiertes Subjekt um seiner individuellen Reproduktion willen realisiert. Gerade dieser auf dem Subjekt lastende objektive Zwang verlangt die starke Identifikation mit der gesellschaftlichen Heteronomie. Dieser Zwang der Individualisierung und Sozialisierung identifiziert den Willen des Rechtssubjekts mit der staatlich rational organisierten gesellschaftlichen Reproduktion, dem jeweils konkreten ideellen Gesamtkapitalisten. Damit identifiziert sich der Wille des Staatsbürgersubjekts mit dem jeweils politischen Ausdruck der Garantie der subjektiven, besonderen Reproduktion: dem bürgerlichen Nationalstaat. Deshalb werden jetzt Nationalismus, Nationalstaat und Kapital zum Gegenstand.

\subsubsection{Sozialisation I: Thesen zum Nationalismus}

Der moderne Nationalstaat ist vom bürgerlichen, kapitalistischen Staat nicht zu trennen, denn dieser ist seine Identität. ${ }^{981}$ Eine andere Form der Ausprägung hatte er nicht; und wird er schwerlich je haben. Der moderne Nationalstaat ist deshalb auch so wenig zeitlos wie der Kapitalismus und die bürgerliche Gesellschaft. Die Existenz von bürgerlicher Nation und kapitalistischem Staat ist insofern dialektisch zu vermitteln. Der „kapitalistische Staat“ ${ }^{\star 982}$ findet nun auch nach Poulantzas seinen Ausdruck im ,nationalen Volksstaat" ${ }^{\text {“ }}$.

Poulantzas unterstellt der Nation dann jedoch eine historische Kontinuität, womit er sie ontologisiert. So sei „die Nation (...) nicht mit der modernen Nation und dem Nationalstaat identisch, wie man ihn bei der Entstehung des Kapitalismus im Westen antrifft. (...) Es handelt sich hier um ein Kernproblem [gemeint ist das Kernproblem der Marxisten mit der Nation, B.E.B.]: eine Realität, die Nation, wird als ökonomisch-politischer und kultureller Gegenstand in seiner grundlegenden Beziehung zu den gesellschaftlichen Klassen untersucht, die permanent auf die wesentliche politisch-strategische Frage des proletarischen Internationalismus

\footnotetext{
981 Nation, Volk, Gesellschaft und Staat werden nach der Französischen Revolution zu austauschbaren Begriffen: „Nor is it surprising that movements seeking to represent an entire society or ,people should envisage its existence essentially in terms of that of an independent or at least an autonomous state. State, nation and society converged." (Hobsbawm: Mass-Producing Traditions, S. 265.) Siéyes beispielsweise versteht in Was ist der Dritte Stand? unter, la nation' dasselbe, was Rousseau unter , le peuple‘ verstand. (Vgl. Löwith: Von Hegel zu Nietzsche, S. 259.) Die Nazis hingegen trennen die Begriffe Nation und Volkstum, um die biologistische Karte von Volk zu spielen. Damit soll der bürgerlich-demokratische Hintergrund des Nationenbegriffs seit der Französischen Revolution vermieden werden: „Was verstehen die deutschen Nationalsozialsozialisten unter Volkstum und Rasse, und warum bestehen sie auf Oberhoheit? Warum vermeiden sie so ostentativ den Gebrauch des gängigen Begriffes ,Nation'?“ (Neumann: Behemoth, S. 131.)

982 Poulantzas: Staatstheorie, S. 40.

983 Ebd.
} 
verweist." "984 Und so argumentiert Poulantzas auch vollkommen konsequent, wenn er schreibt: „Der kapitalistische Staat funktioniert auf der Grundlage der Nation. “985 Damit existiert die Nation für Poulantzas bereits vor dem kapitalistischen bürgerlichen Staat, und der bürgerliche Staat erscheint als etwas der Nation fremdes, ihr und ihrer Ursprünglichkeit nur historisch oktroyiertes. Folglich spricht Poulantzas der Nation etwas Primäres, nahezu mythisches, zu: Ihr korrespondiere etwas, was dem kapitalistischen, ,nationalen Volksstaat ${ }^{6}$ vorausgehe.

Solch ein Schein der mythischen Ursprünglichkeit der Nation ist jedoch als ein ideologisches Resultat einer historisch kurzen Tradition der nationalistischen Bewegungen zu sehen. Weil die Geschichte des kapitalistischen Nationalstaates so kurz ist, erfinden Nationalisten ihren ,eigenen' Nationen erst eine Tradition. Ohne

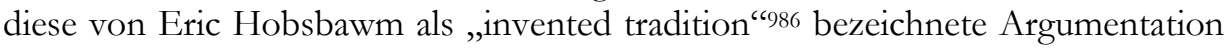
kommt auch kein bürgerlicher Nationalismus aus. Sie suggeriert die angebliche Ewigkeit der politischen Nation als traditioneller Volkszusammenhang, was auf eine scheinbar nationale Homogenität über alle historischen Differenzen hinweg anspielt. Die erfundene Tradition suggeriert ideologisch die scheinbare Ewigkeit der Volksgemeinschaft (zumeist) innerhalb der Grenzen des bürgerlichen Staats, und zwar ungeachtet aller historisch kriegerischen Auseinandersetzungen und sozialen Kämpfe auf den jeweiligen Gebieten etc. Die moderne politische Herrschaftseinheit der bürgerlichen Nation wird dadurch weit zurück in die vorbürgerliche Geschichte gelegt. ${ }^{987}$ Als scheinbar ontologisches Ewigkeitsmodell legen die Nationalisten den eigenen, jungen Nationalstaat nicht völlig intentionslos ideologisch vor sein eigentliches Konstitutionsdatum zurück. Eine solche „continuity with the past “"988 schiebt man der (eigenen) bürgerlichen Nation aus Interesse der Herrschaftssicherung ex post unter. Das ist jedoch eine äußerliche, an Nation und Nationalstaat kreativ erst herangetragene geschichtliche Kontinuität, weil der bürgerliche Nationalstaat erst das Phänomen des postrevolutionären Bürgertums sein kann. Das befriedigt daneben auch noch den allgemeinen Hang zum Ursprünglichen als dem Wahren und Richtigen, was die eigene Nation als eine historisch Althergebrachte im Ansehen erhöhen soll. 989

Doch die unterstellte Kontinuität der Nation liegt auch im Begriff der Nation selbst begründet, der tatsächlich weit in die Geschichte zurückverweist und durch den dieses Moment der langen Geschichte von Nationen scheinbar ein Funda-

\footnotetext{
${ }^{984}$ Ebd., S. 123.

985 Ebd., S. 130.

986 Hobsbawm: Inventing Traditions, S. 1.

987 Am schottischen Kilt und dessen Geschichte, als eines erst im Zuge der Industrialisierung entwickelten Kleidungsstücks, lässt sich die nationalistische Ideologie von der konstruierten Ewigkeit auch nationaler Symbole gut beschreiben. (Vgl. Trevor-Roper: The Invention of Tradition, S. 15 ff.)

988 Hobsbawm: Inventing Traditions, S. 1.

989 „Die Verbindung zwischen dem Begriff der Nation und dem Begriff des Volkes war in der Tat eine bedeutende Neuerung, die den Kern des jakobinischen Selbstverständnisses und anderer revolutionärer Gruppierungen ausmachte.“ (Hardt/Negri: Empire, S. 115.)
} 
ment in der Sache hat. Der Begriff Nation entsteht insofern nicht erst mit der bürgerlichen Gesellschaft: „Der Begriff der Nation entwickelte sich auf dem Boden des ständisch-feudalen und absolutistischen Staates. “990 Doch diese längere Geschichte des Begriffs der Nation verweist zugleich auf eine unbedingte historische Diskontinuität, weil über den reflektierten Begriff der Nation auch unterschiedliche gesellschaftsgeschichtliche Herrschaftsmomente in der Geschichte kenntlich werden. Die Nation wird in der bürgerlichen Gesellschaft inzwischen auch ganz anders als noch zu Zeiten des Feudalismus begriffen. Im Feudalismus wird der rein unpolitische Geburtszusammenhang von Bevölkerungsgruppen als Nation bezeichnet. ${ }^{991}$ Erst die moderne Nation wird zu dem entscheidend politisierten Begriff in den modernen Gesellschaften, in dem sich dann nach 1776/1789 unmittelbar (staats-)politisches und staatsrechtliches verschränkt, wodurch sich der Nationenbegriff jedoch auch qualitativ von seiner Tradition und Bedeutung entfernt: „Durch die Französische Revolution ist überhaupt erst die französische Nation als eine politische entstanden. In der vorbürgerlichen Gesellschaft verstand man unter ,Nation" hauptsächlich eine - die Juden." "992 Jegliche im vorbürgerlichen Sinn als Nation begriffene feudale Gruppierungen werden im Zusammenhang der bürgerlichen Gesellschaft nun auch aufgelöst. Denn in der postrevolutionären bürgerlichen Gesellschaft beansprucht die Nation für sich und ihr Staatsgebiet den allgemein staatsbezogenen, identitätsstiftenden Nationenbegriff. Der moderne Nationalstaat macht seine Untertanen auf seinem Staatsgebiet ausnahmslos zu national homogenisierten Staatsbürgern. Die vorbürgerlich zunächst herrschaftstechnisch noch ganz unbedeutende, unpolitische, völlig heterogene Bevölkerung wird insofern erst durch die bürgerlichen Revolutionen zum homogenen (Staats-)Volk gemacht, zur einheitlichen Nation eines Staats erklärt. Der konstituierte Staat kann durch diese Homogenisierung auch erst zum ,nationalen Volksstaat ' werden. Eine jüdische Nation in der postrevolutionär konstituierten französischen Nation, eine, fremde ${ }^{c}$ Nation auf dem Gebiet des neu konstituierten Nationalstaats Frankreich, kann es dann auch nicht mehr geben, weil eine Nation in der Nation die Homogenität und Souveränität des Nationalstaats schon im Begriff seiner politischen Entstehung in Frage stellen würde: „Die Proklamation der Menschenrechte löst die Juden als Nation auf in die konstituierte Französische Nation." "993

Mit der Auflösung der feudalen Nationen werden im Resultat jedoch nicht nur die Juden unter das allgemeine Gesetz der bürgerlichen Gesellschaft gezwungen und von ihren vorbürgerlichen, nationalen Privilegien befreit: „Kurz, der Eintritt der Juden in die bürgerliche Gesellschaft geschieht durch Unterwerfung." ${ }^{\text {"9994 Der }}$

\footnotetext{
990 Hardt/Negri: Empire, S. 107.

991 Vgl. Claussen: Vom Judenhass zum Antisemitismus, S. 68.

992 Ebd.

993 Ebd., S. 68.

994 Claussen: Grenzen der Aufklärung, S. 127.
} 
Nationalstaat organisiert sich seine Staatsbürger und subsumiert sie allesamt unter seine Nationalstaatlichkeit. Insofern mit der bürgerlichen Gesellschaft die moderne Nation intellektuell als Ordnungsmoment des bürgerlichen Staates nach den Bauernbefreiungen entsteht, entsteht damit auch eine qualitativ neue Konnotation des Begriffs Nation unter historisch veränderten, ökonomisch-politischen Verhältnissen. Der Begriff der politischen Nation bezieht sich inzwischen also auf ein bereits konstituiertes Staatsgebiet mit einheitlichen, allgemeinen Gesetzen, die für alle Staatsbürger ausnahmslos gelten. Der vorbürgerliche Nationenbegriff ist deshalb mit dem bürgerlichen, sich inzwischen auf einen bestimmten politischen Staatszusammenhang beziehenden Nationenbegriff nicht zu verwechseln, weil die politische Konnotation des Begriffs eine gänzlich andere ist. Eine Kontinuität des Nationenbegriffs durch die unterschiedlichen Gesellschaftsformationen hindurch lässt sich darum nicht begründen. Als inzwischen innenpolitischer Ordnungsbegriff ist der Begriff der politischen Nation als Staat ungemein modern: „Das entscheidende Charakteristikum der modernen Nation und von allem, was mit ihr zusammenhängt“, so Hobsbawm, „,ist ihre Modernität.“995 Diese Diskontinuität des Nationenbegriffs durch den gesellschaftlichen Wandel übersieht Poulantzas, wenn er die Nation entsprechend ontologisiert.

Die Modernität des Nationalstaats muss zur Bevölkerung, den neuen Bürgern, jedoch zunächst einmal durchdringen. Durch die Konstitution des kapitalistischen Staates kommt es deshalb zu einem Nationalismus von oben, weil dieser sich innerhalb seines neu konstituierten Staatsgebiets seine Staatsbürger rekrutiert. ${ }^{996}$ Die politische Einheit Nation braucht unbedingt ein homogenisiertes, (selbst-) bewusstes Staatsvolk, das sich mit ihr identifiziert. Die Konstitution des bürgerlichen Staates ruft deswegen auch gleich eine einheitsstiftende Nationalisierungswelle hervor, mit Hilfe derer das gewonnene Gebiet im Bewusstsein der neu formierten Untertanen als einheitliches politisches (Staats-)Gebiet mit einheitlichen Gesetzen verfestigt wird. Das Gebiet wird beispielsweise zu Zwecken des kapitalistischen Warenhandels juristisch als eine (Markt-)Einheit homogenisiert, womit der Nationalstaat die materiellen Voraussetzungen der kapitalistischen Produktionsweise vereinheitlicht. Selbst dort, wo man es nicht vermuten würde, führt der Versuch, die kapitalistische Produktion im Nationalstaat zu homogenisieren, Regie. Mit der im Zuge der Konsolidierung des Nationalstaats eingeführten Amtsoder Nationalsprache, die grammatikalisch auf dem jeweiligen Staatsgebiet offiziell verbindlich wird - und es ist an dieser Stelle interessant zu erfahren, wie modern etwa Grammatiken sind 997 -, wird das Herrschaftsgebiet des Staats vereinheitlicht. In Zukunft sollen nämlich Arbeiter wie Warenhändler des neu konstituierten,

\footnotetext{
995 Hobsbawm: Nationen und Nationalismus, S. 25.

996 Vgl. Ebd., S. 58.

997 Vgl. Poulantzas: Staatstheorie, S. 87.
} 
nationalen Binnenmarkts problemloser miteinander kommunizieren können ${ }^{998}$ : „Der kapitalistische Staat etabliert die Vereinheitlichung der Sprache durch die Schaffung der Nationalsprache und die Zerstörung der anderen Sprachen. (...) Nicht umsonst sind die Grammatik und die Orthographie vom Staat systematisiert, wenn nicht gar entdeckt und dann zu Machtnetzen verknüpft worden." "999

Die modellhaft angeführten Anordnungen der Nationalisierung von oben sind jedoch nur die eine Seite des Nationalismus. Den Aktionen der Staatsmacht entspricht auch ein sich in den bürgerlichen Subjekten willentlich ausprägender Nationalismus in Wort und Tat. Dieser ist nicht das nebensächliche Produkt vereinzelter Wirr- oder Hitzköpfe, sondern er bezieht sich systematisch vermittelt auf die offensichtliche nationalistische Realität der kapitalistischen Moderne; darin hat er sein entscheidendes fundamentum in re. Die Nation ist eine vom Staat vereinheitlichte Gruppe von Staatsbürgern, denen die Rechte zum Vorteil ihrer eigenen Reproduktion vom jeweiligen Nationalstaat garantiert werden. Auf diesen, Vorteil' bei der eigenen Reproduktion hat sich jeder Staatsbürger willentlich zu berufen, wenn er auf dem jeweiligen Staatsgebiet überleben will. So steht der Nationalismus im Zusammenhang mit der klassenunabhängigen, willentlichen Anerkennung des bürgerlichen Nationalstaats durch das beherrschte und in ihn zwangsintegrierte Subjekt als Staatsbürger: „Denn es gibt keine soziale Schicht, Klasse, Elite, die prima facie für den Nationalismus prädestiniert oder gegen ihn gefeit ist. “1000 In der dem Subjekt abgetrotzten, willentlichen Anerkennung der bürgerlichen Gesellschaft über den abgeschlossenen Vertrag zum Zwecke der individuellen Selbsterhaltung liegt deshalb die Anlage eines jeden Nationalismus begründet, wenn dieser universell sein soll. Auf den nationalstaatlich gesicherten Vertrag hat sich, wie oben deutlich wurde, jeder der mit Rechten ausgestattete Bürger affirmativ anerkennend zu beziehen, möchte er seine Selbsterhaltung im entsprechenden politischen Staatsgebiet realisieren, weshalb die Anlage des subjektiven Nationalismus in den Zusammenhängen der kapitalistischen Gesellschaft liegt.

Mit diesem herausgearbeiteten, erzwungenen, positiven Bezug auf den bürgerlichen Nationalstaat zum eigenen überlebenswichtigen Vorteil erweist sich auch das Argument Lenins als falsch, denn Lenin ist der Überzeugung, dass der moderne Nationalismus ein alleiniges Erkennungszeichen für eine proletarische Kleinbürgerlichkeit sei. ${ }^{1001}$ Der bürgerliche, moderne Nationalismus ist für Lenin, wie auch schon der Antisemitismus (vgl. z.B. 5.1.2), ein bloß die Arbeiterklasse zerstäubendes, reaktionäres Moment, welches die Bourgeoisie geschickt zu Herrschaftszwecken für sich zu nutzen wisse: „Die ausbeutenden Klassen bedürfen der politischen Herrschaft im Interesse der Aufrechterhaltung der Ausbeutung,

\footnotetext{
${ }^{998}$ Eine Einheitssprache existiert zwar in den USA de jure nicht, de facto aber ist es, aus gutem und selbsterklärendem Grund, das Englische.

999 Poulantzas: Staatstheorie, S. 86 f.

1000 Wehler: Nationalismus, S. 41.

1001 Vgl. Lenin: Kritische Bemerkungen zur nationalen Frage, S. 1 ff.
} 
d.h. im eigennützigen Interesse einer verschwindend kleinen Minderheit gegen die ungeheure Mehrheit des Volkes. “1002 In Staat und Revolution bestimmt Lenin den kapitalistischen Staat deshalb partikularistisch als rein funktionellen Staat der Kapitalistenklasse, der Bourgeoisie. Die oben erarbeitete Identifikation der Arbeiter mit dem Staat über die vertragliche Zirkulation kann für Lenin darum auch nur eine Erfüllung des probaten Mittels zum partikularen Zweck der Bourgeoisie sein. Die Arbeiterklasse sitze deshalb als unterdrückte Klasse bloß durchgängig einem Schwindel der Bourgeoisie auf. Aus sich heraus müsste die Arbeiterklasse jedoch streng inter- oder besser: antinational und klassenbewusst denken. Mit dem richtigen Klassenbewusstsein dürften die Proletarier deshalb kein Interesse in oder an dem bürgerlichen Staat haben und auch keine Nationalisten mehr sein. Ihr eigentlich klassenbewusster Internationalismus werde der Arbeiterklasse jedoch von der Bourgeoisie mittels des angebotenen Nationalismus ausgetrieben; der Arbeiterklasse werde über den Nationalismus die Integration in den bürgerlichen Nationalstaat bzw. den Kapitalismus angeboten. Diese sie pazifizierende Integration habe jedoch allein das perfide Ziel, sie weiterhin und auch in Zukunft ausbeutbar zu halten. Der Nationalismus sei insofern lediglich das intellektuelle Werkzeug der Bourgeoisie zum eigenen, materiellen Zweck: die Arbeiterklasse noch besser zu beherrschen: „Der streitbare bürgerliche Nationalismus, der die Arbeiter abstumpft, verdummt und entzweit, um sie am Gängelband der Bourgeoisie zu führen. “"1003

Lenin löst den Nationalismus mithilfe seiner Klassentheorie deshalb einfach von seinen innersten materiellen Voraussetzungen ab: dem Zwang der einzelnen Subjekte, die eigene Reproduktion innerhalb der nationaler Grenzen realisieren zu müssen. Dem Nationalismus wesentliches reflektiert er nicht, weshalb der Nationalismus für ihn zur substanzlosen Idee wird, der nichts transzendent materielles korrespondiere. Unter dem Vorzeichen der Selbsterhaltung als Eigentümer, der auf den seine Rechte garantierenden Staat angewiesen ist, kann der Nationalismus jedoch nicht ein solches Zeichen unreflektierter Kleinbürgerlichkeit sein, sondern er ist das Resultat der dem Subjekt transzendenten, materiellen, gesellschaftlichökonomischen totalen Zusammenhänge der bürgerlichen Gesellschaft. Ohne die Dialektik von Ökonomie und Recht, Staat und Kapital ist er generell undenkbar. Vor allem bietet er sich für die selbstbewussten Rechtssubjekte durch die Anerkennung der nationalen Rechtsprechung an, die systematisch zwecks der allgemeinen Konkurrenz anerkannt werden muss. Jede Vertragsunterzeichnung in der bürgerlichen Gesellschaft ist, wie oben schon dargestellt (vgl. 3.6.1), im Zusammenhang der willentlichen Anerkennung des Staates und seiner für alle gleichermaßen geltenden gesetzlichen Regeln der kapitalistischen Ökonomie zu sehen. Jeder abgeschlossene Vertrag ist deshalb auch immer gleich die Affirmation des Nationalstaats durch das unterzeichnende Subjekt. Der Vertragsabschluss ist inso-

1002 Lenin, Staat und Revolution, a.a.O., S. 29.

${ }^{1003}$ Lenin: Kritische Bemerkungen zur nationalen Frage, S. 10. 
fern die Affirmation der herrschaftlichen Instanzen des Nationalstaates, der allein diese Vertragsgültigkeit objektiv garantiert.

Mit jeder Vertragsunterzeichnung affirmiert das Staatsbürgersubjekt also die eigenen objektiven Voraussetzungen der eigenen Selbsterhaltung im Nationalstaat. Dadurch wird es erst in den heteronomen, herrschaftlichen Zusammenhang der kapitalistischen Gesellschaft integrativ und aktiv eingebunden. Oben wurde bereits der Zwang aller selbstbewussten Subjekte bezüglich ihrer Vertragsgebundenheit angeführt, der dabei auch völlig unabhängig von Klasse, ,Geldmacht' etc. wirkt. Aus den materiell bestimmbaren Gründen des Zwangs zur eigenen Reproduktion wird sich insofern die Affirmation des bürgerlichen Nationalstaats als besonderer Zweck der instrumentellen Vernunft gesetzt. Ohne wirklich willentlich Nationalist sein zu müssen bleibt darum selbst noch dasjenige Subjekt für das Weiterleben der Nation und damit der gesellschaftlichen Herrschaft verantwortlich, das mit jeder Vertragsunterzeichnung das nationale Recht und damit die Selbstbegründung der Nation anerkennt. Jedes Staatsbürgersubjekt unterschiedslos trägt deshalb seinen entsprechenden Teil zum Fortbestand des Nationalstaates bei: „Weil die Mitglieder der kapitalistischen Gesellschaft in der Verfolgung ihres individuellen Nutzens die Schädigung der anderen betreiben, sind sie auf eine Macht angewiesen, die getrennt vom ökonomischen Leben die Anerkennung von Eigentum und Person garantiert. Ihren negativen Bezug aufeinander ergänzen sie um ihre gemeinsame Unterwerfung unter eine Gewalt, die ihre Sonderinteressen beschränkt. Neben ihren ökonomischen Geschäften sind sie politische Bürger, sie wollen die staatliche Herrschaft, weil sie ihren Sonderinteressen nur nachgehen können, indem sie von ihnen auch abstrahieren. Der bürgerliche Staat ist also die Verselbständigung ihres abstrakt freien Willens. “1004

Im Prozess der formell-juristischen Anerkennung aus ganz subjektiven Interessen der Selbsterhaltung spielt es deshalb auch keine gewichtige Rolle, ob die eigene politische Nation oder eine andere oder gar keine gut gefunden wird, weil die Anerkennung des bürgerlichen Staates und seiner kapitalistischen Zirkulationsund Produktionssphäre dem Subjekt transzendent schon oktroyiert ist. Dialektisch erweist sie sich als gewollte Anerkennung, weil nur so die eigene Selbsterhaltung innerhalb der gesellschaftlichen Totalität realisiert werden kann. Die internationale Konkurrenz zwischen kapitalistischen Staaten - auch durch die sich öffnende Möglichkeit alternierender Produktionsstandorte - nötigt daneben auch noch das sich in einem bestimmten kapitalistischen Nationalstaat reproduzierende Subjekt, in diesem internationalen Kampf der eigenen Nation, selbst als aufgeklärter Antinationalist, ,die Daumen zu drücken'. Schon allein weil in jeder Überlegung der verantwortlichen Charaktermasken des Kapitals, Produktionsstandorte in andere Länder zu verlegen, tendenziell eine lebensbedrohliche Aussage für lohnarbeitende Subjekte steckt, nämlich dass ihr eigener Lebensstandard sinke - geschweige

${ }^{1004}$ Resultate Bd. 3: Der bürgerliche Staat, S. 11. 
denn der nationale ${ }^{1005}$, vollzieht das Subjekt diesen Akt der nationalistischen Affirmation, damit der eigene ,Lebensstandard' gehalten oder nach Möglichkeit zum Besseren hin verändert wird. Es affirmiert sich dadurch als lebendiges Subjekt. So vereinheitlichen sich im bürgerlichen Nationalstaat zwangsläufig die Interessen von noch so kritischen Staatsbürgern. Der Nationalismus zeigt sich darum immer in Verbindung mit der existentiellen Sorge um den eigenen, den nationalen und den damit vermittelten relativen individuellen Wohlstand der Bevölkerung.

Damit die Subjekte ihr eigenes Leben, d.h. ihre eigene Reproduktion, in den Grenzen der bürgerlichen Produktionsweise, egal wie prekär, sicherstellen können, hoffen die Staatsbürgersubjekte auf den Erfolg des eigenen Nationalstaats. Vermeintliche Gefährder eines auch noch so prekären gesellschaftlichen, Wohlstands ${ }^{`}$ - ob als Chiffre der Hetze dafür nun der Ausländer, Jude oder der Banker gesetzt wird - werden deshalb gerne als antinationale, feindliche Subjekte denunziert, die den gesellschaftlichen Reichtum und damit den der wirklichen Staatsbürgersubjekte senken: „Auch heute gibt es keine Rassisten. Niemand hat etwas gegen Türken und Flüchtlinge an sich. Es ist die Sorge um den nationalen und individuellen Wohlstand, die sie als Störenfriede ausmacht.“"1006 Nicht blind, sondern durchaus selbstbewusst willentlich, weil individualistisch und instrumentell zweckbezogen, erfüllt das lebendige Subjekt damit einen objektiv gesellschaftlichen Zwang. Deswegen kann sich mit dem ausgeführten, auf dem selbstbewussten Subjekt lastenden allgemeinen Zwang zur willentlichen Anerkennung des Nationalstaats und seiner allgemeinen Rechtsprechung von der Leninschen Überzeugung, dass der Nationalismus ein nur chimärisches Propagandakonstrukt und vom elitären Subjekt bloß erdacht sei, um klassensubjektive Zwecke besser zu erreichen, verabschiedet werden. Und trotzdem hält sich bis heute die entscheidende Überzeugung in verschiedenen Nationalismustheorien, dass der Nationalismus etwas den bürgerlichen Gesellschaften äußerliches, nur an sie herangetragenes sei. ${ }^{1007}$ Noch heute macht man den Nationalismus deswegen zu einer kreativen Erfindung von gewitzten bürgerlichen Subjekten, die damit nur ,ihr ${ }^{\varsigma}$ großbürgerliches Terrain sichern würden - und dafür extra die allgemeinen bürgerlichen Gesetze geschaffen hätten. Auch Eric Hobsbawm beschreibt in Nationen und Nationalismus einen solch eindimensional gedachten, elitären und ideellen Nationalismus von oben, der den beherrschten Subjekten zunächst das Bewusstsein vom Nationalstaat einimpfe: „In den Tagen Mazzinis spielte es keine Rolle, daß für die Große Mehrheit der Italiener das Risorgimento nicht existierte, so daß Massimo d'Azeglio in der ersten Sitzung des Parlaments eines gerade vereinten Italiens seinen berühm-

\footnotetext{
1005 Vgl. Bulthaup: Elemente des Antisemitismus, S. 128.

1006 Claudia Kalász, Extremismus? - Elemente der Xenophobie, in: Gesellschaftswissenschaftliches Institut (GI) e.V. (Hrsg.): Traditionell kritische Theorie. Zehn Überlegungen zu verschiedenen Gegenständen,, S. 35 f.

1007 Vgl. u.a. Gellner: Nationalismus; drslb.: Nationalismus uns Moderne; Kohn: Die Idee des Nationalismus; Wehler: Nationalismus.
} 
ten Ausspruch tun konnte: ,Wir haben Italien geschaffen, jetzt müssen wir Italiener schaffen."“1008

Diese nationalistische ,Bewusstseinsmanipulation“ durch die Elite kann jedoch wirklich nur ausschließlich für die ,Tage Mazzinis‘ gelten. Das stellt Hobsbawm auch präzise wie adäquat dar. ${ }^{1009}$ Derart kreativ und bloß eine Erfindung der bürgerlichen, nationalen Elite zu ihren Zwecken kann der bürgerliche Nationalismus in seiner Fortführung allein schon deshalb nicht sein, weil, selbst wenn die persönliche Anerkennung des Staates durch das Subjekts ausbleiben sollte, das Staatsbürgersubjekt den Nationalstaat über den heteronomen Zwang zur eigenen Reproduktion bestätigen muss. Dieser universelle Zwang auf alle Subjekte ist als Argument gegen die reine Kreativität des Nationalismus zu Herrschaftszwecken nicht zu unterschätzen. Selbst das, völkischste' Volk hat sein materielles Substrat deshalb in einem nationalen bürgerlichen Staat; oder zumindest in einer geschichtsbezogenen Staatsidee. Die These von der Einrichtung des Nationalstaates als funktionalistischer Staat der Kapitalistenklasse mag zunächst zwar mit historischen Beispielen belegt werden können, wenn man sich die Gründung der ersten Nationalstaaten einmal genauer anschaut, 1010 aber die Akzeptanz und tiefgreifende Identifikation aller Schichten mit dem Nationalstaat lässt sich mit offener Herrschaft der Kapitalistenklasse oder der Bourgeoisie, wie etwa mit dem Zensuswahlrecht etc., nicht begründen. Sie lässt sich erst mit der wirkmächtigen Totalität des kapitalistischen Systems, das alle Subjekte ausnahmslos in sich als Mittel zum ihnen transzendenten gesellschaftlichen Zweck integriert, erklären. Das Urteil von der Kreativität der Elite in der Erfindung der Formen von Unterdrückung versteckt deshalb bloß strukturelle Gründe des Nationalismus, die dagegen in den ökonomischen Zwecken der einzelnen, zum Mittel gemachten selbstbewussten Subjekte liegen. Auch die Kapitalistenklasse zeigte sich im fortdauernden kapitalistischen Nationalstaat genauso in Zirkulation und Produktion gefangen, da das heteronome und ihnen transzendente Zwangsmodell nicht (mehr) in ihrem Interesse hat liegen können. Die vermeintlich historische Freude der Kapitalistenklasse über die zunächst erfolgreiche Konzeption eines die eigenen Interessen repräsentierenden Staates dürfte schnell verflogen sein, als Fabrikgesetzgebung und Beschränkungen des Arbeitstages objektiv und unter Androhung von Zwang gegen jeden Einzelkapitalisten vom Staat durchgesetzt wurden.

Andererseits ist sicherlich auch nicht zu unterschätzen, dass der Nationalismus immer wieder als Modell der Rechtfertigung von gesellschaftlicher Herrschaft durch den Staat gewählt wird. Die Subjekte sollen dadurch von der Richtigkeit der

\footnotetext{
1008 Hobsbawm: Nationen und Nationalismus, S. 58.

1009 Dies sieht Hans-Ulrich Wehler anders: Der „Nationalismus“ erschüfe sich ,anfangs seine Nation“. (Wehler, Nationalismus, S. 17.) Dieser Subjektivismus wird weiter unten kritisiert.

1010 Das inzwischen historische Zensuswahlrecht kann stellvertretend dafür stehen, dass die gesellschaftliche Herrschaft von der Kapitalistenklasse zunächst organisiert wurde.
} 
Herrschaft des jeweils partikularen Nationalstaats überzeugt werden ${ }^{1011}$; aber eben auch hier alle Subjekte gleichermaßen und nicht abhängig von ihrer Klassenzugehörigkeit. Ansonsten könnte sich der Nationalstaat als gesellschaftliches Herrschaftsmoment in seinen bestimmten Grenzen nicht derart nachhaltig in den Köpfen verfestigen. Dem Staatsgefüge kommt, bezüglich der eigenen Konsolidierung, der gelebte Nationalismus der meisten Subjekte offensichtlich positiv entgegen. Hobsbawm schreibt: „Es spielte nicht einmal für jene eine Rolle, die ,die polnische Frage ${ }^{6}$ erörterten, daß wahrscheinlich die meisten polnischsprechenden Bauern (...) sich noch gar nicht als nationalistische Polen fühlten; oder wie der endgültige Befreier Polens, Marschall Pilsudski, es auf seine Weise ausdrückte: ,Der Staat macht die Nation, nicht die Nation den Staat.“"1012 Deshalb fördert der bürgerliche Nationalstaat auch die positive Bezugnahme auf ihn als universellen Volksstaat über das Maß der sowieso über das mit ihm zusammenhängende Vertragsrecht erzwungenen Affirmation hinaus. Jedes positive branding des Nationalstaats hilft, ihn in den Köpfen der eigenen Untertanen positiv zu verfestigen. Es hilft in dem Zusammenhang allerdings auch, ihn noch über die eigenen Grenzen hinaus als rechtmäßigen Staat innerhalb der Staatenkonkurrenz anerkennen zu lassen. Fußballwelt- oder Europameisterschaften, Olympische Spiele oder sonstige Sportgroßereignisse konsolidieren insofern alle teilnehmenden einzelnen Nationalstaaten als international anerkannte Nationen. Nationale Selektionen werden insofern nicht nur für die eigenen ,Fans' identitätsstiftend aufgebaut, damit jene als Repräsentanten ,ihrer' Nation akzeptiert und angefeuert werden können, sondern auch, damit sie von gegnerischen ,Fans ${ }^{`}$ als Selektion einer ordentlichen, anerkannten Nation bewundert werden können. ${ }^{1013}$ Auch andere identitätsstiftende Maßnahmen, wie etwa die reißerische nationalistische Rhetorik gegen die „Pleite-Griechen" 1014 bezüglich der Griechenlandkrise in der medialen deutschen Öffentlichkeit fallen dabei unter das Stichwort eines positiven brandings des eigenen Nationalstaats; ob sozialer, ökonomischer oder politischer couleur. ${ }^{1015}$

\footnotetext{
1011 Vgl. Hobsbawm: Nationen und Nationalismus, S. 58. 1012 Ebd.

1013 Eine Mannschaft Transnistriens beispielsweise - ein de-facto-Regime, das aber Teil des anerkannten und souveränen Staats Moldawiens ist - gibt es nicht, weshalb die Existenz Transnistriens auch weitestgehend unbekannt bleibt. Transnistrien ist als Staat nicht international anerkannt: „Transnistria is a breakaway state, recognized by no sovereign nation.“ (cnn.com: To Russia with love? Transnistria, a territory caught in a time warp.) 1014 bildblog.de: Selfies gegen Griechenland. Presserat missbilligt ,Bild‘

1015 Die Griechenlandkrise ist für den Nationalismus in Deutschland wie den restlichen EU-Staaten überhaupt als identitätsstiftendes Moment nicht zu unterschätzen: „In der Mehrzahl der Medien wird versucht, dieser neoliberalen Marschroute mit zwei ,Argumenten' Volkstümlichkeit zu verschaffen: Einerseits hätte seinerzeit die griechische Regierung sich den Zugang zur Währungsunion mit statistischen Manipulationen verschafft; andererseits hätten die Griechen jahrelang über ihre Verhältnisse gelebt und somit die Krise ihrer Staatsfinanzen selbst verursacht.“ (Kritidis: Testfeld Griechenland.)
} 
Viele Nationalismustheorien lassen jenes transzendente, materielle Substrat des Nationalismus allerdings außer Acht, wenn sie sich von den durchaus lückenhaften Modellen der Erklärung des Nationalismus als bloßes Werkzeug wie im Marxismus-Leninismus verabschieden wollen. Ihre falsche Kritik am MarxismusLeninismus bringt im Resultat jedoch eine problematische Intersubjektivierung des Nationalismus mit sich. Diese arbeitet nicht etwa die fehlende Substanz des Nationalismus im Leninschen Modell heraus, sondern recht substanzlos nehmen die intersubjektivistischen Kritiker einzelne Subjekte für ihren persönlichen Nationalismus in die Pflicht. Die viel entscheidende Frage bleibt in erster Linie jedoch die danach, warum es überhaupt zum Nationalismus kommt. Erst im nächsten Schritt, wenn die systematischen Gründe des Nationalismus bekannt sind, kann man Subjekte dann persönlich als Nationalisten kritisieren. Wenn jedoch zunächst nicht einmal deutlich wird, was der Nationalismus ist und wo er systematisch herkommt, dann kann man ihn auch nicht adäquat im Subjekt, geschweige denn in der Gesellschaft nachweisen; weil man in dem Fall immer nur ein verzerrtes Bild vom Nationalismus vorliegen hat.

Der vielleicht prominenteste Beitrag zu einer kritischen Bestimmung des Nationalismus als eine bloß kreative und falsche Vorstellung von einzelnen Subjekten, die mit diesen falschen Vorstellungen auch erst den Nationalstaat konsolidieren würden, ist der Versuch Benedict Andersons aus Die Erfindung der Nation ${ }^{1016}$. Die Nation sei von den Untertanen bloß subjektiv vorgestellt, „weil die Mitglieder selbst der kleinsten Nation die meisten anderen niemals kennen, ihnen begegnen oder auch nur von ihnen hören werden, aber im Kopf eines jeden die Vorstellung ihrer Gemeinschaft existiert." ${ }^{\text {"1017 }}$ Das lässt den oben vorgestellten impliziten materiellen Zwang jedoch vermissen, der sich um die subjektive, instrumentelle Anerkennung des Nationalstaats als Bedingung der Möglichkeit der individuellen Reproduktion aller Staatsbürgersubjekte in der totalen kapitalistischen Produktionsweise bzw. Gesellschaftsform und den Zwang der Rekrutierung als Staatsbürger dreht. Die Nation werde als nur intersubjektiv Vorgestellte zu einem Resultat des falschen individuellen Bewusstseins, womit sie, konstruktivistisch (vgl. dazu 2.5.1), zum völlig freiwilligen Resultat vermeintlich freiwillig vergesellschafteter, selbstbewusster Subjekte wird. So kann der Nationalismus, d.h. der nationalistische Akt als Handlungsrealität, von Anderson nicht mehr als ein mehr oder weniger notwendiges Moment bei der Realisation der Selbsterhaltung in der totalen Gesellschaft gefasst werden. Er wird einseitig zum Resultat einer völlig freien Meinungsäußerung, das aus einer subjektiven Konstruktion folgt. Der Nationalismus wird also zu einem aus dem autonomen Willen des Subjekts gestifteten Phänomen. Die Ursache des Nationalismus wird für Anderson somit zur reinen Kopfsache, weil das Konstrukt Nation erst durch das nationalistische Bewusstsein geschaffen wird.

1016 Anderson: Die Erfindung der Nation.

1017 Ebd., S. 15. 
Selbst der Kinderpass müsste dann jedoch eine freie Entscheidung des noch nicht aktuell willensfähigen und noch nicht voll selbstbewussten Subjekts sein.

Zudem setzt Anderson mit seinem subjektivistischen Konstruktivismus auch noch Wille und (nationalistisches) Bewusstsein gleich, was sich mit Adornos Kritik an Kants transzendentalem Idealismus als identitätsphilosophischer, positivistischer Fehlschluss erweist (vgl. 2.3.1). Alle bürgerlichen und selbstbewussten Subjekte müssten für Anderson demnach vollkommen autonom in ihrem Willen bestimmt sein, weil aus dem freien Bewusstsein zugleich ein freier Wille folge. Die Subjekte haben sich oben zwar auch nicht als heteronom in ihrem Bewusstsein determiniert erwiesen, wohl aber, durch die Verflechtungen von Subjekt und Objekt in Gesellschaft, in ihrem Willen und Handeln als unfreie Subjekte gezeigt (vgl. 2.3.1). Auch die oben ausgeführte Horkheimersche Differenzierung der einen Vernunft, zumal seine Ausführungen zur instrumentellen Vernunft (vgl. 2.3.2), als zur eigenen, individuellen Reproduktion notwendige Mittel-Zweckbestimmung, reflektiert der strenge Subjektivismus Andersons demnach offensichtlich nicht. Die Subjekte scheinen ihre materielle Reproduktion für Anderson scheinbar ohne heteronome Institutionen des Zwangs zu realisieren und ohne, dass sie dabei mit anderen Subjekten in einer erzwungenen klasseninternen Konkurrenz stehen. Nicht nur, dass sich die Existenz des Nationalstaats nicht konsistent aus den Gedanken von Nationalisten erklären lässt (vgl. 3.1.1), auch wird die Welt durch den idealistischen Konstruktivismus eins mit dem identifizierenden Geist, indem Nationalismus und Nation undifferenziert miteinander identifiziert werden. Denken und gesellschaftliches Sein werden damit identifiziert, was dem Nationalismus als gedachtem und deswegen realisierten Phänomen, wenn auch implizit, einen höheren Sinn unterstellt: „Wenn die Welt wahrhaft eins mit dem Geist wäre, wenn die Welt Produkt des Geistes, vom Geist durchherrscht, ja vom Geist hervorgebracht wäre, dann besagte das mit unausweichlicher Notwendigkeit, daß die Welt in ihrer daseienden Gestalt selber sinnvoll wäre." "1018

Andersons Urteil, dass die Nation als „begrenzt und souverän“1019 eine nur subjektiv Vorgestellte sei, die sich nur aufgrund der tradierten Einbildung real reproduziere, entpuppt sich insofern als Reproduktion eines strengen Idealismus. Das Phänomen Nationalismus hat nach Anderson keine gewisse Selbstständigkeit, die in der gesellschaftlichen Systematik begründet liegt, also aus der dem Subjekt vorrängigen gesellschaftlichen Sache kommt. Allein aus der Kraft nominalistisch zusammengefasster Bewusstseine resultiert für Anderson deshalb die Kraft des gesellschaftlichen Seins. Nicht aus einer kontingenten Geschichte der Gewalt entsteht darum ein von jedem einzelnen Subjekt abgelöster, verselbstständigter gesellschaftlicher Zwangszusammenhang mit der Bezeichnung Nationalstaat, der die jeweiligen kapitalistischen Eigentumsverhältnisse objektiv schützt; erst aus dem Nationalismus der vielen Einzelnen entstünde nach Anderson der historisch

1018 Adorno: Vorlesung über Negative Dialektik, S. 90.

1019 Anderson: Die Erfindung der Nation, S. 15. 
gewordene bürgerliche Nationalstaat. So erst würden sich die Subjekte, ihre` nationalistische Realität selbst durch ihr falsches Denken materiell konstruieren - und die vom Staat geschützten kapitalistischen Eigentumsverhältnisse wären demnach unvermittelt aus Subjekt gestiftet. Das generelle Urteil, die Nation existiere nur deshalb, weil ihre Ursache allein subjektiv nationalistisch vorgestellt sei und ihr kein materielles Korrelat adäquat entspreche, ist eine Aufnahme subjektivistischer Positionen durch Anderson. Seine Ausführungen sind Resultat eines schon kritisierten klassischen idealistischen Sozialkonstruktivismus. Unter den Prämissen subjektivistischer Interpretationen hätte die Idee der Nation also gar kein materielles, historisches Korrelat. Der Nationalismus der Subjekte wird damit jedoch zu einer substanzlosen wie überflüssigen Tautologie. Mit den dem Subjekt transzendenten Zwecken und Gründen, die sich vermittelt dann wieder in ihm finden, könnte er nicht erklärt werden. Er wäre deshalb unerklärlich, weil die Zwecke, die das Subjekt mit seinem Nationalismus verfolgt, nicht in und aus der Welt wären. Dergleichen irrational und substanzlos kann der Nationalismus jedoch aus seinen nachgewiesenen, ganz materiellen Gründen der erzwungenen gesellschaftlichen Integration nicht sein. Im Fall seines tautologischen Auftretens bräuchte man sich dann, als Konsequenz, auch nicht mehr mit der wesentlichen, rationalgesellschaftlichen Begründung des Phänomens zu beschäftigen. Denn wesentliche Begründungen des subjektiven Denkens und Handelns als in der heteronomen Materialität der totalen bürgerlichen Gesellschaft und ihrer allgemeinen Reproduktion liegend - dem spezifisch organisierten Eingriff in den Naturzusammenhang gäbe es in dem Fall nicht. Während Anderson jedes materielle Korrelat des Nationalismus in den Abgründen des selbstbewussten, aber dann doch falsch über Gesellschaft und Vergesellschaftung denkenden Subjekts verschwinden lässt, sieht Lenins idealistische Interpretation des Nationalismus zumindest noch, trotz aller falschen Ablösung von den transzendenten materiellen Bedingungen, einen politischen, bewussten Plan einer partikularen Klasse, der Bourgeoisie, am Werk, die sich ihre materiellen Reproduktionsbedingungen mittels des konstituierten kapitalistischen Nationalstaats schaffe.

Ein subjektiv gelebter Nationalismus, die affirmative Zustimmung des Subjekts zum Nationalstaat, wird nun zwar auch immer frei vom selbstbewussten Subjekt gewählt, anders als die bloß abstrakte Zustimmung des Subjekts zu Gesellschaftlichem ist er allerdings konkret eine nicht notwendige Äußerung innerhalb der objektiv erzwungenen Vergesellschaftung des Subjekts. Der Nationalismus wird insofern nicht als adäquate Haltung der Selbstbestimmung direkt von außen dem selbstbewussten Subjekt aufgezwungen. ${ }^{1020}$ Das macht den Nationalstaat aber trotzdem nicht zu einem verabsolutierten materiellen Konstrukt aus intersubjektivem, falschem Begriff wie bei Anderson, sondern er ist real. Auch Wehler verhan-

\footnotetext{
1020 Sicher kann sich der Nationalismus dann auch autonom in über die politisch begrenzenden, formellen Bestimmungen der Nation hinausgehend verselbstständigen; oder es kann sich eine Nation als Idee vorgestellt werden, die historisch nicht einmal namentliche Anklänge findet.
} 
delt den bürgerlichen Nationalismus im Stile Andersons nur als „Demiurg der neuen Wirklichkeit“1021 und als ,ingeniöse soziale Erfindung“"1022. Auch bei ihm korrespondiert der subjektiven Konstruktion des gesellschaftlichen (Nation-)Seins kein äußeres, durch materielle, ökonomische Prozesse verselbständigtes reales Etwas. Wäre aber die bürgerliche Nation lediglich als ein solch falsches, nationalistisches Kopfkonstrukt wirklich, oder auch, wie bereits Renan schreibt, ein nur "geistiges Prinzip"1023, an das die Nationalisten - weshalb dann auch immer glauben, so würde die Nation auch nur im Kopf der nationalistischen Subjekte existieren und auch nur deshalb eine soziale Wirklichkeit sein. Als soziale Phänomene würden Nation und Nationalismus dann zum einen unmittelbar identifiziert und zum anderen würden sie nur deshalb existieren und sich reproduzieren können, weil sie in Gedanken wären. Nation und Nationalismus hätten die wirkliche, materielle Substanz nicht, die über alle einzelnen lebendigen Subjekte und ihr Denken hinausgeht. Letztendlich wäre es dann eine auch nur individualpsychologisch zu beantwortende Frage, warum die Subjekte an dem falschen politischen Ausdruck Nation überhaupt festhalten. Mit dieser Auffassung vom subjektiven Nationalismus als die objektive Nation erst konstruierender handelt man sich darum einen krassen logischen Fehler des Deduktionismus - aus dem Begriff des Nationalismus folge notwendig die reale Nation - ein. Der bürgerliche Nationalstaat würde nach konstruktivistisch-subjektivistischer Lesart auch gegenwärtig nicht wesentlich mit der Organisation der allgemeinen Reproduktion und der erzwungenen Individualisierung zusammenhängen, sondern er würde folglich, wie zum Beispiel die Nationalismusforscherin Machteld Venken meint, nur aufgrund von nationalistischen Kampagnen weiterbestehen können. ${ }^{1024}$ Und die Nation würde durch konstruierte Kampagnen zu subjektiven, partikularen Zwecken aufrechterhalten werden - eine These, die unbemerkt wiederum an die Leninsche These zum Nationalismus anschließt, diese dabei aber noch ihres letzten übrigbleibenden emanzipativen Rests an Materialität beraubt. Nach Venken müsste und könnte man Nationalisten deshalb, weil eben der Nationalismus auf einer Kampagne beruht, mit fruchtbaren Gegenkampagnen, also Bildung etc. antworten. Brächte man dadurch dann die nationalistische Einbildung der Subjekte zum Verschwinden, verschwände nach dem konstruktivistischen Subjektivismus auch nicht nur der Nationalismus, sondern letztlich auch noch der nur kampagnengestützte Nationalstaat. Wird dagegen jedoch das herausgearbeitete materielle fundamentum in re des Nationalismus bedacht, dass er also wesentlich mit substantieller

\footnotetext{
1021 Wehler: Nationalismus, S. 13.

1022 Ebd., S. 24.

1023 Renan: Was ist eine Nation?, S. 34. Ein anderes Prinzip als ein geistiges und damit subjektives kann es generell nicht geben (vgl. oben).

1024 derstandard.at: Wie entsteht das Gefühl, Teil einer Nation zu sein?: „Venken untersucht, durch welche staatlichen Kampagnen Kinder und Jugendliche zu vollen Mitgliedern einer Nation erzogen werden sollten; dazu analysiert sie etwa Bildungsangebote, Jugendorganisationen und den Familienalltag in diesen Regionen."
} 
gesellschaftlicher Herrschaft vermittelt sei, dann kann zunächst auch selbst das gebildete Wissen des Subjekts über ihn nichts daran ändern, dass den Subjekten die Zwänge der Reproduktion durch die notwendig zu affirmierende Nation auferlegt werden. Diese Zwänge bleiben als vorrangig objektive Sachzwänge gegenüber jedem Subjekt der totalen bürgerlichen Gesellschaft weiterhin bestehen.

So also können die Gründe und die Motivationen des Nationalismus nicht aus marxistisch-leninistischen Klassenstandpunkten oder aus subjektivistischen Konstruktionen resultieren, sondern sie müssen mit den materiellen Bedingungen der herrschaftlichen Klassengesellschaft erklärt werden. Wenn aber der Maßstab der Kritik des Nationalismus nicht in den materiellen, rational zu bestimmenden Gründen seiner Existenz liegt, sondern einfach und ausschließlich tautologisch ins Subjekt gelegt wird, kann nun auch nicht mehr konsistent gerechtfertigt werden, warum das Denken der nationalistischen Subjekte überhaupt falscher als das Denken der Antinationalisten sei. Es gäbe dann nämlich notwendig keinen objektiven Gegenstand, keinen normativen Maßstab, mit dem dann überhaupt noch kritisch gedacht werden kann. Ein vermittelt objektives, nichttautologisches Urteil über die Zwecke und Bedingungen des Nationalismus bleiben deshalb für eine konsistente und nicht nur abstrakte Kritik des Nationalismus weiterhin vorausgesetzt. Der Gegenstand des Denkens kann nicht ohne Reflexion auf die diesen nichtidentischen Gegenstand erst hervorbringenden politisch-ökonomischen Ursachen kritisiert werden. Das so beliebte subjektivistische Argument, dass Nationalismus, Rassismus und Antisemitismus nur innere, psychische Kämpfe des Subjekts widerspiegeln sollen und diese Phänomene deshalb nicht substantiell mit der politisch-ökonomischen Gesellschaft vermittelt sind, findet sich nun auch im abspaltenden Umgang der Massenmedien mit unpassenden sozialen Phänomenen wieder: „Fremdenhaß erscheint in den Massenmedien als Kriminalität. So ist es möglich, ihn abgesondert, als Fremdkörper darzustellen. Jene Medien präsentieren die Gewalt von rechts als Auswuchs, verantwortet von Extremisten, die aus den sozialen Randgruppen der Gesellschaft kommen, als Straftaten, für die die Justiz oder die Psychiatrie zuständig ist. Sie ermöglichen dem Fernsehzuschauer und Zeitungsleser, sich voller Abscheu von solcher Brutalität abzuwenden, Mitleid mit den Opfern zu haben und blind zu bleiben für den allgemeinen sozialen Zusammenhang, in dem die rechtsradikalen Gewalttaten stehen. Die Darstellung der Medien ist überwiegend (...) unhistorisch und vermeidet gerade, an das wirkliche Fortleben der Bedingungen, die die Judenvernichtung ermöglichten, zu erinnern." ${ }^{1025}$ Dieses Urteil ist letztendlich dem unkritischen, maßstabslosen Relativismus der akademischen Wissenschaften (vgl. 2.1) entsprungen, der inzwischen auch längst bei den Journalisten angekommen ist. ${ }^{1026}$

\footnotetext{
1025 Claudia Kalász, Extremismus? - Elemente der Xenophobie, S. 33 f.

1026 Vgl. dazu auch den zweifelhaften Umgang mit faschistischen Äußerungen generell: Huisken:

Warum Demokraten (Neo-)Faschisten nicht kritisieren, sondern nur verbieten können.
} 


\subsubsection{Sozialisation II: Mehrwertproduktion und Eigentum}

„Das Kapital hat die Mehrarbeit nicht erfunden. Überall, wo ein Teil der Gesellschaft das Monopol der Produktionsmittel besitzt, muß der Arbeiter, frei oder unfrei, der zu seiner Selbsterhaltung notwendigen Arbeitszeit überschüssige Arbeitszeit zusetzen, um die Lebensmittel für den Eigner der Produktionsmittel zu produzieren." ${ }^{\text {"1027 }}$

Die abstrakt allgemeinen Gesetze der bürgerlichen Gesellschaft erlauben es dem Produktionsmitteleigentümer, den historisch unterlegenen Eigentumslosen wiederholt anzuwenden. Diesem kapitalistischen Anwendungsprozess des Arbeiters ist die kapitalistische Mehrwertproduktion wesentlich: „Die kapitalistische Produktion ist nicht nur Produktion von Ware, sie ist wesentlich Produktion von Mehrwert." 1028 Die Mehrwertproduktion ist deshalb der entscheidende Zweck der bürgerlichen Produktions- und Reproduktionsweise. Sie wird durch die ursprüngliche Akkumulation und die aus dieser resultierende gesetzliche Festschreibung von Eigentum erst aktualisiert: „Indes setzt die Akkumulation des Kapitals den Mehrwert, der Mehrwert die kapitalistische Produktion, diese aber das Vorhandensein größerer Massen von Kapital und Arbeitskraft in den Händen von Warenproduzenten voraus. “1029

Ein Mehrwert kann erst durch die Mehrarbeit der in den Naturzusammenhang eingreifenden Subjekte, der Klasse der Produktionsmittellosen, entstehen. Er ist das Resultat der Mehrproduktion gesellschaftlich notwendiger Dinge. Damit steht die Mehrarbeit auch relational zur gesellschaftlich notwendigen Arbeit der gesellschaftlichen Reproduktion. ${ }^{1030}$ Die Arbeitszeit muss demnach, um Mehrarbeit zu sein, immer systematisch ,über den Punkt [der zur subjektiven und gesellschaftlichen Reproduktion notwendigen Arbeitszeit, B.E.B.] hinaus"1031 sein. Wäre sie es nicht, könnte die gesellschaftlich erzwungene Mehrproduktion auch nicht objektiv als solche, als aus Mehrarbeit folgende, bestimmt werden. Kein Urteil über eine nicht notwendige Mehrarbeit wäre demnach erlaubt, wenn die Realisierung von Mehrprodukten mit der menschlichen Arbeit überhaupt identisch sein soll, weil kein vernünftiger Maßstab die Mehrproduktion als Ergebnis von Mehrarbeit identifizieren könnte. Die Mehrproduktion ist damit als eine materiell nicht notwendige, gesellschaftliche Produktion von kapitalistischen Waren bestimmt. Die Differenz von gesellschaftlich notwendiger Arbeit zur Mehrarbeit ist als eine freiheitliche Distanzierung der Gesellschaft von der Naturschranke durch die kapitalistisch produzierende Gesellschaft zu sehen. Das ,über den Punkt hinausgehende` Ar-

\footnotetext{
1027 Marx: Das Kapital, Bd. 1, S. 249.

1028 Ebd., S. 532.

${ }^{1029}$ Ebd., S. 741.

1030 Die gesellschaftlich notwendige Arbeit bezieht sich dabei streng auf ihren materiellen gesellschaftlichen Zusammenhang: die gesellschaftliche Produktivkraft der Gesellschaft. 1031 Marx: Das Kapital, Bd. 1, S. 532.
} 
beitspensum ist insofern eine subjektive, gesellschaftliche Realisierung von Freiheit gegen den immerwährenden Naturzwang, dem „Reich der Notwendigkeit“"1032: „Das Reich der Freiheit beginnt in der Tat erst da, wo das Arbeiten, das durch Not und äußere Zweckmäßigkeit bestimmt ist, aufhört; es liegt also der Natur der Sache nach jenseits der Sphäre der eigentlichen [!] materiellen Reproduktion." 1033

Wenn Mehrarbeit demnach also nicht notwendig ist, sondern erst durch die kapitalistische Produktionsweise als ein Akt subjektiver, gesellschaftlicher Freiheit erst erzwungen wird, kann sie auch kein der Natur menschlicher Arbeit inhärentes Existenzial sein. Die menschliche Arbeit trägt insofern keine „okkulte Qualität“"1034 einer Mehrproduktion aus sich selbst heraus anthropologisch bereits in sich. Die Erpressung des Mehrprodukts muss darum als eine freiheitliche, gesellschaftliche Erpressung erfolgen: „Jede Produktion von Mehrprodukt setzt eine Distanz zu bloßer Natur und ist Realisierung von Freiheit."1035 Die Mehrarbeit der Klasse der Produktionsmittellosen realisiert sich also nur, weil sie durch gesellschaftliche Herrschaft und als Resultat der erzwungenen, sozialen Integration in die Gesellschaft von den Subjekten erpresst wird: „Herrschaft ist nicht die Wirkung der Natur, sondern Ausdruck des Willens, der sich selbst will - der Freiheit." ${ }^{1036}$ Doch die gesellschaftlich gesetzte Freiheit vom Naturzwang durch die Herrschaft ist eine bloß partielle, mitnichten eine universelle Freiheit. Das ist der Bestimmung von der Freiheit der Gattung vom Naturzwang allerdings vollkommen gleichgültig: „Es ist die Freiheit der Gattung in vergegenständlichter Gestalt, von der die Mehrzahl der Bevölkerung nichts hat.،"1037

Würde die menschliche Arbeit hingegen anthropologisch und nicht freiheitlich mehr als notwendig produzieren, könnte auch nur post festum die Verteilung von gesellschaftlichem Reichtum, aber keine Kritik von nicht notwendiger Mehrproduktion und -arbeit formuliert werden. Der objektive Zwang der gesellschaftlichen Realisation des Mehrprodukts als Zwang aus Freiheit hätte demnach nicht substantiell formuliert werden können, weil der gesellschaftliche Zwang dann keiner aus Herrschaft, sondern die Mehrproduktion bloß die entsprechende Realisierung der menschlichen Natur wäre. Erst der gesellschaftliche Zwang aktualisiert jedoch die Mehrproduktion der Produktionsmittellosen, und das ganz vertragsgerecht im Rahmen der bürgerlichen Gesellschaft: „Mitten in der westeuropäischen Gesellschaft, wo der Arbeiter die Erlaubnis, für seine eigne Existenz zu arbeiten, nur durch Mehrarbeit erkauft, wird sich leicht eingebildet, es sei eine der menschlichen Arbeit eingeborne Qualität, ein Surplusprodukt zu liefern.“"1038

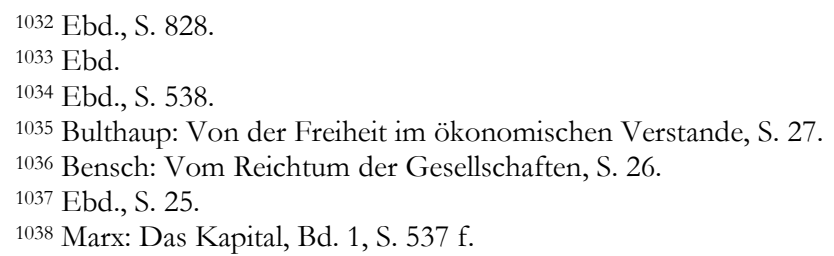


Diesem gesellschaftlichen, legalen Zwang der Realisation des Mehrprodukts kann sich kein lohnarbeitendes Subjekt entziehen. Mehrarbeit wird insofern für jedes durch sein Handeln in die Natur eingreifende Subjekt überlebensnotwendig. Ohne Mehrarbeit zu leisten würde die Selbsterhaltung der Arbeiterklassensubjekte unrealisierbar werden: „Um existieren zu können, muß der Lohnarbeiter Mehrarbeit leisten.“1039 Dieses Zwangsverhältnis ist insofern ein existentieller gesellschaftlicher Zwang, dem nachzugeben dem produktionsmittellosen Subjekt erst sein Überleben sichert. Das Überleben des Produktionsmittellosen zu sichern kann deshalb nicht Zweck der systematisch erzwungenen Mehrarbeit sein, sondern dessen Überleben ist bloß das Mittel zum entsprechenden Zweck des Systems: „Die Einsaugung von Mehrarbeit ist der Zweck, der sich nur durch das Mittel der Erhaltung der Existenz des Lohnarbeiters vermittels des Arbeitslohns dauerhaft realisieren läßt."1040 Der Produktionsmittellose wird darum nicht deshalb als ein variables Produktionsmittel durch den Produktionsmitteleigentümer angewendet, um sein Überleben in der bürgerlichen Gesellschaft zu sichern - „den Lohnarbeitern werden die Mittel zu ihrer Reproduktion nur gewährt, wenn sie ihre Fähigkeit, Mehrwert zu produzieren, ihre Arbeitskraft, vom Kapital in Dienst nehmen lassen."1041 Angewendet wird er vom Produktionsmitteleigentümer deswegen auch nur zur Erfüllung des Zwecks der kapitalistischen Produktionsweise, der Produktion von Mehrwert, der sich anders denn über die Existenz der juristisch von sachlichem Eigentum entfremdeten Subjekte nicht realisieren lässt: „Es ist eine der zivilisatorischen Seiten des Kapitals, daß es diese Mehrarbeit in einer Weise und unter Bedingungen erzwingt, die der Entwicklung der Produktivkräfte, der gesellschaftlichen Verhältnisse und der Schöpfung der Elemente für eine höhere Neubildung vorteilhafter sind als unter den frühern Formen der Sklaverei, Leibeigenschaft usw." 1042

Über die Produktion von Mehrprodukt durch die Eigentumslosen vermittelt sichert sich der Produktionsmitteleigentümer einen Mehrwert durch sein Produktionsmitteleigentum. Damit verschafft sich der Eigentümer, der sich revolutionär willkürlich das Eigentum an Produktionsmitteln angeeignet hat und das er dann postrevolutionär rational zugesichert bekam (vgl. 3.2.1), neben der persönlichen Bereicherung den seinerseits überlebensnotwendigen Konkurrenzvorteil gegenüber anderen Produktionsmitteleigentümern: „Insofern der Mehrwert (...) das Resultat des Ankaufs der Arbeitskraft durch einen Teil des Originalkapitals war,

\footnotetext{
1039 Weyand: Stummer Zwang oder innere Stimmen?, S. 99.

1040 Ebd.

${ }^{1041}$ Bulthaup: Von der Freiheit im ökonomischen Verstande, S. 27.

1042 Marx: Das Kapital, Bd. 3, S. 827. Vgl. auch Das Kapital, Bd. 1, S. 620. Peter Bulthaup spricht vom akkumulierbaren Mehrwert, der Produktion der Produktivität, als dem entscheidenden Zweck der kapitalistischen Produktionsweise und ihrer Mehrwertproduktion: „In der kapitalistischen Produktionsweise, deren Zweck die Produktion von akkumulierbarem Mehrwert ist, bekommt diese Verkehrung der Freiheit der Produzenten die Gestalt der Produktion von Produktivität." (Bulthaup: Von der Freiheit im ökonomischen Verstande, S. 27.)
} 
ein Kauf, der den Gesetzen des Warenaustausches entsprach, und, juristisch betrachtet, nichts voraussetzt als freie Verfügung auf seiten des Arbeiters über seine eignen Fähigkeiten, auf seiten des Geld- oder Warenbesitzers über ihm gehörige Werte." "1043 So erweist sich die Anwendung der Eigentumslosen als ein systematischer Zwang auf die Klasse der Produktionsmitteleigentümer. Die Anwendung der doppelt freien Lohnarbeiter muss dieser deshalb durch seine bloße Funktion als Eigentümer an Produktionsmitteln aus ganz eigenen Reproduktionsgründen wollen; selbst wenn er diesen Prozess der Mehrwertgewinnung vielleicht nicht einmal gutheißt.

Der Zwang zur Mehrproduktion ist unsichtbar. Über den Tausch der Eigentumstitel mithilfe autonomer Vertragsabschlüsse zwischen Eigentümer an Produktionsmitteln und Eigentümer an Ware Arbeitskraft wird er augenscheinlich noch ideologisch pazifiziert (vgl. auch 3.2.2): „Alle Arbeit erscheint als bezahlte Arbeit." ${ }^{1044}$ Mit dem den Ausbeutungsprozess der Mehrarbeit legalisierenden Arbeitsvertrag über die zu leistenden Arbeitsstunden zur eigenen Reproduktion und deren Entlohnung erscheint demzufolge alle Arbeit immer als vom Produktionsmitteleigentümer bezahlte Arbeit: „Die Form des Arbeitslohns löscht also jede Spur der Teilung des Arbeitstags in notwendige Arbeit und Mehrarbeit, in bezahlte und unbezahlte Arbeit aus." 1045 Die vorkapitalistische, vorbürgerliche Herrschaft schickt sich dagegen noch, durch ihre offene Propagierung des Zwangs zur Mehrarbeit, „parasitär und grausam“1046 an. Die für den jeweiligen persönlichen Herren geleistete (Mehr-)Arbeit wird hier als Zwangsarbeit offensichtlich und es gilt hier auch noch kein objektives, in der Zirkulationssphäre der kapitalistischen Produktionsweise liegendes reziprokes Vertragsrecht bei der Ausbeutung der Beherrschten. Den von beherrschten Knechten produzierten Mehrprodukten bemächtigt man sich dabei mittels des physischen Zwangs und den herrschenden Privilegienrechten ${ }^{1047}$ : „Grundlage der Verfügung über die Mehrarbeit ist die Verfügung über den physischen Gewaltapparat.“"1048 Werden in der vorbürgerlichen Gesellschaftsform die Zwänge zur Reproduktion also noch durch persönliche Herrscher aktualisiert, die sich damit vornehmlich ihre eigene Reproduktion organisieren ${ }^{1049}$, ist es in der bürgerlichen Gesellschaft der allgemeine Zwang zur Pro-

\footnotetext{
1043 Marx: Das Kapital, Bd. 1 23, S. 609.

1044 Ebd., S. 562.

1045 Ebd.

1046 Weyand: Stummer Zwang oder innere Stimmen?, S. 98.

1047 „Denn [es] wurde in vorkapitalistischer Zeit ein Teil des erzwungenen Mehrprodukts vom Kle-

rus, vom Adel, von den Freien individuell konsumiert.“ (Bensch: Vom Reichtum der Gesellschaften, S. 34.)

1048 Weyand: Stummer Zwang oder innere Stimmen?, S. 98.

${ }^{1049}$ Vgl. Hegel: Phänomenologie des Geistes, S. 145-155 (Selbständigkeit und Unselbständigkeit des Selbstbewusstseins; Herrschaft und Knechtschaft). Um Mehrarbeit als Gesellschaft überhaupt realisieren zu können, muss bereits ein gewisser Produktivitätsgrad der Gesellschaft vorausgesetzt sein. Dadurch erst kann eine zur Mehrproduktion disponible Arbeitszeit und damit die Freiheit vom Naturzwang freigesetzt werden: „Ohne einen gewissen Produktivitätsgrad der Arbeit keine solche
} 
duktion des gesellschaftlichen Reichtums des Nationalstaats, der Subjekte zur kooperativen Mehrproduktion zwingt. Die in der vorbürgerlichen Gesellschaft immer noch sinnlich wahrnehmbare Mehrarbeit durch entsprechende Abgabeoder Arbeitsprozesse, wird in der bürgerlichen Gesellschaft durch die willentlich abgeschlossene (Arbeits-)Verträge zur eigenen Selbsterhaltung verschleiert, weil hier dem Subjekt eben alle Lohnarbeit als immer wertäquivalent bezahlte Arbeit erscheint.

Der trotzdem mit der Arbeit und den Prozessen zusammenhängende Zwang ist in der bürgerlichen Gesellschaft deshalb also bloß noch der Reflexion zugänglich. Weil die Zwangsarbeit in der bürgerlichen Gesellschaft rechtlich-ökonomisch vermittelt wird, die eine absolute Autonomie des Subjekts über die garantierten objektiven Rechtsgrundsätze vorgibt, nimmt sich das Subjekt ideologisch als ein freies, autonomes Subjekt wahr. Durch die allgemeine Vertragsmündigkeit darf es

disponible Zeit für den Arbeiter, ohne solche überschüssige Zeit keine Mehrarbeit und daher keine Kapitalisten, aber auch keine Sklavenhalter, keine Feudalbarone, in einem Wort keine Großbesitzerklasse.“ (Marx: Das Kapital, Bd. 1, S. 534.) Als adäquates Modell für den gesellschaftlichen Fortschritt durch die bereits realisierte Freiheit vom Naturzwang durch Mehrarbeit gilt das alte Ägypten: Der Bau der Pyramiden kann nur deshalb stattfinden, weil es durch den ökonomischen Fortschritt (z.B. Bewässerungssysteme etc.) bereits möglich ist, einige Untertanen des Pharaos für die Erforschung von Naturzusammenhängen freizustellen und dafür vom direkten Eingriff in den Naturzusammenhang zu ihren eigenen Reproduktionszwecken zu befreien: „Der Materialist Aristoteles hat festgestellt, daß für Menschen alles, was deren notwendige Bedürfnisse und angenehmere Lebensführung angeht, schon geordnet sein muß, ehe sie anfangen können, Wissenschaft zu treiben.“ (Bulthaup: Die wissenschaftliche Hochschule, S. 29.) Die Möglichkeit zur Forschung basiert demnach auf bereits realisierten materiellen Voraussetzungen: durch den erreichten Stand der Produktivkräfte wird es für die altägyptische Herrschaft inzwischen möglich, einen nicht unerheblichen Teil von Menschen für derartig eigensinnige gesellschaftliche Projekte wie den Pyramidenbau, die aus kapitalistischer Sicht faux frais sind, freizustellen: „Es war also Ägypten“, so Aristoteles, „wo zu allererst die Fähigkeiten, mit Zahlen umzugehen, entstanden: dort war nämlich dem Geschlecht der Priester die Zeit dazu freigestellt." (Aristoteles: Metaphysik, 981 b.) Es ist die notwendige Arbeitszeit zur Reproduktion beherrschter Subjekte, die durch die gesellschaftliche Produktivkraftsteigerung dann immer reduziert wird. Die Forschung im alten Ägypten kann sich also deshalb entwickeln, weil inzwischen Wenige überhaupt keine direkte Arbeit am Naturgegenstand zur Realisation ihrer eigenen Reproduktion mehr leisten müssen: „Indes sind die großen Bauwerke des alten Ägyptens dem Umfang seiner Bevölkerung weniger geschuldet, als der großen Proportion, worin sie disponibel war. Wie der individuelle Arbeiter um so mehr Mehrarbeit liefern kann, je geringer seine notwendige Arbeitszeit, so, je geringer der zur Produktion der notwendigen Lebensmittel erheischte Teil der Arbeiterbevölkerung, desto größer ihr für andres Werk disponibler Teil.“ (Marx: Das Kapital, Bd. 1, S. 536.) Die Selbsterhaltung, die notwendige Bedürfnisbefriedigung, wird den Freigestellten von der Herrschaft anders garantiert: Bezahlt wird sie von der Herrschaft vom Überschuss an gesellschaftlicher Mehrarbeit. Diese günstigen materiellen Voraussetzungen potenzieren sich dann auch noch, es wird nach und nach immer mehr Zeit frei, um Dinge zu erforschen und zu entwickeln, die wiederum zu einem weiteren, noch produktiveren Eingriff in den Naturzusammenhang führen etc. Die ägyptische Herrschaft verfügt zu jener Zeit über eine ganze Heerschar von (Arbeits-)Sklaven, die man für die unmittelbar reproduktiven Arbeiten am Naturgegenstand heranzieht und die dafür, um Projekte für den Pharao zu realisieren, aus ihren dörflichen Lebenszusammenhängen entführt werden. (Vgl. Muhs: The Ancient Egyptian Economy, S. 129 f. Vgl. hierzu auch Altenmüller/Moussa: Die Inschrift Amenemhets II. aus dem Ptah-Tempel von Memphis, S. 36.) 
jedoch im Rahmen der gesetzten Grenzen tatsächlich freie Entscheidungen treffen, weshalb es sich durch den Rahmen der Verträge gleich, die Zwänge, in diesem Rahmen mitspielen zu müssen nicht reflektierend, als ein unbedingt freies Subjekt wahrnimmt. Die kapitalistische Produktionsweise setzt auch immer genau auf diese ,autonome Entscheidung' des Subjekts zur eigenen Ausbeutung und dessen Stellen der lebensbedrohlichen Konkurrenz unter erzwungenen instrumentellen Vernunftverhältnissen: „Das Individuationsprinzip, Gesetz der Besonderung, an welche die Allgemeinheit der Vernunft in den Einzelnen geknüpft ist, dichtet diese tendenziell gegen die sie umgreifenden Zusammenhänge ab und befördert dadurch das schmeichelhafte Vertrauen auf die Autarkie des Subjekts. “1050 Aufgrund der subjektiv bewussten Entscheidung zur Ausbeutung durch den allerdings objektiven Vertragszwang scheint es in der vergesellschafteten Gesellschaft für das bürgerliche Bewusstsein ideologisch auch keine Mehrarbeit und keinen solchen Zwang zur Mehrarbeit mehr zu geben. Das erklärt den gesellschaftlichen Schein von subjektiver Autonomie durch den abgesteckten Rahmen juristischer Grenzen des Eigentumsverhältnissses und dem daraus resultierenden Zwang zur Mehrproduktion.

\subsubsection{Sozialisation III: Zwang zur Produktion des Allgemeinwohls}

Durch den gesellschaftlichen Zwang zur Produktion von Mehrprodukt schlägt die eigentliche Gestalt der Freiheit vom Naturzwang, dem freiheitlichen Distanzierungsschritt der Gesellschaft von der Natur, dialektisch in eine gesellschaftliche Unfreiheit um. Dieser Zwang lässt sich so zwar historisch auch bereits für die Feudalgesellschaft anführen. Es lassen sich in der bürgerlichen Gesellschaft im Unterschied zur vorbürgerlichen Gesellschaft jedoch wesentliche Besonderungen, vor allem was die Form der Erpressung von Mehrarbeit angeht, ausmachen.

Die erpresste Gewinnung des Mehrprodukts fällt nun in der bürgerlichen Gesellschaft - neben dem ökonomisch-rechtlichen Zwang, der die persönliche Herrschaft und direkt physische Auspressung des Mehrprodukts verhindert - unter den so versöhnlich klingenden Begriff des juristisch bestimmten Allgemeinwohls. Dieses Allgemeinwohl ist als Ziel und Zweck der gesellschaftlichen, kapitalistischen Produktion formuliert und so auch im deutschen Grundgesetz nachzulesen: „Eigentum verpflichtet. Sein Gebrauch soll zugleich dem Wohle der Allgemeinheit dienen." "1051 In Anlehnung an die postrevolutionäre französische utilité commu$n e^{1052}$ wendet sich die Forderung, dem Allgemeinwohl mit all seinem Eigentum zu dienen, dabei an alle Bürger, weil jeder Bürger in der kapitalistischen Gesellschaft ja auch immer schon Eigentümer ist. Über das gesetzlich garantierte Eigentum soll

\footnotetext{
1050 Adorno: Negative Dialektik, S. 218.

1051 Grundgesetz für die Bundesrepublik Deutschland, Artikel 14, 2.

1052 Formuliert in der oben bereits zitierten französischen Egalitätsklausel: „Les hommes naissent et demeurent libres et égaux en droits. Les distinctions sociales ne peuvent être fondées que sur l'utilité commune." (Déclaration des Droits de l'Homme et du Citoyen de 1789.)
} 
die kapitalistische Produktionsweise und die Gewinnung des Allgemeinwohls zum Wohlergehen aller Einzelnen geregelt werden: „Eine Enteignung ist nur zum Wohle der Allgemeinheit zulässig. " 1053

Im Zusammenhang des durch das Eigentumsverhältnis erpressten Mehrwerts/Mehrprodukts erweist sich das Allgemeinwohl nun als nur abstrakter Ausdruck für etwas inhaltlich sehr Konkretes. Der Begriff des Allgemeinwohls zeigt sich dabei als ein nur anderer Ausdruck für die erzwungene Mehrproduktion und den daraus notwendig folgenden Mehrwert für die Eigentümer an Produktionsmitteln. Aus den erzwungen erarbeiteten Mehrprodukten folgt deshalb immer der gesellschaftliche Reichtum oder eben: das Allgemeinwohl. Der bürgerliche Staat organisiert als objektive Instanz die Gewinnung der Mehrprodukte bzw. des Allgemeinwohls, denn er managt als ideeller Gesamtkapitalist die kapitalistische Produktion überhaupt: „Alle seine Maßnahmen gelten ihm [dem bürgerlichen Staat, B.E.B.] als Mittel zur Steigerung des Allgemeinwohls, d.h. er unterwirft die notwendigen Funktionen seiner Gewalt für die Gesellschaft dem Kriterium des wirtschaftlichen Wachstums: Wirtschaftspolitik." 1054 Durch den allgemeinen Zweck der Produktion des Allgemeinwohls wird deshalb auch noch jeder partikulare Zweck affiziert. Auch die Sozialisation des bürgerlichen Subjekts ist deshalb dem Zweck der Produktion des gesellschaftlichen, kapitalistischen Allgemeinwohls unterworfen. Die Allgemeinwohlsproduktion ist insofern heteronom.

Die eigene Selbsterhaltung ist für das Subjekt in der bürgerlichen Gesellschaft nun gar nicht erst zu leisten, wenn es sich nicht an die objektiven, heteronomen Bedingungen der allgemeinen Reproduktion anpasst. Dafür muss es sich willentlich in die ihm heteronome Gesellschaft integrieren. ${ }^{1055}$ Dieser Zwang zur Produktion von Mehrprodukt, von Allgemeinwohl, ist deshalb kein bloßer Zwang von Außen, sondern dem Willen des Subjekts kongruent. Die Bürger wollen die Produktion von Mehrprodukt und Schaffung von kapitalistischem Allgemeinwohl, weil sie in der bürgerlichen Gesellschaft überleben wollen und müssen. Ihr freier Wille erweist sich deshalb als heteronomer, erzwungener freier Wille zur allgemeinen gesellschaftlichen Kooperation. Der freie Wille des Subjekts, sich an der Mehrproduktion zu alleinigen Zwecken des Allgemeinwohls zu beteiligen, hat deshalb ein materielles, vom einzelnen Subjekt nicht zu veränderndes Substrat in der bürgerlichen Gesellschaft: „Wir sahen ferner: das Kapital - und der Kapitalist ist nur

\footnotetext{
1053 Grundgesetz für die Bundesrepublik Deutschland, Artikel 14, 3.

${ }^{1054}$ Resultate Bd. 3, Der bürgerliche Staat, S. 89.

1055 Bei Hobbes tritt ein positivistisch gedachter Staat auf, der die Summe der Willen der unter ihn befassten Subjekte ist: „Die größte menschliche Macht ist die, welche aus der Verbindung sehr vieler Menschen zu einer Person entsteht, sie mag nun eine natürliche sein wie der Mensch oder aber eine künstliche Person wie der Staat, wenn man nur von dem Willen derselben die Macht aller übrigen abhängt." (Hobbes: Leviathan, S. 80.) Doch die Hobbessche Philosophie beschreibt ambivalent auch die Negativität des Staates gegen jeden Einzelnen. Dafür benutzt Hobbes eine Form des Begriffs des Allgemeinwohls. Den Zwang auf das Subjekt zur Produktion des Allgemeinwohls beschreibt er mit dem gesellschaftlichen Zwang zur Produktion zum „Wobl des Volkes.“ (Vgl. z.B. ebd., S. 278.)
} 
das personifizierte Kapital, fungiert im Produktionsprozeß nur als Träger des Kapitals -, also das Kapital pumpt in dem ihm entsprechenden gesellschaftlichen Produktionsprozeß ein bestimmtes Quantum Mehrarbeit aus dem unmittelbaren Produzenten oder Arbeitern heraus, Mehrarbeit, die jenes ohne Äquivalent erhält und die ihrem Wesen nach immer Zwangsarbeit bleibt, wie sehr sie auch als das Resultat freier kontraktlicher Übereinkunft erscheinen mag. “1056

Das erzwungenermaßen erarbeitete, gesellschaftliche Freiheit vom Naturzusammenhang repräsentierende Mehrprodukt der heteronomen kapitalistischen Gesellschaft ist insofern ein nicht wegzudenkender Teil des juristisch pazifizierten Begriffs des Allgemeinwohls. Das Allgemeinwohl repräsentiert eine zweckgesetzte Gestalt gesellschaftlicher Freiheit, weil der immanente Mehrwert zur Reproduktion der Gesellschaft in der Form eigentlich nicht notwendig ist - und weil es willentlich als nicht notwendiges Mehrprodukt produziert wird. Das Allgemeinwohl ist insofern das kapitalistisch produzierte Wohl der antagonistischen, herrschaftlichen Gesellschaft; was deswegen mit dem Wohlergehen der Einzelnen auch nicht zu verwechseln ist.

1056 Marx: Das Kapital, Bd. 3, S. 827. 


\section{Aufbau- und Zwischenkapitel. Wert, Eigentum und Reichtumsproduktion}

\subsection{Vom Äquivalententausch zur Ware Arbeitskraft}

Zweifelsohne beruht die bürgerliche Gesellschaft mit ihrer erzwungenen Mehrwertproduktion über staatlich garantierte Eigentumstitel auf erkennbaren logischen Voraussetzungen bei der Produktion von nationalem, respektive gesellschaftlichem Reichtum. Die objektive Erkennbarkeit von der bürgerlichen Gesellschaft ist aber nicht nur möglich, weil der Staat die kapitalistische Produktionsweise in ihrer Allgemeinheit und Notwendigkeit schützt, sondern der Staat schützt und reproduziert mit seiner ubiquitären Rechtssphäre etwas Inhaltliches, das in sich objektiv und allgemein ist. Keine Form ohne Inhalt, kein Inhalt ohne Form, da Form kein autosemantischer Begriff sein kann. Die objektive Erkennbarkeit hat mit dem Staat als Institution Voraussetzungen in der historischen enteignenden Gewalt sowie logische in der staatlichen Organisation der kapitalistischen Produktionsweise. Beides, die logischen Voraussetzungen der Organisation der Reproduktion und deren materieller Schutz, bedingen einander. Mit den bereits gelieferten Bestimmungen des historisch gewonnenen Eigentumstitels wurde deutlich, dass ohne staatlich geschützten Eigentumstitel nach den historischen Revolutionen keine kapitalistische Ökonomie möglich wäre. Um die Reflexion der notwendigen, mit Gewalt geschützten Logik der kapitalistischen Produktionsweise 
insbesondere geht es in den folgenden vier Unterabschnitten. Das kann auch erst als Beweis der These von der Gesellschaft als zweiter Natur gesehen werden, weil die Rationalität der bürgerlichen Produktionsweise durch ihre intelligiblen Gesetze der Produktion wie eine erste Natur wirkt.

Zunächst einmal wird in 4.1.1 die Waren- und Wertformanalyse bei Marx reflektiert. Die Waren- und Wertformanalyse bildet die logische Grundlage der Analyse des kapitalistischen Produktionsprozesses im Kapital. Vom Wesentlichen noch abstrahiert, können mit ihr objektive Werten im kapitalistischen Produktionsprozess bestimmt werden.

In 4.1.2 wird die Realität und der Sinn der Objektivität des Warenwerts diskutiert. So geht es hier um die entscheidende Frage, warum der Warenwert überhaupt objektiv bestimmbar ist und nicht etwa willkürlich festgelegt ist. Dies beinhaltet wiederum eine Kritik an subjektivistischen Positionen, die den Wert als intersubjektiven, willkürlich post festum, also nach der Produktion mit ihrer Zurichtung des Naturstoffs, bestimmen.

4.1.3 nimmt Bezug darauf, warum in der Wertformanalyse die Ware Arbeitskraft noch kein konkreter Gegenstand ist, obwohl sie abstrakt zum Gegenstand wird.

4.1.4 ergründet dann die Notwendigkeit der Ware Arbeitskraft bei der gesellschaftlichen Reichtumsproduktion.

\subsubsection{Zur Waren- und Wertformanalyse. Reflexion der Zirkulationssphäre}

Die für die Marxsche Theorie so wichtige Analyse der Wertform erstreckt sich im Kapital über die gesamten ersten drei Kapitel. ${ }^{1057}$ Analysiert wird hier die logische und erkenntnistheoretische Grundlage der kapitalistischen, auf Mehrwertproduktion basierenden Gesellschaftsform. Auf gesellschaftliche Herrschaft, Aneignung, Privateigentum an Produktionsmitteln etc. wird in der Wertformanalyse allerdings noch kein direkter Bezug genommen. Das verweist an der Stelle auf eine ausschließlich logische Reflexion des Kapitalverhältnisses in ihr - auf eine analytische Ahistorizität in ihrer Abhandlung. ${ }^{1058}$ Es ist deshalb allein die logische Zirkulation der Waren, die Marx in den ersten drei Kapiteln näher betrachtet. Zu Beginn des Kapitals interessiert ihn also zunächst einmal nur die logische Oberfläche der kapitalistischen Produktionsweise, die Sphäre der Zirkulation: „Die Oberfläche der Zirkulation kennt weder Klassen, noch Ausbeutung, noch Dynamik. Alle Begriffe, mit denen Marx versucht, diese Dynamik zu erfassen, wie Akkumulation des Kapitals, formelle und reelle Subsumtion, tendenzieller Fall der Profitrate, Steigerung der Produktivkraft der Arbeit, sind auf dieser Stufe noch nicht zu entfalten."1059

\footnotetext{
1057 Marx: Das Kapital, Bd. 1, S. 49-160.

1058 Marx ist deshalb nicht, wie Adorno meint, ein „Verächter der Erkenntnisthorie“. (Adorno:

Negative Dialektik, S. 179.)

1059 Hanloser/Reitter: Der bewegte Marx, S. 11.
} 
Weil bloß Analyse der Zirkulationssphäre, lässt sich in der Wertformanalyse auch noch nicht der bereits kennengelernte physische Eigentumstitel an Ware Arbeitskraft auffinden. ${ }^{1060}$ Unter den noch ahistorischen Voraussetzungen kann deshalb auch überhaupt noch keine Analyse des kapitalistischen Warentauschs und der Mehrwertproduktion stattfinden. Die subjektiv-individuelle Eigenschaft einer Ware, die Ware Arbeitskraft, setzt die kapitalistische Produktionsweise schlechterdings voraus (vgl. 3.6.4).

Die Wertformanalyse scheint zunächst eine vorkapitalistische Produktionsweise zu beschreiben. Es kommt in ihr auch zu recht konkret anmutenden Anspielungen auf vorkapitalistische Warenproduktionen, sie enthält zum Beispiel eine Anspielung auf den attischen Warenmarkt: „Die beiden (...) Eigentümlichkeiten der Äquivalentform werden noch faßbarer, wenn wir zu dem großen Forscher zurückgehn, der die Wertform, wie so viele Denkformen, Gesellschaftsformen und Naturformen zuerst analysiert hat. Es ist dies Aristoteles. "“061 Die Wertformanalyse scheint darum zunächst eine einleitende kritische Analyse historischer, vorkapitalistischer Tauschverhältnisse zu sein - vor allem auch deswegen, weil Marx Aristoteles in ihrer Darstellung auch noch einen „Mangel des Wertbegriffs" "1062 nachweist. Doch Entscheidendes spricht gegen ihre Historisierung: So werden in der Wertformanalyse ausschließlich nützliche Dinge als Waren zu ihren Werten auf der Erscheinungsebene reziprok gegeneinander ausgetauscht. Die jeweils nützlichen Dinge, die die „Privatproduzenten“1063 für den gesellschaftlichen Gebrauch herstellen sind von den Privatproduzenten noch eigens produzierte Waren. Alle für die Produktion der Ware benutzten Mittel befinden sich deshalb auch noch im Besitz des unmittelbaren Produzenten. Gesellschaftliche Herrschaft bzw. gesellschaftlicher Zwang sind in der Wertformanalyse überhaupt noch kein Gegenstand: „Bei der Betrachtung der Warenproduktion und Zirkulation ist nur die bloße Verschiedenheit der Gebrauchswerte vorausgesetzt; was die einzelnen Warenbesitzer wieder zueinander führt, ist ihr Wille, er untersteht keinem Zwang." ${ }^{1064}$ Dass allein der freie Wille die einzelnen Warenbesitzer auf den Markt führt, unterstellt eine völlige Herrschaftslosigkeit im Rahmen der gesellschaftlichen Produktion. Historisch gibt es solch eine frei von gesellschaftlicher Herrschaft seiende Produktion jedoch nicht. Keine bisherige Produktionsform ist derart herrschaftslos und durch den freien Willen der Produzenten geprägt. Es hat auch historisch nie einen Markt gegeben, auf dem die Subjekte ihre eigens und herrschaftsfrei produzierten Dinge als Privatproduzenten, wie in der Wertform-

\footnotetext{
1060 Viele Autoren sehen die Wertformanalyse als eigenständige Analyse des Kapitalismus. Sie übersehen die unbedingte Relationalität des Abschnitts aufgrund seiner Abstraktion von Wesentlichem. Die Begriffe werden hier zur späteren Einholung bloß eingeführt. „Der Anfang des Kapitals ist, weil Anfang, abstrakt." (Kuhne: Begriff und Zitat, S. 24.)

1061 Marx: Das Kapital, Bd. 1, S. 73.

1062 Ebd., S. 74.

1063 Ebd., S. 93.

1064 Bensch: Vom Reichtum der Gesellschaften, S. 36.
} 
analyse unterstellt, friedlich hätten miteinander tauschen können. Einen solch freien Markt beschreibt selbst der in der Wertformanalyse herangezogene Aristo-

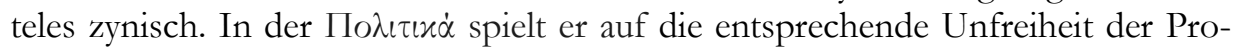
duktion zu seiner Zeit an: ,[W]enn also auch das Weberschiffchen so webte und das Plektron die Kithara schlüge, dann bedürften weder die Baumeister der Gehilfen, noch die Herren der Sklaven."1065

Der in der Wertformanalyse angeführte attische Warenmarkt, auf dem frei getauscht werde, kann deshalb weder als eine Vorstufe eines kapitalistischen Warenmarkts, noch als eine reelle Beschreibung eines historischen (attischen) Warenmarkts begriffen werden. In vorbürgerlichen Gesellschaften hat es nun zwar bereits den Tausch von nützlichen Dingen gegeben, doch Marx verfolgt gerade durch seine Abstraktion von gesellschaftlicher Herrschaft keine Analyse irgendeiner historischen Produktionsform. Die Wertformanalyse beschreibt deshalb zunächst nur den notwendigen Eingriff in den Naturzusammenhang, Arbeit, und den Tausch der Resultate der Arbeit als eine gattungsgeschichtliche Notwendigkeit des Überlebens. Sie ist dabei eine sich noch von jeder historischen Konkretion enthaltende Abstraktion: „Die materielle Reproduktion der Gesellschaft ist Reproduktion der Differenz dieser Gesellschaft zu ihrer naturalen Basis. So ist sie Grundlage aller Geschichte.“1066

Die These, dass nun aus der dargestellten freiheitlichen Warenform das Kapitalverhältnis, in Form eines ableitungstheoretischen Grund-Folge-Verhältnisses, logisch und historisch resultiere, verfolgen viele Theoretiker. Von diesem scheinbar notwendigen Ableitungsverhältnis - wenn logische Warenform, dann Kapitalform - gehen insbesondere die Wertkritiker aus, die sich mit der werttheoretischen Begrifflichkeit aus dem Kapital einer kapitalismuskritischen Gesellschaftskritik widmen. ${ }^{1067}$ Für sie scheint in der Wertformanalyse, vielleicht auch aufgrund des von Marx angeführten, recht verwirrenden Aristotelesbeispiels, eine von allem Inhalt ihres Produktionszwecks geschiedene Ware, eine ideelle Warenform, am historischen Grund des Kapitalverhältnisses zu liegen. Die Warenform begründe das Kapitalverhältnis, das Kapitalverhältnis wird deshalb aus dieser Ware abgeleitet. Die Wertkritiker gehen deshalb davon aus, dass es sich bei der Marxschen Wertformanalyse schon um eine Beschreibung von tatsächlich gewesenen, konkret historischen Produktionsverhältnissen handele.

Die Ableitungen der Kapitalform aus Ware, bzw. aus der Warenform, führen jedoch durch die gesellschaftstheoretische Konkretion des wertformanalytisch

\footnotetext{
1065 Aristoteles: Politik, 1253 b.

1066 Kuhne: Begriff und Zitat bei Marx, S. 9.

1067 Diese neueren, wertkritischen Strömungen der marxistischen Gesellschaftskritik werden von Gerhard Hanloser und Karl Reitter als „Zirkulationsmarxismus“ bezeichnet. (Hanloser/Reitter: Der bewegte Marx, S. 4.) Entscheidende Schriften aus den Reihen der Wertkritik sind u.a.: Backhaus: Dialektik der Wertform; Reichelt: Zur logischen Struktur des Kapitalbegriffs bei Karl Marx; Heinrich: Die Wissenschaft vom Wert. Vorläufer der wertkritischen Schriften sind u.a.: Korsch, Karl Marx; Sohn-Rethel: Warenform und Denkform.
} 
Abstrakten auf nicht klein zu redende Probleme. Stephan Grigat beispielsweise ist ein Wertkritiker, der die Ware bzw. die ideelle, noch spekulative Warenform der Wertformanalyse an den Grund des Kapitalverhältnisses legt. Grigat ignoriert dabei, wie auch viele andere Theoretiker des Werts ${ }^{1068}$, dass die Wertformanalyse nur die einfache, friedliche Zirkulation eigens produzierter Waren beschreibt und schon aus diesem Grund keine historische und/oder kapitalistische Produktionsweise kritisieren kann ${ }^{1069}$ : „Die These, das Kapital könne nicht aus der Ware hergeleitet werden, veranschaulicht die (...) Ignoranz gegenüber der Warenförmigkeit der kapitalistischen Produktionsweise. Nicht nur, daß das Kapital sich erst logischbegrifflich aus der Wertförmigkeit der Arbeitsprodukte ergibt [sic!], sondern auch, daß alle zur stofflichen Erscheinung des Kapitals gehörenden Elemente in der Form der Ware auftreten, zeigt sowohl die Möglichkeit als auch die Notwendigkeit der begrifflichen Entwicklung des Kapitals aus der Ware. "1070 Die wertförmige Ware kann jedoch, gegen Grigat, nicht dergestalt als Idee am Grund des Kapitalverhältnisses liegen, die sich dann durch die Geschichte hindurch kontinuierlich realisiert. Aus der Wertförmigkeit allein kann sich nicht, wie Grigat meint, begrifflich das Kapital entwickeln, weil es, wie Grigat nun auch als bei Marx realisiert unterstellt, erforderlich sei, ,,vom Wert in seiner entwickelten Form in der Bewegung der Zirkulation auszugehen“, um „den Begriff des Kapitals zu entwickeln"1071. Bei Marx hingegen entspringt Materielles, Historisches nicht gleich notwendig aus dem Begriff der Ware. Die kapitalistische Produktionsweise ist für Marx ein Resultat von historisch Kontingentem, der gesellschaftlichen Gewalt der ursprünglichen Akkumulation, gewesen (vgl. dazu 3.1.2). ${ }^{1072}$ Mit Logik und Begriff hat die historische, revolutionäre Aneignung von Produktionsmitteln und damit die ursprüngliche Schaffung antagonistischer Klassen deswegen keinerlei Berührungspunkte. Von Grigat wird die kapitalistische Ware dagegen jedoch abstrakt von der diskontinuierlichen Geschichte gelöst, weil er die Marxschen Kategorien der Wertformanalyse als wesentliche Erklärung des mehrwertheckenden Kapitalismus hypostasiert. Sein logischer Schluss der Deduktion des Kapitals aus der Warenförmigkeit unterstellt dabei eine Notwendigkeit, nämlich dass es aus der

\footnotetext{
1068 Auch Wolfram Pfreundschuh geht von einer streng logischen Ableitung aus: „Die Eigentümlichkeit der bürgerlichen Gesellschaft bestimmt sich aus dem Warentausch, worin - gesellschaftlich begriffen - allgemein Wert entsteht und durch den Wert der Dinge sich das gesellschaftliche Verhältnis der Menschen bestimmt. Sie produzieren zwar, um ihre Produkte auch zu konsumieren, aber was ihnen als gesellschaftlicher Zusammenhang gegenständlich (objektiv) einzig verbleibt ist der Wert - als Kapitalform, die sich im Allgemeinen den Menschen entzieht und gegen sie mächtig wird.“ (Pfreundschuh: Entfremdung.)

${ }^{1069}$ Vgl. Michael Heinrich, Kritik der politischen Ökonomie, S. 61: „Die tauschenden Personen sind in ihren Handlungen zwar frei, als Warenbesitzer müssen sie aber den ,Gesetzen der Warennatur ${ }^{6}$ folgen." Heinrich beachtet die Abstraktionen von Marx nicht als solche und unterstellt eine konkrete, historische Richtigkeit seiner Überlegungen, um ein eigenes Programm aufzuziehen.

1070 Grigat: Fetisch und Freiheit, S. 201.

1071 Ebd., S. 202.

1072 Vgl. hierzu Kuhne: Begriff und Zitat bei Marx, S. 20 ff.
} 
logischen einfachen Warenform der Wertformanalyse sogleich zur historischen, tatsächlichen kapitalistischen Produktionsform mit Mehrwert etc. komme.

Die Wertformanalyse lässt für Grigat insofern schon auf die historisch spätere Kapitalform schließen. Sein deduktiver Schluss der kapitalistischen Produktionsform aus der einfachen Warenform impliziert deswegen auch eine Identität von Logik und Geschichte. Der Wertformanalyse kämen demnach historische Momente zu, weswegen sie auch keine bloße Abstraktion von jeglichem Material sein könne, mit der nur der Begriff der Ware eingeführt werde. Der Kapitalismus scheint, wie für seine Verfechter ${ }^{1073}$ so auch für seine Kritiker wie Grigat, auf einem reziproken vorkapitalistischen Warenhandel zu beruhen, der dann mit der Zeit als immer lukrativer gilt und der sich darum im 18., bzw. 19. Jahrhundert aus ökonomischen Gründen der gesteigerten Quantität bis hin zur Ubiquität des kapitalistischen Warentauschs herausentwickle. Dass es zu dieser kontinuierlichen historischen Entwicklung hin zum Kapitalismus komme, ist die Konsequenz aus der Unterstellung Grigats, dass die Warenform der Wertformanalyse die Voraussetzungen des Kapitalismus bereits in sich tragen würde. Selbst die spezifischen, juristischen Eigentumsformen müssten demnach bereits in der Marxschen Wertformanalyse zu finden sein. Der Warenhandel vorkapitalistischer Gesellschaften wäre demzufolge nur quantitativ, nicht aber qualitativ vom kapitalistischen Warenhandel zu unterscheiden.

Solche Thesen der historischen Kontinuität sind allerdings nicht neu, sondern sie lassen sich bereits in der Geschichte des Marxismus finden. Auch Engels verliert durch die Entfaltung der Ware in der Zeit schon entscheidende Differenzen, die Produktionsphasen als jeweilige Epochenmerkmale der Geschichte, aus dem Blick. Die Ware wird ihm dadurch zum Subjekt der Geschichte. Unterschiede als qualitativ gedachte Differenzen, nicht einmal bloß als Verschiedenes - in der gesellschaftlichen Herrschaft und von Produktionsformen werden ihm dadurch irrelevant. Die Ware entfalte sich aber für Engels nicht nur in der Geschichte, sie entfalte aus sich heraus deterministisch Geschichte: Sie wird zum Subjekt der Geschichte. ${ }^{1074}$ Auch Engels ahistorisiert damit den kapitalistischen Warenbegriff, indem er ihn nicht als mit der objektiven Garantie von Eigentum durch den bürgerlichen Staat unmittelbar verbunden begreift. Die Geschichte scheint für ihn den kapitalistischen Warentausch bereits zu einer Zeit zu kennen, als dieser sich seiner selbst noch nicht als kapitalistischer Warentausch bewusst sein konnte. In Die Entwicklung des Sozialismus von der Utopie zur Wissenschaft heißt es: „Wir bezeichnen als, Warenproduktion' diejenige ökonomische Phase, in welcher die Gegenstände nicht nur für den Gebrauch der Produzenten, sondern auch für Zwecke des Austausches produziert werden, d.h. als Waren, nicht als Gebrauchswerte. Diese Phase reicht von den ersten Anfängen der Produktion für den Austausch bis herab in unsre gegenwärtige Zeit; sie erlangt ihre volle Entwicklung erst unter

1073 So z.B. auch bei Schenk: Geschichte und Ordnungstheorie der Handelsfunktionen.

1074 Vgl. Engels: Die Entwicklung des Sozialismus von der Utopie zur Wissenschaft, S. 18. 
der kapitalistischen Produktion [!], d.h. unter Bedingungen, wo der Kapitalist, der Eigentümer der Produktionsmittel, gegen Lohn Arbeiter beschäftigt, Leute, die aller Produktionsmittel, ihre eigne Arbeitskraft ausgenommen, beraubt sind, und den Überschuß des Verkaufspreises [sic!] der Produkte über seine Auslagen einsteckt.“1075 Damit identifiziert also auch Engels logisches und historisches und nimmt die transzendente Kontingenz der Geschichte als eine durch diskontinuierliche Gewalt geprägte Geschichte nicht ernst: „Die Kritik der Ökonomie, selbst nach gewonnener Methode [sic!], konnte noch auf zweierlei Weise angelegt werden: historisch oder logisch. Da in der Geschichte, wie in ihrer literarischen Abspiegelung [sic!], die Entwicklung im ganzen und großen auch von den einfachsten zu den komplizierteren Verhältnissen fortgeht, so gab die literargeschichtliche Entwicklung der politischen Ökonomie einen natürlichen Leitfaden, an den die Kritik anknüpfen konnte, und im ganzen und großen würden die ökonomischen Kategorien dabei in derselben Reihenfolge erscheinen wie in der logischen Entwicklung. “"1076

So enthebt Engels das kapitalistische Wertgesetz konsequent der rein begrifflichen Spekulation, das jedoch nicht ohne Grund am abstrakten Anfang des Kapitals steht; und der selbst als Anfang bei Marx noch ohne politisch-ökonomische Substanz ist. Er macht die ,ökonomische Kategorie“ damit zu einer historisch vergangenen ökonomischen Realität, die angeblich mit der Wertformanalyse logisch, begrifflich, beschrieben werde. Engels wehrt damit die Gültigkeit des Wertgesetzes als spekulative Kategorie der kapitalistischen Produktionsweise ab, indem er sie einfach mit historischem Inhalt füllt. Dadurch aber überfrachtet er das Wertgesetz. Marx' kategoriale Spekulation wird von ihm als eine wissenschaftliche Beschreibung angeblich vorkapitalistischer Produktionsformen für bare Münze genommen, die zu seiner postrevolutionären Zeit längst verschwunden seien, weil die historisch subjektivierte Ware sich veränderte. Dem Wertgesetz wird damit unterstellt, dass es die wissenschaftlich adäquate Beschreibung einer historischen Produktionsweise sei, weshalb es auch zur Darstellung dieser vergangenen Produktionsweise herangezogen werden könne: „Mit einem Wort: das Marxsche Wertgesetz gilt allgemein, soweit überhaupt ökonomische Gesetze gelten, für die ganze Periode der einfachen Warenproduktion, also bis zur Zeit, wo diese durch den Eintritt der kapitalistischen Produktionsform eine Modifikation erfährt. (...) Das Marxsche Wertgesetz hat also ökonomisch-allgemeine Gültigkeit für eine Zeitdauer, die vom Anfang des die Produkte in Waren verwandelnden Austausches bis ins fünfzehnte Jahrhundert unsrer Zeitrechnung dauert. (...) [D]as Wertgesetz hat also geherrscht während einer Periode von fünf bis sieben Jahrtausenden.“1077

1075 Ebd.

1076 Engels/Marx: Zur Kritik der Politischen Ökonomie, S. 474 f.

1077 Engels: Ergänzung und Nachtrag zum III. Buche des ,Kapital', S. 909. 
Doch nicht nur Engels überführt das abstrakt Logische der Wertformanalyse in Historisches. Auch der Historiker Haumann ist der Auffassung, dass die vorbürgerliche Handelsform wissenschaftlich adäquat mit der Wertformanalyse beschrieben werden könne. Die traditionelle Rolle der Juden als Händler und Vermittler im Zarenreich sieht Haumann darum „,mit der einfachen Warenproduktion verbunden (...), bei der die Juden aufgrund ihrer besonderen Rechtsposition über Kredit- und Tauschwesen herausragende Mittlerdienste leisteten. Mit dem Übergang zur entfalteten Warenproduktion, zur kapitalistischen Produktionsweise, verloren sie nach und nach ihre Funktion." "1078 So wird ihm die Ware ebenfalls zum deterministisch interpretierten Subjekt der Geschichtsbewegung. Ganz ähnlich subjektiviert Detlef Horster die Ware als Bewegungsform der Geschichte, was an der Stelle auch auf die schulemachende Interpretationsweise der Marxschen Wertformanalyse durch Engels hinweist. Die kapitalistische Produktionsweise entwickelt sich für Horster aus der einmal historisch initiierten Warenzirkulation, die dem Kapitalismus zeitlich vorausgehe. Die Warenzirkulation, einmal historisch initiiert, führe somit kausal von der einfachen Warenform zur Kapitalform: „Die kapitalistische Produktion entwickelt sich aus der Warenzirkulation, die ihren Ausgangspunkt am Rande der naturwüchsigen Gemeinwesen hat."“1079

Im Kapital ist hingegen nur die kapitalistische Warenform Gegenstand, weshalb Marx hier auch keine Hypostasierung der Ware als Subjekt der Geschichte vornimmt. Als rein begriffliche Darstellung liegt die Warenanalyse deshalb auch nur vermeintlich historisch am Grund des Kapitalverhältnisses. Die drei ersten Kapitel des Kapitals bilden bei Marx insofern bloß den Anfang einer Begründung der kapitalistischen Produktionsweise und der Begründung der objektiven Wertform. Aus der Warenanalyse lässt sich jedoch kein für die kapitalistische Produktionsform so notwendiger objektiver Wertbegriff begründen, aus der einfachen Wertförmigkeit der Arbeitsprodukte entspringt darum auch kein Kapitalverhältnis: „Das Resultat der Warenanalyse ist wesentlich negativ: aus den Bestimmungen von Ware und Geld ist ein objektiver Wertbegriff nicht zu begründen. Die diskursive Entwicklung des Wertbegriffs ist keine Abfolge von reinen ökonomischen Formbestimmungen. Sie ist vielmehr auf nicht-deduzierbare gegenständliche und historische Voraussetzungen verwiesen." ${ }^{1080}$ Die für den objektiven Wertbegriff unentbehrlichen Voraussetzungen der historischen, ursprünglichen Gewalt bei der Konstitution der bürgerlichen Gesellschaft (vgl. Kap. 3) werden insofern in den vorgestellten Ableitungsthesen seit Engels konsequent durchs Kleinreden ihrer Wichtigkeit für die Konstitution des Kapitalverhältnisses missachtet.

Historisch ist die These von der dem Kapitalismus vorausgehenden einfachen Warenform als vorkapitalistische Produktionsweise gänzlich unhaltbar. Die Unterstellung, dass eine abstrakte Kategorie historische Wirklichkeit als Epoche bekä-

\footnotetext{
1078 Haumann: Geschichte der Ostjuden, S. 96.

1079 Horster: Ernst Bloch, S. 31.

1080 Kuhne: Begriff und Zitat bei Marx, S. 18.
} 
me, führt deshalb auch nur in einen kontingenzlosen Zirkel gesellschaftstheoretischer Aporie und nicht zu einer adäquaten Darstellung gesellschaftlicher Herrschaftsverhältnisse. Die Wertformanalyse ist deshalb nicht schon die hinreichende Bedingung der Erklärung der kapitalistischen Produktionsweise und auch keine Begründung einer geschichtlichen Produktionsform. Die Wertformanalyse, die der einfachen Warenproduktion unterstellt bleibt, ist zwar eine notwendige Bedingung bei der Erklärung der kapitalistischen Produktionsweise und ihrer objektiven Bewegungsgesetze, doch sie ist keine Beschreibung der totalen kapitalistischen Gesellschaft. Mit ihr werden ,lediglich`spekulative Begriffe entwickelt, die Marx dann erst später einholt. Wenn jedoch aus der Entfaltung der logischen Warenform notwendig das Kapitalverhältnis resultieren soll, muss bereits im zirkulationstheoretischen Waren- und Wertverhältnis das auf die kapitalistische Produktion notwendig verweisende Kapitalverhältnis angelegt sein. Wenn also die logischabstrakte Warenform in sich schon Kapitalform sein soll, müsste der reziproke Tausch von Äquivalenten in der Wertformanalyse - der ja nie historisches Dasein hatte - schon eine konsistente Erklärung der (zukünftigen) Kapitalakkumulation enthalten.

Folgt aus dem reziprok-logischen Tausch der Zirkulationssphäre selbst gleich das Mehr über ihn hinaus, müsste er allerdings von Beginn an ein ungleicher Tausch sein - eine willkürliche Aneignung von Eigentumstiteln. Die Abstraktion vom Material in der Wertformanalyse wäre dann keine logische Abstraktion von Etwas mehr, sondern sie enthielte bereits eine konkrete Erklärung der Gewinnung gesellschaftlichen Reichtums. Der logische, reziproke Tausch von Eigentumstiteln wäre damit als ein Betrug ausgemacht: und die Abstraktion der Wertformanalyse von der tatsächlichen Ausbeutung hinfällig. Ohne, dass historisch kontingente Momente als notwendige Momente der Erklärung von der gesellschaftlichen Reichtumsproduktion hinzutreten, müsste aus dem in der Wertformanalyse dargestellten, von Wesentlichem noch abstrahierenden Äquivalententausch das Mehr über ihn hinaus entstehen. Trotz allgemeiner, objektiver Gesetze und autonomer Willensverhältnisse beim Vertragsabschluss wäre die gesellschaftliche Reichtumsproduktion der bürgerlichen Gesellschaft demnach ein völlig undurchsichtiger Betrugszusammenhang.

Davon auszugehen, dass die kapitalistische Reichtumsproduktion ein Betrugszusammenhang sei, führt allerdings auf ein recht unwegsames theoretisches Terrain: Wenn Adorno schreibt, dass es beim Äquivalententausch „,mit rechten und doch nicht mit rechten Dingen“1081 zuginge, vermutet er jenen Betrug bereits als im bürgerlichen Vertragswesen des reziproken Tauschs selbst liegenden. ${ }^{1082}$ Aus der äquivalent-reziproken Zirkulation der Waren entspringe demnach das Mehrprodukt. Dieser Argumentationslinie vom Betrug bei der Reichtumsproduktion

1081 Adorno: Soziologie und empirische Forschung, S. 209.

1082 Das konnte jedoch mit dem Begriff der fictio juris bereits ausgeschlossen werden (vgl. 3.4). 
folgend, bezeichnet Grigat den Tausch von Äquivalenten als einen „Schein“1083 der wertformanalytischen Gerechtigkeit. Dass der Äquivalententausch ein trügerischer Schein der Herrschaft sei, stimmt hinsichtlich des Tauschverhältnisses von Lohn und wirklich geleisteter Arbeit (vgl. 3.6.3). Dieses Verhältnis in der Zirkulation der Werte von Eigentumstiteln ist in der Wertformanalyse allerdings noch gar kein Gegenstand, weil sie vom Lohnarbeiter und Leister der mehrwertproduzierenden Arbeit, auf dem das Tauschverhältnis Lohn gegen wirklich geleistete Arbeit beruht, noch abstrahiert. Der als eine reine Illusion von Gerechtigkeit begriffene Schein könnte aber auch nur durch einen idealistischen, als Chimäre gedachten totalen Verblendungszusammenhang aufrechterhalten werden. Eine Objektivität als ihm immanentes rationales Maß der Reziprozität, Gültigkeit zumal, könne ihm dann gar nicht zukommen. Unter diesen Begebenheiten realisiere sich die Gewinnung von Mehrwert auch nicht durch die bürgerlichen Gesetze der Zirkulationssphäre hindurch, weil er durch über den betrügerischen Tausch angeeignete Mehrarbeit entstünde. Die warentauschende Gesellschaft der Wertformanalyse wäre demzufolge, so die Unterstellung, eine Gesellschaft, die damit beständig ihre eigenen logischen Gesetze der Äquivalenz und die vertraglichen und geschützten Gesetze der Egalität breche. Dass das allerdings nicht der Fall sein kann und der gesellschaftliche Reichtum der kapitalistischen Produktionsweise sich nicht aus dem Äquivalententausch der Wertformanalyse ergibt, nicht einmal aus einem Nicht-Äquivalententausch, macht Marx im Kapital deutlich: „Werden Äquivalente ausgetauscht, so entsteht kein Mehrwert, und werden Nicht-Äquivalente ausgetauscht, so entsteht auch kein Mehrwert. Die Zirkulation oder der Warentausch schafft keinen Wert." ${ }^{\prime 1084}$

Grigat und Adorno liegen in der Vermutung - dass die Zirkulation und damit der Tausch der Eigentumstitel mit der Reichtumsproduktion unmittelbar zusammenhänge - jedoch auch nicht ganz falsch. Die Reichtumsproduktion geht nicht mit dem, aber auch nicht ohne den Äquivalententausch der Zirkulationssphäre. Dieser Widerspruch des Äquivalententauschs in sich, als eine in ihm liegende Äquivokation, muss gedacht werden, weil der Äquivalententausch als Moment der kapitalistischen Mehrwertproduktion derart ambivalent real ist. Marx schreibt: „Kapital kann also nicht aus der Zirkulation entspringen, und es kann ebensowenig aus der Zirkulation nicht entspringen. Es muss zugleich in ihr und nicht in ihr entspringen. "“085 Das Kapital, gesellschaftlicher Reichtum, entspringt eben auch aus der Zirkulation, weil ja alle Realisation von Werten bezüglich der gesellschaftlichen Reichtumsproduktion im Kapitalismus über den Tausch der Ware auf dem Markt läuft. Diesen ,Umweg` über die Zirkulationssphäre muss also jede produzierte Ware der Produktionssphäre bei ihrer Wertverwertung nehmen, weil die Zirkulationssphäre die Sphäre des Umschlags der Waren ist; und weshalb sie auch

\footnotetext{
1083 Grigat: Fetisch und Freiheit, S. 59.

1084 Marx: Das Kapital, Bd. 1, S. 177 f.

1085 Ebd., S. 180.
} 
die Sphäre der kapitalistischen Wertrealisation überhaupt bleibt. In ihr erst kann es über den Umschlag der Waren zur Realisation der Werte kommen, die bereits produziert und den Waren deswegen objektiv schon inhärent sind. Die in der Produktion entstandenen objektiven Werte der Waren werden hier also überhaupt erst realisiert. Die Zirkulationssphäre ist deshalb genau so ein Moment des Kreislaufs der kapitalistischen Produktionsweise wie die Produktionssphäre.

Leitet man aber aus der Warenform die Kapitalform ab, die bereits Mehrwertproduktion voraussetzt, so erliegt man bloß dem Schein der Zirkulationssphäre. Denn die heteronome kapitalistische Mehrproduktion für andere Zwecke kann aus dem unterstellten wechselseitigen Äquivalententausch von Eigentum nicht entspringen. Kein funktionalistisches Sein des selbstbewussten Subjekts für anderes als es selbst ließe sich deshalb aus der Wertformanalyse deduzieren. ${ }^{1086}$ So unterliegen in der spekulativen Wertformanalyse die Zwecke des Austauschs von nützlichen Dingen immer noch den völlig autonomen Zwecken des einzelnen Warenbesitzers, die er darüber frei realisiert. Nimmt man den Äquivalententausch der Eigentumstitel aus der Perspektive der formellen Logik ernst, kann aus ihm auch gar kein gesellschaftlicher Reichtum entstehen. Einzig der Betrug über den Preisaufschlag über die Warenwerte ließe bestimmte Subjekte zu mehr Geld kommen als andere. Engels unterstellt einen solchen Betrug im obigen Zitat, wenn er vom „Überschuß des Verkaufspreises der Produkte“ spricht, den der Kapitalist „über seine Auslagen einsteckt.“ Die wechselseitige Übervorteilung durch Wenige verschiebt den Reichtum an Eigentum jedoch einzig von einer Person zur anderen. Der allgemeine, gesellschaftliche Reichtum bliebe dadurch weiterhin unangetastet. Absolut gesehen wäre, nur weil Einer mehr Geld als der Andere hat, kein gesellschaftlicher Reichtum entstanden: „Behaupten, der Mehrwert für den Produzenten entspringe daraus, daß die Konsumenten die Ware über den Wert zahlen, heißt nur den einfachen Satz maskieren: Der Warenbesitzer besitzt als Verkäufer das Privilegium, zu teuer zu verkaufen." ${ }^{1087}$ Der Erklärungsversuch von Reichtum aus dem quid pro quo von gleichen Werten heraus gleicht dabei der grenznutzentheoretischen, subjektiven Werttheorie. Deren Kernaussage, dass Reichtum aus geschickten Handlungen Einzelner zu ihren Gunsten entspringe, verallgemeinert übervorteilende Einzelakte einfach als eine gesellschaftlich gewinnbringende Maßnahme. 1088 Privater Reichtum kann so selbstverständlich entstehen. Durch einen trickbedingten oder bedürfnisbedingten ungleichen Tausch mögen sich für einzelne Händler preisliche Gewinne ergeben, weil der Warenbesitzer als Verkäufer das Privileg besitzt, seine Ware teurer als zu ihrem Wert zu verkaufen (s.o.). Der einzelne Warenbesitzer hat insofern immer die Möglichkeit, sich durch den Tausch von quantitativ und qualitativ gleichen Waren zu bereichern. In der Dialektik der

\footnotetext{
1086 Vgl. hierzu auch Kuhne: Begriff und Zitat bei Marx, S. 43 ff.

1087 Marx: Das Kapital, Bd. 1, S. 176.

1088 Vgl. zum besseren Verständnis der subjektiven Werttheorie neben den Schriften von Mises', Schumpeters und Böhm von Bawerks vor allem: von Hayek: Preise und Produktion.
} 
Aufklärung sprechen auch Adorno und Horkheimer deshalb von einem ,Privileg des Verkäufers'.1089 Dieser habe die „List als Mittel des Tausches“"1090 auf seiner Seite, weshalb trotz der Erfüllung des „Vertrag[s] (...) der Partner betrogen“1091 werde. Dieses Privileg trete vor allem im von Max Weber angeführten „,Gelegenheitstausch““ d'er „frühen Antike“"1092 auf. Damals hätten sich einzelne Verkäufer an ihrem Gegenüber trotz des erfüllten ,Vertrags' ${ }^{`}$ - wie ernst man den nicht staatlich-objektiv gesicherten Vertrag in solchen Gesellschaften überhaupt nehmen kann - durch listigen Betrug bereichert.

Solche sich aus der List ergebenden subjektiven Gewinne, die erschlichene, unlautere Gewinne sind, können sich nun jedoch für Grigat nur als „Arbitragege-

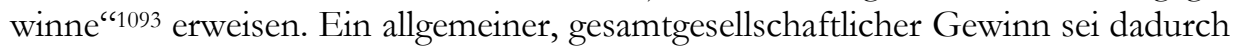
nämlich ,auf längere Zeit betrachtet unmöglich.“"1094 Sofern bei Marx der gesellschaftliche und nicht der private Reichtum aus dem Tausch von Äquivalenten und nicht aus dem Tausch von Äquivalenten entsteht, ist und bleibt die Wertformanalyse und ihr reziproker Tausch eben keine hinreichende Erklärung für die Gewinnung gesellschaftlichen Reichtums: „Die konsequenten Vertreter der Illusion, daß der Mehrwert aus einem nominellen Preiszuschlag entspringt oder aus dem Privilegium des Verkäufers, die Ware teuer zu verkaufen, unterstellen daher eine Klasse die nur kauft, ohne zu verkaufen, also auch nur konsumiert ohne zu produzieren." "1095 Das macht den grenznutzentheoretischen Ansatz bei der Erklärung von gesellschaftlichem Reichtum gänzlich obsolet. Grigat spricht insofern ganz richtig von Arbitragegewinnen durch List oder einfach Herrschaftsprivilegien. Er ist jedoch grundsätzlich der Auffassung, dass die notwendige Ableitung des Kapitalverhältnisses aus der Zirkulationssphäre, aus der Warenform möglich sei. Deshalb widerspricht er sich, weil sich dann folgerichtig aus dem reziproken äquivalenten Tausch der Warenform die Mehrwertproduktion ergeben müsste, was die gesellschaftliche Reichtumsproduktion damit wiederum aus dem äquivalenten Warentausch begründen würde. Die Begriffe der Wertformanalyse subsistieren allerdings nicht in sich, weshalb man, wenn der Gewinn nationalen Reichtums erklärt werden soll, die logischen Grenzen und Kategorien der Wertformanalyse überschreiten muss. Die vom Wesentlichen abstrahierenden Begriffe der Wertformanalyse verweisen deshalb auf ein notwendig historisches Material, das nicht in den anfänglichen Kategorien der politischen Ökonomie selbst gefunden werden kann und auch nicht logisch aus der Begrifflichkeit der Wertformanalyse folgt. Deswegen liegt in der nur begrifflich-logisch arbeitenden Wertformanalyse auch nicht schon der Grund des materiellen Kapitalverhältnisses. Der wahre Grund für

\footnotetext{
${ }^{1089}$ Vgl. Adorno: Dialektik der Aufklärung, S. 79 f.

1090 Ebd., S. 79.

1091 Ebd.

1092 Ebd.

1093 Grigat: Fetisch und Freiheit, S. 44.

${ }^{1094}$ Ebd.

1095 Marx: Das Kapital, Bd. 1, S. 176.
} 
die Produktion von nationalem Reichtum ist an historischer Stelle zu suchen; und auch zu finden.

\subsubsection{Reflexionen zur Objektivität des Warenwerts}

Mit der noch in der spekulativen Begriffslogik steckenbleibenden Wertformanalyse ist Marx dem Geheimnis der objektiven kapitalistischen Wertproduktion über den Tausch von Eigentumstiteln allerdings auf der Spur. Selbst wenn sich mit der Wertformanalyse der objektive Wertbegriff der kapitalistischen Produktionsweise noch nicht wesentlich begründen lässt, ist die in sich subsistierende, idealistische Begriffslogik der Erklärung der kapitalistischen Gewinnung gesellschaftlichen Reichtums nicht vollkommen äußerlich. Die Wertformanalyse lässt sich deshalb auch nicht einfach aus der Systematik der Erklärung der kapitalistischen Produktionsweise ablösen (vgl. 4.1.1). Das würde daneben ihre Gegenständlichkeit im Kapital in Zweifel ziehen. In der Wertformanalyse werden begriffliche, voraussetzungsreiche logische Grundlagen der kapitalistischen Wertproduktion angesprochen und eingeführt, die das Kapital begrifflich begleiten, auch wenn sich die Vorzeichen später ändern. Nur, weil sich der objektive Wertbegriff der kapitalistischen Produktionsweise in der Wertformanalyse nicht begründen lässt, weil wesentliche Voraussetzungen aufgrund des Fehlens der Waren Arbeitskraft noch nicht entwickelt sind, heißt das also nicht, dass in ihr nicht schon eine rationale Objektivität des Warenwerts in der kapitalistischen Produktionsweise Gegenstand ist. In ihr geht es zunächst um den reziproken Tausch von Waren, den Tausch von gesellschaftlichen Gebrauchswerten, von gesellschaftlich „nützliche[n] Ding[en]“"1096 gegeneinander - und wie dieser bedürfnisbefriedigende gesellschaftliche Gebrauchswert gezwungen ist, sich immer auch im exakt bemessenen gesellschaftlichen und objektiven Tauschwert auszudrücken.

Der quantitativ-identische Austausch von in sich äquivalenten Warenwerten kann überhaupt auch nur dann Evidenz haben, wenn sich die qualitativ verschiedenen Dinge, die als Waren wechselseitig getauscht und dafür aufeinander bezogen werden, auf etwas ihnen der Quantität nach objektiv Gemeinsames beziehen lassen. Notwendig und allgemein nachvollziehbar wird der in der Wertformanalyse objektiv dargestellte Tausch also immer erst durch ein gewisses Quantum, das die qualitativ unterschiedenen Waren als Drittes quantitativ miteinander vergleichbar werden lässt. Erst ein fundamentales, die quantitative Wertgleichheit auf sich beziehendes Drittes kann die unterschiedlichen Dinge als Waren als in sich erkennbar bestimmen: „Nur als Ausdrücke derselben Einheit sind sie gleichnamige, daher kommensurable Größen.“" 1097 Nur so ließe sich auch nicht alles Mögliche, und auch noch völlig chaotisch, gegeneinander austauschen. Auf die Substanz des Wertes wird später noch eingegangen.

1096 Marx: Das Kapital, Bd. 1, S. 49.

1097 Ebd., S. 64. 
Der Gebrauchswertseite nach qualitativ Gleiches wird auf dem Markt nicht getauscht werden. Nur der idealen Wertseite nach Gleiches wird hier, in der freiheitlichen Zirkulationssphäre, gegen etwas der stofflichen Gebrauchswertseite nach Verschiedenem getauscht. So wird im äquivalenten Tauschverkehr der Waren eine quantitative Identifikation von qualitativ nichtidentischen Gebrauchswerten von Waren vorgenommen. Diese Dialektik von Stoff und Form, Qualität und Quantität des Warendings garantiert allein den wechselseitigen Tausch von sachlichen Dingen - und damit den rationalen Austausch der Dinge auf dem jedoch noch ideellen, vom Wesentlichen abstrahierenden Markt. Der Vergleich von der Sache nach qualitativ verschiedenen Dingen unterstellt demnach also eine quantitative Vergleichbarkeit als deren objektive Bestimmtheit. Würde es solch inhärentes objektives $\mathrm{Ma} ß$ der Vergleichbarkeit von zu tauschenden Waren nicht geben, wäre der Vergleich und Tausch der mit Eigentumstiteln behafteten Waren nur rein subjektiv und willkürlich; der Äquivalententausch wäre von Subjekten bloß konstruktivistisch erdacht. Wenn die Warenwerte derart subjektivistisch, wie Wertbestimmungen auf Spielmarken, aufgefasst werden, hätten sie dergleichen keinerlei Bezug auf irgendein fundamentum ihrer äquivalenten Austauschbarkeit als bereits produzierte Dinge. Die gegenseitige, relationale Bezugnahme von Waren aufeinander wäre demnach eine nur spontane, vollkommen irrationale Beziehung von Waren aufeinander. Eine solch zwecklose, willkürliche Handlungsweise des Austauschs könnte dann jedoch überhaupt nicht erklären, wie Waren allgemein rational getauscht werden. Als nur äußerlich aufgeklebte Etiketten wären die Werte den Waren nicht immanent objektiv. Wenn sie aber objektiv als Äquivalente getauscht werden, muss eine immanente Objektivität der allgemeinen Vergleichbarkeit immer schon vorausgesetzt sein. Nur vorm Hintergrund einer solch rationalen Allgemeinheit und Notwendigkeit im äquivalenten Tausch der Zirkulationssphäre stünden deshalb nicht alle Waren in völlig willkürlichen, irrationalen Relationen zueinander.

Hätten die Waren dieses gemeinsame objektive Quantum als objektive Bestimmung ihres Wertes nicht, könnten sie deshalb nicht auf jene selbe objektive Einheit einer kommensurablen quantitativen Größe reduziert werden. Ohne die objektive Bestimmtheit wären Waren wiederum nur die chaotische Aneinanderreihung von Dingen, denen völlig willkürlich Werte zugesprochen werden. Sie wären dann keine intelligiblen Dinge, deren objektiver Wert in eine subjektive Erkenntnis fällt. Durch diese objektive Bestimmung aber werden sie als Wertdinge überhaupt erst ein schützenswertes Eigentum in der bürgerlichen Gesellschaft. Weil es in der kapitalistischen Produktionsweise keine Willkür des Austauschs der wertvollen Eigentumstitel oder Waren gibt, weil den Eigentumstiteln eine objektive Wertigkeit als mobile oder immobile Waren zukommt, unterliegen Waren als Eigentumstitel erst dem staatlichen Schutz. Dieser staatliche Schutz wäre demnach auch vollkommen sinnlos, wenn die Aneignung oder Abstoßung der Dinge völlig willkürlich vonstatten ginge und die objektive Wertigkeit der Waren in ihrem Aus- 
tausch relativ gleichgültig wäre. Unter anderen ökonomischen Vorzeichen würde dieser objektive Schutz von objektiven Werten als Eigentumstitel gar keinen Sinn haben. Die implizite Begründung der Ware als schützenswerter Eigentumstitel liegt darum in der Wertformanalyse begründet, die den Tauschverkehr im Kapital grundlegend bestimmt. Nur solange sich der Tausch auf rational bestimmbare Voraussetzungen der Werte, ein ihnen gegenüber Drittes, berufen kann, hat der Warentausch in der Zirkulationssphäre auch ein wirkliches fundamentum der Austauschbarkeit, wie dann auch erst der Schutz dieser Werte durch den Staat dadurch sinnvoll wird. Dieses vergleichende Fundament der Austauschbarkeit von Dingen zu begründen ist deshalb der entscheidende Gegenstand der Wertformanalyse.

Durch das identitätsstiftende fundamentum in re der Waren steckt notwendig ein Syllogismus in der Bestimmung des objektiven Warenbezugs aufeinander, weil mit dem jeweiligen Austausch der Bezug der beiden auszutauschenden Waren auf ein Drittes erforderlich wird. Der Syllogismus ist ein zwingend formeller Schluss, den W.F. Haug als „die Größe und zugleich die Armut der klassischen formalen Logik"1098 bezeichnet. Zwei ungleiche Prämissen sind objektiv dann als gleich zu behandeln, wenn beide, schlussgefolgert, bei ihrer Verknüpfung miteinander als Gleiche auf ein ihnen gemeinsames Drittes verweisen. So ermöglicht der Syllogismus erst den Zusammenschluss zweier zunächst ungleicher Aussagen, wenn sie denn in einem Dritten, über die Logik des Schließens vermittelt, miteinander identisch sind: „Unmittelbar sind A und B ungleich, A ₹ B. Wenn aber A gleich C, erste Prämisse oder erster Vordersatz, und B gleich C, zweiter Vordersatz, dann gilt der Schluß: A gleich B. Wenn A gleich C, B gleich C, dann A gleich B. “1099 Auf die quantitative Wertgleichheit von qualitativ unterschiedenen Waren im Äquivalententausch übertragen heißt das: Die verschiedenen Relata (Relata meint die verschiedenen Arbeitsprodukte als eigentümliche Waren) müssen sich nach Marx durch ein tertium comparationis allgemein und notwendig objektiv aufeinander beziehen lassen. Ihre objektive Bestimmtheit, auch der Ware Geld ${ }^{1100}$, liegt darin auch erst begründet.

\footnotetext{
1098 Haug: Vorlesungen zur Einführung ins ,Kapital', S. 92.

1099 Ebd., S. 93.

${ }^{1100}$ Das zeigt Marx im Kapital und den posthum veröffentlichten Theorien über den Mehrwert. Im ersten Band des Kapital argumentiert Marx vor allem gegen den subjektiven Werttheoretiker und Utilitaristen Bailey (Vgl. Marx: Das Kapital, Bd. 1, S. 64.): „,[w]eil er es in der monetary expression ausgedrückt findet, braucht er nicht zu ,begreifen', wodurch dieser Ausdruck möglich wird (...) und was er in der Tat ausdrückt.“ (Marx: Das Kapital, Bd. 3, S. 155.) Dass Bailey nicht begreife, wodurch der objektive Geldwert der kapitalistischen Ökonomie möglich werde, meint, dass er den erscheinenden Ausdruck des Geldwerts nicht auf seine wesentliche, materielle Bestimmung zurückführt. Er begreife den objektiven Wert des Geldes nicht als mit der Warenproduktion und der Wertschöpfungskette vermittelt und den Geldwert nicht als den bloß abstraktesten Ausdruck der Warenform überhaupt, nicht als „allgemeine(s) Äquivalent“, (Marx: Das Kapital, Bd. 1, S. 104.), das deshalb wie jede andere Ware mit einem substantiellen, gesellschaftlichen Wert objektiv vermittelt bleibt. Geld wird zu etwas Abstraktem, das der eigenen materiellen Vermittlung völlig Enthoben ist. Der Geldwert wird für
} 
Auf das, was dem Ausdruck des Werts oder der Wertgleichheit von zwei Dingen quantitativ zugrunde liegt, schließt Marx von der quantitativ bestimmten Relation der sachlich verschiedenen Dinge als zweckmäßig produzierte gesellschaftliche Dinge. Gesellschaftliche Produkte sind abstrakt betrachtet Resultate menschlicher Arbeit schlechthin, menschlicher Arbeit in Raum und Zeit. Sie haben ein in sich identisches und rationalisierbares (Arbeitszeit-)Moment. Sie sind Resultate menschlicher Arbeit in der Zeit, sie sind Resultate von aus Menschenhand produziertem und geformtem Naturstoff. Als menschlich bearbeitete Stoffe werden sie als Ausdruck des herstellenden lebendigen Subjekts miteinander allgemein und notwendig miteinander vergleichbar. Als die Produkte menschlicher Arbeit in der Zeit werden sie insofern miteinander identisch als nichtidentische, gegeneinander austauschbare Dinge. Mittels der gesellschaftlich durchschnittlichen, notwendigen Arbeitszeit wird die quantitative Verausgabung von qualitativer, menschlicher Arbeitszeit somit zum objektiven Größenmaß der Ware: „Es ist also nur das Quantum gesellschaftlich notwendiger Arbeit oder die zur Herstellung eines Gebrauchswerts gesellschaftlich notwendige Arbeitszeit, welche seine Wertgröße bestimmt." "1101

Diese notwendige Arbeitszeit ist die Substanz des Werts der Ware im Kapital: „Wir kennen jetzt die Substanz des Werts. Es ist die Arbeit. Wir kennen sein Größenmaß. Es ist die Arbeitszeit. Seine Form, die den Wert eben zum Tausch-Wert stempelt, bleibt zu analysieren." ${ }^{1102}$ Durch die quantitative Zeitidentität können die konkret nützlichen Waren als konkrete Dinge abstrakt menschlicher Arbeit als in sich identisch aufeinander bezogen werden: als der Möglichkeit nach miteinander identifizierbare verallgemeinerte Dinge, weil in sie alle die zeitgleiche „produktive Verausgabung von menschlichem Hirn, Muskel, Nerv, Hand usw.“1103 eingeflossen ist. Jene von Marx als „Arbeit überhaupt“1104 bezeichnete allgemein menschliche Arbeit am Naturgegenstand in der Zeit abstrahiert ob ihrer eigenen quantitativen Bestimmung von jedem Inhalt der Produktion und deshalb scheinbar auch von der Produktionsweise. So wird die abstrakte, von allen Qualitäten befreite menschliche Arbeit die alleinige Formerin der Wertsubstanz aller produzierten Dinge - und zwar im Sinne einer komparativen Abstraktion. Sie ist quantitativ geleistete menschliche Arbeit überhaupt an einem völlig beliebigen Naturgegenstand: „Der Wert einer Ware ist bestimmt durch das in ihr inkorporierte Quantum der wertbildenden Substanz Arbeit überhaupt.“1105 Die Arbeit überbaupt

Bailey völlig willkürlich, rational lässt er sich nicht erklären. Diese Form eines rücksichtslosen Enthebens der Geldwerte aus der kapitalistischen Produktionsweise findet man noch heute in populistischen wie wissenschaftlichen Kritiken von Gesellschaft und Ökonomie; vgl. Simmel: Die Philosophie des Geldes.

${ }_{1101}$ Marx: Das Kapital, Bd. 1, S. 54.

1102 Ebd., S. 55, Fn.

1103 Ebd., S. 58.

1104 Ebd., S. 59

1105 Kuhne: Begriff und Zitat bei Marx, S. 21. 
abstrahiert, neben dem konkreten stofflichen Inhalt, auch noch von staatlich geschützten Eigentumstiteln. Die nützliche Eigenschaft der Arbeit, konkrete, aber vor allem brauchbare Dinge herzustellen, wird so dialektisch vermittelt eine conditio sine qua non der allgemein menschlichen Arbeit überhaupt. Ihre Qualität kommt vor allem in Quantität zur Geltung. Die rein quantitative Wertsubstanz Arbeit überhaupt ist deshalb die von allen qualitativ konkreten Arbeiten abstrahierte, verallgemeinerte gesellschaftliche Durchschnittsarbeit in generale an einem völlig unbestimmt bleibenden Naturstoff: Die ,abstrakt menschliche Arbeit“"1106 gegenüber allen besonderen „konkret (...) nützliche[n] Arbeiten“1107 an bestimmten Naturgegenständen. Die Arbeit überhaupt erweist sich insofern als die Substanz aller menschlich produzierten Dinge, und jede auf dem Markt erscheinende Ware hat in ihr ihren wesentlichen, objektiven Bezugspunkt. Schon für Aristoteles ${ }^{1108}$ bezeichnet der Begriff der Substanz das, was den vielen verschiedenen Dingen als ein einheitliches, als ihre „objektiv seiende Form“"1109, zukommt.

Weil sie von allen bearbeiteten Gegenständen als logische Einheit zur Bestimmung von quantitativ identischem abstrahiert, heißt die Arbeit überhaupt für HansJürgen Krahl auch „Arbeit schlechthin.“1110 Diese gesellschaftlich benötigte durchschnittliche Arbeit schlechthin zur Herstellung des Dings bestimmt letztendlich das „Größenmaß" ${ }^{\prime 1111}$ des Werts im reziproken Austausch mit anderen Produkten. Die gesellschaftlich durchschnittliche Arbeitszeit als Bezugseinheit der Waren ist die „objektiv sich durchsetzende“1112 Zeit menschlicher Arbeit an einem (un-) bestimmten Stoff, die trotzdem immer auf den konkreten Stoff der arbeitstechnischen Formung verwiesen bleibt. Die vollkommen inhaltslos bestimmte Arbeitszeit macht die Waren überhaupt erst zu objektiv identifizierbaren Dingen auf dem Markt. Im Tauschwert manifestiert sich deshalb die quantitativ bestimmte Zeit des qualitativ handfesten Einwirkens eines Subjekts auf das tatsächlich konkrete, gebrauchswertliche Material. Und durch die in sie eingeflossene verausgabte zwecksetzende menschliche abstrakte Arbeit in der durchschnittlichen Zeit der Arbeit als objektive Bezugseinheit der Waren aufeinander lässt sich ihr Wertausdruck erst auf etwas allgemein objektives zurückführen. Diese objektive Bezugseinheit ist insofern der Grund dafür, dass sich die qualitativ verschiedenen Gebrauchswerte im Tauschwert quantitativ miteinander identifizieren lassen. Die Arbeit überhaupt mit all ihren Implikationen zeigt sich damit als die wesentlich objektive, quantitativ sich manifestierende Gesetzmäßigkeit hinter den produzierten Dingen, die auf dem Markt mit dieser objektiven Manifestation in Erscheinung treten und dann auch erst als geschützte Eigentumstitel miteinander in Beziehung treten.

\footnotetext{
1106 Marx: Das Kapital, Bd. 1, S. 61.

${ }^{1107}$ Ebd., S. 61.

1108 Vgl. Aristoteles: Metaphysik, 1028a ff.

1109 Adorno: Philosophische Terminologie, S. 36.

1110 Krahl: Zur Wesenslogik der Marxschen Warenanalyse, S. 32.

1111 Marx: Das Kapital, Bd. 1, S. 55, Fn.

1112 Krahl, Konstitution und Klassenkampf, S. 71.
} 
Gerade weil die produzierten Dinge objektiv als verallgemeinerte, wertgleiche Waren auf den Markt des Austauschs geworfen werden können, gibt es bereits vor dem Tauschakt einen der Ware objektiv inhärierenden Wert. Neben der menschlichen Arbeit ist der auf dem Markt angebotenen Ware auch durch die in ihr verarbeiteten Rohstoffe bereits ein bestimmbarer Wert immanent. (Wenn Ware verschrottet wird, hat das die Zerstörung ihres gesellschaftlichen Werts und Gebrauchswerts zur Folge). Deshalb ist die entsprechende Diskussion, ob der Warenwert in der Produktion oder erst in der Zirkulation entsteht auch nicht ,unsin-

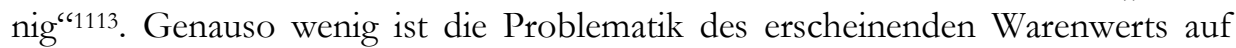
dem Markt ein Scheinproblem: Solange es überhaupt um den objektiven Maßstab einer wissenschaftlichen Beschäftigung mit dem Wert der Ware gehen soll, muss die Diskussion um die quantitative Objektivität des Warenwerts geführt werden.

Weil der Wert den zirkulierenden, unterschiedlichen Waren objektiv inhärent ist, ist deswegen auch immer derselbe objektive Wert in Produktion wie Zirkulation Gegenstand, auch wenn dieser im mannigfaltigen Austausch gegen andere Werte von gleicher quantitativer Größe auf dem Markt erst offenbar wird ${ }^{1144}$ : „Der Sache nach ist es derselbe Wert, der in der Produktionssphäre geschaffen und der in der Zirkulationssphäre als Geld realisiert wird." ${ }^{1115}$ Der durch die inhärente Quantität an menschlichen Arbeitsstunden am Naturstoff vorhandene objektive Wert geht bzw. kommt dem bereits produzierten Ding deshalb nicht, wie durch Zauberei, mal ab, mal zu. Ein gesellschaftliches Verhältnis bei der kapitalistischen Wertproduktion suspendiert insofern nicht von rationaler Objektivität, wie Grigat meint, nur weil der „Wert nichts Natürliches, sondern etwas rein Gesellschaftliches" 1116 sei. Grigat unterstellt deshalb nominalistisch, dass der Wert, weil rein gesellschaftlich, irreal sei: „Der Wert der Waren ist insoweit nichts Reales [sic!], als er nicht greifbar ist [sic!!]. Er existiert nur aufgrund eines bestimmten gesellschaftlichen Verhältnisses der Menschen. Seine Existenzform ist es, Ausdruck dieses gesellschaftlichen Verhältnisses von Menschen zu sein." "1117 Seine Gesellschaftlichkeit aber macht den Wert nicht gleich zu etwas irrational irrealem. Gerade weil der Wert gesellschaftlich ist, ist er objektiv und rational über den Bezugspunkt Arbeit überhaupt an einem bestimmten Naturstoff, über seine Substanz, in seiner Entstehung nachvollziehbar. Greifbar ist der Wert zwar, ganz richtig wie Grigat meint, nur mittels der subjektiven Reflexion. Das jedoch kann nicht heißen, dass er, nur weil er sich damit als ein abstrakt vom Subjekt gedachtes ,gesellschaftliches Verhältnis` erweist, gleich irrational und irreal sei. Über die rati-

1113 Grigat: Fetisch und Freiheit, S. 46.

1114 Das ist nur teilweise richtig. Man hat die Produktionsschritte nicht umsonst vereinheitlicht und findet sie im Kapitalismus möglichst alle unter einem Dach zusammengefasst und Produktionsbänder in ihrer Geschwindigkeit so eingestellt, dass das gewünschte Ergebnis erzielt wird etc. Vgl. Marx: Das Kapital, Bd. 1, S. 341 ff.

1115 Bulthaup: Elemente des Antisemitismus, S. 124.

1116 Grigat, Fetisch und Freiheit, S. 46.

1117 Ebd., S. 51. 
onal nachvollziehbare Objektivität des Warenwerts durch die Wertsubstanz Arbeit überhaupt - als Arbeit in bestimmter Zeit - ist und bleibt die Ware immer objektiv, rational erkennbar und tauschbar. Grigats Argumentation erinnert deshalb nicht ganz zu Unrecht an den nominalistischen Platonismusvorwurf von Marx an Hegels Wesen (vgl. 2.5.2).

Auch andere Theoretiker ${ }^{1118}$ unterstellen einen strengen Subjektivismus bezüglich der Warenwerte. Michael Heinrich schreibt: „Wertsubstanz und damit auch Wertgegenständlichkeit kommt den Dingen hingegen nur zu, wenn sie sich im Austausch aufeinander beziehen." 1119 Marx hat jedoch, was in diesem Unterabschnitt bereits deutlich geworden ist, mit der Wertformanalyse nicht herausgestellt, wie auch Aron fälschlicherweise behauptet, „,daß die Waren nur einen Wert besitzen, wenn eine Nachfrage nach ihnen besteht." 1120 Die Waren repräsentieren bei geringer Nachfrage lediglich keine gesellschaftlich notwendige Arbeit.

\subsubsection{Zur Logik der hinausweisenden Abstraktion: Vom Sinn der Abwesenheit der Ware Arbeitskraft in der Wertformanalyse}

Eine Erklärung der gesellschaftlichen Reichtumsproduktion in der bürgerlichen Gesellschaft, die notwendig über den freien Tausch auf dem Markt realisiert wird, muss benennen, was den Mehrwert wie produziert. Es ist dies die Ware Arbeitskraft, die die einzig variable Ware im Kapitalismus darstellt - und die dadurch im Prozess der Wertschöpfung ,dehnbar' wird (vgl. insbes. 4.1.4). In der Geschichte entdeckt Marx diese Ware Arbeitskraft als Unsystematisches, Nicht-logisches, Nichtbegriffliches. Deswegen fehlt jene mehrwertheckende Ware, die warenförmige Quelle des kapitalistischen Reichtums, in der von gesellschaftlicher Herrschaft und Geschichte freigehaltenen, weil nur begriffslogischen, Wertformanalyse auch noch (vgl. 4.1.1): „Der Begriff der Ware Arbeitskraft ist aber in der Warenanalyse noch nicht eingeführt. “1121 Erst die Geschichte präsentiert dem Geldbesitzer seine verwertbare Reichtumsquelle in Form der freien und mobilen Ware Arbeitskraft: „Um aus dem Verbrauch einer Ware Wert herauszuziehn, müßte unser Geldbesitzer so glücklich sein, innerhalb der Zirkulationssphäre, auf dem Markt, eine Ware zu entdecken, deren Gebrauchswert selbst die eigentümliche Beschaffenheit besäße, Quelle von Wert zu sein, deren wirklicher Verbrauch also selbst Vergegenständlichung von Arbeit wäre, daher Wertschöpfung." "1122 Mit der Ware Arbeitskraft findet der Geldbesitzer also erst ein entsprechendes warendingliches Vermögen vor, das über den in der Wertformanalyse gegenständlichen Äquivalententausch von Eigentum hinausgeht und die damit überhaupt erst die entschei-

\footnotetext{
1118 Vgl. z.B. die auch von Grigat als Stichwortgeber angeführten Sturm: Der ökonomische Wert; Scheit: Suicide Attack.

1119 Heinrich: Kritik der politischen Ökonomie, S. 51.

1120 Aron: Hauptströmungen des soziologischen Denkens, Erster Band, S. 146.

1121 Kuhne: Begriff und Zitat bei Marx, S. 24.

1122 Marx: Das Kapital, Bd. 1, S. 181.
} 
dende Quelle von Mehrwert sein kann: „Und der Geldbesitzer findet auf dem Markt eine solche spezifische Ware vor - das Arbeitsvermögen oder die Arbeitskraft." ${ }^{1123}$ Erst mit dem freien und mobilen Arbeiter kann der allgemeine Warentausch der kapitalistischen Produktionsweise überhaupt realisiert werden, der in der Mehrproduktion und dem Mehrwert resultiert. Die kapitalistische Mehrwertproduktion verlangt deshalb auch ,systematisch“ nach der „Existenz des [doppelt, B.E.B.] freien Arbeiters auf dem Warenmarkt" ${ }^{\text {"1124. }}$

Die „eigentümliche Ware"1125 fällt aber, obwohl sie eine Mehrwertproduzierende und damit Besondere darstellt, die „keine Ware wie jede andere ist" ${ }^{\star 1126}$, trotzdem nicht aus dem ubiquitären Zusammenhang von Eigentum und Äquivalententausch in der Zirkulationssphäre heraus. Von der Quelle des Reichtums der kapitalistischen Produktionsweise abstrahiert Marx in der Wertformanalyse zunächst nur, um hier schon einmal die entscheidenden Begriffe bzw. Kategorien der kapitalistischen Produktionsweise einzuführen, die für das Verständnis von kapitalistischer Mehrwertproduktion unabdingbar sind. Von der historischen Ware Arbeitskraft abstrahiert Marx an der Stelle der Analyse kapitalistischer Verhältnisse deshalb schon bewusst. Von allem historischen wird in der Wertformanalyse abstrahiert, weshalb die Wertformanalyse auch nicht - wie bei Engels, Haumann etc. - eine Beschreibung historischer Gesellschaftsformen ist. Die Ware Arbeitskraft ist dabei auch kein aus der Logik der Begriffe der Wertformanalyse deduzierbares Resultat, sondern ein nichtidentisch historisches Resultat. ${ }^{1127}$ Weil Nichtbegriffliches/Nichtidentisches in der in sich geschlossenen, stringenten Begriffslogik der Wertformanalyse jedoch keinen Platz findet, ist hier auch die entscheidende und einzig mehrwertheckende Ware noch kein Gegenstand. Die Begriffe der Wertformanalyse sind nun auch viel zu eng gesteckt, als dass sie als in sich subsistierende Begrifflichkeit den historischen Gegenstand der Mehrwertgewinnung aus sich und dem eingeführten Äquivalententausch begreifen könnten. Wenn Frank Kuhne ihre Begrenztheit als das alles entscheidende „aporetische Resultat der Warenanalyse " ${ }^{\text {11128 }}$ beschreibt, spielt er auf dieses Hinausweisen der systematischen Begriffe aus sich selbst auf ein sie erst bedingendes materielles, historisches Korrelat an.

Damit wird die konkrete, diskontinuierliche Geschichte indirekt zur Grundlage der logischen Abstraktion, die Marx in der Wertformanalyse vornimmt. Historisch ist die Ware Arbeitskraft für die Entwicklung der Begriffslogik der Wertformanalyse nämlich bereits vorausgesetzt. Die historisch erlangte Verfügungsgewalt über die Ware Arbeitskraft und ihr garantiertes Eigentum lässt erst die kapitalistische

\footnotetext{
1123 Ebd.

1124 Krahl: Zur Wesenslogik der Marxschen Warenanalyse, S. 42.

1125 Marx: Das Kapital, Bd. 1, S. 184.

1126 Hanloser/Reitter: Der bewegte Marx, S. 34.

1127 Vgl. Marx: Das Kapital, Bd. 1, S. 741 ff. (24. Kapitel)

1128 Kuhne: Begriff und Zitat bei Marx, S. 32.
} 
Produktionsweise und damit auch die ihr logisch vorausgesetzte, abstrakte Wertformanalyse funktionieren und existieren. Mithilfe der Ware Arbeitskraft realisieren sich deshalb die zunächst noch spekulativen Begriffe der Wertformanalyse überhaupt erst: „Der Anfang des Kapitals ist, weil Anfang, abstrakt.“1129 Die nichtsystematische, diskontinuierliche Bedingung ist deshalb die systematische Bedingung des Systems der gesellschaftlichen Reichtumsproduktion als Mehrwertproduktion. Paradoxerweise muss damit von einer systematischen Funktion des Nicht-Systematischen durch die willkürlichen, gewaltsamen historische Bedingungen gesprochen werden. So wird der Lohnarbeiter zum unabdingbaren Moment des systematischen Prozesses der totalen kapitalistischen Produktionsweise als eines gesellschaftlichen Prozesses in Zeit und Welt - und die Lohnarbeiter sind das unmittelbar nichtidentische Moment der entscheidenden Vermittlung des Ganzen.

Der mittels Geschichte initiierte Prozess gesellschaftlicher Reichtumsproduktion unterliegt einer reflexiven Entwicklung, das heißt, er prozessiert. Die kapitalistische Produktionsweise wird über die bürgerliche Revolution initiiert. Die rein begrifflich verfahrende allgemeine Warenform und die damit verbundenen Eigentumsverhältnisse resultieren insofern aus der Gewalt der begriffslosen Kontingenz. Selbst das nur begrifflich festgeschriebene Eigentum an Produktionsmitteln könnte den inhaltlichen Zweck der Mehrwertproduktion nicht erfüllen, solange der Eigentümer der dinglichen Reproduktionsmittel nicht auch auf die historisch ihm zugeschobenen doppelt freien Lohnarbeiter als die vermittelnden Anwender seines dinglichen, fixen Eigentum zugreifen kann: „Zunächst entdeckte Wakefield in den Kolonien, daß das Eigentum an Geld, Lebensmitteln, Maschinen und andren Produktionsmitteln einen Menschen noch gar nicht zum Kapitalisten stempelt, wenn die Ergänzung fehlt, der Lohnarbeiter, der andere Mensch, der sich selbst freiwillig zu verkaufen gezwungen ist. " 1130 Ohne nichtsystematische, besondere Ware Arbeitskraft und allgemeine Warenform als in sich vermittelte Momente kapitalistischer Produktionsweise ließe sich der allgemeine, gesellschaftliche Tausch von Waren als Eigentumstitel in der wertverwertenden bürgerlichen Gesellschaft zu quantitativ gleichen Werten nicht adäquat begreifen, geschweige denn realisieren. Weil die allgemeine Wertformanalyse ohne die Ware Arbeitskraft als einziges Eigentum der Produktionsmittellosen deshalb vollkommen uninspiriert bleiben müsste, liegt gerade in der Abstraktion von dieser als Eigentumstitel die Notwendigkeit ihrer Existenz. Der allgegenwärtige Zugriff auf alle Waren auf dem Markt, wozu der Zugriff auf die Ware Arbeitskraft zählt, muss deshalb von Marx in der logisch verfahrenden Analyse der Wertform bereits abstrakt unterstellt sein. Sie bildet die logische, zirkulationstheoretische Voraussetzung der kapitalistischen Produktionsweise ohne bestimmten Inhalt.

${ }^{1129}$ Ebd., S. 24.

1130 Marx: Das Kapital, Bd. 1, S. 793. 
Aus streng logischen Gründen abstrahiert Marx in der Wertformanalyse jedoch deshalb von der Arbeitskraft als Ware und als Eigentum, weil in den ersten Kapiteln des Kapitals allein die Möglichkeiten der Zirkulation von Warenprodukten, von aus dem Eingriff in den Naturzusammenhang entstandenen Waren Gegenstand ist. Das sich ausgleichende logische Nullsummenspiel des Äquivalententauschs kann insofern zwar die Produktion von gesellschaftlichem Reichtum unter kapitalistischer Produktionsweise noch nicht lichten. Dafür befördert die Wertformanalyse aber entscheidende und wegweisende logische Grenzen der Erklärung der kapitalistischen Produktionsform aus der Zirkulationssphäre zutage, die auf diskontinuierliche materielle Momente der Reichtumsproduktion notwendig hinweisen, von denen in ihr aber noch bewusst abstrahiert wird. Das ist der entscheidende Zweck und terminus ad quem der Wertformanalyse: ihr systematischer wie impliziter Verweis auf das notwendig materielle Moment als erst sinnstiftendes Moment der kapitalistischen Produktionsweise.

Eine weitere Begründung der bewussten, systembedingten Abstraktion vom materiell Wesentlichen in der Wertformanalyse liefern die in ihr eingeführten Begriffe selbst. Durch das Auftauchen der Ware Arbeitskraft im Kapital131 werden die Begriffe der Wertformanalyse nicht gleich als obsolete Begriffe abgeschafft. Die Begrifflichkeit der Wertformanalyse bekommt ihren eigentlichen Sinn erst, sobald die freie, mobile Ware Arbeitskraft im Kapital auftaucht. Marx abstrahiert deshalb bei der Betrachtung der Zirkulation der Waren nur mittels der negierenden Reflexion von allem notwendig historischen Material der kapitalistischen Reichtumsproduktion. Die kategoriale Form der wissenschaftlichen Erklärung des gesellschaftlichen Reichtums ist, wie schon jede kategoriale Form, auf ihr raumzeitliches, nichtsystematisches geschichtliches Material der Vermittlung angewiesen - auf ein Material, das über die Tautologie von sozialwissenschaftlichen Begriffen und Logik bereits hinaus ist. Pointiert heißt das, dass die Spekulationen der Wertformanalyse mit der Ware Arbeitskraft ihr historisches Material bekommen, was sie als anfängliche Spekulationen erst in ihrem Dasein als Spekulationen berechtigt. Die doppelt freien Lohnarbeiter sind dieses vermittlungsbedingende Etwas der allgemeinen kapitalistischen Reproduktion. Sie sind insofern dasjenige Moment der kapitalistischen Produktionsform, das die Vermittlung des Kapitalverhältnisses als ihr notwendig Unmittelbares überhaupt erst ermöglicht. Dieses Material, der mobile, freie Lohnarbeiter, bildet den grundlegenden Stoff des gesellschaftlichen Reichtums und wird deshalb bei den rein logisch verfahrenden Begriffsbestimmungen der politischen Ökonomie als unmittelbares, zunächst bloß unbestimmt bleibendes Korrelat bereits abstrakt mitgeführt. Weil jede Abstraktion immer nur von Etwas abstrahieren kann, das Dasein bereits in der Welt und schon deshalb vermittelt im Kopf des Autors hat, wird also historisches Material

1131 Vgl. ebd., S. 161 ff. 
bei der Marxschen Ausarbeitung der Wertformanalyse mit-, aber eben noch nicht ausgeführt.

\subsubsection{Zur Ware Arbeitskraft im Eigentumstausch}

Der Beweis eines notwendig hinzutretenden Moments zur Realisation der gesellschaftlichen Reichtumsproduktion durch die Form und ihre Grenzen der Erklärung selbst ist auch einer wider die ideologischen Auffassungen vom Gewinn des gesellschaftlichen Reichtums durch simplen, in Begriffen verbleibenden, Äquivalententausch der Wertformanalyse. Wenn aus dem reziproken Äquivalententausch der Wertformanalyse selbst der gesellschaftliche Reichtum im Kapitalismus folgen soll, heißt das, dass das Tauschprinzip oder der allgemeine Tausch „das Gesetz, nach dem die Fatalität der Menschheit abrollt" "1132 sei; dies formuliert Adorno inhaltlich mehrfach. ${ }^{1133}$ Oben in der Untersuchung wurde jedoch bereits offensichtlich, dass aus Wertformanalyse und logischem, äquivalentem Tausch die auf Gewalt beruhende kapitalistische Mehrprodukt- oder Mehrwertproduktion, der

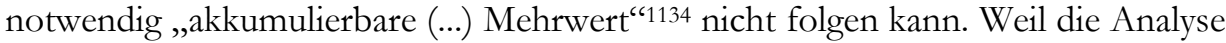
der Wertform noch inhaltsloses, zirkuläres Verum ohne Gegenstand ist, erwies sich deshalb die logische Ableitung der allgemeinen kapitalistischen Produktion aus der Wertformanalyse bereits als falsch. Andererseits bleibt die Wertformanalyse der kapitalistischen Mehrwertproduktion immer auch gegenständlich, was an der Stelle einen belastenden Widerspruch beschreibt. Der äquivalente Tausch bleibt der kapitalistischen Produktionsweise formell immer gegenständlich. Kein Tauschvertrag innerhalb der gesellschaftlichen Totalität wird hinterlistig gebrochen, um Kapital zu akkumulieren.

Garantiert wird die kapitalistische Reichtumsproduktion erst mit der historisch durch den Gewaltakt gewonnenen menschlichen Ware Arbeitskraft als zugleich staatlich geschütztem Eigentumstitel. Zuvor konnte es noch keinen Kapitalismus, keine kapitalistisch organisierte Mehrproduktion etc. geben. Erst historisch kontingente Voraussetzungen ihrer Schaffung stellen das nichtidentische, historische $\mathrm{Ma} \beta$ des allgemeinen Tauschwerts im Kapitalismus bereit. Durch den Staat werden die Voraussetzungen der kapitalistischen Produktionsweise in ihrer Existenz sowohl verlängert wie abgesichert (vgl. Kap. 3). Die produktive Arbeit der sachlich Eigentumslosen am fremden Eigentum zu eigenen Reproduktionszwecken mündet in einer gesellschaftlich notwendigen Arbeitszeit, die für die Produktion der jeweiligen Dinge gesellschaftlich durchschnittlich benötigt wird. Sie ist das notwendige tertium comparationis der Wertvergleichbarkeit der Dinge auf dem Markt. Erst durch dieses die Dinge vergleichbar machende Dritte, geleistet in der

\footnotetext{
1132 Adorno: Soziologie und empirische Forschung, S. 209.

1133 Vgl. hierzu Weyand: Adornos Kritische Theorie des Subjekts, S. 65 ff.

1134 Zum Begriff des ,akkumulierbaren Mehrwerts“vgl. Bensch: Vom Reichtum der Gesellschaften, S. $51 \mathrm{ff}$.
} 
Zeit durch die freie, mobile Ware Arbeitskraft auf einem bestimmten Stand der Produktivkraft, objektiviert sich der Tauschwert des Dings auf dem Markt zum allgemeinen Äquivalent, zum Tauschwert überhaupt: „Das bloße Tauschverhältnis setzt noch nicht den Tauschwert als allgemeines Äquivalent, dessen Maß, die für die Produktion der Tauschobjekte aufgewendete gesellschaftlich notwendige Arbeitszeit, erst dann zu einem allgemeinen wird, wenn ein erheblicher Teil der Bevölkerung aus von den objektiven Bedingungen der Produktion entblößten Arbeitern besteht.“" 1135

Die spezifische Ware Arbeitskraft kann sich als Eigentum dabei entgeltlich wie jede andere Ware angeeignet werden. Wie jede andere Ware ist sie ebenfalls durch eine immanente Doppelcharakterlichkeit bestimmt. Sie besitzt, trotz ihrer Besonderheit als menschliche Ware, der ,gewöhnlichen' Ware wesentliche Bedingungen. Sie besitzt genauso die Erscheinungsweisen des Werts, Gebrauchs- und Tauschwert. ${ }^{1136}$ Deshalb ist auch die Ware Arbeitskraft eine ,gesellschaftliche Form“1137. Sie hat insofern auch einen gesellschaftlichen Wert ,gleich dem jeder andren Ware“"1138. Ihrer gesellschaftlichen Form korrespondiert dabei ebenfalls ein objektiver „stoffliche(r) Inhalt" ${ }^{“ 1139}$, weshalb die Ware Arbeitskraft, wie jede andere eigentümliche Ware auch, ihr stoffliches Implikat als Korrelat mit sich führt: etwas unmittelbar Daseiendes, das lebendige, individuelle Subjekt. Auch die Ware Arbeitskraft führt demnach also ihr materielles Substrat als Urteil über ihre Existenz mit sich: in dem Fall die physische Person. Als von den Möglichkeiten seiner Subsistenz revolutionär Freigesetztes wird das Subjekt deshalb zu eigenen Reproduktionszwecken zum physischen Träger des gesellschaftlichen Werts der Ware Arbeitskraft als sein einziges Eigentum (vgl. 3.2 ff.). Dem reflexiven, selbstbewussten Subjekt kommt bei der objektiven Bestimmung der Ware Arbeitskraft insofern eine enorme Bedeutung zu. Auf das unmittelbar physische Material der verdinglichten Körperlichkeit, dem materiellen Substrat der Ware Arbeitskraft, wird der

\footnotetext{
1135 Bulthaup, Zum Problem des Übergangs vom Feudalismus zum Kapitalismus, S. 51.

1136 Dass beides, Tausch- und Gebrauchswert, ,nur ${ }^{\star}$ Erscheinungsformen der Ware sind und sie nicht im Verhältnis Wesen - Erscheinung zueinander stehen, übersieht Habermas. Er scheitert an der unaufgelösten Ambivalenz der Ware in der Erscheinungsform, da er das wirkliche Wesen der Ware, die entscheidende Wertsubstanz der Ware, nicht begreift. Indem er den gesellschaftlichen, inneren Widerspruch der Ware als Allgemeines und Besonderes, als Tausch- und Gebrauchswert in der Erscheinungsweise des Werts trivialisiert, scheitert er an der Bestimmung des Doppelcharakters der Ware und der daran anschließenden Frage, auf was dieser Doppelcharakter der Ware wesentlich denn verweist. Für ihn ist der Tauschwert also nicht eine bloße Erscheinungsweise des Werts der Ware auf dem Markt, sondern bereits das Wesen der Ware selbst. In der Theorie des kommunikativen Handelns schreibt er, Marx analysiere im Kapital „die Doppelform der Ware als Gebrauchs- und Tauschwert und die Umwandlung ihrer Naturalform in die Wertform mit Hilfe des Hegelschen Begriffs der Abstraktion, wobei sich Gebrauchs- und Tauschwert wie Wesen und Erscheinung zueinander verhalten." (Habermas: Theorie des kommunikativen Handelns, Bd. 1, S. 477.)

1137 Marx: Das Kapital, Bd. 1, S. 50.

1138 Ebd., S. 184.

1139 Ebd.
} 
Kapitalismus auch in Zukunft immer angewiesen bleiben: „Soweit sie Wert, repräsentiert die Arbeitskraft selbst nur ein bestimmtes Quantum in ihr vergegenständlichter gesellschaftlicher Durchschnittsarbeit. Die Arbeitskraft existiert nur als Anlage des lebendigen Individuums. Ihre Produktion setzt also seine Existenz voraus. Die Existenz des Individuums gegeben, besteht die Produktion der Arbeitskraft in seiner eignen Reproduktion oder Erhaltung [?]." "1140 Die Doppelcharakterlichkeit der Ware kommt demnach also auch der mit Körperlichkeit begabten Ware als eine Eigenschaft ihres zu veräußerlichenden Eigentums als deren allgemeine Bestimmung zu.

Für die Ware Arbeitskraft wird dabei die gesellschaftlich durchschnittliche Zeit, die sie jeweils für die eigene Reproduktion benötigt, wertbildend. Die Produktion des Werts der Ware Arbeitskraft, bemessen in der gesellschaftlich durchschnittlichen Reproduktionsdauer des lebendigen Subjekts in der Zeit als der ,,reine[n] Negation der endlichen Dinge" "1141, ist das, was auf der Erscheinungsebene nun nicht unmittelbar sichtbar wird. Insofern bemisst sich der Wert der Ware Arbeitskraft wie der Wert aller anderen Waren nach der gesellschaftlich notwendigen Arbeitszeit, die zur Produktion -, oder in dem Fall besser ausgedrückt: zur überlebenswichtigen Reproduktion erforderlich ist. Wie die dingliche Ware in einer bestimmten gesellschaftlichen Durchschnittsarbeitszeit produziert wird, so reproduziert sich die verdinglichte Ware Arbeitskraft dementsprechend durch die gesellschaftlich notwendige Arbeitszeit, die dem Besitzer von nichts als dem Eigentum an Ware Arbeitskraft sein bloßes Überleben sichert und die zugleich ihren eigenen Wert schafft. Die reflexive Subjektivität schützt deshalb auch nicht vor der allgemeinen Verdinglichung als ein allgemeines lebendiges Warending.

Die Ware Arbeitskraft wird insofern ein eigentümlicher, tauschbarer Gegenstand - tauschbar auf dem Markt zu einem bestimmten Wert, der sich an der Zeit zu ihrer eigenen Reproduktion festmacht. Der zur Reproduktion der Ware Arbeitskraft benötigte Wert, der Wert ihres einfachen sese conservare, zu ihrer einfachen Selbsterhaltung als lebendiges Subjekt, spiegelt sich in ihrem Tauschwert wider: im für sie auf dem Markt vertraglich festgelegten und bezahlten Tauschwert/Preis (oder umgangssprachlich: im Lohn, wobei Wert und Preis der Ware Arbeitskraft stark voneinander abweichen können). Dieser Wert des einfachen sese conservare ist das Wesen der Ware Arbeitskraft, ihre Substanz. Es ist die notwendige Arbeitszeit zu ihrer eigenen Reproduktion, die Zeit, sich selbst verdinglicht als Ware im kapitalistischen Produktionsprozess, der Totalität der bürgerlichen Gesellschaft, zu erhalten: um sich selbst als nützlicher Gebrauchswert im Produktionsprozess weiterhin konkurrenzfähig zu erhalten - und damit vermittelt die Klasse der Proletarier zu reproduzieren. Wie bei jedem anderen Äquivalententausch auch kauft also der Käufer der Ware Arbeitskraft in der bürgerlichen Gesellschaft vertraglich ihren spezifischen Gebrauchswert und zahlt dann dafür

1140 Ebd., S. 184 f.

${ }^{1141}$ Krahl: Konstitution und Klassenkampf, S. 73. 
äquivalent ihren jeweiligen gesellschaftlichen Tauschwert: „Der Wert [der Ware Arbeitskraft, B.E.B.] wiederum ist bestimmt wie der jeder anderen Ware auch, nämlich durch die Menge an vergegenständlichter Arbeit, die in ihr steckt, kurzum, durch die gesellschaftliche Arbeitszeit, die zur ,Produktion' des Arbeiters und seiner Arbeitsfähigkeit nötig sind.“"1142 Der Wert der menschlichen Ware berechnet sich dabei sowohl nach den physischen wie psychischen Komponenten ihrer lebens- und kapitalnotwendigen Erhaltung. Der gesellschaftliche Wert der Ware Arbeitskraft repräsentiert also die Summe an gesellschaftlich notwendigen Lebensmitteln, die die Reproduktion des Arbeiters, beziehungsweise die Reproduktion der Arbeiterklasse als Klasse insgesamt sichert. Die Summe repräsentiert insofern den gesellschaftlich äquivalenten Warenkorb, der zum Überleben des einzelnen (Durchschnitts-)Arbeiters (und damit der kapitalistischen Produktionsweise) reicht. Der Wert der Ware Arbeitskraft ist allerdings von Nation zu Nation und Produktivkraftstufe zu Produktivkraftstufe variabel, weil die Summe der Lebensmittel des Arbeiters zu seiner eigenen Reproduktion (und eventuell der seiner Familie ${ }^{1143}$ ) nicht für alle Zeiten fix, sondern auch immer marktabhängig ist. Die Summe der Lebensmittel bleibt zudem auch noch Teil von Vertragsverhandlungen und kann, in Form einer Korrektur des veränderlichen Lohns, jeweils gedrückt oder erhöht werden: „Andrerseits ist der Umfang sog. notwendiger Bedürfnisse, wie die Art ihrer Befriedigung, selbst ein historisches Produkt und hängt daher großenteils von der Kulturstufe eines Landes, unter anderem auch wesentlich davon ab, unter welchen Bedingungen, und daher mit welchen Gewohnheiten und Lebensansprüchen die Klasse der freien Arbeiter sich gebildet hat." "1144

Eine Mehrwertproduktion durch die legale Absicherung eines Vertrags hindurch ist jedoch nur dann möglich, wenn der Lohnarbeiter systematisch über die Zeit für seine eigene Reproduktion hinaus arbeitet. Der Lohn wird nie, um die kapitalistische Mehrwertproduktion nicht zu gefährden, derart erhöht, dass er die gesamte geleistete Arbeit des Lohnarbeiters repräsentieren wird. Für die Reichtumsproduktion über den Äquivalententausch durch den Äquivalententausch hindurch, durch alle politisch-ökonomische Gerechtigkeit hindurch, wird deshalb der Tausch von wirklich geleisteter Arbeit des Arbeiterklassensubjekts am Naturgegenstand gegen den diesem eigentumstechnisch zustehenden Lohn entscheidend. An der Stelle kommt der Doppelcharakter der subjektiven Ware Arbeitskraft ins Spiel: Durch die Vermittlung von Tausch- und Gebrauchswert als auch immanente Qualität der Ware Arbeitskraft kann das dialektisch in sich vermittelt

\footnotetext{
1142 Haug: Vorlesungen zur Einführung ins Kapital, S. 32.

1143 „Die Summe der zur Produktion der Arbeitskraft notwendigen Lebensmittel schließt also die Lebensmittel der Ersatzmänner ein, d.h. der Kinder der Arbeiter, so daß sich diese Race eigentümlicher Warenbesitzer auf dem Warenmarkte verewigt.“ (Marx: Das Kapital, Bd. 1, S. 186.) 1144 Ebd., S. 185.
} 
andere des erscheinenden Werts der Ware, der Gebrauchswert, von Eigentümern der Produktionsmittel angewendet werden.

In der Intention des Warenkaufs lässt sich zwar beim Kauf der Ware Arbeitskraft vorerst kein Unterschied gegenüber dem Kauf von anderen feilgebotenen Waren auf dem Markt feststellen. Hier wie dort geht es beim allgemeinen Warentausch von Äquivalenten in der Zirkulationssphäre formell mit rechten Dingen zu. Der Eigentümer an Produktionsmitteln kauft den historisch Eigentumslosen ganz legal, weil dieser Person des bürgerlichen Rechts und wollendes, freies bürgerliches Subjekt ist. Der Eigentümer von Produktionsmitteln bezahlt im konkreten Produktionsprozess den Arbeiter für die Zeit seiner Anwendung am Ende vertragsgerecht und dieser bekommt auch den marktüblichen oder ausgehandelten Tauschwert für seine Ware Arbeitskraft in Form eines Lohns. Im Falle des Tauschs vom Eigentum Arbeitskraft gegen den Lohn ist also der Äquivalententausch realisiert. Der Arbeiter muss mit dem Tausch ,zufrieden' sein, weil er seine gesellschaftlich notwendige Arbeitszeit zu seiner eigenen Reproduktion bezahlt bekommt und der Arbeitsvertrag damit realiter erfüllt wird. Er darf somit in der jeweiligen Gesellschaft überleben. Der Eigentümer an Produktionsmitteln eignet sich, vermittelt über den Tauschwert, jedoch auch den Gebrauchswert der Ware Arbeitskraft für sich und zur gesetzlich geregelten Vernutzung an. Dies erweist sich als die von Marx herausgestellte besondere Eigenschaft der „eigentümliche(n) Ware“1145 Arbeitskraft. Die besondere Ware Arbeitskraft verhält sich im Verwertungsprozess an dieser Stelle insofern anders als alle anderen dinglichen Waren, weil sie sich als variable, subjektgebundene Ware anders verhalten kann. Allein die Ware Arbeitskraft ist das besondere, lebendige Produktionsmittel, welches den eigenen Wert mittels seiner Anwendung auch reproduzieren muss, indem es den durch den Eigentumstitel ihm entfremdeten Arbeitsgegenständen neuen Wert zusetzt: „Die Existenz des Individuums gegeben, besteht die Produktion der Arbeitskraft in seiner eignen Reproduktion oder Erhaltung. “1146

Diese Vermehrung von Wert gerade durch ihre Anwendung ist der entscheidende Unterschied der Ware Arbeitskraft zur herkömmlichen, handwerklich produzierten Ware. Andere Waren können als rein technisches Produktionsmittel im Produktionsprozess angewendet immer bloß ihren eigenen Wert aufs neue Produkt übertragen. Die Anwendung der Ware Arbeitskraft, des lebendigen und gerade weil lebendiges Subjekts, geht hierüber jedoch hinaus, obwohl auch die Ware Arbeitskraft formell verdinglichte Ware wie jede andere ist. So bringt erst die vom Produktionsmitteleigentümer miterworbene Anwendung ihres Gebrauchswerts das mehr an Wert mit sich, das damit über den gesellschaftlich notwendigen Wert zur Reproduktion des Arbeiterklassesubjekts hinaus ist: „Das was als Arbeitslohn gezahlt wird, ist der Preis für die Ware Arbeitskraft, eine Ware, die wie alle anderen Waren Gebrauchswert und Wert hat. Ihr Gebrauchswert für den Käufer, also 
den Kapitalisten, ist, daß diese Ware vernutzt werden kann zur Wertproduktion, genauer zur Produktion von mehr Wert, als sie hat und als in Lohnform für sie gegeben werden muß, das heißt zur Verwertung: dabei unterscheiden sich Arbeitskraft und Arbeit wie Gebrauchswert und tatsächlicher Gebrauch. Der Wert wiederum ist bestimmt wie der jeder anderen Ware auch, nämlich durch die Menge an vergegenständlichter Arbeit, die in ihr steckt, kurzum, durch die gesellschaftliche Arbeitszeit, die zur ,Produktion' des Arbeiters und seiner Arbeitsfähigkeit nötig sind." 1147

Nur aus der besonderen Ware Arbeitskraft lässt sich vom Käufer demnach mehr herausziehen, als in sie investiert wurde. So hat der Eigentümer an Produktionsmitteln nicht etwa trotz des Äquivalententauschs einen Wertzuwachs in den ,von $\mathrm{ihm}^{6}$ produzierten Dingen zu verzeichnen, sondern durch den allgemein vertragsgerechten Äquivalententausch und der allgemeinen Doppelcharakterlichkeit der Waren als Eigentumstitel hindurch realisiert sich erst der Wertzuwachs. Auch das macht den dialektischen Zusammenhang von Zirkulation und Produktion der kapitalistischen Gesellschaftsform deutlich. Das entscheidende Moment dieser Realisation von kapitalistischem Reichtum durch die Anwendung der Ware Arbeitskraft liegt demnach unabdingbar in der vertragsrechtlich vermittelten Erlaubnis der Anwendung und Vernutzung ihres Gebrauchswerts. Nur durch den vertragsgerechten, legalen Prozess der Mehrwertproduktion hindurch kommt es also für den Eigentümer an Produktionsmitteln und gesamtgesellschaftlich zu einem Wertzuwachs der mit der Ware Arbeitskraft produzierten Produkte. Auch wenn im legalen Arbeitsvertrag die Mehrarbeit nicht explizit benannt wird, muss diese Mehrarbeit geleistet werden, um sich in der bürgerlichen Gesellschaft als Subjekt zu reproduzieren (vgl. auch 3.6.3). Vom doppelt freien Lohnarbeiter als Träger der Ware Arbeitskraft wird, aus der allgemeinen Rechtsprechung resultierend, vertragsrechtlich demnach immer mehr Wert auf das hergestellte Produkt übertragen als vom Kapitalisten ursprünglich an Wert für den Lohnarbeiter veräußert wird: „Der Kapitalist zahlt (...) den Tageswert der Arbeitskraft. Ihr Gebrauch, wie der jeder anderen Ware, z.B. eines Pferdes, das er für einen Tag gemietet, gehört ihm also für den Tag. Dem Käufer der Ware gehört der Gebrauch der Ware, und der Besitzer der Arbeitskraft gibt in der Tat nur den von ihm verkauften Gebrauchswert, indem er seine Arbeit gibt. Von dem Augenblicke, wo er in die Werkstätte des Kapitalisten trat, gehörte der Gebrauchswert seiner Arbeitskraft, also ihr Gebrauch, die Arbeit, dem Kapitalisten. Der Kapitalist hat durch den Kauf der Arbeitskraft die Arbeit selbst als einen lebendigen Gärungsstoff den toten ihm gleichfalls gehörigen Bildungselementen des Produkts einverleibt. Von seinem Standpunkt ist der Arbeitsprozeß nur die Konsumtion der von ihm gekauften Ware Arbeitskraft, die er jedoch nur konsumieren kann, indem er ihr Produktionsmittel zusetzt. Der Arbeitsprozeß ist ein Prozeß zwischen Dingen, die der

1147 Haug: Vorlesungen zur Einführung ins ,Kapital‘, S. 32. 
Kapitalist gekauft hat, zwischen ihm gehörigen Dingen. Das Produkt dieses Prozesses gehört ihm daher ganz ebensosehr als das Produkt des Gärungsprozesses in seinem Weinkeller." "1148

Allein über das besondere Moment der Körperlichkeit der Ware Arbeitskraft als einziges Eigentum der lebendigen Produktionsmittellosen also kann sich der Eigentümer im regelkonformen Verlauf eines vertragsgerechten Arbeitsprozesses der bürgerlichen Gesellschaft ganz legal unbezahlte Arbeit der Ware Arbeitskraft aneignen. Im Produktionsprozess ist deshalb das unmittelbar mitangeeignete physische Moment der Ware Arbeitskraft das entscheidende momentum. Nur die Körperlicbkeit des Arbeiterklassesubjekts selbst, gepaart mit formellen Verträgen, lässt über jeden formellen Tausch von Äquivalenten hinausgehen. Damit realisiert sich die Ungleichheit des Tauschs bei realisierter formeller Gleichheit des Tauschs, bei objektiver Realität des Äquivalententauschs: „Der Kapitalist zahlt nicht das von den Arbeitern geschaffene Wertprodukt, sondern er zahlt den Wert der Arbeitskraft." ${ }^{1149}$ So also bleibt die produktive Mehrwertgewinnung in der bürgerlichen Gesellschaft über den vertragsgerechten Tausch von Eigentumstiteln in der Zirkulationssphäre vermittelt, sie entsteht deshalb aus dem legalen, staatlich geschützen Verhältnis: der inhaltlichen Exploitation der Eigentumslosen an Produktionsmitteln bei formeller, juristischer Gerechtigkeit. Darum ist die Mehrproduktion von Waren und die dafür stattfindende Mehrwertgewinnung auch kein hinterhältiger Betrug oder listiger Bruch des freien Willens der Vertragspartner. ${ }^{1150}$ Die kapitalis-

\footnotetext{
1148 Marx: Das Kapital, Bd. 1, S. 200.

1149 Heinrich: Kritik der politischen Ökonomie, S. 94.

1150 Politiker, Gewerkschaftsfunktionäre und Akademiker gehen davon aus, dass der freiwillig abgeschlossene bürgerliche Vertrag, der das Verhältnis der Ausbeutung legalisiert, der spürbaren Ungerechtigkeit ein Ende setzen kann (vgl. auch 3.2 ff.). Der Inhaber des Lehrstuhls für Praktische Philosophie/Rechts- und Sozialphilosophie an der Humboldt-Universität Berlin, Volker Gerhardt, ebenfalls Mitglied des Deutschen Ethikrats, schreibt: „In einer von Macht und Gewalt dominierten Welt muss die Kraft, die von bloßen Ideen ausgeht, ganz unwahrscheinlich wirken. Erkennen wir jedoch, dass die Politik bereits in ihren Anfängen auf das Recht angewiesen ist und dass sich ihre Geschichte als ein fortgesetzter Kampf um das Recht darstellen lässt, erscheint das nicht mehr ganz so unglaubwürdig. Tatsächlich nimmt das Menschenrecht Einsichten auf, die von Anfang an mit dem Recht verbunden sind. In allen Fällen geht es um die Lebenssicherung von Individuen, denen die gleiche Freiheit zugestanden werden muss, wenn man sie als Untertanen vom Vorteil des Stillhaltens überzeugen oder als Bürger zur Mitwirkung gewinnen will.“ (Gerhardt: Gleiches Recht für alle.) Auch die Forderung nach gerechten oder gerechteren (!) Löhnen gehört in den Zusammenhang der Unterstellung, dass der durchgesetzte Tausch von Äquivalenten in der bürgerlichen Gesellschaft den Menschen Gerechtigkeit und mehr (!) Freiheit bringe: „Es war eine Erkenntnis aus den jahrelangen Streitigkeiten, dass das Problem der ungerechten Löhne in dem Ungleichgewicht zwischen Arbeit und Kapital zu suchen war." (Dodu: Die Tarifautonomie im Wandel der Gesellschaft, S. 28.) Das ist ein skeptisch verzweifelter Appell und kein kritischer Ruf nach einer Abschaffung des von den Autoren selbst konstruierten Mangels der bürgerlichen Gesellschaft. Im Prinzip trifft sich diese Vorstellung von Freiheit der Gewerkschafter und bürgerlichen Linken mit der ihres vermeintlich größten Feindes: dem Liberalismus. Ludwig von Mises spricht nämlich in seiner systematischen Darstellung des bürgerlichen Liberalismus davon, dass dieser jene Freiheit, die ihm potentiell innewohne, realiter noch nicht entfalten konnte. Dass, was mit bürgerlicher Freiheit und Gleichheit
} 
tische Mehrproduktion ist somit konsequentes Resultat eines gerechten Vertragsabschlusses in der bürgerlichen Gesellschaft, des Arbeitsvertragsabschlusses, der von den Bürgern, die entsprechend „freie, rechtlich ebenbürtige Personen“1151 sind, reziprok abgeschlossen wird.

Hegel beschreibt das Verhältnis von Vertrag und Willen in seiner Rechtsphilosophie demnach adäquat: „Der Vertrag setzt voraus, daß die darein Tretenden sich als Personen und Eigentümer anerkennen; da er ein Verhältnis des objektiven Geists ist, so ist das Moment der Anerkennung schon in ihm enthalten und vorausgesetzt (vgl. \35; 57 Anm.). "1152 Das meint, dass auch der Lohnarbeitsvertrag von den von persönlichen Herrschaftsverhältnissen des Feudalismus oder der Sklavenhaltergesellschaft längst emanzipierten Bürgern und wechselseitig sich anerkennenden und anerkannten Eigentümern abgeschlossen wird. ${ }^{1153}$ Niemand kann und wird in der bürgerlichen Gesellschaft zum Abschluss eines solchen Vertrages mit Gewalt und unwillentlich gezwungen werden - das wäre illegal und wider den freien Vertrag: „Ein erzwungener Vertrag, in den von einer Seite nichts an Gerechtigkeit eingegangen ist und der schon durch den Zwang, unter dem er abgeschlossen wurde, in den Augen des Gezwungenen neue Ungerechtigkeit geschaffen hat, wird nur so lange gehalten werden, wie der Zwang andauert.“1154

Alles geht in der Zirkulationssphäre deshalb mit allgemein freiem Willen vor sich. So wird die Produktion von gesellschaftlichem Reichtum in der bürgerlichen Gesellschaft zu einem allseits legalen Zwang, der in der universalen Freiheit des

\footnotetext{
gemeint ist, sei mit kapitalistischer Produktionsweise noch nicht realisiert - was de facto und de jure so wenig adäquat ist wie bei Gerhardt und Dodu. Kritisiert wird durch von Mises genauso idealistisch, dass der Begriff seinen Ansprüchen in der Wirklichkeit nicht gerecht werde. Für ihn liegt diese Mangelhaftigkeit allerdings in der unveränderbaren Anthropologie des Menschen. Aufgrund seiner mangelhaften anthropologischen Voraussetzungen sei der Mensch zur wirklichen bürgerlichen Freiheit nicht fähig. (Vgl. Ludwig von Mises, Liberalismus, S. 12 ff.) Von Mises verkehrt seine festgestellten Mängel also in die größtmögliche bereits realisierte Freiheit, während Gerhardt und Dodu diese Mängel zumindest noch zum Anlass nehmen, gesellschaftliche Verbesserungen einzufordern. 1151 Marx: Das Kapital, Bd. 1, S. 190.

1152 Hegel: Grundlinien der Philosophie des Rechts, S. 153.

${ }^{1153}$ Hegel verabsolutiert durch seine Affirmation des bürgerlichen Staates (Vgl. 2.4.1, 2.4.2) dieses Vertragsverhältnis, so dass er in seiner Rechtsphilosophie den Tauschvertrag auch als Schenkungsvertrag interpretiert: „Formell ist der Vertrag, insofern die beiden Einwilligungen, wodurch der gemeinsame Wille zustande kommt, das negative Moment der Entäußerung einer Sache und das positive der Annahme derselben, an die beiden Kontrahenten verteilt sind; - Schenkungsvertrag. Reell aber kann er genannt werden, insofern jeder der beiden kontrahierenden Willen die Totalität dieser vermittelnden Momente ist, somit darin ebenso Eigentümer wird und bleibt; - Tauschvertrag.“ (ebd., \ 76, S. 159.) Der aus der Geschichte resultierende Zwang, der die allgemeine und oben bereits beschriebene fictio juris des bürgerlichen Rechts zur Folge hat, geht ihm bewusst aufgrund seines idealistischen Positivismus verloren. Die bürgerliche Gesellschaft mit ihrem allgemeinen und objektiven Rechtsprinzip erscheint ihm, wie den bürgerlichen Rechtstheoretikern, Politikern etc., als Reich der Freiheit. Sie erscheint als tatsächlich befriedete Gesellschaft und allgemeine Verwirklichung des römischen do ut des, wodurch auch noch der Sklavenhaltergesellschaft des alten Roms die Absolution erteilt wird.

${ }^{1154}$ Henke: Recht und Staat, S. 207.
} 
Subjekts und des Vertrags verborgen liegt. Über den willentlich abgeschlossenen Vertrag vermittelt dehnt sich die notwendige Arbeitszeit für das Subjekt der Arbeiterklasse um ein Vielfaches über das eigentliche gesellschaftliche Maß aus, denn der Lohnarbeiter kann nicht einfach gehen, sobald er das Wertäquivalent seiner eigenen Anwendung produziert hat. Das wäre ein Bruch des freien Vertrags und folglich illegal. In dem Fall würde der Lohnarbeiter seinen rechtmäßigen Anwender, den Produktionsmitteleigentümer, bestehlen. Jener Rechtsbruch durch ,subjektive Vorteilsnahme wird in der bürgerlichen Gesellschaft strafrechtlich geregelt: „Wird bei der Arbeitszeit vom Arbeitnehmer geschummelt, wird dies als Betrug gegenüber dem Arbeitgeber angesehen. Schließlich wird eine Arbeitszeit bezahlt, obwohl diese gar nicht geleistet wurde. Gerichte sehen den Arbeitszeitbetrug als einen korrekten Grund für eine verhaltensbedingte Kündigung an." ${ }^{1155}$ Der Produktionsmitteleigentümer hat dagegen unter Androhung von Strafe dafür zu sorgen, dass der Lohnarbeiter dem geschlossenen Vertrag entsprechend bezahlt wird: „Durch den Dienstvertrag wird derjenige, welcher Dienste zusagt, zur Leistung der versprochenen Dienste, der andere Teil zur Gewährung der vereinbarten Vergütung verpflichtet.“"1156

1155 abmahnung.org: Arbeitszeitbetrug.

1156 Bürgerliches Gesetzbuch, \611,1. 



\section{Der moderne Antisemitismus und seine gegenwärtig gesellschaftskritische Reflexion}

\subsection{Zur Wertkritischen Theorie des Antisemitismus}

In 5.1.1 wird den weiteren Ausführungen zunächst eine notwendige Interpretation des Marxschen Fetischabschnitts vorangestellt, die für den kritischen Weg der Reflexion der modernen Antisemitismustheorie in dieser Arbeit Grundlegend wird.

5.1.2 setzt sich dann explizit anhand der Theorien von Grigat und Postone mit der wertkritischen Antisemitismustheorie und ihren Interpretationen von Gesellschaft und Ökonomie auseinander. Hier werden dann logische Probleme der wertkritischen Antisemitismustheorie offenbart, die einen logischen flashback in die marxistisch-leninistische Gesellschaftstheorie zur Folge haben.

Dieser Rückfall ist explizit in 5.1.3 Gegenstand, der ein schon frei resümierender Unterabschnitt über den Gegenstand des modernen Antisemitismus ist. In ihm werden wesentlichen Dinge der Ausarbeitung herangezogen, um auf die vorher ausgemachten Probleme der wertkritischen Antisemitismustheorie und ihrer Bestimmung des Gegenstandes moderner Antisemitismus hinzuweisen. Insofern leitet 5.1.3 bereits das dann folgende Resümee der Arbeit ein. 


\subsubsection{Zum notwendig falschen Bewusstsein als richtiges Bewusstsein}

Marx setzt sich in der oben bereits gegenständlichen Wertformanalyse mit dem Begriff des Fetischs, des falschen Bewusstseins, auseinander. Adorno führt seinen Ideologiebegriff ${ }^{1157}$ mit dem falschen Bewusstsein im Kapital nahezu parallel. ${ }^{1158}$ Doch offensichtlich führen weder Marx noch Engels aus, was sie unter falschem Bewusstsein oder Ideologie verstehen: „Ihr Begriff der Ideologie, weit entfernt eindeutig zu sein, ist zuerst aber eine Verdichtung von Problemen. "1159 Das erklärt die unscharfe Interpretation wie auch die schwierigen Einordnungen der Termini - sowie das undeutliche Verhältnis der Begriffe zueinander. Die Diskussion, ob falsches Bewusstsein in den Begriff der Ideologie überhaupt gänzlich zu überführen ist, ist insofern alles andere als einfach. ${ }^{1160}$ Auch der vielfach in der Theoriegeschichte unterschiedlich interpretierte Ideologiebegriff ist schwer einheitlich zu fassen. ${ }^{1161}$ Die unterschiedlichen Interpretationen lassen deshalb auch keinerlei Selbstverständlichkeit im Umgang mit dem Begriff zu: „Am Begriff der Ideologie“, schreibt Claussen nicht grundlos, ,scheiden sich die Geister.“"1162

Auf der Internetplattform indymedia.org heißt es beispielsweise, die Begriffe von Ideologie und falschem Bewusstsein unumwunden miteinander identifizierend: „Der Antisemitismus ist der Wahnsinn, welcher als notwendig falsches Bewusstsein aus den warenförmigen Verhältnissen, die heute global anzutreffen sind, erwächst. (...) In diesem Zustand entsteht Ideologie, weil das menschliche Denken die Ursachen der geschichtlichen Bewegung nicht durchschaut."1163 Doch kann mit diesem Begriff von Ideologie, der hier mit Wahnsinn und bestimmten Inhalten identifiziert wird, der Gegenstand Antisemitismus überhaupt begriffen werden? Adornos Überlegungen geben darüber einigen Aufschluss. Beide Termini, falsches Bewusstsein und Ideologie, bezeichnen ja auch bei ihm Identisches (s.o.).

1157 In einem späteren Aufsatz führt er an, dass Ideologie „falsches Bewußtsein“ sei. (Adorno: Beitrag zur Ideologienlehre, S. 465)

1158 Kuhne: Marx’ Ideologiebegriff im Kapital, S. 9: „Die hier zu erhärtende These ist, daß der im Kapital implizit enthaltene Ideologiebegriff sich mit Adornos Definition deckt - wenngleich nicht mit allem, was Adorno weiter dazu ausführt.“

1159 Historisch-Kritisches Wörterbuch des Marxismus, Band 6/I, S. 681.

1160 Vgl. Kuhne: Marx’ Ideologiebegriff im Kapital, S. 9 ff.

1161 So wird in der Wissenssoziologie nach Karl Mannheim unter Ideologie die ideelle Ausformulierung von Vorstellungen und Leitbildern (Wertvorstellungen) von Gruppen gesehen, mit denen sie ihr praktisches Handeln begründen. Dieser Ideologiebegriff hat sich in der heutigen Öffentlichkeit durchgesetzt, jede Partei, jede Gruppierung hat heute ibre Ideologie. Karl Mannheim formuliert jenen totalen Ideologiebegriff, womit er die Standpunktabhängigkeit jeder Aussage als ideologisch und instrumentell in Betracht ziehen möchte. Sein totaler Ideologiebegriff hinkt jedoch genau an der Stelle, wo er selbst standpunktabhängig sein soll. Mannheim sieht das und begründet deshalb eine freischwebende Intelligenz, die über der Standpunktabhängigkeit schwebe. Das würde entweder die Sozialwissenschaft zu einer elitären Wissenschaft von Wenigen machen und die Einsicht standpunktabhängiger Subjekte in Wahrheit und Objektivität verneinen, oder aber die ganze Konstruktion seines Ideologiebegriffs zerfällt. (Vgl. dazu Mannheim: Ideologie und Utopie.)

1162 Claussen: Vergangenheit mit Zukunft, S. 30.

1163 indymedia.de: Antisemitismus und Antiamerikanismus. 
Deswegen scheint es zunächst so, als sei sein Ideologiebegriff mit dem auf indymedia.org formulierten identisch. Die Ideologie oder das falsche Bewusstsein ist für Adorno aber immer auch gleich eine dialektische „Verschränkung des Wahren und Unwahren, die sich von der vollen Wahrheit ebenso scheidet wie von der bloßen Lüge" "1164. Das an dieser Stelle einmal ernstgenommen, können Ideologie und falsches Bewusstsein, anders als auf indymedia.org, nicht einfach mit einer inhaltlich vollkommen falschen politischen Propaganda verwechselt werden. Diese Verwechslung von Ideologie und Propaganda geht ihrerseits auf einen historisch lange währenden Substanzverlust des Ideologiebegriffs zurück, der ihn dadurch erst mit dem Propagandabegriff identisch werden lässt. ${ }^{1165}$ Adorno beschreibt diesen Substanzverlust des Ideologiebegriffs in den Geisteswissenschaften schon in einer seiner frühen Vorlesungen: „, [O]der man hat einen der wichtigsten Begriffe, den der Ideologie, um alle Schärfe gebracht, indem man ihn formal als Zuordnung bestimmter Bewußtseinsinhalte an bestimmte Gruppen bestimmte, ohne die Frage nach Wahrheit oder Unwahrheit der Inhalte selbst mehr aufkommen zu lassen." "1166

Die begriffliche Verwechslung von Ideologie und Propaganda lässt sich insofern mit den obigen Ausführungen Adornos schon ausschließen, weil eine bloße Lüge, d.h. Propaganda, dem Ideologiebegriff als der dialektischen, momentanen Verschränkung von wahr und falsch gegenübersteht. Weil mit Ideologie nicht wie mit der offensichtlichen Lüge zu Propagandazwecken nur ein bestimmter politischer Zweck des cui bono verfolgt wird, verweist der Ideologiebegriff sogleich auch auf ein Tieferliegendes, auf die in der Gesellschaftsstruktur selbst liegenden, kategoriellen Begründungen in sich objektiver, rationaler Aussagen über Gesellschaft. Ideologische Aussagen über gesellschaftliche Gegenstände sind insofern nicht ganz falsch, aber auch nicht richtig oder wahr. Dieser tiefgreifend gedachte Zusammenhang von wahr und falsch hinsichtlich des Ideologiebegriffs und Gesellschaft lässt sich dabei am besten mit den Überlegungen von Marx aufzeigen: Mittels seiner Distinktion von Nationalökonomie (bürgerlicher Ökonomie) und Vulgärökonomie versucht Marx im Kapital, eine blanke Propaganda von wissenschaftlich anspruchsvollen, rational aufgebauten ideologischen Theorieversuchen zu trennen. Nur Propagandisten würden demnach vulgärökonomische Aussagen vertreten, weshalb sie einzig eine „Apologetik“1167 von gesellschaftlichen Verhältnissen bloß zum eigenen Vorteil betreiben würden. Vulgärökonomen nähmen ihre Theorien insofern selbst nicht ernst und würden auch gar nicht erst versuchen, sich ernsthaft mit den Dingen zu beschäftigen: „Sie [die Vulgärökonomie, B.E.B.] glaubt im Gegensatz zu Spinoza, daß die ,Unwissenheit ein hinreichender Grund

\footnotetext{
1164 Kuhne: Marx' Ideologiebegriff im Kapital, S. 9.

1165 Vgl. Adorno: Die Aktualität der Philosophie, S. 341.

1166 Ebd.

1167 Marx: Das Kapital, Bd. 1, S. 21.
} 
ist. “" ${ }^{1168}$ Deshalb sei ihre Propaganda auch ausschließlich ein instrumentelles Mittel zum Zweck.

Dagegen habe die Nationalökonomie oder Politische Ökonomie einen noch akademischen Anspruch - selbst wenn ihre wissenschaftlichen Bestimmungen falsch sein sollten und ihre Fehler sie in ihren Urteilen so einschränkend packe und an phänomenologische Folgefehler fessele, dass sie nicht mehr über sich selbst hinausgelangen könne - und sie sich deswegen im Resultat der Vulgärökonomie angleiche. Die Nationalökonomie treffe aber zumindest durch ihren Versuch, am Gegenstand etwas rational zu beweisen, etwas, was gesellschaftlich wahr sei, oder: durch die falsche Gesellschaft würden Argumente der Nationalökonomie zumindest phänomenologisch wahr: „Obgleich sie das Gesetz nie formuliert hat, hängt die klassische Ökonomie instinktiv daran fest, weil es eine notwendige Konsequenz des Wertgesetzes überhaupt ist." "1169 Ihr wesentliches Problem, warum sie mit ihren Ergebnissen einzig den phänomenologischen Schein reproduziere, sei, dass sie die Reflexion ihrer Bedingungen nicht leiste und sie deshalb das große Ganze nicht aufzeige. Das mache sie als Ideologie, vor allem von der höheren Ebene der Totalität reflektiert, erst unwahr. ${ }^{1170}$

Das vorgestellte Problem von der immanenten Objektivität bei gleichzeitig transzendenter Falschheit einer Aussage kann durch die Interpretation des Fetischabschnitts verdeutlicht werden. Diese Interpretation verdeutlicht, was Marx unter falschem Bewusstsein und Ideologie sowie unter einer Gesellschaft, die Ideologie wahr macht, obwohl sie falsch ist, versteht. Der Fetischabschnitt bleibt nun noch in die rein begriffslogische Wertformanalyse des Kapitals integriert. Jene Wertformanalyse ist der bereits vorgestellten einfachen Warenproduktion unterstellt. Der Kapitalismus konnte deswegen in ihr nur abstrakt, nicht jedoch schon konkret Gegenstand sein (vgl. 4.1.1): „Um es systematischer zu fassen: Marx zeigt, dass die Oberfläche der Zirkulation gar nicht aus sich selbst begriffen werden kann, alle Kategorien bedürfen einer Weiterentwicklung aus der Perspektive des Klassengegensatzes, der in den ersten beiden Abschnitten noch gar nicht analysiert und daher noch gar nicht systematisch entwickelt werden kann." ${ }^{1171}$ Der Abschnitt über den Warenfetisch erscheint insofern noch „auf der Ebene der

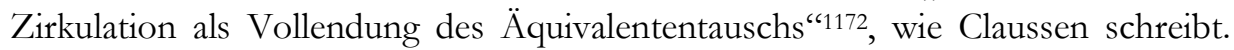
Marx abstrahiert in ihm also immer noch von der materiellen Voraussetzung kapitalistischer Produktionsweise: der Ware Arbeitskraft. Marx abstrahiert im Fetischabschnitt deswegen auch immer noch vom materiellen Substrat der totalen kapitalistischen Mehrwertgewinnung. Weil aber die kapitalistische Mehrwertproduktion nur entscheidend materiell durch die Ware Arbeitskraft hindurch vermittelt über-

\footnotetext{
1168 Ebd., S. 325.

1169 Ebd., S. 325.

1170 Vgl. ebd., S. 94, Fn. 31; Marx, Zur Kritik der politischen Ökonomie, S. 46.

1171 Hanloser/Reitter: Der bewegte Marx, S. 5.

1172 Claussen: Grenzen der Aufklärung, S. 146.
} 
haupt stattfinden kann, ist also auch im Fetischabschnitt noch nicht die kapitalistische Gesellschaftsform oder gesellschaftliche Herrschaft Gegenstand, sondern „bloß` „eine Gesellschaft von Warenproduzenten“"1173. Der Warenproduzent produziert hier im Fetischabschnitt also noch immer ideell subsistenzwirtschaftlich, um sein jeweiliges Bedürfnis zu realisieren - und nicht reell heteronom bereits zu fremden Zwecken. Die Analyse des Tauschs der Ware auf dem Markt analysiert hier deshalb noch eine ahistorische Herrschaftslosigkeit der allgemeinen Reziprozität (vgl. 4.1.1). Nur der reziproke, von allem materialen Gehalt zunächst noch abstrahierende Warentausch ist demnach im Fetischabschnitt unterstellt: „Eine Gesellschaft, wie sie in den ersten zwei Kapiteln des Kapital unterstellt ist, gibt es nicht und kann es nicht geben, weder historisch noch logisch." "1174

Wie in der Wertformanalyse überhaupt wird also auch im Fetischabschnitt die auf dem Markt zu tauschende Ware noch ausnahmslos von den einzelnen „Privatproduzenten“"1175 produziert (vgl. 4.1.1). Diese Privatproduzenten verkaufen dabei ihre eigens produzierten „Privatarbeiten"1176 und tauschen diese Waren dann allein mit autonomer, selbstbestimmter Intention auf dem Markt reziprok. Selbst noch im dritten Kapitel des Kapitals begleitet Marx nur den einen, von ihm sinnbildlich angeführten privaten Warenbesitzer, auf den fiktiven, nichthistorischen Markt: „unsren altbekannten Leinweber z.B.“"1177. Weil deshalb der heteronome Zwang der gesellschaftlichen Totalität im Fetischabschnitt, wie in der Wertformanalyse überhaupt, noch kein Gegenstand ist, handelt es sich hier immer noch um eine offensichtliche Abstraktion vom kapitalistisch Wesentlichen. Der Fetischabschnitt ist insofern als eine rein erkenntnistheoretische Reflexion von Subjekt und Objekt zu bestimmen, von Subjekt und Gesellschaft in dem Fall, weshalb sich Marx auch alles andere als ein „Verächter der Erkenntnistheorie“"1178 erweist. Erkenntnistheoretisch versucht Marx insofern also das (falsche) Bewusstsein der privatproduzierenden Warenbesitzer - deren Existenz selbst schon eine reflektierende Abstraktion von Geschichte und Herrschaft ist - zu den produzierten Dingen einer warenproduzierenden Gesellschaft zu bestimmen. ${ }^{1179}$

Mit dem falschen Bewusstsein beschreibt Marx die Wahrnehmung des Warentauschs durch die selbstbewussten Subjekte. Der Abschnitt über den Fetisch handelt insofern vom Bewusstsein des Subjekts in der bürgerlichen Gesellschaft, die immer eine warenproduzierende und -tauschende Gesellschaft ist. Die Stellung des Bewusstseins zu den produzierten Waren wird innerhalb des gesellschaftlichen Tauschverkehrs beschrieben. Untersucht wird also, pointierter ausgedrückt, die Stellung des Bewusstseins des tauschenden Subjekts zur umgebenden Tauschge-

\footnotetext{
1173 Marx: Das Kapital, Bd. 1, S. 93.

1174 Hanloser/Reitter: Der bewegte Marx, S. 12.

1175 Marx: Das Kapital, Bd. 1, S. 93.

1176 Ebd.

1177 Ebd., S. 119.

1178 Adorno: Negative Dialektik, S. 179.

1179 Vgl. Marx: Das Kapital, Bd. 1, S. 95 f.
} 
sellschaft, zur noch vom Wesentlichen abstrahierten Oberfläche der kapitalistischen Gesellschaft, in der die kapitalistische Reichtumsproduktion auch überhaupt nicht sichtbar ist. Weil die Prozesse der Mehrwertproduktion beim Warentausch also nicht sichtbar werden, kann Marx an der Stelle auch noch von allem materialen Gehalt abstrahieren, wenn er allein die Stellung des Bewusstseins des Subjekts zu Waren und deren Tausch untersucht. Der Fetischabschnitt stellt deswegen ein von allen materiellen Substraten entblößtes Selbstbewusstsein der Tauschgesellschaft dar. Von Material und Herrschaft wird auf dem ideellen Markt der Wertformanalyse deshalb noch abstrahiert, weil das Bewusstsein von den Dingen, die dem Subjekt als Ware gegenübertreten, innerhalb der Tauschgesellschaft ein Allgemeines und damit auch ein von besonderer materieller Herrschaft Unabhängiges ist. ${ }^{1180}$

Marx hatte also nicht vor, schon gleich zu Beginn des Kapitals die kapitalistische Gesellschaft grundlegend zu kritisieren. Er schrieb deshalb auch kein Buch über den Fetisch in all seinen verschiedenen Varianten, sondern über das Kapital - selbst wenn der Fetischbegriff auch nicht allein auf den Fetischabschnitt des Kapitals beschränkt bleibt. ${ }^{1181}$ Jedoch sind alle nach dem Fetischabschnitt auftauchenden Begriffsvariationen, wie Kapitalfetisch, Geldfetisch etc. nur Varianten, die immer auf seinen Ursprung verwiesen sind.

Für das selbstbewusste Subjekt ist das richtige Begreifen der Zusammenhänge in der Zirkulationssphäre eine unmittelbar objektive Bedingung seines sese conservare. Die warenproduzierende Gesellschaft ist deshalb notwendig eine, über die sich nach Marx „objektive Gedankenformen“"1182 ausprägen. Diese objektiven Gedankenformen sind deswegen notwendige Gedankenformen des sich reproduzierenden Subjekts von der es umgebenden warenproduzierenden Gesellschaft. Sie sind das falsche Bewusstsein, die Ideologie als individuelle Bewusstseinsformen des selbstbewussten Subjekts - ganz obne jeden bestimmten Inhalt. In diesen Bewusstseinsformen objektivieren sich, vermittels der subjektiven Tätigkeit an der Oberfläche der Gesellschaft, Kategorien über die Gesellschaft: „Für eine Gesellschaft von Warenproduzenten, deren allgemein gesellschaftliches Produktionsverhältnis darin besteht, sich zu ihren Produkten als Waren, also als Werten, zu verhalten und in dieser sachlichen Form ihre Privatarbeiten aufeinander zu beziehn als gleiche menschliche Arbeit, ist das Christentum mit seinem Kultus des abstrakten Menschen, namentlich in seiner bürgerlichen Entwicklung, dem Protestantismus, Deismus usw., die entsprechende Religionsform. " ${ }^{1183}$ Es ist also jenes Bewusstsein, das die Subjekte vom freien Warentausch in der Zirkulationssphäre haben: die

\footnotetext{
${ }^{1180}$ Gesellschaftliche Herrschaft, Gewalt und die Ideologie der gleichen Chancen sind im Bewusstsein des bürgerlichen Subjekts nicht gegenständlich. Das Selbstbewusstsein der bürgerlichen Gesellschaft wird im Bewusstsein der Staatssubjekte reproduziert, die Sphäre der Zirkulation überhaupt erwies sich als freiheitliche, ideologische Sphäre (vgl. insbesondere 3.2.2).

1181 Vgl. hierzu Grigat: Fetisch und Freiheit, S. 61 ff.

1182 MEW 23, S. 90.

1183 Marx: Das Kapital, Bd. 1, S. 93.
} 
Vorstellungen des, freien privaten Warenproduzenten' vom Tausch, der sein Eigentum in autonomer Eigenregie herstellt und dann tauscht - und der seine Selbsterhaltung scheinbar ganz autonom realisiert. Als reale, historische Personen gab es solch selbstbestimmte Subjekte allerdings so wenig wie eine solch freie, warentauschende Gesellschaft, in der sie existiert hätten. ${ }^{1184}$

Die Tätigkeit des Subjekts in der fiktiven warenproduzierenden Gesellschaft ist dabei eine selbstbewusste Tätigkeit. Das falsche Bewusstsein ist insofern ein adäquates, richtiges Bewusstsein des freien Subjekts von der es umgebenden Tauschgesellschaft. Das falsche Bewusstsein ist darum auch das adäquate Urteil des Subjekts über die äquivalententauschende Gesellschaft, innerhalb derer das Subjekt sich denkend und handelnd bewegen und reproduzieren muss. Deshalb hat der ideologische Fetisch seinen Grund in der gesellschaftlichen Warendistribution und der Reflexivität der warenproduzierenden Gesellschaft, als dessen in sich rationale Erscheinung er sich darum notwendig präsentiert: „Derartige Formen bilden eben die Kategorien der bürgerlichen Ökonomie. Es sind gesellschaftlich gültige, also objektive Gedankenformen für die Produktionsverhältnisse dieser historisch bestimmten gesellschaftlichen Produktionsweise, der Warenproduktion." "1185 Damit wird also offenbar, dass der Fetischabschnitt das formelle Bewusstsein des Subjekts in einer scheinbar kooperativen Tauschgesellschaft beschreibt, ohne dass hier jedoch die bürgerliche Gesellschaft als politische Ökonomie in ihrer konkreten Totalität schon Gegenstand ist. Die kapitalistische Produktionssphäre mit der gesellschaftlichen Reichtumsproduktion existiert im Fetischabschnitt deshalb noch gar nicht, weil sie im ideologischen Bewusstsein der integrierten Subjekte auch nicht existiert. Es ist insofern die Ideologie der Zirkulationssphäre, die vom Wesentlichen der kapitalistischen Produktionsweise allerdings immer noch abstrahiert. Ideologie ist deshalb nicht nur für Adorno, sondern auch für Marx ein von der Gesellschaft nicht zu trennendes adäquates Urteil über die Gesellschaft.

Mit der über die eigene Selbsterhaltung erzwungenen Integration in den Prozess der Zirkulation der warentauschenden Gesellschaft bekommt die ideologische Denkform des falschen Bewusstseins der privaten Warenproduzenten ihr unmittelbares fundamentum in re in der Gesellschaft bzw. im Tausch selbst. Das notwendig falsche Bewusstsein unterliegt als Ideologiebegriff deshalb keinem logischen Fehler in der Bezeichnung, weil dieses Bewusstsein notwendig zum Überleben des Subjekts innerhalb der integralen, kooperativen Gesellschaft ist. In der totalen Gesellschaft muss das Subjekt seine Reproduktion realisieren, dabei sind die Prozesse hinter dem funktionalisierten Subjekt auch immer gleichgültig. Das vermittelt den erkenntnistheoretischen Abschnitt über den Fetisch mit der gesell-

\footnotetext{
${ }^{1184}$ Die Gesellschaftsform des Fetischabschnitts gibt es, entgegen der These Hanlosers und Reitters, logisch durchaus. Denken existiert auch fernab eines tatsächlichen Materials - quod erat demonstrandum. (Vgl. Hanloser/Reitter: Der bewegte Marx, S. 12 u. 39.)

1185 Marx: Das Kapital, Bd. 1, S. 90.
} 
schaftlichen Realität, in der „der sogenannte wirkliche Lebensprozeß der einzelnen bestimmt ist durch den ungegenständlichen Verwertungsprozeß des Kapitals. “1186 Der Terminus des notwendig falschen Bewusstseins ist deshalb auch nichts anderes als das falsche Bewusstsein, das allerdings das richtige Bewusstsein von den dem Subjekt abstrakten gesellschaftlichen Verhältnissen ist. Das notwendig falsche Bewusstsein ist demnach das überlebensnotwendig richtige Bewusstsein des Subjekts von der allgemeinen Reproduktion. Die Komplikationen des Bewusstseins im Fetischabschnitts sind somit keine wirklichen Komplikationen subjektiver Erkenntnis, sondern die unkomplizierte Adäquanz von Bewusstsein und scheinbarer Gesellschaft, also von Subjekt und phänomenologischem Objekt; „und da sie gewohnt sind, sich darin [den gesellschaftlichen Verhältnissen, B.E.B.] zu bewegen, findet ihr Verstand nicht den geringsten Anstoß daran." "1187 Die Ideologie als notwendig falsches Bewusstsein ist deshalb also die Übereinstimmung von Bewusstsein und phänomenologischen gesellschaftlichen Prozessen, die damit so wahrgenommen werden wie sie tatsächlich, also scheinbar sind. Dieses Moment von der identischen Adäquanz in der Ideologie deckt Robert Menasse in der Pbänomenologie der Entgeisterung erhellend auf: „Notwendig, weil wirklicher Ausdruck wirklicher Verhältnisse, falsch, weil je beschränkter, einseitiger, unvollkommener Ausdruck der im Ganzen antagonistischen, zerrissenen Verhältnisse, weil Reflex und nicht Reflexion, bloßer Ausdruck und nicht Erkenntnis der Wirklichkeit.“"1188

Das adäquate Bewusstsein von den phänomenologischen Dingen, wie sie sind, ist das bereits angeführte Wahrheitsmoment der Ideologie (vgl. auch 2.1), Fetisch und notwendig falsches Bewusstsein sind die richtige Rezeption der verdinglichten Umwelt. Die Zirkulationssphäre scheint in der Ideologie, und sie erscheint dem selbstbewussten, instrumentellen Denken dabei ganz richtig. Das Subjekt denkt insofern die objektiven gesellschaftlichen Verhältnisse adäquat, weil es sie so denkt, wie sie dem Subjekt in der Zirkulation vermittelt erscheinen - und wie sie erscheinen, sind sie phänomenologisch wirklich. Deshalb schreibt Marx im Fetischabschnitt: „Den letzteren [den Produzenten, B.E.B.] erscheinen daher die gesellschaftlichen Beziehungen ihrer Privatarbeiten als das, was sie sind [sic!], d.h. nicht als unmittelbar gesellschaftliche Verhältnisse der Personen in ihren Arbeiten selbst, sondern vielmehr als sachliche Verhältnisse der Personen und gesellschaftliche Verhältnisse der Sachen. "1189 So liegen den sich aus dem ideologischen Fetischismus der Ware ergebenden Verdinglichungen von (inter-)subjektiven Beziehungen adäquate Ergebnisse einer instrumentellen Reflexion von Gesellschaft zugrunde. Gerade weil also das ideologische Bewnsstsein mit den gesellschaftlichen Verbältnissen der zirkulierenden Erscheinung übereinstimmt, ist es falsches Bewusstsein: ein richtiges Bewusstsein vom falschen gesellschaftlichen Ganzen, falsches Bewusstsein einer falschen gesellschaft-

\footnotetext{
1186 Kuhne: Marx’ Ideologiebegriff, S. 24.

1187 Marx: Das Kapital, Bd. 3, S. 787.

1188 Menasse: Die Phänomenologie der Entgeisterung, S. 18.

1189 Marx: Das Kapital, Bd. 1, S. 87.
} 
lichen Totalität: „Doch indem ihr Bewußtsein der gesellschaftlichen Realität adäquat ist, ist es notwendig falsch, weil Bewußtsein einer falschen Realität."1190

Wenn Adorno auf das Unwahre im Ideologiebegriff hinweist, bezieht sich dies deshalb ausschließlich auf das konkrete gesellschaftliche Ganze, das in der Ideologie selbst als Bezugspunkt wiederum abgeschnitten bleibt. Wenn also die instrumentelle Vernunft des Subjekts den gesellschaftlichen Gegenstand phänomenologisch schon ganz richtig begreift, so ist es das gesellschaftlich Objektive, die wesentliche Totalität der bürgerlichen Gesellschaft hinter diesen Erscheinungen, die falsch ist. Erst eine emphatische Ideologiekritik bleibt deshalb nicht auf das richtige Bewusstsein von den gesellschaftlichen Verhältnissen beschränkt, sondern transzendiert dieses instrumentelle Bewusstsein via objektive Vernunft. Erst diese Spontaneität des dialektischen Ichs (vgl. hierzu 2.6.4) eröffnet dem vergesellschafteten Subjekt also die entsprechende Möglichkeit, das Ganze oder die bürgerliche Totalität als „das Unwahre" 1191 , als Herrschaft und Zwang, konsistent zu bestimmen. ${ }^{1192}$ Erst eine Reflexion auf das gesellschaftlich Ganze und seine Zwecke, auf die gesellschaftliche Reichtumsproduktion aus Zwang und nicht aus Freiheit etc., leistet die Entschlüsselung entscheidender Bedingungen, die z.B. die klassische Nationalökonomie nicht leistet oder aus bestimmten ideologischen Gründen auch nicht leisten kann. Die Reflexion auf das Ganze lässt das vermittelt Unwahre als herrschaftliches Moment im Ideologiebegriff erst herausarbeiten, wohingegen das ideologische Bewusstsein das nur instrumentell reflektierte Material nicht universell reflektiert. Das erinnert auch nicht grundlos an die bereits kennengelernten Ausführungen Horkheimers zur instrumentellen Vernunft (vgl. 2.3.2). Wenn Marx herausstellt, dass die klassische Politische Ökonomie ihre eigenen Bedingungen nicht reflektiert (s.o.), entspricht das ziemlich genau den obigen Bestimmungen Horkheimers: Dadurch, dass die immanent rationalen, historischen Zwecke der bürgerlichen Gesellschaft nicht reflektiert werden, wird auch das große Ganze, die Totalität der bürgerlichen Gesellschaft als Irrationalität, weil herrschaftlicher Zwang, nicht reflektiert. Das falsche, instrumentelle Bewusstsein ist jedoch deshalb wahr, weil es gesellschaftliche Prozesse phänomenologisch richtig wahrnimmt und wiedergibt - aber genauso auch falsch, weil es eben die totale Gesellschaft hinsichtlich ihrer Zwecke, die mit keinem Subjekt übereinstimmen können (vgl. Kap. 3), nicht reflektiert.

Weil der Fetischabschnitt also nur die Reflexion des Subjekts auf die phänomenologische Objektivität, das gesellschaftliche Außen der faktischen Realität, ist, kann in ihm auch noch kein sozialer Gegenstand (wie beispielsweise der moderne

\footnotetext{
1190 Kuhne: Das Subjekt der Kritik der politischen Ökonomie, S. 79.

1191 Adorno: Minima Moralia, S. 55.

1192 Die ,richtige Gesellschaft‘ ist deshalb auch nicht als „Diktum“ (Grigat: Fetisch und Freiheit, S. 55.) positiv der eigenen Kritik voranzustellen, sondern nur mühsam negativ lässt sich bestimmen, was Gesellschaft ist: Herrschaft, Zwang, Gewalt etc. Was daraus folgt, mag klar sein, kann aber, anders auch als in Marx' Frühschriften, nicht positiv gezeichnet werden, ohne wiederum dem Idealismus und Subjektivismus zu verfallen.
} 
Antisemitismus) Thema sein: „Der Antisemitismus gehört auch in der bürgerlichen Gesellschaft nicht notwendig als Inhalt zum falschen Bewußtsein.“1193 Die Erkenntnistheorie im Fetischabschnitt reflektiert ja nun ausschließlich formell auf das eigene Verhältnis zu Gesellschaft: Das Bewusstsein hat hier deswegen überhaupt noch keinen konkret objektiven Gegenstand und ist auch nicht auf die gesellschaftliche Totalität gerichtet. Eine Erkenntnistheorie ist, wenn man so möchte, schon traditionell von der Erkenntnis der Dinge streng zu unterscheiden. Die Erkenntnistheorie ist nur der Inbegriff der Reflexion auf die Möglichkeit von Erkenntnis. Erkenntnis ist hier die Erkenntnis des Subjekts schlechthin. Zwar wird die Objektivität logisch schon vorausgesetzt, inhaltlich ist sie jedoch kein Gegenstand. Genau das wird im Fetischabschnitt deutlich, weil hier die konkrete Objektivität der bürgerlichen Gesellschaft noch kein Gegenstand ist. Die Marxsche Erkenntnistheorie im Fetischabschnitt des Kapitals kann deshalb auch schon aus logischen Gründen überhaupt noch nicht über soziale Phänomene wie den Antisemitismus etc. urteilen.

\subsubsection{Fetisch ohne Freiheit, Phänomene ohne Wesen}

Trotz der reflektierenden Abstraktion vom konkreten Herrschaftsverhältnis der warenproduzierenden Gesellschaft und der Inhaltslosigkeit des Fetischs wird der in der Sphäre der Zirkulation und des reziproken Warentauschs verbleibende erkenntnistheoretische Abschnitt über den Fetischcharakter der Ware für das Ganze der Marxschen Gesellschafts- bzw. Kapitalkritik genommen. Er wird sogar noch als besonders wegweisend für eine konsistente materialistische Gesellschaftskritik angepriesen. ${ }^{1194}$ Karl Korsch ${ }^{1195}$ schreibt, dass der Fetischabschnitt des Kapitals „,nicht nur den Kern der Marxschen Kritik der Politischen Ökonomie, sondern damit zugleich den Kern der ganzen im Kapital enthaltenen Theorie und die ausdrücklichste und genaueste Formulierung des theoretischen und geschichtlichen Standpunkts der ganzen materialistischen Gesellschaftslehre" ${ }^{1196}$ enthalte. Auch Georg Lukács geht davon aus, dass „das Kapitel über den Fetischcharakter der Ware den ganzen historischen Materialismus, die ganze Selbsterkenntnis des Proletariats als Erkenntnis der kapitalistischen Gesellschaft (und die der früheren Stufen zu ihr) in sich verbirgt." ${ }^{1197}$ Der Fetischabschnitt gilt ihnen damit als Grundlage der emanzipativen Gesellschaftskritik schlechthin.

\footnotetext{
${ }^{1193}$ Claussen: Grenzen der Aufklärung, S. 78.

${ }^{1194}$ So auch in vielen modernen Auseinandersetzungen mit Marx und der Frage nach der ,Methode in der sogenannten Rekonstruktionsdebatte (vgl. z.B. Backhaus: Dialektik der Wertform; Reichelt: Zur logischen Struktur des Kapitalbegriffs bei Karl Marx: Heinrich: Die Wissenschaft vom Wert.). Dass Methode und Dialektik sich nicht vertragen, wurde oben bereits deutlich.

1195 Adorno hält Korsch zurecht für einen Positivisten: „Nun Brecht hatte ja auf Grund seiner Freundschaft mit Karl Korsch eine gewisse Neigung zu dem Positivismus.“ (Adorno: Vorlesung zur Einleitung in die Soziologie, S. 37.)

1196 Korsch: Karl Marx, S. 101.

${ }^{1197}$ Lukács: Geschichte und Klassenbewußtsein, S. 287 f.
} 
Für die in den 90er Jahren des 20. Jahrhunderts aufkommende wertkritische Antisemitismustheorie gilt an der Stelle nichts anderes. Sie versucht den Fetischabschnitt mittels der Thesen der wertkritischen Neuen-Marx-Lektüre ${ }^{1198}$ für die Antisemitismustheorie fruchtbar zu machen. Weil die Neue-Marx-Lektüre den Marxschen Ideologiebegriff aus dem Fetischkapitel des Kapitals und den Vorarbeiten zugrunde legt, um damit den Kapitalismus und die Gesellschaft in Gänze zu erklären ${ }^{1199}$, werden von der wertkritischen Antisemitismustheorie im Anschluss daran dann mit dem Fetischabschnitt auch soziale Phänomene wie der moderne Antisemitismus erklärend kritisiert. Viele moderne ideologiekritische Arbeiten über den Antisemitismus knüpfen deshalb nicht mehr, anders als Salzborn, Claussen, Rensmann etc., an den entsprechend grundlegenden Text der Kritischen Theorie über den Antisemitismus an: die ,Elemente des Antisemitismus'von Horkheimer und Adorno aus der Dialektik der Aufklärung.

Die neue, wertkritische Antisemitismustheorie möchte also aus der Kritik des Bewusstseins von gesellschaftlichen Zusammenhängen, wie sie in dem erkenntnistheoretischen Fetischabschnitt Gegenstand sind, einen konsistenten Zusammenhang der Kritik der bürgerlichen Gesellschaft und des modernen Antisemitismus formulieren. Somit wird von ihr eine Kritik oder Theorie über den Antisemitismus verfasst, die ihn als ein soziales Phänomen in den Zusammenhang eines falschen Bewusstseins des Subjekts von den gesellschaftlichen Verhältnissen stellt. Dadurch nimmt sie jedoch gesellschaftlich Wesentliches völlig aus der Diskussion. Von Postone, dem Begründer der wertkritischen Antisemitismuskritik, werden zwar noch gesellschaftliche Zusammenhänge des Antisemitismus benannt und die Kritik des Bewusstseins bringt auch das Selbstverständnis mit, eine substantielle Kritik der bürgerlichen Gesellschaft zu sein. Es stellt sich dennoch die entscheidende Frage, ob Postones Begriff von Gesellschaft die oben entwickelten materiellen Zwänge und damit die Totalität der bürgerlichen Gesellschaft überhaupt reflektieren kann.

In relativer Übereinstimmung mit Postone und der Neuen-Marx-Lektüre ${ }^{1200}$ verfasst Stephan Grigat eine Antisemitismustheorie, die, wie er selbst schreibt, „als

\footnotetext{
1198 Angefangen mit der 1970 vorgelegten Dissertation von Helmut Reichelt: Zur logischen Struktur des Kapitalbegriffs bei Karl Marx. Jan Hoff legt sich auf die 60er Jahre als Beginn der Neuen-MarxLektüre fest: „Hans-Georg Backhaus und sein Forscherkollege Helmut Reichelt rückten seit den 60er Jahren eine spezifisch ,qualitative' Problematik im Marxschen Werk in den Mittelpunkt". (Hoff: Marx global, S. 85.) Der Begriff Neue-Marx-Lektüre entstammt allerdings einem sehr viel später veröffentlichten Werk. (Vgl. Backhaus: Dialektik der Wertform, S. 9.)

${ }^{1199}$ Vgl. z.B. Backhaus: Dialektik der Wertform; Reichelt: Zur logischen Struktur des Kapitalbegriffs bei Karl Marx; Heinrich: Die Wissenschaft vom Wert.

${ }^{1200}$ Vgl. Grigat: Fetisch und Freiheit, S. 13: „Aus diesem Zusammenhang [der Beschäftigung mit der Marxschen Werttheorie, B.E.B.] und seinem Umfeld sind eine Reihe von Arbeiten entstanden oder neu aufgelegt worden, die sich mit Fachproblemen der Kritik der politischen Ökonomie auseinandersetzen, und auf die sich Darstellungen vor allem im zweiten Kapitel der vorliegenden Studie stützen können." Es folgt dann der Hinweis auf Heinrich, Backhaus und Reichelt.
} 
eine Art Einführung in antideutsche Wertkritik nützlich sein kann"1201. Grigat verknüpft dabei Überlegungen zum Fetischcharakter der Ware mit einer kritischen Theorie zum modernen Antisemitismus. In Fetisch und Freiheit zeigt er sich deshalb nicht nur davon überzeugt, dass sich ,aus der Theorie des Warenfetischismus (...) eine radikale Gesellschaftskritik ableiten und begründen“"1202 lasse. Auch könne mittels dieser Form der Gesellschaftskritik der moderne Antisemitismus grundlegend kritisiert werden. Grigat möchte darum „die Bedeutung der Marxschen Fetischkritik für eine kritische Theorie des Antisemitismus" ${ }^{\text {"1203 }}$ herausarbeiten.

Marx selbst behauptet dagegen an keiner Stelle, dass der Fetischabschnitt jener entscheidende Kern der Gesellschaftskritik sei, der er für die Wertkritiker ist; und mit dem sich ferner noch jedes Phänomen der bürgerlichen Gesellschaft erklären ließe. Nach der Einordnung und Interpretation in 5.1.1 lässt sich der Fetischabschnitt auch schwerlich als ein solcher Kern einer materiellen, politisch ökonomischen Gesellschaftskritik ausmachen. In ihm wird beispielsweise solch Substantielles der kapitalistischen Produktionsweise wie die Ware Arbeitskraft als objektive Ware noch gar nicht entwickelt. Auch zeigt sich im Fetischabschnitt die kapitalistische Produktionsweise als noch nicht entfaltet, weil Marx in der gesamten Wertformanalyse aus Gründen der Entwicklung der kritischen Begriffe noch von einer vom wesentlichen abstrahierenden, nicht-existentiellen Gesellschaftsform ausgeht (vgl. 4.1.1). Der Wert der Ware zeigt sich nun auch noch als die abstrakteste Erscheinungsform des kapitalistischen Reichtums ${ }^{1204}$ und die Wertformanalyse verwies durch ihr negatives Resultat auf weiteres, notwendig materielles - im weiteren Verlauf des Kapitals erst noch Einzuholendes. Auch ein konsistenter Begriff des Kapitals, von Totalität etc., ließe sich auf der Ebene der phänomenologischen Darstellung der Zirkulation der Waren, wie sie die Wertformanalyse ist, noch gar nicht begründen. Allein deswegen scheint es nahezu unmöglich, mithilfe der Begrifflichkeit aus der Wertformanalyse einen bestimmten Akt gesellschaftlicher Herrschaft zu kritisieren. Das aber hält die wertkritische Antisemitismustheorie, bereits in statu nascendi, nicht davon ab, dies doch zu tun.

Postone, der Vorreiter der wertkritischen Antisemitismustheorie, versucht deshalb, über den Marxschen Begriff des Fetischs das gesellschaftliche Phänomen des modernen Antisemitismus kritisch zu begründen. Wie für Grigat funktioniert deswegen auch für ihn die Begründung des Phänomens Antisemitismus ,natürlich nicht so ganz ohne Marx." "1205 Postone versucht dabei jedoch, den modernen Antisemitismus nicht mit den wesentlichen Bestimmungen aus der Kritike der politischen

\footnotetext{
1201 Ebd., aus dem Vorwort.

1202 Ebd., S. 56.

1203 Ebd., S. 23.

1204 ... - wie die Ware im Kapital sogleich als nur Abgeleitetes des gesellschaftlichen Reichtums eingeführt wird. Marx: Das Kapital, Bd. 1, S. 49: „Der Reichtum der Gesellschaften, in welchem kapitalistische Produktionsweise herrscht, erscheint als ,ungeheure Warensammlung', die einzelne Ware als seine Elementarform."

1205 Vgl. Grigat: Logik und Struktur des Antisemitismus.
} 
Ökonomie zu erklären, sondern eben nur mit dem speziellen, bereits kennengelernten, noch abstrakt eingeschränkten Begriffsinstrumentarium des Fetischabschnitts. Denn „[d]er moderne Antisemitismus“ sei „eine besondere Form des Fetischs.“" 1206

Postone sprengt also im Rahmen seiner Antisemitismuskritik eines der einleitenden Momente der Erklärung des Kapitalismus, den Fetischabschnitt, als ein verabsolutiertes Element aus dem Marxschen Systemzusammenhang des Kapitals heraus. Marx' Kapital- und Gesellschaftskritik bleibt ihm zwar bei der Erklärung von gesellschaftlichen Phänomenen noch ein wesentlicher und wichtiger Bestandteil. Den offensichtlichen Zusammenhang von den kapitalistischen Verhältnissen als Wesen der gesellschaftlichen Erscheinung möchte Postone nach eigener Aussage gar nicht aufgeben, was man mit den obigen Ausführungen zum Fetischabschnitt allerdings vermuten könnte. Postone interpretiert das Wesen des Kapitalismus allerdings ganz anders als das gesellschaftliche Wesen der sozialen Erscheinung in dieser Untersuchung bereits bestimmt wurde (vgl. vor allem 2.5.2). Für ihn liegt das Wesen der Phänomene nicht in den substanziellen Gesetzen der in ihrer Totalität gedachten politischen Ökonomie, die im sozialen Phänomen manifest werden, sondern einzig im falschen Bewusstsein der Subjekte, im Fetisch: und damit insbesondere in der Begrifflichkeit der Wertformanalyse: „Diese Überlegungen führen zu Marx’ Begriff des Fetischs, einem Begriff, der die Grundlage einer historischen Erkenntnistheorie bildet, die sich in der Unterscheidung zwischen dem Wesen der kapitalistischen Verhältnisse und ihrer Erscheinungsform gründet.“" ${ }^{207}$ Postone gibt in seiner Gesellschaftstheorie den Wesensbegriff also zumindest sprachlich nicht auf. Das soziale Phänomen der bürgerlichen Gesellschaft soll bei ihm insofern weiterhin im wesentlichen Kontext der kapitalistischen Gesellschaftsform reflektiert werden. Mithilfe des Fetischbegriffs aus dem Kapital entwirft er deshalb eine wertkritische Antisemitismustheorie, die nach eigener Aussage vermittelt in den entsprechenden Rahmen einer wertkritischen, kapitalismuskritischen Gesellschaftskritik gehöre - die die kapitalistische Produktionsweise also anhand ihres für Postone wesentlichen Begriffs, dem Wert, kritisiere. ${ }^{1208}$

Der Fetischbegriff bekommt damit für Postone vermittelt eine derart zentrale Wichtigkeit fürs wesentliche Begreifen der kapitalistischen Produktionsweise, dass er für ihn auch zum noch einzig materialistischen Moment der Erklärung des modernen Antisemitismus wird. Der Fetischbegriff alleine bilde ,die Grundlage einer historischen Erkenntnistheorie“1209, die für Postone die einzig noch mögliche

\footnotetext{
1206 Postone: Der Holocaust und der Verlauf des 20. Jahrhunderts, S. 144.

1207 Ebd., S. 182.

1208 Vgl. Postone: Antisemitismus und Nationalsozialismus, S. 182 ff.; Grigat: Fetisch und Freiheit, S. 10: „Dagegen soll in der vorliegenden Studie der Versuch unternommen werden, die in der Marxschen Kritik der politischen Ökonomie gründende Kritik des Fetischismus nicht nur als zentralen Bestandteil des Marxschen Werkes, sondern als unabdingbar für jegliche Bemühung um Freiheit darzustellen."

1209 Postone: Antisemitismus und Nationalsozialismus, S. 182.
} 
emanzipative gesellschaftstheoretische Erklärung des modernen Antisemitismus sei. Postones These, dass erst das auf den Antisemitismus übertragene Konzept des Fetischbegriffs das einzige Mittel einer konsequenten modernen Antisemitismuskritik sein könne, wird dann auch für alle späteren wertkritischen Arbeiten zum modernen Antisemitismus grundlegend.1210 Postones Konzeption der Antisemitismuskritik mutet dabei zunächst einmal wie ein Paradigmenwechsel in der mit Marx arbeitenden kritischen Antisemitismustheorie an. Sein offensiver Versuch, über den in phänomenologischen Erörterungen des Kapitals steckenbleibenden Fetischbegriff (vgl. 5.1.1) den modernen Antisemitismus wesentlich zu kritisieren, unterzieht dabei alle bereits vorangegangenen Formen der kritischen Antisemitismustheorie einer entsprechenden Kritik. Mit dem Fetischbegriff soll dabei gleichzeitig, ex negativo, ein neuer, moderner Weg der materialistischen Kritik des Antisemitismus (und der Gesellschaft) eingeleitet werden. Dieser einzig kritische Weg soll die Tür für eine reinigende Selbstreflexion der bisherigen Antisemitismustheorie aufstoßen. Die älteren Erklärungsversuche des modernen Antisemitismus werden von Postone vor allem deswegen angezählt, weil sie sich allein auf „Kapitalismus, Rassismus, Bürokratie, sexuelle Unterdrückung oder die autoritäre Persönlichkeit stützen“1211 würden. Damit bliebe ihre Stoßrichtung jedoch viel zu allgemein. Durch diese theoretische Beschränkung der traditionellen kritischen Theorien könne der wirkliche Kern des modernen Antisemitismus nicht wesentlich begriffen werden. Deshalb konnten die vorangegangenen Theorien auch keine korrekte Aussage über ,ihre' sozialen Phänomene je tätigen. ${ }^{1212}$ Vor allem aber soll mit der strengen Fokussierung auf den Fetischbegriff eine Kritik an dem in Grigats Augen ,sozialdemokratischen und bolschewistischen Traditionsmarxismus “"1213 geliefert werden. ${ }^{1214}$ Anders als Grigat sieht Postone diese Kritik zu-

\footnotetext{
1210 Siehe zum Beispiel auch bei Heinrich: Kritik der politischen Ökonomie, S. 191: „Es ist der Kapitalfetisch in seiner entwickelsten Gestalt als zinstragenes Kapital, der hier [im modernen Antisemitismus, B.E.B] personalisiert wird.“ Auch Detlev Claussen schreibt: „Die entindividualisierende Versachlichung liegt in der Logik universalen Tauschverkehrs begründet, die das Spezifische und damit auch das Historische und Individuelle unter Gesellschaftliches subsumiert." (Claussen: Grenzen der Aufklärung, S. 65.) Der Tausch jedoch ist begründet in der Produktion, dem Profit und dem Eigentumsverhältnis (s.o.).

1211 Postone: Antisemitismus und Nationalsozialismus, S. 178.

1212 Das wird daneben auch noch als generelles Problem der Gesellschaftstheorie ausgemacht. Besonders aber in Bezug auf den Antisemitismus sei gravierend, dass Theorien ohne entscheidenden Bezug auf den Fetischabschnitt inhaltlich leer bleiben müssten: „Postone beginnt seine Analyse des modernen Antisemitismus mit der Feststellung, dass bestimmte Aspekte der Ausrottung des europäischen Judentums so lange unerklärlich bleiben müssten, wie der Antisemitismus als bloßes Beispiel für Vorurteile, Fremdenhass und Rassismus im Allgemeinen behandelt werde, also so lange, wie der Glaube fortbestehe, dass Antisemitismus lediglich ein Beispiel für Sündenbockstrategien sei, deren Opfer auch Mitglieder irgendeiner anderen Gruppe hätten gewesen sein können.“ (Salzborn: Antisemitismus als negative Leitidee der Moderne, S. 158 f.)

1213 Grigat: Fetisch und Freiheit, S. 13.

${ }^{1214}$ Hanloser/Reitter: Der bewegte Marx, S. 21: „Die Entstehung des Zirkulationsmarxismus lässt sich nur vor dem Hintergrund eines leninistisch überformten Marxismus verstehen, der unverholen
} 
nächst als noch nicht ganz so dringend an, selbst wenn er Grigat die kritische Grundlage für seine Thesen liefert. Postone schreibt bezüglich des ,Traditionsmarxismus' entsprechend konkret: „Die Bezeichnung ,traditioneller Marxismus“ bezieht sich dabei nicht auf irgendeine besondere geschichtliche Tendenz innerhalb des Marxismus, sondern allgemein auf sämtliche Theorien, die den Kapitalismus vom Standpunkt der Arbeit aus analysieren und davon ausgehen, daß diese Gesellschaft durch Klassenbeziehungen, das Privateigentum an Produktionsmitteln und eine durch den Markt regulierte Wirtschaft ihrem Wesen nach bestimmt sei. Gemeint sind also alle Theorien, die die Herrschaftsverhältnisse vor allem als Klassenherrschaft und Ausbeutung verstehen."1215 Trotz einer sich also weiterhin an Marx orientierenden Gesellschaftstheorie wird sich von beiden Autoren besonders offensiv von der leninistischen Marxinterpretation in der Geschichte abgegrenzt. Lenins Theorie habe eine für Postone wie Grigat gleichermaßen zu kritisierende Partikularität des modernen Antisemitismus konzipiert. Diese Partikularität sei das Resultat einer politischen Verengung der Marxschen Theorie durch Lenin. Diese politische Verengung resultiere darin, dass auch und vor allem Lenins Theorie über den Fetisch charakter- und konturlos bleibe: „Lenin verwendet den Fetischbegriff relativ beliebig und kaum im Sinne der Marxschen Fetischkritik."1216 Alle marxistisch-leninistischen Autoren könnten deshalb in der Folge den modernen Antisemitismus, durch ihre theoretische Beliebigkeit hinsichtlich des Fetischbegriffs, nur als das rationale Resultat einer Bewusstseinsmanipulation der persönlich Beherrschten durch die persönlich Herrschenden sehen, was seine universellen gesellschaftlichen Gründe notwendig vernachlässigen würde. In der tatsächlich recht engen Konzeption gesellschaftlicher Realität erfüllt der moderne Antisemitismus für die Marxisten-Leninisten deshalb immer nur den einen und gleichen partikularen Zweck der Ablenkung von der wahren persönlichen Herrschaft in der bürgerlichen Gesellschaft: Die Herrscher schöben den Juden über antisemitische Stereotypen die gesellschaftliche Herrschaft demnach bloß geschickt unter, um damit von sich selbst als den eigentlichen Potentaten in der Gesellschaft abzulenken. ${ }^{1217}$ In Über die Pogrombetze gegen die Juden schreibt Lenin dementsprechend bezüglich des modernen Antisemitismus: „Auch in anderen Ländern [als dem Zarenreich, B.E.B.] hat man nicht selten Gelegenheit, zu sehen, daß die Kapitalisten Feindschaft gegen die Juden schüren, um den Blick des Arbeiters zu trüben, um seine Aufmerksamkeit von dem wirklichen Feind der Werktätigen - vom Kapital - abzulenken." ${ }^{218}$ Solch eine Leninsche Partikularisierung und Funktionalisierung des modernen Antisemitismus kann nun nur ein offen-

\footnotetext{
zu einer Legitimationswissenschaft der die Produktivkräfte entfaltenden und zuweilen brutal sich entwickelnden realen sozialistischen Länder wurde.“

1215 Postone: Zeit, Arbeit und gesellschaftliche Herrschaft, S. 27.

1216 Grigat: Fetisch und Freiheit, S. 89.

1217 Vgl. Postone: Antisemitismus und Nationalsozialismus, S. 171.

1218 Lenin: Über die Pogromhetze gegen die Juden.
} 
sichtliches Resultat der systematischen Konzeption - die dann auch vom Marxismus-Leninismus in ihren Klassenkampfkonzepten übernommen wurde - einer individuellen Vorteilsnahme mittels des Antisemitismus durch die ohnehin bei Lenin personalisierte Kapitalistenklasse sein. Weil der Marxismus-Leninismus also generell die so anfechtbare These vertrete, dass sich die herrschende Klasse mit der bürgerlichen Gesellschaft ihre persönliche Herrschaft gesichert hätte, funktionalisiere diese Klasse die sozialen Phänomene wie den Antisemitismus einfach auch zu ihrem propagandistischen Instrument zum Zwecke ihrer persönlichen Herrschaft um. Insofern wird die Aufgabe des objektiven Klassenbegriffs durch Personalisierung also ebenfalls von den Theoretikern des Marxismus-Leninismus übernommen. Nur so, im Zuge einer Klassenkampfkonzeption, kann man dann auch konsequent von der Funktionalisierung des Antisemitismus sprechen. ${ }^{1219}$ Lenin gibt den objektiven Klassenbegriff (vgl. dazu auch 2.6.3) ja tatsächlich subjektivistisch/nominalistisch mittels seiner Personalisierungen auf, indem er die Bourgeoisie bekanntlich personalisierte (vgl. dazu 3.4.1). Der moderne Antisemitismus wird von Lenin deswegen auch, als Resultat seines Subjektivismus der Klassen, systematisch zum bloß funktionellen Klassenkampfmoment ohne materielles Substrat in der kapitalistischen Gesellschaft selbst umfunktioniert - womit er zum Propagandabegriff der herrschenden Klasse und nicht zur Ideologie der bürgerlichen Gesellschaft wird.

Derart einfach, als nur zentralisiertes, instrumentell-rationales Moment von persönlichen Herrschaftsinteressen der Bourgeoisie gegen das Proletariat könne der moderne Antisemitismus, und vor allem die Vernichtung der Juden, so Postone, nicht erklärt werden: „Diese Form des Funktionalismus kann (...) die NichtFunktionalität der Vernichtung der Juden nicht adäquat erklären. “1220 Die Ablenkungstaktikthese Lenins und ,der Marxisten-Leninisten' könne die notwendig universellen Gründe des modernen Antisemitismus, wie Grigat und Postone anmerken, wirklich nicht substantiell erklären. Als ausschließlich klassenkampfspezifisches Phänomen ließe sich der moderne Antisemitismus, wie Grigat und Postone richtig anmerken, tatsächlich nicht mehr in seinem gesellschaftlichen Wesen begreifen. Er wäre der Gesellschaft damit, subjektivistisch interpretiert, tatsächlich äußerlich und nicht mehr substantiell mit ihr, oder vielmehr durch sie und ihre Totalität hindurch, vermittelt. Zwar lässt sich auch von einer dirigierten Manipulation der Proletarier durch die Bourgeoisie mithilfe des Antisemitismus sprechen, beispielsweise zum Vorteil einer Absicherung von staatlicher Herrschaft oder auch zur Verfolgung staatlicher Zwecke, die selbstverständlich allein der Bourgeoisie als Klasse helfen. So argumentieren zunächst auch Adorno und Horkheimer in der Dialektik der Aufklärung, womit sie abermals an Lenins Theorie anknüpfen (vgl. zu

\footnotetext{
1219 „Klassenkampf ist einer der Schlüsselbegriffe des Marxismus, allerdings, wie der Begriff ,Klasse“, keiner, den Marx eingeführt hat.“" (Historisch-Kritisches Wörterbuch des Marxismus, Band 7/I, S. 835.)

1220 Postone: Antisemitismus und Nationalsozialismus, S. 183, Fn. 13.
} 
den offensichtlichen Anknüpfungspunkten auch 3.5): „Seine Zweckmäßigkeit [des Antisemitismus, B.E.B.] für die Herrschaft liegt zutage. Er wird als Ablenkung, billiges Korruptionsmittel, terroristisches Exempel verwandt."“221 Davon aber unabhängig, dass Adorno und Horkheimer enorme Vorteile eines Antisemitismus bei der Beherrschung der Massen sehen, liegen die wesentlichen Gründe seiner Existenz aber auch für die Autoren der Dialektik der Aufklärung woanders (vgl. 1).1222 Die Erklärung des Antisemitismus wäre ansonsten wiederum auch nur subjektivistisch - und damit tautologisch. Es muss also, und darin sind sich wertkritische und kritische Theoretiker einig, wesentliche Gründe für die Existenz des Antisemitismus überhaupt geben, die, wie Postone und Grigat richtig schreiben, klassenübergreifend und damit allgemein und notwendig sein müssen, weil das Phänomen Antisemitismus sich nicht nur auf eine Klasse spezifisch festschreiben lässt, sondern der moderne Antisemitismus ein solch universelles Phänomen der totalen bürgerlichen Gesellschaft ist. Dieses universelle Moment des Antisemitismus muss allein um der Wahrheit einer substantiellen Theorie über den Antisemitismus willen herausgearbeitet werden.

Grigat und Postone haben, als in der Tradition der Wertkritiker stehende Theoretiker, nun ihre ganz konkreten Vorstellungen davon, warum sich der moderne Antisemitismus so universal zeige. Unisono sind beide der Überzeugung, dass gerade und ausschließlich das erkenntnistheoretisch behaftete Fetischkapitel die universelle Antwort auf die Frage des Warum? des modernen Antisemitismus fernab jeder Klassenspezifikationen liefere. Allein mit der Erkenntnistheorie des Kapitals und den darin entwickelten zentralen Begriffen des Fetischs und des falschen Bewusstseins könne demnach die Universalität des Antisemitismus in der bürgerlichen Gesellschaft dezidiert herausgearbeitet werden. Allein die erkenntnistheoretischen Reflexionen des Kapitals sollen also Aufschluss über die gesellschaftliche Universalität des sozialen Phänomens geben. Dass der Antisemitismus in der Gesellschaft der Form nach zwar ganz richtig klassenunabhängig und damit universal ist, kann an dieser Stelle aber wiederum auch nicht, gegen Grigat und Postone, heißen, dass sich Inhalt wie Zweck seiner Äußerung nicht trotzdem klassenspezifisch in einer antagonistischen Klassengesellschaft verschieden äußern können; wie bereits das obige Adorno-Zitat offenbarte.

Mit dem von Postone und Grigat herangezogenen, nur erkenntnistheoretischen Fetischbegriff stößt man deshalb bei der Erklärung von gesellschaftlichen Phänomenen bzw. Gesellschaft an materielle Grenzen. Man stößt mit ihm an materielle Grenzen der Erklärung von Dingen, weil diese mit der sauberen, logisch-systematischen Begrifflichkeit des Fetischabschnitts einfach nicht erfasst

\footnotetext{
1221 Adorno/Horkheimer: Dialektik der Aufklärung, S. 194.

1222 Bereits in der Einleitung wurde die entsprechende Stelle aus der Dialektik der Aufklärung zitiert, wonach der moderne Antisemitismus für Adorno und Horkheimer seinen ,spezifisch ökonomischen Grund' habe und nicht einen niederen, der allein im Subjekt und seiner spezifischen Vorteilsnahme innerhalb der bürgerlichen Totalität liege.
} 
werden können, weil sie über die logische Begrifflichkeit der Wertformanalyse hinausgehen und die auf historisches Material verweisen. Grigat stellt mit seiner wertkritischen Kritik am Traditionsmarxismus deshalb auch nicht nur die historisch und materialistisch zu erklärenden Bedingungen der kapitalistische Gesellschaft in Frage (vgl. 3 ff.), er stellt dabei auch offen die objektive, antagonistische Klassengesellschaft in Frage. Damit umgeht er die Reflexion auf die Grenzen der Marxschen Erkenntnistheorie und ist sich auch über den bereits in 5.1.1 angeführten Mangel bei einer materialistischen Erklärung von Gesellschaft mit erkenntnistheoretischen Voraussetzungen allein nicht bewusst: „Während für die Hauptströmungen des Marxismus der Klassenbegriff stets als zentrale Kategorie nicht nur der eigenen Theoriebildung, sondern auch der Marxschen Kritik der politischen Ökonomie galt, betont die fundamentale Wertkritik die Zentralität der zu Beginn des Kapitals entwickelten Kategorien wie Ware und Wert und kommt zu dem Schluß, daß die Klasse bei Marx immer schon eine ,sekundäre, abgeleitete Kategorie ist." "1223 Indem sich Grigat dadurch von der substantiellen antagonistischen Klassengesellschaft selbst theoretisch befreit, indem er den Begriff der Klasse eliminiert, möchte er eigentlich nur den philosophisch und politisch zu eng argumentierenden ,Traditionsmarxismus ${ }^{6}$ kritisieren und überwinden, weil dieser mit dem überholten Klassenkampfkonzept das Phänomen Antisemitismus nicht mehr hinreichend erklären könne. Die Durchführung der Kritik in Fetisch und Freibeit lässt seine eigene Gesellschaftstheorie jedoch über jedes materielle Substrat erhaben werden. Nach dem substantiellen Wahrheitsmoment des Klassenbegriffs in der bürgerlichen Gesellschaft selbst, als außerhalb des Bewusstseins liegendes materielles Moment der antagonistischen kapitalistischen Gesellschaftsform, und ob dieser deshalb nicht wesentlicher Bestandteil bei einer Kritik der bürgerlichen Gesellschaft bleibt, fragt Grigat dabei nun gar nicht mehr. Deshalb fällt auch er dann, genau an dieser entscheidenden Stelle, auf einen verdinglichten Subjektivismus zurück, der sich logisch unumwunden an Lenins subjektivistischen Interpretationen des Klassenantagonismus anschließen lässt. Die Existenz der Klassen scheint sich für Grigat allein subjektivistisch interpretiert über ein fetischisiertes Klassenbewusstsein zu beweisen, weil er die Phänomenologie des Fetischabschnitts auf die mit diesem gar nicht zu begreifenden Klassenantagonismus überträgt. Die Klassen werden ihm deshalb zu einem Konstrukt des Bewusstseins, zu einem Resultat des „Fetisch[s] des Klassenbewußtseins“1224; wodurch sie ihrer Objektivität in einer antagonistischen Klassengesellschaft beraubt werden.

Mit einer derartigen idealistischen Konstruktion bleibt der Wertkritiker Grigat jedoch notwendig in einem Zirkel des Bewusstseins gefangen. Aus dem entsprechenden Idealismus kommt er logisch auch nicht mehr heraus. Er schreibt, voraussetzend, dass das Bewusstsein das Sein bestimme: „Klassenbewußtsein wird geradezu antikommunistisch, denn kommunistisches Bewußtsein ist, wenn es um

1223 Grigat: Fetisch und Freiheit, S. 208 f.

${ }^{1224}$ Ebd., S. 208. 
die Abschaffung der Klassen geht, mit Klassenbewußtsein unvereinbar.“1225 Durch diese logische Hommage an die Widerspiegelungstheorie verliert der Begriff der Klasse aber all seine gesellschaftliche und wissenschaftliche Objektivität in der bürgerlichen Gesellschaft, die er trotz eines empirisch fehlenden Klassenkampfs und -bewusstseins jedoch haben muss. ${ }^{1226}$ Das idealistische Urteil Grigats - zusammengefasst ,nur wenn Klassenbewusstsein, dann auch Klasse ${ }^{6}$ - entpuppt sich als jener durch und durch subjektivistische Konstruktivismus, den Adorno in Spätkapitalismus oder Industriegesellschaft? wie folgt an anderen, zeitgenössischen Theorien kritisiert: Adornos explizite Kritik an diesen zeitgenössischen Theorien kann insofern, an der Stelle übergreifend, auch für Grigats nominalistisch-idealistische Theorie der Klassen gelten: „Daß von einem proletarischen Klassenbewußtsein in den maßgebenden Ländern nicht kann gesprochen werden, widerlegt nicht an sich, im Gegensatz zur communis opinio, die Existenz von Klassen: Klasse war durch die Stellung zu den Produktionsmitteln bestimmt, nicht durchs Bewußtsein ihrer Angehörigen." ${ }^{1227}$

Auch Postone schafft schon, wie später Grigat, nominalistisch den objektiven Klassenbegriff ab und reiht sich damit in die subjektivistische Stoßrichtung der modernen Gesellschaftswissenschaften ein. Deutlich wird dabei auch, dass er Grigat nicht nur die dann von ihm dann noch ausgeschlachteten wertkritischen Stichworte in die Hand legt. Postone stellt seinerseits schon den „Untergang von

\footnotetext{
1225 Ebd., S. 210.

1226 Adorno spricht vom Kardinalfehler in der modernen Soziologie, den objektiven Klassenbegriff aufgegeben zu haben: „In den augenblicklich vorherrschenden Strömungen der Soziologie wird dieser Ausgang [vom objektiven Klassenbegriff, B.E.B.] weithin als dogmatisch abgelehnt.“ (Adorno: Spätkapitalismus oder Industriegesellschaft?, S. 355.) Beispiele hierfür lassen sich viele anführen: Der Soziologe Ulrich Beck beispielsweise hält das Bewusstsein von der Klassenzugehörigkeit für das alleinige Merkmal ihrer objektiven Existenz: „Wir leben trotz fortbestehender und neu entstehender Ungleichheiten heute in der Bundesrepublik bereits in Verhältnissen jenseits der Klassengesellschaft, in denen das Bild der Klassengesellschaft nur noch mangels einer besseren Alternative am Leben erhalten wird." (Beck: Risikogesellschaft, S. 121.) Auch Michael Hardt und Antonio Negri geben in Empire den Begriff der Klasse als Substanzbegriff auf. Erst der „Sachverhalt, nämlich innerhalb des Kapitalverhältnisses zu sein und es aufrecht zu erhalten“, definiere „das Proletariat als Klasse." (Hardt/Negri: Empire, S. 67.) Und auch das bekannte Schichtmodell der modernen Soziologie lässt sich als subjektivistische Negation der Marxschen objektiven Klassentheorie lesen. Ob die ,nivellierte Mittelstandsgesellschaft ' Schelskys, das berühmte Dahrendorfhäuschen oder dann dessen renovierter Ausbau durch Rainer Geißlers Schichtmodell: All jene Versuche, postmarxistisch die bürgerliche Gesellschaft ,neu' zu erklären laufen auf eine folgenreiche, subjektivistische Ablehnung der Klassentheorie als objektive Erklärung der kapitalistischen Produktionsweise hinaus (vgl. Schelsky: Die Arbeit tun die anderen. Klassenkampf und Priesterherrschaft der Intellektuellen, S. 173 ff.; Dahrendorf: Gesellschaft und Demokratie in Deutschland; Geißler/Meyer: Die Sozialstruktur Deutschlands.). Mit einem Gefühl, Bewusstsein oder der erzwungenen Eingebundenheit in den Kapitalismus allein hat der objektive Begriff der Klasse aber nicht nur bei Marx oder Adorno nichts zu tun: „Als Klassen stehen sich Arbeiter und Kapitalisten vermittelt durch das gesellschaftliche Gesamtkapital gegenüber.“ (Weyand: Stummer Zwang oder innere Stimmen?, S. 104.) 1227 Adorno: Spätkapitalismus oder Industriegesellschaft?, S. 358.
} 
traditionellen sozialen Klassen und Schichten [sic!]“1228 fest. Weil aber die Antisemitismustheorie auf die klassenantagonistische bürgerliche Gesellschaft und eines ihrer entscheidenden Phänomene reflektieren muss, wenn denn moderner Antisemitismus und bürgerliche Gesellschaft bzw. Herrschaft überhaupt zusammenhängen sollen, muss sie auch auf den wesentlichen Begriff der ökonomisch bedingten Klasse innerhalb der kapitalistischen Produktionsweise reflektieren. Das aber machen Grigat und Postone mit ihrer wertkritischen Konzeption der Kritik gerade nicht. Der Subjektivismus Grigats und Postones, der ihren Antisemitismusbegriff, wie sich auch noch im weiteren Verlauf der Untersuchung zeigen wird, krass affektiert, kommt insofern schon an dieser Stelle ihrer Aufgabe des objektiven Klassenbegriffs mehr als deutlich zum Vorschein.

Wie aber soll nun die wertkritische Alternative der Erklärung des modernen Antisemitismus, die mit dem Fetischbegriff aus dem Kapital allein arbeitet und den objektiven Klassenbegriff verabschiedet, zu den nur vermeintlich alles erklärenden Klassenkampfkonzepten der Marxisten-Leninisten, aussehen? Der moderne Antisemitismus wird sowohl von Postone als auch von Grigat als soziales Phänomen allein an die generellen Vergegenständlichungsprozesse der bürgerlichen Gesellschaft angelehnt. Der moderne Antisemitismus wird als Fetisch über die Bestimmung als falsches Bewusstsein von den gesellschaftlichen Verhältnissen kritisiert: „Ein Aspekt des Fetischs ist also, daß kapitalistische gesellschaftliche Beziehungen nicht als solche in Erscheinung treten und sich zudem antinomisch, als Gegensatz von Abstraktem und Konkretem, darstellen. " ${ }^{1229}$ Für Grigat sei der moderne Antisemitismus deshalb ein Ausdruck einer „unbegriffene[n] Verdinglichung sozialer Zusammenhänge "1230. Überhaupt hänge in der wertverwertenden bürgerlichen Gesellschaft einiges an der Verdinglichung von intersubjektiven Beziehungen und der Verschleierung der wahren Verhältnisse: „Wesen und Existenzbedingung des Warenfetischismus ist es, von den Individuen nicht als solcher wahrgenommen zu werden. " ${ }^{231}$ Zunächst einmal lässt schon dieser Satz Grigats nach den oben durchgeführten Untersuchungen zum Fetischabschnitt in 5.1.1 aufhorchen. Warum sollte der Warenfetischismus überhaupt als Fetischismus von den Individuen wahrgenommen werden, wenn der Fetisch doch nach Marx nur die richtige, phänomenologische Wahrnehmung der gesellschaftlichen Verhältnisse der Tauschgesellschaft ist? Denn, wie in 5.1.1 herausgearbeitet wird, müsste jede richtige Wahrnehmung von Gesellschaft und ihrer Phänomene, wie sie sind, fetischistisch sein, weil notwendig fetischistisch. Warum also soll dann nach Grigat die bloß korrekte Wahrnehmung der allgegenwärtig vergegenständlichten Form von Beziehungen in einer ubiquitären Warengesellschaft überhaupt problematisch sein?

\footnotetext{
1228 Postone: Antisemitismus und Nationalsozialismus, S. 180.

1229 Postone: Antisemitismus und Nationalsozialismus, S. 184.

1230 Grigat: Antisemitismus und Fetischismus.

1231 Grigat: Fetisch und Freiheit, S. 50.
} 
Die generelle Verdinglichung der Produkte, als auf dem Markt der warentauschenden Gesellschaft zur bloß quantitativen Ware werdende qualitative Produkte, ist dem Fetischabschnitt zufolge ja nur das bloße Resultat der Tauschgesellschaft, das sich im Bewusstsein der Subjekte widerspiegelt. Eine bloße Quantifizierung von Dingen zu Tauschzwecken auf dem Markt vorzunehmen ist ja nun auch nicht falsch - und diese bloße Quantifizierung bedeutet auch nicht gleich eine Verschleierung der wahren Verhältnisse, die die Qualität einfach hinter den nur noch quantifizierten Dingen versteckt. Qualität geht generell nicht in der Quantiät verloren, weil, dialektisch gesprochen, ohne Qualität auch keine keine Quantität ist; weil ja jeder Quantität immer auch etwas qualitativ Bestimmtes zugrunde liegen muss. ${ }^{1232}$ Nach Marx ist deshalb auch die persönliche Verhältnisse über diese Quantifizierungstendenz verdinglichende Wahrnehmung, das falsche Bewusstsein, schon die (ideologisch) richtige Wahrnehmung der Zirkulationssphäre der Tauschgesellschaft, weil das Subjekt auf dem Markt notwendig quantifizieren, verdinglichen muss. Nach Marx kann die generelle Wahrnehmung des Subjekts von der eigenen Umwelt deshalb auch immer nur die formell richtige Form des Denkens über die Tauschgesellschaft hervorbringen. Warenform und Denkform stehen im Marxschen Fetischabschnitt deshalb also zunächst einmal als nur rein logischer Identitätssatz zueinander. ${ }^{1233}$ Die Form abstrahiert insofern jeweils von jeglichem Inhalt, ist also nicht selbst schon dieser; deswegen erweist es sich auch als unmöglich, den Antisemitismus als eine Denkform zu bezeichnen. Das Bewusstsein der freien Privatproduzenten im Fetischabschnitt, die in der Geschichte nicht einmal existierten, bezieht sich zwar auch bei Marx schon auf Gegenständliches, aber, weil philosophische Erkenntnistheorie, eben auch nur auf ein abstrakt Gegenständliches, das sich auf die objektiven gesellschaftlichen Gegenstandsformen ohne spezifischen Inhalt überhaupt bezieht - Objektives wird also immer nur in Bezug auf die generelle gesellschaftliche, abstrakte Gegenständlichkeit (fernab von hinzutretender materieller Geschichte) gedacht.

Von Marx wird im Fetischabschnitt somit lediglich die reflexive Verwiesenheit von der denkenden Subjektivität und der Objektivität gesellschaftlicher Produktion aufeinander nachgewiesen; aber nur im Sinne der Bedingung der Möglichkeit

1232 „Quantifizierungen sind aber immer Quantifizierungen von qualitativ Bestimmten.“ (Weyand: Adornos Kritische Theorie des Subjekts, S. 50.)

${ }^{1233}$ Deshalb bedingt auch das Eine nicht das Andere. Der Versuch Sohn-Rethels, die Denkform aus der Warenform zu begründen, um eine „materialistische Erklärung des Denkens“ (Sohn-Rethel: Warenform und Denkform, S. 27.) zu beweisen, interpretiert dieses Verhältnis deshalb nicht im Sinne Marx'. Er gibt mit seinem Versuch vielmehr einer subjektivistischen Widerspiegelungstheorie etwas vor, obwohl Sohn-Rethel eigentlich mit dem Interesse antrat, den Idealismus ,vom Kopf auf die Füße“ (Drslb.: Das Geld, die bare Münze des Apriori, S. 21.) zu stellen. Wenn er jedoch dergleichen das Denken aus der vergesellschafteten Warenform ableitet, als ,gesellschaftlich bedingt" bestimmt (drslb.: Warenform und Denkform, S. 27.), und Subjekt somit nicht autonom (vgl. 2.2 ff.) sondern eben aus etwas anderem entstanden erklärt, interpretiert er das Denken des Subjekts als immer deterministisch aus Gesellschaft stammend. Keine Befreiung von dieser Gesellschaft wäre dann mehr ausweisbar. 
von adäquater subjektiver Erkenntnis des phänomenologischen gesellschaftlichen Außen. Ein solcher von Marx begründeter Identitätssatz kann deshalb zunächst also auch nichts weiteres als die formelle Stellung des Bewusstseins zum gesellschaftlichen Außen, in dem Fall auch nur die Stellung zur abstrakten Warenzirkulation in der Tauschgesellschaft, begründen. Eine solch reine, abstrakte Denkregel der Subjekt-Objekt-Relation kann aus sich heraus eben nicht schon das andere des Begriffs, materielles Substrat, setzen. Über mögliche gesellschaftliche Inhalte des Bewusstseins, wie das soziale Phänomen Antisemitismus als Resultat des subjektiven Handelns beispielsweise, hat eine solche reine Denkregel überhaupt keine Macht. Die nur kategoriale Form des zirkulierenden Werts hat deshalb, wie anhand der Interpretation der ersten drei Kapitel des Kapitals dargestellt, ihren nichtidentischen Inhalt, ihren historisch notwendigen Inhalt, noch nicht. Bei Marx trug die Warenform im Fetischabschnitt deshalb auch genauso wenig bereits ein bestimmtes Material mit sich, wie die Denkform im Fetischabschnitt auch keinen bestimmten Inhalt des Bewusstseins ausprägt. Der Ideologiebegriff des Kapitals hat also streng genommen gar keinen Inhalt, sondern verweist lediglich auf die immerwährende Adäquanz vom lebendigen Subjekt der Praxis und phänomenologischer Gesellschaft.

Diese rein phänomenologische Feststellung aus dem Fetischabschnitt müssen Postone und Grigat nun aber vehement bestreiten, wenn nach ihrer wertkritischen Interpretation jene nach Marx richtige Wahrnehmung der allgemeinen Reproduktion konsequent, also notwendig, zur gesellschaftlichen Erscheinung des modernen Antisemitismus führt. Wie aber soll nach wertkritischer Lesart aus der bei Marx noch völlig inhaltslosen Stellung von Waren- und Denkform ein falscher Inhalt des Bewusstseins wie der Antisemitismus überhaupt folgen? Aus den erkenntnistheoretischen Voraussetzungen des Fetischabschnitts selbst könnte, streng nach Marx, kein antisemitisches Urteil oder überhaupt irgendein soziales Phänomen eskamotiert werden, weil allein auch schon die Notwendigkeit einer Ableitung einer falschen Denkform aus der Warenform logisch viel zu kurz gedacht ist: „Ideologie in diesem strikten Sinne gibt es nur in der entfalteten bürgerlichen Gesellschaft; die Marxsche Theorie untersucht aber nicht ihre Inhalte, sondern ihre Formation." ${ }^{1234}$

Ein (falscher) Inhalt des (falschen) Bewusstseins kann also aus der bei Marx richtigen Wahrnehmung der Warenform logisch schon überhaupt nicht entspringen. Für Postone folgt dann allerdings aus dieser richtigen phänomenologischen Wahrnehmung der Warentauschgesellschaft durch das selbstbewusste Subjekt logisch, also notwendig dieser objektiv falsche Gegenstand oder Inhalt des Bewusstseins: der moderne Antisemitismus, der ideologisch die „abstrakte Dimension des Kapitalismus ausgerechnet an den Juden festmachte." "1235 In seiner modernen Gestalt sei der Antisemitismus für Postone deshalb also zu einer notwendigen

${ }^{1234}$ Claussen: Grenzen der Aufklärung, S. 77.

1235 Postone: Der Holocaust und der Verlauf des 20. Jahrhunderts, S. 144. 
Folge des abstrakten Verwertungsprozesses des Kapitals selbst geworden, in dem „kapitalistische Formen gesellschaftlicher Beziehungen nicht als solche“, also rein, erscheinen, sondern „sich in vergegenständlichter Form“1236 ausdrückten. Nach Postone folgt also aus der Form des falschen Denkens über die warentauschende Vergesellschaftung genau das, was mit dem Marxschen Fetischabschnitt gar nicht möglich war zu bestimmen: ein antisemitisches Urteil der vergesellschafteten Subjekte, also ein Inhalt des Bewusstseins: „Dennoch gilt es hervorzuheben, daß eine sorgfältige Überprüfung des modernen antisemitischen Weltbildes das Vorliegen einer Denkform deutlich werden läßt, in der die rasche Entwicklung des industriellen Kapitalismus durch den Juden personifiziert und identifiziert wird.“1237 Das impliziert zudem auch noch, dass alleine das Denken der vergesellschafteten Subjekte über den Kapitalismus falsch sei, nicht jedoch dieser selbst; und diese negativen Phänomene wie der Antisemitismus sich deshalb allein aus dem falschen Denken über die Warentauschgesellschaft entfalten würden. Der Kapitalismus selbst, wenn er richtig gedacht wird, muss für Postone demnach unproblematisch sein - und dürfte dann auch den modernen Antisemitismus nicht kennen.

Die Unmöglichkeit und Problematik der Ableitung der in sich schon widersprüchlichen ,bestimmten Denkform' aus der Warenform ist an dieser Stelle weiter zu verfolgen. Aus den Marxschen Kategorien der Wertformanalyse, die ja nur der Ausdruck der richtigen Wahrnehmung der phänomenologischen Zirkulationssphäre sind, sollen bei Postone also bestimmte (falsche) Denkinhalte wie der Antisemitismus oder auch andere gesellschaftliche Phänomene entspringen. Die formelle Abhandlung der Erkenntnistheorie im Fetischabschnitt würde demnach nach wertkritischer Lesart also gleich auch etwas über die Gegenstände und eben nicht nur die abstrakte Gegenständlichkeit, die zweifelsohne noch in den Bedingungen der Möglichkeit von subjektiver Erkenntnis gefangen bleibt, aussagen. Aus den Kategorien selbst, aus den objektiven Gedankenformen der bürgerlichen Gesellschaft heraus - ohne dass diesen Gegenständliches oder Geschichtliches selbst bei Marx zukommt - müsse also bei Postone gleich ein spezifischer Inhalt dieser Formen, zumal noch logisch der objektiv falsche, folgen. So schreibt Postone: „Die Marxschen Kategorien beziehen sich simultan auf besondere gesellschaftliche Verhältnisse und Denkformen." "1238 Die Ware als Form, als Warenform, drückt nun auch für Grigat „zwangsläufig (...) bestimmte [! Denkformen“1239 aus, um den Antisemitismus als falschen Inhalt des Bewusstseins überhaupt deklarieren zu können. Solch widerspiegelungstheoretisch determiniertes (falsches) Bewusstsein gesellschaftlicher Abbilder könnte aber gar keinen objektiven Gegenstand mehr haben, wenn nicht aus der zirkulierenden Warenform selbst nur die adäquate, objektive Gedankenform über den Gegenstand der Warenzirkulation

\footnotetext{
1236 Ebd., S. 182

1237 Ebd., S. 180.

1238 Ebd., S. 183.

${ }^{1239}$ Grigat: Fetisch und Freiheit, S. 283.
} 
folgt, sondern immer gleich auch ein falsches Urteil über die Warenförmigkeit aus dieser schon entspringt - worauf dann auch noch die inhaltliche Ausprägung eines sozialen Phänomens folgt, das objektiv ja notwendig falsch sein soll: „Als Objekt drückt die Ware soziale Verhältnisse aus und verschleiert sie zugleich. Diese Verhältnisse haben keine andere, davon unabhängige Ausdrucksform." ${ }^{2240}$

Grigat ist nun auch noch der Überzeugung, dass der Antisemitismus nichts einfach komplementär-ideologisch durch die kapitalistische Gesellschaftsform und ihre juristische Organisation der politischen Ökonomie Hinzutretendes sei, also nichts aus der Totalität der bürgerlichen Gesellschaft sich erklärendes sei, sondern er bloß die logische, notwendige Konsequenz aus der kapitalistischen Warenform, eben die besagte bestimmte falsche Denkform der kapitalistischen Gesellschaft sein könne: „Insofern ist der Antisemitismus nichts einfach Hinzutretendes, sondern sowohl theoretisch als auch historisch mit dem Waren-, Geld- und Kapitalfetisch Zusammenhängendes. “" 241 Das führt nun dazu, dass für Grigat allein in der falschen Wahrnehmung der damit offensichtlich auch, wie bei Postone, ergo: richtigen kapitalistischen Gesellschaft die Begründung des Phänomens Antisemitismus liege - und nicht in der gesellschaftlichen Herrschaftsgeschichte, die sich erst mit den Bestimmungen der Totalität der bürgerlichen Gesellschaft begreifen lasse: „Erklärt werden kann nicht mehr der Antisemitismus, sondern nur mehr die Gesellschaft, der er strukturell [sic!] innewohnt.“1242 Eigentlich soll nach Grigat deshalb die kapitalistische Gesellschaft, die von Grigat damit auch noch auf die Bestimmungen aus der Wertformanalyse reduziert wird, wenn sie denn einfach einmal nur richtig erklärt werde, in der Konsequenz auch den (modernen) Antisemitismus hinter sich lassen. Da sich nun aber notwendig die bestimmte Denkform Antisemitismus aus der Warenform ableitet und die Warenform jetzt nur richtig wahrgenommen werden soll, um die Gesellschaft vom Antisemitismus zu befreien, führt die Argumentation auch gleich auf einen immanenten logischen Widerspruch: Denn die Warenform wird ja nach Marx von der Denkform immer schon richtig wahrgenommen, das falsche Bewusstsein war ja das richtige Bewusstsein von den phänomenologischen, sich in der Gesellschaft individuierenden Dingen. Weil der moderne Antisemitismus der bürgerlichen Gesellschaft, d.h. bei Grigat der Warenförmigkeit, strukturell, wesentlich innewohnt, ist es auch konsequent, ihn deshalb mit Notwendigkeit aus dem Wesen der bürgerlichen Gesellschaft, für Grigat die Warenform (s.o.), entspringen zu lassen. Wenn Wesen somit aber auch gleich Erscheinung sein soll1243, würde sich das antisemitische Bild von den Juden

\footnotetext{
1240 Postone: Antisemitismus und Nationalsozialismus, S. 182.

1241 Grigat: Fetisch und Freiheit, S. 289.

1242 Ebd., S. 280.

1243 Damit widerspricht Grigat aber seinem eigenen Programm: „Die beiden wesentlichen Elemente aus der Methode [sic!] der Marxschen Kritik der politischen Ökonomie, die auch für die vorliegende Studie Bedeutung haben, sind die Entfaltung der Differenz von Wesen und Erscheinung, was als zentrales methodisches Element einer Kritik des Fetischismus bezeichnet werden kann." (Ebd., S. 17.)
} 
in der bürgerlichen Gesellschaft, wie Grigat auch veranschlagt, tatsächlich ,aus sich selbst“"1244 erklären. Anstatt gar nicht, weil ohne Maßstab, mehr erklärt zu werden, weil der Antisemitismus dann ein irrationales Phänomen ohne Zweck und von unbestimmter Herkunft sein müsste, wird seine Erklärung einfach mit der allerdings auch noch subjektivistischen Erklärung des Wesens der kapitalistischen Produktionsweise identifiziert.

Mit dieser subjektivistisch-positivistischen Erklärung des Antisemitismus aus sich selbst heraus entledigt sich diese Analogisierung von Waren- und Denkform bei der Erklärung des modernen Antisemitismus nun auch noch jeder konkreten, materiellen Geschichte. Weil sich eine wertkritische Antisemitismustheorie dann nicht mehr der Geschichte, und auch nicht der spezifischen Geschichte des Antisemitismus, annehmen kann, kann sie auch den wirklichen, materiellen Grund nicht mehr angeben, warum und zu welchem Vorteil die Juden überhaupt mit dem Kapitalismus identifiziert werden: „Die abstrakte Herrschaft des Kapitals, wie sie besonders mit der raschen Industrialisierung einhergeht, verstrickte die Menschen in das Netz dynamischer Kräfte, die, weil sie nicht durchschaut zu werden vermochten, in Gestalt des ,Internationalen Judentums' wahrgenommen wurden.“1245 Allein also aus dem falschen Bewusstsein des Subjekts, das die Zirkulationssphäre falsch wahrnehme, solle demnach der moderne Antisemitismus herrühren. So aber liefert Postone in keiner Weise eine materielle Begründung des modernen Antisemitismus. Selbst wenn Postone offenbart, dass die Juden aufgrund der verhängnisvollen Geschichte mit ihm verbunden werden, grenzt sein theoretischer Subjektivismus notwendig entscheidend Substantielles des Antisemitismus aus. So fußen die Personifikation und Identifikation der Juden mit der kapitalistischen Moderne für ihn zunächst zwar auch auf vermeintlich nichtidentischen historischen Implikationen: „Es handelt sich dabei nicht um die bloße Wahrnehmung der Juden als Träger von Geld - wie im traditionellen Antisemitismus; vielmehr werden sie für ökonomische Krisen verantwortlich gemacht und mit gesellschaftlichen Umstrukturierungen und Umbrüchen identifiziert, die mit der raschen Industrialisierung einhergehen: explosive Verstädterung, der Untergang von traditionellen sozialen Klassen und Schichten, das Aufkommen eines großen, in zunehmenden Maße sich organisierenden industriellen Proletariats und so weiter.“"1246 Doch diese historischen Implikationen können die Personifizierung und Identifizierung des Kapitalismus mit den Juden nur noch analytisch beschreiben. Sie können die wirklichen historischen und materiellen Gründe des Antisemitismus und seine rationale Fortführung als moderner Antisemitismus in der bürgerlichen Gesellschaft aus gesellschaftlicher Herrschaft heraus und der Totalität der bürgerlichen Produktionsweise nicht erklären. Für Postone kann der moderne Antisemitismus deshalb nur noch aus der falsch wahrgenommenen Warenform

\footnotetext{
1244 Ebd., S. 280.

1245 Postone: Antisemitismus und Nationalsozialismus, S. 181.

1246 Ebd., S. 180.
} 
stammen, was aber einer nur zirkulären, subjektivistischen Erklärung des modernen Antisemitismus gleichkommt. Es gäbe an der Stelle für Postone deshalb keinen rationalen, also gesellschaftliche und persönliche Zwecke bedienenden Grund für den Antisemitismus, sondern er würde allein aus der Verblendung des Bewusstseins des antisemitischen Subjekts resultieren.

Der Grund für den weiterhin bestehenden Antisemitismus in der bürgerlichen Gesellschaft kann jedoch, anders als bei Postone und Grigat, nicht aus dem kapitalistischem Verwertungsprozess oder eben der phänomenologischen Zirkulationssphäre erklärt werden. Denn die Motivation, als lebendiges Subjekt der Praxis antisemitisch zu handeln, kann in den verhängnisvollen totalen Zusammenhang von Gesellschaft und Individuum, Kapitalismus und Subjekt, erst durch ein materielles Moment der Nichtidentität hineingetragen werden: „Jeder Versuch, die Besonderheit der Opfer der Aggression aus dem Verwertungsprozeß des Kapitals zu erklären, verwickelt unausweichlich sich in Widersprüche, weil dieser Verwertungsprozeß eben gleichgültig ist gegen jede Besonderheit."1247 Aus der nur phänomenologischen Zirkulationssphäre, aus der allgemeinen bürgerlichen Gleichheit aller Staatsbürger vor dem Gesetz, die sich zweifelsfrei postrevolutionär und real zeigte, kann der besondere Opferstatus der Juden oder anderer Gruppen demnach überhaupt nicht resultieren (vgl. auch 3.2 ff.). Der Antisemitismus zieht seine aggressive Motivation in der bürgerlichen Gesellschaft aus etwas anderem, etwas gesellschaftlich erst Hinzutretendem. Erst post festum wird auf das historische Moment der Diffamierung der Juden zurückgegriffen, denn es bietet sich für das instrumentell in der bürgerlichen Gesellschaft handelnde Subjekt zweckmäßig rationell an, antisemitisch zu sein; ein Antisemitismus kann sich durchaus positiv auf die Realisierung der eigenen materiellen Zwecke in der kapitalistischen Gesellschaftsform auswirken. Der moderne Antisemitismus wird deswegen auch nicht aus der Form der kapitalistischen Vergesellschaftung selbst heraus gestiftet, er kann deshalb nicht mit Notwendigkeit in der bürgerlichen Gesellschaft entstehen. Er ist ein historisch hinzutretendes Moment aus der kontingenten, nichtidentischen Geschichte als in der Totalität der bürgerlichen Gesellschaft liegendes - die sein zu begreifendes Wesen als soziale Erscheinung ist - Moment. Form und Inhalt der bürgerlichen Totalität verbinden sich insofern im modernen Antisemitismus verhängnisvoll miteinander, weil Form und Material dialektisch ineinander sind. Der Antisemitismus lässt sich mit seiner Zweckmäßigkeit für das Subjekt zum Vorteil seiner Reproduktion in die bürgerliche Gesellschaft einbinden, kann aber nicht notwendig seinen Grund in der bürgerlichen Gesellschaft haben.

Aus dem kapitalistischen Verwertungsprozess selbst, aus der Phänomenologie der Zirkulationssphäre, können diese Zwecke der Aufrechterhaltung des Antise-

\footnotetext{
1247 Bulthaup: Elemente des Antisemitismus, S. 119 f. Ausgangspunkt sind die Marxschen Ausführungen des Kommunistischen Manifests, die das Niederreißen aller feudaler Schranken, persönlicher Unterschiede und Privilegien zum Zweck der Kapitalakkumulation im Kapitalismus beschreiben. (Vgl. hierzu Marx/Engels: Das Kommunistische Manifest, S. 464 ff.
} 
mitismus allein schon durch die persönliche Gleichgültigkeit der Zirkulationssphäre gegen jede Besonderheit nicht ersichtlich sein. Deshalb könnte auch durch das richtige Bewusstsein von den gesellschaftlichen Verhältnissen in der Zirkulationssphäre, dass es nach Marx ja schon immer ist, der Antisemitismus nicht abgeschafft werden, weil die wesentlichen Bedingungen der gesellschaftlichen Herrschaft eben auch nicht im Bewusstsein der lebendigen bürgerlichen Subjekte liegen, sondern der in den Kapiteln 3 und 4 ausführlich beschriebenen transzendenten Heteronomie der bürgerlichen Gesellschaft - als Totalität gedacht - wesentlich entstammen. Die totale bürgerliche Gesellschaft zwingt die lebendigen Subjekte immer, auch wider besseres Wissen, zur freiwilligen Reproduktion in ihr. Der so antagonistischen bürgerlichen Gesellschaft hat sich jedes Subjekt der Praxis zu Reproduktionszwecken willentlich unterzuordnen, in dieser Totalität des Reproduktionszusammenhangs hat sich jedes lebendige, sich selbst reproduzierende Subjekt dafür gegen die klasseninterne Konkurrenz durchzusetzen. Jeder Vorteil zugunsten der eigenen Reproduktion wird dabei gnadenlos aus ganz eigenem Interesse an der Selbsterhaltung ausgenutzt: „So sind für diejenigen, die kein anderes Eigentum besitzen als ihre Arbeitskraft, Vorstellungen von nationaler Expansion, wie von Ausgrenzung einzelner auf dem Markt für Arbeitskräfte drängender Gruppen, wie immer auch deren Mitglieder als Mitglieder dieser Gruppen identifiziert werden mögen, plausibel. Ihnen scheint die Behauptung einleuchtend, diejenigen, die zuviel seien, nährten sich als arbeitsscheue Elemente parasitär von den Resultaten der Arbeit derjenigen, deren Lohn kaum für das Lebensnotwendige ausreicht. Ideologien des nationalistischen Imperialismus, wie die des Fremdenhasses, haben eine quasi natürliche Massenbasis im Proletariat.“1248 Dass dabei, weil gesellschaftliche Totalität des erzwungenen Reproduktionszusammenhangs, auch die Eigentümer an Produktionsmitteln in diesem Überlebenskampf konkurrierend zueinander stehen, wurde oben bereits mehr als deutlich. Deswegen hat der Fremdenhass ja auch eine ,quasi natürliche Massenbasis' in der Bourgeoisie.

Die Fetischisierung des modernen Antisemitismus kann demnach, weil Warenform gleich ,bestimmte Denkform' sei, eine nur in idealistischen Konstruktionen notwendig gefangen bleibende Methodisierung des äußeren Materials sein. Würde also das falsche Bewusstsein und damit der Antisemitismus aus den gesellschaftlichen (Tausch-)Verhältnissen nicht nur komplementär, sondern dergestalt notwendig entspringen, so könnten die Subjekte ihr eigenes Bewusstsein auch weder als falsches, noch als richtiges Bewusstsein der gesellschaftlichen Verhältnisse begreifen. Sie würden deshalb auch nur noch notwendige Vorstellungen als gedankliche Abbilder der Realität besitzen, womit sie aber keine selbstbewussten Subjekte mehr wären. Zur spontanen Reflexion des Verhältnisses ihres ideologischen Bewusstseins zur (gesellschaftlichen) Realität könnten sie demnach, durch die idealistische Konstruktion, überhaupt nicht in der Lage sein - Bewusstsein und äußere

1248 Bulthaup: Elemente des Antisemitismus, S. 123. 
Realität würden für sie insofern immer unmittelbar und reflexartig identisch bleiben. Jedes nachvollziehbare und damit wissenschaftlich erst bearbeitbare Urteil über einen äußeren Gegenstand, auch das antisemitische Urteil, kann jedoch nur über die Vernunft des reflexiven und selbstbewussten, autonomen Subjekts als Tätigkeit vermittelt gebildet werden. Das antisemitische Urteil ist also ohne mit dem Bewusstsein des lebendigen Subjekts der Praxis vermittelt seiendes gar nicht zu denken. Wenn nach Postone dieses Bewusstsein immer gleich ein determiniert falsches Bewusstsein von den Dingen sei, womit es notwendig auch, wie er schreibt, in den „Erscheinungsformen der gesellschaftlichen Verhältnisse befangen"1249 bleibt, könnte das Subjekt vom äußeren Gegenstand aber auch nie ein adäquates, wesentliches Verständnis erlangen; weil es, wie es von Postone identitätsphilosophisch veranschlagt wird, immer nur in den phänomenologischen gesellschaftlichen Verhältnissen be- und gefangen bliebe. Der Antisemitismus wäre in der Konsequenz auch nicht mehr als Willensverhältnis bestimmt, sondern er wäre ein bloß irrationales Reagieren auf Gesellschaft.

Damit wäre, was sich bereits länger ankündigte, der Maßstab der Kritik des Antisemitismus auch bei Postone (und vermittelt auch bei Grigat) logisch in Frage gestellt (vgl. dazu 2.1). Denn die Formierung des wertkritischen falschen Bewusstseins als Erklärung von Kapital und gesellschaftlichen Phänomenen stellt sich damit notwendig als eine bloße Variante einer abbildtheoretischen Widerspiegelungstheorie dar, die ebenfalls den nichtidentischen Gegenstand nicht mehr als autonomen Gegenstand begreifen kann. Damit wäre die logische Konsequenz der Kritik des modernen Antisemitismus als falsches Bewusstsein also nicht, dass die kapitalistische Gesellschaft als das wesentliche Konstituens des erscheinenden modernen Antisemitismus abzuschaffen sei, sondern eben die antagonistische bürgerliche Gesellschaft einfach nur vom Subjekt richtig wahrgenommen werden müsse, um darüber dann die kritischen, falschen Phänomene wie den Antisemitismus abzuschaffen. Von der Wertkritik wird damit insofern unterstellt, dass sich die gesellschaftliche Freiheit bereits verwirklicht habe, diese jedoch aufgrund der Fehlstellung des Bewusstseins zur freiheitlichen Realität nicht erkannt werden könne. Doch, um nochmals Robert Menasse zu bemühen: „Zwar hat sich am erreichten Stand der Geschichte Freiheit umfassend entfaltet, weshalb das absolute Wissen darin zu sich selbst kommen konnte, aber diese Freiheit hat sich nur im Selbstbewußtsein der bürgerlichen Gesellschaft entfaltet und nicht in Wirklichkeit.“"1250 Eine Kritik am falschen Denken von Subjekten ist eben noch keine Kritik an gesellschaftlichen Bedingungen, die dieses Denken erst hervorbringen.

\footnotetext{
1249 Postone: Antisemitismus und Nationalsozialismus, S. 183.

${ }^{1250}$ Menasse: Phänomenologie der Entgeisterung, S. 13.
} 


\subsubsection{Zu Postones (negativer) Widerspiegelungstheorie}

Mit der wertkritischen Erklärung wird also auch von der im Erkenntnisprozess konstitutiven Rolle des reflexiven Subjekts und seiner spontanen Vernunft abstrahiert. Ein Subjektbegriff, wie er in dieser Arbeit entwickelt wurde (vgl. z.B. 2.2 ff.), fehlt. Die wertkritische Antisemitismustheorie nimmt mit der widerspiegelungstheoretischen Annäherung an den Gegenstand deshalb von einem Subjektbegriff Abstand, mit dem oben bereits im ersten Kapitel das Subjekt als selbstbewusstes, gegen seine eigenen Voraussetzungen denkendes, reflexives Subjekt bestimmt wurde (vgl. Kap. 2). Weil Grigat und Postone durch ihre wertkritischen Bestimmungen das reflexive Subjekt aufgeben, weil die Vernunft und ihre Widersprüche also in der wertkritischen Theorie durch ihre Anlehnung an eine subjektivistische Widerspiegelungstheorie nicht mehr auftreten, wird bei der Analyse des Kapitals wie der sozialen Erscheinungen implizit auch das revolutionäre Potential des autonomen, widerständigen Subjektbegriffs der Philosophiegeschichte aufgegeben. Deshalb wird das seiner selbst bewusste Subjekt in der wertkritischen Reflexion auch zum vollends heteronom bestimmten, blinden, instrumentellen Mittel des notwendig und immer heteronomen gesellschaftlichen Zwecks degradiert. Das Subjekt als selbstbewusstes, emphatisches Subjekt, das wie oben bestimmt reflexiv gegen seine eigenen Voraussetzungen denken kann, kann es also gerade durch die kennen gelernten deterministischen Voraussetzungen der Theorien Postones und Grigats, die Identität von Warenform und Denkform etc., nicht mehr geben. Das Subjekt kann insofern auch lediglich noch dem blinden instrumentellen Denken verpflichtet sein, womit es jedoch auch notwendig kein selbstbewusstes Subjekt der Praxis mehr ist (vgl. 3.2 ff.).

Durch diesen Subjektivismus knüpft die wertkritische Antisemitismuskritik, allerdings ungewollt, auch an die Widersprüche des Widerspiegelungsmarxismus an. ${ }^{1251}$ Man dachte ja eigentlich, dass man gerade mit der Wertkritik gegen den die Widerspiegelungstheorie offensiv formulierenden Marxismus-Leninismus angetreten sei und über diesen mit dem Fetischbegriff erhaben zu sein (vgl. hierzu 5.1.2). Mit ihrer Übernahme der Widerspiegelungstheorie kann eine emanzipative Überwindung der gegebenen gesellschaftlichen Verhältnisse von Postone und Grigat logisch ebenso wenig gedacht werden, weil ein kritischer Standpunkt des Denkens fernab der gesellschaftlichen Bedingtheit des Denkens und des Handelns aus dem notwendigen Warentausch logisch nicht mehr eingenommen werden könnte. Unter diesen Voraussetzungen der Kritik könnte sich die Kritik an Gesellschaft, wenn ein bestimmtes Urteil über den ihr nichtidentischen Gegenstand abgeleitet folgen muss, eben nicht mehr konsistent ausweisen. Durch die Notwendigkeit des

\footnotetext{
1251 Vgl. Lenin: Materialismus und Empiriokritizismus, S. 38: „Der Materialist Friedrich Engels z.B:, der nicht unbekannte Mitarbeiter von Marx und Mitbegründer des Marxismus, spricht in seinen Werken ständig und ausschließlich von den Dingen und ihren Gedankenabbildern, wobei es selbstverständlich ist, daß diese Gedankenabbilder nicht anders als aus den Empfindungen entstehen.“
} 
Resultats, wenn Warenform dann ,bestimmte Denkform Antisemitismus', könnte insofern also keine kritische Reflexion des eigenen Denkens durch das Subjekt mehr stattfinden.

Die Widerspiegelungstheorie hat nun konsequenterweise auch keinen Subjektbegriff, weil sie keinen braucht. Die Aufgabe des reflexiven Subjektbegriffs erweist sich für die wertkritischen Reflexionen deshalb auch nur als konsequent. Das notwendig falsch wahrgenommene gesellschaftliche Sein soll demnach unmittelbar das Bewusstsein in seiner Falschheit als antisemitisches Bewusstsein prägen. Dieses falsche Denken muss dabei nun aus einer undialektischen Identifikation von Subjekt und nichtidentischem Außen folgen. Als solch absolut aufeinander Verwiesenes sind beide Momente, Subjekt und Objekt, in sich identisch und das Objekt kann demnach auch nicht mehr auch als anderes, dem Subjekt vorrangiges, identifizierbar sein - Subjekt kann also nicht mehr als auch autonomes, widerständiges Subjekt gegenüber dem Objekt ausweisbar sein. Weil damit die Logik der Identität notwendig allein im Subjekt ist und aus diesem kommt, wird alles notwendig dialektisch über diese Identifikation hinaus seiende sogleich negiert (vgl. dazu 2.4.3). Das aber ist eine tautologische Konstruktion, die deshalb auch lediglich in den Grenzen der instrumentellen Subjektivität gefangen bleibt. Das Subjekt bliebe demnach auch in Zukunft notwendig in den gesellschaftlichen Verhältnissen gefangen, weil es aus der heteronomen Gesellschaft nicht, anders als oben bestimmt wurde (vgl. 2.3.1), als reflexives, widerständig vernünftiges Subjekt jemals noch emanzipativ heraustreten könnte. Damit also wird eine handfeste subjektivistische Aporie gezimmert, mit der, aufgrund ihrer eigenen Voraussetzungen, gesellschaftliche Emanzipation nicht mehr gedacht werden kann.

Gefordert wird nun dagegen aber, sowohl von Postone als auch von Grigat, die Bildung eines richtigen Bewusstseins, um dadurch den modernen Antisemitismus abzuschaffen, um also eine Korrektur des in der Verdinglichung des Warenfetischismus gefangenen falschen Bewusstseins zu erreichen. Eine solche Forderung muss sich dabei jedoch immer schon genau auf das oben von mir mittels der philosophischen Exkurse dargestellte reflexive, selbstbewusste Subjekt stützen, das einzig über sein eigenes, es präformierende Material der Möglichkeit nach reflexiv hinaus denken kann. Allein nämlich das selbstbewusste, widerständige Subjekt der Praxis kann sich aus dem eigenen Gefängnis des instrumentellen Daseins und Bewusstseins der Möglichkeit nach befreien. Eine solche Spontaneität des reflexiven Subjekts, das eben als lebendiges Subjekt auch und immer gegen seine gesellschaftlichen Bedingungen vernünftig denken kann, weil auch Praxis und Theorie nicht undialektisch ineinander fallen, wäre nun mit der wertkritischen Antisemitismustheorie durch ihre theoretische Anlehnung an die Widerspiegelungstheorie logisch gar nicht begründbar. Mit der subjektlosen identitätsphilosophischen Interpretation von (falschem) Bewusstsein und Sein wäre deshalb letzten Endes auch überhaupt keine wesentliche Erklärung der sozialen Verhältnisse und Phänomene mehr möglich. Denn wenn das Subjekt nicht auch als autonomes, 
widerständiges Subjekt trotz aller es instrumentalisierenden Heteronomie gedacht wird, ließe sich weder der Kapitalismus, noch der Antisemitismus, noch die Vorgeschichte des Antisemitismus oder auch die ihn transzendierenden Momente substantiell erklären. Nur deswegen, weil sich die subjektiven Denkformen als spontan erwiesen haben und eben nicht als gesellschaftlich notwendig und kausal aus Etwas entsprungene, und sie deshalb auch nicht gänzlich deterministisch in Gesellschaft aufgehen, sondern in ihnen selbst immer noch das Moment der Autonomie emphatisch vorausgesetzt wird, hat sich eine Kritik an den eigenen gesellschaftlichen Voraussetzungen oben überhaupt gegen jeden absoluten Verblendungszusammenhang erst als möglich erwiesen (vgl. dazu 2.3.2; 2.6.4). In dieser Untersuchung konnte auch bereits bewiesen werden, dass Dialektik ohne das Moment des Unmittelbaren gar nicht emanzipativ funktionieren kann (vgl. 2.4.3; 2.4.4; 2.4.5). Bei der wertkritischen Antisemitismustheorie fehlt diese Spontaneität des Subjekts jedoch genauso wie die dialektisch notwendige Vorrangigkeit der Materie, die in den Reflexionen zu Adornos negativer Dialektik zum Gegenstand wurden.

Dadurch, dass der im Fetischabschnitt gegenständliche Warenfetisch, dem als Erscheinungsform noch der reziproke Tausch von herrschaftslos produzierten Dingen zugrunde liegt, von Postone nun zum wesentlichen Abschnitt der Erklärung des Kapitalismus gemacht wird, wird von der adäquaten Wahrnehmung der Zirkulationssphäre durch das lebendige Subjekt insofern erwartet, dass sie rein aus sich heraus das falsche (nicht im Sinne des richtigen) Bewusstsein wie die falsche Wahrnehmung der eigentlich richtigen Tauschgesellschaft sei. In der Fetischtheorie Postones finden sich deshalb, durch seine eindimensionale Zentrierung auf den aus dem Gesamtzusammenhang der bürgerlichen Totalität herausgesprengten Fetisch, wie auch schon in der abbildtheoretischen Widerspiegelungstheorie des von Postone kritisierten Marxismus-Leninismus, notwendig idealistische Momente, die die wertkritische Theorie über den modernen Antisemitismus von einer wirklich materiellen Kritik der Gesellschaft entfernen. Das sinnlich wahrnehmbare Ding der kapitalistischen Außenwelt, die Ware, führe demnach für Postone notwendig zu seinem verkebrten Abbild im menschlichen Bewusstsein. Zu dieser negativen Widerspiegelung der Warenform im Bewusstsein komme es, weil von Postones wertkritischen Antisemitismustheorie die Autonomie des Objekts als widerständiges Moment gegen das Subjekt nicht anerkannt wird, genauso wenig wie auch das Moment der Autonomie des Subjekts gegen das determinierende Objekt anerkannt wird. Dergleichen undialektisch abbildtheoretisch könnte der Prozess der Erkenntnis jedoch überhaupt nur verlaufen, sobald logisch die sinnliche Erscheinung der Dinge die unmittelbare Manifestation ihres Wesens wäre. Insofern wären essentia und res in der Bestimmung des Fetischs der Wertkritik tautologisch wieder eins, dabei auch gleichgültig, ob aus der Warenform eine falsche, bestimmte Denkform folge. Das aber wäre nun ein Rückfall auf die Geschichte der Philosophie vor dem materialistischen Marx des Kapitals, der eine solche Tautologie hier 
implizit wie explizit vor allem mittels des objektiven Wertbegriffs und des nichtnominalistischen Arbeitsbegriffs kritisiert (vgl. etwa 2.5.2).1252

Die Wertkritik mündet so, durch ihre Bemühung des Fetischbegriffs und ihrer negativen Widerspiegelungstheorie, nun auch noch in einen reinen Materialismus. Weil er ein reiner Materialismus ist, kann er deshalb auch nicht sein, für was er sich hält: ein das Wesentliche erklärender Materialismus ${ }^{1253}$, der das dem Subjekt vorrangig Objektive, auch wenn es ,nur' der Gegenstand der Gesellschaft ist, emphatisch als transzendentes Objekt ernst nimmt. Der reine Materialismus der Wertkritik fällt deswegen auf die unweigerlichen Konstituentien der Realität zurück, die aber logisch als diese Realität in den Konstituentien nicht vollständig aufgehen kann. Dies aber ist der idealistischen, negativen Widerspiegelungstheorie der Wertkritik, genauso wie schon der Marxistisch-Leninistischen Widerspiegelungstheorie, kein Gegenstand. Durch eine Identifikation von Ding/Ware und Bewusstsein existiert kein dem Bewusstsein mehr vorrangig Nichtidentisches. Alles soll deshalb für die Wertkritik in der Identität eines noch herrschaftsfreien Äquivalententauschs aufgehen. Eine solche Verengung auf die begriffslogische Herleitung des Kapitalismus aus der aus logischen Gründen schon existierenden Ware in der Wertformanalyse, ohne dabei die historischen Implikationen zu seiner Durchsetzung und Erhaltung, auch in der Zirkulationssphäre selbst (vgl. 3), ernst zu nehmen, verweist wiederum auf den impliziten Idealismus der Form bei Postone und Grigat - der ein Resultat ihres theoretischen Subjektivismus ist.

Die wertkritische Antisemitismustheorie verzettelt sich also gerade durch die verabsolutierte Identifikationsbestimmung von Subjekt und Objekt ohne entsprechenden Subjektbegriff in einer positivistischen und nominalistischen Position. Ein vereinzeltes Element der kapitalistischen Produktionsweise wie der Warentausch - das eben auch noch allein aus der Empirie, der subjektiven Wahrnehmung der Zirkulation, stammt! -, soll demnach funktional für die Erkenntnis so wesentlicher Begebenheiten wie der kapitalistischen Produktion und der totalen gesellschaftlichen Herrschaft sein. Weil sich in der bei Marx noch von allem Inhalt gelösten Warenform und seiner fetischistischen Wahrnehmung, wie für Korsch (s.o.), angeblich der gesamte Materialismus gewissermaßen als Fingerabdruck des Ganzen finde, sei die Warenform insofern alleinige und wesentliche Grundlage einer materialistischen Gesellschaftskritik. Für die Erkenntnis der gesellschaftlichen Herrschaft und der reflexiven Kapitalakkumulation bedarf es nun jedoch der Erkenntnis von verschiedenen, vermittelten Momenten der politischökonomischen Totalität in sich, die in ihrer heteronomen Objektivität durch ihre naturgleichen Strukturgesetze, wenn auch nicht absolut, erkannt werden kann. Die Totalität der kapitalistischen Produktionsweise muss also durch das Subjekt insofern bestimmbar bleiben und sie ist deshalb auch nicht gleich etwas Irrationales,

1252 Vgl. Haag: Der Fortschritt in der Philosophie, S. 107 ff.

1253 Vgl. Grigat: Fetisch und Freiheit, S. 17. 
nur weil die Erkenntnis der Totalität nur begrifflich dargestellt werden kann und aus dem rein deiktischen Verfahren ausscheidet.

Dass die Totalität und damit die Gesellschaft nur begrifflich dargestellt werden kann, das wurde bereits mit dem Rückgriff auf den in der Wertkritik substantiell aufgegebenen objektiven Klassenbegriff nachgewiesen (vgl. 5.1.2). Der nur unter Bezug auf die objektive Stellung der Klasse aufs totale Gesamtkapital herauszuarbeitende Klassenbegriff ist dabei nicht der sinnlichen Erfahrung zugänglich, sondern der Klassengegensatz lässt sich erst durch die begriffliche Reflexion eines selbstbewussten Subjekts überhaupt erschließen: „Der Klassengegensatz ist der Erfahrung der Individuen entzogen, d.h. die konkrete Gestalt der Herrschaft ist in der bestehenden Gesellschaft nicht der Erfahrung, sondern nur der Reflexion zugänglich."1254 Aus dem Begriff des Warenfetischs aber konnte sich der objektive Klassenantagonismus der kapitalistischen Produktionsweise beispielsweise noch gar nicht deduzieren lassen; weshalb er von Grigat dann wohl auch aufgegeben wird (vgl. 5.1.2). Aus der Identität von Warenform und Denkform lässt sich demnach, also ohne die über die Wertformanalyse immer hinausgehende Geschichte, der tatsächliche Antagonismus der Klassen nicht erschließen, weil er auf eine vernünftige Reflexion eines selbstbewussten Subjekts verwiesen bleibt. Denn nur das autonome, nichtdeterminiert denkende Subjekt, das über die Instrumentalität der Gesellschaft hinausgehen kann, kann den wesentlichen Antagonismus der Gesellschaft reflexiv überhaupt noch erschließen. Die transzendente, objektive gesellschaftliche Herrschaft kann demnach nur durch das reflexive, gegen seine eigenen Voraussetzungen denken könnende Subjekt reflektiert werden. Die antagonistische, kapitalistische Klassengesellschaft muss insofern einen noumenalen, aber subjektiv immer erkennbaren Charakter haben, logisch also durch Theorie erfahrbar bleiben.

Von Postone und den wertkritischen Antisemitismustheoretikern wird diese Autonomie des Subjekts, gegen seine eigenen gesellschaftlichen Voraussetzungen denken zu können, durch die identitätsphilosophische Determination des Subjekts aus anderem, aus seinen Voraussetzungen, jedoch gerade abgeschafft. Postone kann sich deshalb, weil dergleichen kein kritischer Maßstab eines selbstbewussten Subjekts möglich ist, der Abschaffung des Antisemitismus im Resultat auch nur noch versichern, so wie die revolutionäre Aufhebung des Kapitalismus dann als anscheinend völlig spontane Aktion, also ohne jeden Denkprozess etc., einfach passieren solle. Die Spontaneität des Subjekts, die oben beschrieben wurde, ist und bleibt jedoch eine Spontaneität des Bewusstseins, die Wille und Handeln affektiert. Sie kann nicht eine bloße Spontaneität des Handelns sein, das seinen eigenen Zweck nicht kennt (vgl. dazu 2.3.2). Postone kann also durch die reine Ableitung der Denkformen aus der Warenform als identisch aus ihr entsprungene demnach kein wissenschaftliches Prinzip mehr angeben, wie es überhaupt zu einer Abschaf-

1254 Weyand: Adornos Kritische Theorie des Subjekts, S. 78. 
fung des Antisemitismus oder die ihn bedingenden gesellschaftlichen politischökonomischen Strukturen kommen kann. Die falsche Wahrnehmung des Verwertungsprozesses der Gesellschaft produziert ihm zufolge ja immer wieder nur ein falsches Bewusstsein, was im antisemitischen Handeln resultiert etc. In Bezug auf das zu denkende Befreiungsmoment der Gesellschaft vom Antisemitismus - als Gesamtsubjekt Gesellschaft, ohne als antagonistische Gesellschaft noch ,Feind des Subjekts' (vgl. 2.5.3) zu sein - bliebe somit auch einzig noch, wie schon bei Ernst Bloch in Bezug auf das Befreiungsmoment überhaupt, das „Prinzip Hoff-

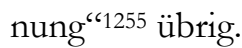

Ohne die sich selbstreflektierende, spontan bestimmte Vernunft des lebendigen Subjekts der Praxis, und damit, einen Schritt weitergedacht, eine die Zwecke der totalen Gesellschaft prüfenden Moral, kann die gesellschaftliche Freiheit von Postone also genauso wenig wie die Überwindung des Antisemitismus gedacht werden. Ohne die Moral, die die gesellschaftliche Produktion auf ihre Zwecke hin abklopft und nicht deterministisch in der Zirkulation der Wertformanalyse stecken bleibt, kann demnach also auch keine theoretische Kritik an den notwendig die Subjekte präformierenden antagonistischen Verhältnissen geäußert werden: „Die Unverträglichkeit der kapitalistischen Produktion mit gesellschaftlicher Produktion kann sich gar nicht aus bloß ökonomischen Betrachtungen ergeben, weil der Begriff einer wahrhaft gesellschaftlichen Produktion als Antizipation menschenwürdiger Verhältnisse schon geschichts- und moralphilosophische Elemente einbezieht." "1256 Jene moralphilosophischen und geschichtsphilosophischen Elemente wurden in dieser Arbeit in Kapitel 2 und 3 bereits erschlossen. Nur die normative Kritik kann demnach eine solide und konsistente Grundlage einer Gesellschaftskritik bilden, weil sie nicht in Form eines naturalistischen Fehlschlusses von den unmittelbaren Seinssätzen der politischen Ökonomie auf notwendig transzendente Sollenssätze schließt.

Der moderne Antisemitismus wird von der wertkritischen Antisemitismustheorie im Stile Postones und Grigats insofern mittels der verabsolutierten Verbindung von modernem Antisemitismus mit der kapitalistischen Gesellschaft, die dabei auf den Tausch in der Zirkulationssphäre restringiert wird, gleichzeitig derart universalisiert, dass dadurch dann auch noch die letzte Ecke von Freiheit in der bürgerlichen Gesellschaft okkupiert würde, indem die wertkritische Antisemitismustheorie das gegen seine eigenen Voraussetzungen der Möglichkeit nach spontan denken könnende selbstbewusste, lebendige Subjekt der Praxis aus der Theorie notwendig verbannt. Die bürgerliche Gesellschaft wird durch die verabsolutierte Verbindung von Antisemitismus und kapitalistischer Gesellschaft zu einer notwendig antisemitischen Gesellschaft ohne jeden Rückzugsort für die subjektive, freiheitliche Spontaneität, weshalb dann, selbstwidersprüchlich allemal, auch das substantielle kritische Denken gegen gesellschaftliche Phänomene wie den Anti-

1255 Bloch: Das Prinzip Hoffnung.

1256 Städtler: Geschichte oder Tendenz, S. 134. 
semitismus notwendig fehlt. Die bürgerliche Gesellschaft wird damit zu einer prinzipiell antisemitischen Gesellschaft aus sich selbst heraus. Zusammengefasst: Wenn also bürgerliche Gesellschaft und Warentausch, dann auch immer gleich der aus dem falschen Bewusstsein notwendig folgende moderne Antisemitismus.

Grigat sieht allerdings, dass der eigene Standpunkt der Kritik von Gesellschaft und dem sozialen Phänomen des modernen Antisemitismus viel zu eng gefasst ist, wenn aus der Warenform eine bestimmte Denkform, also ein Inhalt wie der moderne Antisemitismus, mit einem gewissen Automatismus folgen soll. Er versucht deshalb, die Postonesche These von der Warenform, aus der ein bestimmter und falscher Inhalt als Denkform sogleich entspringe, zu verkehren; dadurch versucht er, der aporetischen, deterministischen Widerspiegelung des Bewusstseins aus dem gesellschaftlichen Sein zu entgehen. Gegen die negative Widerspiegelungstheorie Postones schreibt er, dass nicht „der Warenform ein Bewußtseinsinhalt, sondern nur umgekehrt ein Bewußtseinsinhalt, in diesem Fall der moderne Antisemitismus, der Warenform zugeordnet" ${ }^{\text {"1257 }}$ werde. Aber beide Wendungen bauen - als ineinandergreifende Varianten, die Bewusstsein und Realität oder eben vice versa unmittelbar identifizieren - immer noch auf derselben idealistischen und widerspiegelungstheoretischen Aporie bei der Angabe des Maßstabs der Kritik auf. Von Grigat wird dadurch also auch nicht konsistent erklärt werden können, woher denn der antisemitische Inhalt des Bewusstseins, der dann der Warenform zugeordnet wird, überhaupt stamme.

1257 Grigat: Fetisch und Freiheit, S. 289. 



\section{Résumé}

Am Schluss einer wissenschaftlichen Untersuchung stellt sich die Frage, was aus ihr folgt, bzw. was aus den in ihr durchgeführten Reflexionen folgt. Dafür müssen sich die vielen Stunden des angestrengten, schweißtreibenden Denkens nochmals vor Augen geführt werden. Es ist hier im Résumé deshalb an der Zeit, die möglicherweise lose gebliebenen Fäden aus der Untersuchung zusammenzuknüpfen und auch die Scherben, die man in ihrem Laufe hoffentlich hier und da hinterließ, als wichtige Bausteine des Ganzen, als Bausteine einer kritischen Reflexion, zu identifizieren. Dadurch soll nicht positiv wieder etwas aufgebaut werden - vor allem, weil man sich ja gerade die Mühe machte zu beweisen, dass eine dialektische Kritik nicht hegelianisch in etwas Erbaulichem enden sollte. Sondern es soll in diesem Résumé den eigenen kritischen Gedanken insofern auch jenseits eines späten, versöhnenden Blicks auf den untersuchten Gegenstand Luft verschafft werden. Deshalb geht es hier insbesondere um die Reflexion des kritischen Gehalts der Untersuchung, und zwar mit der entscheidenden Frage im Hinterkopf, ob das kritische Projekt insgesamt gelungen ist - und sicherlich auch, was als Aufgabe für die Zukunft bleibt oder aus der Untersuchung folgt.

Schon als die erstmals bereits in der Einleitung dieser Untersuchung gestellte Frage nach dem Wesen des sozialen Phänomens moderner Antisemitismus aufkam war sofort auch die Totalität der Gesellschaft Gegenstand, von der der mo- 
derne Antisemitismus sich nicht abtrennen ließ. Der moderne Antisemitismus wurde insofern bereits in der Einleitung als ein Phänomen der bürgerlichen Gesellschaft verhaftet, weil ja jedes soziale Phänomen sich als ein Phänomen in und ein Phänomen der bürgerlichen Gesellschaft erweist, also als ein Phänomen, das seine wesentlichen Bedingungen in der bürgerlichen Gesellschaft und damit auch in ihrer spezifisch kapitalistischen Produktionsweise hat. Ziemlich schnell wurde dann in der Untersuchung, nämlich bereits in 2.1, deutlich, dass mit subjektivistischen Voraussetzungen, mit Wahrheitsfeindlichkeit, Faktenzentriertheit etc. (nicht nur) der Gegenstand der Antisemitismusforschung nicht zu begreifen ist. Um gegen den Positivismus und Subjektivismus substantiell etwas beweisend in der Hand zu haben wurde gezeigt, dass über die sozialen Fakten, den Antisemitismus in diesem Fall, genauso wie über bloße Definitionen des Antisemitismus hinausgegangen werden muss. Dabei wurde vor allem deutlich, dass man über den Positivismus nicht vermeintlich kritisch hinaus ist, nur weil man die Bestimmung relationaler Eigenschaften der Dinge favorisiert und alle Fakten als irgendwie miteinander zusammenhängend interpretiert - und letztendlich diesen Funktionszusammenhang Gesellschaft nennt. Solch ein Vorgehen erwies sich als nur scheinbar emanzipativ. Es wurde deshalb in der Untersuchung argumentiert, dass man die Fakten gegen den Positivismus substanziell als aus dem gesellschaftlichen Wesen stammend identifizieren und dann auch noch in den Kontext der gesellschaftlichen Totalität stellen muss. Dafür, so wurde oben deutlich, muss man sich jedoch intensiv mit Begriffen wie Wahrheit, Wesen, Totalität und Phänomen auseinandersetzen.

So wurden Wahrheit, Wesen, Totalität, Phänomen zu alles entscheidenden Termini, die in der Untersuchung selbstverständlich in einen entsprechenden intellektuellen Zusammenhang gestellt werden mussten. Dadurch, dass diese Begriffe emphatisch Gegenstand wurden konnte auch überhaupt erst fruchtbar erzählt werden, was denn z.B. den modernen Antisemitismus als soziales Phänomen überhaupt ausmacht. Die gesellschaftliche Totalität, in die das soziale Phänomen offensichtlich wesentlich eingebunden ist und bleibt, muss also eingehend emphatisch reflektiert werden, wenn man wahre Aussagen über das Phänomen Antisemitismus machen möchte. Dem modernen Antisemitismus als Phänomen erwies sich die bürgerliche Produktionsweise also dementsprechend als wesentlich. Die bürgerliche, kapitalistische Produktionsweise war wiederum nicht ohne einen emphatischen Begriff von der bürgerlichen Gesellschaft zu denken, weshalb der moderne Antisemitismus nicht ohne die Darstellung der gesamten bürgerlichen Totalität gedacht werden konnte, in deren Zusammenhang er ja unmittelbar steht.

Zunächst sollte in der Untersuchung, um die gesellschaftliche Totalität überhaupt als von jedem einzelnen Subjekt unabhängig denken zu können und auch um zu beweisen, dass die Objektivität, die Wahrheit etc. nicht etwas dem Objekt durch Subjekt wieder nur subjektivistisch übergestülptes ist, mit philosophischen Gedanken zu Wahrheit und Objektivität gearbeitet werden. Mit der hier in $2.2 \mathrm{ff}$. 
reflektierten Philosophie der Moderne, der Kants insbesondere, konnte dabei nachgewiesen werden, dass die Autonomie des Objekts - in dem Falle durch seine unbekannte Ursache aller Erscheinungen, dem Ding an sich - eine entscheidende antisubjektivistische Bestimmung genauso wie die Autonomie des Subjekts ist. Schon Kant geht in seinem transzendentalen Idealismus von einer gewissen Widerständigkeit beider in sich vermittelter Momente gegeneinander aus. Jener schon emanzipative Antisubjektivismus Kants, den er dann jedoch selbst, weil Idealist, wieder einkassierte, ist dabei zur entscheidenden Grundlage der kritischen Gesellschaftstheorie des Subjekts geworden. Das antisubjektivistische, emanzipative Moment Kants für eine kritische Theorie versuchte die Untersuchung in 2.3 deutlich zu machen, vor allem mit den Reflexionen Adornos auf das Kantische Transzendentalsubjekt. Mit seinen an Kant anschließenden Reflexionen, die den Gegenstand als dem Subjekt gegenüber notwendig transzendent bestimmen und die damit gegen den Idealismus schwere logische wie historische Geschütze gleichermaßen auffahren, weist Adorno nach, dass nicht nur der Naturgegenstand, sondern auch die auf strukturellen Gesetzen beruhende Gesellschaft etwas dem Subjekt gegenüber vorrangiges sei (vgl. 2.3 ff.). Weil das soziale Phänomen immer gleich in den totalen Zusammenhang von Gesellschaft fällt, kann es insofern also nur wirklich begriffen werden, wenn die Vorrangigkeit der Gesellschaft als eine zweite Natur ernst genommen wird und das Phänomen eben nicht tautologisch aus dem Subjekt konstruiert wird. Das wurde dann in der Untersuchung in 2.5 mit Marxschen Bestimmungen zum Wesen und dem an Marx anschließenden Unwesensbegriff von Adorno weiter ausgeführt. Der Unwesensbegriff Adornos machte dabei auch nochmals vor allem die Vermittlung von antagonistischer Gesellschaft und sozialem Phänomen deutlich.

Daran anschließend konnte in der Untersuchung auch noch gezeigt werden, dass das Handeln der Subjekte in der Gesellschaft nicht etwa ein autonomes Handeln ist, sondern durch die Eingebundenheit des Subjekts in die gesellschaftliche Totalität, die wiederum eigene Zwecke autonom verfolgt, eingebunden bleibt. Das ist ein entscheidender Faktor bei der Bestimmung des subjektiven Handelns, das so in 2.6 in den Zusammenhang der gesellschaftlichen Totalität eingebunden wurde. Durch diese Eingebundenheit des subjektiven Handelns in die gesellschaftliche Totalität konnte auch die Ideologie des Individualismus als eine nur verkümmerte Kritik an Gesellschaft herausgestellt werden, an deren Verkümmertheit aber zumindest so viel wahr ist, dass der Individualismus dem Subjekt das predigt, was es ohnehin in der Gesellschaft zu tun hat: sich um seine Selbsterhaltung möglichst gewinnbringend selbst zu kümmern. Jeder kulturell propagierte Individualismus, der auf eine gewisse Extravaganz einzelner Personen setzt, zeigt im Endeffekt nun auch genau das gewinnbringende Moment für das Subjekt auf: Das Subjekt macht sich und seine ,Persönlichkeit‘ zur Marke, um sich dadurch letztendlich selbst besser vermarkten zu können. Die das Subjekt mit seinem Handeln, Denken, seinen Bedürfnissen etc. einbindende gesellschaftliche Totalität selbst wurde inso- 
fern auch deshalb ein konkreter Gegenstand der Untersuchung, um das, was hinter den Phänomenen das Subjekt auch in seinem Handeln bestimmt, einmal als derart wesentliche Bestimmung aufzuzeigen. So wurden zum einen die Zwecke deutlich gemacht, die die historische Totalität der bürgerlichen Gesellschaft erst bedingten, genauso wie die Rationalität der bürgerlichen Gesellschaft sowohl in ihrer Form wie dialektisch begriffen auch bei der Organisation der allgemeinen Reproduktion nachgewiesen wurde. Entscheidend blieb dabei immer der Hinweis darauf, dass in beiden sich aus der Geschichte der Aneignung ergebenden Klassen, deren Bestimmung sich objektiv aufs gesellschaftliche Gesamtkapital bezieht, kein Subjekt, egal welcher Klasse es angehört, sich von aus dieser Geschichte resultierendem Zwang und Herrschaft freimachen kann. Das ist mit den Bestimmungen zum ideellen Gesamtkapitalisten Staat als entscheidende Herrschaftsinstanz geschehen.

Diese Bestimmungen der gesellschaftlichen Herrschaft auf jedes einzelne Subjekt zogen sich wie ein roter Faden durchs 3. Kapitel der Untersuchung. Hier wurde nicht nur insbesondere in 3.1.1 deutlich, dass die Konkurrenz das alles entscheidende Moment der kapitalistischen Produktionsweise ist. Die Konkurrenz von allen Klassenmitgliedern untereinander konnte dabei als wesentlich für die Subjekte der Praxis bei der Realisierung ihrer eigenen Lebenserhaltung, als entscheidend beim Kampf ums Überleben dargestellt werden. Als Einzelner, oder besser: als auf sich allein gestelltes Subjekt der Praxis, so konnte nachgewiesen werden, kann man in der bürgerlichen Gesellschaft überhaupt nicht überleben. In der kooperativ in den Naturzusammenhang eingreifenden Gesellschaft hat man seine eigene Reproduktion notwendig mit anderen und durch andere zu realisieren. Ohne, dass in diesem Zusammenhang der eigenen Reproduktion ein gewisses ,Durchsetzungsvermögen' entwickelt wird, kann das Subjekt der Praxis in der bürgerlichen Gesellschaft nicht überleben. Gegen die eigene, klasseninterne Konkurrenz braucht es deshalb immer entscheidende Vorteile, die das allgemeine Recht hingegen formell nicht liefert (vgl. 3.2 ff.). Der Antisemitismus erweist sich deshalb als ein entsprechendes Moment, das einen entscheidenden Vorteil für das Subjekt der Praxis bei der Realisation seiner Selbsterhaltung bedeuten kann. Obwohl es aus rein juristisch formellen Gründen den Antisemitismus in der bürgerlichen Gesellschaft, und damit auch deren Ideologie nach, nicht geben dürfte, gibt es ihn praktisch in der bürgerlichen Gesellschaft aus den Gründen des Zwangs zur eigenen Reproduktion dennoch. Die eigene Reproduktion wird einfacher, wenn eine Gruppe, der man nicht angehört, aus dem Pool der Konkurrenten ausgestoBen wird.

Weil in 3.2.2 der Untersuchung dann verdeutlicht wurde, wie der bürgerliche Staat selbst schon bestimmt, welches Subjekt welche Rechte auf seinem Hoheitsgebiet hat, konnte hier offensichtlich werden, dass sich eben auch nicht alle Subjekte im Staat auf die gleichen Rechte in gleicher Weise berufen können und das wiederum trotzdem nicht der formellen Gleichheit, wie mit Kelsen bewiesen, 
entgegensteht; der Staat gruppiert also durch die formelle Gleichheit hindurch. Das überhaupt gibt der Unterscheidung von Subjekten in Menschengruppen erst ihr fundamentum in re: „Die Konstruktion von biologischen Menschenrassen, die sich dann kulturell hierarchisieren lassen, läßt sich wissenschaftlich nicht halten. Aber offensichtlich besteht auch ein tiefes Bedürfnis von Menschengruppen, sich von anderen abzugrenzen und die spontane Bevorzugung des Eigenen vor dem Fremden oder Anderen zu legitimieren." 1258 In der Darstellung der Totalität wurde deshalb darauf hingewiesen, dass ein Vorteil gegenüber der Konkurrenz, die sich z.B. auf den Schutz des ,fremden' Staates nicht wirklich berufen kann etc., nicht nur das einzelne Subjekt scheinbar besser dastehen lässt: Die allgemeine Konkurrenz kann demnach auch begründen, warum es so etwas wie einen Antisemitismus ohne Juden gibt. Das antisemitische Subjekt, das sich gegen seine eigene quantité negliable vehement zu wehren versucht, verweist dabei auf die Subjekte, die historisch schon seit längerer Zeit ganz offen quantité negliable sind: die Juden. Darüber sichert sich das Subjekt zum einen entweder eine psychische Genugtuung oder eben zum anderen, viel entscheidender: mögliche materielle Vorteile.

Gerade weil der moderne Antisemitismus Ideologie ist, erwies er sich darum als wahr und falsch zugleich. Wahr ist er, weil die bürgerliche Gesellschaft ihn wahr macht, und er in ihr sein fundamentum hat. Im Rahmen der Untersuchung wurde gezeigt, dass jeder Akt, die Konkurrenz auszustechen, sich in der bürgerlichen, kapitalistischen Gesellschaft als ein rationaler Akt im Kampf um die eigene Selbsterhaltung erweist. Um möglichst rational Konkurrenten auszuschalten sucht man sich deshalb bereits historisch stigmatisierte Gruppen wie die Juden aus. Antisemitisches Handeln bekommt dadurch eine gesellschaftliche Rationalität, weil die kapitalistische Produktionsweise diese Rationalität des Subjekts fordert. Falsch und irrational ist der Antisemitismus, und das ist entscheidend, weil das Subjekt dann doch keinen entscheidenden gesellschaftlichen Vorteil durch ihn erfährt - das aber nur, wenn man die Totalität der bürgerlichen Gesellschaft reflektiert. Insgesamt kann man die bürgerliche Gesellschaft zwar, so wie sie in der Untersuchung dargestellt wurde, als eine herrschaftliche, jedes Subjekt zwingende kapitalistische Gesellschaft bestimmen. Dieser Herrschaft und dieses Zwangs aber bedarf es jedoch nicht, denn aus der Perspektive des gesellschaftlich Ganzen erweisen sie sich auch im Rahmen dieser Untersuchung als irrational. Die Zwecke des Einzelnen erweisen sich insgesamt nie als der Zweck der Einrichtung der kapitalistischen Gesellschaftsform, und der Einzelne hat deshalb auch generell nichts von ihrer Einrichtung. Insofern wurde in dieser Untersuchung die Gesellschaft, in der ein Phänomen wie der moderne Antisemitismus entstehen kann, nicht als freie, emanzipative und aufgeklärte Gesellschaft dargestellt; und aus der herausgearbeiteten gesellschaftlichen Unfreiheit entsteht ein gesellschaftliches Phänomen wie der moderne Antisemitismus erst.

1258 Claussen, Was heißt Rassismus?, S. 2. 
Insofern liegt das fundamentum in re des modernen Antisemitismus in der bürgerlichen Gesellschaft und ihrer systematischen Konkurrenz. Der moderne Antisemitismus ist deshalb auch nicht irrational, sondern lässt sich rational in die gesellschaftlichen Zwecksetzungen des einzelnen Subjekts einordnen. Der moderne Antisemitismus entspringt der bürgerlichen Gesellschaft darum auch nicht notwendig, sondern aus bestimmten gesellschaftlichen, systematischen Gründen der gesellschaftlichen Herrschaft. Der moderne Antisemitismus ist darum auch nicht ohne die bürgerliche, kapitalistische Gesellschaft zu denken; aber eine bürgerliche Gesellschaft könnte sehr wohl ohne das konkrete Phänomen Antisemitismus gedacht werden, wenn andere soziale Phänomene seinen Platz einnehmen - was allerdings zum jetzigen Zeitpunkt der Geschichte recht unwahrscheinlich ist.

Dass die Gesellschaft nun nicht die Zwecke des einzelnen Subjekts verfolgt, sondern diese immer nur zu Mitteln im gesellschaftlichen Reproduktionsprozess zum Zweck der Produktion des gesellschaftlichen Reichtums herabstuft, war ein ausgebreiteter, entscheidender Gegenstand in dieser Arbeit. All diese Dinge sind deshalb zu reflektieren, wenn man den modernen Antisemitismus als ein soziales Phänomen beschreibt, das in der heutigen Gesellschaft leider eine unerwartet offene, allerorten sichtbare Renaissance erfährt. Man kann zwar viel Vereinzeltes dafür verantwortlich machen, warum der moderne Antisemitismus in der Form existiert, wie er existiert: Wirtschaftskrise, allgemeine Perspektivlosigkeit, hohe Arbeitslosigkeit, schlechte Bildung etc. Doch mit der Untersuchung konnte entscheidend bewiesen werden: Dies als entscheidende Ursache für den sich gesellschaftlich verstärkt artikulierenden Antisemitismus anzuführen ist zwar für etwaige präzise Analysen des Phänomens wichtig - doch wesentlich wirken hinter dem Gesellschaftsphänomen gesellschaftliche Kräfte ökonomischer Natur, die so einfach nicht aus der Welt zu schaffen sind, wie die Untersuchung bewies; weshalb der moderne Antisemitismus auch nicht so einfach aus der Welt zu schaffen ist, selbst wenn man partikulare Momente seiner Existenz in den Griff bekommen sollte. 


\section{Literaturverzeichnis}

Abendroth, Wolfgang: Das Grundgesetz. Eine Einführung in seine politischen Probleme, Pfullingen 1966.

abmahnung.org: Arbeitszeitbetrug. Arbeitsrechtliche Abmahnung: Betrug bei der Arbeitszeit, http://www.abmahnung.org/arbeitszeitbetrug/

(Zuletzt abgerufen 15.06.2016).

Adler, Alfred: Menschenkenntnis, Frankfurt a.M. 1972.

Adorno, Theodor W.: Anmerkungen zum sozialen Konflikt heute, GS 8, Frankfurt a.M. 1998.

Adorno, Theodor W.: Ästhetische Theorie, GS 7, Frankfurt a. M. 1998.

Adorno, Theodor W.: Beitrag zur Ideologienlehre, GS 8, Frankfurt a.M. 1998.

Adorno, Theodor W.: Die Aktualität der Philosophie, GS 1, Frankfurt a.M. 1998.

Adorno, Theodor W.: Drei Studien zu Hegel, GS 5, Frankfurt a.M. 1998.

Adorno, Theodor W.: Einleitung zu Emile Durkheim, ,Soziologie und Philosophie', GS 8, Frankfurt a.M. 1998.

Adorno, Theodor W.: Einleitung zum ,Positivismusstreit in der deutschen Soziologie', GS 8, Frankfurt a.M. 1998.

Adorno, Theodor W.: Glosse über Persönlichkeit, GS 10.2, Frankfurt a.M. 1998.

Adorno, Theodor W.: Gesellschaft, GS 8, Frankfurt a.M. 1998.

Adorno, Theodor W.: Gesellschaftstheorie und empirische Forschung, Gesammelte Schriften 8, Frankfurt a.M. 1998.

Adorno, Theodor W.: Kants ,Kritik der reinen Vernunft‘, Frankfurt a.M. 1995.

Adorno, Theodor W.: Marginalien zu Theorie und Praxis, GS 10.2, Frankfurt a.M. 1998.

Adorno, Theodor W.: Meinung, Wahn, Gesellschaft, GS 10.2, Frankfurt a.M. 1998.

Adorno, Theodor W.: Metaphysik. Begriff und Probleme, Frankfurt a.M. 2006.

Adorno, Theodor W.: Minima Moralia, GS 4, Frankfurt a.M. 1998.

Adorno, Theodor W.: Negative Dialektik, GS 6, Frankfurt a.M. 1998.

Adorno, Theodor W.: Notiz über sozialwissenschaftliche Objektivität, GS 8, Frankfurt a.M. 1998.

Adorno, Theodor W.: Ontologie und Dialektik, Frankfurt a.M. 2008.

Adorno, Theodor W.: Philosophische Terminologie, Band 1, Frankfurt a.M. 1973.

Adorno, Theodor W.: Postscriptum, GS 8, Frankfurt a.M. 1998.

Adorno, Theodor W.: Probleme der Moralphilosophie, Frankfurt a.M. 2010.

Adorno, Theodor W.: Reflexionen zur Klassentheorie, GS 8, Frankfurt a.M. 1998. 
Adorno, Theodor W.: Sexualtabu und Recht heute, Gesammelte Schriften Bd. 10.2, Frankfurt a.M. 1998.

Adorno, Theodor W.: Soziologie und empirische Forschung, in, ders.,

Gesammelte Schriften Bd. 8, Frankfurt a.M. 1998.

Adorno, Theodor W.: Spätkapitalismus oder Industriegesellschaft, GS 8, Frankfurt a. M. 1998.

Adorno, Theodor W.: Studies in the Authoritarian Personality, GS 9.1, Frankfurt a.M. 1998.

Adorno, Theodor W.: Thesen über Bedürfnis, GS 8, Frankfurt a.M. 1998.

Adorno, Theodor W.: Über Statik und Dynamik als soziologische Kategorien, GS 8, Frankfurt a.M. 1998.

Adorno, Theodor W.: Vorlesungen über Negative Dialektik, Frankfurt a. M. 2007.

Adorno, Theodor W.: Vorlesung zur Einleitung in die Erkenntnistheorie, Frankfurt a.M. o.J.

Adorno, Theodor W.: Vorlesung zur Einleitung in die Soziologie, Frankfurt a.M. 1973.

Adorno, Theodor W.: Vorworte zu den ,Frankfurter Beiträgen zur Soziologie (Paul W. Massing, Vorgeschichte des politischen Antisemitismus, Frankfurt a.M. 1959), GS 20.2, Frankfurt a.M. 1998.

Adorno, Theodor W.: Was bedeutet: Aufarbeitung der Vergangenheit, GS 10.2, Frankfurt a.M. 1998.

Adorno, Theodor W.: Zu Subjekt und Objekt, GS 10.2, Frankfurt a.M. 1998.

Adorno, Theodor W.: Zum Verhältnis von Soziologie und Psychologie, GS 8, Frankfurt a. M. 1998.

Adorno, Theodor W.: Zur Bekämpfung des Antisemitismus heute, GS 20.1, Frankfurt a.M. 1998.

Adorno, Theodor W:: Zur gesellschaftlichen Lage der Musik, GS 18, Frankfurt a.M. 1998.

Adorno, Theodor W.: Zur Lehre von der Geschichte und von der Freiheit, Frankfurt a. M. 2006.

Adorno, Theodor W.: Zur Metakritik der Erkenntnistheorie, GS 5, Frankfurt a.M. 1998.

Adorno, Theodor W./Horkheimer, Max: Dialektik der Aufklärung. Philosophische Fragmente, GS 3 (Adorno), Frankfurt a.M. 1998.

Agamben, Giorgio: Homo Sacer. Die souveräne Macht und das nackte Leben, Frankfurt a. M. 2002.

von Alemann, Heine (Hrsg.): René König Schriften, Zur Konstitution moderner Gesellschaften. Studien zur Frühgeschichte der Soziologie, Opladen 2000.

Allport, Gordon W.: The Nature of Prejudice, Cambridge 1954. 
Allport, Gordon W.: Vorwort, in: Simmel, Ernst (Hrsg.): Antisemitismus, Frankfurt a. M. 2002.

Altenmüller, Hartwig/Moussa, Ahmed: Die Inschrift Amenemhets II. aus dem Ptah-Tempel von Memphis. Ein Vorbericht., in: Studien zur Altägyptischen Kultur 18, Hamburg 1991.

amadeu-antonio-stiftung.de: Vorstellungstext, http:/ /www.amadeu-antoniostiftung.de/wir-ueber-uns / (Zuletzt abgerufen 08.02.2016).

amadeu-antonio-stiftung.de: Was ist Antisemitismus?, http://www.amadeuantonio-stiftung.de/die-stiftung-aktiv/themen/gegen-as/antisemitismusheute/ (Zuletzt abgerufen 08.02.2016).

amnesty.de: Menschenrechte sind grenzenlos, https://www.amnesty.de/jahresbericht/2013/menschenrechte$\%$ E2\%80\%A8sind-grenzenlos (Zuletzt abgerufen 04.01.2018)

Anderson, Benedict: Die Erfindung der Nation. Zur Karriere eines folgenreichen Konzepts, Frankfurt a. M. 1996.

Apel, Karl-Otto: Transformation der Philosophie, 2 Bände, Frankfurt a.M. 1973.

von Aquin, Thomas: Summa Theologiae, http://www.corpusthomisticum.org/sth1015.html\#29338

(Zuletzt abgerufen 20.01.2016).

archive.org: Rede von Bundespräsident Roman Herzog vor der EnqueteKommission ,SED-Diktatur“ in Berlin, https://web.archive.org/web/ 20090611035320/http://www.bundespraesident.de/-,2.12036/Rede-vonBundespraesident-Roma.htm?global.printview $=2$

(Zuletzt abgerufen 25.06.2016).

archives.org: Declaration of Independence, http:/ /www.archives.gov/exhibits/ charters/declaration_transcript.html (Zuletzt abgerufen 23.07.2014).

Arendt, Hannah: Elemente und Ursprünge totaler Herrschaft. Antisemitismus, Imperialismus, totale Herrschaft, Frankfurt a.M. 2003.

Arendt, Hannah: Macht und Gewalt, München 2003.

Aristoteles: Metaphysik. Übersetzt, mit einer Einleitung versehen von Hans Günther Zekl, Würzburg 2003.

Aristoteles: Politik, München 2003.

Aron, Raymond: Hauptströmungen des soziologischen Denkens, Erster Band, Köln 1971.

Austin, John L.: Zur Theorie der Sprechakte (How to do things with words), Stuttgart 2002.

Backhaus, Hans-Georg: Dialektik der Wertform. Untersuchungen zur Marxschen Ökonomiekritik, Freiburg 1997.

Bakunin, Michail: Gott und der Staat, Grafenau 1998. 
Beck, Ulrich: Risikogesellschaft, Frankfurt a. M. 1986.

Becker-Schmidt, Regina: Adornos Gesellschaftstheorie. Anstoß für feministische

Kritik und Herausforderung zum Weiterdenken, in: Zuckermann, Moshe

(Hrsg.): Theodor W. Adorno, Philosoph des beschädigten Lebens, Göttingen 2004.

Beckett, Samuel: Warten auf Godot, Frankfurt a.M. 2011.

Bein, Alex: Die Judenfrage. Biographie eines Weltproblems, Band 2, Stuttgart 1980.

Benjamin, Walter: Der Begriff der Kunstkritik in der deutschen Romantik, Frankfurt a.M. 1973.

Benjamin, Walter: Gesammelte Schriften, Bd. V.1, Frankfurt a. M. 1996.

Benjamin, Walter: Sprache und Geschichte. Philosophische Essays (Über den Begriff der Geschichte), Stuttgart 1992.

Benjamin, Walter: Über den Begriff der Geschichte, in: ders.: Sprache und Geschichte. Philosophische Essays, Stuttgart 2005.

Bensch, Hans-Georg: Vom Reichtum der Gesellschaften. Mehrprodukt und

Reproduktion als Freiheit und Notwendigkeit in der Kritik der Politischen

Ökonomie, Lüneburg 1995.

Bensch, Hans-Georg/Kuhne, Frank (Hrsg.): Das Automatische Subjekt bei Marx.

Studien zum Kapital, Lüneburg 1998.

Benz, Wolfgang: Was ist Antisemitismus, Bonn 2004.

Berger, Maxi: Arbeit, Selbstbewusstsein und Selbstbestimmung bei Hegel. Zum

Wechselverhältnis von Theorie und Praxis, Berlin 2012.

Berger, Peter L./Luckmann, Thomas: Die gesellschaftliche Konstruktion der

Wirklichkeit, Frankfurt a. M. 1980.

Bergmann, Werner: Geschichte des Antisemitismus, München 2006.

Bergmann, Werner: Was sind Vorurteile?, in: Informationen zur politischen

Bildung: Vorurteile (Heft 271), 2005.

Bergmann, Werner: Politische Psychologie des Antisemitismus. Kritischer Literaturbericht, in: König, Helmut (Hrsg.): Politische Psychologie heute, Leviathan Sonderheft Nr. 9/1988, S. 217-234.

bildblog.de: Selfies gegen Griechenland. Presserat missbilligt ,Bild‘, http://www.bildblog.de/tag/pleite-griechen/ (Abgerufen 28.04.2016).

Bloch, Ernst: Das Prinzip Hoffnung (3 Bände), Frankfurt a.M. 1970.

Bloch, Ernst: Subjekt-Objekt. Erläuterungen zu Hegel, Frankfurt a. M. 1972.

bmfsfj.de: Schwangerschaftsabbruch nach \218 Strafgesetzbuch, http:/ / www.bmfsfj.de/BMFSFJ/gleichstellung,did=98262.html (Zuletzt abgerufen 30.05.2016). 
Bourdieu, Pierre: Die feinen Unterschiede. Kritik der gesellschaftlichen Urteilskraft, Frankfurt a.M. 1982.

Brainin, Elisabeth: Psychoanalyse des Antisemitismus nach 1945, in: Alphons Silbermann/Julius H. Schoeps (Hrsg.), Antisemitismus nach dem Holocaust. Bestandsaufnahme und Erscheinungsformen in deutschsprachigen Ländern, London/Köln 1986.

von Braun, Christina/Heid, Ludger: Der ewige Judenhass. Studien zur Geistesgeschichte Bd. 12, Berlin 2006.

Brecht, Bertolt: Zum Freitod des Flüchtlings W.B., in: Bertolt Brecht, Werke 4 (Gedichte), Frankfurt a.M. 2005.

Breidbach, Olaf: Die Materialisierung des Ichs. Zur Geschichte der Hirnforschung im 19. und 20. Jahrhundert, Frankfurt a.M., 1997.

Bremer, Helmut/Lange-Vester, Andrea: Soziale Milieus und Wandel der Sozialstruktur, Wiesbaden 2007.

Broder, Henryk M.: Der ewige Antisemit. Über Sinn und Funktion eines beständigen Gefühls, Frankfurt a.M. 1986.

Brown, Susan Love: The Free Market as Salvation from Government: The Anarcho-Capitalist View, in: Carrier, James G. (Hrsg.): Meanings of the Market: The Free Market in Western Culture, Oxford 1997.

Bruhn, Joachim: Studentenfutter. Über die Transformation der materialistischen Kritik in akademischen Marxismus. Antwort auf Ingo Elbe, http://www.ca-ira.net/isf/beitraege/bruhn-studentenfutter.html (Zuletzt abgerufen 15.04.2015).

Brunner, Markus: Entfremdete Menschen, verdinglichte Verhältnisse, http://soziologie.ch/sozmag/sozmag-8/entfremdete-menschenverdinglichte-verhaltnisse.html (Zuletzt abgerufen 14.05.2016).

Bulthaup, Peter: Das Recht der Logik, in: drslb.: Das Gesetz der Befreiung. Und andere Texte, Lüneburg 1998.

Bulthaup, Peter: Die transzendentale Einheit der Apperzeption, das System des Wissens und der Begriff gesellschaftlicher Arbeit, in: drslb.: Zur gesellschaftlichen Funktion der Naturwissenschaften, Lüneburg 1996.

Bulthaup, Peter: Die wissenschaftliche Hochschule: Staatsanstalt oder Gelehrtenrepublik, in: drslb.: Das Gesetz der Befreiung. Und andere Texte, Lüneburg 1998.

Bulthaup, Peter: Elemente des Antisemitismus. Ohne Untertitel, in: drslb.: Das Gesetz der Befreiung. Und andere Texte, Lüneburg 1998.

Bulthaup, Peter: Idealistische und materialistische Dialektik, in: drslb.: Das Gesetz der Befreiung. Und andere Texte, Lüneburg 1998.

Bulthaup, Peter: Herrschaft, Sprache und Revolution, in: drslb.: Das Gesetz der Befreiung. Und andere Texte, Lüneburg 1998. 
Bulthaup, Peter: Möglichkeiten und Grenzen philosophischer Naturerkenntnis, in: drslb.: Das Gesetz der Befreiung. Und andere Texte, Lüneburg 1998.

Bulthaup, Peter: Rechtspragmatik oder von der Zwangsläufigkeit des sittlichen Verfalls der Justiz, in: drslb.: Das Gesetz der Befreiung. Und andere Texte, Lüneburg 1998.

Bulthaup, Peter: Von der Freiheit im ökonomischen Verstande, in: Bensch, HansGeorg/Kuhne, Frank: Das Automatische Subjekt bei Marx, Lüneburg 1998.

Bulthaup, Peter: Zum Problem des Übergangs vom Feudalismus zum Kapitalismus, in: drslb.: Zur gesellschaftlichen Funktion der Naturwissenschaften, Lüneburg 1996.

Bundesministerium für Familie, Senioren, Frauen und Jugend: Gleichstellungspolitik. Politik für Frauen und Männer, http://www.bmfsfj.de/BMFSFJ/ gleichstellung,did=98262.html (Zuletzt abgerufen 30.05.2016).

bundespraesident.de: Rede von Bundespräsident Roman Herzog vor der Enquete-Kommission „,SED-Diktatur“ in Berlin, https://web.archive.org/web/ 20090611035320/http:/ /www.bundespraesident.de/-,2.12036/Rede-vonBundespraesident-Roma.htm?global.printview $=2$ (Zuletzt abgerufen 25.06.2016).

Butler, Judith: Körper von Gewicht. Die diskursiven Grenzen von Geschlecht, Berlin 1995.

Canterbury, Anselm von: Proslogion/Anrede, Stuttgart 2005.

Cassirer, Ernst: Substanzbegriff und Funktionsbegriff, Werksausgabe Bd. 6, Hamburg 2000.

Claussen, Detlev: Grenzen der Aufklärung. Die gesellschaftliche Genese des modernen Antisemitismus, Frankfurt a.M. 2005.

Claussen, Detlev: List der Gewalt. Zur gesellschaftstheoretischen Analyse sozialrevolutionärer Gewalt, Univ.Diss. 1978.

Claussen, Detlev: Vergangenheit mit Zukunft. Über die Entstehung einer neuen deutschen Ideologie, in: drslb.: Aspekte der Alltagsreligion. Ideologiekritik unter veränderten gesellschaftlichen Verhältnissen, Frankfurt a.M. 2000.

Claussen, Detlev: Vom Judenhass zum Antisemitismus, in: drslb.: Aspekte der Alltagsreligion. Ideologiekritik unter veränderten gesellschaftlichen Verhältnissen, Frankfurt a.M. 2000.

cnn.com: To Russia with love? Transnistria, a territory caught in a time warp. http:/ / edition.cnn.com/2014/04/11/world/europe/moldova-russia-frozenconflict/ (Zuletzt abgerufen 28.04.2016).

Comte, Auguste: Die Soziologie. Die positive Philosophie im Auszug (Cours de philosophie positive), Stuttgart 1974. 
conseil-constitutionnel.fr: Déclaration des Droits de l'Homme et du Citoyen de 1789, http://www.conseil-constitutionnel.fr/conseil-constitutionnel/ francais/la-constitution/la-constitution-du-4-octobre-1958/declaration-desdroits-de-l-homme-et-du-citoyen-de-1789.5076.html (Zuletzt abgerufen am 23.07.2014).

Dahrendorf, Ralf: Gesellschaft und Demokratie in Deutschland, München 1977.

Dahrendorf, Ralf: Gesellschaft und Freiheit, München 1961.

David, Marian: The Correspondence Theory of Truth, http://plato.stanford.edu/ entries/truth-correspondence/\#1 (Stanford Encyclopedia of Philosophy), (Zuletzt abgerufen 30.06.2016).

Dawkins, Richard: The Selfish Gene, Oxford 1989.

dejure.org: BGB \ 903. Befugnisse des Eigentümers, https://dejure.org/gesetze/ BGB/903.html (Zuletzt abgerufen 16.07.2016).

dejure.org: Grundgesetz, Artikel 14, http://dejure.org/gesetze/GG/14.html (Zuletzt abgerufen 26.01.2016).

dejure.org: Neuntes Buch Sozialgesetzbuch, Rehabilitation und Teilhabe behinderter Menschen, https://dejure.org/gesetze/SGB_IX/2.html (Zuletzt abgerufen 26.01.2016).

dejure.org: Strafgesetzbuch, http://dejure.org/gesetze/StGB/1.html. (Zuletzt abgerufen 09.06.2016).

Demirovic, Alex: Das Wahr-Sagen des Marxismus: Foucault und Marx, in: PROKLA 38: 2, 179-201.

derstandard.at: Occupy Wall Street. Die antisemitische Schattenseite der Occupy Bewegung, http://derstandard.at/1319181371952/Occupy-Wall-Street-Dieantisemitische-Schattenseite-der-Occupy-Bewegung (Zuletzt abgerufen 10.08.2016).

derstandard.at: Wie entsteht das Gefühl, Teil einer Nation zu sein?, http://derstandard.at/2000003686863/Wie-entsteht-das-Gefuehl-Teil-einerNation-zu-sein (Zuletzt abgerufen 03.07.2016).

Derrida, Jacques: Die Schrift und die Differenz, Frankfurt a.M. 1972.

Derrida, Jacques: Am Nullpunkt der Verrücktheit - Jetzt die Architektur, in: Welsch, Wolfgang (Hrsg.): Wege aus der Moderne. Schlüsseltexte der Postmoderne-Diskussion, Berlin 1994.

Descartes, René: Abhandlung über die Methode des richtigen Vernunftgebrauchs, Heidelberg 1969.

Descartes, René: Über den Menschen sowie Beschreibung des menschlichen Körpers, Heidelberg 1969.

Descartes, René: Meditationen, Hamburg 2009.

Descartes, René: Philosophische Schriften in einem Band, Hamburg 1996. 
deutschlandradiokultur.de: Zehn Jahre nach den Unruhen in den französischen Banlieues, http:/ /www.deutschlandradiokultur.de/zehn-jahre-nach-denunruhen-als-frankreichs-vorstaedte.979.de.html?dram:article_id=335086 (Zuletzt abgerufen 05.12.2015).

Diels, Hermann: Parmenides. Lehrgedicht, Berlin 2003.

Diner, Dan (Hrsg.): Ist der Nationalsozialismus Geschichte? Zu Historisierung und Historikerstreit, Frankfurt a.M. 1987.

Döblin, Alfred: Berlin Alexanderplatz, Düsseldorf/Zürich 2002.

Dreher, Thomas: Aktionstheater als Provokation: groteske Körperkonzeption im Wiener Aktionismus, http://www.dreher.netzliteratur.net (Zuletzt abgerufen 26.03.2018)

Durkheim, Émile: Die Regeln der soziologischen Methode, Neuwied 1961.

Durkheim, Émile: Über die Teilung der sozialen Arbeit, Frankfurt a.M. 1977.

Dodu, Peter: Die Tarifautonomie im Wandel der Gesellschaft. Die Neugestaltung der industriellen Beziehungen im 21. Jahrhundert, München 2010.

Ehrlich, Ernst Ludwig: Luther und die Juden, in: Strauss, Herbert A./Kampe, Norbert (Hrsg.): Antisemitismus. Von der Judenfeindschaft zum Holocaust, Bonn 1984.

Elbe, Ingo: Angst vor der Freiheit. Ist Sartres Existentialismus eine geeignete Grundlage für die Antisemitismustheorie?, http:/ /www.rote-ruhruni.com/cms/IMG/pdf/Sartre.pdf (Zuletzt abgerufen 19.10.2015).

Elias, Norbert: Was ist Soziologie, München 1971.

Enderwitz, Ulrich: Antisemitismus und Volksstaat. Zur Pathologie kapitalistischer Krisenbewältigung, Freiburg 1998.

Engels, Friedrich: Die Entwicklung des Sozialismus von der Utopie zur Wissenschaft, Berlin 1979.

Engels, Friedrich: Ergänzung und Nachtrag zum III. Buche des ,Kapital‘, MEW 23, Berlin 2003.

Engels, Friedrich: Feuerbach, MEW 3, Berlin 1990.

Engels, Friedrich: Karl Marx, Zur Kritik der Politischen Ökonomie (Rezension), MEW 13, Berlin 1981.

Engels, Friedrich: Ludwig Feuerbach und der Ausgang der klassischen deutschen Philosophie, MEW 21, Berlin 1969.

Euchner, Walter: Karl Marx, München 1982.

european-forum-on-antisemitism.org: Definition of Antisemitism, http:/ /www.european-forum-on-antisemitism.org/definition-ofantisemitism/english-english (Zuletzt abgerufen 20.07.2016).

Fenichel, Otto: Elemente einer psychoanalytischen Theorie des Antisemitismus, in: Simmel, Ernst (Hrsg.): Antisemitismus, Frankfurt a.M. 2002. 
Feyerabend, Paul: Erkenntnis für freie Menschen, Frankfurt a.M. 1980.

Feyerabend, Paul: Wider den Methodenzwang. Skizze einer anarchistischen Erkenntnistheorie, Frankfurt a.M. 1976.

Fitzgerald, F. Scott: The Great Gatsby, London/New York 1994.

Foucault, Michel: Dispositive der Macht, Berlin 1978.

Foucault, Michel: Überwachen und Strafen. Die Geburt des Gefängnisses, Frankfurt a.M. 1976.

Freud, Sigmund: Angst und Triebleben (32. Vorlesung), in: drslb.: Vorlesungen zur Einführung in die Psychoanalyse und Neue Folge, Studienausgabe Bd. I, Frankfurt a. M. 1969.

Freud, Sigmund: Die Zerlegung der psychischen Persönlichkeit, in: Studienausgabe Bd. 1: Vorlesungen zur Einführung in die Psychoanalyse. Und Neue Folge, Frankfurt a.M. 1969.

Freud, Sigmund: Jenseits des Lustprinzips, Studienausgabe Bd. III, Frankfurt a.M. 1975.

Freud, Sigmund: Neue Folge der Vorlesungen zur Einführung in die Psychoanalyse, in: Studienausgabe Bd. 1, Frankfurt a.M. 1969.

Freud, Sigmund: Trauer und Melancholie, Studienausgabe Bd. III, Frankfurt a. M. 1975.

Freud, Sigmund: Wege der psychoanalytischen Therapie, in: drslb.: Schriften zur Behandlungstechnik, Studienausgabe Ergänzungsband, Frankfurt a. M. 1975.

Freud, Sigmund: Zwei Kinderneurosen, Studienausgabe Bd. VIII, Frankfurt a.M. 1969.

Friedman, Milton: School of Chicago, University of Chicago Alumni Magazine, 1974, S. 11, zitiert nach Stephen Martin, Remembrance of Things Past: Antitrust, Ideology, and the Development of Industrial Economics, http:// www.krannert.purdue.edu/faculty/smartin/vita/remembrance1205a.pdf, S. 12 (Zuletzt abgerufen 05.09.2016)

Gegenstandpunkt: Anti-Rassismus Konferenz in Südafrika: Vom feinen demokratischen Unterschied zwischen achtens- und verachtenswerten Diskriminierungen, in: Gegenstandpunkt 4-01, München 2001.

Gegenstandpunkt: Der bürgerliche Staat, Resultate Bd. 3, München 2008.

Geier, Manfred: Der Wiener Kreis, Hamburg 1998.

Geißler, Rainer/Meyer, Thomas: Die Sozialstruktur Deutschlands. Zur gesellschaftlichen Entwicklung mit einer Bilanz zur Vereinigung, Wiesbaden 2006.

Gellner, Ernest: Nationalismus, Berlin 1999.

Gellner, Ernest: Nationalismus und Moderne, Hamburg 1995. 
Gerhardt, Volker: Gleiches Recht für alle, http://www.freitag.de/kultur/1034erst-das-menschenrecht-macht-globales-handeln-m-glich (Zuletzt abgerufen 12.03.12).

Gernalzick, Nadja: Medium Geld, in: Schröter, Jens/Schwering, Gregor, Stäheli, Urs (Hrsg.): Media Marx. Ein Handbuch, Bielefeld 2006.

gesetze-im-internet.de: Bürgerliches Gesetzbuch, BGB \ 611: Vertragstypische

Pflichten beim Dienstvertrag, https://www.gesetze-im-

internet.de/bgb/_611.html (Zuletzt abgerufen 01.08.2016).

gesetze-im-internet.de: Bürgerliches Gesetzbuch, BGB \ 611,

https:/ /www.gesetze-im-internet.de/bgb/_611.html

(Zuletzt abgerufen 01.08.2016).

gesetze-im-internet.de: Grundgesetz für die Bundesrepublik Deutschland, Artikel

14, http://www.gesetze-im-internet.de/gg/art_14.html

(Zuletzt abgerufen 20.05.2016).

gesetze-im-internet.de: Grundgesetz für die Bundesrepublik Deutschland, Artikel

20, http://www.gesetze-im-internet.de/gg/art_20.html (Zuletzt abgerufen

20.05.2016).

gesetze-im-internet.de: Strafgesetzbuch (StBG), \264 Subventionsbetrug,

http://www.gesetze-im-internet.de/stgb/_264.html

(Zuletzt abgerufen 05.07.2016).

Global Forum for Combating Antisemitism: Measuring the Hate. The State of

Antisemitism in Social Media, http://mfa.gov.il/MFA/ForeignPolicy/

AntiSemitism/Pages/Measuring-the-Hate-Antisemitism-in-Social-Media.aspx (Zuletzt abgerufen 06.06.2016).

Goldhagen, Daniel Jonah: Hitlers willige Vollstrecker. Ganz gewöhnliche Deutsche und der Holocaust, Berlin 1998.

Goldmann, Lucien/Lefebvre, Henri: Der dialektische Materialismus, Frankfurt a. M. 1966.

Goldmann, Lucien/Lefebvre, Henri: Kritik des Alltagslebens, Kronberg 1977.

gov.il: Measuring the Hate: The State of Antisemitism in Social Media, http://mfa.gov.il/MFA/ForeignPolicy/AntiSemitism/Pages/Measuring-theHate-Antisemitism-in-Social-Media.aspx (Zuletzt abgerufen 06.06.2016).

Grigat, Stephan: Fetisch und Freiheit. Über die Rezeption der Marxschen Fetischkritik, die Emanzipation von Staat und Kapital und die Kritik des Antisemitismus, Freiburg 2007.

Grigat, Stephan: Logik und Struktur des Antisemitismus, http:/ /iskra.blogsport.de/texte/logik-und-struktur-des-antisemitismus-eineeinfuehrung/ (Zuletzt abgerufen 04.08.2016).

Grigat, Stephan: Antisemitismus und Fetischismus, http:/ /www.cafecritique.priv.at/fetisch.html. (Zuletzt abgerufen 09.10.2015) 
Grillparzer, Franz: Sämtliche Werke/Ausgewählte Briefe, Gespräche, Berichte, Bd. 1: Gedichte, Epigramme, Dramen I, München 1969.

Guesnet, François: Polnische Juden im 19. Jahrhundert. Lebensbedingungen, Rechtsnormen und Organisation im Wandel, Köln 1998.

Haag, Karl Heinz: Der Fortschritt in der Philosophie, Frankfurt a.M. 2005.

Habermas, Jürgen: Erkenntnis und Interesse, Frankfurt a.M. 1988.

Habermas, Jürgen: Theorie des kommunikativen Handelns. Band I: Handlungsrationalität und gesellschaftliche Rationalisierung, Frankfurt a.M. 1995.

Habermas, Jürgen: Theorie des kommunikativen Handelns. Zur Kritik der funktionalistischen Vernunft, Frankfurt a.M. 1987.

Habermas, Jürgen: Der philosophische Diskurs der Moderne, Frankfurt a.M. 1985.

Habermas, Jürgen: Wahrheitstheorien, in: Fahrenbach, Helmut (Hrsg.): Wirklichkeit und Reflexion. Walter Schulz zum 60. Geburtstag, Neske/Pfullingen 1973.

Halder, Alois: Philosophisches Wörterbuch, Freiburg 2000.

Hanloser, Gerhard/Reitter, Karl: Der bewegte Marx. Eine einführende Kritik des Zirkulationsmarxismus, Münster 2008.

Hardt, Michael/Negri, Antonio: Empire. Die neue Weltordnung, Frankfurt a.M. 2003.

Hart, H.L.A.: The Concept of Law, Oxford 1961.

Hartmann, Peter C.: Geschichte Frankreichs, München 2007.

Haslbauer, Harald: Eigentum und Person. Begriff, Notwendigkeit und Folgen bürgerlicher Subjektivierung, Münster 2010.

Haug, W.F.: Vorlesungen zur Einführung ins ,Kapital‘, Berlin/Hamburg 1989.

Haumann, Heiko: Geschichte der Ostjuden, München 1990.

Haury, Thomas: Die ideologischen Grundlagen des Antizionismus in der Linken, http://d-a-s-h.org/dossier/07/08_grundlagenantizionismus.html (Zuletzt abgerufen 06.08.2016).

von Hayek, Friedrich August: Preise und Produktion, Wien 1931.

Hegel, G.W.F.: Brief an F.I. Niethammer vom 13. Oktober 1806, in:

J. Hoffmeister, Briefe von und an Hegel, Bd. 1, Berlin 1970.

Hegel, G.W.F.: Das älteste Systemprogramm des deutschen Idealismus (1796 oder 1797), in: ders., Frühe Schriften, Werke, Bd. 1, Frankfurt am Main 1970.

Hegel, G.W.F.: Enzyklopädie der philosophischen Wissenschaften I, Werke 8, Frankfurt a.M. 1986.

Hegel, G.W.F.: Enzyklopädie der philosophischen Wissenschaften II, Werke 9, Frankfurt a.M. 1986. 
Hegel, G.W.F.: Enzyklopädie der philosophischen Wissenschaften III, Werke 10, Frankfurt a.M. 1986.

Hegel, G.W.F.: Grundlinien der Philosophie des Rechts, Werke 7, Frankfurt a.M. 1986.

Hegel, G.W.F.: Phänomenologie des Geistes, Werke 3, Frankfurt a.M. 1986.

Hegel, G.W.F.: System der Philosophie, I. Teil, WW VIII, Stuttgart 1928.

Hegel, G.W.F.: Vorlesungen über die Geschichte der Philosophie I, Frankfurt a.M. 1971.

Hegel, G.W.F.: Vorlesungen über die Philosophie der Geschichte, Werke 12, Frankfurt a. M. 1986.

Hegel, G.W.F.: Wissenschaft der Logik I, Werke 5, Frankfurt a.M. 1986.

Hegel, G.W.F.: Wissenschaft der Logik II, Werke 6, Frankfurt a. M. 1986.

Heidegger, Martin: Sein und Zeit, Tübingen 2001.

Heine, Susanne: Grundlagen der Religionspsychologie. Modelle und Methoden, Göttingen 2005

Heinrich, Michael: Die Wissenschaft vom Wert: die Marxsche Kritik der politischen Ökonomie zwischen wissenschaftlicher Revolution und klassischer Tradition, Hamburg 1991.

Heinrich, Michael: Kritik der politischen Ökonomie. Eine Einführung, Stuttgart 2005.

Heinrich, Michael: Die Marxschen Texte zur Ökonomiekritik, http://www.rote-ruhr-uni.com/cms/Die-Marxschen-Texte-zur.html (Zuletzt abgerufen 25.08.2016).

Heitmeyer, Wilhelm (Hrsg.): Deutsche Zustände, Berlin 2010.

Heitmeyer, Wilhelm: Deutsche Zustände, Folge 1-10, Berlin 2002-2011.

Held, Susann: Eigentum und Herrschaft bei John Locke und Immanuel Kant. Ein ideengeschichtlicher Vergleich, Berlin 2006.

Henke, Wilhelm: Recht und Staat. Grundlagen der Jurisprudenz, Tübingen 1988.

Hensel, Jürgen: Polnische Adelsnation und jüdische Vermittler 1815-1830. Über den vergeblichen Versuch einer Judenemanzipation in einer nichtemanzipierten Gesellschaft, in: Forschungen zur osteuropäischen Geschichte 32, k.A. 1983.

Hessel, Stéphane: Empört Euch!, Berlin 2011.

Hilferding, Rudolf: Das Finanzkapital, Band 1, Frankfurt a.M. 1973.

Historisch-Kritisches Wörterbuch des Marxismus, Band 2, Hamburg 1995.

Historisch-Kritisches Wörterbuch des Marxismus, Band 3, Hamburg 1997.

Historisch-Kritisches Wörterbuch des Marxismus, Band 6/I, Hamburg 2004.

Historisch-Kritisches Wörterbuch des Marxismus, Band 7/I, Hamburg 2008. 
Hobbes, Thomas: Leviathan, Stuttgart 2003.

Hobsbawm, Eric: The Age of Revolution. 1789-1848, New York 1996.

Hobsbawm, Eric: Nationen und Nationalismus. Mythos und Realität, Frankfurt a.M. 2005.

Hobsbawm, Eric/Ranger, Terence (Hrsg.): The Invention of Tradition, Cambridge 2008.

Hoff, Jan: Marx global. Zur Entwicklung des internationalen Marx-Diskurses seit 1965, Berlin 2009.

Hofmann, Werner: Anmerkungen zur klassischen Soziologie, in: Traditionell kritische Theorie. Zehn Überlegungen zu verschiedenen Gegenständen, Würzburg 1995.

Holz, Klaus: Nationaler Antisemitismus. Wissenssoziologie einer Weltanschauung, Hamburg 2001.

Huisken, Freerk: Warum Demokraten (Neo-)Faschisten nicht kritisieren, sondern nur verbieten können, http:/ fhuisken.de/DemFasch.htm (Zuletzt abgerufen 06.09.2016).

Horkheimer, Max: ,Dialektik der Aufklärung‘ und andere Schriften 1940-1950, GS 5, Frankfurt a.M. 1987.

Horkheimer, Max: Die Juden und Europa, in: Zeitschrift für Sozialforschung, Jahrgang 8, München 1980.

Horkheimer, Max: Traditionelle und kritische Theorie, in: drslb.: Traditionelle und kritische Theorie, Frankfurt a.M. 2005.

Horkheimer, Max: Zur Kritik der instrumentellen Vernunft, Frankfurt a.M. 1997.

Horkheimer, Max: Zur Soziologie der Klassenverhältnisse, GS 12, Frankfurt a.M. 1985.

Hornscheidt, Lann: Dynamische Sprache gegen Herrschaft und Diskriminierung http://www.akweb.de/ak_s/ak577/26.htm (Zuletzt abgerufen 03.12.2015).

Horster, Detlef: Ernst Bloch. Eine Einführung, Wiesbaden o.J.

Hölderlin, Friedrich: Vorrede. Segmente einer letzten Fassung, Frankfurter Ausgabe Bd. 10, Neuwied 1984.

Hösle, Vittorio: Die Krise der Gegenwart und die Verantwortung der Philosophie, München 1997.

huffingtonpost.de: Antisemitische Liedzeilen: Xavier Naidoo verbreitet judenfeindliche Klischees, http:/ /www.huffingtonpost.de/2014/10/16/xaviernaidoo-antisemitismus_n_5994710.html (Zuletzt abgerufen 19.05.2016).

Huxley, Aldous: The Doors of Perception, London 1954.

indymedia.org: Antisemitismus und Antiamerikanismus, http://de.indymedia.org/2002/12/37289.shtml

(Zuletzt abgerufen 16.03.2015). 
Jaecker, Tobias: Politische Psychologie des Antisemitismus, http://antisemitismus.net/theorie/jaecker.htm (Zuletzt abgerufen 20.05.2016).

Jäger, Siegfried: Kritische Diskursanalyse. Eine Einführung, Duisburg 1999.

Kalász, Claudia: Extremismus? - Elemente der Xenophobie, in: Gesellschaftswissenschaftliches Institut (GI) e.V.: Traditionell kritische Theorie. Zehn Überlegungen zu verschiedenen Gegenständen, Würzburg 1995.

Kammler, Clemens: Historische Diskursanalyse (Michel Foucault), in: KlausMichael Bogdal (Hrsg.), Neue Literaturtheorien. Eine Einführung, Opladen 1997.

Kant, Immanuel: Die Metaphysik der Sitten, Frankfurt a.M. 1977.

Kant, Immanuel: Kritik der praktischen Vernunft/Grundlegung der Metaphysik der Sitten, Werkausgabe Bd. VII, Frankfurt a.M. 1974.

Kant, Immanuel: Kritik der reinen Vernunft, Hamburg 1998, B XVI.

Kant, Immanuel: Kritik der Urteilskraft, Werkausgabe Band X, Frankfurt a.M. 1974.

Kant, Immanuel: Prolegomena zu einer jeden künftigen Metaphysik, die als Wissenschaft wird auftreten können/Welches sind die wirklichen Fortschritte, die die Metaphysik seit Leibnizens und Wolffs Zeiten in Deutschland gemacht hat?, Frankfurt a. M. 2004.

Katcher, Leo: The Big Bankroll. The Life and Times of Arnold Rothstein, New York 1959.

Karathanassis, Athanasios: Kapitalistische Naturverhältnisse. Ursachen von Naturzerstörungen Begründungen einer Postwachstumsökonomie, Hamburg 2015.

Kelsen, Hans: Reine Rechtslehre, München 1960.

Kelsen, Hans: Was ist Gerechtigkeit?, Stuttgart 2000.

Klärner, Andreas/Kohlstruck, Michael: Rechtextremismus - Thema der Öffentlichkeit und Gegenstand der Forschung, in: dies. (Hrsg.): Moderner Rechtsextremismus in Deutschland, Hamburg 2006.

Knahl, Andreas: Die Steine schreien nicht selbst. Notiz zum Fürsichsein, in: Knahl, Andreas/Müller, Jan/Städtler, Michael (Hrsg.): Mit und gegen Hegel. Von der Gegenstandslosigkeit der absoluten Reflexion zur Begriffslosigkeit der Gegenwart, Lüneburg 2000.

Kohn, Hans: Die Idee des Nationalismus, Frankfurt a. M. 1962.

Konstadinow, F.W. (Gesamtredaktion): Grundlagen der marxistischen Philosophie, Berlin 1959.

Korsch, Karl: Karl Marx, Frankfurt a. M. 1967. 
Krahl, Hans-Jürgen: Zur Wesenslogik der Marxschen Warenanalyse, in: drslb.: Konstitution und Klassenkampf. Zur historischen Dialektik von bürgerlicher Emanzipation und proletarischer Revolution, Frankfurt a. M. 1971.

Krahl, Hans-Jürgen: Ontologie und Eros - zur spekulativen Deduktion der Homosexualität, in: drslb.: Konstitution und Klassenkampf. Zur historischen Dialektik von bürgerlicher Emanzipation und proletarischer Revolution, Frankfurt a. M. 1971.

krebshilfe.de: Krebshilfe http://www.krebshilfe.de/deutsche-krebshilfe/ tochterorganisationen/deutsche-kinderkrebshilfe.html?L $=0 \mathrm{c}$ (Zuletzt abgerufen 26.05.2016).

Kreutzer, Ansgar: Arbeit und Muße. Studien zu einer Theologie des Alltags, Wien/Berlin 2011.

Krijnen, Christian: Selbsterkenntnis und Systemgliederung. Hegel und der südwestdeutsche Neukantianismus, in: Fulda, Hans Friedrich/Krijnen, Christian (Hrsg.): Systemphilosophie als Selbsterkenntnis. Hegel und der Neukantianismus, Würzburg 2006.

Kritidis, Gregor: Testfeld Griechenland. Die Diktatur der Gläubiger ist das Pilotprojekt für den Angriff auf die Unter- und Mittelschichten in ganz Europa, http://www.sopos.org/aufsaetze/4b9914d82c6cc/1.phtml (Zuletzt abgerufen 02.06.2016).

Kropotkin, Peter: Gegenseitige Hilfe in der Tier- und Menschenwelt, Grafenau 2011.

Kuhne, Frank: Begriff und Zitat bei Marx, Lüneburg 1995.

Kuhne, Frank: ,Bloss der Hegel'sche Begriff bringt es fertig, sich ohne äussern Stoff zu objektivieren'. Anmerkungen zu Identität, Unterschied, Verschiedenheit, in: Knahl, Andreas/Müller, Jan/Städtler, Michael (Hrsg.): Mit und gegen Hegel. Von der Gegenstandslosigkeit der absoluten Reflexion zur Begriffslosigkeit der Gegenwart, Lüneburg 2000.

Kuhne, Frank: Das Subjekt der Kritik der politischen Ökonomie, in: Gesellschaftswissenschaftliches Institut (Hrsg.): Traditionell kritische Theorie. Zehn Überlegungen zu verschiedenen Gegenständen, Würzburg 1995.

Kuhne, Frank: Marx’ Ideologiebegriff im Kapital, in: Hans-Georg Bensch, Frank Kuhne, Das Automatische Subjekt bei Marx. Studien zum Kapital, Lüneburg 1998.

Kutschera, Franz von: Sprachphilosophie, München o.J.

Lacan, Jacques: Das Drängen des Buchstabens im Unbewußten oder die Vernunft seit Freud, Schriften II, Weinheim/Berlin 1996.

Laplanche, J./Pontalis, J.-B.: Das Vokabular der Psychoanalyse, Frankfurt a. M. 1973.

Leibniz, G.W.: Die Theodizee. 1710, Hamburg 1968. 
Lemke, Thomas: Marx ohne Anführungszeichen - Der zweite Band der Schriften zeigt Michel Foucault als Kritiker der politischen Anatomie des Körpers, http:/ /www.thomaslemkeweb.de/publikationen/Marx\%20ohne\%20Anfuehr ungszeichen.pdf (Zuletzt abgerufen 14.06.2016).

Lendvai, Paul: Antisemitism without Jews, Garden City 1971.

Lenin, W.I.: Der Imperialismus als höchstes Stadium des Kapitalismus. Gemeinverständlicher Abriß, München 2014.

Lenin, W.I.: Kritische Bemerkungen zur nationalen Frage, http://ciml.250x.com/archive/lenin/german/lenin_kritische_bemerkungen_ nationale_frage_1913.pdf (Zuletzt abgerufen 10.09.2016)

Lenin, W.I.: Materialismus und Empiriokritizismus, Peking 1973.

Lenin, W.I.: Staat und Revolution, München 2012.

Lenin, W. I.: Über die Pogromhetze gegen die Juden, http:/ / www.trend.infopartisan.net/antisemitismus/antisem10.html

Lepenies, Wolf: Melancholie und Gesellschaft, Frankfurt a. M. 1969.

Lewin, Kurt: Resolving social conflicts. Selected papers on group dynamics, New York 1948.

Locke, John: Two Treatises of Government, k.A (Maestro Reprint).

Löwenthal, Leo: Individuum und Terror, in: drslb.: Falsche Propheten. Studien zum Autoritarismus, Schriften Bd. 3, Frankfurt a.M. 1982.

Löwith, Karl: Von Hegel zu Nietzsche. Der revolutionäre Bruch im Denken des neunzehnten Jahrhunderts, Stuttgart 1964.

Ludz, Peter Christian: Ideologiebegriff und marxistische Theorie. Ansätze zu einer immanenten Kritik, Opladen 1976.

Luhmann, Niklas: Soziale Systeme. Grundriss einer allgemeinen Theorie, Frankfurt a.M. 1984.

Lukács, Georg: Geschichte und Klassenbewußtsein, Berlin 1968.

Lukács, Georg: Die Theorie des Romans. Ein geschichtsphilosophischer Versuch über die Formen der großen Epik, München 1994.

Lukács, Georg: Was ist orthodoxer Marxismus?, in: drslb.: Geschichte und Klassenbewußtsein, Berlin 1970.

Lukács, Georg: Zur Ontologie des gesellschaftlichen Seins. Die ontologischen Grundprinzipien von Marx, Darmstadt 1972.

Lyotard, Jean-Francois: Das postmoderne Wissen, Wien 2009.

Mannheim, Karl: Ideologie und Utopie, Frankfurt am Main 2015.

Marx, Karl: Zur Judenfrage, MEW 1, Berlin 2006.

Marx, Karl: Die deutsche Ideologie. Kritik der neuesten deutschen Philosophie in ihren Repräsentanten Feuerbach, B. Bauer und Stirner, und des deutschen Sozialismus in seinen verschiedenen Propheten, MEW 3, Berlin 1990. 
Marx, Karl: Thesen über Feuerbach, MEW 3, Berlin 1990.

Marx, Karl: Das Elend der Philosophie, MEW 4, Berlin 1980.

Marx, Karl/Engels, Friedrich: Das Kommunistische Manifest, MEW 4, Berlin 1980.

Marx, Karl: Lohnarbeit und Kapital, MEW 6, Berlin 1999.

Marx, Karl: Klassenkämpfe in Frankreich, MEW 7, Berlin 1990.

Marx, Karl: Der achtzehnte Brumaire des Louis Bonaparte, MEW 8, Berlin 1972.

Marx, Karl: Zur Kritik der Politischen Ökonomie, MEW 13, Berlin 1981.

Marx, Karl: Über P.J. Proudhon. Brief an J.B.v. Schweitzer, MEW 16, Berlin 1975.

Marx, Karl: Randglossen zu A. Wagners ,Lehrbuch der politischen Ökonomie‘, MEW Bd. 19, Berlin 1987.

Marx, Karl: Das Kapital. Kritik der politischen Ökonomie, Band 1, MEW 23, Berlin 2005.

Marx, Karl: Das Kapital. Kritik der politischen Ökonomie, Band 2, MEW 24, Berlin 2003.

Marx, Karl: Das Kapital. Kritik der politischen Ökonomie, Band 3, MEW 25, Berlin 2003.

Marx, Karl: Theorien über den Mehrwert, MEW 26.1, Berlin 2000.

Marx, Karl: Theorien über den Mehrwert, MEW 26.2, Berlin 2000.

Marx, Karl: Theorien über den Mehrwert, MEW 26.3, Berlin 1993.

Marx, Karl: Grundrisse der Kritik der politischen Ökonomie, MEW 42, Berlin 2005.

Marx, Karl/Engels, Friedrich: Briefwechsel, zitiert nach Frank Kuhne, Begriff und Zitat, Lüneburg 1995.

Marx, Karl: Urtext ,Zur Kritik', https://www.marxists.org/deutsch/archiv/marxengels/1858/urtext/2-5.htm (Zuletzt abgerufen 24.09.2016).

Marx, Karl: Ökonomisch-philosophische Manuskripte, http://www.mlwerke.de/me/me40/me40_562.htm (Zuletzt abgerufen 09.09.2016).

McLean, Paul D./Padgett, John F.: Was Florence a perfectly competitive market? Transactional evidence from the renaissance, in: Theory and Society 26, Netherlands 1997.

Meillassoux, Quentin: Nach der Endlichkeit, Zürich-Berlin 2008.

Menasse, Robert: Phänomenologie der Entgeisterung, Frankfurt a.M. 1995.

Mensching, Günther: Das Allgemeine und das Besondere. Der Ursprung des modernen Denkens im Mittelalter, Stuttgart 1992. 
Mensching, Günther: Nominalistische und realistische Momente des Marxschen Arbeitsbegriffs, in: Gerhard Schweppenhäuser (Hrsg.): Krise und Kritik, Lüneburg 1987.

Mészáros, István: Der Entfremdungsbegriff bei Marx, München 1973.

Meyfeld, Dirk: Volksgeist und Judenemanzipation. Hegels Haltung zur jüdischen Emanzipation und zum Frühantisemitismus seiner Zeit, Berlin 2014.

Mill, John Stuart: A System of Logic, Honululu 2002.

Mises, Ludwig von: Liberalismus, Jena 1927.

Misik, Robert: Kaputtalismus. Wird der Kapitalismus sterben, und wenn ja, würde uns das glücklich machen?, Berlin 2016.

Molinari, Gustave de: Produktion der Sicherheit, Hamburg/Wien o.J.

Moscovici, Serge: Das Zeitalter der Massen. Eine historische Abhandlung über die Massenpsychologie, Frankfurt a. M. 1986.

Negt, Oskar: Lebendige Arbeit, enteignete Zeit. Politische und kulturelle Dimensionen des Kampfes um die Arbeitszeit, Frankfurt a.M. 1984.

Nell-Breuning, Oswald von: Der Lohn als Erwerbsmittel und Eigentumsquelle, in: Eigentum und Eigentümer in unserer Gesellschaftsordnung, Wiesbaden 1960.

Neumann, Franz: Behemoth. Struktur und Praxis des Nationalsozialismus 19331944, Frankfurt a. M. 2004.

niedersachsen.de: Hochschulentwicklungsvertrag und Zielvereinbarungen als Elemente der Hochschulsteuerung in Niedersachsen, http://www.mwk.niedersachsen.de/startseite/themen/hochschulsteuerung/ hochschulentwicklungsvertrag-und-zielvereinbarungen-als-elemente-derhochschulsteuerung-in-niedersachsen-131463.html. (Zuletzt abgerufen 11.05.2016)

Nietzsche, Friedrich: Morgenröte. Gedanken über die moralischen Vorurteile, Das Hauptwerk II, München 1994.

Nietzsche, Friedrich: Die fröhliche Wissenschaft, Das Hauptwerk II, München 1994.

Nietzsche, Friedrich: Also sprach Zarathustra, in: Das Hauptwerk III, München 1994.

Nietzsche, Friedrich: Götzen-Dämmerung oder wie man mit dem Hammer philosophiert, in: Das Hauptwerk IV, München 1994.

ohchr.org: Allgemeine Erklärung der Menschenrechte, http://www.ohchr.org/

EN/UDHR/Documents/UDHR_Translations/ger.pdf

(Zuletzt abgerufen am 28.07.2014).

Ollman, Bertell: Alienation: Marx's Conception of Man in Capitalist Society, Cambridge 1976. 
opinioiuris.de: Bürgerliches Gesetzbuch, BGB \1 Beginn der Rechtsfähigkeit (Kommentar), http://opinioiuris.de/kommentar/bgb/1 (Zuletzt abgerufen 01.08.2016).

Oppolzer, Alfred A.: Entfremdung und Industriearbeit. Die Kategorie der Entfremdung bei Karl Marx, Köln 1974.

Osterhammel, Jürgen: Kolonialismus. Geschichte, Formen, Folgen, München 2006.

ots.at: ,Treffpunkt Medizin' am 4. Februar auf TW1, http:/ /www.ots.at/ presseaussendung/OTS_20110202_OTS0177/treffpunkt-medizin-am-4februar-auf-tw1 (Zuletzt abgerufen am 10.01.2014).

Overtveldt, Johan van: The Chicago School: how the University of Chicago assembled the thinkers who revolutionized economics and business, Chicago 2007.

Pagel, Gerda/Lacan, Jacques, Hamburg 2007.

Paine, Thomas: Common sense, Stuttgart 1982.

Parsons, Talcott: Der Beitrag der Psychoanalyse zu den Sozialwissenschaften, in: Wehler, Hans Ulrich (Hrsg.): Soziologie und Psychoanalyse, Stuttgart 1972.

Parsons, Talcott: Social Systems and the Evolution of Action Theory, New York 1977.

Perels, Joachim: Demokratie und soziale Emanzipation: Beiträge zur Verfassungstheorie der bürgerlichen Gesellschaft und des Sozialismus, Hamburg 1988.

Pfreundschuh, Wolfram: Entfremdung, http://kulturkritik.net/begriffe/ begr_txt.php?lex=entfremdung (Zuletzt abgerufen 26.08.2016).

Piketty, Thomas: Das Kapital im 21. Jahrhundert, München 2014.

Pohrt, Wolfgang: Theorie des Gebrauchswerts. Über die Vergänglichkeit der historischen Voraussetzungen, unter denen allein das Kapital Gebrauchswert setzt, Frankfurt a.M. 1976.

Poliakov, Leon: Geschichte des Antisemitismus, Bd. IV (Die Marranen im Schatten der Inquisition), Frankfurt a.M. 1981.

Poliakov, Leon: Geschichte des Antisemitismus. 8 Bände, Worms/Frankfurt a.M. 1977 bis 1988.

Pollock, Friedrich: Bemerkungen zur Wirtschaftskrise, in: Horkheimer, Max (Hrsg.): Zeitschrift für Sozialforschung, Jahrgang 2, München 1980.

Pollock, Frederick (=Friedrich): State Capitalism, in: Horkheimer, Max (Hrsg.): Zeitschrift für Sozialforschung, Jahrgang 9, München 1980.

Popper, Karl: Die offene Gesellschaft und ihre Feinde. Falsche Propheten: Hegel, Marx und die Folgen, Tübingen 2003, Band II.

Posor, Petja: Der Fall Hoeneß als Skandal in den Medien. Anschlusskommunikation, Authentisierung und Systemstabilisierung, Konstanz 2015. 
Postone, Moishe: Antisemitismus und Nationalsozialismus, in: drslb.: Deutschland, die Linke und der Holocaust, Freiburg 2005.

Postone, Moishe: Der Holocaust und der Verlauf des 20. Jahrhunderts, in: derslb.: Deutschland, die Linke und der Holocaust, Freiburg 2005.

Postone, Moishe: Zeit, Arbeit und gesellschaftliche Herrschaft. Eine neue Interpretation der kritischen Theorie von Marx, Freiburg 2003.

Pott, Marcel: Der Nahost-Konflikt. Schuld und Sühne im gelobten Land - Israels Sonderrolle im Schutz der westlichen Welt, Köln 2004.

Poulantzas, Nicos: Staatstheorie. Politischer Überbau, Ideologie, Autoritärer Etatismus, Hamburg 2002.

pressemeldungen.com: Treffpunkt Medizin, http://www.pressemeldungen.com/ 2011/05/24/treffpunkt-medizin-spezial-am-25-mai-auf-tw1/

(Zuletzt aufgerufen 10.01.2012).

Quesnay, François: Tableau économique, Berlin 1965.

Raab, Selwyn: Five Families: The Rise, Decline, and Resurgence of America's Most Powerful Mafia Empires, New York 2005.

Radbruch, Gustav: Gesetzliches Unrecht und übergesetzliches Recht, SJZ, Jg. 1, Nr. 5, 1946.

Radbruch, Gustav: Rechtsphilosophie I, Heidelberg 1987.

Reese-Schäfer, Walter: Lyotard zur Einführung, Hamburg 1995.

Reichelt, Helmut: Zur logischen Struktur des Kapitalbegriffs bei Karl Marx, Freiburg 2001.

Renan, Ernest: Was ist eine Nation? Rede am 11. März 1882 an der Sorbonne, Hamburg 1996.

Rensmann, Lars: Kritische Theorie über den Antisemitismus. Studien zu Struktur, Erklärungspotential und Aktualität, Hamburg 1998.

Reus, Sebastian: Unglückliches Bewußtsein. Denken ohne Dialektik bei Botho Strauß, Würzburg 2006.

Riesman,David/Glazer, Nathan/Denney, Reuel: The Lonely Crowd. A study of the changing American character, abridged edition with a new foreword, New Haven 1961.

Rohbeck, Johannes: Geschichtsphilosophie zur Einführung, Hamburg 2004.

Rosa, Lisa: Unterricht über Holocaust und Nahostkonflikt: Problematische Schüler oder problematische Schule? In: Amadeu Antonio Stiftung, ,Die Juden sind schuld'. Antisemitismus in der Einwanderungsgesellschaft am Beispiel muslimisch sozialisierter Millieus, Berlin 2009.

Rothbart, Murray: For a New Liberty, https://mises.org/system/tdf/For $\%$ $20 \mathrm{a} \% 20 \mathrm{New} \% 20 \mathrm{Liberty} \% 20 \mathrm{The}^{0} \% 20$ Libertarian $\% 20$ Manifesto_3.pdf?file $=1$ \&type $=$ document (Zuletzt abgerufen 31.08.2016). 
Rothbart, Murray: Law, Property Rights, and Air Pollution, https://mises.org/ system $/$ tdf $/$ Law $\% 2 C \% 20$ Property $\% 20$ Rights $\% 2 \mathrm{C} \% 20$ and $\% 20 \mathrm{Air} \%$ 20Pollution_2.pdf?file=1\&type=document (Zuletzt abgerufen 30.08.2016).

Rothfritz, Lauri Philipp: Die Konvention der Vereinten Nationen zum Schutz der Rechte der Menschen mit Behinderungen. Eine Analyse unter Bezugnahme auf die deutsche und europäische Rechtsebene, Hamburg 2009.

Rousseau, Jean-Jacques: Vom Gesellschaftsvertrag oder Prinzipien des Staatsrechtes (Du Contrat Social ou Principes du Droit Politique), Stuttgart 1977.

Salzborn, Samuel: Antisemitismus. Geschichte, Theorie, Empirie, Baden-Baden 2014.

Salzborn, Samuel: Antisemitismus als negative Leitidee der Moderne. Sozialwissenschaftliche Theorien im Vergleich, Frankfurt a.M. 2010.

Salzborn, Samuel: Kampf der Ideen. Die Geschichte politischer Theorien im Kontext, Baden-Baden 2015.

Salzborn, Samuel: Rechtsextremismus. Erscheinungsformen und Erklärungsansätze, Bonn 2015.

Sartre, Jean-Paul: Das Sein und das Nichts. Versuch einer phänomenologischen Ontologie, Hamburg 2004.

Sartre, Jean-Paul: Marxismus und Existentialismus. Versuch einer Methodik, Hamburg 1964.

Sartre, Jean-Paul: Überlegungen zur Judenfrage, Hamburg 1994.

Saussure, Ferdinand de: Cours de linguistique générale, Tübingen 2013.

Sayers, Sean: Marx und Entfremdung. Aufsätze zu hegelianischen Konzepten, Hamburg 2016.

Scahill, Jeremy: Blackwater: The Rise of the World's Most Powerful Mercenary Army, New York 2007.

Scahill, Jeremy: http://www.thenation.com/article/blackwater\# (Abgerufen 23.07.2014).

Scheit, Gerhard: Suicide Attack. Zur Kritik der politischen Gewalt, Freiburg 2004.

Schelsky, Helmut: Die Arbeit tun die anderen. Klassenkampf und Priesterherrschaft der Intellektuellen, Opladen 1975.

Schenk, Hans-Otto: Geschichte und Ordnungstheorie der Handelsfunktionen, Berlin 1970.

Schmidt, Alfred: Begriff des Materialismus bei Adorno, in: von Friedeburg, Ludwig/Habermas, Jürgen (Hrsg.): Adorno-Konferenz 1983, Frankfurt a.M. 1983.

Schmitt, Carl: Der Führer schützt das Recht. Zur Reichtagsrede Adolf Hitlers vom 13. Juli 1934, http://delete129a.blogsport.de/images/

CS_DerFuehrerschuetztdasRecht.pdf (Abgerufen 19.10.2015). 
Schmitt, Carl: Politische Theologie. Vier Kapitel zur Lehre von der Souveränität, München 1934.

Schneckener, Ulrich: Transnationaler Terrorismus. Charakter und Hintergründe des ,neuen“'Terrorismus, Frankfurt a.M. 2006.

Schopenhauer, Arthur: Die Welt als Wille und Vorstellung, Zürich 1977.

Schröder, Hans-Christoph: Englische Geschichte, München 2006.

Schwarz-Friesel, Monika/Reinharz, Jehuda: Die Sprache der Judenfeindschaft im 21. Jahrhundert, Berlin 2013.

Schweppenhäuser, Gerhard: Theodor W. Adorno zur Einführung, Hamburg 2005.

Schwinn, Thomas: Weltgesellschaft, multiple Moderne und die Herausforderungen für die soziologische Theorie. Plädoyer für eine mittlere Abstraktionshöhe, in: Heintz, Bettina/Münch, Richard/Tyrell, Hartmann (Hrsg.): Weltgesellschaft. Theoretische Zugänge und empirische Problemlagen, Sonderheft Zeitschrift für Soziologie, Stuttgart 2005.

Scruton, Roger: Kant, Freiburg o.J.

Sebag, Lucien: Marxismus und Strukturalismus, Frankfurt a.M. 1967.

Simmel, Ernst: Antisemitismus und Massen-Psychopathologie, in: drslb. (Hrsg.): Antisemitismus, Frankfurt a.M. 2002.

Simmel, Georg: Die Philosophie des Geldes, Gesamtausgabe Bd. 6, Frankfurt a.M. 2011.

Simmel, Georg: Aufsätze 1887-1890. Über sociale Differenzierung. Die Probleme der Geschichtsphilosophie, Frankfurt a.M. 1989.

Smith, Adam: Der Wohlstand der Nationen. Eine Untersuchung seiner Natur und seiner Ursachen, München 2013.

Smith, Eliot R./Mackie, Diane M.: Social Psychology, New York 2007.

Sohn-Rethel, Alfred: Warenform und Denkform, Frankfurt a.M. 1978.

Sohn-Rethel, Alfred: Das Geld, die bare Münze des Apriori, Berlin 1990.

Sombart, Werner: Das Proletariat, in: Buber, Martin (Hrsg.): Die Gesellschaft, Frankfurt a.M. 1906.

spd.de: Finanzmärkte steuern, http://www.spd.de/themen/112502/ koav_finanzmaerkte_steuern.html. (Zuletzt abgerufen 05.07.2016).

Spitteler, Carl: Olympischer Frühling, http://gutenberg.spiegel.de/buch/-1284/17 (Zuletzt abgerufen 16.08.2016).

Städtler, Michael: Geschichte oder Tendenz. Zur Konstruktion der Freiheit als reflexive Negation. In Bensch, Hans-Georg/Kuhne, Frank (Hrsg.): Das Automatische Subjekt bei Marx. Studien zum Kapital, Lüneburg 1998. 
Städtler, Michael: Kant und die Aporetik moderner Subjektivität. Zur Verschränkung historischer und systematischer Momente im Begriff der Selbstbestimmung, Berlin 2011.

Stender, Wolfram: Konstellationen des Antisemitismus. Zur Einleitung, in: Wolfram Stender/Guido Follert/Mihri Özdogan (Hrsg.), Konstellationen des Antisemitismus. Antisemitismusforschung und sozialpädagogische Praxis, Wiesbaden 2010.

Stirner, Max: Der Einzige und sein Eigentum, Stuttgart 1972.

Strauss, Herbert A.: Einleitung - Vom modernen Antisemitismus zum neuen Antisemitismus, in: drslb./Bergmann, Werner/Hoffmann, Christhard (Hrsg.): Der Antisemitismus der Gegenwart, Frankfurt a. M. 1990.

Strauss, Herbert A./Kampe, Norbert (Hrsg.): Antisemitismus. Von der Judenfeindschaft zum Holocaust, Frankfurt a. M. 1984.

Sturm, Reinhold: Der ökonomische Wert. Fragen der Werttheorie, der Produktionspreise und der gesamtgesellschaftlichen Reproduktion, in: Moeschl, Peter/Sturm, Reinhold: Allgemeine Werttheorie. der streit, Nr. 41/42, Wien 1991.

sueddeutsche.de: ,Ich habe gelernt: Nie wieder Auschwitz‘. Die Erinnerung gehört zu den Leitlinien von Außenminister Joschka Fischer, http://www.sueddeutsche.de/politik/fischer-ich-habe-gelernt-nie-wiederauschwitz-1.915701 (Zuletzt abgerufen 29.01.2016).

tagesspiegel.de: Schulpflicht. Erst mit der Weimarer Republik galt sie in ganz Deutschland, http://www.tagesspiegel.de/wissen/schulpflicht-erst-mit-derweimarer-republik-galt-sie-in-ganz-deutschland/10294688.html (Zuletzt abgerufen 02.08.2016).

tagesspiegel.de: Veganer und Drogen. Hört erstmal auf zu koksen!, http://www.tagesspiegel.de/berlin/veganer-und-drogen-hoert-erst-mal-aufzu-koksen/11943180.html (Zuletzt abgerufen 23.08.2016).

Thamer, Hans-Ulrich: Die Französische Revolution, München 2004.

Thatcher, Margaret: A life in quotes, http://www.theguardian.com/politics/ 2013/apr/08/margaret-thatcher-quotes (Zuletzt abgerufen: 26.11.2015).

thenation.com: In the (Black)water, http://www.thenation.com/ article/blackwater\# (Zuletzt abgerufen 23.07.2014).

Trittin, Jürgen: Finanzmarkt, http://www.trittin.de/trittin/texte/reden/ 20090327_Finanzmarkt.pdf (Zuletzt abgerufen 15.03.2015).

Türcke, Christoph/Bolte, Gerhard: Einführung in die Kritische Theorie, Darmstadt 1994.

Utsch, Michael: Religionspsychologie. Voraussetzungen, Grundlagen, Forschungsüberblick, Stuttgart 1998. 
Valdeón Buruque, Julio: Judios y Conversos en la Castilla medieval, Valladolid 2004.

Valdés, Juan Gabriel: Pinochet's Economists. The Chicago School of Economics in Chile, Cambridge 1995.

Vester, Michael (Hrsg.): Neue soziale Milieus und pluralisierte Klassengesellschaft, Frankfurt a.M 1992.

Vester, Michael (Hrsg.): Soziale Milieus im gesellschaftlichen Strukturwandel, Frankfurt a.M. 2001.

Villey, Michael: Das römische Recht in Hegels Rechtsphilosophie, in: Materialien zu Hegels Rechtsphilosophie, Frankfurt 1975.

Voltaire: Candide oder die Beste aller Welten, Stuttgart 1971.

Wallat, Hendrik: Das Bewusstsein der Krise. Marx, Nietzsche und die Emanzipation des Nichtidentischen in der politischen Theorie, Bielefeld 2009.

Weber, Max: Wirtschaft und Gesellschaft, Frankfurt a.M. 2005.

Wehler, Hans-Ulrich: Nationalismus. Geschichte, Formen, Folgen, München 2007.

Wehler, Hans-Ulrich: Deutscher Sonderweg oder allgemeine Probleme des westlichen Kapitalismus, in: Merkur 1981.

Weinryb, Bernard D.: Neueste Wirtschaftsgeschichte der Juden in Rußland und Polen. Von der 1. Polnischen Teilung bis zum Tode Alexanders II. (17721881), Hildesheim 1972.

Weiss, Peter: Die Ästhetik des Widerstands, Frankfurt a. M. 1983.

welt.de: Extremisten haben vor allem Lust auf Gewalt, http://www.welt.de/politik/deutschland/article9910973/Extremistenhaben-vor-allem-Lust-auf-Gewalt.html (Zuletzt abgerufen 05.12.2015).

welt.de: Offener Antisemitismus bedroht Europa, http://www.welt.de/politik/article3100537/Offener-Antisemitismusbedroht-Europa.html (Zuletzt abgerufen 25.11.2015).

Wenturis, Nikolaus/Van Hove, Walter/Dreier, Volker: Methodologie der Sozialwissenschaften, Tübingen 1992.

Wesel, Uwe: Geschichte des Rechts in Europa. Von den Griechen bis zum Vertrag von Lissabon, München 2010.

Weyand, Jan: Adornos Kritische Theorie des Subjekts, Lüneburg 2001.

Weyand, Jan: Stummer Zwang oder innere Stimmen? Bemerkungen zur Aufrechterhaltung des Kapitalverhältnisses, in: Bensch, Hans-Georg/Kuhne, Frank (Hrsg.): Das Automatische Subjekt bei Marx. Studien zum Kapital, Lüneburg 1998.

Willms, Gerald: Scientology. Kulturbeobachtungen jenseits der Devianz, Bielefeld 2005. 
Wirth, Hans-Jürgen: Narzissmus und Macht. Zur Psychoanalyse seelischer Störungen in der Politik, Giessen 2002.

wirtschaftslexikon24.com: Property Rights, http://www.wirtschaftslexikon24.com/d/property-rights/propertyrights.htm (Zuletzt abgerufen 14.05.2016).

Wittgenstein, Ludwig: Philosophische Untersuchungen, Oxford 1953.

Wittgenstein, Ludwig: Tractatus logico-philosophicus, Frankfurt a.M. 1998.

Witwer, David: The Most Racketeer-Ridden Union in America: The Problem of Corruption in the Teamsters Union During the 1930s, in: Kreike, Emmanuel/Jordan, William Chester (Hrsg.): Corrupt Histories, University of Rochester Press, 2004.

youthforhumanrights.org: Das Recht auf Eigentum, http:/ /de.youthforhumanrights.org/what-are-human-rights/videos/right-toownership.html (Zuletzt abgerufen 12.09.2016).

youthforhumanrights.org: Jugend für Menschenrechte http://de.youthforhumanrights.org/what-are-human-rights/videos/right-toownership.html (Zuletzt abgerufen 28.07.2014)

Zehnpfennig, Barbara: Rousseau und Marx oder: Das Ende der Entfremdung, in: Hidalgo, Oliver (Hrsg.): Der lange Schatten des Contrat social. Demokratie und Volkssouveränität bei Jean-Jacques Rousseau, Wiesbaden 2013.

zeit.de: Graumann: Antisemitismus wird immer offener ausgelebt, http://www.zeit.de/news/2014-11/27/deutschland-graumannantisemitismus-wird-immer-offener-ausgelebt-27005605 (Zuletzt abgerufen 25.11.2015).

Ziegler, Dieter: Das wirtschaftliche Großbürgertum, in: Lundgreen, Peter (Hrsg.): Sozial- und Kulturgeschichte des Bürgertums, Göttingen 2000. 
Die moderne sozialwissenschaftliche Antisemitismusforschung vernachlässigt zumeist das gesellschaftliche Wesen des modernen Antisemitismus. Diese Lücke möchte Bengt Erik Bethmann mit dem vorliegenden Buch schließen. Um dieses Anliegen zu realisieren, zieht er die traditionell philosophische Frage nach Phänomen und Wesen in einen modernen, kritischen Kontext von gesellschaftlichem Phänomen und dessen gesellschaftlichem Wesen. Am modernen Antisemitismus zeigt er, dass sich dieses gesellschaftliche Phänomen in der bürgerlichen Gesellschaft überhaupt nicht erklären ließe, ohne die gesellschaftliche Substanz zu reflektieren. 